\title{
Beiträge zur ernährungsphysiologischen Bewertung optimaler Methionin:Cystein Relationen in der Masthähnchenernährung unter besonderer Beachtung hoher Mischungsanteile von Insektenmehlen als alternative Eiweißquelle für Sojaprotein
}

\author{
Dissertation \\ zur Erlangung des Doktorgrades (Dr. sc. agr.) \\ der Fakultät für Agrarwissenschaften \\ der Georg-August-Universität Göttingen \\ vorgelegt von
}

Anne Brede

geboren am 19.02.1990 in Preetz

Göttingen, im Dezember 2018 
1. Gutachter: Prof. Dr. F. Liebert

2. Gutachter: Prof. Dr. W. Windisch

3. Gutachterin: Prof. Dr. M. Gerken

Tag der mündlichen Prüfung: 05.02.19 


\section{Inhaltsverzeichnis}

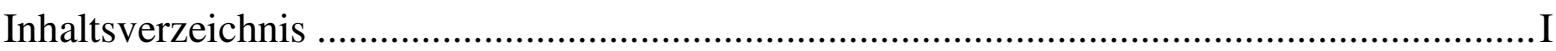

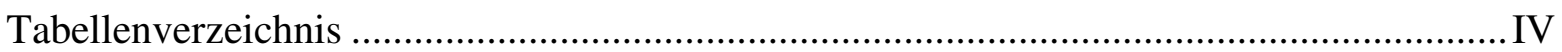

Verzeichnis der Anhangstabellen ................................................................................. VI

Abbildungsverzeichnis..............................................................................................VII

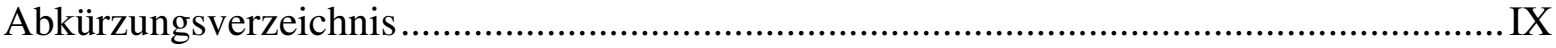

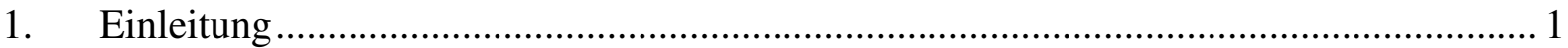

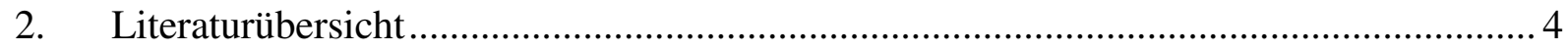

2.1 Die schwefelhaltigen Aminosäuren in der Mastgeflügelernährung.................................... 4

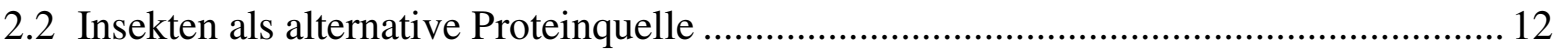

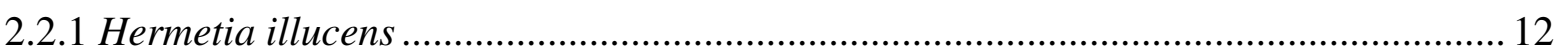

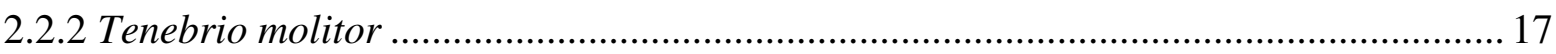

2.2.3 Einsatz von Hermetia illucens und Tenebrio molitor in der Masthähnchenfütterung.. 20

2.2.4 Mögliche Einsatzbeschränkungen ............................................................................. 22

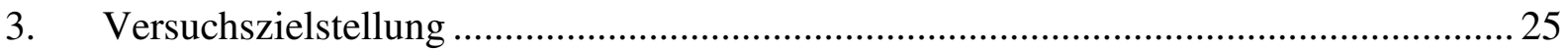

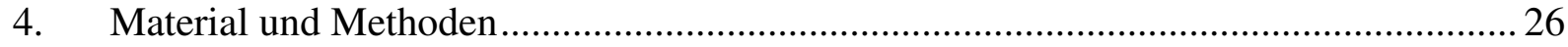

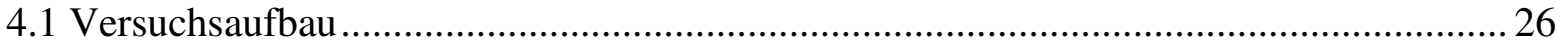

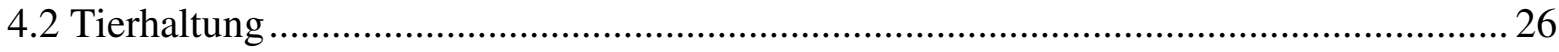

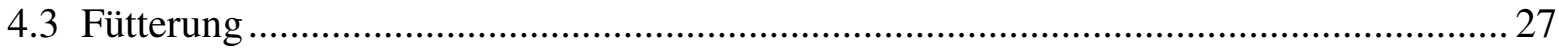

4.4 Datenerfassung und Probennahme ............................................................................ 35

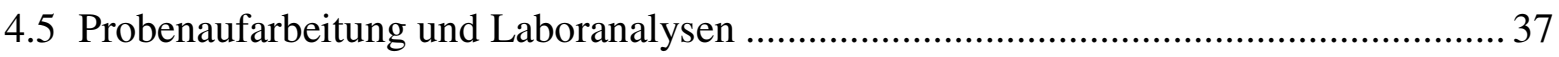

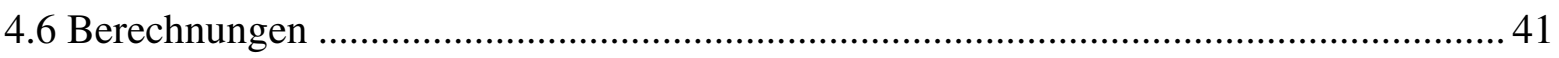

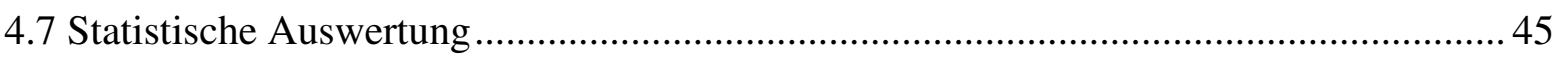

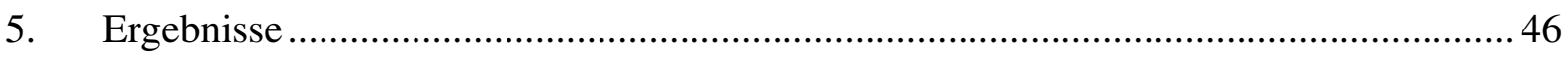

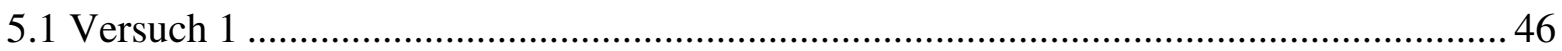

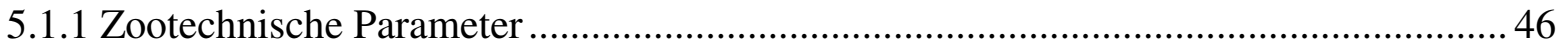

5.1.2 Scheinbare praecaecale Verdaulichkeit .....................................................................5 50

5.1.3 Proteinqualität und Met-Wirksamkeit..................................................................... 51 


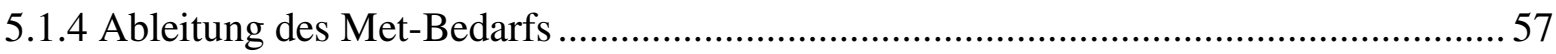

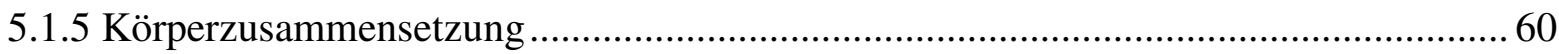

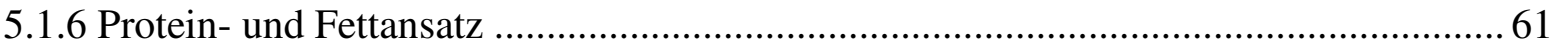

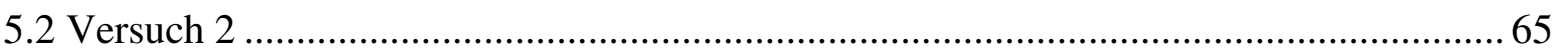

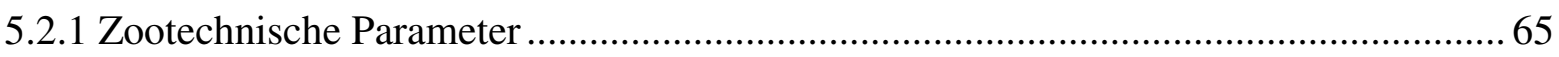

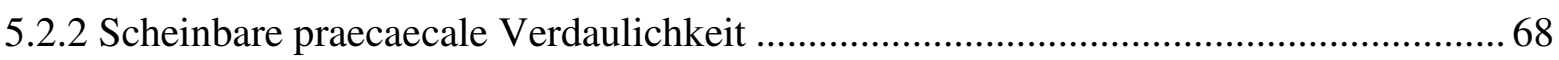

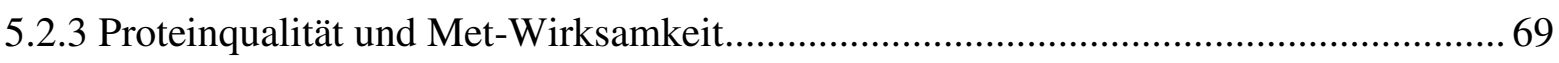

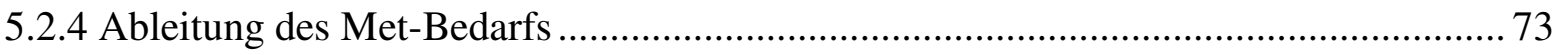

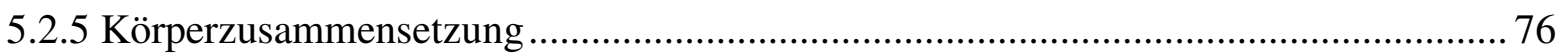

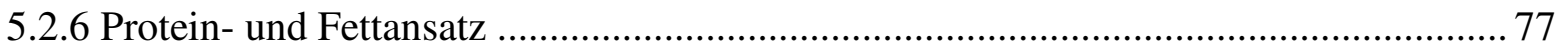

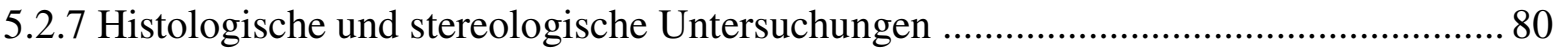

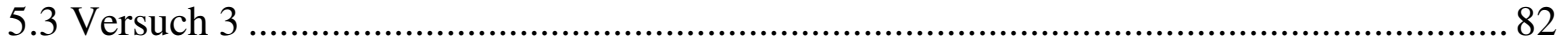

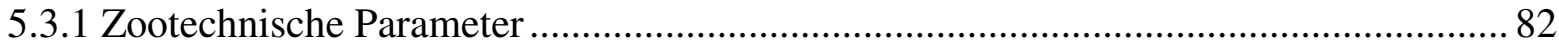

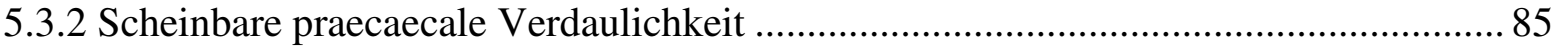

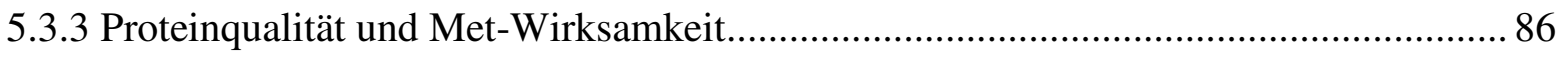

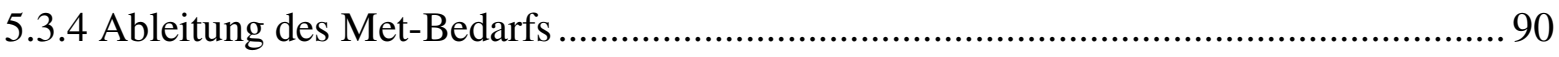

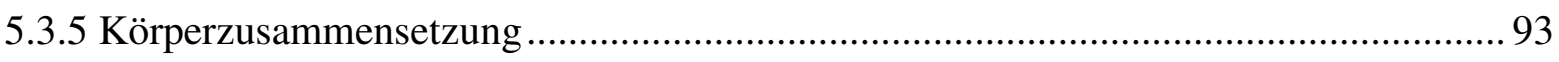

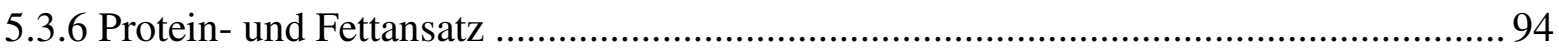

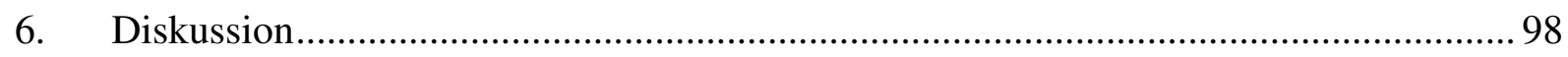

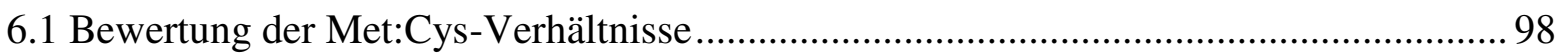

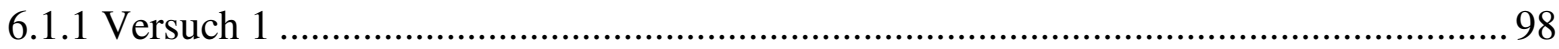

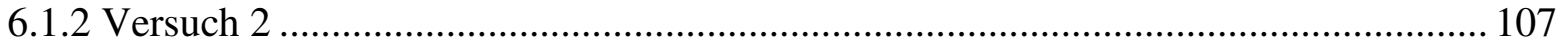

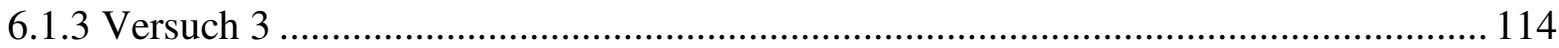

6.2 Bewertung der Eignung von Hermetia illucens und Tenebrio molitor als Proteinquelle

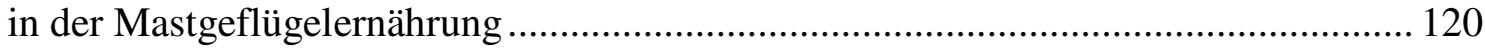

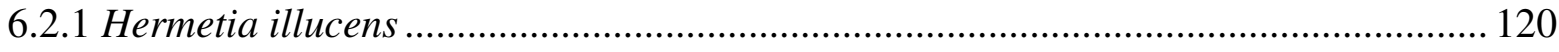

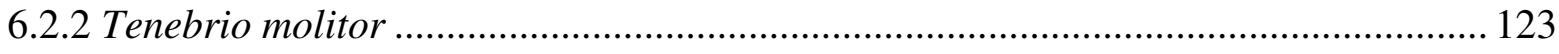

6.2.3 Vergleich von Hermetia illucens und Tenebrio molitor .......................................... 127 


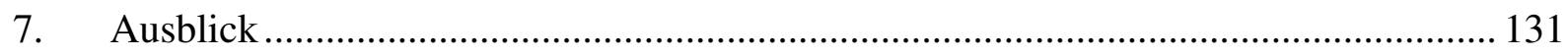

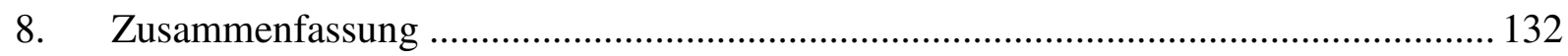

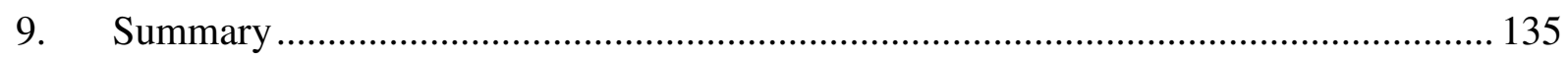

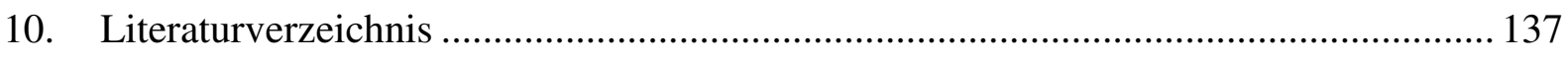

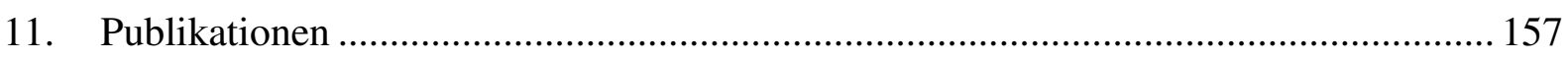

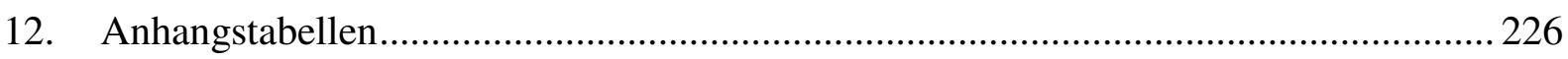

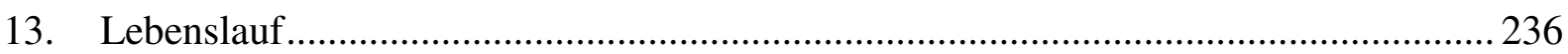

14. Wissenschaftliche Publikationen und Beiträge zu wissenschaftlichen Tagungen ........ 237

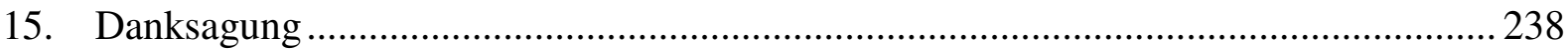




\section{Tabellenverzeichnis}

Tabelle 1: Altersabhängige Gehalte und Relationen zwischen den S-haltigen Aminosäuren in den Federn und im federlosen Ganzkörper von Masthähnchen (nach Wecke et al., 2018a).

Tabelle 2: Gehalte und Relationen zwischen den S-haltigen Aminosäuren in ausgewählten Insektenarten.

Tabelle 3: Literaturangaben zum Rohnährstoffgehalt von Hermetia illucens Larven (in $\% \mathrm{TM}$ ).

Tabelle 4: Literaturangaben zum Gehalt ausgewählter Aminosäuren in Hermetia illucens Larven.

Tabelle 5: Literaturangaben zum Fettsäuregehalt in Hermetia illucens Larven

(\% der Gesamt-FS).

Tabelle 6: Literaturangaben zum Rohnährstoffgehalt von Tenebrio molitor Larven (in \% TM).

Tabelle 7: Literaturangaben zum Gehalt ausgewählter Aminosäuren in Tenebrio molitor

Larven.

Tabelle 8: Literaturangaben zum Fettsäuregehalt in Tenebrio molitor Larven (\% der Gesamt-FS).

Tabelle 9: Gehalte an Rohnährstoffen und ausgewählten Aminosäuren

Tabelle 10: Ausgewählte Angaben zur Zusammensetzung der Futtermischungen der Versuchsgruppen A-F (g/kg FM) in Versuch 1

Tabelle 11: Rohnährstoff- und Aminosäuregehalt des Tenebrio molitor Presskuchens.

Tabelle 12: Ausgewählte Angaben zur Zusammensetzung der Futtermischungen der Versuchsgruppen A-F (g/kg FM) in Versuch 2.

Tabelle 13: Ausgewählte Angaben zur Zusammensetzung der Futtermischungen der Versuchsgruppen A-H (g/kg FM) in Versuch 3.

Tabelle 14: Ergebnisse der zootechnischen Parameter der Starter- (Tag 1-21) und Growerphase (Tag 22-35) in Versuch 1.

Tabelle 15: Ergebnisse der zootechnischen Parameter des gesamten Versuchs 1

(Tag 1-35).

Tabelle 16: Mittlere Ergebnisse zur scheinbaren praecaecalen Verdaulichkeit (\%) des Rohproteins und ausgewählter Aminosäuren der Versuchsgruppen in Versuch 1.

Tabelle 17: Ergebnisse der Proteinqualitätsbewertung in Versuch 1.

Tabelle 18: Abgeleiteter Met-Bedarf in Abhängigkeit von Met:Cys-Verhältnis, Rohproteinansatz und täglicher Futteraufnahme in der Starterphase (Tag 1-21) von Versuch 1 (Mittlere LM:500g).

Tabelle 19: Abgeleiteter Met-Bedarf in Abhängigkeit von Met:Cys-Verhältnis, Rohproteinansatz und täglicher Futteraufnahme in der Growerphase (Tag 22-35) von Versuch 1 (Mittlere LM:1500g). 
Tabelle 20: Mittlere Körperzusammensetzung der Tiere am Ende der Starter- (Tag 21) und Growerphase (Tag 35) von Versuch 1.

Tabelle 21: Ergebnisse der zootechnischen Parameter der Starter- (Tag 1-21) und Growerphase (Tag 22-35) in Versuch 2.

Tabelle 22: Ergebnisse der zootechnischen Parameter des gesamten Versuchs 2 (Tag 1-35).

Tabelle 23: Mittlere Ergebnisse zur scheinbaren praecaecalen Verdaulichkeit (\%) des Rohproteins und ausgewählter Aminosäuren der Futtermischungen der Versuchsgruppen C (TMP 50:50) und F (SES 50:50) in Versuch 2.

Tabelle 24: Ergebnisse der Proteinqualitätsbewertung in Versuch 2.

Tabelle 25: Abgeleiteter Met-Bedarf in Abhängigkeit von Met:Cys-Verhältnis, Rohproteinansatz und täglicher Futteraufnahme in der Starterphase (Tag 1-21) von Versuch 2 (Mittlere LM:500g).

Tabelle 26: Abgeleiteter Met-Bedarf in Abhängigkeit von Met:Cys-Verhältnis, Rohproteinansatz und täglicher Futteraufnahme in der Growerphase (Tag 22-35) von Versuch 2 (Mittlere LM:1500g).

Tabelle 27: Mittlere Körperzusammensetzung der Tiere am Ende der Starter- (Tag 21) und Growerphase (Tag 35) von Versuch 2.

Tabelle 28: Ergebnisse der Makroskopie in Versuch 2

Tabelle 29: Ergebnisse der relativen primären Schleimhautoberfläche $\left(S_{\mathrm{pm}}\right)$, relativen Zottenoberfläche $\left(S_{\mathrm{v}}\right)$ und dem Zotten-/Kryptenepithelvolumenverhältnisses $\left(\mathrm{V}_{\mathrm{ve}} / \mathrm{V}_{\mathrm{ce}}\right)$ in den drei Dünndarmabschnitten in Versuch 2.

Tabelle 30: Ergebnisse der zootechnischen Parameter der Starter- (Tag 1-21) und Growerphase (Tag 22-35) in Versuch 3.

Tabelle 31: Ergebnisse der zootechnischen Parameter des gesamten Versuchs 3 (Tag 1-35).

Tabelle 32: Mittlere Ergebnisse zur scheinbaren praecaecalen Verdaulichkeit (\%) des Rohproteins und ausgewählter Aminosäuren der Futtermischungen der Versuchsgruppen D (TMP pK) und H (HM pK) in Versuch 3.

Tabelle 33: Ergebnisse der Proteinqualität in Versuch 3.

Tabelle 34: Abgeleiteter Met-Bedarf in Abhängigkeit von Met:Cys-Verhältnis, Rohproteinansatz und täglicher Futteraufnahme in der Starterphase (Tag 1-21) von Versuch 3 (Mittlere LM:500g).

Tabelle 35: Abgeleiteter Met-Bedarf in Abhängigkeit von Met:Cys-Verhältnis, Rohproteinansatz und täglicher Futteraufnahme in der Growerphase (Tag 22-35) von Versuch 3 (Mittlere LM:1500g).

Tabelle 36: Mittlere Körperzusammensetzung der Tiere am Ende der Starter(Tag 21) und Growerphase (Tag 35) von Versuch 3. 


\section{Verzeichnis der Anhangstabellen}

Anhangstabelle 1: Analysierte Rohnährstoff- und Aminosäuregehalte der verwendeten Einzelfuttermittel........................................................................... 226

Anhangstabelle 2: Zusammensetzung des verwendeten Premixes. .................................... 227

Anhangstabelle 3: Zusammensetzung der in Versuch 1 verwendeten Futtermischungen..... 228

Anhangstabelle 4:Rohnährstoff- und Aminosäure-Gehalte der in Versuch 1 verwendeten Futtermischungen. ........................................................................... 229

Anhangstabelle 5: Zusammensetzung der in Versuch 2 verwendeten Futtermischungen. .... 230

Anhangstabelle 6: Rohnährstoff- und Aminosäuregehalt der in Versuch 2 verwendeten

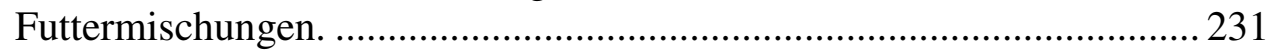

Anhangstabelle 7: Zusammensetzung der in der Starterphase (Tag 1-21) von Versuch 3 verwendeten Futtermischungen.

Anhangstabelle 8: Rohnährstoff- und Aminosäuregehalt der in der Starterphase (Tag 1-21) von Versuch 3 verwendeten Futtermischungen.

Anhangstabelle 9: Zusammensetzung der in der Growerphase (Tag 22-35) von Versuch 3 verwendeten Futtermischungen.

Anhangstabelle 10: Rohnährstoff- und Aminosäuregehalt der in der Growerphase (Tag 22-35) von Versuch 3 verwendeten Futtermischungen. 


\section{Abbildungsverzeichnis}

Abbildung 1: Vergleich der weltweiten Fleischproduktion 2005/2007 und 2050 (nach FAO, 2012).

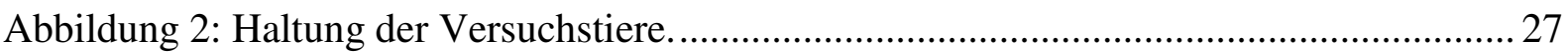

Abbildung 3: Teilentfettetes Hermetia illucens Mehl........................................................... 29

Abbildung 4: Presskuchen aus Tenebrio molitor ................................................................ 32

Abbildung 5: Der Gastrointestinaltrakt eines Masthähnchens. Orange markiert:

Darmabschnitt zur Chymusentnahme (nach Leeson und Summers, 2001)...... 35

Abbildung 6: Übersicht über die Probennahme der Dünndarmschnitte (Bild: Gruber-

Dujardin).

Abbildung 7: Zählereignisse zur Berechnung des Zotten- und Kryptenepithelvolumens

(Bild: Gruber-Dujardin)

Abbildung 8: Repräsentative Versuchstiere aus Versuchsgruppe A (HM 40:60, links) und

Versuchsgruppe C (HM 50:50, rechts) in Versuch 1 an Tag 35.................... 50

Abbildung 9: Met-Wirksamkeit $\left(b c^{-1}\right)$ und Met-Konzentration $(\mathrm{g} / 16 \mathrm{gN})$ in der

Starterphase (Tag 1-21) von Versuch 1...................................................... 54

Abbildung 10: Met-Wirksamkeit $\left(b c^{-1}\right)$ und Met-Konzentration $(\mathrm{g} / 16 \mathrm{gN})$ in der Growerphase (Tag 22-35) von Versuch 1.................................................. 55

Abbildung 11: Met-Wirksamkeit $\left(b c^{-1}\right)$ und Met-Konzentration $(\mathrm{g} / 16 \mathrm{gN})$ des gesamten

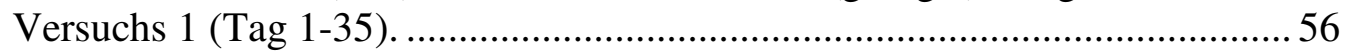

Abbildung 12: Protein- und Fettansatz in der Starterphase (Tag 1-21) von Versuch 1.......... 62

Abbildung 13: Protein- und Fettansatz in der Growerphase (Tag 22-35) von Versuch 1........ 63

Abbildung 14: Protein- und Fettansatz im gesamten Versuchszeitraum (Tag 1-35) von Versuch 1

Abbildung 15: Met-Wirksamkeit $\left(b c^{-1}\right)$ und Met-Konzentration $(\mathrm{g} / 16 \mathrm{gN})$ in der Starterphase (Tag 1-21) von Versuch 2.

Abbildung 16: Met-Wirksamkeit $\left(b c^{-1}\right)$ und Met-Konzentration $(\mathrm{g} / 16 \mathrm{gN})$ in der Growerphase (Tag 22-35) von Versuch 2.

Abbildung 17: Met-Wirksamkeit $\left(b c^{-1}\right)$ und Met-Konzentration $(\mathrm{g} / 16 \mathrm{gN})$ des gesamten Versuchs 2 (Tag 1-35)................................................................................ 72

Abbildung 18: Protein- und Fettansatz in der Starterphase (Tag 1-21) von Versuch 2.......... 78

Abbildung 19: Protein- und Fettansatz in der Growerphase (Tag 22-35) von Versuch 2....... 79

Abbildung 20: Protein- und Fettansatz im gesamten Versuchszeitraum (Tag 1-35) von Versuch 2.

Abbildung 21: Met-Wirksamkeit $\left(b c^{-1}\right)$ und Met-Konzentration $(\mathrm{g} / 16 \mathrm{gN})$ in der Starterphase (Tag 1-21) von Versuch 3.

Abbildung 22: Met-Wirksamkeit $\left(b c^{-1}\right)$ und Met-Konzentration $(\mathrm{g} / 16 \mathrm{gN})$ in der Growerrphase (Tag 22-35) von Versuch 3.

Abbildung 23: Met-Wirksamkeit $\left(b c^{-1}\right)$ und Met-Konzentration $(\mathrm{g} / 16 \mathrm{gN})$ des gesamten Versuchs 3. 
Abbildung 24: Protein- und Fettansatz in der Starterphase (Tag 1-21) von Versuch 3.......... 95

Abbildung 25: Protein- und Fettansatz in der Growerphase (Tag 22-35) von Versuch 3........ 96

Abbildung 26: Protein- und Fettansatz im gesamten Versuchszeitraum (Tag 1-35) von Versuch 3 


\section{Abkürzungsverzeichnis}

\begin{tabular}{|c|c|}
\hline $\mathrm{ADF}$ & Säure-Detergenzien-Faser \\
\hline ADL & Säure-Detergenzien-Lignin \\
\hline $\operatorname{Arg}$ & Arginin \\
\hline AS & Aminosäure(n) \\
\hline BSE & Bovine spongiforme Enzephalopathie \\
\hline Cys & Cystein \\
\hline $\mathrm{d}$ & Tag \\
\hline FA & Futteraufwand \\
\hline FI & Futteraufnahme \\
\hline FM & Frischmasse \\
\hline FS & Fettsäure(n) \\
\hline GIT & Gastrointestinaltrakt \\
\hline His & Histidin \\
\hline HM & teilentfettetes Hermetia illucens Mehl \\
\hline IAAR & Ideales Aminosäuren-Verhältnis (engl. ideal amino acid ratio) \\
\hline Ile & Isoleucin \\
\hline LAAI & $\begin{array}{l}\text { tägliche Aufnahme an limitierender Aminosäure pro kg metabolische } \\
\text { Lebendmasse }\end{array}$ \\
\hline LAVES & $\begin{array}{l}\text { Niedersächsisches Landesamt für Verbraucherschutz und } \\
\text { Lebensmittelsicherheit }\end{array}$ \\
\hline Leu & Leucin \\
\hline $\mathrm{LM}$ & Lebendmasse \\
\hline $\mathrm{LM}_{\mathrm{kg}}{ }^{0,67}$ & metabolische Lebendmasse \\
\hline LMZ & Lebendmassezunahme \\
\hline Lys & Lysin \\
\hline Met & Methionin \\
\hline MHA & Methionin-Hydroxy-Analog \\
\hline $\operatorname{MLM}_{\mathrm{kg}}{ }^{0,75}$ & mittlere metabolische Lebendmasse \\
\hline
\end{tabular}


NDF

$\mathrm{p}$

PAP

PAS

$\mathrm{pcV}$

Phe

$\mathrm{PNu}$

$\mathrm{PNu}_{\text {std. }}$

SAS

SES

Thr

TM

TMP

Trp

Val

VDLUFA

XA

XF

XL

XLD

XP

XPD
Neutrale Detergenzienfaser

Irrtumswahrscheinlichkeit

verarbeitetes tierisches Protein (engl. processed animal protein)

Periodic acid-Schiff Reaktion

praecaecale Verdaulichkeit

Phenylalanin

physiologischer Nutzwert

standardisierter physiologischer Nutzwert

schwefelhaltige Aminosäuren

Sojaextraktionsschrot

Threonin

Trockenmasse

Tenebrio molitor Presskuchen

Tryptophan

Valin

Verband Deutscher Landwirtschaftlicher Untersuchungs- und Forschunganstalten e.V.

Rohasche

Rohfaser

Rohfett

Rohfettansatz

Rohprotein

Rohproteinansatz 


\section{Einleitung}

\section{Einleitung}

Laut FAO wird die Weltbevölkerung bis 2050 auf 9,2 Mrd. Menschen ansteigen. Das entspricht einem Anstieg von über einem Drittel und bedeutet, dass die Nahrungsmittelproduktion um $70 \%$ gesteigert werden muss, um alle Menschen ernähren zu können (FAO, 2009a, b). Die weltweit produzierte Menge an Fleisch, Milchprodukten und Eiern wird deshalb voraussichtlich auf 455 Mio. $\mathrm{t}$ in 2050 ansteigen und das größte Wachstum wird im Bereich der Geflügelproduktion erwartet (FAO, 2012; s. Abb. 1).

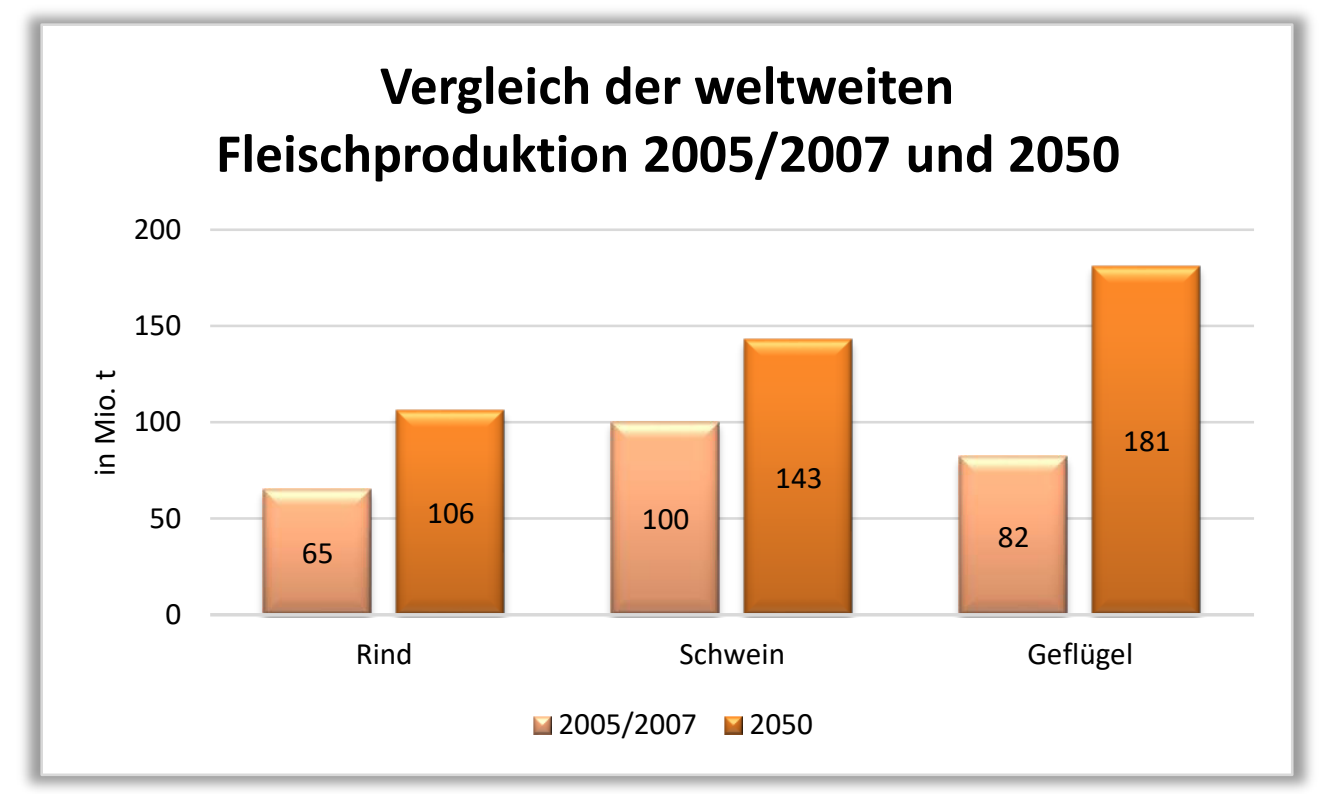

Abbildung 1: Vergleich der weltweiten Fleischproduktion 2005/2007 und 2050 (nach FAO, 2012).

In der EU wurden im Jahr 2017 rund 488 Mio. t Futter eingesetzt (FEFAC, 2018) und insgesamt nehmen die Futterkosten 50-70\% der gesamten Produktionskosten ein (Spring, 2013). Ein Ansatz zur Senkung der Kosten ist die Absenkung des Rohprotein(XP)-Gehaltes im Futter. Diese Maßnahme führt neben finanziellen Vorteilen auch zu geringeren $\mathrm{N}$-Ausscheidungen und somit $\mathrm{zu}$ Minderungen der Emissionen in der Nutztierhaltung sowie zu einer geringeren Stoffwechselbelastung für die Tiere (s. z.B. Ferguson et al., 1998; Bregendahl et al., 2002). Um den XP-Gehalt weiter abzusenken, ohne dass dies mit negativen Auswirkungen auf die Leistung der Tiere verbunden ist, sind noch genauere Kenntnisse über den Aminosäure(AS)-Bedarf der Tiere essentiell.

Eine Möglichkeit die AS-Bedarfsrelationen zuverlässig zu beschreiben, bietet das IdealeAminosäuren-Verhältnis (IAAR, engl. für ideal amino acid ratio). Es wurde erstmals von Cole 
et al. (1980) für die Schweineernährung empfohlen und für die Geflügelernährung seitdem beständig weiterentwickelt. Das Prinzip des IAAR besteht darin, eine möglichst ideale Balance zwischen den einzelnen AS im Futter herzustellen (Dozier und Mercier, 2013). Alle AS werden hierbei im Verhältnis zu Lysin (Lys) angegeben. Lys wird aus dem Grund als Referenz-AS genutzt, dass es hauptsächlich für den Proteinansatz verwendet wird, die Analyse gut standardisiert ist und ausreichend zuverlässige Bedarfsangaben bekannt sind (Baker und Han, 1994; Emmert und Baker, 1997; Mack et al., 1999). Es gibt bereits viele Studien, die sich mit dem IAAR in der Ernährung von Masthähnchen befasst haben (u.a. Baker und Han, 1994; Mack et al., 1999; Baker et al., 2002; Goulart et al., 2011; Salehifar et al., 2012; Pastor et al., 2013; Wecke und Liebert, 2013; Wecke et al., 2013). Die schwefelhaltigen AS (SAS) Methionin (Met) und Cystein (Cys) werden in den Untersuchungen i.d.R. als Summe angeben, doch aufgrund der engen metabolischen Beziehung dieser beiden AS zueinander (s. Literaturübersicht) ist auch das Met:Cys-Verhältnis bei der optimalen AS-Versorgung von großer Bedeutung. Literaturangaben über das optimale Verhältnis schwanken zum Teil jedoch sehr deutlich, was eine klare Empfehlung erschwert. Während z.B. einige Autoren (Sasse und Baker, 1974; Featherston und Rogler, 1978; Sell et al., 1980; Tsiagbe et al., 1987; Dilger und Baker, 2007, 2008a) einen negativen Einfluss eines Met-Anteils von $<50 \%$ der SAS auf die Futteraufnahme (FI) und das Wachstum von Masthähnchen beobachteten, empfahlen andere Studien einen solchen Anteil an Met (Graber et al., 1971; Sünder et al., 2015a; Ohta und Ishibashi, 1994). Sowohl ein zu hoher Met- als auch Cys-Anteil an den SAS führen jedoch zu einer Verschlechterung der Wachstumsleistung und wirken sich zudem auf die Körperzusammensetzung der Tiere aus (s. z.B. Graber und Baker, 1971; Sekiz et al., 1975; Featherston und Rogler, 1978; Harter und Baker, 1978; Dilger und Baker, 2007, 2008a, b; Bunchasak, 2009; Conde-Aguilera et al., 2013, 2016). Aus diesem Grund sollen die im Rahmen der vorliegenden Arbeit durchgeführten Untersuchungen dazu beitragen, das optimale Met:Cys-Verhältnis in Futtermischungen für Masthähnchen weiter eingrenzen zu können, um eine bedarfsgerechte Versorgung der Tiere zu gewährleisten und Stoffwechselbelastungen sowie Leistungseinbußen zu minimieren.

Ca. 28\% der Rohstoffe, die in der Mischfutterproduktion in Deutschland eingesetzt werden, sind Ölkuchen, Expeller und Extraktionsschrote, von denen etwa die Hälfte aus Sojabohnen hergestellt wird (DVT, 2016). Auch in der Geflügelernährung ist Soja die am häufigsten eingesetzte Proteinquelle (Baker, 2009). Aufgrund der prognostizierten Steigerung der weltweiten Geflügelproduktion wird sich der Proteinbedarf für die Mischfutterherstellung ebenfalls deutlich erhöhen. Da sich der Anbau von Soja jedoch wegen des Mangels an 


\section{Einleitung}

nutzbarem Land nicht unbegrenzt steigern lässt (Veldkamp et al., 2012) und zudem in der Gesellschaft vermehrt in der Kritik steht, ist die Suche nach alternativen Proteinquellen ein aktuelles Thema in der Tierernährung. Ziel ist es, die Einsatzmengen von Soja in den Futtermischungen $\mathrm{zu}$ reduzieren. Eine vielversprechende alternative Proteinquelle sind Insekten, da diese sich durch einen hohen XP-Gehalt und eine günstige AS-Zusammensetzung auszeichnen. Bisherige Versuche (z.B. Bovera et al., 2015; Marono et al., 2015; Cullere et al., 2016; Maurer et al., 2016; Biasato et al., 2016, 2018a, b; Neumann et al., 2018a, b; Velten et $a l ., 2018 \mathrm{a}, \mathrm{b})$ haben gezeigt, dass der Einsatz verschiedener Insektenarten in der Ernährung von Geflügel ohne größere Probleme bei der AS-Versorgung möglich ist. Diese These sollte durch die durchgeführten Versuche weiterhin untermauert werden. Hierfür wurden in Futtermischungen für Masthähnchen sowohl ein teilentfettetes Mehl aus Larven der Schwarzen Soldatenfliege Hermetia illucens (HM) als auch ein Presskuchen aus den Larven des Mehlwurmkäfers Tenebrio molitor (TMP) als Proteinquelle eingesetzt und mit dem traditionellen Proteinträger Sojaextraktionsschrot (SES) verglichen.

Ziel dieser Arbeit war es somit, das optimale Met:Cys-Verhältnis in der Ernährung von Masthähnchen weiter zu präzisieren und hierbei die Larven der Schwarze Soldatenfliege Hermetia illucens und des Mehlkäfers Tenebrio molitor als alternative Proteinquelle einzusetzen, um deren Einsatzmöglichkeiten weiter zu evaluieren und zu prüfen, ob diese neuen Proteinträger einen Einfluss auf das optimale Met:Cys-Verhältnis in der Hähnchenmast haben. 


\section{Literaturübersicht}

\subsection{Die schwefelhaltigen Aminosäuren in der Mastgeflügelernährung}

Im Zuge der Einarbeitung in das Thema der vorliegenden Dissertation wurde eine ausführliche Literaturrecherche zum Thema SAS in der Ernährung von Mastgeflügel durchgeführt und die Ergebnisse in einer Übersichtsarbeit zusammengefasst, diskutiert und kritisch hinterfragt. Dabei wurde nicht nur auf Angaben zu Gehalten an SAS in Futtermitteln und im Tierkörper, sondern auch auf den Stoffwechsel der SAS sowie Möglichkeiten zur Bedarfsermittlung und aktuelle Versorgungsempfehlungen eingegangen. Es wurde deutlich, dass die Bedarfsbewertung nicht zuletzt aufgrund des engen metabolischen Zusammenhangs zwischen Met und Cys (möglicher Met-Abbau zur Deckung des Cys-Bedarfs) sowie den jeweils vorliegenden unterschiedlichen experimentellen Bedingungen erschwert wird. Kenntnisse über den Bedarf an den Gesamt-SAS reichen demnach nicht aus, sondern müssen unbedingt das Met:Cys-Verhältnis berücksichtigen. Die vollständige Übersichtsarbeit (Brede et al., 2018) findet sich in Anhang dieser Dissertation (Publikation I). Da die hierfür durchgeführte Literaturrecherche jedoch bereits einige Zeit zurückliegt, soll nachfolgend eine Aktualisierung vorgenommen werden.

\section{$\underline{\text { Vorkommen schwefelhaltiger Aminosäuren }}$}

Wie von Brede et al. (2018) berichtet, weist das Federprotein eine hohe Konzentration an Cys auf, während Met dagegen hauptsächlich im Protein der Muskulatur und der Innereien zu finden ist. Dies spiegelt sich auch in den Werten in Tabelle 1 wider. Wecke et al. (2018a) stellten zudem einen signifikanten Einfluss des Alters der Tiere auf den AS-Gehalt in den Körperfraktionen fest. So nahm der Gehalt an Met und Cys im Federprotein bis zum Ende der Starterphase zu und im Anschluss wieder ab. Im Gegensatz dazu konnte im federlosen Ganzkörper eine altersabhängige Abnahme des Cys-Gehaltes beobachtet werden, während der Met-Gehalt bis Tag 36 stetig anstieg. Der Cys-Gehalt im Ganzkörper nahm bis Tag 15 ab und stieg danach wieder an, es konnten jedoch keine signifikanten Veränderungen des Met-Gehaltes ab Tag 8 festgestellt werden. Während der Met-Gehalt in allen Körperfraktionen der weiblichen Tiere signifikant höher war, lag im federlosen Ganzkörper auch der Cys-Gehalt signifikant höher als bei den männlichen Tieren. 
Tabelle 1: Altersabhängige Gehalte und Relationen zwischen den S-haltigen Aminosäuren in den Federn und im federlosen Ganzkörper von Masthähnchen (nach Wecke et al., 2018a).

\begin{tabular}{|c|c|c|c|c|c|c|}
\hline \multirow{2}{*}{$\begin{array}{l}\text { Alter der } \\
\text { Tiere (d) }\end{array}$} & \multirow[t]{2}{*}{ Körperfraktion } & \multirow{2}{*}{$\begin{array}{c}\text { Rohprotein } \\
\text { (g/kg TM) }\end{array}$} & \multicolumn{3}{|c|}{$\begin{array}{c}\text { AS-Gehalte } \\
(\mathrm{g} / \mathbf{1 6 g N})\end{array}$} & \multirow[t]{2}{*}{ Met:Cys } \\
\hline & & & Lys & Met & Cys & \\
\hline 1 & \multirow{6}{*}{ Federn } & $1013^{a}$ & $\begin{array}{l}1,49^{\mathrm{c}} \\
(100)\end{array}$ & $\begin{array}{c}0,38^{\mathrm{e}} \\
(26)\end{array}$ & $\begin{array}{l}6,07^{\mathrm{c}} \\
(407)\end{array}$ & $1: 16,0$ \\
\hline 8 & & $996^{\mathrm{ab}}$ & $\begin{array}{l}2,09^{b} \\
(100)\end{array}$ & $\begin{array}{c}0,52^{\mathrm{c}} \\
(25)\end{array}$ & $\begin{array}{l}6,45^{\text {bc }} \\
(309)\end{array}$ & $1: 12,4$ \\
\hline 15 & & $963^{c}$ & $\begin{array}{l}2,43^{\mathrm{a}} \\
(100)\end{array}$ & $\begin{array}{c}0,60^{\mathrm{a}} \\
(25)\end{array}$ & $\begin{array}{l}6,74^{\mathrm{ab}} \\
(277)\end{array}$ & $1: 11,2$ \\
\hline 22 & & $974^{\mathrm{bc}}$ & $\begin{array}{l}2,36^{\mathrm{a}} \\
(100)\end{array}$ & $\begin{array}{c}0,56^{\mathrm{b}} \\
(24)\end{array}$ & $\begin{array}{l}7,14^{\mathrm{a}} \\
(303)\end{array}$ & $1: 12,8$ \\
\hline 29 & & $984^{\mathrm{abc}}$ & $\begin{array}{l}2,13^{b} \\
(100)\end{array}$ & $\begin{array}{c}0,50^{\mathrm{cd}} \\
(24)\end{array}$ & $\begin{array}{l}7,22^{\mathrm{a}} \\
(339)\end{array}$ & $1: 14,4$ \\
\hline 36 & & $991^{\mathrm{abc}}$ & $\begin{array}{l}2,05^{\mathrm{b}} \\
(100)\end{array}$ & $\begin{array}{c}0,47^{\mathrm{d}} \\
(23)\end{array}$ & $\begin{array}{l}6,87^{\mathrm{ab}} \\
(335)\end{array}$ & $1: 14,6$ \\
\hline 1 & \multirow{6}{*}{$\begin{array}{l}\text { Federloser } \\
\text { Ganzkörper }\end{array}$} & $708^{a}$ & $\begin{array}{l}6,51 \mathrm{~d} \\
(100)\end{array}$ & $\begin{array}{l}1,92^{\mathrm{c}} \\
(30)\end{array}$ & $\begin{array}{c}1,07^{\mathrm{a}} \\
(16)\end{array}$ & $1: 0,6$ \\
\hline 8 & & $651^{\mathrm{b}}$ & $\begin{array}{l}6,75^{\mathrm{c}} \\
(100)\end{array}$ & $\begin{array}{l}1,92^{\mathrm{c}} \\
(28)\end{array}$ & $\begin{array}{c}1,00^{\mathrm{b}} \\
(15)\end{array}$ & $1: 0,5$ \\
\hline 15 & & $634^{\mathrm{bc}}$ & $\begin{array}{l}6,83^{\mathrm{bc}} \\
(100)\end{array}$ & $\begin{array}{l}1,94^{\mathrm{c}} \\
(28)\end{array}$ & $\begin{array}{c}0,95^{\mathrm{bc}} \\
(14)\end{array}$ & $1: 0,5$ \\
\hline 22 & & $629^{\mathrm{bcd}}$ & $\begin{array}{l}6,83^{\mathrm{bc}} \\
(100)\end{array}$ & $\begin{array}{c}1,94^{\mathrm{bc}} \\
(28)\end{array}$ & $\begin{array}{c}0,94^{\mathrm{c}} \\
(14)\end{array}$ & $1: 0,5$ \\
\hline 29 & & $611^{\mathrm{cd}}$ & $\begin{array}{c}7,03^{\mathrm{ab}} \\
(100)\end{array}$ & $\begin{array}{c}2,00^{\mathrm{ab}} \\
(28)\end{array}$ & $\begin{array}{c}0,92^{\mathrm{c}} \\
(13)\end{array}$ & $1: 0,5$ \\
\hline 36 & & $602^{\mathrm{d}}$ & $\begin{array}{c}7,06^{\mathrm{a}} \\
(100)\end{array}$ & $\begin{array}{c}2,01^{\mathrm{a}} \\
(29)\end{array}$ & $\begin{array}{c}0,94^{\mathrm{c}} \\
(13)\end{array}$ & $1: 0,5$ \\
\hline 1 & \multirow{6}{*}{ Ganzkörper } & $739^{\mathrm{a}}$ & $\begin{array}{l}5,81^{\mathrm{b}} \\
(100)\end{array}$ & $\begin{array}{l}1,70^{\mathrm{b}} \\
(29)\end{array}$ & $\begin{array}{l}1,77^{\mathrm{a}} \\
(31)\end{array}$ & $1: 1,0$ \\
\hline 8 & & $667^{\mathrm{b}}$ & $\begin{array}{l}6,43^{\mathrm{a}} \\
(100)\end{array}$ & $\begin{array}{c}1,83^{\mathrm{a}} \\
(29)\end{array}$ & $\begin{array}{c}1,38^{\mathrm{de}} \\
(22)\end{array}$ & $1: 0,8$ \\
\hline 15 & & $648^{b c}$ & $\begin{array}{l}6,54^{\mathrm{a}} \\
(100)\end{array}$ & $\begin{array}{c}1,85^{\mathrm{a}} \\
(28)\end{array}$ & $\begin{array}{c}1,33^{\mathrm{e}} \\
(20)\end{array}$ & $1: 0,7$ \\
\hline 22 & & $648^{b c}$ & $\begin{array}{l}6,48^{a} \\
(100)\end{array}$ & $\begin{array}{l}1,83^{\mathrm{a}} \\
(28)\end{array}$ & $\begin{array}{l}1,42^{\text {cd }} \\
(22)\end{array}$ & $1: 0,8$ \\
\hline 29 & & $633^{\mathrm{c}}$ & $\begin{array}{l}6,58^{\mathrm{a}} \\
(100)\end{array}$ & $\begin{array}{c}1,86^{\mathrm{a}} \\
(28)\end{array}$ & $\begin{array}{c}1,49^{\mathrm{c}} \\
(23)\end{array}$ & $1: 0,8$ \\
\hline 36 & & $629^{c}$ & $\begin{array}{l}6,51^{\mathrm{a}} \\
(100)\end{array}$ & $\begin{array}{c}1,84^{\mathrm{a}} \\
(33)\end{array}$ & $\begin{array}{c}1,58^{\mathrm{b}} \\
(24)\end{array}$ & $1: 0,9$ \\
\hline
\end{tabular}

Angaben als Mittelwerte, unterschiedliche Hochbuchstaben kennzeichnen signifikante Unterschiede $(\mathrm{p}<0,05)$. 
$\underline{\text { Besonderheiten der Analytik der schwefelhaltigen Aminosäuren }}$

Neben dem Alter und dem Geschlecht der Tiere kann auch die Probenaufarbeitung einen Einfluss auf den AS-Gehalt in den Körperfraktionen haben. Hierbei sollte ein besonderes Augenmerk auf den Cys-Gehalt gelegt werden. Ebenso wie von Brede et al. (2018) anhand von vorläufigen Daten dargestellt, beobachteten auch Adler et al. (2018) eine Abnahme des CysGehaltes zum einen durch die Verarbeitung der Federn zu einem Federmehl und zum anderen durch die Prozesse Hydrolysieren und Autoklavieren. Dabei spielte auch die Art des Hydrolysierens und die Dauer des Autoklavierens eine Rolle. Die Autoren empfahlen eine Hydrolyse mit Natriumsulfit $\left(\mathrm{Na}_{2} \mathrm{SO}_{3}\right)$ in geringen Konzentrationen sowie anschließendes Autoklavieren von 60-90 Minuten, um die Verluste an den für das Geflügel essentiellen AS Threonin (Thr), Arginin (Arg) und Cys möglichst gering zu halten. Im Vergleich der AS wurden die größten Verluste aber dennoch für Cys beobachtet. Als mögliche Ursache hierfür gaben Adler et al. (2018) die Oxidation von Cys während der Probenaufarbeitung an. Eine Reduzierung des Cys-Gehaltes beobachteten auch Kaewtapee et al. (2017) bei schrittweiser Erhöhung der Dauer des Autoklavierens von Vollfett-Sojabohnen von 15 auf 60 Minuten und führten dies auf die Maillard-Reaktion zurück.

\section{Bioverfügbarkeit der schwefelhaltigen Aminosäuren aus Futtermitteln}

Da die analysierten AS-Gehalte dem Tier jedoch nicht in vollem Umfang zur Verfügung stehen, wird häufig die Verdaulichkeit als Maß für ihre Verfügbarkeit hinzugezogen. Um zu verhindern, dass mikrobielle Umsetzungen die Verdaulichkeitswerte verfälschen, empfiehlt es sich die praecaecale Verdaulichkeit (pcV) zu ermitteln (Brede et al., 2018). Bei der Bewertung verschiedener Verdaulichkeitswerte gilt es zu beachten, dass unterschiedliche Faktoren wie z.B. die Herkunft und Art der Bearbeitung des Futtermittels sowie Genotyp und Alter der Versuchstiere einen Einfluss auf die Parameter haben können. Darüber hinaus spielt auch der Nährstoffgehalt in der Futtermischung eine Rolle. So steigt laut Cerrate et al. (2018) die scheinbare $\mathrm{pcV}$ von Cys mit einem steigenden Rohfett(XL)-Gehalt signifikant an und die von Met wird ebenfalls tendenziell erhöht. Steigende Gehalte an neutraler Detergenzienfaser (NDF) haben dagegen einen signifikant negativen Effekt auf die scheinbare pcV von Met, während der Einfluss auf die scheinbare $\mathrm{pcV}$ von Cys bis zu einem NDF-Gehalt von $14 \%$ steigt und bei weiterer Steigerung des NDF-Gehaltes wieder sinkt. Olojede et al. (2018) untersuchten den Einfluss der Trocknungsmethode und der Temperatur bei der Aufarbeitung der entnommenen Chymus-Proben auf die scheinbare $\mathrm{pcV}$ der AS. Sie verglichen dabei Gefrier- und Ofentrocknung und Temperaturen von $40 \mathrm{bzw} .55^{\circ} \mathrm{C}$ und stellten keinen signifikanten Einfluss 


\section{Literaturübersicht}

fest. Zusätzlich verglichen die Autoren den Einsatz von Chrom- bzw. Titanoxid als unverdauliche Marker und konnten auch hier keinen Effekt auf die pcV der AS beobachten. Im Gegensatz dazu hatte jedoch die Methode, die zur Sammlung des Chymus angewendet wurde, einen Einfluss. So wurde beim Ausstreifen des Chymus aus dem Darm eine signifikant höhere scheinbare $\mathrm{pcV}$ für Met und Arg ermittelt als beim Ausspülen des entsprechenden Darmabschnittes mit destilliertem Wasser.

\section{$\underline{\text { Palette der schwefelhaltigen Aminosäuren als Futterzusatzstoffe }}$}

Aufgrund der limitierenden Position der SAS in klassischen Proteinträgern für das Geflügel (Warnick und Anderson, 1968; Emmert und Baker, 1997; Baker, 2006; Bunchasak, 2009; Brede et al., 2018) muss in Futtermischungen für Geflügel eine Supplementation dieser AS vorgenommen werden, um den Bedarf zu decken. Diese kann entweder in Form von synthetischem L-Met, DL-Met oder einem Met-Hydroxyanalog (MHA) erfolgen. Über die Wirksamkeit dieser beiden Met-Quellen herrscht zum Teil jedoch Uneinigkeit (s. Brede et al., 2018, Kapitel 2.5). Während Makama et al. (2017) ein signifikant besseres Wachstum von Masthähnchen durch die Supplementation von MHA im Vergleich zu DL-Met feststellten, konnten Hoehler et al. (2005) keine Unterschiede in Bezug auf die Lebendmassezunahme (LMZ) und Futterverwertung beobachten. Willemsen et al. (2011) ermittelten dagegen signifikant höhere Lebendmassen (LM) durch den Einsatz von MHA im Vergleich zu DL-Met, stellten dies jedoch erst in der 6. Lebenswoche fest. Andere Autoren verglichen den Einfluss von L- und DL-Met auf die Leistung von Masthähnchen (Esteve-Garcia und Khan, 2018), Puten (Park et al., 2018) sowie Pekin-Enten (Xue et al., 2018) und konnten keine signifikanten Unterschiede beobachten. Auch ein direkter Vergleich von L-, DL-Met und MHA in der Fütterung von Puten zeigte keinen Effekt auf die Leistung (Jankowski et al., 2017).

Darüber hinaus wird zudem der mögliche Einfluss der Met-Quelle auf das Immunsystem diskutiert. So wurde in mehreren Studien eine Verbesserung des oxidativen Status von Masthähnchen, Puten und Enten durch den Einsatz von MHA verglichen mit DL-Met festgestellt (Fang et al., 2010; Swennen et al., 2011; Willemsen et al., 2011; Jankowski et al., 2017; Zhao et al., 2018) und Park et al. (2018) berichteten von einer stärkeren Verringerung von oxidativem Stress durch L-Met im Vergleich zu DL-Met. Zduńczyk et al. (2017) ermittelten dagegen einen größeren positiven Effekt von DL-Met verglichen mit MHA auf den oxidativen Status von Puten, während Zeitz et al. (2018) sowie Zhang et al. (2018) keinen Einfluss der Met-Quelle auf den oxidativen Status beobachten konnten. 
Bei der Bewertung der Effizienz von MHA und DL-Met kamen sowohl Hoehler et al. (2005) als auch Sauer et al. (2008) und die EFSA (2012) zu dem Schluss, dass MHA eine geringere Bioverfügbarkeit aufweist. Vázquez-Añón et al. (2006, 2017) schlussfolgerten aufgrund der unterschiedlichen chemischem Struktur von MHA und DL-Met, die zu Unterschieden in der Absorption und dem Stoffwechsel beider Met-Quellen führt, unterschiedliche Dosis-WirkungsKurven. Bei gewöhnlichen Einsatzmengen der beiden Met-Quellen sei die Effizienz von MHA und DL-Met jedoch vergleichbar (Vázquez-Añón et al., 2017). Esteve-Garcia und Khan (2018) und Park et al. (2018) untersuchten die relative Bioverfügbarkeit von L- und DL-Met an Masthähnchen und Puten und kamen dabei zu unterschiedlichen Ergebnissen. Während EsteveGarcia und Khan (2018) eine geringere Bioverfügbarkeit für DL-Met feststellten, ermittelten Park et al. (2018) einen höheren Wert als für L-Met.

\section{$\underline{\text { Stoffwechsel der schwefelhaltigen Aminosäuren }}$}

Unabhängig von der Met-Quelle besteht zwischen den beiden SAS Met und Cys ein enger metabolischer Zusammenhang. Über den Abbau von Met über Homocystein (HCy) zu Cys via Transmethylierung und Transsulfurierung (s. Brede et al., 2018) kann ein Cys-Mangel bis zu einem gewissen Grad ausgeglichen werden. In einer aktuellen Studie von Vilar da Silva et al. (2018) wurden die Auswirkungen einer Hemmung der Transsulfurierung bei Masthähnchen untersucht. Die Autoren stellten negative Auswirkungen auf das Wachstum der Tiere, die Entwicklung der Federfollikel und die Dicke der Epidermis fest. Dabei trat der Effekt auf Haut und Federn früher auf als auf das Wachstum der Tiere (Tag 10 vs. Tag 35). Dies ist jedoch nicht verwunderlich, da nach Untersuchungen von Wecke et al. (2017) der Federanteil ab der zweiten Lebenswoche ansteigt und dem Cys somit in diesem Altersabschnitt offensichtlich eine besondere Bedeutung zukommt.

Während der vollständige Abbau von Met über HCy zu Cys irreversibel ist (Brosnan und Brosnan, 2006), besteht die Möglichkeit der Remethylierung von HCy zu Met. Diese kann entweder über eine Folsäure- und Vitamin $B_{12}$-abhängige Met-Synthase oder eine Betain-HCyMethyltransferase erfolgen, ihre quantitative Bedeutung beim Geflügel ist jedoch unbekannt (Pillai et al., 2006). Dennoch untersuchten Aggrey et al. (2018) den Einfluss eines Met-Mangels auf die Remethylierung und stellten fest, dass sie in der Leber und im Duodenum über eine Folsäure- und Vitamin $\mathrm{B}_{12}$-abhängige Met-Synthase abläuft. Im Pectoralis major und Musculus gastrocnemius erfolgte sie dagegen mittels Betain-HCy-Methyltransferase. Ein Mangel an Met führte zu einer Herabregulierung einiger Methyltransferasen in der Leber, was wiederum geringe Gehalte an S-Adenosylmethionin bewirkte und oxidativen Stress auslösen kann 


\section{Literaturübersicht}

(Aggrey et al., 2018). In der Muskulatur hatte der Met-Mangel dagegen eine Hochregulierung der Methyltransferasen zur Folge (Aggrey et al., 2018). Dies führte die Autoren zu der Schlussfolgerung, dass die Gene im Met-Stoffwechsel in den Geweben unterschiedlich reguliert werden.

\section{Wechselwirkungen mit Cholin und Betain}

Eine der vielen Funktionen von Met ist die Versorgung mit Methylgruppen, die unter anderem für die Synthese von Carnitin und Kreatin benötigt werden (Schutte et al., 1997). Da neben dem Met beispielsweise auch Cholin und Betain im Stoffwechsel als Methylgruppenlieferanten dienen können, wurde bereits vielfach untersucht, ob der Einsatz dieser Verbindungen eine Met-Sparwirkung hat. Betain ist ein Osmolyt, der unter anderem Dehydrierungen entgegenwirken und die mikrobielle Fermentation im Gastrointestinaltrakt (GIT) verbessern kann (Saeed et al., 2017). Die organische Base Cholin ist beispielsweise am Aufbau der Zellmembran beteiligt (Fuller, 2004). Chen et al. (2018) supplementierten bis zu $1000 \mathrm{mg} / \mathrm{kg}$ Betain zu einer Futtermischung für Masthähnchen mit einem den Versorgungsempfehlungen des NRC (1994) entsprechenden Met-Gehalt und stellten durch die Betain-Gabe eine signifikant bessere Futterverwertung sowie signifikant höheres Wachstum fest. Mahmoudi et al. (2018) schlossen aus ihren Untersuchungen, dass die notwendige Met-Zufuhr von Masthähnchen bei Hitzestress um 20\% reduziert werden kann, wenn 320 mg/kg Betain, bis zu $560 \mathrm{mg} / \mathrm{kg}$ Cholin oder eine Kombination aus $160 \mathrm{mg} / \mathrm{kg}$ Betain und $140 \mathrm{mg} / \mathrm{kg}$ Cholin supplementiert wird. Demnach können sowohl Betain als auch Cholin das Met zwar nicht ersetzen, aber zu einer Verbesserung der Nutzung von Met im Stoffwechsel beitragen.

\section{$\underline{\text { Bedarf an schwefelhaltigen Aminosäuren }}$}

Da die SAS in Futtermischungen für Geflügel i.d.R. limitierend wirken, muss wie bereits erwähnt eine Supplementation mit synthetischem Met erfolgen. Um eine optimale Supplementation zu gewährleisten, sind Kenntnisse über den Bedarf der Tiere an diesen AS unbedingt notwendig. Eine Möglichkeit Bedarfsempfehlungen für die SAS zu formulieren, stellt das bereits beschriebene IAAR-Konzept dar. In der Arbeit von Brede et al. (2018) sind Angaben zum idealen Verhältnis der SAS zum Lys in Tabelle 7 aufgeführt. Idealerweise werden Met und Cys dabei separat betrachtet, häufig werden sie aber dennoch als Summe angegeben. Auch Spek (2018) nahm keine Einzelbetrachtung der SAS vor und führte eine Meta-Analyse mit insgesamt 15 Studien auf Basis der standardisierten praecaecal verdaulichen AS durch. Die Auswertung ergab ein ideales SAS:Lys-Verhältnis von 73:100 für die LMZ und 
von 74:100 für die Futterverwertung von Masthähnchen im Alter von 10-24 Tagen. Diese Werte ordnen sich in die von Brede et al. (2018) genannten Verhältnisse ein. Aktuelle Studien, in denen eine Einzelbetrachtung der SAS vorgenommen wurde, können in diesem Zusammenhang nicht aufgeführt werden.

\section{Auswirkungen unterschiedlicher Versorgungsgrade}

Der optimale SAS-Gehalt in Futtermischungen für Masthähnchen hängt unter anderem vom Produktionsziel ab (Carvalho et al., 2018). Eine bedarfsdeckende Supplementation von Met hat dabei positive Effekte auf die Leistung der Tiere (Jahanian und Khalifeh-Gholi, 2018; Jariyahatthakaij et al., 2018; Pontin et al., 2018), eine leichte Überdosierung bringt dagegen keine weitere Verbesserung (Jahanian und Khalifeh-Gholi, 2018; Pontin et al., 2018). Sowohl ein Mangel als auch ein Überschuss an Met führen jedoch zu einem signifikant schlechteren Wachstum (Wen et al., 2017; Peng et al., 2018; Xue et al., 2018).

Darüber hinaus hat der Versorgungsgrad mit Met auch einen Einfluss auf das Immunsystem und die Körperzusammensetzung der Tiere. Wu et al. (2018) beobachteten bei Met-Mangel einen signifikanten Rückgang des Immunglobulin-Gehaltes im Duodenum und Jejunum von wachsenden Masthähnchen und Jahanian und Khalifeh-Gholi (2018) fanden einen negativen Effekt auf die Antikörper-Antwort gegen virale und nicht-virale Antigene. Auch in den Untersuchungen von Zhang und Guo (2018) führte ein Mangel an Met zu einem Rückgang der Immunkompetenz.

Hohe Met-Dosen unterstützen den Körper dagegen bei der Abwehr gegen eine Eimeria tenella Infektion, verbessern die Immunfunktion und Darmmorphologie und verringern Läsionen im Caecum sowie die Anzahl der Oozyten in den Exkrementen (Lai et al., 2018).

Zusätzlich bewirkt eine Unterversorgung mit Met auch eine Steigerung der Expression entzündlicher Cytokine, was zu einer Fettakkumulation in der Leber und damit verbunden zu möglichen Verletzungen der Hepatozyten führt (Peng et al., 2018). Durch eine bedarfsdeckende Gabe von Met kann der Fettansatz dagegen verringert werden (Jariyahatthakaij et al., 2018).

Die beschriebenen Auswirkungen unterschiedlicher Met-Versorgungsgrade sind im Einfluss auf den Met-Stoffwechsel begründet. Durch eine Überversorgung mit Met kann unter Umständen auch der Bedarf an Cys gedeckt werden, ohne dass es durch den Abbau von Met zu einem Mangel an dieser AS kommt. Um diese Theorie zu bestätigen, sind jedoch Kenntnisse über den Cys-Gehalt in den eingesetzten Futtermischungen notwendig. Gleiches gilt für einen Met-Mangel, der durch eine gleichzeitige Unterversorgung mit Cys weiter verstärkt würde. 
$\underline{\text { Der Gehalt an schwefelhaltigen Aminosäuren in Insektenprotein }}$

Um die Tiere bedarfsdeckend versorgen zu können, sind neben den bereits erwähnten Kenntnissen über den Bedarf selbstverständlich auch Kenntnisse über den Gehalt der SAS in den eingesetzten Futtermitteln essentiell. Der SAS-Gehalt klassischer, ausgewählter Einzelfuttermittel, die in der Ernährung von Mastgeflügel eingesetzt werden, wurde bereits von Brede et al. (2018) aufgeführt. Neben den klassischen Proteinträgern wie SES rücken jedoch alternative Proteinquellen wie z.B. Insekten vermehrt in den Fokus der Tierernährung und kommen auch in den im Rahmen der vorliegenden Dissertation durchgeführten Untersuchungen zum Einsatz. Aus diesem Grund soll hier ein kurzer Überblick über die SASGehalte verschiedener Insektenarten (Tab. 2) gegeben werden, die für die Geflügelfütterung von Interesse sind. Den höchsten Gehalt an den SAS weisen die adulten Tiere von Musca domestica auf. Der Wert ist vergleichbar mit dem SAS-Gehalt in Weizen und Gerste. Die anderen hier aufgeführten Insektenarten zeichnen sich durch Gehalte an Met und Cys aus, die sich auf einem ähnlichen Niveau wie die Gehalte in Ackerbohnen, Erbsen und SES befinden. Auffällig ist zudem, dass das als optimal geltende Met:Cys-Verhältnis von 1:1 in keiner der Insektenarten erreicht wird und auch die Verhältnisse der SAS zu Lys stark von den Literaturempfehlungen (s. Brede et al., 2018, Tab 7) abweichen.

Tabelle 2: Gehalte und Relationen zwischen den S-haltigen Aminosäuren in ausgewählten Insektenarten.

\begin{tabular}{|c|c|c|c|c|c|c|}
\hline \multirow{2}{*}{ Insektenart } & \multirow{2}{*}{$\begin{array}{c}\mathrm{XP} \\
(\mathrm{g} / \mathrm{kg} \mathrm{FM})\end{array}$} & \multicolumn{4}{|c|}{$\mathrm{AS}(\mathrm{g} / 16 \mathrm{gN})$} & \multirow{2}{*}{ Met:Cys } \\
\hline & & Lys & Met & Cys & Met+Cys & \\
\hline $\begin{array}{l}\text { Acheta domesticus } \\
\qquad(\text { Nymphe })^{1}\end{array}$ & 154 & $\begin{array}{l}5,39 \\
(100)\end{array}$ & $\begin{array}{l}1,30 \\
(24)\end{array}$ & $\begin{array}{l}0,84 \\
(16)\end{array}$ & $\begin{array}{l}2,14 \\
(40)\end{array}$ & $1: 0,7$ \\
\hline $\begin{array}{l}\text { Acheta domesticus } \\
\qquad \text { (Adulte })^{1}\end{array}$ & 205 & $\begin{array}{l}5,37 \\
(100)\end{array}$ & $\begin{array}{l}1,46 \\
(27)\end{array}$ & $\begin{array}{l}0,83 \\
(16)\end{array}$ & $\begin{array}{l}2,29 \\
(43)\end{array}$ & $1: 0,6$ \\
\hline $\begin{array}{l}\text { Hermetia illucens } \\
\qquad(\text { Larven })^{2}\end{array}$ & 175 & $\begin{array}{l}6,80 \\
(100)\end{array}$ & $\begin{array}{l}1,93 \\
(28)\end{array}$ & $\begin{array}{l}0,58 \\
(9)\end{array}$ & $\begin{array}{l}2,51 \\
(37)\end{array}$ & $1: 0,3$ \\
\hline $\begin{array}{l}\text { Musca domestica } \\
\qquad(\text { Adulte })^{2}\end{array}$ & 197 & $\begin{array}{l}6,40 \\
(100)\end{array}$ & $\begin{array}{l}2,96 \\
(46)\end{array}$ & $\begin{array}{l}0,71 \\
(11)\end{array}$ & $\begin{array}{l}3,68 \\
(58)\end{array}$ & $1: 0,2$ \\
\hline 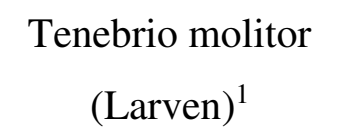 & 187 & $\begin{array}{l}5,46 \\
(100)\end{array}$ & $\begin{array}{l}1,28 \\
(23)\end{array}$ & $\begin{array}{l}0,86 \\
(16)\end{array}$ & $\begin{array}{l}2,14 \\
(39)\end{array}$ & $1: 0,7$ \\
\hline $\begin{array}{l}\text { Tenebrio molitor } \\
{\text { (Adulte })^{1}}\end{array}$ & 237 & $\begin{array}{l}4,43 \\
(100)\end{array}$ & $\begin{array}{l}1,27 \\
(29)\end{array}$ & $\begin{array}{l}0,68 \\
(15)\end{array}$ & $\begin{array}{l}1,94 \\
(44)\end{array}$ & $1: 0,5$ \\
\hline
\end{tabular}

${ }^{1}$ Finke (2002), ${ }^{2}$ Finke (2013) 


\section{Literaturübersicht}

Aufgrund der Besonderheiten im AS-Profil der Insekten stellt sich die Frage, ob ihr Einsatz in Futtermischungen für Geflügel womöglich das optimale Met:Cys-Verhältnis beeinflusst. Aus diesem Grund wird im nachfolgenden Kapitel zunächst näher auf die grundsätzliche Eignung von Insekten als alternative Proteinquelle eingegangen.

\subsection{Insekten als alternative Proteinquelle}

Insekten (aus dem Lateinischen, insectum = eingeschnitten) gehören zu den Arthropoden und zeichnen sich neben einem in drei Teile geteilten Körper, der von einem Exoskelett aus Chitin geschützt wird, durch das Vorhandensein von 6 Beinen und Facettenaugen aus (FAO, 2013). Es wird vermutet, dass es 6-10 Mio. Spezies gibt, bis heute wurden jedoch erst 1 Mio. Spezies beschrieben (FAO, 2013). Insekten sind bereits Teil der Ernährung von $1 \mathrm{Mrd}$. Menschen weltweit und 1900 Arten gelten als essbar (Jansson und Berggren, 2015). Neben der Verwendung in der Humanernährung wächst auch das Interesse daran, Insekten als alternative Proteinquelle in der Tierernährung einzusetzen, um traditionelle Futtermittel wie z.B. Soja und Fischmehl anteilig oder vollständig zu ersetzen (van Raamsdonk et al., 2017). Ein Grund für ihre grundsätzliche Eignung ist ihre Nährstoffzusammensetzung, so sind Insekten eine gute Quelle für Protein, Fett, Vitamine und Mineralstoffe (Khan, 2018). Makkar et al. (2014) berichteten von XP-Gehalten zwischen $42 \%$ und 63\% und XL-Gehalten von bis zu 36\%. Die Proteinqualität wird dabei als vergleichbar mit der von Kasein oder Soja eingeordnet (Rumpold und Schlüter, 2013). Zusätzlich sind Insekten reich an Kupfer, Eisen, Magnesium, Mangan, Phosphor, Selen und Zink sowie Vitamin B 2 , B 5 und Biotin (Rumpold und Schlüter, 2013). Es gilt jedoch zu bedenken, dass die Nährstoffgehalte sowohl von der Insektenart als auch dem Entwicklungsstadium abhängen.

Im Folgenden werden die im Rahmen der vorliegenden Dissertation verwendeten Insektenarten Hermetia illucens und Tenebrio molitor genauer beschrieben.

\subsubsection{Hermetia illucens}

Die Schwarze Soldatenfliege Hermetia illucens (Linnaeus) ist eine große wespenähnliche Fliege, die ursprünglich aus den tropischen und gemäßigten Regionen Amerikas stammt (Zhang et al., 2010). Sie gehört zur Ordnung der Diptera und zur Familie der Stratiomyidae (Devic und Fahmi, 2014) und ist mittlerweile in allen gemäßigten und tropischen Regionen der Welt zu finden (Byrd und Castner, 2010). Die Larven erreichen eine Länge von ca. $20 \mathrm{~mm}$ und eine Breite von $6 \mathrm{~mm}$, die adulten Tiere sind ca. 13 bis $20 \mathrm{~mm}$ lang (Devic und Fahmi, 2014). 
Während die Weibchen schwarz-blau gefärbt sind und die Männchen einen bräunlichen Bauch haben, sind die Larven grau bis braun (Byrd und Castner, 2010).

Die Weibchen leben fünf bis acht Tage und produzieren in dieser Zeit ca. 900 Eier (Williams, 2010), die sie in engen Reihen (Devic und Fahmi, 2014) vorzugsweise in trockenen Dung oder in verrottendes organisches Material ablegen. Die Entwicklung der Larven verläuft über fünf Larvenstadien (Devic und Fahmi, 2014), ein kompletter Lebenszyklus vom Ei bis zum adulten Tier dauert ca. 35 bis 60 Tage (Williams, 2010).

Die Larven der Schwarzen Soldatenfliege weisen einen hohen Rohnährstoffgehalt auf. Hervorzuheben sind hier vor allem der XP- und der XL-Gehalt (Tab. 3), der einen Einsatz der unbehandelten Larven in der Tierernährung einschränkt. In der Regel werden teilentfettete Larvenmehle eingesetzt, deren XP-Gehalt den in den unbehandelten Larven übersteigt. Auffällig sind zudem die großen Schwankungsbreiten vor allem im Rohasche(XA)- und Rohfaser(XF)-Gehalt, die in den unterschiedlichen Aufzuchtbedingungen der Larven begründet sein können. Der XF-Gehalt bedarf zudem zusätzlicher Beachtung.

Da die Fraktion der Säure-Detergenzien-Faser (ADF) in Insekten Stickstoff (N) enthält, ist zu vermuten, dass der XF-Gehalt z.T. aus Chitin besteht (Finke, 2007). Chitin ( $\beta$-(1,4)-Poly-NAcetyl D-Glucosamin) ist nach Cellulose das zweithäufigste Polysaccharid, das unter anderem typischerweise als $\alpha$-kristalline Form im Exoskelett von Insekten vorkommt (Lee et al., 2009; Waśko et al., 2016) und in seiner Struktur Cellulose stark ähnelt (Merzendorfer, 2006). Chitin dient der Erhöhung der Stabilität des Exoskeletts (Merzendorfer, 2006), dabei liegt es meistens in einer Matrix mit anderen Inhaltsstoffen wie z.B. Proteinen und Mineralstoffen vor (Kramer und Koga, 1986). Es ist stark hydrophob, d.h. es ist in Wasser und den meisten organischen Lösungsmitteln unlöslich und weist einen N-Gehalt von 5-8\% auf (Dutta et al., 2004). Über den Chitin-Gehalt in Hermetia illucens finden sich in der Literatur nur wenige Angaben. Diener et al. (2009) gaben einen Gehalt von 8,7\% Chitin in der Trockenmasse (TM) in Hermetia illucens Präpuppen an, Finke (2013) 5,4\% in der TM in den Larven. Der Gehalt scheint zudem bis zu einem gewissen Grad durch das Substrat, auf dem die Larven aufgezogen werden, beeinflusst werden zu können. Meneguz et al. (2018) stellten durch den Einsatz von Abfällen aus der Bierherstellung im Vergleich zu Abfällen aus der Weinherstellung eine signifikante Verringerung des Chitin-Gehaltes in den Larven von Hermetia illucens von 5,3 auf 1,4 g/kg TM fest. Der Vergleich einer Mischung aus Gemüse- und Obstabfällen und reinen Gemüseabfällen zeigte dagegen keinen signifikanten Effekt. Hier lagen die Chitin-Gehalte in den Larven bei 6,2 bzw. 5,6 g/kg TM. 
Häufig wird der Chitin-Gehalt mittels Bestimmung des ADF-Gehaltes ermittelt. Dies ist jedoch eine sehr ungenaue Methode. Hahn et al. (2018) verglichen diese klassische Bestimmungsmethode mit einer Kombination aus ADF und Säure-Detergenzien-Lignin (ADL) und einer Messung der Acetylgruppen. Sie kamen zu dem Schluss, dass beide neuen Methoden eine genauere Bestimmung des Chitin-Gehaltes ermöglichen, die ADF-ADL-Bestimmung jedoch Vorteile in der praktischen Durchführung hat. Song et al. (2018) verwendeten dagegen eine Methode, bei der die Probe bei verschiedenen Temperaturen mit $\mathrm{NaOH}$ versetzt wird.

Zusätzlich gilt es zu bedenken, dass der im Chitin enthaltene $\mathrm{N}$ bei der N-Bestimmung miterfasst wird, was in der Folge zu einer leichten Überschätzung des XP-Gehalts in den Insekten führen kann. Dies gaben auch Jonas-Levi und Itzhak Martinez (2017) an und empfahlen den Anteil an unverdaulichem N (wie z.B. der in Chitin gebundene N) vom Gesamt$\mathrm{N}$-Gehalt zu subtrahieren und einen neuen für alle Insektenarten geltenden Umrechnungsfaktor einzuführen. Laut Janssen et al. (2017) hat Chitin einen Anteil von 3,0-6,8\% am Gesamt-NGehalt und der Proteinumrechnungsfaktor für Insektenlarven sollte 4,76 betragen, um eine Überschätzung desXP-Gehaltes zu vermeiden.

Tabelle 3: Literaturangaben zum Rohnährstoffgehalt von Hermetia illucens Larven (in \% TM).

\begin{tabular}{cccccll}
\hline XP & XL & XA & XF & ADF & NDF & \multicolumn{1}{c}{ Quelle } \\
\hline 42,1 & 26,0 & 20,6 & 7,0 & k.A. & k.A. & Makkar et al., 2014 \\
40,4 & 33,5 & 7,1 & 9,7 & k.A. & k.A. & Józefiak et al., 2018 \\
46,7 & 42,2 & 5,6 & 1,6 & k.A. & k.A. & Ruhnke et al., 2018 \\
45,1 & 36,1 & 9,0 & k.A. & 7,7 & 9,8 & Finke, 2013 \\
43,2 & 28,0 & 16,6 & k.A. & k.A. & k.A. & Newton et al., 2005 \\
37,2 & 30,8 & 13,5 & k.A. & k.A. & k.A. & Tschirner und Simon, 2015 \\
42,3 & 27,1 & 11,0 & k.A. & k.A. & k.A. & Veldkamp und Bosch, 2015 \\
\hline
\end{tabular}

Für die Eignung als Proteinquelle ist neben dem XP-Gehalt vor allem der Gehalt an AS von entscheidender Bedeutung. Das AS-Muster der Larven von Hermetia illucens (Tab. 4) ist vergleichbar mit dem von SES (Veldkamp und Bosch, 2015) und weist eine Limitierung im Gehalt an Met und Cys auf. Somit stellen die Larven eine gute AS-Quelle dar. Allerdings gilt es, das relativ weite Methionin:Cystein-Verhältnis zu beachten. 


\section{Literaturübersicht}

Tabelle 4: Literaturangaben zum Gehalt ausgewählter Aminosäuren in Hermetia illucens Larven.

\begin{tabular}{cc}
\hline Aminosäure & Gehalt $(\mathrm{g} / 16 \mathrm{gN})$ \\
\hline Lys & $5,98 \pm 0,52$ \\
Met & $1,57 \pm 0,31$ \\
Cys & $0,67 \pm 0,25$ \\
Thr & $3,63 \pm 0,18$ \\
Arg & $4,97 \pm 0,88$ \\
Leu & $6,67 \pm 0,55$ \\
Ile & $4,14 \pm 0,41$ \\
His & $3,04 \pm 0,34$ \\
Phe & $4,06 \pm 0,58$ \\
Trp & $1,17 \pm 0,39$ \\
Val & $6,06 \pm 1,02$
\end{tabular}

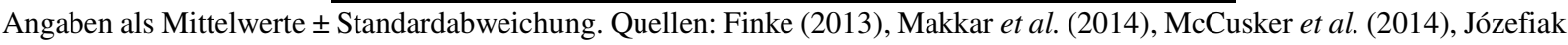
und Engberg (2015), Tschirner und Simon (2015), Veldkamp und Bosch (2015), Neumann et al. (2018a, b), Velten et al. (2018b).

Das Fettsäuren(FS)-Muster der Hermetia illucens Larven (Tab. 5) weist einen besonders hohen Anteil gesättigter FS auf, der nach Ramos-Bueno et al. (2016) und Liu et al. (2017) bei 85\% bzw. ca. 90\% liegt. Im Unterschied zu anderen Insektenarten ist vor allem der Anteil an Laurinsäure besonders hoch. Während z.B. die argentinische Schabe, Heimchen oder auch der Gelbe Mehlwurm Tenebrio molitor (s. Kapitel 2.2.2) <0,5\% Laurinsäure an den Gesamt-FS enthalten, liegt der Gehalt in Hermetia illucens Larven bei ca. 50\% (Oonincx et al., 2015). Außerdem übersteigt auch der Gehalt an Myristinsäure den in anderen Insektenarten (Oonincx et al., 2015). Allerdings variiert der FS-Gehalt in Abhängigkeit des Alters der Larven. So steigt der Gehalt an Caprin-, Laurin- und Myristinsäure mit zunehmendem Alter der Larven, während der Anteil an Palmitin-, Stearin-, Öl- und Linolsäure abnimmt (Liu et al., 2017). 


\section{Literaturübersicht}

Tabelle 5: Literaturangaben zum Fettsäuregehalt in Hermetia illucens Larven (\% der Gesamt-FS).

\begin{tabular}{|c|c|c|c|}
\hline Fettsäure & $\begin{array}{l}\text { Kroeckel } \\
\text { et al. } \\
\text { (2012) }\end{array}$ & $\begin{array}{l}\text { Liland } \\
\text { et al. } \\
\text { (2017) }\end{array}$ & $\begin{array}{c}\text { Schiavone } \\
\text { et al. } \\
(2017)\end{array}$ \\
\hline Caprinsäure 10:0 & 0,90 & k.A. & 1,43 \\
\hline Laurinsäure 12:0 & 47,00 & 40,60 & 52,6 \\
\hline Myristinsäure 14:0 & 6,50 & 8,50 & 8,54 \\
\hline Myristolensäure 14:1 & k.A. & k.A. & 0,17 \\
\hline Pentadecansäure 15:0 & k.A. & k.A. & k.A. \\
\hline Palmitinsäure 16:0 & 15,00 & 14,80 & 10,9 \\
\hline Palmitoleinsäure 16:1 & 3,10 & 2,00 & 1,98 \\
\hline Margarinsäure 17:0 & k.A. & k.A. & k.A. \\
\hline Margaroleinsäure 17:1 & k.A. & k.A. & k.A. \\
\hline Stearinsäure 18:0 & 2,20 & 2,50 & 1,53 \\
\hline Ölsäure 18:1 & 14,00 & 8,80 & 6,16 \\
\hline Linolsäure 18:2 & 9,40 & 17,90 & 11,6 \\
\hline Linolensäure 18:3 & 0,80 & 1,40 & 1,01 \\
\hline Arachinsäure 20:0 & k.A. & k.A. & k.A. \\
\hline Gondosäure 20:1 & $<0,01$ & k.A. & k.A. \\
\hline Arachidonsäure 20:4 & $<0,10$ & n.d. & 0,29 \\
\hline Behensäure 22:0 & k.A. & k.A. & k.A. \\
\hline
\end{tabular}

Zusätzlich ist zu bedenken, dass sich der Nährstoffgehalt in Hermetia illucens vor allem auch abhängig von dem Substrat, auf dem die Larven gezogen werden, verändern kann. Laut Spranghers et al. (2017) sind dabei vor allem der XL- und XA-Gehalt beeinflussbar. Tschirner und Simon (2015) beobachteten, dass sich der XL-Gehalt in den Larven bei Einsatz eines faserreichen Substrates signifikant von 30,8 \% auf 3,4\% in der TM verringerte, während der XP- und XA-Gehalt signifikant zunahmen. Durch den Einsatz eines proteinreichen Substrates konnte dagegen der Gehalt an XA signifikant verringert werden, wohingegen der XP- und XLGehalt signifikant anstiegen. Meneguz et al. (2018) untersuchten den Einfluss verschiedener Substrate aus Lebensmittelabfällen auf die Nährstoffzusammensetzung von Hermetia illucens Larven. Der Einsatz einer Mischung aus Gemüse- und Obstabfällen führte im Vergleich zu einem Substrat aus 100\% Gemüseabfällen zu signifikant höheren XL-Gehalten, während der Gehalt an XP und XA signifikant abnahm. Der Vergleich von Abfällen aus der Wein- und 
Bierherstellung ergab signifikant höhere XA- und XL-Gehalte durch den Einsatz von Abfällen aus der Weinherstellung als Substrat. Diese Ergebnisse sind auf die unterschiedlichen Nährstoffgehalte der Substrate zurückzuführen.

Darüber hinaus ist auch der FS-Gehalt in den Larven stark abhängig von der Zusammensetzung und der Art des Substrates. So führt ein hoher Anteil an Omega-3-FS im Substrat beispielsweise durch den Einsatz von Seetang, Fischmehl oder Fischabfällen zu einem erhöhten Gehalt dieser FS in den Larven (Barroso et al., 2017; Liland et al., 2017; St-Hilaire et al., 2007). In den Versuchen von Meneguz et al. (2018) bewirkte sowohl der Einsatz der Mischung aus Gemüseund Obstabfällen als auch der Abfälle aus der Weinherstellung signifikant höhere Gehalte an ungesättigten FS in den Larven. Dementsprechend ist die Wahl des richtigen Substrates bei der Produktion von Hermetia illucens ein wichtiger Faktor im Hinblick auf die ernährungsphysiologischen Eigenschaften und damit verbunden mit der Eignung als Futtermittel. Hier muss jedoch auch die Rechtslage (s. Kapitel 2.2.4) berücksichtigt werden, die eine Aufzucht auf Abfällen nicht zulässt. Der positive Effekt der Umwandlung von Abfällen in hochwertiges Protein kann dementsprechend gegenwärtig nicht ausgenutzt werden.

\subsubsection{Tenebrio molitor}

Der Mehlkäfer Tenebrio molitor ist eine Käferart (Coleoptera), die zur Familie Tenebrionidae gehört. Ursprünglich ist diese Art in Europa beheimatet, ist mittlerweile jedoch ubiquitär (Prabhakar, 2006). Die adulten Käfer sind schwarz-braun und ca. $1 \mathrm{~cm}$ lang (Ghaly und Alkoaik, 2009). Im Durchschnitt legt ein Weibchen 400-500 ovale weiße Eier entweder einzeln oder in Gruppierungen in geeignetes Material (Ghaly und Alkoaik, 2009). Die Eier sind von einem klebrigen Sekret bedeckt (Cotton, 1927) und bei Temperaturen um $25^{\circ} \mathrm{C}$ schlüpfen nach etwa 2 Wochen die Larven. Sie sind weiß und ca. $2 \mathrm{~mm}$ lang. Mit der Zeit nehmen sie eine gelb-braune Farbe an und wachsen auf eine Größe von bis $\mathrm{zu} 2,5 \mathrm{~cm}$. Unter optimalen Bedingungen dauert das Larvenstadium 6-8 Monate. Die Dauer des Puppenstadiums variiert je nach Umgebungstemperatur zwischen 6 und 18 Tagen. Die Puppen haben eine Länge von etwa $1 \mathrm{~cm}$ und im Gegensatz zu vielen anderen Insektenspezies keinen Kokon (Ghaly und Alkoaik, 2009). Sowohl die Larven als auch die adulten Tiere leben vorzugsweise in gelagertem Getreide (Howard, 1955) und richten dort große Schäden an (Siemianowska et al., 2013).

Die in Tabelle 6 dargestellten Literaturangaben zum Rohnährstoffgehalt der Larven von Tenebrio molitor zeigen hohe XP- und XL-Gehalte auf. Während der Gehalt an XL mit ca. 30\% mit dem der Hermetia illucens Larven vergleichbar ist, ist der XP-Gehalt mit ca. 50\% deutlich höher. Der XA-Gehalt in den Tenebrio molitor Larven ist dagegen im Vergleich eher gering 


\section{Literaturübersicht}

und weist keine so großen Schwankungsbreiten auf. Die im vorherigen Kapitel zu Hermetia illucens beschriebene Sonderrolle des XF-Gehaltes gilt auch für Tenebrio molitor. Im Vergleich scheint Tenebrio molitor jedoch einen geringeren Gehalt an Chitin aufzuweisen. Finke (2007) ermittelte für die adulten Tiere einen Gehalt von $137,2 \mathrm{mg} / \mathrm{kg}$ TM und für die hormonell behandelten Larven (Giant Mealworm) von 55,7 mg/kg TM. Song et al. (2018) gaben einen Chitin-Gehalt von 4,92\% in den Larven von Tenebrio molitor an. Dementsprechend dürfte auch die Überschätzung des XP-Gehaltes geringer ausfallen als bei der Bestimmung in Hermetia illucens.

Tabelle 6: Literaturangaben zum Rohnährstoffgehalt von Tenebrio molitor Larven (in \% TM).

\begin{tabular}{ccccccl}
\hline XP & XL & XA & XF & ADF & NDF & \multicolumn{1}{c}{ Quelle } \\
\hline 47,7 & 37,7 & 3,0 & 5,0 & k.A. & k.A. & Ramos-Elorduy et al., 2002 \\
48,4 & 38,5 & 2,8 & 8,5 & k.A. & k.A. & Rumpold und Schlüter, 2013 (Mittelwerte) \\
52,4 & 24,7 & 3,6 & 2,0 & k.A. & k.A. & Zielińska et al., 2015 \\
56,3 & 25,3 & 4,5 & 8,5 & k.A. & k.A. & Józefiak et al., 2018 \\
51,9 & 31,1 & 4,3 & k.A. & 0,5 & 14,5 & Barker et al., 1998 \\
49,1 & 35,2 & 2,4 & k.A. & 6,6 & 15,0 & Finke, 2002 \\
52,8 & 36,1 & 3,1 & k.A. & 6,5 & k.A. & Makkar et al., 2014 \\
58,4 & 30,1 & 4,8 & k.A. & 6,6 & k.A. & Sánchez-Muros et al., 2016 \\
\hline
\end{tabular}




\section{Literaturübersicht}

Der Gehalt ausgewählter AS in den Larven von Tenebrio molitor (Tab. 7) ist vergleichbar mit dem der Hermetia illucens Larven und SES. So weisen sie ebenfalls ein ausbalanciertes ASMuster mit einer Limitierung durch Met und Cys sowie ein weites Methionin:CysteinVerhältnis auf.

Tabelle 7: Literaturangaben zum Gehalt ausgewählter Aminosäuren in Tenebrio molitor Larven.

\begin{tabular}{cc}
\hline Aminosäure & Gehalt $(\mathrm{g} / 16 \mathrm{gN})$ \\
\hline Lys & $5,00 \pm 1,22$ \\
Met & $1,28 \pm 0,32$ \\
Cys & $0,80 \pm 0,18$ \\
Thr & $3,55 \pm 0,60$ \\
Arg & $4,36 \pm 1,21$ \\
Leu & $7,73 \pm 2,18$ \\
Ile & $4,08 \pm 1,10$ \\
His & $2,86 \pm 0,73$ \\
Phe & $3,25 \pm 0,88$ \\
Trp & $0,91 \pm 0,10$ \\
Val & $5,62 \pm 1,05$
\end{tabular}

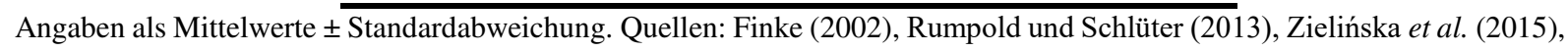
Józefiak und Engberg (2015), Sánchez-Muros et al. (2016).

Das FS-Muster der Tenebrio molitor Larven (Tab. 8) zeigt dagegen deutliche Unterschiede zu dem der Hermetia illucens Larven. So liegt der Anteil gesättigter FS bei lediglich 25\% (Zielińska et al., 2015) und Laurinsäure kommt nur in sehr geringen Mengen vor. Öl-, Linolund Palmitinsäure machen dagegen den größten Anteil der FS aus. Ebenso wie bei den Hermetia illucens Larven besteht auch bei Tenebrio molitor die Möglichkeit, das FS-Muster über die Ernährung der Larven zu beeinflussen. So war der Gehalt an gesättigten FS in auf Weizenbrot aufgezogen Larven signifikant höher als bei einer Mischung aus Bierhefe, Weizen-, Hafer- und Maismehl als Aufzuchtsubstrat (Dreassi et al., 2017). Auch der Einsatz von Leinsamen im Substrat führte zu erhöhten Gehalten an mehrfach ungesättigten FS, insbesondere an Linolensäure (Francardi et al., 2017). 


\section{Literaturübersicht}

Tabelle 8: Literaturangaben zum Fettsäuregehalt in Tenebrio molitor Larven (\% der Gesamt-FS).

\begin{tabular}{lccc}
\hline Fettsäure & $\begin{array}{c}\text { Fast } \\
(1966)\end{array}$ & $\begin{array}{c}\text { Siemianowska } \\
\text { et al. }(2013)\end{array}$ & $\begin{array}{c}\text { Sánchez-Muros } \\
\text { et al. (2015) }\end{array}$ \\
\hline Caprinsäure 10:0 & k.A. & k.A. & k.A. \\
Laurinsäure 12:0 & k.A. & 0,36 & k.A. \\
Myristinsäure 14:0 & 1,50 & 4,22 & 2,20 \\
Myristolensäure 14:1 & k.A. & k.A. & k.A. \\
Pentadecansäure 15:0 & k.A. & k.A. & k.A. \\
Palmitinsäure 16:0 & 23,60 & 21,53 & 16,60 \\
Palmitoleinsäure 16:1 & 4,50 & 1,86 & 2,20 \\
Margarinsäure 17:0 & k.A. & k.A. & k.A. \\
Margaroleinsäure 17:1 & k.A. & k.A. & k.A. \\
Stearinsäure 18:0 & 1,40 & 6,89 & 3,40 \\
Ölsäure 18:1 & 44,70 & 51,74 & 43,55 \\
Linolsäure 18:2 & 24,10 & 12,09 & 30,35 \\
Linolensäure 18:3 & 1,50 & 0,12 & 1,10 \\
Arachinsäure 20:0 & k.A. & 0,74 & k.A. \\
Gondosäure 20:1 & k.A. & k.A. & n.d. \\
Arachidonsäure 20:4 & k.A. & k.A. & k.A. \\
Behensäure 22:0 & k.A. & k.A. & k.A. \\
\hline
\end{tabular}

\subsubsection{Einsatz von Hermetia illucens und Tenebrio molitor in der}

\section{Masthähnchenfütterung}

Es existieren bereits mehrere Studien, in denen die Einsatzmöglichkeiten von Hermetia illucens in der Fütterung von Masthähnchen untersucht wurden. So setzten Leiber et al. (2017) und Onsongo et al. (2018) bis zu 15\% Hermetia illucens Mehl in Futtermischungen für wachsende Broiler ein und konnten keine negativen Effekte auf das Wachstum und die Futterverwertung beobachten. In einer Untersuchung von Moula et al. (2018) hatte der Einsatz von $8 \%$ frischen Hermetia illucens Larven bis zur 6. Lebenswoche der Tiere ebenfalls keinen Effekt auf die Futterverwertung und das Wachstum. Über die 6. Lebenswoche hinaus wiesen die Tiere durch den Einsatz der Hermetia illucens Larven jedoch höhere LM auf. Velten et al. (2018a) ersetzten 50\% des SES in einer Futtermischung für Masthähnchen mit teilentfettetem Hermetia illucens Mehl und stellten dabei einen positiven Effekt auf das Wachstum und die Futterverwertung fest. In einer weiteren Untersuchung beobachteten dieselben Autoren (Velten et al., 2018b) 
keine Unterschiede in der Proteinqualität sowie der scheinbaren $\mathrm{pcV}$ des XP und ausgewählter AS bei einem Austauschniveau von ebenfalls 50\%. Neumann et al. (2018a) verglichen den Effekt eines 50, 75 und 100\%igen Austauschs von SES durch teilentfettetes Hermetia illucens Mehl in Futtermischungen für Broiler im Altersbereich von 1-34 Tagen. Während sich ein 50 und 100\%iger Austausch positiv auf die finale LM auswirkten, führte ein Austauschniveau von 75\% zu keinen signifikanten Unterschieden. Die Futterverwertung war jedoch in allen Futtermischungen gegenüber der Kontrolle signifikant verbessert. In einer weiteren Studie (Neumann et al., 2018b) konnten im Gegensatz dazu jedoch keine signifikanten Unterschiede in Bezug auf die finale LM und die Futteraufnahme bei einem 100\%igen Austausch von SES durch Hermetia illucens Mehl beobachtet werden. Sowohl Neumann et al. (2018a, b) als auch Velten et al. (2018a, b) wiesen aber darauf hin, dass Futtermischungen mit Hermetia illucens Mehl ohne eine bedarfsgerechte Supplementation von AS zu signifikant schlechteren Ergebnissen führten als die Kontrolle.

Auch Tenebrio molitor Mehl wurde bereits in verschiedenen Untersuchungen in Futtermischungen für Masthähnchen eingesetzt. Während Khan et al. (2018) durch den Einsatz von $8,1 \%$ Tenebrio molitor Mehl eine signifikante Verringerung der Futteraufnahme und des Wachstums feststellten, beobachteten Ramos-Elorduy et al. (2002) und Bovera et al. (2015, 2016) bei Einsatzmengen von bis zu 10 bzw. 29,65\% keinen signifikanten Einfluss auf diese Parameter. In den Untersuchungen von Ballitoc und Sun (2013) sowie Biasato et al. (2018a) wiesen die Tiere durch den Einsatz von Futtermischungen mit 2 bzw. bis zu 15\% Tenebrio molitor Mehl dagegen signifikant höhere finale LM auf. Der Einsatz von bis zu 15\% Tenebrio molitor Mehl in Futtermischungen für weibliche Masthähnchen hatte lediglich im Altersbereich von 1-21 Tagen positive Auswirkungen auf die Lebendmassezunahme und die Futteraufnahme (Biasato et al., 2018b). Ähnliche Unstimmigkeiten herrschen in Bezug auf die Futterverwertung. Ramos-Elorduy et al. (2002) und Józefiak et al. (2018) konnten keinen Effekt des Tenebrio molitor Mehls auf die Futterverwertung feststellen, Ballitoc und Sun (2013) beobachteten eine signifikante Verschlechterung. Im Gegensatz dazu war die Futterverwertung in den Versuchen von Bovera et al. (2015, 2016) und Khan et al. (2018) in den Futtermischungen mit Tenebrio molitor Mehl signifikant verbessert. Eine signifikante Verbesserung stellten auch Biasato et al. (2018b) bei weiblichen Masthähnchen im Alter von 12-25 Tagen fest, während sie bei männlichen Tieren eine signifikante Verschlechterung über den gesamten Altersabschnitt von 1-53 Tagen beobachteten (Biasato et al., 2018a). 


\section{Literaturübersicht}

Somit gibt es insbesondere beim Einsatz von Tenebrio molitor in Futtermischungen für Masthähnchen noch Optimierungsbedarf, eine finale Bewertung der Einsatzmöglichkeiten als Proteinquelle ist deshalb erschwert. Darüber hinaus fehlen Angaben über eine mögliche Beeinflussung der Met-Wirksamkeit und des resultierenden optimalen Met:Cys-Verhältnisses im Futter von Masthähnchen durch die Verwendung von Hermetia illucens und Tenebrio molitor.

\subsubsection{Mögliche Einsatzbeschränkungen}

Zurzeit ist der Einsatz von verarbeiteten Insekten in der Geflügelfütterung in der EU rechtlich nicht erlaubt. Laut der Verordnung (EG) 1069/2009 über tierische Nebenprodukte fallen bearbeitete Insekten unter den Begriff PAP (processed animal protein), dessen Einsatz in der Tierernährung die nach der BSE-Krise entstandene Verordnung (EG) 999/2001 verbietet. Mittlerweile ist die Fütterung von sieben Insektenarten in verarbeiteter Form an aquatische Nutztiere zwar erlaubt, für alle anderen Nutztiere gilt das Verbot jedoch weiterhin (Derrien und Boccuni, 2018). Sollte das Verbot aufgehoben werden, müssen Insekten jedoch den Anforderungen der Richtlinie 2002/32/EC über unerwünschte Stoffe in Futtermitteln entsprechen (Lähteenmäki-Uutela et al., 2017).

Die EFSA (2015) stellte heraus, dass zur möglichen Akkumulation von Toxinen und Schwermetallen in Insekten kaum Untersuchungen vorliegen und empfahl weitere Forschung auf diesem Gebiet. In den letzten Jahren wurden deshalb vermehrt Studien, die diese Fragestellung betreffen, durchgeführt. Bosch et al. (2017) gaben bis zu 0,5 mg Aflatoxin B1/kg TM zu dem Substrat für Hermetia illucens und Tenebrio molitor Larven hinzu und konnten in den Tenebrio molitor Larven lediglich einen geringen Gehalt, der 10\% der erlaubten Menge entsprach, feststellen. In den Hermetia illucens Larven lag der Gehalt sogar unter der Messgrenze. Camenzuli et al. (2018) setzten im Substrat für Hermetia illucens Larven Aflatoxin B1, Deoxynivalenol, Ochratoxin A und Zearalenon in Mengen ein, die den Grenzwert in Futtermitteln bis um das 25-fache überschritten. Sie analysierten die Larven sowohl auf den Gehalt der entsprechenden Mykotoxine als auch auf den Gehalt an einigen Metaboliten und konnten keine Akkumulation feststellen. Purschke et al. (2017) untersuchten ebenfalls den Einfluss erhöhter Mycotoxingehalte im Substrat für Hermetia illucens und konnten weder eine Akkumulation von Aflatoxin B1/B2/G2, Deoxynivalenol, Ochratoxin A und Zearalenon noch von verschiedenen Pestiziden in den Larven ermitteln. Die Zugabe von Seetang, der hohe Gehalte an Cadmium und Arsen aufweist, zum Substrat für Hermetia illucens Larven in Höhe von $20 \%$ führte dagegen dazu, dass die Cadmium- und Arsengehalte in den Larven über dem 
erlaubten Grenzwert lagen (Biancarosa et al., 2018). Purschke et al. (2017) stellten im Substrat von Hermetia illucens Gehalte von $1,5 \mathrm{mg} / \mathrm{kg}$ Cadmium und 15,2 mg/kg Blei ein und ermittelten in den Larven eine Akkumulation beider Schwermetalle, die den Grenzwert der in Futtermitteln erlaubten Gehalte überschritt. Ein Arsen-Gehalt von 3,0 mg/kg hatte dagegen keinen solchen Effekt. Auch van der Fels-Klerx et al. (2016) untersuchten den Einfluss erhöhter Gehalte an Cadmium (bis zu 1,0 mg/kg), Blei (bis zu $10 \mathrm{mg} / \mathrm{kg}$ ) und Arsen (bis zu 4,0 mg/kg) im Substrat für Hermetia illucens und Tenebrio molitor Larven. Sie stellten eine Akkumulation von Cadmium und Blei in den Hermetia illucens Larven und von Arsen in den Tenebrio molitor Larven fest und schlussfolgerten daraus, dass die Höchstwerte für Schwermetalle im Substrat für Insektenlarven abhängig von der Insektenart festgelegt werden sollten. Laut der EU Verordnung 1069/2009 sind Insekten jedoch Nutztiere, was bedeutet, dass nur Materialien der Kategorie 3 (K3) als Futtermittel bzw. Substrat eingesetzt werden dürfen. Erlaubt sind dementsprechend nur Materialien, die in der Verordnung 68/2013 aufgelistet sind (Smith und Barnes, 2015) und es gelten auch die für Futtermittel festgelegten Grenzwerte.

Darüber hinaus wird über einen negativen Einfluss des Chitin-Gehaltes diskutiert. Eine lange Zeit galt Chitin als unverdaulich, doch Tabata et al. (2017) konnten saure Chitinase, die Chitinenthaltende Organismen spaltet, im GIT von Broilern feststellen. Und auch Koh und Iwamae (2013) berichteten von einer Chitin-Verdauung durch Mukosa-Enzyme im Drüsenmagen von Masthähnchen. Sie beobachteten jedoch auch, dass die Chitinase-Aktivität nicht durch den Chitingehalt beeinflusst werden kann. Auch Jeuniaux und Cornelius (1978) gaben an, dass die Chitinase von der Magenschleimhaut sezerniert wird, während sie laut Hossain und Blair (2007) wahrscheinlich mikrobiellen Ursprungs ist. Fütterungsversuche mit Masthähnchen haben gezeigt, dass ein Chitin-Gehalt von bis zu 3,9\% in der Futtermischung keinen Einfluss auf das Wachstum, die FI und die Futterverwertung hat (Razdan und Pettersson, 1994; Khempaka et al., 2006, 2011). In einer Studie von Nuengjamnong und Angkanaporn (2018) führte der Einsatz von $2 \mathrm{~g} / \mathrm{kg}$ des Chitin-Abkömmlings Chitosan zu einer signifikanten Verbesserung der Futterverwertung. Allerdings liegt die Verdaulichkeit des Chitins nur bei 1832\% (Jeuniaux und Cornelius, 1978; Khempaka et al., 2006, 2011). Welchen Einfluss dies auf die Verdaulichkeit der Nährstoffe der gesamten Futtermischung hat, ist jedoch unklar. Während Khempaka et al. (2011) keinen signifikanten Unterschied in der Verdaulichkeit der organischen Masse, TM und XA durch den Einsatz von bis zu 3,8\% Chitin am Ende des GIT fanden, war in einer anderen Untersuchung der Autoren (Khempaka et al., 2006) die Verdaulichkeit der TM bei einem Chitin-Gehalt von 3,9\% signifikant verringert. Razdan und Pettersson (1994) konnten zwar keinen signifikanten Einfluss von 0,3\% Chitin auf die scheinbare pcV des XL, der Stärke 


\section{Literaturübersicht}

und der organischen Masse beobachten, stellten jedoch einen signifikanten negativen Effekt auf die scheinbare $\mathrm{pcV}$ des XP fest.

Bereits Koide (1998) berichtete von antimikrobiellen Eigenschaften von Chitin in vitro. Versuche an Masthähnchen (Nuengjamnong und Angkanaporn, 2018) konnten durch den Einsatz von Chitosan eine signifikante Verringerung der E. coli Bakterien im Caecum zeigen. Gleichzeitig wurde die Darmfunktion verbessert. In anderen Studien wurde durch die Supplementation von Chitosan bzw. Chito-Oligosacchariden eine signifikante Reduzierung von Salmonella Thyphimuricum und E. coli Baktererien beobachtet (Li et al., 2007; Balicka-Ramisz et al., 2008). Zudem wirkt Chitosan in ähnlichem Umfang wie ein Antibiotikum gegen eine Kokzidien-Infektion von Broilern (Menconi et al., 2014). Chito-Oligosaccharide und OligoChitosan lösen eine Steigerung der Immunglobuline im Serum aus und unterstützen die Entwicklung der Organe des Immunsystems (Deng et al., 2008; Huang et al., 2007). Ibitoye et al. (2018) stellten ebenso wie Nuengjamnong und Angkanaporn (2018) eine Verbesserung der Morphologie des Jejunums durch Chitin und Chitosan aus Shrimps sowie Chitosan aus Grillen fest, der Einsatz von aus Grillen gewonnenem Chitin hatte dagegen einen negativen Effekt. Demnach scheint es durchaus Unterschiede zwischen Chitin aus verschiedenen Quellen zu geben. Eine Untersuchung über die Struktur des Chitins in den Larven und adulten Tieren von Hermetia illucens ergab jedoch keine signifikanten Unterschiede (Waśko et al., 2016).

Basierend auf den Literaturangaben zum Chitin-Gehalt von Hermetia illucens und Tenebrio molitor sind die Chitin-Gehalte jedoch selbst in Futtermischungen, in denen 100\% des SES durch Insektenmehl ausgetauscht wurde, als gering einzuschätzen und eine negative Beeinflussung der Leistung und der Verdaulichkeit ist unwahrscheinlich. 


\section{Versuchszielstellung}

Die vorliegende Dissertation hatte zum Ziel, das optimale Met:Cys-Verhältnis in Futtermischungen für wachsende Broiler weiter einzugrenzen. Der Fokus lag hierbei auf den Auswirkungen verschiedener Met:Cys-Verhältnisse auf die Leistungs- und Verwertungsparameter sowie die Körperzusammensetzung der Tiere. Darüber hinaus sollten Einflüsse auf die komplexe Proteinqualität und die Met-Wirksamkeit untersucht werden, um so abschätzen zu können, welches Met:Cys-Verhältnis im Futter durch eine bedarfsgerechte Versorgung mit Cys zu einer Minimierung des Met-Abbaus im Stoffwechsel führt. Hierfür wurden drei Wachstumsversuche mit anschließender Ganzkörperanalyse durchgeführt, in denen Futtermischungen mit einem vollständigen Austausch von SES durch Mehle aus den Larven der Schwarzen Soldatenfliege Hermetia illucens und des Mehlkäfers Tenebrio molitor eingesetzt wurden. Zusätzlich sollten die Auswirkungen des Einsatzes der Insektenmehle auf die zootechnischen Leistungen, die Körperzusammensetzung der Tiere sowie auf die scheinbare pcV des XP und ausgewählter AS in den Futtermischungen untersucht werden. Außerdem wurden histologische und stereologische Untersuchungen durchgeführt, um negative Auswirkungen des Einsatzes von Tenebrio molitor auf die Darmgesundheit ausschließen zu können. Da beide Insektenmehle neben einer Limitierung durch die SAS ein weites Met:Cys-Verhältnis aufweisen, stellte sich zudem die Frage, ob durch die extrem hohen Mischungsanteile das optimale Met:Cys-Verhältnis im Masthähnchenfutter beeinflusst wird. 


\section{Material und Methoden}

\subsection{Versuchsaufbau}

Im Rahmen der vorliegenden Arbeit wurden drei Wachstumsversuche mit wachsenden männlichen Masthähnchen und anschließender Ganzkörperanalyse für Nährstoffansatzberechnungen durchgeführt. Ebenso erfolgte die Messung der scheinbaren pcV. Jeder der Versuche hatte eine Gesamtdauer von 35 Tagen und wurde in eine Starter- (Tag 121) und eine Growerphase (Tag 22-35) eingeteilt.

\subsection{Tierhaltung}

Die durchgeführten Experimente wurden dem Niedersächsischen Landesamt für Verbraucherschutz und Lebensmittelsicherheit (LAVES) angezeigt und in den Versuchseinrichtungen der Abteilung Tierernährungsphysiologie der Georg-AugustUniversität Göttingen durchgeführt. Für jeden der drei Versuche wurden 250 männliche Eintagsküken der Genetik Ross 308 von der Pro Care Brüterei in Elsnigk bezogen. Die Küken wurden zunächst in Bodenhaltung auf Holzspänen bei einer Raumtemperatur von ca. $33^{\circ} \mathrm{C}$ gehalten. Am Tag nach ihrer Ankunft wurden die Tiere einzeln gewogen und in die Versuchsgruppen eingeteilt. Ziel war es, dass sich die mittlere LM der Gruppen zu Versuchsbeginn nicht voneinander unterschied. Es kamen in Versuch 1 und 2 jeweils 6 Versuchsgruppen mit je 40 Tieren zum Einsatz. Die Tiere wurden in Gruppen von jeweils 5 Tieren, also in 8 Bodenhaltungsboxen pro Versuchsgruppe gehalten. Versuch 3 bestand aus 8 Versuchsgruppen mit je 30 Tieren pro Gruppe, die in jeweils 6 Boxen mit je 5 Tieren gehalten wurden. Die Boxen hatten die Maße von 70 x $150 \mathrm{~cm}$ (Versuchseinheit 1) bzw. 108 x $120 \mathrm{~cm}$ (Versuchseinheit 2) und waren mit einer selbstfülllenden Kunststofftränke ausgestattet. Das Futter wurde in einem langen Futtertrog vorgelegt. Die Haltung erfolgte während des gesamten Versuches auf Holzspänen. Beide Versuchseinheiten waren mit einem $\mathrm{Zu}$ - und Abluftsystem ausgestattet und es wurde ein Hell:Dunkel-Rhythmus von 23:1 h angewandt. Die Temperatur lag zu Beginn der Versuche bei ca. $33^{\circ} \mathrm{C}$ und wurde im weiteren Verlauf langsam auf ca. $21^{\circ} \mathrm{C}$ abgesenkt. Die Haltung der Reservetiere erfolgte analog in einem separaten Raum. 


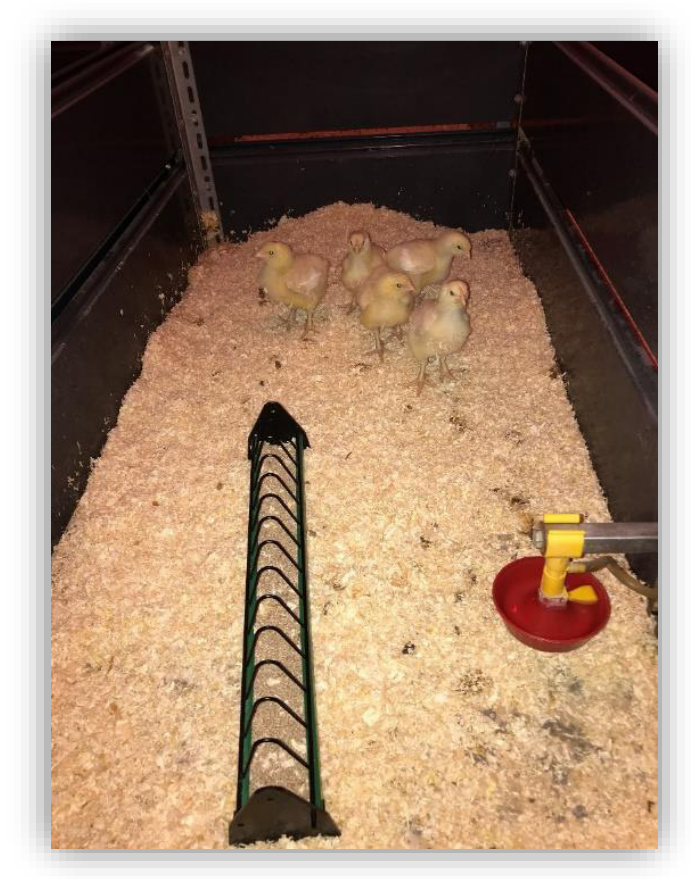

Abbildung 2: Haltung der Versuchstiere.

\subsection{Fütterung}

Sowohl die Versuchs- als auch die Reservetiere hatten während des gesamten Versuchszeitraumes freien Zugang zu Futter und Wasser. Die Berechnung der Futtermischungen erfolgte mit Hilfe des Programmes WinFumi (Vers. 3.9, HYBRIMIN®, Hessisch Oldendorf, Deutschland) auf Grundlage der analysierten Rohnährstoff- und ASGehalte der verwendeten Einzelkomponenten. Das Versuchsfutter wurde in pelletierter Form vorgelegt. Um eine homogene Einmischung sicherzustellen, wurde eine Vormischung aus der Vitaminvormischung, den Mineralstoffen, den zugesetzten AS sowie ggf. einem unverdaulichen Marker hergestellt (Mischer Typ M20MK, Gebrüder Lödige Maschinenbau GmbH, Paderborn, Deutschland). Im Anschluss wurde die Vormischung mit den restlichen Komponenten der Futtermischungen mit einem Mischer der Marke Lödige (Typ FM150D.1MZ, Gebrüder Lödige Maschinenbau GmbH, Paderborn, Deutschland) gemischt und mit einer Pelletiermaschine (Typ 3530FPP20, R.A. Lister \& Co Ltd., Dursley, Großbritannien) pelletiert. In der Starterphase hatten die Pellets einen Durchmesser von 2mm, in der Growerphase wurde dieser auf $4 \mathrm{~mm}$ angehoben. Sowohl die Tröge als auch die Tränken wurden zweimal täglich kontrolliert und ggf. gereinigt und aufgefüllt. Die Reservetiere erhielten pelletiertes Standardfutter auf Soja-Basis. Im Folgenden werden nur ausgewählte 
Angaben zur Zusammensetzung der Futtermischungen gemacht. Die detaillierten Informationen finden sich im Anhang (Anhangstabelle 3, 5, 7 und 8).

Versuch 1:

In Versuch 1 diente ein teilentfettetes Mehl der Schwarzen Soldatenfliegenlarve Hermetia illucens (HM) als alternative Proteinquelle. Das HM wurde von der Hermetia Futtermittel GbR (Baruth/Mark, Deutschland) bezogen. Die Larven der Schwarzen Soldatenfliege wurden nach einer 20-tägigen Aufzuchtphase auf Roggenmehl und Weizenkleie gesammelt, 14 Stunden bei $65-70^{\circ} \mathrm{C}$ getrocknet und anschließend mit einer Schneckenpresse (Typ AP08, Reinartz GmbH \& Co. KG, Neuss, Deutschland) teilentfettet und zu einem Mehl verarbeitet. Ein Überblick über den Rohnährstoff- und AS-Gehalt des teilentfetteten Mehls wird in Tabelle 9 vermittelt.

Tabelle 9: Gehalte an Rohnährstoffen und ausgewählten Aminosäuren des teilentfetteten Hermetia illucens Mehls.

\begin{tabular}{lc}
\hline Nährstoffgehalt & Hermetia illucens Mehl \\
\hline TM (\%) & 94,5 \\
XP (\% TM) & 57,9 \\
XL (\% TM) & 14,1 \\
XF (\% TM) & 10,9 \\
XA (\% TM) & 7,5 \\
\hline Aminosäuregehalt (g/16gN) & \\
\hline Lys & 5,42 \\
Met & 1,24 \\
Cys & 0,80 \\
Thr & 3,57 \\
Arg & 4,12 \\
Leu & 6,24 \\
Ile & 3,86 \\
His & 2,73 \\
Val & 5,36 \\
\hline
\end{tabular}


Das teilentfettete HM lag in pulvriger Form vor (s. Abb. 3) und wurde vor der Herstellung der Futtermischungen nicht weiter bearbeitet.

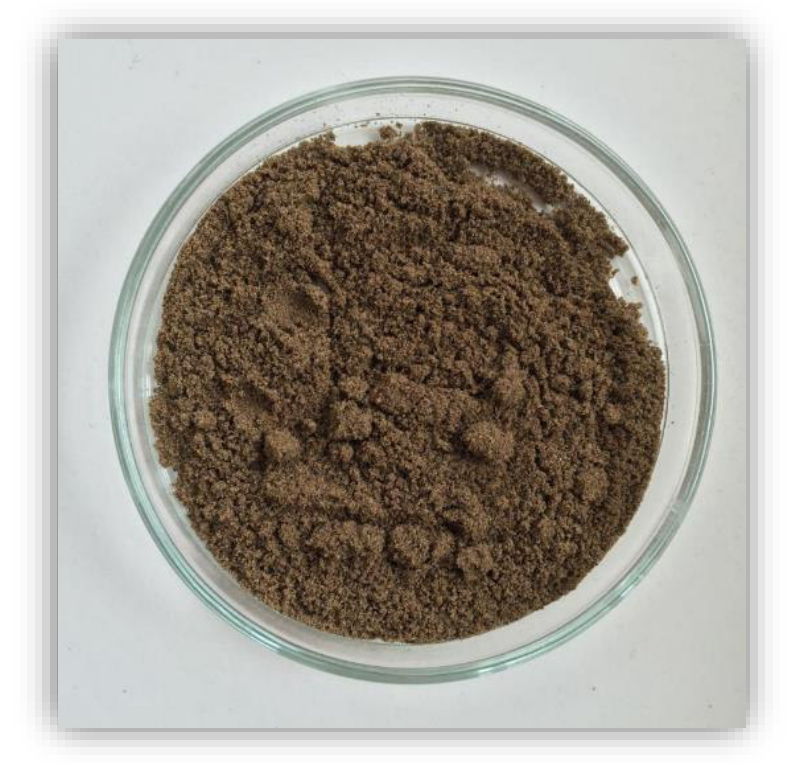

Abbildung 3: Teilentfettetes Hermetia illucens Mehl.

Es wurden 5 Futtermischungen auf Basis von Weizen und Mais hergestellt, in denen das HM die Hauptproteinquelle war und die sich lediglich in ihrem Met:Cys-Verhältnis unterschieden (40:60; 45:55; 50:50; 55:45; 60:40). Um den Futterwert der alternativen Proteinquelle einordnen zu können, wurde zudem eine Futtermischung, in der statt des HM SES verwendet wurde, als Kontrolle eingesetzt. In dieser Mischung lag das Met:Cys-Verhältnis bei 50:50. Um eine klare Limitierung der SAS sicherzustellen, wurde das Verhältnis der SAS zu Lys in allen Futtermischungen auf 0,50 eingestellt. Der angestrebte Lys-Gehalt lag bei 1,35\% in der Starterund 1,25\% in der Growerphase, die Gehalte aller anderen AS, mit Ausnahme von Isoleucin (Ile) und Leucin (Leu) entsprachen dem IAAR nach Wecke und Liebert (2013). Die Rohnährund Mineralstoffgehalte wurden nach den Angaben der GfE (1999) und Pastor (2014) entsprechend eingestellt. Die Futtermischungen für die Growerphase wurden durch Verdünnung der Futtermischungen der Starterphase mit Weizenstärke hergestellt, um das Verhältnis der Proteinträger und damit die AS-Verhältnisse in den Mischungen konstant zu halten. Zusätzlich wurde in den Futtermischungen für die Growerphase Titandioxid als unverdaulicher Marker eingesetzt, um die scheinbare $\mathrm{pcV}$ des XP und der AS messen zu können. Tabelle 10 zeigt ausgewählte Angaben zu den verwendeten Futtermischungen in diesem Versuch. 
Material und Methoden

Tabelle 10: Ausgewählte Angaben zur Zusammensetzung der Futtermischungen der Versuchsgruppen AF (g/kg FM) in Versuch 1.

\begin{tabular}{|c|c|c|c|c|c|c|}
\hline \multirow{4}{*}{ Versuchsgruppe } & $\begin{array}{c}\mathbf{A} \\
\text { (Starter/ }\end{array}$ & $\begin{array}{c}\text { B } \\
\text { (Starter/ }\end{array}$ & $\begin{array}{c}\mathbf{C} \\
\text { (Starter/ }\end{array}$ & $\begin{array}{c}\mathbf{D} \\
\text { (Starter/ }\end{array}$ & $\begin{array}{c}\mathbf{E} \\
\text { (Starter/ }\end{array}$ & $\begin{array}{c}\mathbf{F} \\
\text { (Starter/ }\end{array}$ \\
\hline & Grower) & Grower) & Grower) & Grower) & Grower) & Grower) \\
\hline & $\mathrm{HM}$ & HM & $\mathrm{HM}$ & HM & HM & SES \\
\hline & $40: 60$ & $45: 55$ & $50: 50$ & $55: 45$ & $60: 40$ & $50: 50$ \\
\hline HM & $230 / 212,8$ & $230 / 212,8$ & $230 / 212,8$ & $230 / 212,8$ & $230 / 212,8$ & - \\
\hline Sojaextraktionsschrot & - & - & - & - & - & $350 / 323,8$ \\
\hline Weizen & $500 / 462,5$ & $500 / 462,5$ & $500 / 462,5$ & $500 / 462,5$ & $500 / 462,5$ & $398 / 368,2$ \\
\hline Mais & $140 / 129,5$ & $140 / 129,5$ & $140 / 129,5$ & $140 / 129,5$ & $140 / 129,5$ & $112 / 103,6$ \\
\hline $\mathrm{XP}(\mathrm{g} / \mathrm{kg} \mathrm{TM})^{1}$ & $238 / 222$ & $239 / 220$ & $234 / 221$ & $233 / 225$ & $233 / 216$ & $229 / 211$ \\
\hline $\mathrm{AME}_{\mathrm{n}}(\mathrm{MJ} / \mathrm{kg} \mathrm{TM})^{2}$ & $15,8 / 15,8$ & $15,8 / 15,8$ & $15,8 / 15,8$ & $15,8 / 15,8$ & $15,8 / 15,8$ & $14,2 / 14,5$ \\
\hline Lysin $(g / 16 g N)^{3}$ & $6,16 / 6,16$ & $6,16 / 6,16$ & $6,16 / 6,17$ & $6,16 / 6,17$ & $6,16 / 6,17$ & $6,41 / 6,42$ \\
\hline $\operatorname{Met}(g / 16 g N)^{3}$ & $1,22 / 1,23$ & $1,38 / 1,39$ & $1,54 / 1,54$ & $1,69 / 1,70$ & $1,85 / 1,90$ & $1,61 / 1,61$ \\
\hline Met+Cys $(\mathrm{g} / 16 \mathrm{gN})^{3}$ & $3,08 / 3,08$ & $3,08 / 3,08$ & $3,08 / 3,08$ & $3,08 / 3,08$ & $3,08 / 3,08$ & $3,21 / 3,21$ \\
\hline SAS:Lys & 0,50 & 0,50 & 0,50 & 0,50 & 0,50 & 0,50 \\
\hline Met:Cys & $40: 60$ & $45: 55$ & $50: 50$ & $55: 45$ & $60: 40$ & $50: 50$ \\
\hline
\end{tabular}

${ }_{1}^{1}$ mindestens in Doppelbestimmung analysiert, Werte wurden anschließend gemittelt; ${ }^{2} \mathrm{~N}$-korrigierte umsetzbare Energie, kalkuliert nach WPSA (1984); ${ }^{3}$ aus den analysierten AS-Gehalten der Komponenten ermittelt. 
Versuch 2:

Die Futtermischungen in Versuch 2 wurden analog zu denen in Versuch 1 konzipiert. Statt des HM wurde jedoch Presskuchen aus Larven des Mehlkäfers Tenebrio molitor (TMP) als Proteinquelle verwendet. Die ofengetrockneten Larven wurden aus China bezogen und unter fachlicher Betreuung durch das IFF in Braunschweig in einer Schneckenpresse (Typ AP08, Reinartz GmbH \& Co. KG; Neuss, Deutschland) mit 6-Lochscheiben teilentfettet. Hierfür erfolgte zunächst eine Erwärmung der Larven auf $52{ }^{\circ} \mathrm{C}$. Während des Entfettungsprozesses erreichte der Presskuchen eine Temperatur von $100^{\circ} \mathrm{C}$. Der Rohnährstoff- und AS-Gehalt des Presskuchens wird in Tabelle 11 dargestellt.

Tabelle 11: Rohnährstoff- und Aminosäuregehalt des Tenebrio molitor Presskuchens.

\begin{tabular}{lc}
\hline Nährstoffgehalt & Tenebrio molitor Presskuchen \\
\hline TM (\%) & 95,1 \\
XP (\% TM) & 70,7 \\
XL (\% TM) & 10,4 \\
XF (\% TM) & 7,6 \\
XA (\% TM) & 4,1 \\
\hline Aminosäuregehalt (g/16gN) & \\
\hline Lys & 6,04 \\
Met & 1,25 \\
Cys & 0,92 \\
Thr & 4,15 \\
Arg & 5,25 \\
Leu & 7,49 \\
Ile & 4,11 \\
His & 3,10 \\
Val & 5,45 \\
\hline
\end{tabular}


Der TMP hatte eine grobkörnige Struktur (s. Abb. 4) und wurde vor der Herstellung der Futtermischungen in den Versuchseinrichtungen der Abteilung Tierernährungsphysiologie der Georg-August-Universität Göttingen mit einer herkömmlichen Schrotmühle (Typ RVO332, Neurero Farm- und Fördertechnik GmbH, Melle, Deutschland) fein vermahlen, um ein homogenes Vermischen mit den anderen Einzelfuttermitteln sicherzustellen.

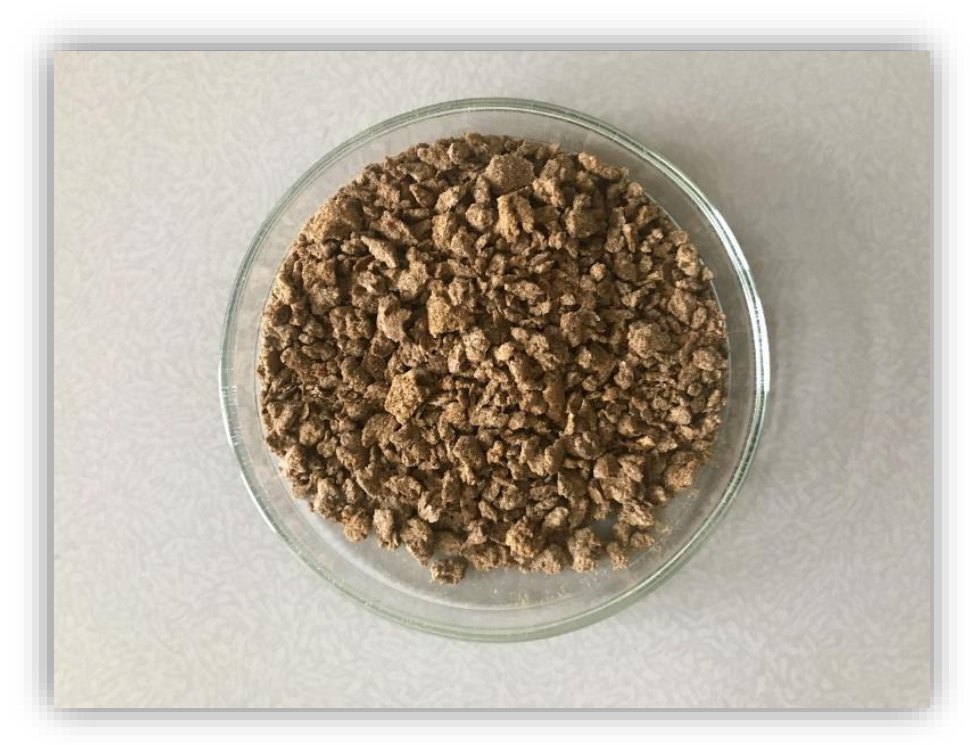

Abbildung 4: Presskuchen aus Tenebrio molitor.

Tabelle 12 zeigt ausgewählte Angaben zu den verwendeten Futtermischungen in diesem Versuch. 
Material und Methoden

Tabelle 12: Ausgewählte Angaben zur Zusammensetzung der Futtermischungen der Versuchsgruppen AF (g/kg FM) in Versuch 2.

\begin{tabular}{|c|c|c|c|c|c|c|}
\hline \multirow{4}{*}{ Versuchsgruppe } & $\begin{array}{c}\mathbf{A} \\
\text { Starter/ }\end{array}$ & $\begin{array}{c}\text { B } \\
\text { Starter/ }\end{array}$ & $\begin{array}{c}\text { C } \\
\text { Starter/ }\end{array}$ & $\begin{array}{c}\text { D } \\
\text { Starter/ }\end{array}$ & $\mathbf{E}$ & $\begin{array}{c}\mathbf{F} \\
\text { (Starter/ }\end{array}$ \\
\hline & Grower) & Grower) & Grower) & Grower) & Grower) & Grower) \\
\hline & TMP & TMP & TMP & TMP & TMP & SES \\
\hline & $40: 60$ & $45: 55$ & $50: 50$ & $55: 45$ & $60: 40$ & $50: 50$ \\
\hline TMP & $160 / 148,8$ & $160 / 148,8$ & $160 / 148,8$ & $160 / 148,8$ & $160 / 148,8$ & - \\
\hline Sojaextraktionsschrot & - & - & - & - & - & $321 / 298,5$ \\
\hline Weizen & $580 / 539,4$ & $580 / 539,4$ & $580 / 539,4$ & $580 / 539,4$ & $580 / 539,4$ & $374 / 347,8$ \\
\hline Mais & $160 / 148,8$ & $160 / 148,8$ & $160 / 148,8$ & $160 / 148,8$ & $160 / 148,8$ & $170 / 158,1$ \\
\hline $\mathrm{XP}(\mathrm{g} / \mathrm{kg} \mathrm{TM})^{1}$ & $226 / 214$ & $230 / 211$ & $224 / 213$ & $225 / 214$ & $226 / 217$ & $230 / 217$ \\
\hline $\mathrm{AME}_{\mathrm{n}}(\mathrm{MJ} / \mathrm{kg} \mathrm{TM})^{2}$ & $15,1 / 15,1$ & $15,1 / 15,1$ & $15,1 / 15,1$ & $15,1 / 15,1$ & $15,1 / 15,1$ & $14,7 / 14,9$ \\
\hline Lysin $(g / 16 g N)^{3}$ & $6,69 / 6,69$ & 6,69 / 6,69 & $6,69 / 6,69$ & $6,69 / 6,69$ & 6,69 / 6,69 & $6,64 / 6,64$ \\
\hline $\operatorname{Met}(g / 16 g N)^{3}$ & $1,33 / 1,34$ & $1,50 / 1,51$ & $1,67 / 1,68$ & $1,84 / 1,84$ & $2,00 / 2,01$ & $1,66 / 1,66$ \\
\hline Met+Cys $(\mathrm{g} / 16 \mathrm{gN})^{3}$ & $3,34 / 3,35$ & $3,34 / 3,35$ & $3,34 / 3,35$ & $3,34 / 3,35$ & $3,37 / 3,37$ & $3,32 / 3,32$ \\
\hline SAS:Lys & 0,50 & 0,50 & 0,50 & 0,50 & 0,50 & 0,50 \\
\hline Met:Cys & $40: 60$ & $45: 55$ & $50: 50$ & $55: 45$ & $60: 40$ & $50: 50$ \\
\hline
\end{tabular}

${ }^{1}$ mindestens in Doppelbestimmung analysiert, Werte wurden anschließend gemittelt; ${ }^{2} \mathrm{~N}$-korrigierte umsetzbare Energie, kalkuliert nach WPSA (1984); ${ }^{3}$ aus den analysierten AS-Gehalten der Komponenten ermittelt.

Versuch 3:

In Versuch 3 sollten die beiden alternativen Proteinquellen Hermetia illucens und Tenebrio molitor direkt miteinander verglichen werden. Hierfür wurden auf Grundlage der Ergebnisse der Versuche 1 und 2 jeweils Met:Cys-Verhältnisse von 50:50, 55:45 und 60:40 eingestellt, da in diesem Bereich das Optimum erwartet werden konnte. Die Grundstruktur der Futtermischungen war analog zu den ersten beiden Versuchen. Auch hier wurde das Verhältnis der SAS zu Lysin auf 0,50 eingestellt. Der Lys-Gehalt lag bei 1,35\% in der Starter- und 1,25\% in der Growerphase, die Gehalte aller anderen AS entsprachen dem IAAR nach Wecke und Liebert (2013). In den HM-Futtermischungen wurden im Vergleich zu Versuch 1 jedoch auch 
Ile und Leu supplementiert. Zusätzlich wurde von beiden alternativen Proteinquellen eine positive Kontrolle (pK) mit vollständigem SAS-Ausgleich erstellt, das Verhältnis der SAS zu Lys lag bei 0,74. Ausgewählte Angaben zu den Futtermischungen finden sich in Tabelle 13.

Tabelle 13: Ausgewählte Angaben zur Zusammensetzung der Futtermischungen der Versuchsgruppen AH (g/kg FM) in Versuch 3.

\begin{tabular}{|c|c|c|c|c|c|c|c|c|}
\hline \multirow{5}{*}{ Versuchsgruppe } & $\overline{\mathbf{A}}$ & $\overline{\mathbf{B}}$ & $\overline{\mathbf{C}}$ & $\overline{\mathbf{D}}$ & $\overline{\mathbf{E}}$ & $\bar{F}$ & $\overline{\mathbf{G}}$ & $\overline{\mathbf{H}}$ \\
\hline & (Starter/ & (Starter/ & (Starter/ & (Starter/ & (Starter) & (Starter/ & (Starter/ & (Starter/ \\
\hline & Grower) & Grower) & Grower) & Grower) & Grower) & Grower) & Grower) & Grower) \\
\hline & TMP & TMP & TMP & $\mathrm{pK}$ & HM & HM & HM & $\mathrm{pK}$ \\
\hline & $50: 50$ & $55: 45$ & $60: 40$ & $50: 50$ & $50: 50$ & $55: 45$ & $60: 40$ & $50: 50$ \\
\hline \multirow{2}{*}{ TMP } & $162 /$ & $162 /$ & $162 /$ & $157 /$ & \multirow{2}{*}{-} & \multirow{2}{*}{-} & \multirow{2}{*}{ - } & \multirow{2}{*}{ - } \\
\hline & 150,7 & 150,7 & 150,7 & 146,0 & & & & \\
\hline \multirow{2}{*}{ HM } & \multirow{2}{*}{ - } & \multirow{2}{*}{-} & \multirow{2}{*}{ - } & \multirow{2}{*}{ - } & $185,5 /$ & 185,5 / & $185,5 /$ & $181 /$ \\
\hline & & & & & 172,5 & 172,5 & 172,5 & 168,3 \\
\hline \multirow{2}{*}{ Weizen } & $580 /$ & $580 /$ & $580 /$ & $600 /$ & $560 /$ & $560 /$ & $560 /$ & $560 /$ \\
\hline & 539,4 & 539,4 & 539,4 & 558 & 520,8 & 520,8 & 520,8 & 520,8 \\
\hline \multirow{2}{*}{ Mais } & $160 /$ & $160 /$ & $160 /$ & $140 /$ & $150 /$ & $150 /$ & $150 /$ & $140 /$ \\
\hline & 148,8 & 148,8 & 148,8 & 130,2 & 139,5 & 139,5 & 139,5 & 130,2 \\
\hline \multirow{2}{*}{$\mathrm{XP}(\mathrm{g} / \mathrm{kg} \mathrm{TM})^{1}$} & $231 /$ & $232 /$ & $233 /$ & $231 /$ & $230 /$ & $228 /$ & $229 /$ & $229 /$ \\
\hline & 216 & 217 & 216 & 217 & 213 & 212 & 216 & 213 \\
\hline $\mathrm{AME}_{\mathrm{n}}$ & $15,1 /$ & $15,1 /$ & $15,1 /$ & $15,0 /$ & $15,1 /$ & $15,1 /$ & $15,1 /$ & $15,1 /$ \\
\hline$(\mathrm{MJ} / \mathrm{kg} \mathrm{TM})^{2}$ & 15,0 & 15,0 & 15,0 & 15,0 & 15,0 & 15,0 & 15,0 & 15,0 \\
\hline \multirow{2}{*}{ Lysin $(g / 16 g N)^{3}$} & $6,65 /$ & $6,65 /$ & $6,65 /$ & $6,64 /$ & $6,58 /$ & $6,58 /$ & $6,58 /$ & $6,60 /$ \\
\hline & 6,63 & 6,64 & 6,64 & 6,62 & 6,56 & 6,56 & 6,56 & 6,58 \\
\hline \multirow{2}{*}{$\operatorname{Met}(\mathrm{g} / 16 \mathrm{gN})^{3}$} & $1,66 /$ & $1,83 /$ & $2,00 /$ & $2,53 /$ & $1,65 /$ & $1,81 /$ & $1,97 /$ & $2,51 /$ \\
\hline & 1,66 & 1,83 & 1,99 & 2,52 & 1,64 & 1,81 & 1,97 & 2,50 \\
\hline Met+Cys & $3,33 /$ & $3,33 /$ & $3,35 /$ & $4,91 /$ & $3,30 /$ & $3,30 /$ & $3,29 /$ & $4,88 /$ \\
\hline$(g / 16 g N)^{3}$ & 3,32 & 3,32 & 3,35 & 4,90 & 3,29 & 3,28 & 3,28 & 4,87 \\
\hline SAS:Lys & 0,50 & 0,50 & 0,50 & 0,74 & 0,50 & 0,50 & 0,50 & 0,74 \\
\hline Met:Cys & $50: 50$ & $55: 45$ & $60: 40$ & $50: 50$ & $50: 50$ & $55: 45$ & $60: 40$ & $50: 50$ \\
\hline
\end{tabular}

${ }^{1}$ mindestens in Doppelbestimmung analysiert, Werte wurden anschließend gemittelt; ${ }^{2} \mathrm{~N}$-korrigierte umsetzbare Energie, kalkuliert nach WPSA (1984); ${ }^{3}$ aus den analysierten AS-Gehalten der Komponenten ermittelt. 


\subsection{Datenerfassung und Probennahme}

Erfassung der zootechnischen Parameter und Probennahme für die Ganzkörperanalyse

Für die Erfassung der zootechnischen Parameter wurden die Tiere einmal wöchentlich gewogen. Das Futter wurde zu Beginn jeder Woche für jede Box in einem Eimer eingewogen und am Ende der jeweiligen Woche erfolgte die Rückwaage der Futterreste. So wurden die Lebendmasseentwicklung, die FI und der Futteraufwand (FA) ermittelt. Am Ende der Starterphase (Tag 21) wurde aus jeder Box ein repräsentatives Tier für die Ganzkörperanalyse ausgewählt, nach 24-stündiger Nüchterung mittels $\mathrm{CO}_{2}$ euthanasiert und bis zur weiteren Analyse bei $-20^{\circ} \mathrm{C}$ eingefroren. Dies erfolgte analog am Ende der Growerphase (Tag 35) und in allen drei Versuchen.

\section{$\underline{\text { Chymusentnahme }}$}

Am Versuchsende wurde außerdem die scheinbare $\mathrm{pcV}$ gemessen. Hierfür wurden in Versuch 1 pro Futtermischung 20 Tiere ausgewählt. 12 Stunden vor der Tötung wurden die Tiere genüchtert und 2 Stunden vor der Tötung wurde das Futter wieder vorgelegt. Dadurch sollte eine hohe FI und damit verbunden eine möglichst große und vergleichbare Chymusmenge erreicht werden. 5 Tiere einer Versuchsgruppe bildeten eine Poolprobe. Diese 5 Tiere wurden zusammen euthanasiert und anschließend entsprechend der von Kluth et al. (2005) und Kluth und Rodehutscord (2009) beschriebenen Methode die letzten zwei Drittel des Dünndarmabschnittes vom Meckel'schen Diverticulum bis etwa $2 \mathrm{~cm}$ vor Einmündung der Blinddärme in das terminale Ileum entnommen (s. Abb. 5). Aus diesem Darmabschnitt wurde dann der Chymus ausgestreift und nach der Probennahme bei $-20^{\circ} \mathrm{C}$ bis zur Analyse gelagert.

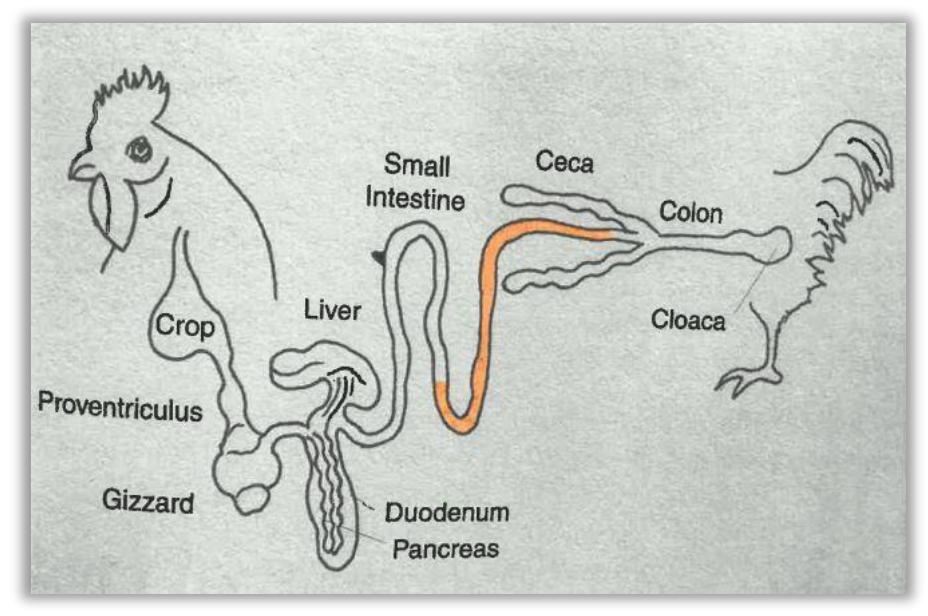

Abbildung 5: Der Gastrointestinaltrakt eines Masthähnchens. Orange markiert: Darmabschnitt zur Chymusentnahme (nach Leeson und Summers, 2001). 
Für die Messung der scheinbaren pcV in Versuch 2 wurden 3x5 Tiere der Futtermischungen $\mathrm{C}$ (TMP 50:50) und F (Soja 50:50) verwendet. Es wurde analog zu Versuch 1 vorgegangen, allerdings wurden die Tiere in diesem Fall nicht genüchtert, da im vorangegangen Versuch nur sehr wenig Chymus gewonnen werden konnte.

In Versuch 3 wurden für die Messung der scheinbaren $\mathrm{pcV}$ aus beiden positiven Kontrollgruppen D (TMP) und H (HM) jeweils 3 Poolproben á 6 Tiere nach der beschriebenen Vorgehensweise genommen. Auch in diesem Versuch wurden die Tiere zuvor nicht genüchtert.

\section{Proben für die morphologischen und stereologischen Untersuchungen}

In Versuch 2 erfolgten zusätzlich morphologische und stereologische Untersuchungen des Dünndarms. Hierfür wurden jeweils 5 Tiere der Gruppen A (TMP 40:60), E (TMP 60:40) und F (SES 50:50) verwendet. So sollte zum einen ein möglicher Einfluss des Met:CysVerhältnisses und zum anderen der Art der Proteinquelle untersucht werden. Die entsprechenden Tiere wurden 12 Stunden vor der Probennahme genüchtert und ebenfalls mit $\mathrm{CO}_{2}$ euthanasiert. Die Probennahme erfolgte in den Versuchseinrichtungen der Abteilung Tierernährungsphysiologie der Georg-August-Universität Göttingen in Zusammenarbeit mit einer Fachtierärztin für Pathologie direkt nachdem der Tod der Tiere festgestellt wurde.

Es wurde der gesamte GIT entnommen und sofort in gekühlte physiologische Kochsalzlösung $(0.9 \%)$ gegeben. Nachdem das Pankreas entfernt und gewogen wurde, konnte der Dünndarm in die Teile Duodenum (D1, vom Muskelmagen bis zum Ende der Duodenumschleife/Pankreas), proximales Jejunum (D2, vom Ende der Duodenumschleife bis zum Meckel'schen Divertikel) und distales Jejunum (D3, vom Meckel'schen Divertikel bis zum Blinddarmansatz) unterteilt werden. Jeder dieser Abschnitte wurde gewogen, gemessen und in fünf gleich große Segmente eingeteilt. Beim proximalen Segment wurde daraufhin eine zufällige Position für ein ca. $2 \mathrm{~cm}$ breites Untersegment bestimmt, welches in 2 Teile geschnitten wurde. Das erste Teilstück (a) wurde in Kochsalzlösung (0,9\%) gespült und als geschlossener Ring in einer Kassette in 4\%iger Formalinlösung konserviert. Das zweite Teilstück (b) wurde an der Mesenterialseite aufgeschnitten, aufgeklappt, die Breite gemessen, in gekühlter physiologischer Kochsalzlösung gespült und ebenfalls in einer Kassette in 4 \%iger Formalinlösung konserviert. Dieses Verfahren wurde für alle Darmabschnitte und Segmente angewendet, wobei die zufällige Position für das Untersegment für alle Segmente eines Darmabschnittes die gleiche war. Zum besseren Verständnis wird das Entnahmeverfahren in Abbildung 6 graphisch dargestellt. 


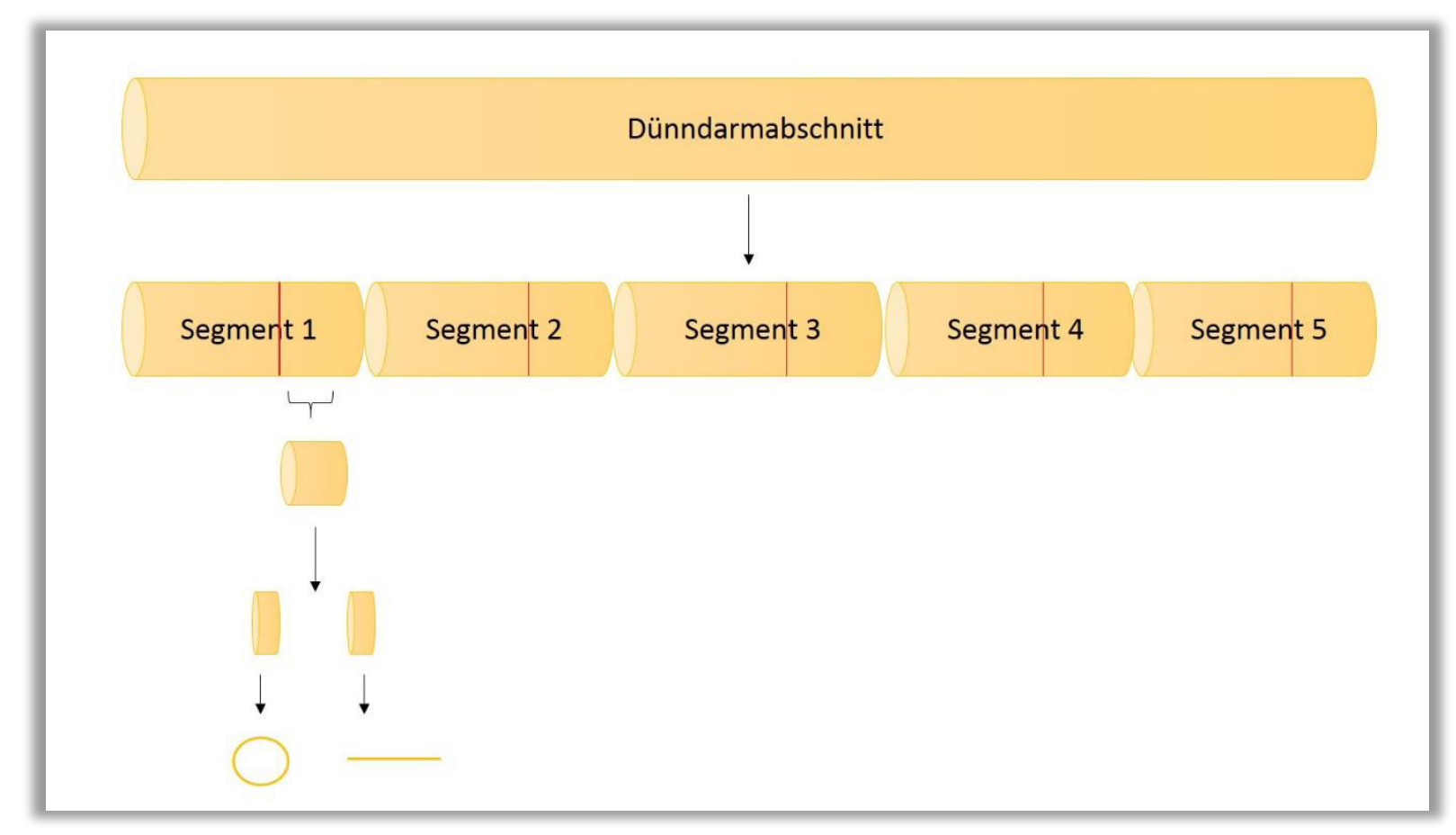

Abbildung 6: Übersicht über die Probennahme der Dünndarmschnitte (Bild: Gruber-Dujardin).

\subsection{Probenaufarbeitung und Laboranalysen}

Sämtliche Futtermittel-, Ganzkörper- und Chymusproben wurden im Labor der Tierernährungsphysiologie Göttingen aufbereitet und analysiert.

\section{$\underline{\text { Futtermittel }}$}

Um die Futtermischungen exakt dem Bedarf der Tiere entsprechend berechnen zu können, wurden die eingesetzten Futtermittel vor Beginn der Versuche auf ihren Rohnährstoff- und ASGehalt analysiert. Hierfür wurden die Proben für die Vollanalyse auf $1 \mathrm{~mm}$ und für die ASAnalyse auf 0,5 mm vermahlen (Typ ZM1, Retsch KG, Haan, Deutschland). Die Analyse der Rohnährstoffe erfolgte dabei nach den Methoden der VDLUFA (Naumann und Bassler, 19762004). Der N-Gehalt wurde durch Anwendung der Dumas-Methode (TruMac@, Leco Instrument GmbH, Mönchengladbach, Deutschland) bestimmt. Hierbei wird das organische Material in der Probe vollständig verbannt und die Verbrennungsgase über heißes Kupfer geleitet, um Sauerstoff zu entfernen und Stickoxide in molekularen N umzuwandeln. Dieses Gasgemisch wird im Anschluss durch eine $\mathrm{CO}_{2}-/ \mathrm{H}_{2} \mathrm{O}-\mathrm{Falle}$ geleitet und der molekulare $\mathrm{N}$ mittels eines Wärmeleitfähigkeitsdetektors bestimmt. Der XP-Gehalt wird durch Multiplikation des N-Gehaltes mit dem Faktor 6,25 berechnet. Die AS-Analytik erfolgte mittels Ionenaustauschchromatographie (Biochrom30, ONKEN GmbH, Gründau, Deutschland) mit 
vorangehender saurer Hydrolyse ohne bzw. mit Oxidationsschritt zur Bestimmung der SAS. Bei der Ionenaustauschchromatographie liegen die AS als Kationen vor und werden in einer Pufferlösung ( $\mathrm{pH}$ 2,20) auf eine Säule aufgetragen. Mittels verschiedener Pufferlösungen werden sie im Anschluss schrittweise wieder von der Säule eluiert. Die unterschiedlichen Eigenschaften der AS bewirken so eine Auftrennung und eine anschließende Nachsäulenderivatisierung mit Ninhydrin ermöglicht die photometrische Detektion der AS. Als interner Standard wurde Norleucin verwendet.

Zwecks Überprüfung der Mischgenauigkeit wurden zudem auch die Rohnährstoff- und ASGehalte der hergestellten Futtermischungen mittels der beschriebenen Verfahren analysiert.

\section{Ganzkörper}

Für die Probenaufarbeitung wurden die Tiere im gefrorenen Zustand einzeln mit einer Bandsäge (Model FK 22, Bizerba SE \& Co. KG, Balingen, Deutschland) zerteilt und durch fünfmalige Nutzung eines herkömmlichen Fleischwolfs (Model EM 82 VL-S, Edertal Elektromotoren GmbH \& Co. KG, Wabern, Deutschland) und eines Stabmixers homogenisiert. Anschließend wurde eine repräsentative Probe gefriergetrocknet (Model $\alpha$ 1-4®, Christ GmbH, Osterode am Harz, Deutschland), mit einem Mixer nochmals zerkleinert und homogenisiert und nach den bereits beschriebenen Methoden auf ihren TS-, N- und XA-Gehalt hin analysiert. Der XLGehalt im Tierkörper wurde in Übereinstimmung mit Hancock et al. (1995) und Wecke et al. (2018b) als Differenz berechnet (XL = $100-\mathrm{XP}-\mathrm{XA})$ und in \% der TM ausgewiesen.

\section{$\underline{\text { Chymus }}$}

Für die Messung der scheinbaren pcV wurden die Chymus-Proben gefriergetrocknet (Model $\alpha$ 1-4®, Christ GmbH, Osterode am Harz, Deutschland), mit einer Kaffeemühle homogenisiert und anschließend auf ihren N- und AS-Gehalt nach den bereits beschriebenen Methoden analysiert. Die Bestimmung des Titandioxids erfolgte im Kjeldahlaufschluss nach Brandt und Allam (1987). Diese Methode macht es sich zu Nutze, dass Titandioxid in heißer, konzentrierter Schwefelsäure langsam löslich ist und in schwefelsauren Lösungen mit Wasserstoffperoxid einen stabilen, gelben Farbkomplex bildet. Dieser Farbkomplex wird bei 450nm photometrisch gemessen. 


\section{$\underline{\text { Histologische und stereologische Untersuchungen }}$}

Die histologischen und stereologischen Untersuchungen fanden in der Pathologie am Deutschen Primatenzentrum (DPZ) in Göttingen statt.

Zunächst wurde von jedem in 4\%iger Formalinlösung konservierten Teilstück b (s. Kapitel 4.4) eines Untersegments drei Stanzproben ( $5 \mathrm{~mm}$ ) entnommen und halbiert. So entstanden sechs Stücke eines Untersegments, die im Anschluss zusammen mit Teilstück a in einen Paraffinblock eingebettet (EG 1150, Leica Biosystems, Wetzlar, Deutschland) und danach fortlaufend bei $4 \mu \mathrm{m}$ zerschnitten wurden. Die anschließende Einfärbung erfolgte entweder mit Hämatoxylin-Eosin oder der PAS-Reaktion (Multistainer ST 5020, Leica Biosystems, Wetzlar, Deutschland).

Die Untersuchung aller entnommenen Proben der Dünndarmabschnitte wurde von einem zertifizierten tierärztlichen Pathologen durchgeführt, der keine Kenntnisse über die unterschiedlichen Versuchsgruppen hatte. Im ersten Schritt wurden Bilder der Proben bei einer maximalen digitalen Vergrößerung (x20) eingescannt (Slide Scanner Aperio CS2, Leica Biosystems, Wetzlar, Deutschland), geeignete Bildausschnitte als Bilddatei (jpg) gespeichert und anschließend bei Bedarf bearbeitet. Die stereologische Untersuchung erfolgte mittels computer-basierter Software (STEPanizer ${ }^{\odot}$ Version 1, 8). Für jedes Segment der drei Darmabschnitte wurden drei zufällig gewählte Sichtfelder $(800$ x $800 \mu \mathrm{m})$ digital um den Faktor 6 vergrößert und evaluiert. Hierfür wurden auf jedem Sichtfeld gebogene Testlinien (Cycloids) mit einer definierten Länge verwendet. Die Zottenoberfläche konnte über Schnittpunkte mit den Testlinien nach der Methode von Tschanz et al. (2011) bestimmt werden. Zusätzlich wurden zudem die Testpunkte in einem Sichtfeld gezählt, an denen das Ende einer Testlinie auf das Epithelium der Zotten bzw. Krypten traf (s. Abb. 7). 


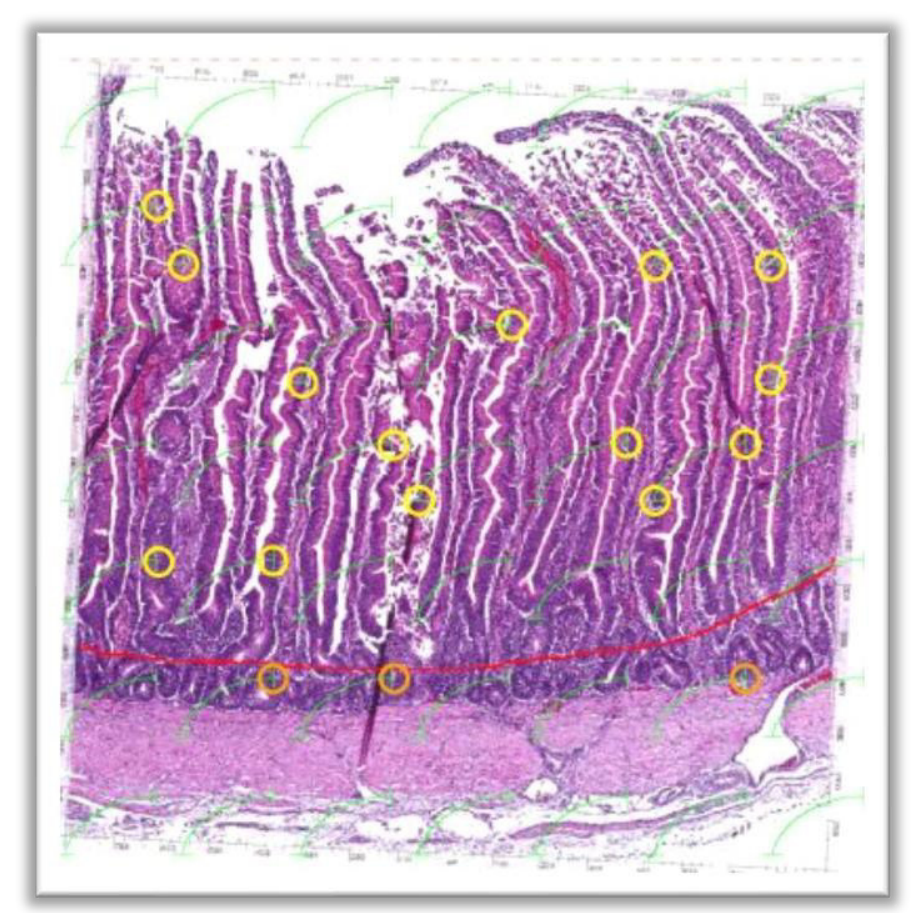

\begin{abstract}
Abbildung 7: Zählereignisse zur Berechnung des Zotten- und Kryptenepithelvolumens (Bild: GruberDujardin). Gelbe Kreise: Schnittpunkte der Linienenden mit dem Zottenepithel; Orangefarbene Kreise: Schnittpunkte der Linienenden mit dem Kryptenepithel.
\end{abstract}

Folgende Parameter wurden anhand der Daten ermittelt:

$\underline{\text { Makroskopie }}$

1) Lebendmasse

2) Relative Dünndarmmasse (DDM)

\title{
$\underline{\text { Histologie }}$
}

Stereologie von drei Dünndarmabschnitten:

1) Relative Zottenoberfläche $\left(S_{v}\right)$

2) Relative Schleimhautoberfläche $\left(S_{p m}\right)$

3) Verhältnis Zotten-/Kryptenepithelvolumen $\left(\mathrm{V}_{\mathrm{ve}} / \mathrm{V}_{\mathrm{ce}}\right)$ 


\subsection{Berechnungen}

Lebendmassezunahme

$\mathrm{LMZ}=(\mathrm{LM}$ Versuchsende $-\mathrm{LMVersuchsanfang}) /$ Anzahl Versuchstage

wobei $\mathrm{LMZ}=$ tägliche $\mathrm{LMZ} \quad[\mathrm{g} / \mathrm{d}]$

$$
\mathrm{LM}=\mathrm{LM} \quad[\mathrm{g}]
$$

Futteraufwand

$\mathrm{FA}=\mathrm{FI} / \mathrm{LMZ}$

wobei FA $\quad=$ Futteraufwand $[\mathrm{g} / \mathrm{g}]$

FI $=$ FI $[\mathrm{g} \mathrm{TM} / \mathrm{d}]$

$\underline{\text { Proteinaufwand }}$

Proteinaufwand $=$ XPI / LMZ

wobei XPI $=$ XP-Aufnahme $\quad[\mathrm{g}$ XP $($ in $\operatorname{der} \mathrm{TM}) / \mathrm{d}]$

Energieaufwand

Energieaufwand = Energieaufnahme $/$ LMZ

wobei Energieaufnahme

$[\mathrm{kJ}$ ME (in der TM)/d]

\section{Nährstoffansatz}

Der Nährstoffansatz wurde als Differenz zwischen der Nährstoffmenge im Tierkörper am Ende der Versuchsperiode und der Nährstoffmenge im Körper der Nulltiere ermittelt. Da sich die Genetik der Tiere in den letzten Jahren nicht entscheidend verändert hat, wurden für diese Versuche keine Nulltiere genommen, sondern auf Ergebnisse von Pastor (2014) mit Tieren der gleichen Genetik zurückgegriffen.

$\begin{aligned} \mathrm{ND}= & {[(\mathrm{N}-\text { Menge im Tierkörper }} \\ & / \text { Ande }- \text { N-Menge im Tierkörper Anfang }) \\ & \text { Anzahl Versuchstage }] / \text { metabolische LM }\end{aligned}$

wobei ND $=\mathrm{N}$-Ansatz $\left[\mathrm{mg} / \mathrm{LM}_{\mathrm{kg}}{ }^{0,67} / \mathrm{d}\right]$

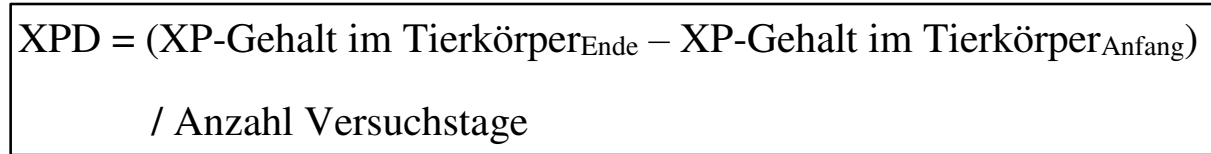

wobei XPD = Rohproteinansatz

$[\mathrm{g} / \mathrm{d}]$ 
wobei XLD = Rohfettansatz

$[\mathrm{g} / \mathrm{d}]$

$\underline{\text { Scheinbare praecaecale Verdaulichkeit }}$

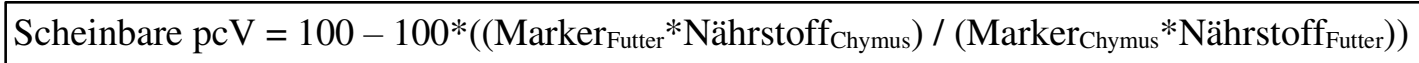

wobei Marker Futter

= Konzentration des Markers im Futter [\% TM]

Marker Chymus

$=$ Konzentration des Markers im Chymus [\% TM]

Nährstoff Chymus $_{\text {}}$

= Konzentration des Nährstoffs im Chymus [\% TM]

Nährstoff Futter

= Konzentration des Nährstoffs im Futter [\% TM]

$\underline{\text { Parameter des N-Verwertungsmodells }}$

Das für die weiteren Auswertungen verwendete N-Verwertungsmodell wurde von Gebhardt (1966) mit dem Ziel entwickelt, die N-Aufnahme $\mathrm{zu}$ standardisieren und die Proteinqualitätsparameter somit besser vergleichen zu können (Liebert, 2015). Es wurde seitdem stetig weiterentwickelt und ist in zahlreichen Publikationen beschrieben (z.B. Liebert und Gebhardt, 1986, 1987, 1988a, b; Samadi und Liebert, 2006, 2007; Pastor et al., 2013; Liebert, 2008, 2015, 2017; Khan et al., 2015a; Wecke et al., 2016; Samadi et al., 2017).

Die verwendeten Modellparameter sind:

$$
\mathrm{NR}=\mathrm{NR}_{\max } \mathrm{T}\left(1-\mathrm{e}^{-\mathrm{b}^{*} \mathrm{NI}}\right)
$$

$$
\mathrm{ND}=\mathrm{NR}_{\max } \mathrm{T}\left(1-\mathrm{e}^{-\mathrm{b}^{*} \mathrm{NI}}\right)-\mathrm{NMR}
$$

$$
\begin{aligned}
& \text { wobei NR = N-Retention (ND+NMR) } \quad\left[\mathrm{mg} / \mathrm{LM}_{\mathrm{kg}}{ }^{0,67} / \mathrm{d}\right] \\
& \text { NRmaxT = theoretisches Maximum der NR }\left[\mathrm{mg} / \mathrm{LM}_{\mathrm{kg}}{ }^{0,67} / \mathrm{d}\right] \\
& \text { e } \quad=\text { Grundzahl der natürlichen Logarithmen } \\
& \text { NI = N-Aufnahme } \quad\left[\mathrm{mg} / \mathrm{LM}_{\mathrm{kg}}{ }^{0,67} / \mathrm{d}\right] \\
& \text { ND } \quad \text { N-Ansatz } \quad\left[\mathrm{mg} / \mathrm{LM}_{\mathrm{kg}}{ }^{0,67} / \mathrm{d}\right] \\
& \text { NMR = N-Erhaltungsbedarf } \quad\left[\mathrm{mg} / \mathrm{LM}_{\mathrm{kg}}{ }^{0,67} / \mathrm{d}\right] \\
& b \quad=\text { Anstieg der N-Retentionskurve, Ausdruck der Futterproteinqualität, } \\
& \text { unabhängig von der Höhe der NI }
\end{aligned}
$$


Für den theoretischen Wert $\mathrm{NR}_{\max } \mathrm{T}$ wurde von Wecke et al. (2016) für die Starterphase ein Wert von $4240 \mathrm{mg} / \mathrm{LM}_{\mathrm{kg}}{ }^{0,67} / \mathrm{d}$ und für die Growerphase ein Wert von $3440 \mathrm{mg} / \mathrm{LM}_{\mathrm{kg}}{ }^{0,67} / \mathrm{d}$ übernommen. Für den Gesamtversuch wurde ein Wert von $3840 \mathrm{mg} / \mathrm{LM}_{\mathrm{kg}}{ }^{0,67} / \mathrm{d}$ zugrunde gelegt. $\mathrm{Zu}$ beachten ist, dass dieser Wert unter anderem von der Tierart, dem Alter, dem Geschlecht und dem Genotyp der Tiere abhängt und unter normalen Produktionsbedingungen nicht erreicht werden kann. Er beschreibt das Verhältnis zwischen der wirklichen RetentionsRate und dem angenommenen genetischen Potential. Der N-Erhaltungsbedarf (NMR) wurde, ebenfalls basierend auf den Ergebnissen Wecke et al. (2016), mit $240 \mathrm{mg} / \mathrm{LM}_{\mathrm{kg}}{ }^{0,67} / \mathrm{d}$ in beiden Wachstumsphasen angenommen.

Der $b$-Wert lässt sich durch Logarithmieren und Umformen der oben angegebenen Gleichung berechnen, er ermöglicht eine Bewertung der Futterproteinqualität unabhängig von der NAufnahme. $b$ hat keine Dimension und wird nachfolgend mit $\mathrm{b} \times 10^{6}$ angegeben.

$\mathrm{b}=\ln N R_{\max } \mathrm{T}-\ln \left(\mathrm{NR}_{\max } \mathrm{T}-\mathrm{NR}\right) / \mathrm{NI}$

Die Wirksamkeit einer AS kann durch den abgeleiteten Parameter $b c^{-1}$ beschrieben werden. Dieser beschreibt den nachweislich linearen Zusammenhang zwischen der Konzentration der limitierenden AS (c) in $\mathrm{g} / 16 \mathrm{gN}$ und der Proteinqualität $b$ (z.B. Liebert und Gebhardt 1986; 1987; 1988a, b; Thong und Liebert, 2004; Samadi und Liebert, 2006). Somit ist die berechnete Wirksamkeit einer AS unabhängig von der Höhe der Aufnahme dieser AS.

$b c^{-1}=[\ln N R \max T-\ln (\mathrm{NRmax} \mathrm{T}-\mathrm{NR}) / \mathrm{NI}] / \mathrm{c}$

wobei $\mathrm{c}=$ Konzentration der limitierenden Aminosäure $\quad[\mathrm{g} / 16 \mathrm{gN}]$

Ist die Wirksamkeit der limitierenden AS bekannt, kann mit Hilfe der folgenden Gleichung der Bedarf an dieser AS ermittelt werden:

$\mathrm{LAAI}=\left[\operatorname{lnNR} \mathrm{max}_{\max } \mathrm{T}-\ln \left(\mathrm{NR}_{\max } \mathrm{T}-\mathrm{NR}\right)\right] /\left(16^{*} \mathrm{bc}^{-1}\right)$

wobei LAAI = tägliche Aufnahme der limitierenden AS abhängig von der Leistung und AS-Wirksamkeit $\quad\left[\mathrm{mg} / \mathrm{LM}_{\mathrm{kg}}{ }^{0,67}\right]$

Hierfür muss aber der originäre Wert für Parameter $b$ verwendet werden, d.h. ohne Multiplikation mit $10^{6}$. Der tägliche Met-Bedarf wurde in Abhängigkeit vom angestrebten täglichen Rohproteinansatz (XPD) und der realen Futteraufnahme ermittelt. Diese wurden so gewählt, dass sie im in den Versuchen 1-3 ermittelten Rahmen lagen. Für die Berechnungen 
wurden ein NMR von $240 \mathrm{mg} / \mathrm{LM}_{\mathrm{kg}}{ }^{0,67}$ und ein $\mathrm{NR}_{\max } \mathrm{T}$ von 4240 bzw. $3440 \mathrm{mg} / \mathrm{LM}_{\mathrm{kg}}{ }^{0,67}$ (Starter- bzw. Growerphase) zugrunde gelegt. Ausgehend von der beim jeweiligen Met:CysVerhältnis erreichten maximalen Met-Wirksamkeit $\left(b c^{-1}\right)$ in der jeweiligen Wachstumsphase wurde dann der Met-Bedarf berechnet.

Zusätzlich wurde für eine komplexe Bewertung der Proteinqualität auch der physiologische Nutzwert $(\mathrm{PNu})$ berechnet. Der $\mathrm{PNu}$ beschreibt die Gesamtverwertung des Proteins und berücksichtigt dabei neben den Prozessen bei der Verdauung auch die Verwertung im Intermediärstoffwechsel. Zusätzlich fließt der N-Erhaltungsbedarf mit ein.

$\mathrm{PNu}(\%)=(\mathrm{NR} / \mathrm{NI}) * 100$

Da die klassischen Proteinqualitätsparameter jedoch von der Höhe der N-Aufnahme beeinflusst sind (Block und Mitchell, 1946; Thong und Liebert, 2004; Wecke und Liebert, 2009), wird bei Anwendung des Göttinger Modells die N-Aufnahme standardisiert (s. z.B. Thong und Liebert, 2004; Wecke und Liebert, 2009; Pastor et al., 2013; Liebert, 2017; Neumann et al., 2018a, b; Velten et al., 2018b). Der standardisierte $\mathrm{PNu}\left(\mathrm{PNu}_{\text {std. }}\right)$ berechnet sich wie folgt:

$\mathrm{PNu}_{\text {std. }}(\%)=\mathrm{NRmaxT} *\left[\left(1-\mathrm{e}^{-\mathrm{b} * \mathrm{NIstd}}\right) / \mathrm{NI}_{\mathrm{std} .}\right] * 100$

wobei $\mathrm{NI}_{\text {std. }}=$ standardisierte $\mathrm{N}$-Aufnahme $\quad\left[\mathrm{mg} / \mathrm{LM}_{\mathrm{kg}}{ }^{0,67} / \mathrm{d}\right]$

Es wurde für $\mathrm{NI}_{\text {std. }}$ basierend auf der durchschnittlich realisierten NI in der Starterphase ein Wert von $3300 \mathrm{mg} / \mathrm{BW}_{\mathrm{kg}}{ }^{0,67}$, in der Growerphase von $3000 \mathrm{mg} / \mathrm{BW}_{\mathrm{kg}}{ }^{0,67}$ und für den gesamten Versuchszeitraum von $3200 \mathrm{mg} / \mathrm{BW}_{\mathrm{kg}}{ }^{0,67}$ verwendet.

\section{Makroskopie und Histologie}

Im Rahmen der makroskopischen und histologischen Untersuchungen wurden verschiedene Parameter berechnet, die den Gesundheitsstatus des Darms der Tiere beschreiben.

1) Primäre Schleimhautoberfläche

Die Schätzung der primären Schleimhautoberfläche auf makroskopischer Ebene erfolgte entsprechend der Methode nach Makanya et al. (1995). Hierfür wird der durchschnittliche Umfang der Dünndarmsegmente mit der Länge des entsprechenden Darmabschnittes multipliziert. 
wobei $\mathrm{c}=$ durchschnittlicher Umfang aller Dünndarmsegmente

1 = Länge des Darmabschnittes

2) Zottenoberfläche

Die Zottenoberfläche berechnet sich auf Basis der primären Schleimhautoberfläche und des Zottenvergrößerungsfaktors. Dieser Faktor ergibt sich aus den Schnittpunkten der verwendeten Testlinien mit der Zottenoberfläche und der primären Schleimhautoberfläche und gibt indirekt Auskunft über die Länge und Breite der Zotten.

$\mathrm{S}_{\mathrm{v}}=\mathrm{S}_{\mathrm{pm}} * \mathrm{Ss}_{(\mathrm{v}, \mathrm{pm})}$

wobei $\mathrm{Ss}_{(\mathrm{v}, \mathrm{pm})}=$ Zottenvergrößerungsfaktor

3) Verhältnis Zotten-/Kryptenepithelvolumen

Das Verhältnis des Zotten- und Kryptenepithelvolumens wurde entsprechend den Angaben von Mayhew (1991) und Nyengaard und Alwasel (2014) basierend auf den Schnittpunkten der Linienenden mit dem Zotten- bzw. Kryptenepithel wie folgt ermittelt:

$\mathrm{V}_{\mathrm{ve}} / \mathrm{V}_{\mathrm{ce}}=\mathrm{P}_{\mathrm{ve}} / \mathrm{P}_{\mathrm{ce}}$

wobei $\mathrm{P}_{\mathrm{ve}}=$ Schnittpunkte der Linienenden mit dem Zottenepithel

$\mathrm{P}_{\mathrm{ce}}=$ Schnittpunkte der Linienenden mit dem Kryptenepithel

\subsection{Statistische Auswertung}

Die statistische Auswertung wurde mit Hilfe der Software SPSS (IBM SPSS Statistics, Version 23.0) durchgeführt. Es wurde eine einfaktorielle Varianzanalyse mit einer Signifikanzgrenze von $\mathrm{p}<0,05$ unter Anwendung des Tukey- oder Games-Howell-Tests in Abhängigkeit der Homo- oder Heterogenität der Varianzen (mit Hilfe des Levene-Tests verifiziert) durchgeführt. Die Ergebnisse werden als Mittelwert \pm Standardabweichung dargestellt, verschiedene Hochbuchstaben kennzeichnen signifikante Unterschiede zwischen den Gruppen. Ausreißer wurden unter Anwendung des Dixon-Tests ermittelt.

Für die Auswertung der histologischen und stereologischen Untersuchungen wurde ebenfalls eine einfaktorielle Varianzanalyse mit Kurskal-Wallis Test verwendet. Die Ergebnisse werden als Mittelwerte mit den dazugehörigen Variationskoeffizienten dargestellt, die als Standardabweichung geteilt durch das entsprechende Gruppenmittel bestimmt wurden. 


\section{Ergebnisse}

Nachfolgend werden die Ergebnisse der drei Versuche einzeln vorgestellt. Die Angaben erfolgen als Gruppenmittelwerte, tierindividuelle Einzeldaten finden sich auf der beigefügten CD-ROM. Die Standardisierung des PNu zur Beschreibung der Proteinqualität hatte den Zweck, mögliche Unterschiede in der Höhe der NI auszugleichen und so einen direkten Vergleich zwischen den Versuchsgruppen zu ermöglichen. Da die Unterschiede in der realisierten NI jedoch verhältnismäßig gering ausfielen, zeigte die Standardisierung keinen nennenswerten Effekt. Aus diesem Grund werden die Parameter $b, \mathrm{PNu}$ und $\mathrm{PNu}_{\text {std. }}$ zusammengefasst beschrieben und später auch diskutiert.

\subsection{Versuch 1}

Versuch 1 hatte die Bewertung verschiedener Met:Cys-Verhältnisse von 40:50, 45:55, 50:50, 55:45 und 60:40 zum Ziel. Zusätzlich fand ein Vergleich der Proteinquellen HM und SES statt. Die Ergebnisse der einzelnen erhobenen Parameter werden in der Folge beschrieben.

\subsubsection{Zootechnische Parameter}

Tabelle 14 vermittelt eine Übersicht zu den Wachstumsdaten. Am Ende der Starterphase hatten die Tiere der Versuchsgruppen C (HM 50:50) und F (SES 50:50) die höchste finale LM und dementsprechend auch die höchste tägliche LMZ, es gab jedoch nur numerische Unterschiede zu Versuchsgruppe E (HM 55:45). Während es zwischen den Tieren der Versuchsgruppen B (HM 45:55), C (HM 50:50), D (HM 55:45) und E (HM 60:40) keine signifikanten Unterschiede bezüglich der FI gab, nahmen die Tiere aus Versuchsgruppe F (SES 50:50) signifikant ( $<$ < 0,05) mehr Futter auf. Dies zeigte sich auch im FA. Allerdings waren die Unterschiede im FA zwischen den Versuchsgruppen C-F nicht signifikant und Versuchsgruppe F (SES 50:50) unterschied sich auch nur numerisch von Versuchsgruppe B (HM 45:55). Im Hinblick auf den Proteinaufwand gab es keine signifikanten Unterschiede zwischen den Versuchsgruppen B-F. Der Energieaufwand war in den beiden Versuchsgruppen $\mathrm{C}$ und $\mathrm{F}$ mit einem Met:CysVerhältnis von 50:50 am niedrigsten, jedoch nur mit numerischen Unterschieden zu den Versuchsgruppen D (HM 55:45) und E (HM 60:40). Die Tiere aus Versuchsgruppe A (HM 40:60) nahmen signifikant $(\mathrm{p}<0,05)$ weniger Futter auf als die Tiere der anderen Versuchsgruppen. Dies wirkte sich deutlich auf alle anderen zootechnischen Parameter aus.

Auch am Ende der Growerphase wiesen die Tiere der Versuchsgruppen C (HM 50:50) und F (SES 50:50) die höchste finale LM und tägliche LMZ auf, jedoch nur mit tendenziellen Unterschieden zu Versuchsgruppe D (HM 55:45). Die Tiere aus Versuchsgruppe F (SES 50:50) zeigten genau wie in der Starterphase die höchste FI, allerdings ohne signifikante Unterschiede 
zu denen aus Versuchsgruppe C (HM 50:50). Der FA unterschied sich dagegen signifikant (p $<0,05)$ zwischen diesen beiden Versuchsgruppen und war im Vergleich aller Versuchsgruppen in Versuchsgruppe F am höchsten. Die Tiere der Versuchsgruppe A (HM 40:60) zeigten auch in der Growerphase die niedrigste FI und wiesen die geringste $(\mathrm{p}<0,05)$ finale LM auf. Im Gegensatz zur Starterphase gab es in der Growerphase bezüglich des Protein- und Energieaufwands keine signifikanten Unterschiede zwischen den Versuchsgruppen. 
Tabelle 14: Ergebnisse der zootechnischen Parameter der Starter- (Tag 1-21) und Growerphase (Tag 22-35) in Versuch 1.

\begin{tabular}{|c|c|c|c|c|c|c|}
\hline Met:Cys & $\begin{array}{c}\text { A } \\
\text { HM } \\
40: 60\end{array}$ & $\begin{array}{c}\text { B } \\
\text { HM } \\
45: 55\end{array}$ & $\begin{array}{c}\mathrm{C} \\
\mathrm{HM} \\
\mathbf{5 0 : 5 0}\end{array}$ & $\begin{array}{c}\text { D } \\
\text { HM } \\
55: 45\end{array}$ & $\begin{array}{c}E \\
H M \\
60: 40\end{array}$ & $\begin{array}{c}\text { F } \\
\text { SES } \\
\mathbf{5 0 : 5 0}\end{array}$ \\
\hline \multicolumn{7}{|c|}{ Starterphase (Tag 1-21) } \\
\hline $\mathrm{LM}_{\text {Beginn }}(\mathrm{g})$ & $\begin{array}{l}55 \\
\pm 0\end{array}$ & $\begin{array}{l}55 \\
\pm 1\end{array}$ & $\begin{array}{l}55 \\
\pm 0\end{array}$ & $\begin{array}{l}55 \\
\pm 0\end{array}$ & $\begin{array}{l}55 \\
\pm 1\end{array}$ & $\begin{array}{l}55 \\
\pm 1\end{array}$ \\
\hline $\mathrm{LM}_{\text {Final }}(\mathrm{g})$ & $\begin{array}{l}622^{\mathrm{a}} \\
\pm 91\end{array}$ & $\begin{array}{l}847^{b} \\
\pm 72\end{array}$ & $\begin{array}{l}978^{\mathrm{cd}} \\
\pm 83\end{array}$ & $\begin{array}{l}911^{\mathrm{bcd}} \\
\pm 78\end{array}$ & $\begin{array}{l}879^{\mathrm{bc}} \\
\pm 72\end{array}$ & $\begin{array}{l}1020^{\mathrm{d}} \\
\pm 46\end{array}$ \\
\hline $\mathrm{LMZ}(\mathrm{g} / \mathrm{d})$ & $\begin{array}{l}27^{\mathrm{a}} \\
\pm 4\end{array}$ & $\begin{array}{l}38^{\mathrm{b}} \\
\pm 3\end{array}$ & $\begin{array}{l}44^{\mathrm{cd}} \\
\pm 4\end{array}$ & $\begin{array}{l}41^{\text {bcd }} \\
\pm 4\end{array}$ & $\begin{array}{l}39^{b c} \\
\pm 3\end{array}$ & $\begin{array}{l}46^{\mathrm{d}} \\
\pm 2\end{array}$ \\
\hline $\mathrm{FI}(\mathrm{g} \mathrm{TM} / \mathrm{d})$ & $\begin{array}{l}40,3^{\mathrm{a}} \\
\pm 4,7\end{array}$ & $\begin{array}{l}51,1^{\mathrm{b}} \\
\pm 4,5\end{array}$ & $\begin{array}{l}54,4^{\mathrm{b}} \\
\pm 4,3\end{array}$ & $\begin{array}{l}51,7^{\mathrm{b}} \\
\pm 2,7\end{array}$ & $\begin{array}{l}49,9^{\mathrm{b}} \\
\pm 5,0\end{array}$ & $\begin{array}{l}61,7^{\mathrm{c}} \\
\pm 4,6\end{array}$ \\
\hline $\begin{array}{c}\text { FA } \\
(\mathrm{g} F \mathrm{~F} / \mathrm{g} \text { LMZ) }\end{array}$ & $\begin{array}{r}1,51^{\mathrm{a}} \\
\pm 0,15\end{array}$ & $\begin{array}{l}1,36^{\mathrm{ab}} \\
\pm 0,07\end{array}$ & $\begin{array}{l}1,24^{\mathrm{c}} \\
\pm 0,07\end{array}$ & $\begin{array}{l}1,27^{\mathrm{bc}} \\
\pm 0,08\end{array}$ & $\begin{array}{l}1,27^{\mathrm{bc}} \\
\pm 0,09\end{array}$ & $\begin{array}{l}1,34^{\mathrm{abc}} \\
\pm 0,06\end{array}$ \\
\hline $\begin{array}{l}\text { Proteinaufwand } \\
\text { (g XPI / g LMZ) }\end{array}$ & $\begin{array}{r}0,37^{\mathrm{a}} \\
\pm 0,04\end{array}$ & $\begin{array}{l}0,33^{\mathrm{ab}} \\
\pm 0,02\end{array}$ & $\begin{array}{c}0,30^{\mathrm{b}} \\
\pm 0,02\end{array}$ & $\begin{array}{c}0,31^{\mathrm{b}} \\
\pm 0,02\end{array}$ & $\begin{array}{l}0,31^{\mathrm{b}} \\
\pm 0,02\end{array}$ & $\begin{array}{l}0,31^{\mathrm{b}} \\
\pm 0,01\end{array}$ \\
\hline $\begin{array}{c}\text { Energieaufwand } \\
(\mathrm{kJ} \mathrm{ME} \mathrm{/} \\
\text { g LMZ) }\end{array}$ & $\begin{array}{l}23,87^{\mathrm{a}} \\
\pm 2,44\end{array}$ & $\begin{array}{l}21,45^{\mathrm{ab}} \\
\pm 1,06\end{array}$ & $\begin{array}{l}19,60^{c} \\
\pm 1,13\end{array}$ & $\begin{array}{l}20,14^{\mathrm{bc}} \\
\pm 1,20\end{array}$ & $\begin{array}{l}20,13^{\mathrm{bc}} \\
\pm 1,50\end{array}$ & $\begin{array}{l}19,00^{c} \\
\pm 0,89\end{array}$ \\
\hline \multicolumn{7}{|c|}{ Growerphase (Tag 22-35) } \\
\hline $\mathrm{LM}_{\text {Final }}(\mathrm{g})$ & $\begin{array}{l}1307^{\mathrm{a}} \\
\pm 227\end{array}$ & $\begin{array}{l}1780^{\mathrm{b}} \\
\pm 150\end{array}$ & $\begin{array}{l}2064^{c} \\
\pm 232\end{array}$ & $\begin{array}{l}1838^{\mathrm{bc}} \\
\pm 153\end{array}$ & $\begin{array}{l}1628^{b} \\
\pm 161\end{array}$ & $\begin{array}{l}2108^{c} \\
\pm 150\end{array}$ \\
\hline $\operatorname{LMZ}(\mathrm{g} / \mathrm{d})$ & $\begin{array}{l}49^{\mathrm{a}} \\
\pm 11\end{array}$ & $\begin{array}{l}67^{\mathrm{bc}} \\
\pm 10\end{array}$ & $\begin{array}{r}78^{c} \\
\pm 13\end{array}$ & $\begin{array}{l}66^{\mathrm{bc}} \\
\pm 8\end{array}$ & $\begin{array}{l}54^{\mathrm{ab}} \\
\pm 7\end{array}$ & $\begin{array}{l}78^{\mathrm{c}} \\
\pm 8\end{array}$ \\
\hline $\mathrm{FI}(\mathrm{g} \mathrm{TM} / \mathrm{d})$ & $\begin{array}{r}77,5^{\mathrm{a}} \\
\pm 16,3\end{array}$ & $\begin{array}{l}99,4^{\mathrm{bc}} \\
\pm 12,7\end{array}$ & $\begin{array}{l}114,1^{\mathrm{cd}} \\
\pm 14,2\end{array}$ & $\begin{array}{l}102,5^{b c} \\
\pm 10,2\end{array}$ & $\begin{array}{l}86,3^{\mathrm{ab}} \\
\pm 8,6\end{array}$ & $\begin{array}{l}131,2^{\mathrm{d}} \\
\pm 12,5\end{array}$ \\
\hline $\begin{array}{c}\text { FA } \\
(\mathrm{g} \mathrm{FI} / \mathrm{g} \mathrm{LMZ})\end{array}$ & $\begin{array}{l}1,59^{\mathrm{ab}} \\
\pm 0,11\end{array}$ & $\begin{array}{l}1,51^{\mathrm{b}} \\
\pm 0,17\end{array}$ & $\begin{array}{c}1,49^{\mathrm{b}} \\
\pm 0,12\end{array}$ & $\begin{array}{l}1,55^{\mathrm{ab}} \\
\pm 0,07\end{array}$ & $\begin{array}{l}1,62^{\mathrm{ab}} \\
\pm 0,09\end{array}$ & $\begin{array}{r}1,69^{\mathrm{a}} \\
\pm 0,03\end{array}$ \\
\hline $\begin{array}{l}\text { Proteinaufwand } \\
\text { (g XPI / g LMZ) }\end{array}$ & $\begin{array}{c}0,36 \\
\pm 0,02\end{array}$ & $\begin{array}{c}0,34 \\
\pm 0,04\end{array}$ & $\begin{array}{c}0,34 \\
\pm 0,03\end{array}$ & $\begin{array}{c}0,35 \\
\pm 0,02\end{array}$ & $\begin{array}{c}0,37 \\
\pm 0,02\end{array}$ & $\begin{array}{c}0,37 \\
\pm 0,01\end{array}$ \\
\hline $\begin{array}{c}\text { Energieaufwand } \\
(\mathrm{kJ} \text { ME / } \\
\text { g LMZ) }\end{array}$ & $\begin{array}{l}25,05 \\
\pm 1,78\end{array}$ & $\begin{array}{l}23,75 \\
\pm 2,72\end{array}$ & $\begin{array}{l}23,41 \\
\pm 1,88\end{array}$ & $\begin{array}{r}24,50 \\
\pm 1,11\end{array}$ & $\begin{array}{l}25,63 \\
\pm 1,49\end{array}$ & $\begin{array}{c}24,53 \\
\pm 0,50\end{array}$ \\
\hline
\end{tabular}

Angaben als Mittelwerte \pm Standardabweichung, unterschiedliche Hochbuchstaben kennzeichnen signifikante Unterschiede $(p$ $<0,05)$. 
Tabelle 15 zeigt die Ergebnisse der zootechnischen Parameter für den gesamten Versuchszeitraum von Versuch 1. Sie unterstreichen die Ergebnisse der Starter- und der Growerphase. Auch in der Gesamtbetrachtung wiesen die Tiere der Versuchsgruppen C (HM 50:50) und F (SES 50:50) die höchste finale LM, tägliche LMZ und FI auf, sie unterschieden sich aber nur numerisch von Versuchsgruppe D (HM 55:45). Beim FA unterschieden sich die Versuchsgruppen C (HM 50:50) und F (SES 50:50) jedoch signifikant ( $\mathrm{p}<0,05)$ voneinander. Sowohl der Protein- als auch der Energieaufwand waren bei Betrachtung des gesamten Versuchs in Versuchsgruppe C (HM 50:50) am niedrigsten, es gab jedoch nur numerische Unterschiede zu den Versuchsgruppen B (HM 45:55), D (HM 55:45), E (HM 60:40) und F (SES 50:50). Die geringe FI der Tiere aus Versuchsgruppe A (HM 40:60) wirkte sich auch in der Gesamtbetrachtung deutlich auf die anderen Parameter aus und Abbildung 8 veranschaulicht den großen Unterschied im Wachstum zwischen den Tieren dieser Versuchsgruppe und denen aus Versuchsgruppe C (HM 50:50).

Tabelle 15: Ergebnisse der zootechnischen Parameter des gesamten Versuchs 1 (Tag 1-35).

\begin{tabular}{|c|c|c|c|c|c|c|}
\hline Met:Cys & $\begin{array}{c}A \\
H M \\
40: 60\end{array}$ & $\begin{array}{c}\text { B } \\
\text { HM } \\
45: 55\end{array}$ & $\begin{array}{c}\mathrm{C} \\
\mathrm{HM} \\
\mathbf{5 0 : 5 0}\end{array}$ & $\begin{array}{c}\text { D } \\
\text { HM } \\
55: 45\end{array}$ & $\begin{array}{c}\mathrm{E} \\
\mathrm{HM} \\
60: 40\end{array}$ & $\begin{array}{c}\text { F } \\
\text { SES } \\
50: 50\end{array}$ \\
\hline $\operatorname{LM}_{\text {Beginn }}(\mathrm{g})$ & $\begin{array}{r}55 \\
\pm 0\end{array}$ & $\begin{array}{r}55 \\
\pm 1\end{array}$ & $\begin{array}{r}55 \\
\pm 0\end{array}$ & $\begin{array}{l}55 \\
\pm 0\end{array}$ & $\begin{array}{r}55 \\
\pm 1\end{array}$ & $\begin{array}{r}55 \\
\pm 1\end{array}$ \\
\hline $\mathrm{LM}_{\text {Final }}(\mathrm{g})$ & $\begin{array}{l}1307^{\mathrm{a}} \\
\pm 227\end{array}$ & $\begin{array}{l}1780^{\mathrm{b}} \\
\pm 150\end{array}$ & $\begin{array}{l}2064^{c} \\
\pm 232\end{array}$ & $\begin{array}{l}1838^{\mathrm{bc}} \\
\pm 153\end{array}$ & $\begin{array}{l}1628^{b} \\
\pm 161\end{array}$ & $\begin{array}{l}2108^{c} \\
\pm 150\end{array}$ \\
\hline LMZ (g/d) & $\begin{array}{l}36^{\mathrm{a}} \\
\pm 7\end{array}$ & $\begin{array}{l}49^{b} \\
\pm 4\end{array}$ & $\begin{array}{l}57^{\mathrm{c}} \\
\pm 7\end{array}$ & $\begin{array}{l}51^{b c} \\
\pm 4\end{array}$ & $\begin{array}{l}45^{\mathrm{b}} \\
\pm 5\end{array}$ & $\begin{array}{l}59^{c} \\
\pm 4\end{array}$ \\
\hline FI (g TM/d) & $\begin{array}{l}55,2^{\mathrm{a}} \\
\pm 9,0\end{array}$ & $\begin{array}{l}70,5^{\text {bc }} \\
\pm 6,2\end{array}$ & $\begin{array}{l}78,3^{\mathrm{c}} \\
\pm 7,1\end{array}$ & $\begin{array}{l}72,0^{\mathrm{bc}} \\
\pm 5,1\end{array}$ & $\begin{array}{l}64,5^{\mathrm{ab}} \\
\pm 5,8\end{array}$ & $\begin{array}{l}89,5^{\mathrm{c}} \\
\pm 7,2\end{array}$ \\
\hline $\begin{array}{c}\text { FA } \\
(\mathrm{g} F I / g \text { LMZ) }\end{array}$ & $\begin{array}{l}1,55^{\mathrm{ab}} \\
\pm 0,08\end{array}$ & $\begin{array}{l}1,43^{\mathrm{ac}} \\
\pm 0,10\end{array}$ & $\begin{array}{l}1,37^{\mathrm{c}} \\
\pm 0,08\end{array}$ & $\begin{array}{c}1,42^{\mathrm{c}} \\
\pm 0,03\end{array}$ & $\begin{array}{l}1,44^{\mathrm{bc}} \\
\pm 0,06\end{array}$ & $\begin{array}{r}1,53^{\mathrm{a}} \\
\pm 0,03\end{array}$ \\
\hline $\begin{array}{l}\text { Proteinaufwand } \\
\text { (g XPI / g LMZ) }\end{array}$ & $\begin{array}{r}0,36^{\mathrm{a}} \\
\pm 0,02\end{array}$ & $\begin{array}{r}0,34^{\mathrm{b}} \\
\pm 0,03\end{array}$ & $\begin{array}{c}0,32^{\mathrm{b}} \\
\pm 0,02\end{array}$ & $\begin{array}{c}0,33^{\mathrm{b}} \\
\pm 0,01\end{array}$ & $\begin{array}{c}0,34^{\mathrm{b}} \\
\pm 0,01\end{array}$ & $\begin{array}{l}0,34^{\mathrm{ab}} \\
\pm 0,01\end{array}$ \\
\hline $\begin{array}{c}\text { Energieaufwand } \\
\text { (kJ ME / } \\
\text { g LMZ) }\end{array}$ & $\begin{array}{l}24,45^{\mathrm{a}} \\
\pm 1,23\end{array}$ & $\begin{array}{l}22,62^{\mathrm{ab}} \\
\pm 1,56\end{array}$ & $\begin{array}{l}21,62^{\mathrm{b}} \\
\pm 1,25\end{array}$ & $\begin{array}{l}22,36^{\mathrm{b}} \\
\pm 0,42\end{array}$ & $\begin{array}{l}22,70^{\mathrm{ab}} \\
\pm 0,90\end{array}$ & $\begin{array}{l}21,92^{\mathrm{b}} \\
\pm 0,46\end{array}$ \\
\hline
\end{tabular}

Angaben als Mittelwerte \pm Standardabweichung, unterschiedliche Hochbuchstaben kennzeichnen signifikante Unterschiede (p $<0,05)$. 


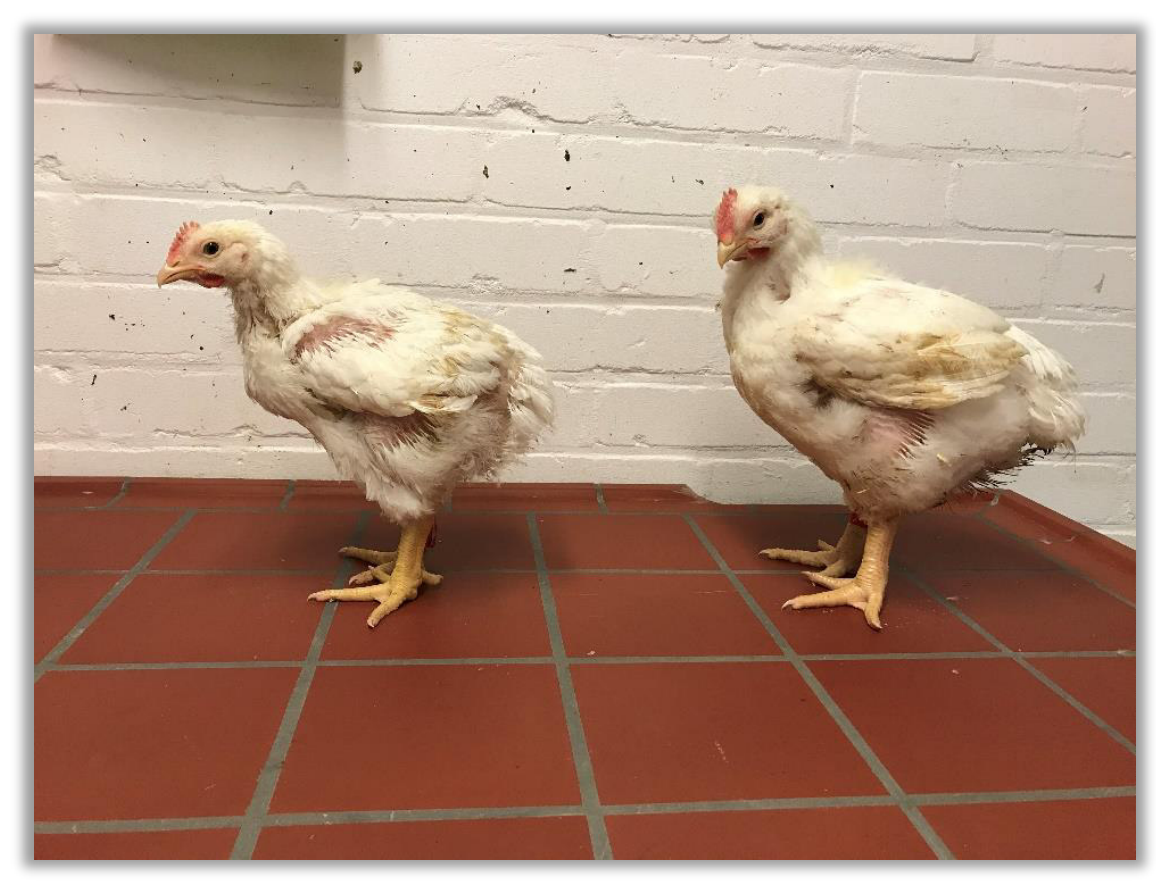

Abbildung 8: Repräsentative Versuchstiere aus Versuchsgruppe A (HM 40:60, links) und Versuchsgruppe C (HM 50:50, rechts) in Versuch 1 an Tag 35.

\subsubsection{Scheinbare praecaecale Verdaulichkeit}

Die Ergebnisse der scheinbaren pcV fasst Tab. 16 zusammen. Die scheinbare pcV des XP lag in den Futtermischungen in einem Bereich von 76 bis knapp 80\%. Die Werte für die ausgewählten AS lagen bei $\geq 80 \%$, lediglich Cys, Thr und Val wiesen etwas niedrigere Werte auf. In den Versuchsgruppen A-E mit HM unterschied sich weder die scheinbare pcV des XP noch der AS signifikant voneinander. Lediglich die scheinbare $\mathrm{pcV}$ von Met erhöhte sich mit steigendem Met-Anteil an den SAS, was zu einem signifikanten $(\mathrm{p}<0,05)$ Unterschied zwischen Versuchsgruppe A (HM 40:60) und E (HM 60:40) führte. Die Versuchsgruppen C (HM 50:50) und F (SES 50:50) wiesen keine signifikanten Unterschiede in der scheinbaren pcV des XP und der AS auf. 
Tabelle 16: Mittlere Ergebnisse zur scheinbaren praecaecalen Verdaulichkeit (\%) des Rohproteins und ausgewählter Aminosäuren der Versuchsgruppen in Versuch 1.

\begin{tabular}{|c|c|c|c|c|c|c|}
\hline Met:Cys & $\begin{array}{c}A \\
\text { HM } \\
40: 60\end{array}$ & $\begin{array}{c}\text { B } \\
\text { HM } \\
45: 55\end{array}$ & $\begin{array}{c}\mathrm{C} \\
\text { HM } \\
\mathbf{5 0 : 5 0}\end{array}$ & $\begin{array}{c}\text { D } \\
\text { HM } \\
55: 45\end{array}$ & $\begin{array}{c}\mathrm{E} \\
\mathrm{HM} \\
60: 40\end{array}$ & $\begin{array}{c}\text { F } \\
\text { SES } \\
50: 50\end{array}$ \\
\hline $\mathrm{XP}$ & $\begin{array}{c}74,2 \\
\pm 4,0\end{array}$ & $\begin{array}{r}76,7 \\
\pm 2,8\end{array}$ & $\begin{array}{r}76,0 \\
\pm 2,9\end{array}$ & $\begin{array}{r}79,2 \\
\pm 2,7\end{array}$ & $\begin{array}{r}79,6 \\
\pm 2,0\end{array}$ & $\begin{array}{r}77,7 \\
\pm 1,9\end{array}$ \\
\hline Lys & $\begin{array}{r}83,4 \\
\pm 2,2\end{array}$ & $\begin{array}{r}84,9 \\
\pm 3,4\end{array}$ & $\begin{array}{r}83,4 \\
\pm 3,9\end{array}$ & $\begin{array}{r}86,7 \\
\pm 2,5\end{array}$ & $\begin{array}{c}88,1 \\
\pm 1,6\end{array}$ & $\begin{array}{r}83,4 \\
\pm 2,0\end{array}$ \\
\hline Met & $\begin{array}{l}82,1^{\mathrm{a}} \\
\pm 2,2\end{array}$ & $\begin{array}{c}85,8^{\mathrm{ab}} \\
\pm 4,5\end{array}$ & $\begin{array}{l}87,6^{a b} \\
\pm 5,4\end{array}$ & $\begin{array}{c}88,3^{\text {ab }} \\
\pm 2,6\end{array}$ & $\begin{array}{l}91,3^{b} \\
\pm 1,6\end{array}$ & $\begin{array}{l}83,6^{\mathrm{a}} \\
\pm 2,2\end{array}$ \\
\hline Cys & $\begin{array}{l}66,6^{\mathrm{b}} \\
\pm 4,0\end{array}$ & $\begin{array}{l}68,2^{\mathrm{b}} \\
\pm 3,6\end{array}$ & $\begin{array}{c}61,6^{\mathrm{ab}} \\
\pm 4,1\end{array}$ & $\begin{array}{l}69,8^{\mathrm{b}} \\
\pm 4,8\end{array}$ & $\begin{array}{l}63,3^{\mathrm{b}} \\
\pm 6,1\end{array}$ & $\begin{array}{l}52,7^{\mathrm{a}} \\
\pm 1,0\end{array}$ \\
\hline Thr & $\begin{array}{c}73,2^{\mathrm{ab}} \\
\pm 2,2\end{array}$ & $\begin{array}{c}76,2^{\mathrm{ab}} \\
\pm 4,3\end{array}$ & $\begin{array}{l}72,9^{\mathrm{ab}} \\
\pm 4,1\end{array}$ & $\begin{array}{c}77,7^{\mathrm{ab}} \\
\pm 3,0\end{array}$ & $\begin{array}{l}78,8^{b} \\
\pm 2,6\end{array}$ & $\begin{array}{l}69,5^{\mathrm{a}} \\
\pm 5,7\end{array}$ \\
\hline Arg & $\begin{array}{c}88,4^{\mathrm{ab}} \\
\pm 1,7\end{array}$ & $\begin{array}{c}89,0^{\mathrm{ab}} \\
\pm 2,5\end{array}$ & $\begin{array}{c}87,7^{\mathrm{ab}} \\
\pm 3,0\end{array}$ & $\begin{array}{l}89,9^{b} \\
\pm 2,2\end{array}$ & $\begin{array}{l}91,3^{b} \\
\pm 1,2\end{array}$ & $\begin{array}{l}84,9^{\mathrm{a}} \\
\pm 1,4\end{array}$ \\
\hline His & $\begin{array}{r}79,9 \\
\pm 2,2\end{array}$ & $\begin{array}{r}81,2 \\
\pm 2,9\end{array}$ & $\begin{array}{r}80,4 \\
\pm 3,2\end{array}$ & $\begin{array}{c}83,1 \\
\pm 2,7\end{array}$ & $\begin{array}{r}84,3 \\
\pm 1,7\end{array}$ & $\begin{array}{r}81,3 \\
\pm 1,7\end{array}$ \\
\hline Ile & $\begin{array}{r}80,9 \\
\pm 1,9\end{array}$ & $\begin{array}{r}82,3 \\
\pm 3,8\end{array}$ & $\begin{array}{r}81,0 \\
\pm 4,2\end{array}$ & $\begin{array}{r}83,9 \\
\pm 2,9\end{array}$ & $\begin{array}{r}85,4 \\
\pm 2,2\end{array}$ & $\begin{array}{r}79,3 \\
\pm 2,0\end{array}$ \\
\hline Leu & $\begin{array}{c}81,7^{\mathrm{ab}} \\
\pm 2,2\end{array}$ & $\begin{array}{c}83,3^{\mathrm{ab}} \\
\pm 4,6\end{array}$ & $\begin{array}{c}81,7^{\mathrm{ab}} \\
\pm 4,0\end{array}$ & $\begin{array}{c}84,8^{a b} \\
\pm 2,8\end{array}$ & $\begin{array}{l}86,3^{b} \\
\pm 1,9\end{array}$ & $\begin{array}{l}79,7^{\mathrm{a}} \\
\pm 2,1\end{array}$ \\
\hline Phe & $\begin{array}{r}83,3 \\
\pm 1,8\end{array}$ & $\begin{array}{r}85,0 \\
\pm 3,9\end{array}$ & $\begin{array}{r}82,8 \\
\pm 3,7\end{array}$ & $\begin{array}{r}86,3 \\
\pm 2,6\end{array}$ & $\begin{array}{r}84,4 \\
\pm 1,9\end{array}$ & $\begin{array}{r}82,0 \\
\pm 1,6\end{array}$ \\
\hline Val & $\begin{array}{l}73,4^{\mathrm{ab}} \\
\pm 2,7\end{array}$ & $\begin{array}{c}76,2^{\mathrm{ab}} \\
\pm 3,8\end{array}$ & $\begin{array}{c}73,9^{\mathrm{ab}} \\
\pm 3,2\end{array}$ & $\begin{array}{l}78,7^{\mathrm{b}} \\
\pm 2,5\end{array}$ & $\begin{array}{l}79,6^{\mathrm{b}} \\
\pm 2,8\end{array}$ & $\begin{array}{l}71,5^{\mathrm{a}} \\
\pm 2,2\end{array}$ \\
\hline
\end{tabular}

Angaben als Mittelwerte \pm Standardabweichung, unterschiedliche Hochbuchstaben kennzeichnen signifikante Unterschiede (p $<0,05)$.

\subsubsection{Proteinqualität und Met-Wirksamkeit}

In Tabelle 17 werden die Ergebnisse der Proteinqualitätsbewertung in Versuch 1 dargestellt. In der Starterphase wies Versuchsgruppe F (SES 50:50) den höchsten N-Ansatz auf, unterschied sich jedoch nur numerisch von Versuchsgruppe C (HM 50:50). Versuchsgruppe A (HM 40:60) zeigte den signifikant $(\mathrm{p}<0,05)$ niedrigsten Wert, zwischen den übrigen Versuchsgruppen B (HM 45:55), D (HM 55:45) und E (HM 60:40) gab es dagegen keine signifikanten Unterschiede. Die Proteinqualität, ausgedrückt durch die Kennzahlen $b, \mathrm{PNu}$ und $\mathrm{PNu}_{\text {std., war }}$ in Versuchsgruppe A (HM 40:60) am geringsten und in den Versuchsgruppen B (HM 45:55) und C (HM 50:50) signifikant ( $\mathrm{p}<0,05)$ verbessert. In den Versuchsgruppen D (HM 55:45) und E (HM 60:40) lag sie dagegen tendenziell wieder etwas niedriger. 
In der Growerphase zeigte Versuchsgruppe C (HM 50:50) den höchsten N-Ansatz, jedoch nur mit numerischen Unterschieden zu den Versuchsgruppen B (HM 45:55), D (HM 55:45) und F (SES 50:50). Die Versuchsgruppen A (HM 40:60) und E (HM 60:40) wiesen die niedrigsten Werte auf. Eine ähnliche Tendenz war auch in Bezug auf die Proteinqualität erkennbar. Während Versuchsgruppe A (HM 40:60) die niedrigsten Werte für $b, \mathrm{PNu}$ und $\mathrm{PNu}_{\text {std. }}$ zeigte, konnte in Versuchsgruppe C (HM 50:50) der höchste Wert für diese Parameter beobachtet werden. In den Versuchsgruppen B (HM 45:45) und C (HM 50:50) war die Proteinqualität auch in der Growerphase signifikant $(\mathrm{p}<0,05)$ verbessert, im Gegensatz zur Starterphase führte eine Erhöhung des Met-Anteils auf 55 bzw. 60\% der SAS in Versuchsgruppe D und E allerdings zu einer signifikanten $(\mathrm{p}<0,05)$ Verringerung der Parameter. Versuchsgruppe F (SES 50:50) unterschied sich nicht signifikant von Versuchsgruppe C (HM 50:50), überraschenderweise aber ebenso wenig von allen anderen Versuchsgruppen.

Betrachtet man die Ergebnisse für den gesamten Versuchszeitraum, wies Versuchsgruppe A (HM 40:60) ebenso wie in den einzelnen Wachstumsphasen den niedrigsten N-Ansatz auf. Der höchste Wert konnte in Versuchsgruppe F (SES 50:50) beobachtet werden, er unterschied sich jedoch nur numerisch von dem in Versuchsgruppe C (HM 50:50). Zwischen den Versuchsgruppen B (HM 45:55), D (HM 55:45) und E (HM 60:40) gab es keine signifikanten Unterschiede. Die Proteinqualität (b, PNu und $\mathrm{PNu}_{\text {std. }}$ ) war ebenfalls in Versuchsgruppe A (HM 40:60) am geringsten ( $<$ <,05) und konnte in Versuchsgruppe B (HM 45:45) bzw. C (HM 50:50) signifikant ( $<<0,05)$ verbessert werden. In den Versuchsgruppen D (HM 55:45) und E (HM 60:40) nahm die Proteinqualität, ebenso wie in der Growerphase beobachtet, signifikant $(\mathrm{p}<0,05) \mathrm{ab}$. 
Tabelle 17: Ergebnisse der Proteinqualitätsbewertung in Versuch 1.

\begin{tabular}{|c|c|c|c|c|c|c|}
\hline Met:Cys & $\begin{array}{c}\mathrm{A} \\
\mathrm{HM} \\
\mathbf{4 0 : 6 0}\end{array}$ & $\begin{array}{c}\text { B } \\
\text { HM } \\
\mathbf{4 5 : 5 5}\end{array}$ & $\begin{array}{c}\mathrm{C} \\
\mathrm{HM} \\
\mathbf{5 0 : 5 0}\end{array}$ & $\begin{array}{c}\text { D } \\
\text { HM } \\
55: 45\end{array}$ & $\begin{array}{c}\mathrm{E} \\
\mathrm{HM} \\
60: 40\end{array}$ & $\begin{array}{c}\text { F } \\
\text { SES } \\
\mathbf{5 0 : 5 0}\end{array}$ \\
\hline \multicolumn{7}{|c|}{ Starterphase (Tag 1-21) } \\
\hline $\mathrm{c}_{\text {Met }}(\mathrm{g} / 16 \mathrm{gN})$ & 1,223 & 1,380 & 1,542 & 1,691 & 1,849 & 1,607 \\
\hline $\begin{array}{c}\mathrm{ND} \\
\left(\mathrm{mg} / \mathrm{LM}_{\mathrm{kg}} 0,67 / \mathrm{d}\right)\end{array}$ & $\begin{array}{l}1294^{\mathrm{a}} \\
\pm 91\end{array}$ & $\begin{array}{l}1511^{\mathrm{b}} \\
\pm 81\end{array}$ & $\begin{array}{l}1636^{\mathrm{cd}} \\
\pm 58\end{array}$ & $\begin{array}{c}1594^{\mathrm{bc}} \\
\pm 57\end{array}$ & $\begin{array}{l}1576^{\mathrm{bc}} \\
\pm 56\end{array}$ & $\begin{array}{l}1706^{\mathrm{d}} \\
\pm 33\end{array}$ \\
\hline $\begin{array}{l}\text { Modellparameter } \\
\qquad b\left(* 10^{6}\right)\end{array}$ & $\begin{array}{l}140^{\mathrm{a}} \\
\pm 15\end{array}$ & $\begin{array}{l}157^{\mathrm{b}} \\
\pm 9\end{array}$ & $\begin{array}{l}178^{\mathrm{c}} \\
\pm 11\end{array}$ & $\begin{array}{l}174^{\mathrm{bc}} \\
\pm 11\end{array}$ & $\begin{array}{l}175^{\mathrm{bc}} \\
\pm 13\end{array}$ & $\begin{array}{l}175^{\mathrm{c}} \\
\pm 8\end{array}$ \\
\hline $\mathrm{PNu}(\%)$ & $\begin{array}{l}47,6^{\mathrm{a}} \\
\pm 4,6\end{array}$ & $\begin{array}{l}51,7^{\text {ab }} \\
\pm 2,6\end{array}$ & $\begin{array}{l}57,2^{\mathrm{c}} \\
\pm 3,1\end{array}$ & $\begin{array}{l}56,2^{\text {bc }} \\
\pm 3,1\end{array}$ & $\begin{array}{l}56,7^{\text {bc }} \\
\pm 4,1\end{array}$ & $\begin{array}{l}55,5^{\text {bc }} \\
\pm 2,6\end{array}$ \\
\hline $\mathrm{PNu}_{\text {std. }}(\%)$ & $\begin{array}{l}47,3^{\mathrm{a}} \\
\pm 4,0\end{array}$ & $\begin{array}{l}52,0^{b} \\
\pm 2,2\end{array}$ & $\begin{array}{l}57,1^{\mathrm{c}} \\
\pm 2,5\end{array}$ & $\begin{array}{l}56,0^{\mathrm{bc}} \\
\pm 2,7\end{array}$ & $\begin{array}{l}56,2^{\text {bc }} \\
\pm 3,1\end{array}$ & $\begin{array}{l}56,4^{\mathrm{c}} \\
\pm 1,9\end{array}$ \\
\hline \multicolumn{7}{|c|}{ Growerphase (Tag 22-35) } \\
\hline $\mathrm{c}_{\text {Met }}(\mathrm{g} / 16 \mathrm{gN})$ & 1,227 & 1,387 & 1,543 & 1,695 & 1,852 & 1,605 \\
\hline $\begin{array}{c}\mathrm{ND} \\
\left(\mathrm{mg} / \mathrm{LM}_{\mathrm{kg}} 0,67 / \mathrm{d}\right)\end{array}$ & $\begin{array}{l}1185^{\mathrm{ab}} \\
\pm 155\end{array}$ & $\begin{array}{l}1412^{\mathrm{c}} \\
\pm 165\end{array}$ & $\begin{array}{l}1532^{c} \\
\pm 170\end{array}$ & $\begin{array}{l}1383^{b c} \\
\pm 122\end{array}$ & $\begin{array}{l}1156^{\mathrm{a}} \\
\pm 111\end{array}$ & $\begin{array}{l}1519^{c} \\
\pm 100\end{array}$ \\
\hline $\begin{array}{l}\text { Modellparameter } \\
\qquad b\left(* 10^{6}\right)\end{array}$ & $\begin{array}{l}189^{\mathrm{a}} \\
\pm 16\end{array}$ & $\begin{array}{l}222^{b c} \\
\pm 32\end{array}$ & $\begin{array}{l}235^{\mathrm{c}} \\
\pm 27\end{array}$ & $\begin{array}{l}215^{\mathrm{abc}} \\
\pm 12\end{array}$ & $\begin{array}{l}195^{\mathrm{ab}} \\
\pm 13\end{array}$ & $\begin{array}{l}212^{\mathrm{abc}} \\
\pm 7\end{array}$ \\
\hline $\mathrm{PNu}(\%)$ & $\begin{array}{l}50,3^{\mathrm{a}} \\
\pm 3,3\end{array}$ & $\begin{array}{l}55,8^{b} \\
\pm 6,4\end{array}$ & $\begin{array}{l}57,3^{\mathrm{b}} \\
\pm 4,1\end{array}$ & $\begin{array}{l}54,5^{\mathrm{ab}} \\
\pm 1,8\end{array}$ & $\begin{array}{l}52,3^{\text {ab }} \\
\pm 2,4\end{array}$ & $\begin{array}{l}52,0^{\mathrm{ab}} \\
\pm 0,9\end{array}$ \\
\hline $\mathrm{PNu}_{\text {std. }}(\%)$ & $\begin{array}{l}49,6^{\mathrm{a}} \\
\pm 3,1\end{array}$ & $\begin{array}{l}55,5^{\mathrm{bc}} \\
\pm 5,5\end{array}$ & $\begin{array}{l}57,9^{c} \\
\pm 4,4\end{array}$ & $\begin{array}{c}54,4^{\text {abc }} \\
\pm 2,3\end{array}$ & $\begin{array}{l}50,8^{\mathrm{ab}} \\
\pm 2,5\end{array}$ & $\begin{array}{c}54,0^{\mathrm{abc}} \\
\pm 1,3\end{array}$ \\
\hline \multicolumn{7}{|c|}{ Gesamte Versuchsphase (Tag 1-35) } \\
\hline $\mathrm{c}_{\text {Met }}(\mathrm{g} / 16 \mathrm{gN})$ & 1,225 & 1,384 & 1,543 & 1,693 & 1,581 & 1,606 \\
\hline $\begin{array}{c}\mathrm{ND} \\
\left(\mathrm{mg} / \mathrm{LM}_{\mathrm{kg}}{ }^{0,67} / \mathrm{d}\right)\end{array}$ & $\begin{array}{l}1250^{\mathrm{a}} \\
\pm 101\end{array}$ & $\begin{array}{l}1461^{\mathrm{b}} \\
\pm 60\end{array}$ & $\begin{array}{l}1594^{\mathrm{cd}} \\
\pm 83\end{array}$ & $\begin{array}{c}1509^{\mathrm{bc}} \\
\pm 57\end{array}$ & $\begin{array}{l}1408^{\mathrm{b}} \\
\pm 65\end{array}$ & $\begin{array}{l}1631^{\mathrm{d}} \\
\pm 55\end{array}$ \\
\hline $\begin{array}{l}\text { Modellparameter } \\
\qquad b\left(* 10^{6}\right)\end{array}$ & $\begin{array}{l}160^{\mathrm{a}} \\
\pm 11\end{array}$ & $\begin{array}{l}183^{\mathrm{b}} \\
\pm 12\end{array}$ & $\begin{array}{l}203^{c} \\
\pm 14\end{array}$ & $\begin{array}{c}193^{\mathrm{bc}} \\
\pm 7\end{array}$ & $\begin{array}{c}187^{\mathrm{b}} \\
\pm 9\end{array}$ & $\begin{array}{c}193^{\mathrm{bc}} \\
\pm 6\end{array}$ \\
\hline $\mathrm{PNu}(\%)$ & $\begin{array}{l}48,5^{\mathrm{a}} \\
\pm 2,8\end{array}$ & $\begin{array}{l}53,1^{b} \\
\pm 3,1\end{array}$ & $\begin{array}{l}57,2^{\mathrm{c}} \\
\pm 3,0\end{array}$ & $\begin{array}{l}55,5^{\mathrm{bc}} \\
\pm 1,5\end{array}$ & $\begin{array}{l}55,1^{\mathrm{bc}} \\
\pm 2,5\end{array}$ & $\begin{array}{l}54,1^{\mathrm{bc}} \\
\pm 1,6\end{array}$ \\
\hline $\mathrm{PNu}_{\text {std. }}(\%)$ & $\begin{array}{l}48,0^{\mathrm{a}} \\
\pm 2,5\end{array}$ & $\begin{array}{l}53,1^{b} \\
\pm 2,6\end{array}$ & $\begin{array}{l}57,3^{c} \\
\pm 2,7\end{array}$ & $\begin{array}{l}55,3^{\text {bc }} \\
\pm 1,4\end{array}$ & $\begin{array}{l}54,1^{\mathrm{b}} \\
\pm 2,0\end{array}$ & $\begin{array}{l}55,3^{\text {bc }} \\
\pm 1,1\end{array}$ \\
\hline
\end{tabular}

Angaben als Mittelwerte \pm Standardabweichung, unterschiedliche Hochbuchstaben kennzeichnen signifikante Unterschiede $(\mathrm{p}$ $<0,05)$. 
In den Abb. 9 - 11 sind die abgeleiteten Parameter zur Met-Wirksamkeit dargestellt. Die absolut höchste Met-Wirksamkeit $\left(b c^{-1}\right)$ konnte in der Starterphase in Versuchsgruppe C (HM 50:50) beobachtet werden (Abb. 9), es gab jedoch nur numerische Unterschiede zu den Versuchsgruppen A (HM 40:60), B (HM 45:55) und F (SES 50:50). Ein Met-Anteil von 55\% (Versuchsgruppe D) bzw. 60\% (Versuchsgruppe E) führte dagegen zu einer signifikant ( $\mathrm{p}$ 0,05) verringerten Effizienz der AS.

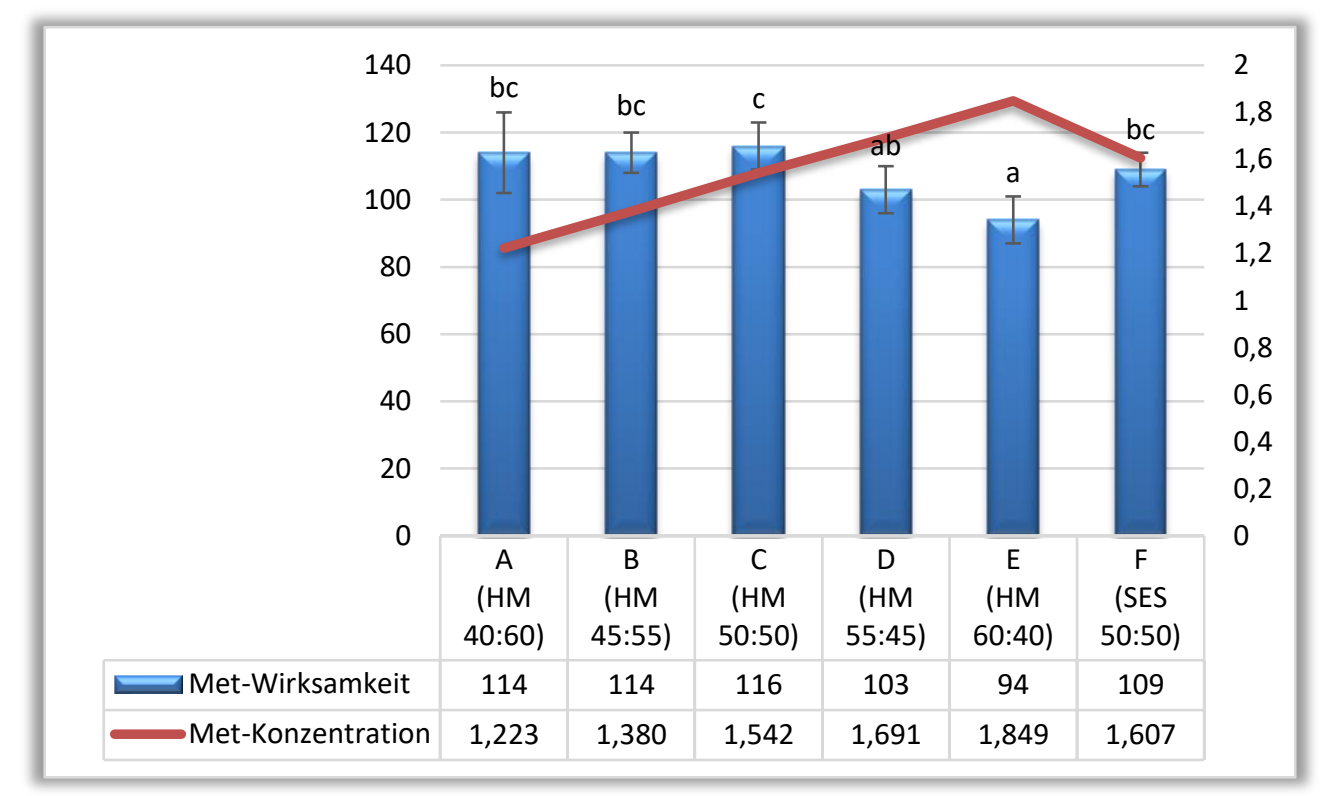

Abbildung 9: Met-Wirksamkeit $\left(b c^{-1}\right)$ und Met-Konzentration (g/16gN) in der Starterphase (Tag 1-21) von Versuch 1. Angaben als Mittelwerte \pm Standardabweichung, unterschiedliche Buchstaben kennzeichnen signifikante Unterschiede $(\mathbf{p}<0,05)$.

In der Growerphase (Abb. 10) war die Met-Wirksamkeit genauso wie in der Starterphase in den HM-Versuchsgruppen mit einem Met-Anteil von $\leq 50 \%$ (Versuchsgruppe A-C) am größten und sank in den anderen Versuchsgruppen signifikant $(\mathrm{p}<0,05) \mathrm{ab}$. Im Vergleich zur Starterphase war die Met-Wirksamkeit in Versuchsgruppe F (SES 50:50) allerdings signifikant ( $\mathrm{p}<0,05)$ geringer als in Versuchsgruppe A (HM 40:60) und B (HM 45:55). 


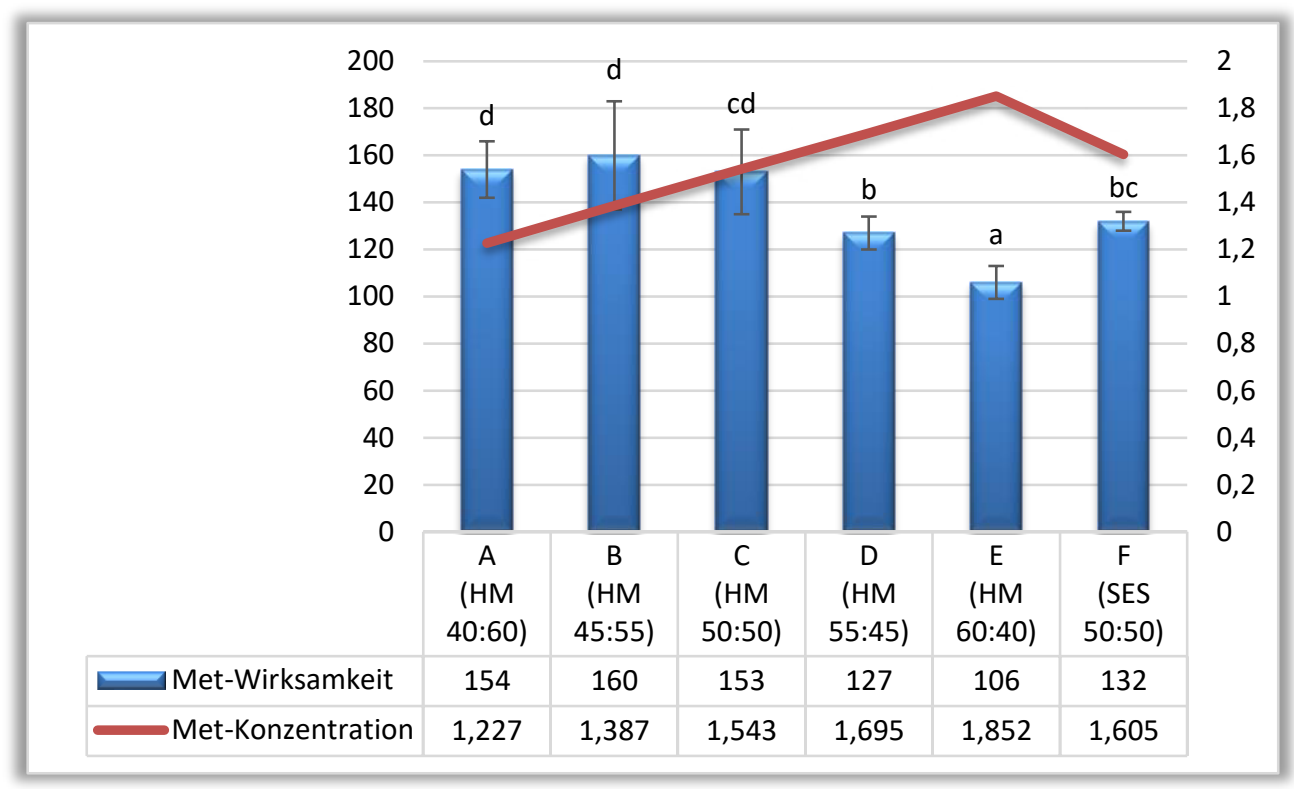

Abbildung 10: Met-Wirksamkeit $\left(b c^{-1}\right)$ und Met-Konzentration (g/16gN) in der Growerphase (Tag 22-35) von Versuch 1. Angaben als Mittelwerte \pm Standardabweichung, unterschiedliche Buchstaben kennzeichnen signifikante Unterschiede $(\mathbf{p}<0,05)$.

Im Vergleich mit den einzelnen Wachstumsphasen werden die Unterschiede in der MetWirksamkeit zwischen den Versuchsgruppen in der Gesamtbetrachtung (Abb. 11) noch deutlicher. Der höchste Wert konnte in den Versuchsgruppen A (HM 40:60), B (HM 45:55) und C (HM 50:50) beobachtet werden. Zu Versuchsgruppe F (SES 50:50) gab es nur numerische Unterschiede. Die Met-Wirksamkeit in den Versuchsgruppen D (HM 55:45) und E (HM 60:40) unterschied sich signifikant $(\mathrm{p}<0,05)$ sowohl voneinander als auch von den in den anderen Versuchsgruppen ermittelten Werten. 


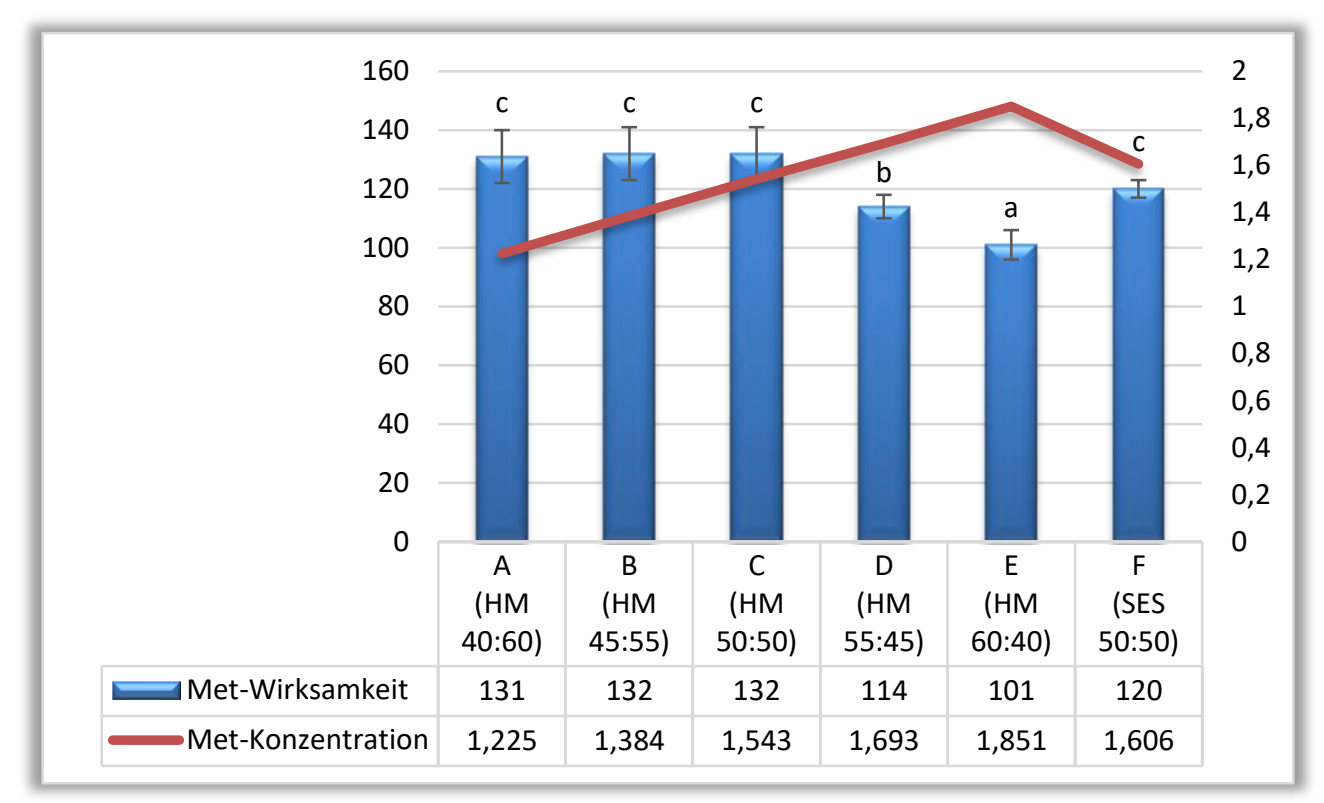

\begin{abstract}
Abbildung 11: Met-Wirksamkeit $\left(b c^{-1}\right)$ und Met-Konzentration (g/16gN) des gesamten Versuchs 1 (Tag 1-35). Angaben als Mittelwerte \pm Standardabweichung, unterschiedliche Buchstaben kennzeichnen signifikante Unterschiede $(p<0,05)$.
\end{abstract}

Grundsätzlich sollte bei der Betrachtung der Ergebnisse bedacht werden, dass der Parameter b eine komplexe Proteinbewertung ermöglicht, dabei jedoch nicht die AS-Zusammensetzung des Proteins berücksichtigt wird (Liebert, 2017). Die AS-Wirksamkeit $\left(b c^{-1}\right)$ wird dagegen basierend auf der ermittelten Proteinqualität $(b)$ und der Konzentration (c) der limitierenden AS (in diesem Fall Met) in der Futtermischung berechnet. Dabei wird sowohl die Verdaulichkeit als auch die postabsorptive Verwertung der limitierenden AS berücksichtigt. Somit ermöglicht die Met-Wirksamkeit eine umfassendere Bewertung der Met:Cys-Verhältnisse. 


\subsubsection{Ableitung des Met-Bedarfs}

Basierend auf Gleichung [13] erfolgte die Ableitung von Met-Bedarfswerten. Abhängig von der für die verschiedenen Met:Cys-Verhältnisse ermittelten Met-Wirksamkeit wurde der MetBedarf in Abhängigkeit der Zielgrößen XPD und FI berechnet. Hierbei wurde eine Höhe des Proteinansatzes von 6, 8 und $10 \mathrm{~g} / \mathrm{d}$ in der Starter- und 12, 16 und $20 \mathrm{~g} / \mathrm{d}$ in der Growerphase ausgewählt. Die verwendete Höhe der FI lag mit 50, 60 und 70 g/d in der Starter- sowie 120, 130 und $140 \mathrm{~g} / \mathrm{d}$ in der Growerphase in einem Bereich, der in den durchgeführten Versuchen realisiert wurde.

Tabelle 18 zeigt die Ergebnisse für den abgeleiteten Met-Bedarf in der Starterphase. Es wird deutlich, dass die Met:Cys-Verhältnisse von $\leq$ 50:50 zu einem geringeren Met-Bedarf und damit verbunden zu geringeren optimalen Met-Konzentrationen im Futter führten. Die Bedarfswerte waren zudem bei einem Met:Cys-Verhältnis von 50:50 und dem Einsatz von HM niedriger als bei gleichem Met:Cys-Verhältnis und dem Einsatz von SES.

Ein Met:Cys-Verhältnis von 55:45 bzw. 60:40 bewirkte dagegen eine Erhöhung des MetBedarfs und der optimalen Met-Konzentration im Futter. Zusätzlich zeigte sich erwartungsgemäß, dass ein steigender XPD eine Steigerung des Met-Bedarfs bedingte und die optimale Konzentration im Futter sank, wenn die Tiere mehr Futter aufnahmen.

In der Growerphase (Tab. 19) stieg der tägliche Met-Bedarf im Vergleich zur Starterphase an, die optimale Met-Konzentration im Futter war jedoch geringer. Die Abhängigkeiten vom Met:Cys-Verhältnis sowie vom XPD und der FI waren analog zur Starterphase. 
Tabelle 18: Abgeleiteter Met-Bedarf in Abhängigkeit von Met:Cys-Verhältnis, Rohproteinansatz und täglicher Futteraufnahme in der Starterphase (Tag 1-21) von Versuch 1 (Mittlere LM:500g).

\begin{tabular}{|c|c|c|c|c|c|c|c|c|c|c|c|c|c|c|c|c|c|c|}
\hline \multirow{3}{*}{ Met:Cys } & \multicolumn{18}{|c|}{ Met-Bedarf } \\
\hline & \multicolumn{3}{|c|}{ HM } & \multicolumn{3}{|c|}{ HM } & \multicolumn{3}{|c|}{ HM } & \multicolumn{3}{|c|}{ HM } & \multicolumn{3}{|c|}{ HM } & \multicolumn{3}{|c|}{ SES } \\
\hline & \multicolumn{3}{|c|}{$40: 60$} & \multicolumn{3}{|c|}{$45: 55$} & \multicolumn{3}{|c|}{$50: 50$} & \multicolumn{3}{|c|}{$55: 45$} & \multicolumn{3}{|c|}{$60: 40$} & \multicolumn{3}{|c|}{$50: 50$} \\
\hline $\begin{array}{l}\text { Met-Wirksamkeit } \\
\qquad\left(b c^{-1}\right)\end{array}$ & & 114 & & & 114 & & & 116 & & & 103 & & & 94 & & & 109 & \\
\hline $\begin{array}{l}\text { XP-Ansatz } \\
\qquad(\mathrm{g} / \mathrm{d})\end{array}$ & 6 & 8 & 10 & 6 & 8 & 10 & 6 & 8 & 10 & 6 & 8 & 10 & 6 & 8 & 10 & 6 & 8 & 10 \\
\hline $\begin{array}{c}\text { Met-Bedarf } \\
\left(\mathrm{mg} / \mathrm{LM}_{\mathrm{kg}}{ }^{0,67}\right)\end{array}$ & 296 & 422 & 587 & 296 & 422 & 587 & 291 & 415 & 577 & 327 & 467 & 649 & 359 & 512 & 712 & 309 & 441 & 614 \\
\hline $\begin{array}{l}\text { Met-Bedarf } \\
\qquad(\mathrm{g} / \mathrm{d})\end{array}$ & 186 & 265 & 369 & 186 & 265 & 369 & 183 & 261 & 362 & 206 & 294 & 408 & 225 & 322 & 447 & 194 & 278 & 386 \\
\hline & & & im & Met-K & onzer & ratio & in de & Futte & miscl & $\operatorname{lng}($ & ) in $A$ & häng & keit & on de & Futte & aufn: & hme & \\
\hline $\begin{array}{l}\text { Futteraufnahme } \\
\qquad(\mathrm{g} / \mathrm{d})\end{array}$ & & & & & & & & & & & & & & & & & & \\
\hline 50 & 0,37 & 0,53 & 0,74 & 0,37 & 0,53 & 0,74 & 0,37 & 0,52 & 0,73 & 0,41 & 0,59 & 0,82 & 0,45 & 0,64 & 0,89 & 0,39 & 0,56 & 0,77 \\
\hline 60 & 0,31 & 0,44 & 0,62 & 0,31 & 0,44 & 0,62 & 0,30 & 0,43 & 0,60 & 0,34 & 0,49 & 0,68 & 0,38 & 0,54 & 0,75 & 0,32 & 0,46 & 0,64 \\
\hline 70 & 0,27 & 0,38 & 0,53 & 0,27 & 0,38 & 0,53 & 0,26 & 0,37 & 0,52 & 0,29 & 0,42 & 0,58 & 0,32 & 0,46 & 0,64 & 0,28 & 0,40 & 0,55 \\
\hline
\end{tabular}


Tabelle 19: Abgeleiteter Met-Bedarf in Abhängigkeit von Met:Cys-Verhältnis, Rohproteinansatz und täglicher Futteraufnahme in der Growerphase (Tag 22-35) von Versuch 1 (Mittlere LM:1500g).

\begin{tabular}{|c|c|c|c|c|c|c|c|c|c|c|c|c|c|c|c|c|c|c|}
\hline \multirow[b]{2}{*}{ Met:Cys } & \multicolumn{18}{|c|}{ Met-Bedarf } \\
\hline & \multicolumn{3}{|c|}{$\begin{array}{c}\text { HM } \\
40: 60\end{array}$} & \multicolumn{3}{|c|}{$\begin{array}{c}\text { HM } \\
45: 55\end{array}$} & \multicolumn{3}{|c|}{$\begin{array}{c}\text { HM } \\
50: 50\end{array}$} & \multicolumn{3}{|c|}{$\begin{array}{c}\text { HM } \\
55: 45\end{array}$} & \multicolumn{3}{|c|}{$\begin{array}{c}\text { HM } \\
60: 40\end{array}$} & \multicolumn{3}{|c|}{$\begin{array}{c}\text { SES } \\
50: 50\end{array}$} \\
\hline $\begin{array}{c}\text { Met-Wirksamkeit } \\
\qquad\left(b c^{-1}\right)\end{array}$ & \multicolumn{3}{|c|}{154} & \multicolumn{3}{|c|}{160} & \multicolumn{3}{|c|}{153} & \multicolumn{3}{|c|}{127} & \multicolumn{3}{|c|}{106} & \multicolumn{3}{|c|}{132} \\
\hline $\begin{array}{l}\text { XP-Ansatz } \\
\qquad(\mathrm{g} / \mathrm{d})\end{array}$ & 12 & 16 & 20 & 12 & 16 & 20 & 12 & 16 & 20 & 12 & 16 & 20 & 12 & 16 & 20 & 12 & 16 & 20 \\
\hline $\begin{array}{c}\text { Met-Bedarf } \\
\left(\mathrm{mg} / \mathrm{LM}_{\mathrm{kg}}{ }^{0,67}\right)\end{array}$ & 277 & 411 & 612 & 267 & 396 & 589 & 279 & 414 & 616 & 336 & 499 & 742 & 403 & 597 & 889 & 324 & 480 & 714 \\
\hline $\begin{array}{l}\text { Met-Bedarf } \\
\text { (g/d) }\end{array}$ & 364 & 540 & 803 & 350 & 519 & 773 & 366 & 543 & 809 & 441 & 654 & 974 & 529 & 784 & 1167 & 425 & 629 & 937 \\
\hline 120 & 0,30 & 0,45 & 0,67 & 0,29 & 0,43 & 0,64 & 0,31 & 0,45 & 0,67 & 0,37 & 0,55 & 0,81 & 0,44 & 0,65 & 0,97 & 0,35 & 0,53 & 0,78 \\
\hline 130 & 0,28 & 0,42 & 0,62 & 0,27 & 0,40 & 0,60 & 0,28 & 0,42 & 0,62 & 0,34 & 0,50 & 0,75 & 0,41 & 0,60 & 0,90 & 0,33 & 0,48 & 0,72 \\
\hline 140 & 0,26 & 0,39 & 0,57 & 0,25 & 0,37 & 0,55 & 0,26 & 0,39 & 0,58 & 0,32 & 0,47 & 0,70 & 0,38 & 0,56 & 0,83 & 0,30 & 0,45 & 0,67 \\
\hline
\end{tabular}




\subsubsection{Körperzusammensetzung}

Die Ergebnisse zur mittleren Körperzusammensetzung der Tiere aus Versuch 1 sind in Tabelle 20 dargestellt. Am Ende der Starterphase (Tag 21) hatten die Tiere aus Versuchsgruppe F (SES 50:50) den höchsten ( $\mathrm{p}<0,05)$ XP-Gehalt. Die Tiere aus Versuchsgruppe A (HM 40:60) wiesen einen niedrigeren $(\mathrm{p}<0,05)$ XP-Gehalt auf, unterschieden sich aber ebenfalls signifikant $(\mathrm{p}<$ $0,05)$ von denen der anderen Versuchsgruppen. Der XL-Gehalt war dagegen in den Tieren aus Versuchsgruppe D (HM 60:40) am höchsten, unterschied sich aber nur numerisch von dem Gehalt in den Tieren aus Versuchsgruppe B (HM 45:55), C (HM 50:50) und E (HM 60:40). Die Tiere aus Versuchsgruppe A (HM 40:60) und F (SES 50:50) wiesen dagegen signifikant ( $\mathrm{p}$ $0,05)$ geringere XL-Gehalte auf. Im Gegensatz dazu war der XA-Gehalt in den Tieren aus Versuchsgruppe A (HM 40:60) signifikant ( $<$ 0,05) am höchsten, während für die Tiere aus Versuchsgruppe C (HM 50:50), D (HM 55:45) und E (HM 60:40) die signifikant (p < 0,05) geringsten Gehalte ermittelt wurden.

Am Ende der Growerphase (Tag 35) war der XP-Gehalt in den Tieren aus Versuchsgruppe F (SES 50:50) signifikant $(\mathrm{p}<0,05)$ höher als in den anderen Versuchsgruppen. Der XL-Gehalt war dagegen signifikant $(\mathrm{p}<0,05)$ geringer. Zwischen den Tieren der anderen Versuchsgruppen gab es weder im XP- noch im XL-Gehalt signifikante Unterschiede. Der XA-Gehalt war analog zur Starterphase in Versuchsgruppe A (HM 40:60) am höchsten, es gab jedoch nur numerische Unterschiede zu den Gehalten von Versuchsgruppe B (HM 45:55) und F (SES 50:50). Der niedrigste XA-Gehalt wurde in den Tieren aus Versuchsgruppe C (H 50:50) ermittelt, er unterschied sich aber nicht signifikant von Versuchsgruppe B (HM 45:55), D (HM 55:45) und E (HM 60:40). 
Tabelle 20: Mittlere Körperzusammensetzung der Tiere am Ende der Starter- (Tag 21) und Growerphase (Tag 35) von Versuch 1.

\begin{tabular}{|c|c|c|c|c|c|c|}
\hline Met:Cys & $\begin{array}{c}\mathrm{A} \\
\mathrm{HM} \\
\mathbf{4 0 : 6 0}\end{array}$ & $\begin{array}{c}\text { B } \\
\mathrm{HM} \\
\mathbf{4 5 : 5 5}\end{array}$ & $\begin{array}{c}\mathrm{C} \\
\mathrm{HM} \\
\mathbf{5 0 : 5 0}\end{array}$ & $\begin{array}{c}\mathrm{D} \\
\mathrm{HM} \\
\mathbf{5 5 : 4 5}\end{array}$ & $\begin{array}{c}\mathrm{E} \\
\mathrm{HM} \\
\mathbf{6 0 : 4 0}\end{array}$ & $\begin{array}{c}\mathrm{F} \\
\mathrm{SES} \\
\mathbf{5 0 : 5 0}\end{array}$ \\
\hline \multicolumn{7}{|c|}{ Ende der Starterphase (Tag 21) } \\
\hline $\begin{array}{l}\mathrm{TM} \\
(\%)\end{array}$ & $\begin{array}{l}31,5^{\mathrm{a}} \\
\pm 1,2\end{array}$ & $\begin{array}{l}33,6^{\mathrm{b}} \\
\pm 0,9\end{array}$ & $\begin{array}{l}33,9^{b} \\
\pm 0,8\end{array}$ & $\begin{array}{l}34,5^{\mathrm{b}} \\
\pm 0,6\end{array}$ & $\begin{array}{l}35,4^{b} \\
\pm 0,9\end{array}$ & $\begin{array}{l}31,2^{\mathrm{a}} \\
\pm 0,9\end{array}$ \\
\hline $\begin{array}{c}\mathrm{XP} \\
(\% \mathrm{TM})\end{array}$ & $\begin{array}{l}51,0^{\mathrm{b}} \\
\pm 1,7\end{array}$ & $\begin{array}{l}48,2^{\mathrm{a}} \\
\pm 1,5\end{array}$ & $\begin{array}{l}47,8^{\mathrm{a}} \\
\pm 1,1\end{array}$ & $\begin{array}{l}47,7^{\mathrm{a}} \\
\pm 1,0\end{array}$ & $\begin{array}{l}47,4^{\mathrm{a}} \\
\pm 1,3\end{array}$ & $\begin{array}{l}54,2^{c} \\
\pm 1,7\end{array}$ \\
\hline $\begin{array}{c}\mathrm{XL} \\
(\% \mathrm{TM})\end{array}$ & $\begin{array}{l}39,6^{\mathrm{a}} \\
\pm 1,9\end{array}$ & $\begin{array}{l}43,8^{\mathrm{b}} \\
\pm 1,8\end{array}$ & $\begin{array}{l}44,8^{b} \\
\pm 1,3\end{array}$ & $\begin{array}{l}45,0^{\mathrm{b}} \\
\pm 1,3\end{array}$ & $\begin{array}{l}45,2^{\mathrm{b}} \\
\pm 1,6\end{array}$ & $\begin{array}{l}37,4^{\mathrm{a}} \\
\pm 1,9\end{array}$ \\
\hline $\begin{array}{c}\mathrm{XA} \\
(\% \mathrm{TM})\end{array}$ & $\begin{array}{c}9,4^{\mathrm{c}} \\
\pm 0,5\end{array}$ & $\begin{array}{c}8,1^{b} \\
\pm 0,6\end{array}$ & $\begin{array}{c}7,4^{\mathrm{a}} \\
\pm 0,2\end{array}$ & $\begin{array}{c}7,4^{\mathrm{a}} \\
\pm 0,4\end{array}$ & $\begin{array}{r}7,4^{\mathrm{a}} \\
\pm 0,3\end{array}$ & $\begin{array}{c}8,4^{\mathrm{b}} \\
\pm 0,4\end{array}$ \\
\hline \multicolumn{7}{|c|}{ Ende der Growerphase (Tag 35) } \\
\hline $\begin{array}{l}\mathrm{TM} \\
(\%)\end{array}$ & $\begin{array}{c}35,8^{\mathrm{ab}} \\
\pm 1,4\end{array}$ & $\begin{array}{c}36,5^{\mathrm{abc}} \\
\pm 1,2\end{array}$ & $\begin{array}{l}37,5^{\mathrm{bc}} \\
\pm 0,8\end{array}$ & $\begin{array}{l}37,4^{\mathrm{bc}} \\
\pm 1,2\end{array}$ & $\begin{array}{l}37,6^{\mathrm{c}} \\
\pm 1,2\end{array}$ & $\begin{array}{l}34,9^{\mathrm{a}} \\
\pm 1,3\end{array}$ \\
\hline $\begin{array}{c}\mathrm{XP} \\
(\% \mathrm{TM})\end{array}$ & $\begin{array}{l}47,1^{\mathrm{a}} \\
\pm 1,9\end{array}$ & $\begin{array}{l}46,3^{\mathrm{a}} \\
\pm 2,0\end{array}$ & $\begin{array}{l}45,7^{\mathrm{a}} \\
\pm 0,7\end{array}$ & $\begin{array}{l}45,7^{\mathrm{a}} \\
\pm 1,4\end{array}$ & $\begin{array}{l}45,7^{\mathrm{a}} \\
\pm 1,4\end{array}$ & $\begin{array}{l}51,8^{b} \\
\pm 2,6\end{array}$ \\
\hline $\begin{array}{c}\mathrm{XL} \\
(\% \mathrm{TM})\end{array}$ & $\begin{array}{l}45,0^{b} \\
\pm 2,6\end{array}$ & $\begin{array}{l}46,3^{\mathrm{b}} \\
\pm 2,5\end{array}$ & $\begin{array}{l}47,5^{b} \\
\pm 1,0\end{array}$ & $\begin{array}{l}47,5^{\mathrm{b}} \\
\pm 1,6\end{array}$ & $\begin{array}{l}47,3^{b} \\
\pm 1,7\end{array}$ & $\begin{array}{l}40,6^{\mathrm{a}} \\
\pm 3,1\end{array}$ \\
\hline $\begin{array}{c}\mathrm{XA} \\
(\% \mathrm{TM})\end{array}$ & $\begin{array}{c}8,0^{\mathrm{c}} \\
\pm 0,7\end{array}$ & $\begin{array}{l}7,4^{\mathrm{abc}} \\
\pm 0,6\end{array}$ & $\begin{array}{c}6,8^{\mathrm{a}} \\
\pm 0,4\end{array}$ & $\begin{array}{l}6,9^{\mathrm{ab}} \\
\pm 0,4\end{array}$ & $\begin{array}{l}7,0^{\mathrm{ab}} \\
\pm 0,5\end{array}$ & $\begin{array}{l}7,7^{\mathrm{bc}} \\
\pm 0,6\end{array}$ \\
\hline
\end{tabular}

Angaben als Mittelwerte \pm Standardabweichung, unterschiedliche Hochbuchstaben kennzeichnen signifikante Unterschiede (p $<0,05)$.

\subsubsection{Protein- und Fettansatz}

Die Abb. 12-14 fassen die beobachteten Ansatzwerte zusammen. In der Starterphase (Abb. 12) wiesen die Tiere der Versuchsgruppe F (SES 50:50) den höchsten XPD auf, es gab jedoch nur numerische Unterschiede zu Versuchsgruppe C (HM 50:50) und D (HM 55:45). Die HMVersuchsgruppen C (HM 50:50), D (HM 55:45) und E (HM 60:40) unterschieden sich ebenfalls nicht signifikant voneinander. In Versuchsgruppe A (HM 40:60) wurde der signifikant ( $\mathrm{p}$ $0,05)$ geringste XPD beobachtet. Der Rohfettansatz (XLD) war in Versuchsgruppe C (HM 50:50) am höchsten, allerdings ohne signifikante Unterschiede zu Versuchsgruppe D (HM 55:45) und E (HM 60:40). Versuchsgruppe F (SES 50:50) erzielte einen signifikant ( $p<0,05)$ geringeren XLD als Versuchsgruppe C (HM 50:50). Ebenso wie der XPD war auch der XLD der Tiere aus Versuchsgruppe A (HM 40:60) am geringsten ( $\mathrm{p}<0,05)$. 


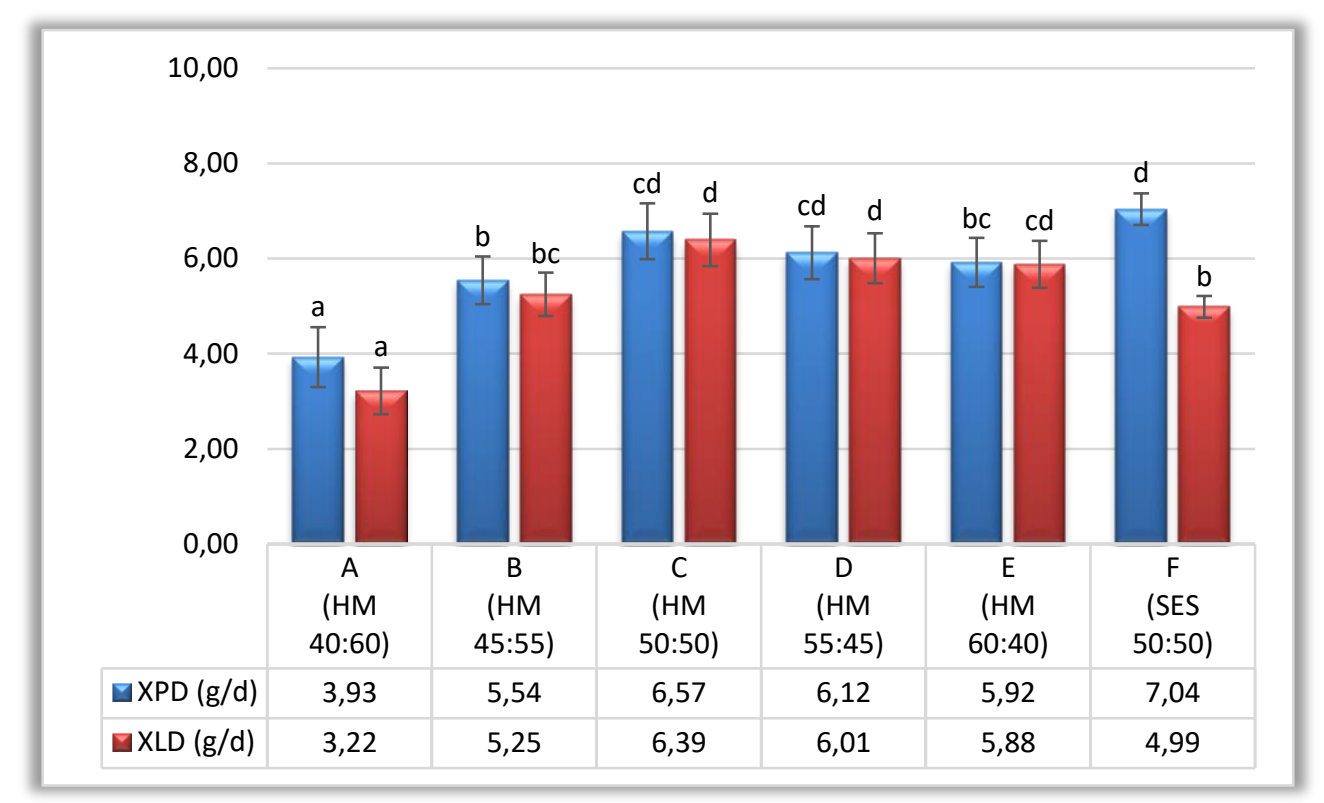

\begin{abstract}
Abbildung 12: Protein- und Fettansatz in der Starterphase (Tag 1-21) von Versuch 1. Angaben als Mittelwerte \pm Standardabweichung, unterschiedliche Buchstaben kennzeichnen signifikante Unterschiede $(\mathbf{p}<\mathbf{0 , 0 5})$.
\end{abstract}

Ebenso wie in der Starterphase war auch in der Growerphase (Abb. 13) der XPD in Versuchsgruppe F (SES 50:50) am höchsten, es gab nur tendenzielle Unterschiede zu Versuchsgruppe C (HM 50:50). Im Gegensatz zur Starterphase verringerte sich der XPD in den Versuchsgruppen D (HM 55:45) und E (HM 60:40) im Vergleich zu Versuchsgruppe C. So unterschied sich der XPD in Versuchsgruppe E (HM 60:40) nur numerisch von dem in Versuchsgruppe A (HM 40:60), in der der geringste Wert beobachtet wurde. Der XLD war in Versuchsgruppe C (HM 50:50) am höchsten, mit signifikanten $(\mathrm{p}<0,05)$ Unterschieden zu allen anderen Versuchsgruppen außer Gruppe D (HM 55:45). Auch hier wurde der niedrigste Wert in Versuchsgruppe A (HM 40:60) festgestellt, dieser unterschied sich jedoch nur numerisch von dem in Versuchsgruppe B (HM 45:55), E (HM 60:40) und F (SES 50:50) beobachteten XLD. 


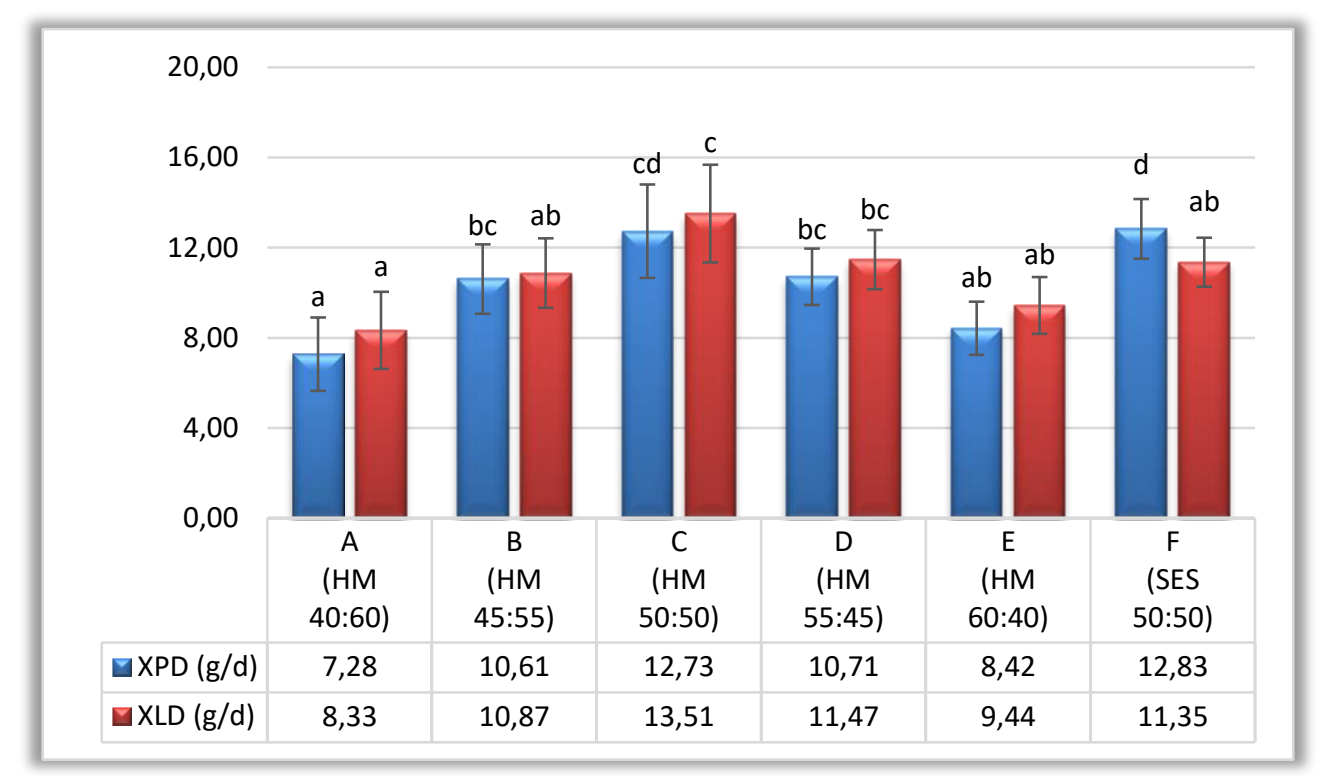

Abbildung 13: Protein- und Fettansatz in der Growerphase (Tag 22-35) von Versuch 1. Angaben als Mittelwerte \pm Standardabweichung, unterschiedliche Buchstaben kennzeichnen signifikante Unterschiede $(\mathbf{p}<\mathbf{0 , 0 5})$.

Bei Betrachtung des gesamten Versuchszeitraums (Abb. 14) wurde der höchste XPD wiederum in Versuchsgruppe F (SES 50:50) ermittelt, er unterschied sich signifikant $(\mathrm{p}<0,05)$ von allen anderen Versuchsgruppen mit Ausnahme von Gruppe C (HM 50:50). Ebenso wie in der Growerphase wurde in den Versuchsgruppen D (HM 55:45) und E (HM 60:40) eine Verminderung des XPD beobachtet. Versuchsgruppe A (HM 40:60) wies den geringsten Wert auf ( $\mathrm{p}<0,05)$. Der XLD war analog zur Growerphase in Versuchsgruppe C (HM 50:50) am höchsten und es gab nur numerische Unterschiede zu Versuchsgruppe D (HM 55:45). In Versuchsgruppe A (HM 40:60) wurde wieder der geringste Wert festgestellt ( $<<0,05)$, die anderen Versuchsgruppen B (HM 45:55), D (HM 55:45) und E (HM 60:40) unterschieden sich dagegen nicht signifikant voneinander. 


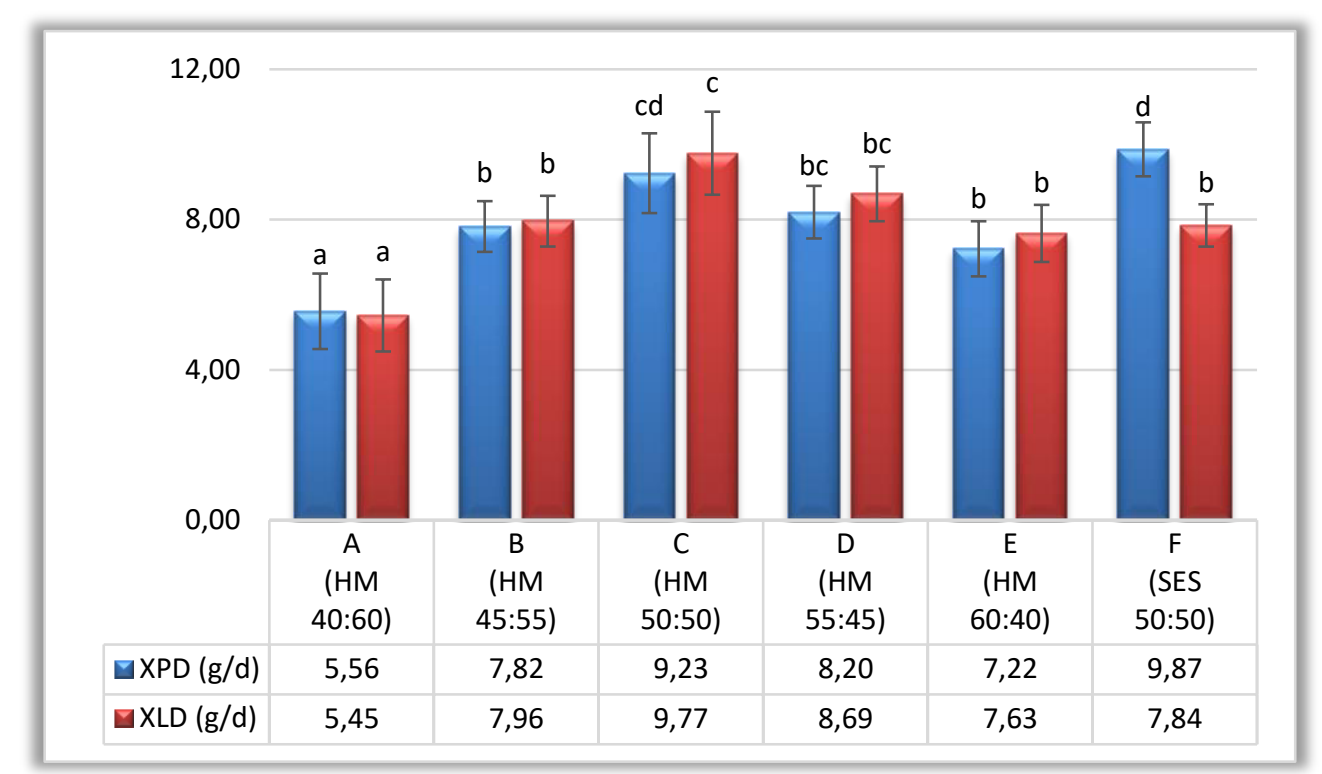

Abbildung 14: Protein- und Fettansatz im gesamten Versuchszeitraum (Tag 1-35) von Versuch 1. Angaben als Mittelwerte \pm Standardabweichung, unterschiedliche Buchstaben kennzeichnen signifikante Unterschiede $(\mathbf{p}<\mathbf{0 , 0 5})$.

Demnach zeigten in Versuch 1 alle erfassten Parameter einen Beeinflussung durch die Met:CysVerhältnisse. Für eine abschließende Bewertung werden sie in Kapitel 6.1.1 ausführlich zusammenfassend diskutiert. 


\subsection{Versuch 2}

Nachfolgend werden die Ergebnisse aus Versuch 2 beschrieben. Ebenso wie in Versuch 1 wurden verschiedene Met:Cys-Verhältnisse von 40:60, 45:55, 50:50, 55:45 und 60:40 bewertet. Als alternative Proteinquelle wurde in diesem Versuch jedoch TMP verwendet.

\subsubsection{Zootechnische Parameter}

Am Ende der Starterphase von Versuch 2 (Tab. 21) wies Versuchsgruppe F (SES 50:50) die höchste finale LM, tägliche LMZ und FI auf, jedoch gab es nur tendenzielle Unterschiede zu den Versuchsgruppen C (TMP 50:50), D (TMP 55:45) und E (TMP 60:40). Auch der FA sowie der Protein- und Energieaufwand unterschieden sich nicht signifikant zwischen diesen Versuchsgruppen. In Versuchsgruppe A (TMP 40:60) wurde eine signifikant $(\mathrm{p}<0,05)$ verringerte FI beobachtet, was in der Folge auch die anderen zootechnischen Parameter signifikant $(\mathrm{p}<0,05)$ negativ beeinflusste.

Am Ende der Growerphase wurde wiederum die höchste finale LM und tägliche LMZ in Versuchsgruppe C (TMP 50:50) beobachtet. Es gab keine signifikanten Unterschiede zu den Versuchsgruppen D (TMP 55:45) und F (SES 50:50). Die FI war in Versuchsgruppe F (SES 50:50) am höchsten und unterschied sich signifikant $(\mathrm{p}<0,05)$ von allen anderen Versuchsgruppen außer von Gruppe C (TMP 50:50). Die hohe FI führte zu einem signifikant ( $\mathrm{p}<0,05$ ) höheren FA in Versuchsgruppe F (SES 50:50), der in der Höhe vergleichbar mit dem in Versuchsgruppe A (TMP 40:60) war. Diese Versuchsgruppe zeigte ebenso wie in der Starterphase die schlechtesten Ergebnisse. Der FA der anderen Versuchsgruppen unterschied sich dagegen nicht signifikant voneinander. Die Versuchsgruppen C (TMP 50:50) und D (TMP 55:45) wiesen sowohl den niedrigsten Protein- als auch Energieaufwand auf, unterschieden sich jedoch nur numerisch von den Versuchsgruppen A (TMP 40:60), B (TMP 45:55) und E (TMP 60:40). 
Tabelle 21: Ergebnisse der zootechnischen Parameter der Starter- (Tag 1-21) und Growerphase (Tag 22-35) in Versuch 2.

\begin{tabular}{|c|c|c|c|c|c|c|}
\hline Met:Cys & $\begin{array}{c}\text { A } \\
\text { TMP } \\
40: 60\end{array}$ & $\begin{array}{c}\text { B } \\
\text { TMP } \\
45: 55\end{array}$ & $\begin{array}{c}\mathrm{C} \\
\text { TMP } \\
\mathbf{5 0 : 5 0}\end{array}$ & $\begin{array}{c}\text { D } \\
\text { TMP } \\
55: 45\end{array}$ & $\begin{array}{c}\mathrm{E} \\
\text { TMP } \\
60: 40\end{array}$ & $\begin{array}{c}\text { F } \\
\text { SES } \\
\mathbf{5 0 : 5 0}\end{array}$ \\
\hline \multicolumn{7}{|c|}{ Starterphase (Tag 1-21) } \\
\hline $\operatorname{LM}_{\text {Beginn }}(\mathrm{g})$ & $\begin{array}{r}49 \\
\pm 0\end{array}$ & $\begin{array}{r}49 \\
\pm 0\end{array}$ & $\begin{array}{r}49 \\
\pm 0\end{array}$ & $\begin{array}{l}49 \\
\pm 0\end{array}$ & $\begin{array}{r}49 \\
\pm 0\end{array}$ & $\begin{array}{r}49 \\
\pm 0\end{array}$ \\
\hline $\mathrm{LM}_{\text {Final }}(\mathrm{g})$ & $\begin{array}{l}537^{\mathrm{a}} \\
\pm 89\end{array}$ & $\begin{array}{l}749^{\mathrm{b}} \\
\pm 82\end{array}$ & $\begin{array}{l}981^{\mathrm{c}} \\
\pm 91\end{array}$ & $\begin{array}{l}968^{c} \\
\pm 51\end{array}$ & $\begin{array}{l}1005^{\mathrm{c}} \\
\pm 92\end{array}$ & $\begin{array}{l}1017^{\mathrm{c}} \\
\pm 42\end{array}$ \\
\hline $\mathrm{LMZ}(\mathrm{g} / \mathrm{d})$ & $\begin{array}{l}23^{\mathrm{a}} \\
\pm 4\end{array}$ & $\begin{array}{l}33^{\mathrm{b}} \\
\pm 4\end{array}$ & $\begin{array}{l}44^{\mathrm{c}} \\
\pm 4\end{array}$ & $\begin{array}{l}44^{\mathrm{c}} \\
\pm 2\end{array}$ & $\begin{array}{l}46^{\mathrm{c}} \\
\pm 4\end{array}$ & $\begin{array}{l}46^{\mathrm{c}} \\
\pm 2\end{array}$ \\
\hline $\mathrm{FI}(\mathrm{g} \mathrm{TM} / \mathrm{d})$ & $\begin{array}{l}39,6^{\mathrm{a}} \\
\pm 4,9\end{array}$ & $\begin{array}{l}46,3^{\mathrm{a}} \\
\pm 4,6\end{array}$ & $\begin{array}{l}55,8^{b} \\
\pm 4,4\end{array}$ & $\begin{array}{l}53,7^{\mathrm{b}} \\
\pm 2,7\end{array}$ & $\begin{array}{l}56,1^{b} \\
\pm 6,0\end{array}$ & $\begin{array}{l}60,5^{b} \\
\pm 3,7\end{array}$ \\
\hline $\begin{array}{c}\text { FA } \\
(\mathrm{g} \mathrm{FI} / \mathrm{g} \mathrm{LMZ})\end{array}$ & $\begin{array}{r}1,74^{\mathrm{a}} \\
\pm 0,29\end{array}$ & $\begin{array}{l}1,40^{\mathrm{ab}} \\
\pm 0,14\end{array}$ & $\begin{array}{r}1,26^{\mathrm{b}} \\
\pm 0,05\end{array}$ & $\begin{array}{r}1,23^{\mathrm{b}} \\
\pm 0,05\end{array}$ & $\begin{array}{c}1,23^{\mathrm{b}} \\
\pm 0,06\end{array}$ & $\begin{array}{l}1,31^{\mathrm{ab}} \\
\pm 0,06\end{array}$ \\
\hline $\begin{array}{l}\text { Proteinaufwand } \\
\text { (g XPI / g LMZ) }\end{array}$ & $\begin{array}{r}0,40^{\mathrm{a}} \\
\pm 0,07\end{array}$ & $\begin{array}{l}0,32^{\mathrm{ab}} \\
\pm 0,03\end{array}$ & $\begin{array}{c}0,29^{b} \\
\pm 0,01\end{array}$ & $\begin{array}{c}0,28^{\mathrm{b}} \\
\pm 0,01\end{array}$ & $\begin{array}{c}0,28^{\mathrm{b}} \\
\pm 0,02\end{array}$ & $\begin{array}{r}0,30^{\mathrm{b}} \\
\pm 0,02\end{array}$ \\
\hline $\begin{array}{c}\text { Energieaufwand } \\
\text { (kJ ME / } \\
\text { g LMZ) }\end{array}$ & $\begin{array}{l}26,19^{a} \\
\pm 4,35\end{array}$ & $\begin{array}{l}21,08^{\mathrm{ab}} \\
\pm 2,12\end{array}$ & $\begin{array}{l}18,99^{b} \\
\pm 0,78\end{array}$ & $\begin{array}{l}18,52^{b} \\
\pm 0,80\end{array}$ & $\begin{array}{l}18,58^{b} \\
\pm 0,96\end{array}$ & $\begin{array}{l}19,36^{\mathrm{b}} \\
\pm 0,93\end{array}$ \\
\hline \multicolumn{7}{|c|}{ Growerphase (Tag 22-25) } \\
\hline $\mathrm{LM}_{\text {Final }}(\mathrm{g})$ & $\begin{array}{l}1379^{\mathrm{a}} \\
\pm 204\end{array}$ & $\begin{array}{l}1830^{b} \\
\pm 177\end{array}$ & $\begin{array}{l}2378^{c} \\
\pm 221\end{array}$ & $\begin{array}{l}2174^{\mathrm{c}} \\
\pm 122\end{array}$ & $\begin{array}{l}2185^{c} \\
\pm 165\end{array}$ & $\begin{array}{l}2247^{\mathrm{c}} \\
\pm 119\end{array}$ \\
\hline $\operatorname{LMZ}(\mathrm{g} / \mathrm{d})$ & $\begin{array}{r}60^{\mathrm{a}} \\
\pm 10\end{array}$ & $\begin{array}{l}77^{\mathrm{b}} \\
\pm 8\end{array}$ & $\begin{array}{l}100^{c} \\
\pm 13\end{array}$ & $\begin{array}{l}86^{\mathrm{bc}} \\
\pm 7\end{array}$ & $\begin{array}{l}84^{b} \\
\pm 9\end{array}$ & $\begin{array}{l}88^{\mathrm{bc}} \\
\pm 9\end{array}$ \\
\hline $\mathrm{FI}(\mathrm{g}$ TM/d) & $\begin{array}{l}106,1^{\mathrm{a}} \\
\pm 23,1\end{array}$ & $\begin{array}{c}124,3^{\mathrm{ab}} \\
\pm 5,9\end{array}$ & $\begin{array}{l}148,0^{\mathrm{cd}} \\
\pm 13,6\end{array}$ & $\begin{array}{c}129,0^{\mathrm{bc}} \\
\pm 8,6\end{array}$ & $\begin{array}{l}129,8^{\mathrm{bc}} \\
\pm 13,4\end{array}$ & $\begin{array}{l}155,8^{d} \\
\pm 13,6\end{array}$ \\
\hline $\begin{array}{c}\text { FA } \\
(\mathrm{g} \mathrm{FI} / \mathrm{g} \mathrm{LMZ})\end{array}$ & $\begin{array}{l}1,78^{\mathrm{ab}} \\
\pm 0,41\end{array}$ & $\begin{array}{l}1,62^{\mathrm{ab}} \\
\pm 0,15\end{array}$ & $\begin{array}{c}1,49^{\mathrm{b}} \\
\pm 0,10\end{array}$ & $\begin{array}{c}1,50^{\mathrm{b}} \\
\pm 0,04\end{array}$ & $\begin{array}{l}1,55^{\mathrm{ab}} \\
\pm 0,13\end{array}$ & $\begin{array}{l}1,78^{\mathrm{a}} \\
\pm 0,16\end{array}$ \\
\hline $\begin{array}{l}\text { Proteinaufwand } \\
\text { (g XPI / g LMZ) }\end{array}$ & $\begin{array}{l}0,38^{\mathrm{ab}} \\
\pm 0,09\end{array}$ & $\begin{array}{l}0,34^{\mathrm{ab}} \\
\pm 0,03\end{array}$ & $\begin{array}{r}0,32^{\mathrm{b}} \\
\pm 0,02\end{array}$ & $\begin{array}{r}0,32^{\mathrm{b}} \\
\pm 0,01\end{array}$ & $\begin{array}{l}0,33^{\mathrm{ab}} \\
\pm 0,03\end{array}$ & $\begin{array}{r}0,38^{\mathrm{a}} \\
\pm 0,03\end{array}$ \\
\hline $\begin{array}{c}\text { Energieaufwand } \\
\text { (kJ ME / } \\
\text { g LMZ) }\end{array}$ & $\begin{array}{l}26,97^{\mathrm{ab}} \\
\pm 6,25\end{array}$ & $\begin{array}{l}24,53^{\text {ab }} \\
\pm 2,33\end{array}$ & $\begin{array}{l}22,56^{\mathrm{b}} \\
\pm 1,55\end{array}$ & $\begin{array}{l}22,67^{b} \\
\pm 0,61\end{array}$ & $\begin{array}{l}23,36^{\mathrm{ab}} \\
\pm 1,98\end{array}$ & $\begin{array}{l}26,57^{\mathrm{a}} \\
\pm 2,37\end{array}$ \\
\hline
\end{tabular}

Angaben als Mittelwerte \pm Standardabweichung, unterschiedliche Hochbuchstaben kennzeichnen signifikante Unterschiede $(\mathrm{p}$ $<0,05)$. 
Die Betrachtung des gesamten Versuchszeitraumes (Tab. 22) zeigte ebenfalls die höchste finale LM und tägliche LMZ in Versuchsgruppe C (TMP 50:50), wobei nur numerische Unterschiede zu den Versuchsgruppen D (TMP 55:45), E (TMP 60:40) und F (SES 50:50) vorlagen. Ebenso wie in der Growerphase nahmen die Tiere aus Versuchsgruppe F (SES 50:50) mehr Futter auf als die der anderen Versuchsgruppen, was zu einem signifikant $(\mathrm{p}<0,05)$ höheren FA führte. Gleiches gilt für den Protein- und Energieaufwand. Zwischen den Versuchsgruppen C (TMP 50:50), D (TMP 55:45) und E (TMP 60:40) gab es dagegen keine signifikanten Unterschiede. Die signifikant ( $\mathrm{p}<0,05)$ geringere FI der Tiere aus Versuchsgruppe A (TMP 40:60) führte ebenso wie in der Starter- und Growerphase zu signifikant $(p<0,05)$ negativ beeinflussten zootechnischen Parametern.

Tabelle 22: Ergebnisse der zootechnischen Parameter des gesamten Versuchs 2 (Tag 1-35).

\begin{tabular}{|c|c|c|c|c|c|c|}
\hline Met:Cys & $\begin{array}{c}\text { A } \\
\text { TMP } \\
\text { 40:60 }\end{array}$ & $\begin{array}{c}\text { B } \\
\text { TMP } \\
\text { 45:55 }\end{array}$ & $\begin{array}{c}\mathrm{C} \\
\text { TMP } \\
\mathbf{5 0 : 5 0}\end{array}$ & $\begin{array}{c}\text { D } \\
\text { TMP } \\
55: 45\end{array}$ & $\begin{array}{c}\mathrm{E} \\
\mathrm{TMP} \\
60: 40\end{array}$ & $\begin{array}{c}\text { F } \\
\text { SES } \\
\mathbf{5 0 : 5 0}\end{array}$ \\
\hline $\mathrm{LM}_{\text {Beginn }}(\mathrm{g})$ & $\begin{array}{r}49 \\
\pm 0\end{array}$ & $\begin{array}{r}49 \\
\pm 0\end{array}$ & $\begin{array}{r}49 \\
\pm 0\end{array}$ & $\begin{array}{r}49 \\
\pm 0\end{array}$ & $\begin{array}{r}49 \\
\pm 0\end{array}$ & $\begin{array}{l}49 \\
\pm 0\end{array}$ \\
\hline $\mathrm{LM}_{\text {Final }}(\mathrm{g})$ & $\begin{array}{l}1379^{\mathrm{a}} \\
\pm 204\end{array}$ & $\begin{array}{l}1830^{\mathrm{b}} \\
\pm 177\end{array}$ & $\begin{array}{l}2378^{\mathrm{c}} \\
\pm 221\end{array}$ & $\begin{array}{l}2174^{\mathrm{c}} \\
\pm 122\end{array}$ & $\begin{array}{l}2185^{\mathrm{c}} \\
\pm 165\end{array}$ & $\begin{array}{l}2247^{\mathrm{c}} \\
\pm 119\end{array}$ \\
\hline $\mathrm{LMZ}(\mathrm{g} / \mathrm{d})$ & $\begin{array}{l}38^{\mathrm{a}} \\
\pm 6\end{array}$ & $\begin{array}{l}51^{b} \\
\pm 5\end{array}$ & $\begin{array}{l}67^{\mathrm{c}} \\
\pm 6\end{array}$ & $\begin{array}{l}61^{\mathrm{c}} \\
\pm 4\end{array}$ & $\begin{array}{l}61^{\mathrm{c}} \\
\pm 5\end{array}$ & $\begin{array}{l}63^{\mathrm{c}} \\
\pm 3\end{array}$ \\
\hline $\mathrm{FI}(\mathrm{g}$ TM/d) & $\begin{array}{r}66,2^{\mathrm{a}} \\
\pm 11,0\end{array}$ & $\begin{array}{l}77,5^{b} \\
\pm 4,9\end{array}$ & $\begin{array}{l}92,7^{\text {cd }} \\
\pm 7,6\end{array}$ & $\begin{array}{l}83,8^{\mathrm{bc}} \\
\pm 4,4\end{array}$ & $\begin{array}{l}85,6^{\mathrm{bc}} \\
\pm 8,4\end{array}$ & $\begin{array}{l}98,7^{\mathrm{d}} \\
\pm 6,1\end{array}$ \\
\hline $\begin{array}{c}\text { FA } \\
(\mathrm{g} \text { FI /g LMZ) }\end{array}$ & $\begin{array}{l}1,76^{\mathrm{ab}} \\
\pm 0,33\end{array}$ & $\begin{array}{l}1,53^{\mathrm{ab}} \\
\pm 0,14\end{array}$ & $\begin{array}{l}1,40^{\mathrm{b}} \\
\pm 0,06\end{array}$ & $\begin{array}{l}1,38^{b} \\
\pm 0,04\end{array}$ & $\begin{array}{r}1,40^{\mathrm{b}} \\
\pm 0,08\end{array}$ & $\begin{array}{r}1,57^{\mathrm{a}} \\
\pm 0,09\end{array}$ \\
\hline $\begin{array}{l}\text { Proteinaufwand } \\
\text { (g XPI / g LMZ) }\end{array}$ & $\begin{array}{l}0,38^{\mathrm{ab}} \\
\pm 0,07\end{array}$ & $\begin{array}{l}0,33^{\mathrm{ab}} \\
\pm 0,03\end{array}$ & $\begin{array}{c}0,30^{\mathrm{b}} \\
\pm 0,01\end{array}$ & $\begin{array}{l}0,30^{\mathrm{b}} \\
\pm 0,01\end{array}$ & $\begin{array}{l}0,31^{\mathrm{b}} \\
\pm 0,02\end{array}$ & $\begin{array}{r}0,34^{\mathrm{a}} \\
\pm 0,02\end{array}$ \\
\hline $\begin{array}{c}\text { Energieaufwand } \\
\text { (kJ ME / } \\
\text { g LMZ) }\end{array}$ & $\begin{array}{c}26,59^{\mathrm{ab}} \\
\pm 4,94\end{array}$ & $\begin{array}{c}23,15^{\text {ab }} \\
\pm 2,10\end{array}$ & $\begin{array}{l}21,06^{\mathrm{b}} \\
\pm 0,88\end{array}$ & $\begin{array}{l}20,87^{\mathrm{b}} \\
\pm 0,63\end{array}$ & $\begin{array}{l}21,17^{\mathrm{b}} \\
\pm 1,21\end{array}$ & $\begin{array}{l}23,35^{\mathrm{a}} \\
\pm 1,39\end{array}$ \\
\hline
\end{tabular}




\subsubsection{Scheinbare praecaecale Verdaulichkeit}

Die Ergebnisse zur scheinbaren pcV des XP und ausgewählter AS in Versuch 2 fasst Tabelle 23 zusammen. Es wurden Werte zwischen 61 und 85\% erzielt. Die höchste Verdaulichkeit wurden für Arg beobachtet, die niedrigste für Cys. Zwischen den beiden Versuchsgruppen C (TMP 50:50) und F (SES 50:50) gab es mit Ausnahme von Phenylalanin (Phe) keine signifikanten Unterschiede.

Tabelle 23: Mittlere Ergebnisse zur scheinbaren praecaecalen Verdaulichkeit (\%) des Rohproteins und ausgewählter Aminosäuren der Futtermischungen der Versuchsgruppen C (TMP 50:50) und F (SES 50:50) in Versuch 2.

\begin{tabular}{|c|c|c|}
\hline Met:Cys & $\begin{array}{c}\text { C } \\
\text { TMP } \\
50: 50\end{array}$ & $\begin{array}{c}\text { F } \\
\text { SES } \\
50: 50\end{array}$ \\
\hline XP & $\begin{array}{r}74,7 \\
\pm 2,2\end{array}$ & $\begin{array}{r}75,2 \\
\pm 1,3\end{array}$ \\
\hline Lys & $\begin{array}{r}79,2 \\
\pm 3,5\end{array}$ & $\begin{array}{r}80,8 \\
\pm 1,2\end{array}$ \\
\hline Met & $\begin{array}{r}75,8 \\
\pm 4,6\end{array}$ & $\begin{array}{r}80,6 \\
\pm 1,2\end{array}$ \\
\hline Cys & $\begin{array}{r}68,6 \\
\pm 4,4\end{array}$ & $\begin{array}{r}60,9 \\
\pm 2,0\end{array}$ \\
\hline Thr & $\begin{array}{r}67,5 \\
\pm 5,1\end{array}$ & $\begin{array}{r}70,8 \\
\pm 2,8\end{array}$ \\
\hline Arg & $\begin{array}{r}84,4 \\
\pm 2,8\end{array}$ & $\begin{array}{c}85,1 \\
\pm 0,6\end{array}$ \\
\hline His & $\begin{array}{r}74,3 \\
\pm 3,8\end{array}$ & $\begin{array}{r}78,4 \\
\pm 0,7\end{array}$ \\
\hline Ile & $\begin{array}{r}71,9 \\
\pm 4,4\end{array}$ & $\begin{array}{r}76,5 \\
\pm 0,9\end{array}$ \\
\hline Leu & $\begin{array}{r}74,5 \\
\pm 4,6\end{array}$ & $\begin{array}{r}76,6 \\
\pm 1,2\end{array}$ \\
\hline Phe & $\begin{array}{l}70,1^{\mathrm{b}} \\
\pm 4,7\end{array}$ & $\begin{array}{l}79,4^{\mathrm{a}} \\
\pm 0,8\end{array}$ \\
\hline Val & $\begin{array}{r}73,9 \\
\pm 8,9\end{array}$ & $\begin{array}{r}75,1 \\
\pm 1,1\end{array}$ \\
\hline
\end{tabular}

Angaben als Mittelwerte \pm Standardabweichung, unterschiedliche Hochbuchstaben kennzeichnen signifikante Unterschiede (p $<0,05)$. 


\subsubsection{Proteinqualität und Met-Wirksamkeit}

Tabelle 24 zeigt die Ergebnisse zur Bewertung der Proteinqualität in Versuch 2. In der Starterphase wies Versuchsgruppe F (SES 50:50) den höchsten N-Ansatz auf, es gab jedoch nur numerische Unterschiede zu den Versuchsgruppen C (TMP 50:50), D (TMP 55:45) und E (TMP 60:40). Die Proteinqualitätsparameter $b, \mathrm{PNu}$ und $\mathrm{PNu}_{\text {std. }}$ wiesen in Versuchsgruppe D (TMP 55:45) und E (TMP 60:40) die höchsten Werte auf, es gab aber auch hier keine signifikanten Unterschiede zu C (TMP 50:50) und F (SES 50:50). In Versuchsgruppe A (TMP 40:60) wurde sowohl der niedrigste N-Ansatz als auch die geringste Proteinqualität festgestellt, alle Parameter waren in Versuchsgruppe B (TMP 45:55) zum Teil signifikant $(\mathrm{p}<0,05)$ verbessert.

Im Gegensatz zur Starterphase waren in der Growerphase sowohl der N-Ansatz als auch die Proteinqualitätsparameter ( $b$, PNu und $\mathrm{PNu}_{\text {std. }}$ ) in Versuchsgruppe C (TMP 50:50) am höchsten. Es gab jedoch keine signifikanten Unterschiede zu den Versuchsgruppen B (TMP 45:55), D (TMP 55:45) und E (TMP 60:40). Die niedrigsten Werte wies Versuchsgruppe A (TMP 40:60) auf, unterschied sich jedoch nur von Versuchsgruppe C (TMP 50:50) bzw. D (TMP 55:45) signifikant $(\mathrm{p}<0,05)$.

Bei Betrachtung des gesamten Versuchszeitraumes wies Versuchsgruppe F (SES 50:50) den höchsten N-Ansatz auf und es gab, ebenso wie in der Starterphase, keine signifikanten Unterschiede zu den Versuchsgruppen C (TMP 50:50), D (TMP 55:45) und E (TMP 60:40). Die höchste Proteinqualität (b, PNu und $\mathrm{PNu}_{\text {std.) }}$ ) wurde in Versuchsgruppe D (TMP 55:45) beobachtet, wobei auch hier nur numerische Unterschiede zu den Versuchsgruppen C (TMP 50:50), E (TMP 60:40) und F (SES 50:50) festgestellt wurden. Die niedrigsten Werte zeigte, genau wie in den einzelnen Wachstumsphasen, Versuchsgruppe A (TMP 40:60), Versuchsgruppe B (TMP 45:55) wies im Vergleich einen signifikant $(\mathrm{p}<0,05)$ höheren NAnsatz sowie signifikant $(\mathrm{p}<0,05)$ verbesserte Proteinqualitätsparameter auf. 
Tabelle 24: Ergebnisse der Proteinqualitätsbewertung in Versuch 2.

\begin{tabular}{|c|c|c|c|c|c|c|}
\hline Met:Cys & $\begin{array}{c}\text { A } \\
\text { TMP } \\
40: 60\end{array}$ & $\begin{array}{c}\text { B } \\
\text { TMP } \\
45: 55\end{array}$ & $\begin{array}{c}\text { C } \\
\text { TMP } \\
\mathbf{5 0 : 5 0}\end{array}$ & $\begin{array}{c}\text { D } \\
\text { TMP } \\
55: 45\end{array}$ & $\begin{array}{c}\text { E } \\
\text { TMP } \\
\text { 60:40 }\end{array}$ & $\begin{array}{c}\text { F } \\
\text { SES } \\
\mathbf{5 0 : 5 0}\end{array}$ \\
\hline \multicolumn{7}{|c|}{ Starterphase (1-21d) } \\
\hline $\mathrm{c}_{\text {Met }}(\mathrm{g} / 16 \mathrm{gN})$ & 1,339 & 1,506 & 1,677 & 1,839 & 2,010 & 1,662 \\
\hline $\begin{array}{c}\mathrm{ND} \\
\left(\mathrm{mg} / \mathrm{LM}_{\mathrm{kg}} 0,67 / \mathrm{d}\right)\end{array}$ & $\begin{array}{l}1260^{\mathrm{a}} \\
\pm 94\end{array}$ & $\begin{array}{c}1452^{\mathrm{b}} \\
\pm 76\end{array}$ & $\begin{array}{l}1640^{c} \\
\pm 64\end{array}$ & $\begin{array}{l}1672^{c} \\
\pm 36\end{array}$ & $\begin{array}{l}1702^{c} \\
\pm 66\end{array}$ & $\begin{array}{l}1720^{c} \\
\pm 66\end{array}$ \\
\hline $\begin{array}{l}\text { Modellparameter } \\
\qquad b\left(* 10^{6}\right)\end{array}$ & $\begin{array}{l}136^{\mathrm{a}} \\
\pm 23\end{array}$ & $\begin{array}{l}166^{\mathrm{ab}} \\
\pm 16\end{array}$ & $\begin{array}{l}187^{\mathrm{bc}} \\
\pm 8\end{array}$ & $\begin{array}{c}198^{\mathrm{bc}} \\
\pm 9\end{array}$ & $\begin{array}{l}198^{b c} \\
\pm 10\end{array}$ & $\begin{array}{l}186^{b c} \\
\pm 10\end{array}$ \\
\hline $\mathrm{PNu}(\%)$ & $\begin{array}{l}46,5^{\mathrm{a}} \\
\pm 7,3\end{array}$ & $\begin{array}{l}54,9^{\mathrm{ab}} \\
\pm 5,1\end{array}$ & $\begin{array}{l}60,0^{\mathrm{bc}} \\
\pm 2,2\end{array}$ & $\begin{array}{l}62,9^{\mathrm{bc}} \\
\pm 2,6\end{array}$ & $\begin{array}{l}62,8^{\mathrm{bc}} \\
\pm 3,1\end{array}$ & $\begin{array}{l}58,8^{\mathrm{bc}} \\
\pm 2,8\end{array}$ \\
\hline $\mathrm{PNu}_{\text {std. }}(\%)$ & $\begin{array}{l}46,2^{\mathrm{a}} \\
\pm 6,2\end{array}$ & $\begin{array}{l}54,0^{\mathrm{ab}} \\
\pm 4,1\end{array}$ & $\begin{array}{l}59,1^{\text {bc }} \\
\pm 1,9\end{array}$ & $\begin{array}{l}61,4^{b c} \\
\pm 2,0\end{array}$ & $\begin{array}{l}61,6^{\text {bc }} \\
\pm 2,3\end{array}$ & $\begin{array}{l}58,9^{\mathrm{bc}} \\
\pm 2,1\end{array}$ \\
\hline \multicolumn{7}{|c|}{ Growerphase (22-35d) } \\
\hline$c_{\text {Met }}(g / 16 g N)$ & 1,334 & 1,502 & 1,671 & 1,840 & 2,003 & 1,660 \\
\hline $\begin{array}{c}\mathrm{ND} \\
\left(\mathrm{mg} / \mathrm{LM}_{\mathrm{kg}}^{0,67} / \mathrm{d}\right)\end{array}$ & $\begin{array}{l}1547^{\mathrm{a}} \\
\pm 155\end{array}$ & $\begin{array}{c}1672^{\mathrm{ab}} \\
\pm 86\end{array}$ & $\begin{array}{l}1809^{b} \\
\pm 182\end{array}$ & $\begin{array}{c}1691^{\mathrm{ab}} \\
\pm 94\end{array}$ & $\begin{array}{l}1604^{\mathrm{ab}} \\
\pm 140\end{array}$ & $\begin{array}{l}1709^{\mathrm{ab}} \\
\pm 143\end{array}$ \\
\hline $\begin{array}{l}\text { Modellparameter } \\
\qquad b\left(* 10^{6}\right)\end{array}$ & $\begin{array}{l}207^{\mathrm{a}} \\
\pm 43\end{array}$ & $\begin{array}{l}231^{\mathrm{ab}} \\
\pm 24\end{array}$ & $\begin{array}{l}260^{\mathrm{b}} \\
\pm 34\end{array}$ & $\begin{array}{l}258^{b} \\
\pm 10\end{array}$ & $\begin{array}{l}243^{\mathrm{ab}} \\
\pm 29\end{array}$ & $\begin{array}{l}222^{\mathrm{ab}} \\
\pm 23\end{array}$ \\
\hline $\mathrm{PNu}(\%)$ & $\begin{array}{l}50,2^{\mathrm{a}} \\
\pm 9,4\end{array}$ & $\begin{array}{c}54,4^{\mathrm{abc}} \\
\pm 4,7\end{array}$ & $\begin{array}{l}58,5^{\mathrm{bc}} \\
\pm 3,9\end{array}$ & $\begin{array}{l}60,5^{\mathrm{c}} \\
\pm 1,5\end{array}$ & $\begin{array}{l}58,2^{\text {bc }} \\
\pm 4,9\end{array}$ & $\begin{array}{l}51,7^{\mathrm{ab}} \\
\pm 4,1\end{array}$ \\
\hline $\mathrm{PNu}_{\text {std. }}(\%)$ & $\begin{array}{l}52,5^{\mathrm{a}} \\
\pm 8,2\end{array}$ & $\begin{array}{l}57,3^{\mathrm{ab}} \\
\pm 4,2\end{array}$ & $\begin{array}{l}61,9^{\mathrm{b}} \\
\pm 5,0\end{array}$ & $\begin{array}{l}61,8^{b} \\
\pm 1,6\end{array}$ & $\begin{array}{l}59,2^{\text {ab }} \\
\pm 4,6\end{array}$ & $\begin{array}{l}55,7^{\mathrm{ab}} \\
\pm 4,1\end{array}$ \\
\hline \multicolumn{7}{|c|}{ Gesamte Versuchsphase (Tag 1-35) } \\
\hline $\mathrm{c}_{\text {Met }}(\mathrm{g} / 16 \mathrm{gN})$ & 1,336 & 1,504 & 1,673 & 1,840 & 2,006 & 1,661 \\
\hline $\begin{array}{c}\mathrm{ND} \\
\left(\mathrm{mg} / \mathrm{LM}_{\mathrm{kg}}^{0,67} / \mathrm{d}\right)\end{array}$ & $\begin{array}{c}1375^{\mathrm{a}} \\
\pm 84\end{array}$ & $\begin{array}{c}1540^{\mathrm{b}} \\
\pm 61\end{array}$ & $\begin{array}{l}1708^{c} \\
\pm 72\end{array}$ & $\begin{array}{l}1680^{c} \\
\pm 43\end{array}$ & $\begin{array}{l}1663^{c} \\
\pm 55\end{array}$ & $\begin{array}{l}1717^{\mathrm{c}} \\
\pm 52\end{array}$ \\
\hline $\begin{array}{l}\text { Modellparameter } \\
\qquad b\left(* 10^{6}\right)\end{array}$ & $\begin{array}{l}161^{\mathrm{a}} \\
\pm 23\end{array}$ & $\begin{array}{l}191^{\mathrm{b}} \\
\pm 17\end{array}$ & $\begin{array}{l}216^{c} \\
\pm 9\end{array}$ & $\begin{array}{l}223^{c} \\
\pm 8\end{array}$ & $\begin{array}{l}219^{c} \\
\pm 12\end{array}$ & $\begin{array}{l}203^{\mathrm{bc}} \\
\pm 11\end{array}$ \\
\hline $\mathrm{PNu}(\%)$ & $\begin{array}{l}47,7^{\mathrm{a}} \\
\pm 6,4\end{array}$ & $\begin{array}{l}54,7^{b} \\
\pm 4,5\end{array}$ & $\begin{array}{c}59,4^{\text {bcd }} \\
\pm 1,8\end{array}$ & $\begin{array}{l}61,9^{d} \\
\pm 2,0\end{array}$ & $\begin{array}{l}60,9^{\mathrm{cd}} \\
\pm 3,1\end{array}$ & $\begin{array}{l}55,7^{\text {bc }} \\
\pm 2,8\end{array}$ \\
\hline $\mathrm{PNu}_{\text {std. }}(\%)$ & $\begin{array}{l}48,3^{\mathrm{a}} \\
\pm 5,5\end{array}$ & $\begin{array}{l}54,9^{\mathrm{b}} \\
\pm 3,7\end{array}$ & $\begin{array}{l}59,8^{\mathrm{c}} \\
\pm 1,8\end{array}$ & $\begin{array}{l}61,3^{\mathrm{c}} \\
\pm 1,5\end{array}$ & $\begin{array}{l}60,4^{c} \\
\pm 2,3\end{array}$ & $\begin{array}{l}57,3^{\mathrm{bc}} \\
\pm 2,2\end{array}$ \\
\hline
\end{tabular}

Angaben als Mittelwerte \pm Standardabweichung, unterschiedliche Hochbuchstaben kennzeichnen signifikante Unterschiede ( $p$ $<0,05)$. 
In den Abbildungen 15-17 sind die Resultate der Met-Wirksamkeitsbewertung zusammengefasst. Die Met-Wirksamkeit $\left(b c^{-1}\right)$ in der Starterphase (Abb. 15) war in Versuchsgruppe C (TMP 50:50) und F (SES 50:50) am höchsten, unterschied sich allerdings nur numerisch von den Versuchsgruppen A (TMP 40:60), B (TMP 45:55) und D (TMP 55:45). Die niedrigste Met-Wirksamkeit wurde in Versuchsgruppe E (TMP 60:40) beobachtet, es gab jedoch keine signifikanten Unterschiede zu Versuchsgruppe A (TMP 40:60) und B (TMP 45:55).

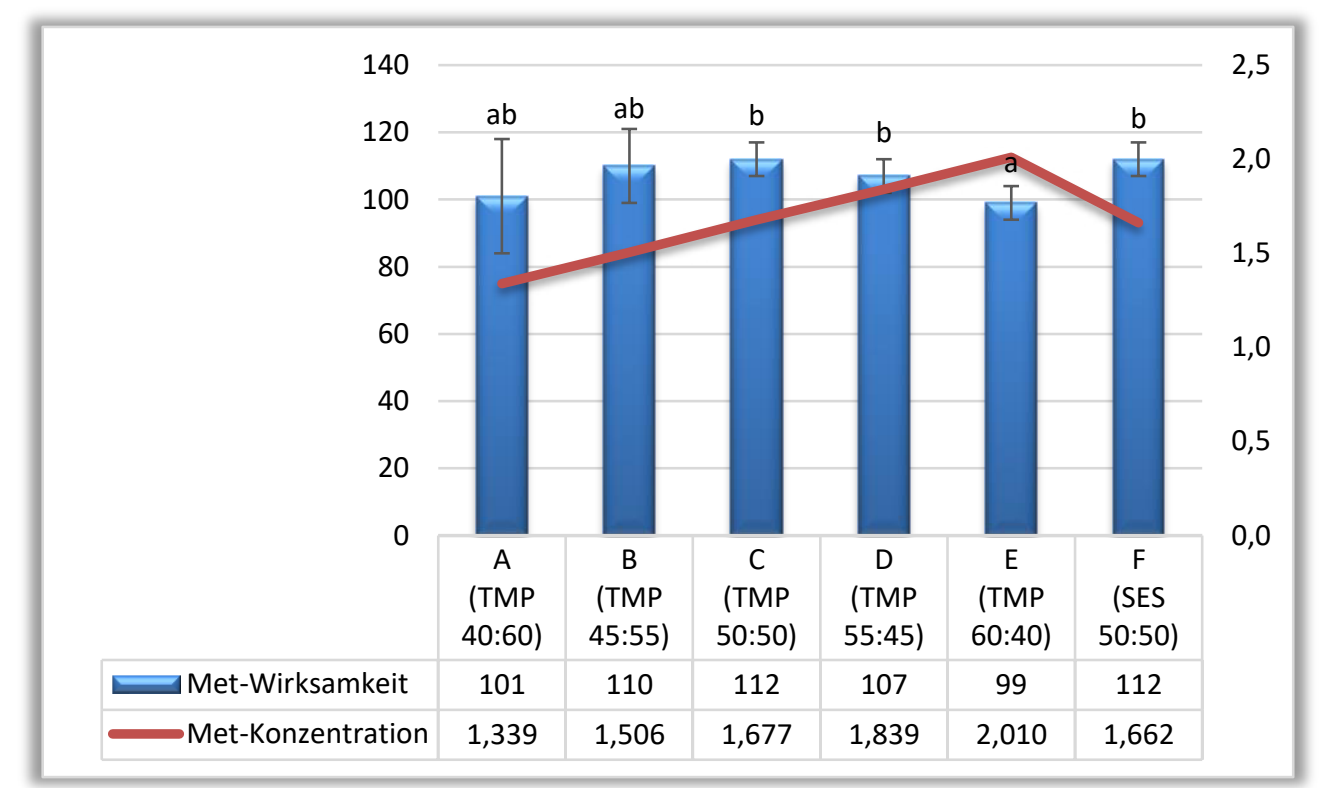

Abbildung 15: Met-Wirksamkeit $\left(b c^{-1}\right)$ und Met-Konzentration $(\mathrm{g} / 16 \mathrm{gN})$ in der Starterphase (Tag 1-21) von Versuch 2. Angaben als Mittelwerte \pm Standardabweichung, unterschiedliche Buchstaben kennzeichnen signifikante Unterschiede $(\mathbf{p}<0,05)$.

Die höchste Met-Wirksamkeit in der Growerphase (Abb. 16) wurde in Versuchsgruppe C (TMP 50:50) festgestellt, allerdings nur mit numerischen Unterschieden $\mathrm{zu}$ allen anderen Versuchsgruppen mit Ausnahme von Gruppe E (TMP 60:40). Versuchsgruppe E (TMP 60:40) wies wiederum die niedrigste Met-Wirksamkeit auf, unterschied sich aber nur numerisch von Versuchsgruppe D (TMP 55:45) und F (SES 50:50). 


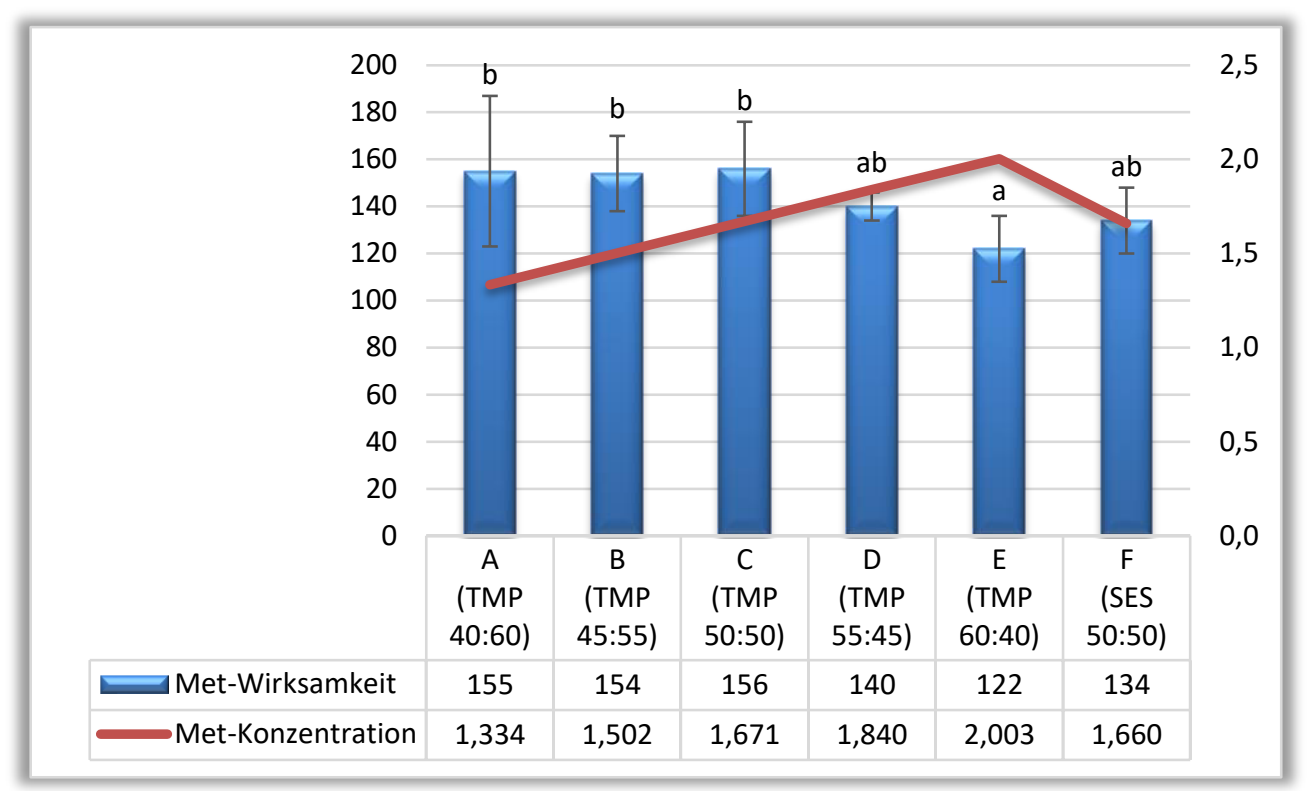

Abbildung 16: Met-Wirksamkeit $\left(b c^{-1}\right)$ und Met-Konzentration (g/16gN) in der Growerphase (Tag 22-35) von Versuch 2. Angaben als Mittelwerte \pm Standardabweichung, unterschiedliche Buchstaben kennzeichnen signifikante Unterschiede $(p<0,05)$.

Bei der Gesamtbetrachtung des Versuchs (Abb. 17) war die Met-Wirksamkeit ebenfalls in Versuchsgruppe C (TMP 50:50) am höchsten und unterschied sich nur von Versuchsgruppe E (TMP 60:40) signifikant ( $<$ 0,05). Ebenso wie in den einzelnen Wachstumsphasen zeigte Versuchsgruppe E (TMP 60:40) die niedrigste Met-Wirksamkeit, es gab jedoch nur numerische Unterschiede zu Versuchsgruppe A (TMP 40:60), D (TMP 55:45) und F (SES 50:50).

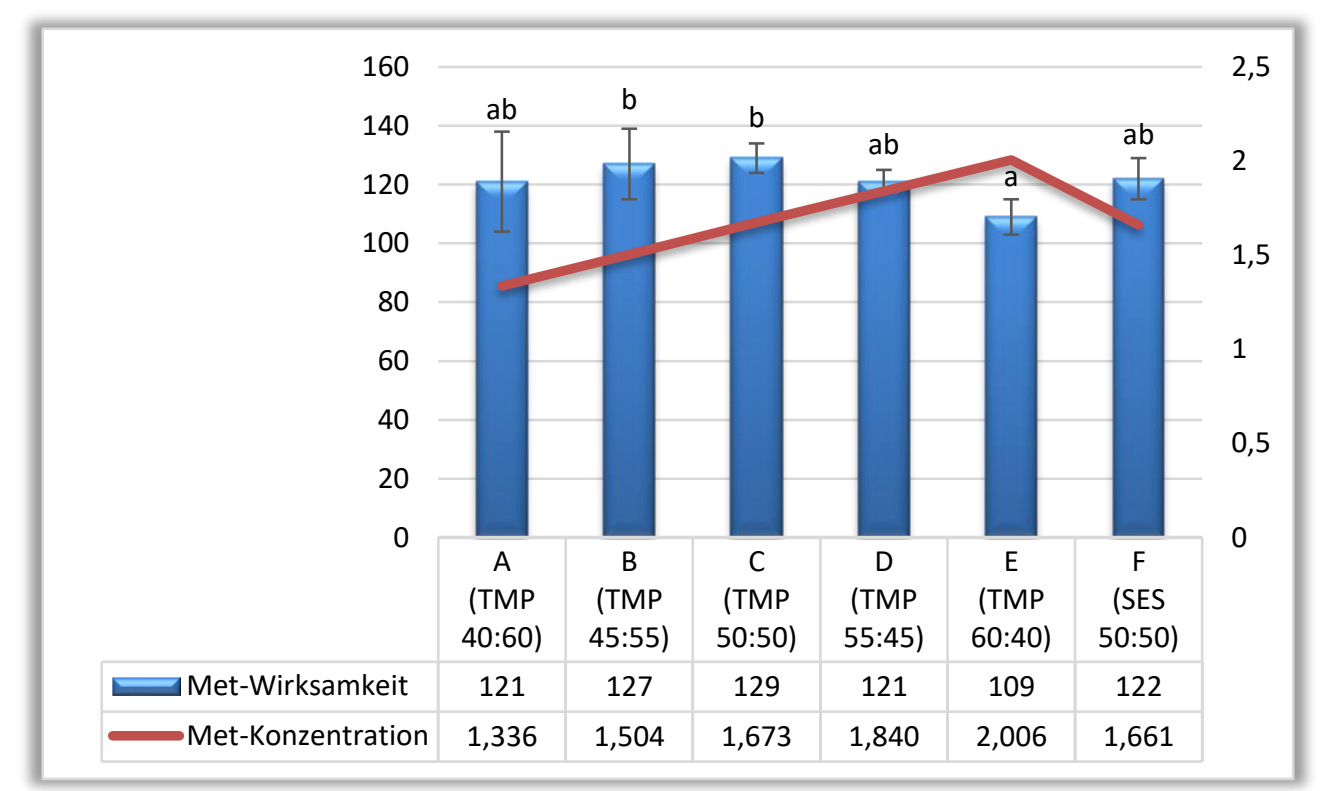

Abbildung 17: Met-Wirksamkeit $\left(b c^{-1}\right)$ und Met-Konzentration (g/16gN) des gesamten Versuchs 2 (Tag 1-35). Angaben als Mittelwerte \pm Standardabweichung, unterschiedliche Buchstaben kennzeichnen signifikante Unterschiede $(p<0,05)$. 


\subsubsection{Ableitung des Met-Bedarfs}

Die Met-Bedarfsableitung in der Starterphase von Versuch 2 (Tab. 25) zeigt wiederum, dass der Met-Bedarf und die optimale Konzentration von Met im Futter bei einem Met:CysVerhältnis von 45:55 bzw. 50:50 am niedrigsten war. Es gab im Gegensatz zu Versuch 1 keine Unterschiede zwischen dem Einsatz von TMP und SES als Hauptproteinquelle. Die für ein Met:Cys-Verhältnis von 40:60 und 55:45 ermittelten Werte lagen etwas höher, befanden sich aber insgesamt auf einem vergleichbaren Niveau. Ein Met:Cys-Verhältnis von 60:40 bewirkte eine weitere Steigerung der abgeleiteten Met-Bedarfswerte und der optimalen MetKonzentration im Futter. Zusätzlich erhöhten sich beide Werte mit steigendem Proteinansatz, während sie mit zunehmender FI sanken.

In der Growerphase (Tab. 26) konnte, ebenso wie in Versuch 2, im Vergleich zur Starterphase ein höherer Met-Bedarf beobachtet werden, die optimale Met-Konzentration im Futter nahm dagegen ab. Auch in diesem Versuch waren die grundsätzlichen Abhängigkeiten vom Met:CysVerhältnis sowie vom XPD und der FI analog zur Starterphase. Es gab jedoch im Gegensatz zur Starterphase und zu Versuch 1 Unterschiede zwischen dem Einsatz von TMP und SES als Hauptproteinquelle. So waren der Met-Bedarf und die optimale Konzentration im Futter bei der Fütterung von SES höher als beim Einsatz von TMP. 
Tabelle 25: Abgeleiteter Met-Bedarf in Abhängigkeit von Met:Cys-Verhältnis, Rohproteinansatz und täglicher Futteraufnahme in der Starterphase (Tag 1-21) von Versuch 2 (Mittlere LM:500g).

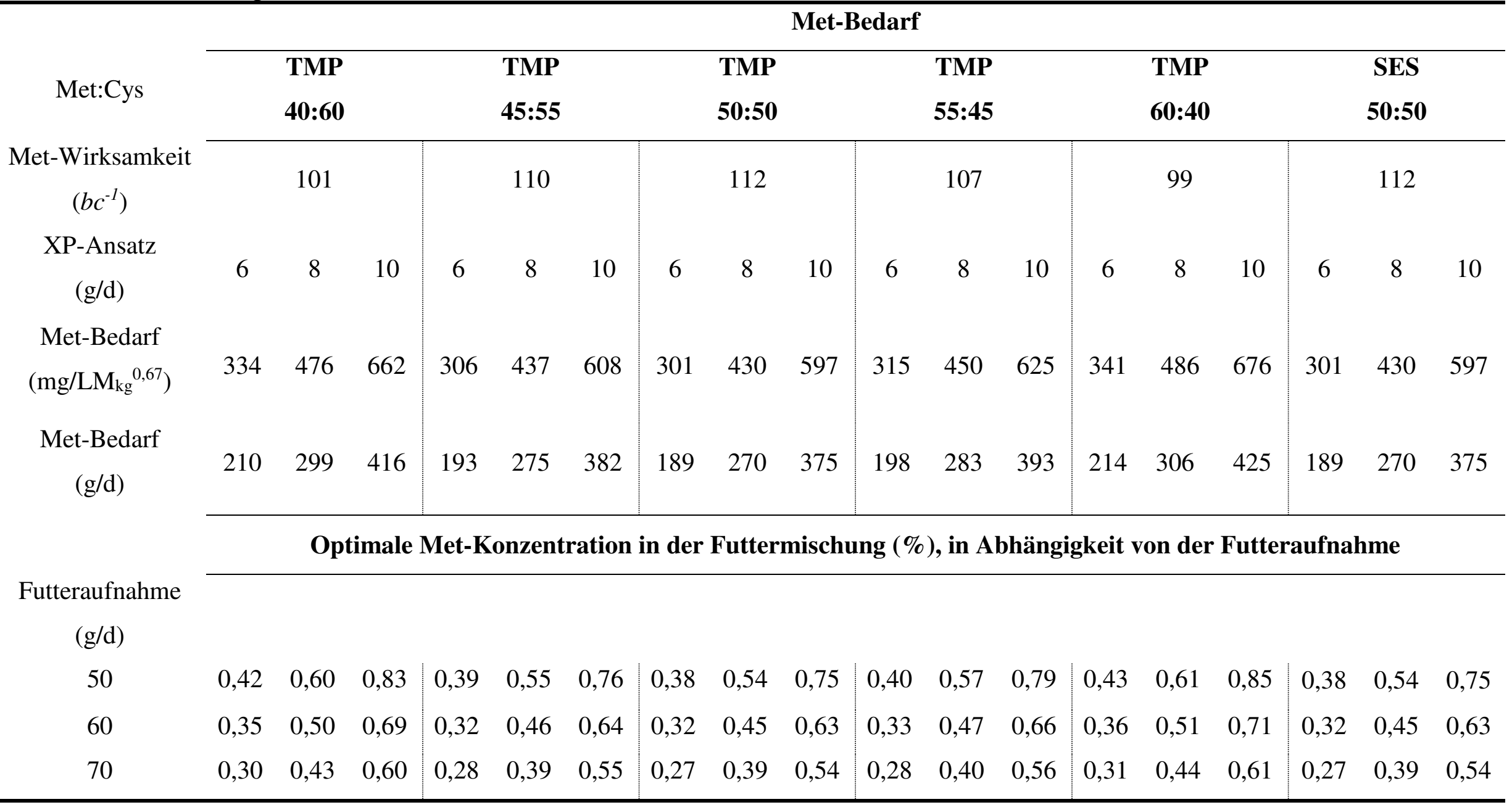


Tabelle 26: Abgeleiteter Met-Bedarf in Abhängigkeit von Met:Cys-Verhältnis, Rohproteinansatz und täglicher Futteraufnahme in der Growerphase (Tag 22-35) von Versuch 2 (Mittlere LM:1500g).

\begin{tabular}{|c|c|c|c|c|c|c|c|c|c|c|c|c|c|c|c|c|c|c|}
\hline \multirow{3}{*}{ Met:Cys } & \multicolumn{18}{|c|}{ Met-Bedarf } \\
\hline & \multicolumn{3}{|c|}{ TMP } & \multicolumn{3}{|c|}{ TMP } & \multicolumn{3}{|c|}{ TMP } & \multicolumn{3}{|c|}{ TMP } & \multicolumn{3}{|c|}{ TMP } & \multicolumn{3}{|c|}{ SES } \\
\hline & \multicolumn{3}{|c|}{$40: 60$} & \multicolumn{3}{|c|}{$45: 55$} & \multicolumn{3}{|c|}{$50: 50$} & \multicolumn{3}{|c|}{$55: 45$} & \multicolumn{3}{|c|}{$60: 40$} & \multicolumn{3}{|c|}{$50: 50$} \\
\hline $\begin{array}{l}\text { Met-Wirksamkeit } \\
\qquad\left(b c^{-1}\right)\end{array}$ & & 155 & & & 154 & & & 156 & & & 140 & & & 122 & & & 134 & \\
\hline $\begin{array}{l}\text { XP-Ansatz } \\
\qquad(\mathrm{g} / \mathrm{d})\end{array}$ & 12 & 16 & 20 & 12 & 16 & 20 & 12 & 16 & 20 & 12 & 16 & 20 & 12 & 16 & 20 & 12 & 16 & 20 \\
\hline $\begin{array}{c}\text { Met-Bedarf } \\
\left(\mathrm{mg}^{\mathrm{L}} \mathrm{LM}_{\mathrm{kg}}{ }^{0,67}\right)\end{array}$ & 376 & 409 & 608 & 277 & 411 & 612 & 274 & 406 & 604 & 305 & 452 & 673 & 350 & 519 & 773 & 319 & 473 & 704 \\
\hline $\begin{array}{l}\text { Met-Bedarf } \\
(\mathrm{g} / \mathrm{d})\end{array}$ & 362 & 536 & 798 & 364 & 540 & 803 & 359 & 533 & 793 & 400 & 594 & 884 & 459 & 681 & 1014 & 418 & 620 & 923 \\
\hline & \multicolumn{18}{|c|}{ Optimale Met-Konzentration in der Futtermischung $(\%)$, in Abhängigkeit von der Futteraufnahme } \\
\hline $\begin{array}{l}\text { Futteraufnahme } \\
\qquad(\mathrm{g} / \mathrm{d})\end{array}$ & & & & & & & & & & & & & & & & & & \\
\hline 120 & 0,30 & 0,45 & 0,67 & 0,30 & 0,45 & 0,67 & 0,30 & 0,44 & 0,66 & 0,33 & 0,50 & 0,74 & 0,38 & 0,57 & 0,85 & 0,35 & 0,52 & 0,77 \\
\hline 130 & 0,28 & 0,41 & 0,61 & 0,28 & 0,42 & 0,62 & 0,28 & 0,41 & 0,61 & 0,31 & 0,46 & 0,68 & 0,35 & 0,52 & 0,78 & 0,32 & 0,48 & 0,71 \\
\hline 140 & 0,26 & 0,38 & 0,57 & 0,26 & 0,39 & 0,57 & 0,26 & 0,38 & 0,57 & 0,29 & 0,42 & 0,63 & 0,33 & 0,49 & 0,72 & 0,30 & 0,44 & 0,66 \\
\hline
\end{tabular}




\subsubsection{Körperzusammensetzung}

Die mittlere Körperzusammensetzung der Tiere aus Versuch 2 wird in Tabelle 27 aufgeführt. Am Ende der Starterphase (Tag 21) wiesen die Tiere aus Versuchsgruppe A (TMP 40:60) den höchsten XP-Gehalt auf, der Wert unterschied sich aber nur numerisch von Versuchsgruppe B (TMP 45:55), D (TMP 55:45), E (TMP 40:60) und F (SES 50:50). Der niedrigste XP-Gehalt wurde in den Tieren aus Versuchsgruppe C (TMP 50:50) beobachtet, er unterschied sich aber ebenfalls nicht signifikant von Versuchsgruppe B (TMP 45:55), D (TMP 55:45), E (TMP 40:60) und F (SES 50:50). Der höchste XL-Gehalt wurde in den Tieren aus Versuchsgruppe C (TMP 50:50) ermittelt, es gab aber nur numerische Unterschiede zu Versuchsgruppe B (TMP 45:55), D (TMP 55:45), E (TMP 40:60) und F (SES 50:50). Alle Versuchsgruppen unterschieden sich jedoch signifikant ( $p<0,05)$ von Versuchsgruppe A (TMP 40:60), deren Tiere den niedrigsten XL-Gehalt aufwiesen. Der XA-Gehalt war dagegen in den Tieren aus Versuchsgruppe A (TMP 40:60) am höchsten und unterschied sich signifikant $(p<0,05)$ von allen anderen Versuchsgruppen.

Am Ende der Growerphase (Tag 35) war der XP-Gehalt in den Tieren aus Versuchsgruppe A (TMP 40:60) am höchsten, es gab jedoch keine signifikanten Unterschiede zu Versuchsgruppe B (TMP 45:55), D (TMP 55:45), E (TMP 60:40) und F (SES 50:50). Auch der niedrigste XPGehalt in den Tieren aus Versuchsgruppe C (TMP 50:50) unterschied sich nur numerisch von denen in Versuchsgruppe B (TMP 45:55), D (TMP 55:45), E (TMP 60:40) und F (SES 50:50). Die Tiere aus Versuchsgruppe C (TMP 50:50) wiesen den höchsten XL-Gehalt auf, unterschieden sich aber ebenfalls nicht signifikant von denen aus Versuchsgruppe B (TMP 45:55), D (TMP 55:45), E (TMP 60:40) und F (SES 50:50). Ebenso wie der niedrigste XPGehalt unterschied sich auch der niedrigste XL-Gehalt in den Tieren aus Versuchsgruppe A (TMP 40:60) nur numerisch von denen in Versuchsgruppe B (TMP 45:55), D (TMP 55:45), E (TMP 60:40) und F (SES 50:50). Den höchsten XA-Gehalt wiesen die Tiere aus Versuchsgruppe A (TMP 40:60) auf, es gab jedoch keine signifikanten Unterschiede zu Versuchsgruppe B (TMP 45:55). Auch zwischen den anderen Versuchsgruppen konnten keine signifikanten Unterschiede festgestellt werden. 
Tabelle 27: Mittlere Körperzusammensetzung der Tiere am Ende der Starter- (Tag 21) und Growerphase (Tag 35) von Versuch 2.

\begin{tabular}{|c|c|c|c|c|c|c|}
\hline Met:Cys & $\begin{array}{c}\mathrm{A} \\
\mathrm{TMP} \\
\mathbf{4 0 : 6 0}\end{array}$ & $\begin{array}{c}\text { B } \\
\text { TMP } \\
\mathbf{4 5 : 5 5}\end{array}$ & $\begin{array}{c}\mathrm{C} \\
\mathrm{TMP} \\
\mathbf{5 0 : 5 0}\end{array}$ & $\begin{array}{c}\mathrm{D} \\
\mathrm{TMP} \\
\mathbf{5 5 : 4 5}\end{array}$ & $\begin{array}{c}\mathrm{E} \\
\mathrm{TMP} \\
\mathbf{6 0 : 4 0}\end{array}$ & $\begin{array}{c}\text { F } \\
\text { SES } \\
\mathbf{5 0 : 5 0}\end{array}$ \\
\hline \multicolumn{7}{|c|}{ Ende der Starterphase (Tag 21) } \\
\hline $\begin{array}{l}\mathrm{TM} \\
(\%)\end{array}$ & $\begin{array}{l}28,7^{\mathrm{a}} \\
\pm 1,5\end{array}$ & $\begin{array}{l}30,4^{\mathrm{ab}} \\
\pm 2,7\end{array}$ & $\begin{array}{l}31,3^{\mathrm{b}} \\
\pm 1,1\end{array}$ & $\begin{array}{l}31,3^{\mathrm{b}} \\
\pm 1,1\end{array}$ & $\begin{array}{l}31,4^{\mathrm{b}} \\
\pm 1,1\end{array}$ & $\begin{array}{c}30,7^{\mathrm{ab}} \\
\pm 0,7\end{array}$ \\
\hline $\begin{array}{c}\mathrm{XP} \\
(\% \mathrm{TM})\end{array}$ & $\begin{array}{l}58,2^{\mathrm{b}} \\
\pm 3,6\end{array}$ & $\begin{array}{l}54,3^{\mathrm{ab}} \\
\pm 4,5\end{array}$ & $\begin{array}{l}52,5^{\mathrm{a}} \\
\pm 1,7\end{array}$ & $\begin{array}{c}53,3^{\mathrm{ab}} \\
\pm 1,5\end{array}$ & $\begin{array}{c}53,1^{\mathrm{ab}} \\
\pm 1,3\end{array}$ & $\begin{array}{c}54,3^{\text {ab }} \\
\pm 1,6\end{array}$ \\
\hline $\begin{array}{c}\mathrm{XL} \\
(\% \mathrm{TM})\end{array}$ & $\begin{array}{l}31,5^{\mathrm{a}} \\
\pm 4,3\end{array}$ & $\begin{array}{l}36,9^{b} \\
\pm 5,6\end{array}$ & $\begin{array}{l}39,4^{\mathrm{b}} \\
\pm 2,1\end{array}$ & $\begin{array}{l}38,7^{\mathrm{b}} \\
\pm 1,9\end{array}$ & $\begin{array}{l}38,9^{b} \\
\pm 1,5\end{array}$ & $\begin{array}{l}37,9^{b} \\
\pm 2,6\end{array}$ \\
\hline $\begin{array}{c}\mathrm{XA} \\
(\% \mathrm{TM})\end{array}$ & $\begin{array}{l}10,3^{b} \\
\pm 0,8\end{array}$ & $\begin{array}{c}8,8^{\mathrm{a}} \\
\pm 1,2\end{array}$ & $\begin{array}{c}8,1^{\mathrm{a}} \\
\pm 0,5\end{array}$ & $\begin{array}{c}8,0^{\mathrm{a}} \\
\pm 0,4\end{array}$ & $\begin{array}{c}8,0^{\mathrm{a}} \\
\pm 0,4\end{array}$ & $\begin{array}{c}7,8^{\mathrm{a}} \\
\pm 1,0\end{array}$ \\
\hline \multicolumn{7}{|c|}{ Ende der Growerphase (Tag 35) } \\
\hline $\begin{array}{l}\mathrm{TM} \\
(\%)\end{array}$ & $\begin{array}{l}32,6^{\mathrm{a}} \\
\pm 1,7\end{array}$ & $\begin{array}{c}33,7^{\mathrm{ab}} \\
\pm 2,0\end{array}$ & $\begin{array}{l}35,3^{\mathrm{c}} \\
\pm 0,9\end{array}$ & $\begin{array}{c}34,8^{a b} \\
\pm 1,1\end{array}$ & $\begin{array}{c}34,1^{\mathrm{ab}} \\
\pm 1,3\end{array}$ & $\begin{array}{l}34,4^{\mathrm{ab}} \\
\pm 2,4\end{array}$ \\
\hline $\begin{array}{c}\mathrm{XP} \\
(\% \mathrm{TM})\end{array}$ & $\begin{array}{l}53,6^{b} \\
\pm 3,5\end{array}$ & $\begin{array}{l}51,4^{\mathrm{ab}} \\
\pm 3,2\end{array}$ & $\begin{array}{l}49,1^{\mathrm{a}} \\
\pm 2,0\end{array}$ & $\begin{array}{l}51,2^{\mathrm{ab}} \\
\pm 2,5\end{array}$ & $\begin{array}{l}51,3^{\text {ab }} \\
\pm 3,0\end{array}$ & $\begin{array}{c}52,7^{\mathrm{ab}} \\
\pm 1,7\end{array}$ \\
\hline $\begin{array}{c}\mathrm{XL} \\
(\% \mathrm{TM})\end{array}$ & $\begin{array}{l}37,6^{\mathrm{a}} \\
\pm 4,3\end{array}$ & $\begin{array}{c}40,7^{\mathrm{ab}} \\
\pm 3,7\end{array}$ & $\begin{array}{l}44,0^{\mathrm{b}} \\
\pm 2,2\end{array}$ & $\begin{array}{c}41,6^{\mathrm{ab}} \\
\pm 2,8\end{array}$ & $\begin{array}{c}41,4^{\mathrm{ab}} \\
\pm 3,5\end{array}$ & $\begin{array}{l}40,2^{\mathrm{ab}} \\
\pm 2,1\end{array}$ \\
\hline $\begin{array}{c}\mathrm{XA} \\
(\% \mathrm{TM})\end{array}$ & $\begin{array}{c}8,8^{\mathrm{c}} \\
\pm 0,8\end{array}$ & $\begin{array}{l}8,0^{\mathrm{bc}} \\
\pm 0,7\end{array}$ & $\begin{array}{c}6,9^{\mathrm{a}} \\
\pm 0,3\end{array}$ & $\begin{array}{l}7,2^{\mathrm{ab}} \\
\pm 0,4\end{array}$ & $\begin{array}{l}7,4^{\mathrm{ab}} \\
\pm 0,6\end{array}$ & $\begin{array}{l}7,1^{\mathrm{ab}} \\
\pm 0,5\end{array}$ \\
\hline
\end{tabular}

Angaben als Mittelwerte \pm Standardabweichung, unterschiedliche Hochbuchstaben kennzeichnen signifikante Unterschiede (p $<0,05)$.

\subsubsection{Protein- und Fettansatz}

In der Starterphase von Versuch 2 (Abb. 18) wurde der höchste XPD bei den Tieren aus Versuchsgruppe F (SES 50:50) beobachtet, es gab jedoch nur numerische Unterschiede zu denen aus den Versuchsgruppen C (TMP 50:50), D (TMP 55:45) und E (TMP 60:40). Die Tiere der Versuchsgruppe A (TMP 40:60) wiesen den signifikant $(\mathrm{p}<0,05)$ geringsten XPD auf. Im Vergleich dazu zeigte Versuchsgruppe B (TMP 45:55) einen signifikant $(\mathrm{p}<0,05)$ erhöhten Wert. Der XLD war in Versuchsgruppe C (TMP 50:50) am höchsten und auch hier lagen keine signifikanten Unterschiede zu den Versuchsgruppen D (TMP 55:45), E (TMP 60:40) und F (SES 50:50) vor. Ebenso wie der XPD war auch der XLD in Versuchsgruppe A (TMP 40:60) am geringsten $(\mathrm{p}<0,05)$ und Versuchsgruppe B (TMP 45:55) wies im Vergleich einen signifikant $(\mathrm{p}<0,05)$ höheren Wert auf. 


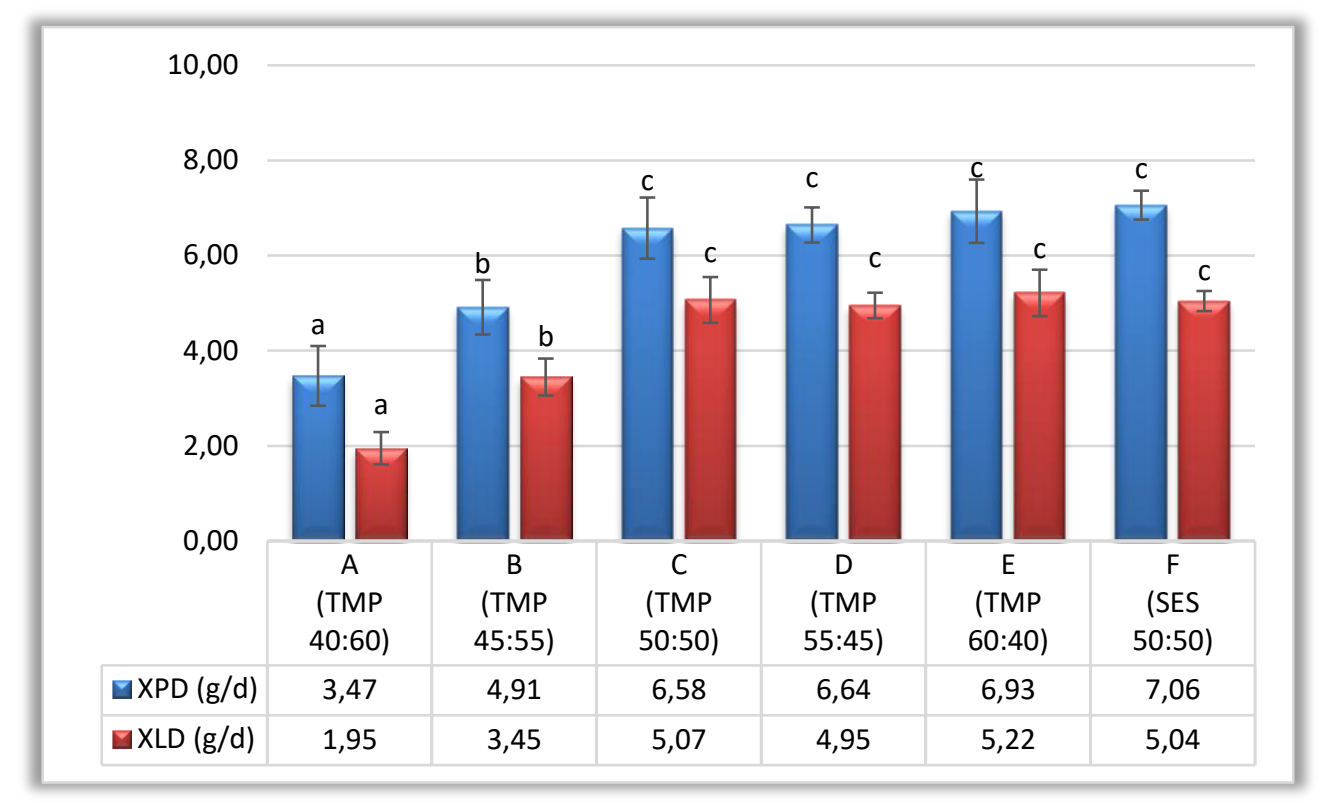

\begin{abstract}
Abbildung 18: Protein- und Fettansatz in der Starterphase (Tag 1-21) von Versuch 2. Angaben als Mittelwerte \pm Standardabweichung, unterschiedliche Buchstaben kennzeichnen signifikante Unterschiede $(\mathbf{p}<\mathbf{0 , 0 5})$.
\end{abstract}

In der Growerphase (Abb. 19) wurde der höchste XPD bei den Tieren aus Versuchsgruppe C (TMP 50:50) beobachtet und es gab, ebenso wie in der Starterphase, nur numerische Unterschiede zu den Versuchsgruppen C (TMP 50:50), D (TMP 55:45) und E (TMP 60:40). Genau wie in der Starterphase wiesen die Tiere der Versuchsgruppe A (TMP 40:60) den niedrigsten Wert auf $(\mathrm{p}<0,05)$. In Versuchsgruppe B (TMP 45:55) wurde im Vergleich dazu ein signifikant $(\mathrm{p}<0,05)$ höherer Wert festgestellt, der sich jedoch nur tendenziell von den Versuchsgruppen D (TMP 55:45) und E (TMP 60:40) unterschied. Die Tiere aus Versuchsgruppe C (TMP 50:50) zeigten den höchsten XLD und unterschieden sich signifikant $(\mathrm{p}<0,05)$ von denen der anderen Versuchsgruppen. Während Versuchsgruppe A (TMP 40:60) wieder den signifikant $(\mathrm{p}<0,05)$ niedrigsten Wert aufwies, unterschied sich der XLD in den Versuchsgruppen B (TMP 45:55), D (TMP 55:45), E (TMP 60:40) und F (SES 50:50) nur numerisch voneinander. 


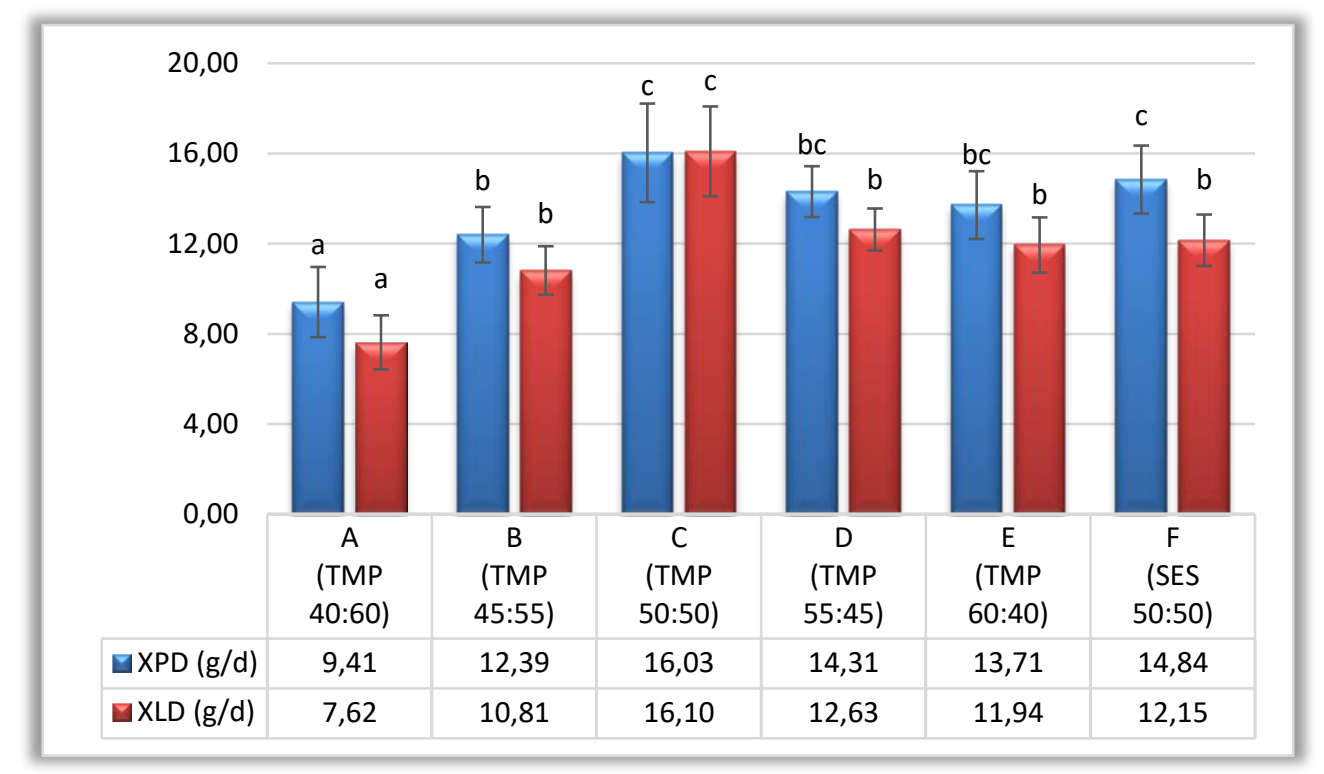

Abbildung 19: Protein- und Fettansatz in der Growerphase (Tag 22-35) von Versuch 2. Angaben als Mittelwerte \pm Standardabweichung, unterschiedliche Buchstaben kennzeichnen signifikante Unterschiede $(\mathbf{p}<\mathbf{0 , 0 5})$.

Bei Betrachtung des gesamten Versuchszeitraumes (Abb. 20) wurde der höchste XPD in Versuchsgruppe C (TMP 50:50) beobachtet und es lagen keine signifikanten Unterschiede zu den Versuchsgruppen D (TMP 55:45), E (TMP 60:40) und F (SES 50:50) vor. Versuchsgruppe A (TMP 40:60) wies ebenso wie in den einzelnen Wachstumsphasen den niedrigsten XPD auf, der Wert in Versuchsgruppe B (TMP 45:55) war im Vergleich dazu signifikant $(\mathrm{p}<0,05)$ höher. Der XLD war in Versuchsgruppe C (TMP 50:50) am höchsten und unterschied sich signifikant $(\mathrm{p}<0,05)$ von den Werten aller anderen Versuchsgruppen. Dabei gab es keine signifikanten Unterschiede zwischen den Versuchsgruppen D (TMP 55:45), E (TMP 60:40) und F (SES 50:50). Der niedrigste XLD ( $<<0,05)$ wurde auch hier in Versuchsgruppe A (TMP 40:60) beobachtet, während sich der Wert in Versuchsgruppe B (TMP 45:55) auf einem mittleren Niveau befand. 


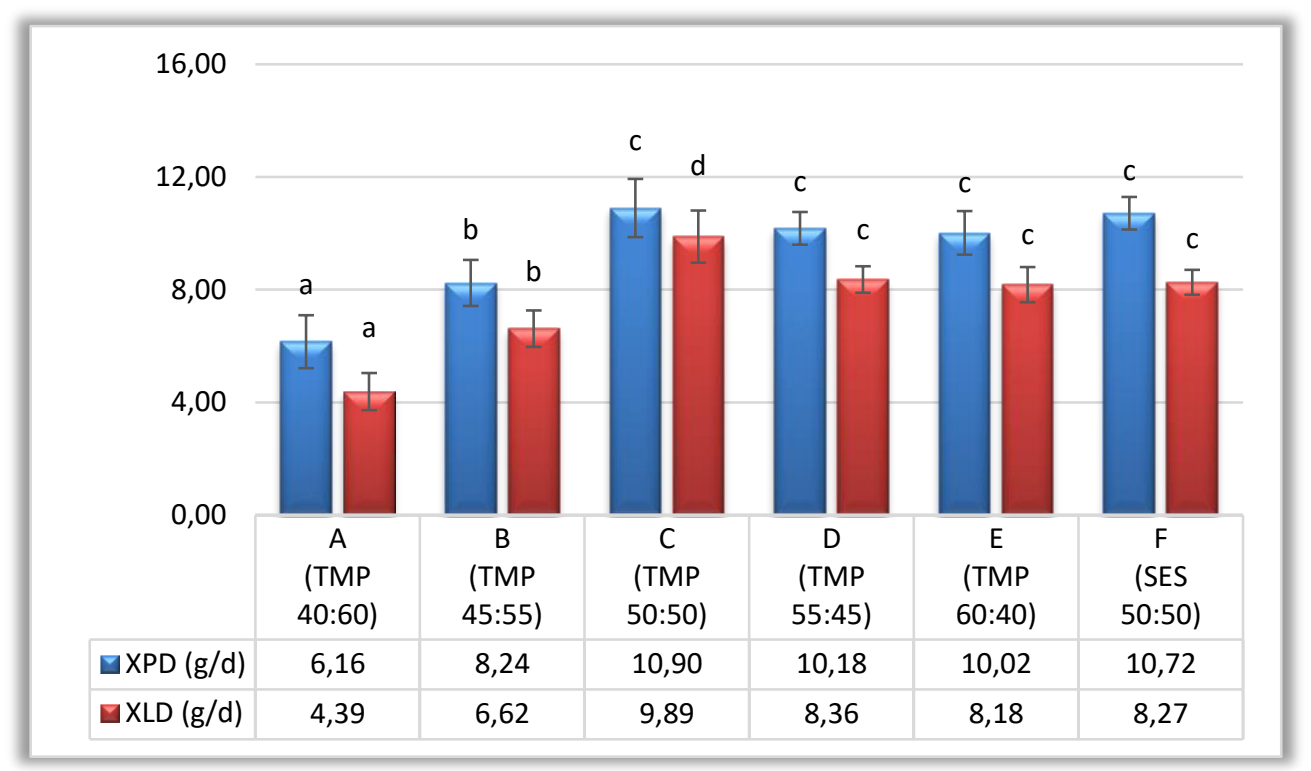

\begin{abstract}
Abbildung 20: Protein- und Fettansatz im gesamten Versuchszeitraum (Tag 1-35) von Versuch 2. Angaben als Mittelwerte \pm Standardabweichung, unterschiedliche Buchstaben kennzeichnen signifikante Unterschiede $(\mathbf{p}<0,05)$.
\end{abstract}

\title{
5.2.7 Histologische und stereologische Untersuchungen
}

In Versuch 2 wurden zusätzliche, ergänzende Untersuchungen zu möglichen vom Met:Cys Verhältnis sowie vom Hauptproteinträger abhängigen histologischen Veränderungen in ausgewählten Versuchsgruppen vorgenommen. Ausgewählte Ergebnisse sind in den Tabellen 28 und 29 zusammengefasst. Die makroskopische Untersuchung der Proben (Tab. 28) ergab ebenso wie die Ergebnisse der zootechnischen Parameter eine signifikant geringere LM in Versuchsgruppe A (TMP 40:60). Die absolute Dünndarmmasse (DDM) unterschied sich nicht signifikant zwischen den Versuchsgruppen. Bezogen auf die LM wies Versuchsgruppe A (TMP 40:60) jedoch eine signifikant höhere DDM auf als Versuchsgruppe E (TMP 40:60).

Tabelle 28: Ergebnisse der Makroskopie in Versuch 2.

\begin{tabular}{|c|c|c|c|c|}
\hline Met:Cys & $\begin{array}{c}\mathrm{A} \\
\mathrm{TMP}(\mathrm{n}=5) \\
40: 60\end{array}$ & $\begin{array}{c}\mathrm{E} \\
\mathrm{TMP}(\mathrm{n}=5) \\
60: 40\end{array}$ & $\begin{array}{c}\mathrm{F} \\
\text { SES }(\mathrm{n}=5) \\
50: 50 \\
\end{array}$ & $\begin{array}{c}\mathrm{p} \\
\text { (ANOVA) }\end{array}$ \\
\hline $\mathrm{LM}(\mathrm{g})$ & $1680,2^{\mathrm{a}}(29 \%)$ & $2667,9^{\mathrm{b}}(10 \%)$ & $2616,8^{b}(16 \%)$ & $P=0,0013$ \\
\hline DDM (g) & $46,3(21 \%)$ & $60,9(12 \%)$ & $60,3(6 \%)$ & \\
\hline Rel. DDM (\% der LM) & $2,8^{\mathrm{a}}(11 \%)$ & $2,3^{\mathrm{b}}(5 \%)$ & $2,3^{\mathrm{a}, \mathrm{b}}(9 \%)$ & $P=0,0079$ \\
\hline
\end{tabular}

Angaben als Mittelwerte und Variationskoeffizienten (\%), unterschiedliche Hochbuchstaben kennzeichnen signifikante Unterschiede zwischen den Versuchsgruppen; DDM = Dünndarmmasse. 
Die stereologische Untersuchung der einzelnen Darmabschnitte (Tab. 29) zeigt lediglich signifikante Unterschiede der relativen $\mathrm{S}_{\mathrm{pm}}$ bezogen auf die LM in D1. In D2 und D3 konnten dagegen nur numerische Unterschiede festgestellt werden. Im Hinblick auf das Zotten/Kryptenepithelvolumenverhältniss $\left(\mathrm{V}_{\mathrm{ve}} / \mathrm{V}_{\mathrm{ce}}\right)$ gab es in keinem Darmabschnitt signifikante Unterschiede zwischen den Versuchsgruppen.

Tabelle 29: Ergebnisse der relativen primären Schleimhautoberfläche $\left(S_{\mathrm{pm}}\right)$, relativen Zottenoberfläche $\left(S_{\mathrm{v}}\right)$ und dem Zotten-/Kryptenepithelvolumenverhältnisses $\left(V_{v e} / V_{c e}\right)$ in den drei Dünndarmabschnitten in Versuch 2.

\begin{tabular}{|c|c|c|c|c|}
\hline Diet & & $\begin{array}{c}\text { Rel. } S_{\mathrm{pm}} \\
\left(\mathrm{cm}^{2} / \mathrm{kg} \mathrm{LM}\right)\end{array}$ & $\begin{array}{c}\text { Rel. } S_{\mathrm{v}} \\
\left(\mathrm{cm}^{2} / \mathrm{kg} \mathrm{LM}\right) \\
\end{array}$ & $\mathrm{V}_{\mathrm{ve}} / \mathrm{V}_{\mathrm{ce}}$ \\
\hline \multicolumn{5}{|c|}{ A (TMP 40:60) } \\
\hline \multirow[t]{3}{*}{$(n=5)$} & D1 & $32,7^{\mathrm{a}}(21 \%)$ & $571,2(27 \%)$ & $4,6(28 \%)$ \\
\hline & D2 & $54,8(19 \%)$ & $897,1(31 \%)$ & $6,0(12 \%)$ \\
\hline & D3 & $50,0(23 \%)$ & $780,9(47 \%)$ & $3,3(29 \%)$ \\
\hline \multicolumn{5}{|c|}{ E (TMP 60:40) } \\
\hline \multirow[t]{3}{*}{$(n=5)$} & D1 & $21,3^{\mathrm{a}, \mathrm{b}}(8 \%)$ & $365,0(9 \%)$ & $4,5(19 \%)$ \\
\hline & D2 & $40,8(18 \%)$ & $727,5(22 \%)$ & $5,9(23 \%)$ \\
\hline & D3 & $37,5(8 \%)$ & $591,6(23 \%)$ & $4,3(23 \%)$ \\
\hline \multicolumn{5}{|c|}{$\overline{F(S E S ~ 50: 50)}$} \\
\hline \multirow[t]{3}{*}{$(n=5)$} & D1 & $19,6^{\mathrm{b}}(13 \%)$ & $362,2(22 \%)$ & $4,5(23 \%)$ \\
\hline & D2 & $43,9(8 \%)$ & $708,2(19 \%)$ & $6,0(37 \%)$ \\
\hline & D3 & $40,1(8 \%)$ & $677,8(32 \%)$ & $4,6(20 \%)$ \\
\hline
\end{tabular}

Angaben als Mittelwerte und Variationskoeffizienten (\%), unterschiedliche Hochbuchstaben kennzeichnen signifikante Unterschiede zwischen den Versuchsgruppen $(\mathrm{p} \leq 0,01)$. D1 = Duodenum; D2 = proximales Jejunum; D3 = distales Jejunum.

Somit zeigte sich auch in Versuch 2 ein Einfluss des Met:Cys-Verhältnisses auf die untersuchten Parameter. Zum Teil ergaben sich jedoch Unterschiede zu den Beobachtungen in Versuch 1. Die Ergebnisse werden in Kapitel 6.1.2 ausführlich verglichen, diskutiert und bewertet. 


\subsection{Versuch 3}

In Versuch 3 sollten die Met:Cys-Verhältnisse 50:50, 55:45 und 60:40 beim vergleichenden Einsatz von HM und TMP bewertet werden. Zusätzlich wurde für jede Proteinquelle jeweils eine pK eingesetzt. Die Ergebnisse werden nachfolgend erläutert.

\subsubsection{Zootechnische Parameter}

Am Ende der Starterphase von Versuch 3 (Tab. 30) wies Versuchsgruppe H (HM pK) die höchste finale LM und tägliche LMZ auf, unterschied sich jedoch nur von den Versuchsgruppen A (TMP 50:50) und C (TMP 60:40) signifikant ( $\mathrm{p}<0,05)$. Zwischen allen anderen Versuchsgruppen gab es keine signifikanten Unterschiede. Die FI war in Versuchsgruppe G (HM 60:40) am höchsten, es gab jedoch nur numerische Differenzen zu den Versuchsgruppen A (TMP 50:50), E (HM 50:50), F (HM 55:45) und H (HM pK). Die niedrigste FI konnte in Versuchsgruppe D (TMP pK) beobachtet werden, sie unterschied sich aber nur tendenziell von den anderen TMP-Versuchsgruppen A-C. Sowohl der FA als auch der Protein- und Energieaufwand waren in Versuchsgruppe D (TMP pK) am niedrigsten, unterschieden sich jedoch nur signifikant $(\mathrm{p}<0,05)$ von den Beobachtungswerten der Versuchsgruppen A (TMP 50:50), C (TMP 60:40), F (HM 55:45) und G (HM 60:40), zwischen denen nur numerische Unterschiede vorlagen.

Ebenso wie in der Starterphase, wies auch am Ende der Growerphase Versuchsgruppe H (HM pK) die höchste finale LM und tägliche LMZ auf. Im Gegensatz zur Starterphase unterschied sie sich jedoch signifikant $(\mathrm{p}<0,05)$ von allen anderen Versuchsgruppen mit Ausnahme von den Gruppen D (TMP pK) und E (HM 50:50). Die niedrigste finale LM und tägliche LMZ wurde in Versuchsgruppe C (TMP 60:40) festgestellt, sie unterschied sich aber nur numerisch von den Versuchsgruppen A (TMP 50:50), B (TMP 55:45), F (HM 55:45) und G (HM 60:40). Die FI war ebenfalls in Versuchsgruppe H (HM pK) am höchsten, es gab allerdings nur zu den Versuchsgruppen C (TMP 60:40) und D (TMP pK) signifikante $(\mathrm{p}<0,05)$ Unterschiede. Die Aufwandsparameter waren in Versuchsgruppe D (TMP pK) am niedrigsten und unterschieden sich signifikant $(\mathrm{p}<0,05)$ von den Werten in Versuchsgruppe A (TMP 50:50), B (TMP 55:45), C (TMP 60:40), E (HM 50:50), F (HM 55:45) und G (HM 60:40), zwischen denen es wiederum nur numerische Unterschiede gab. 
Tabelle 30: Ergebnisse der zootechnischen Parameter der Starter- (Tag 1-21) und Growerphase (Tag 22-35) in Versuch 3.

\begin{tabular}{|c|c|c|c|c|c|c|c|c|}
\hline Met:Cys & $\begin{array}{c}\text { A } \\
\text { TMP } \\
\mathbf{5 0 : 5 0}\end{array}$ & $\begin{array}{c}\text { B } \\
\text { TMP } \\
55: 45\end{array}$ & $\begin{array}{c}\mathrm{C} \\
\mathrm{TMP} \\
60: 40\end{array}$ & $\begin{array}{c}\text { D } \\
\text { TMP } \\
\text { pK }\end{array}$ & $\begin{array}{c}\mathbf{E} \\
\mathrm{HM} \\
\mathbf{5 0 : 5 0}\end{array}$ & $\begin{array}{c}\text { F } \\
\text { HM } \\
55: 45\end{array}$ & $\begin{array}{c}\mathrm{G} \\
\mathrm{HM} \\
60: 40\end{array}$ & $\begin{array}{c}\mathbf{H} \\
\mathbf{H M} \\
\mathbf{p K}\end{array}$ \\
\hline \multicolumn{9}{|c|}{ Starterphase (Tag 1-21) } \\
\hline $\operatorname{LM}_{\text {Beginn }}(\mathrm{g})$ & $\begin{array}{l}58 \\
\pm 0\end{array}$ & $\begin{array}{l}58 \\
\pm 0\end{array}$ & $\begin{array}{l}58 \\
\pm 1\end{array}$ & $\begin{array}{l}58 \\
\pm 1\end{array}$ & $\begin{array}{l}58 \\
\pm 0\end{array}$ & $\begin{array}{l}58 \\
\pm 0\end{array}$ & $\begin{array}{l}58 \\
\pm 0\end{array}$ & $\begin{array}{l}58 \\
\pm 0\end{array}$ \\
\hline $\mathrm{LM}_{\text {Final }}(\mathrm{g})$ & $\begin{array}{l}1100^{\mathrm{a}} \\
\pm 76\end{array}$ & $\begin{array}{l}1109^{\mathrm{ab}} \\
\pm 101\end{array}$ & $\begin{array}{l}1102^{\mathrm{a}} \\
\pm 67\end{array}$ & $\begin{array}{c}1175^{\mathrm{ab}} \\
\pm 79\end{array}$ & $\begin{array}{c}1208^{\mathrm{ab}} \\
\pm 42\end{array}$ & $\begin{array}{c}1175^{\mathrm{ab}} \\
\pm 41\end{array}$ & $\begin{array}{c}1200^{\mathrm{ab}} \\
\pm 54\end{array}$ & $\begin{array}{c}1249^{\mathrm{b}} \\
\pm 57\end{array}$ \\
\hline $\mathrm{LMZ}(\mathrm{g} / \mathrm{d})$ & $\begin{array}{l}50^{\mathrm{a}} \\
\pm 4\end{array}$ & $\begin{array}{l}50^{\mathrm{ab}} \\
\pm 5\end{array}$ & $\begin{array}{l}50^{\mathrm{a}} \\
\pm 3\end{array}$ & $\begin{array}{l}53^{\mathrm{ab}} \\
\pm 4\end{array}$ & $\begin{array}{l}55^{\mathrm{ab}} \\
\pm 2\end{array}$ & $\begin{array}{l}53^{\mathrm{ab}} \\
\pm 2\end{array}$ & $\begin{array}{l}54^{\mathrm{ab}} \\
\pm 3\end{array}$ & $\begin{array}{l}57^{\mathrm{b}} \\
\pm 3\end{array}$ \\
\hline FI (g TM/d) & $\begin{array}{c}64,0^{\text {abcd }} \\
\pm 3,6\end{array}$ & $\begin{array}{l}60,1^{\mathrm{ab}} \\
\pm 4,2\end{array}$ & $\begin{array}{c}61,2^{\mathrm{abc}} \\
\pm 2,7\end{array}$ & $\begin{array}{l}58,8^{\text {a }} \\
\pm 3,3\end{array}$ & $\begin{array}{l}66,0^{\mathrm{cd}} \\
\pm 1,8\end{array}$ & $\begin{array}{l}66,1^{\text {cd }} \\
\pm 2,1\end{array}$ & $\begin{array}{l}67,1^{\mathrm{d}} \\
\pm 0,9\end{array}$ & $\begin{array}{c}64,3^{\mathrm{bcd}} \\
\pm 2,7\end{array}$ \\
\hline $\begin{array}{c}\text { FA } \\
(\mathrm{g} \mathrm{FI} / \mathrm{g} \text { LMZ) }\end{array}$ & $\begin{array}{c}1,30^{\mathrm{a}} \\
\pm 0,12\end{array}$ & $\begin{array}{l}1,20^{\mathrm{abc}} \\
\pm 0,04\end{array}$ & $\begin{array}{l}1,23^{\mathrm{ab}} \\
\pm 0,05\end{array}$ & $\begin{array}{c}1,11^{\mathrm{c}} \\
\pm 0,24\end{array}$ & $\begin{array}{l}1,21^{\mathrm{abc}} \\
\pm 0,03\end{array}$ & $\begin{array}{c}1,24^{\mathrm{a}} \\
\pm 0,04\end{array}$ & $\begin{array}{l}1,24^{\mathrm{ab}} \\
\pm 0,06\end{array}$ & $\begin{array}{l}1,14^{\mathrm{bc}} \\
\pm 0,02\end{array}$ \\
\hline $\begin{array}{l}\text { Proteinaufwand } \\
\text { (g XPI / g } \\
\text { LMZ) }\end{array}$ & $\begin{array}{c}0,30^{\mathrm{a}} \\
\pm 0,03\end{array}$ & $\begin{array}{l}0,28^{\mathrm{abc}} \\
\pm 0,01\end{array}$ & $\begin{array}{l}0,28^{\mathrm{ab}} \\
\pm 0,01\end{array}$ & $\begin{array}{c}0,26^{\mathrm{c}} \\
\pm 0,01\end{array}$ & $\begin{array}{l}0,28^{\mathrm{abc}} \\
\pm 0,01\end{array}$ & $\begin{array}{c}0,29^{\mathrm{a}} \\
\pm 0,01\end{array}$ & $\begin{array}{l}0,28^{\mathrm{ab}} \\
\pm 0,02\end{array}$ & $\begin{array}{l}0,26^{\mathrm{bc}} \\
\pm 0,01\end{array}$ \\
\hline $\begin{array}{c}\text { Energieaufwand } \\
\text { (kJ ME / } \\
\text { g LMZ) }\end{array}$ & $\begin{array}{l}19,50^{\mathrm{a}} \\
\pm 1,85\end{array}$ & $\begin{array}{c}18,11^{\mathrm{abc}} \\
\pm 0,58\end{array}$ & $\begin{array}{l}18,57^{\mathrm{ab}} \\
\pm 0,70\end{array}$ & $\begin{array}{l}16,65^{\mathrm{c}} \\
\pm 0,37\end{array}$ & $\begin{array}{c}18,16^{\mathrm{abc}} \\
\pm 0,41\end{array}$ & $\begin{array}{l}18,73^{\mathrm{a}} \\
\pm 0,58\end{array}$ & $\begin{array}{l}18,64^{\mathrm{ab}} \\
\pm 0,89\end{array}$ & $\begin{array}{l}17,10^{\mathrm{bc}} \\
\pm 0,29\end{array}$ \\
\hline \multicolumn{9}{|c|}{ Growerphase (Tag 22-35) } \\
\hline $\mathrm{LM}_{\text {Final }}(\mathrm{g})$ & $\begin{array}{l}2407^{\mathrm{ab}} \\
\pm 192\end{array}$ & $\begin{array}{l}2383^{\mathrm{ab}} \\
\pm 223\end{array}$ & $\begin{array}{l}2272^{\mathrm{a}} \\
\pm 141\end{array}$ & $\begin{array}{l}2656^{\mathrm{bc}} \\
\pm 173\end{array}$ & $\begin{array}{l}2641^{\mathrm{bc}} \\
\pm 103\end{array}$ & $\begin{array}{l}2491^{\mathrm{ab}} \\
\pm 133\end{array}$ & $\begin{array}{l}2529^{\mathrm{ab}} \\
\pm 162\end{array}$ & $\begin{array}{l}2849^{c} \\
\pm 142\end{array}$ \\
\hline $\operatorname{LMZ}(\mathrm{g} / \mathrm{d})$ & $\begin{array}{l}93^{\mathrm{ab}} \\
\pm 10\end{array}$ & $\begin{array}{l}91^{\mathrm{ab}} \\
\pm 10\end{array}$ & $\begin{array}{l}84^{\mathrm{a}} \\
\pm 8\end{array}$ & $\begin{array}{c}106^{\mathrm{bc}} \\
\pm 7\end{array}$ & $\begin{array}{c}102^{\mathrm{bc}} \\
\pm 5\end{array}$ & $\begin{array}{l}94^{\mathrm{ab}} \\
\pm 7\end{array}$ & $\begin{array}{l}95^{\mathrm{ab}} \\
\pm 8\end{array}$ & $\begin{array}{l}116^{\mathrm{c}} \\
\pm 10\end{array}$ \\
\hline $\mathrm{FI}(\mathrm{g} \mathrm{TM} / \mathrm{d})$ & $\begin{array}{c}158,5^{\mathrm{b}} \\
\pm 8,0\end{array}$ & $\begin{array}{c}145,6^{\mathrm{ab}} \\
\pm 8,1\end{array}$ & $\begin{array}{c}140,1^{\mathrm{a}} \\
\pm 8,0\end{array}$ & $\begin{array}{l}140,3^{\mathrm{a}} \\
\pm 10,1\end{array}$ & $\begin{array}{c}158,9^{\mathrm{b}} \\
\pm 4,9\end{array}$ & $\begin{array}{c}152,0^{\mathrm{ab}} \\
\pm 8,1\end{array}$ & $\begin{array}{c}154,4^{\mathrm{ab}} \\
\pm 9,9\end{array}$ & $\begin{array}{c}159,5^{\mathrm{b}} \\
\pm 7,8\end{array}$ \\
\hline $\begin{array}{c}\text { FA } \\
(\mathrm{g} \mathrm{FI} / \mathrm{g} \mathrm{LMZ})\end{array}$ & $\begin{array}{l}1,71^{\mathrm{a}} \\
\pm 0,17\end{array}$ & $\begin{array}{r}1,61^{\mathrm{a}} \\
\pm 0,11\end{array}$ & $\begin{array}{r}1,68^{\mathrm{a}} \\
\pm 0,09\end{array}$ & $\begin{array}{r}1,33^{\mathrm{c}} \\
\pm 0,07\end{array}$ & $\begin{array}{l}1,55^{\mathrm{ab}} \\
\pm 0,03\end{array}$ & $\begin{array}{c}1,62^{\mathrm{a}} \\
\pm 0,05\end{array}$ & $\begin{array}{c}1,63^{\mathrm{a}} \\
\pm 0,06\end{array}$ & $\begin{array}{l}1,39^{\mathrm{bc}} \\
\pm 0,10\end{array}$ \\
\hline $\begin{array}{l}\text { Proteinaufwand } \\
\text { (g XPI / g } \\
\text { LMZ) }\end{array}$ & $\begin{array}{c}0,37^{\mathrm{a}} \\
\pm 0,04\end{array}$ & $\begin{array}{c}0,34^{\mathrm{a}} \\
\pm 0,02\end{array}$ & $\begin{array}{c}0,36^{\mathrm{a}} \\
\pm 0,02\end{array}$ & $\begin{array}{c}0,28^{\mathrm{b}} \\
\pm 0,01\end{array}$ & $\begin{array}{c}0,33^{\mathrm{a}} \\
\pm 0,01\end{array}$ & $\begin{array}{c}0,35^{\mathrm{a}} \\
\pm 0,01\end{array}$ & $\begin{array}{r}0,35^{\mathrm{a}} \\
\pm 0,01\end{array}$ & $\begin{array}{c}0,30^{\mathrm{b}} \\
\pm 0,02\end{array}$ \\
\hline $\begin{array}{c}\text { Energieaufwand } \\
\text { (kJ ME / } \\
\text { g LMZ) }\end{array}$ & $\begin{array}{l}25,69^{\mathrm{a}} \\
\pm 2,53\end{array}$ & $\begin{array}{l}24,16^{\mathrm{a}} \\
\pm 1,63\end{array}$ & $\begin{array}{l}25,27^{\mathrm{a}} \\
\pm 1,35\end{array}$ & $\begin{array}{l}19,91^{\mathrm{c}} \\
\pm 1,01\end{array}$ & $\begin{array}{l}23,36^{\text {ab }} \\
\pm 0,45\end{array}$ & $\begin{array}{l}24,35^{\mathrm{a}} \\
\pm 0,81\end{array}$ & $\begin{array}{l}24,50^{\mathrm{a}} \\
\pm 0,85\end{array}$ & $\begin{array}{l}20,84^{\mathrm{bc}} \\
\pm 1,45\end{array}$ \\
\hline
\end{tabular}

Angaben als Mittelwerte \pm Standardabweichung, unterschiedliche Hochbuchstaben kennzeichnen signifikante Unterschiede (p $<0,05)$. 
Die Betrachtung der gesamten Versuchsphase (Tab. 31) zeigte, dass, ebenso wie in den einzelnen Versuchsphasen, Versuchsgruppe H (HM pK) die höchste finale LM und tägliche LMZ aufwies und zu den Versuchsgruppen D (TMP pK) und E (HM 50:50) nur numerische Unterschiede bestanden. Zwischen den anderen Versuchsgruppen gab es ebenfalls keine signifikanten Unterschiede, die tendenziell niedrigste finale LM und tägliche LMZ wurden jedoch in Versuchsgruppe C (TMP 60:40) beobachtet. Die höchste FI wurde in Versuchsgruppe E (HM 50:50) festgestellt, sie unterschied sich jedoch nur numerisch von den Werten in den Versuchsgruppen A (TMP 50:50), F (HM 55:45), G (HM 60:40) und H (HM pK). Die niedrigste FI wies Versuchsgruppe D (TMP pK) ohne signifikante Unterschiede zu den Versuchsgruppen B (TMP 55:45) und C (TMP 60:40) auf. Ebenso wie in den einzelnen Versuchsphasen wurden sowohl der niedrigste FA als auch der niedrigste Protein- und Energieaufwand in Versuchsgruppe D (TMP pK) festgestellt, sie unterschieden sich jedoch nur in der Tendenz von den in Versuchsgruppe H ( $\mathrm{HM} \mathrm{pK)} \mathrm{ermittelten} \mathrm{Werten.} \mathrm{Alle} \mathrm{anderen} \mathrm{Versuchsgruppen} \mathrm{wiesen}$ signifikant $(\mathrm{p}<0,05)$ höhere Werte auf, unterschieden sich dabei aber nicht signifikant voneinander.

Tabelle 31: Ergebnisse der zootechnischen Parameter des gesamten Versuchs 3 (Tag 1-35).

\begin{tabular}{|c|c|c|c|c|c|c|c|c|}
\hline Met:Cys & $\begin{array}{c}\text { A } \\
\text { TMP } \\
50: 50\end{array}$ & $\begin{array}{c}\text { B } \\
\text { TMP } \\
55: 45\end{array}$ & $\begin{array}{c}\mathrm{C} \\
\text { TMP } \\
60: 40\end{array}$ & $\begin{array}{c}\text { D } \\
\text { TMP } \\
\text { pK }\end{array}$ & $\begin{array}{c}\mathbf{E} \\
\mathrm{HM} \\
\mathbf{5 0 : 5 0}\end{array}$ & $\begin{array}{c}\text { F } \\
\text { HM } \\
55: 45\end{array}$ & $\begin{array}{c}\text { G } \\
\text { HM } \\
60: 40\end{array}$ & $\begin{array}{c}\text { H } \\
\text { HM } \\
\text { pK }\end{array}$ \\
\hline $\mathrm{LM}_{\text {Beginn }}(\mathrm{g})$ & $\begin{array}{c}58 \\
\pm 0\end{array}$ & $\begin{array}{c}58 \\
\pm 0\end{array}$ & $\begin{array}{r}58 \\
\pm 1\end{array}$ & $\begin{array}{r}58 \\
\pm 1\end{array}$ & $\begin{array}{l}58 \\
\pm 0\end{array}$ & $\begin{array}{c}58 \\
\pm 0\end{array}$ & $\begin{array}{l}58 \\
\pm 0\end{array}$ & $\begin{array}{l}58 \\
\pm 0\end{array}$ \\
\hline $\mathrm{LM}_{\text {Final }}(\mathrm{g})$ & $\begin{array}{l}2407^{\mathrm{ab}} \\
\pm 192\end{array}$ & $\begin{array}{l}2383^{\mathrm{ab}} \\
\pm 223\end{array}$ & $\begin{array}{l}2272^{\mathrm{a}} \\
\pm 141\end{array}$ & $\begin{array}{c}2656^{\mathrm{bc}} \\
\pm 173\end{array}$ & $\begin{array}{c}2641^{\mathrm{bc}} \\
\pm 103\end{array}$ & $\begin{array}{l}2491^{\mathrm{ab}} \\
\pm 133\end{array}$ & $\begin{array}{l}2529^{\mathrm{ab}} \\
\pm 162\end{array}$ & $\begin{array}{l}2849^{\circ} \\
\pm 142\end{array}$ \\
\hline $\operatorname{LMZ}(\mathrm{g} / \mathrm{d})$ & $\begin{array}{l}67^{\mathrm{ab}} \\
\pm 6\end{array}$ & $\begin{array}{l}66^{\mathrm{ab}} \\
\pm 6\end{array}$ & $\begin{array}{l}63^{\mathrm{a}} \\
\pm 4\end{array}$ & $\begin{array}{l}74^{\mathrm{bc}} \\
\pm 5\end{array}$ & $\begin{array}{l}74^{\mathrm{bc}} \\
\pm 3\end{array}$ & $\begin{array}{l}70^{\mathrm{ab}} \\
\pm 4\end{array}$ & $\begin{array}{l}71^{\mathrm{ab}} \\
\pm 5\end{array}$ & $\begin{array}{l}80^{c} \\
\pm 4\end{array}$ \\
\hline $\mathrm{FI}(\mathrm{g}$ TM/d) & $\begin{array}{l}101,8^{c} \\
\pm \\
\pm 5,1\end{array}$ & $\begin{array}{c}94,3^{\mathrm{abc}} \\
\pm 5,0\end{array}$ & $\begin{array}{c}92,8^{\mathrm{ab}} \\
\pm 3,7\end{array}$ & $\begin{array}{l}91,4^{\mathrm{a}} \\
\pm 5,2\end{array}$ & $\begin{array}{l}103,1^{\mathrm{d}} \\
\pm 3,0\end{array}$ & $\begin{array}{c}100,5^{\mathrm{bcd}} \\
\pm 4,1\end{array}$ & $\begin{array}{c}102,0^{\mathrm{cd}} \\
\pm 4,2\end{array}$ & $\begin{array}{l}102,4^{\mathrm{d}} \\
\pm 3,8\end{array}$ \\
\hline $\begin{array}{c}\text { FA } \\
(\mathrm{g} \text { FI /g LMZ) }\end{array}$ & $\begin{array}{r}1,52^{\mathrm{a}} \\
\pm 0,11\end{array}$ & $\begin{array}{r}1,43^{\mathrm{a}} \\
\pm 0,07\end{array}$ & $\begin{array}{c}1,47^{\mathrm{a}} \\
\pm 0,06\end{array}$ & $\begin{array}{r}1,23^{\mathrm{b}} \\
\pm 0,04\end{array}$ & $\begin{array}{r}1,40^{\mathrm{a}} \\
\pm 0,02\end{array}$ & $\begin{array}{l}1,45^{\mathrm{a}} \\
\pm 0,04\end{array}$ & $\begin{array}{r}1,45^{\mathrm{a}} \\
\pm 0,04\end{array}$ & $\begin{array}{l}1,29^{\mathrm{b}} \\
\pm 0,05\end{array}$ \\
\hline $\begin{array}{l}\text { Proteinaufwand } \\
\text { (g XPI / g LMZ) }\end{array}$ & $\begin{array}{r}0,34^{\mathrm{a}} \\
\pm 0,24\end{array}$ & $\begin{array}{r}0,32^{\mathrm{a}} \\
\pm 0,15\end{array}$ & $\begin{array}{c}0,32^{\mathrm{a}} \\
\pm 0,12\end{array}$ & $\begin{array}{l}0,27^{\mathrm{b}} \\
\pm 0,01\end{array}$ & $\begin{array}{l}0,31^{\mathrm{a}} \\
\pm 0,01\end{array}$ & $\begin{array}{r}0,32^{\mathrm{a}} \\
\pm 0,01\end{array}$ & $\begin{array}{c}0,32^{\mathrm{a}} \\
\pm 0,01\end{array}$ & $\begin{array}{r}0,28^{\mathrm{b}} \\
\pm 0,01\end{array}$ \\
\hline $\begin{array}{c}\text { Energieaufwand } \\
(\mathrm{kJ} \text { ME / } \\
\text { g LMZ) }\end{array}$ & $\begin{array}{l}22,88^{\mathrm{a}} \\
\pm 1,65\end{array}$ & $\begin{array}{l}21,40^{\mathrm{a}} \\
\pm 1,08\end{array}$ & $\begin{array}{l}22,08^{\mathrm{a}} \\
\pm 0,84\end{array}$ & $\begin{array}{l}18,51^{b} \\
\pm 0,63\end{array}$ & $\begin{array}{l}21,03^{\mathrm{a}} \\
\pm 0,27\end{array}$ & $\begin{array}{l}21,77^{\mathrm{a}} \\
\pm 0,61\end{array}$ & $\begin{array}{l}21,78^{\mathrm{a}} \\
\pm 0,68\end{array}$ & $\begin{array}{l}19,34^{\mathrm{b}} \\
\pm 0,70\end{array}$ \\
\hline
\end{tabular}

Angaben als Mittelwerte \pm Standardabweichung, unterschiedliche Hochbuchstaben kennzeichnen signifikante Unterschiede (p $<0,05)$. 


\subsubsection{Scheinbare praecaecale Verdaulichkeit}

In Versuch 3 wurde die scheinbare pcV des XP und ausgewählter AS für zwei ausgewählte Versuchsmischungen festgestellt. Die ermittelten Werte (Tab. 32) lagen zwischen ca. 76 und 90\%, wobei die höchsten Werte für Met und die niedrigsten Werte für Valin (Val) beobachtet wurden. Die scheinbare pcV des XP war in Versuchsgruppe D (TMP pK) signifikant ( $<<0,05)$ höher als in Versuchsgruppe $\mathrm{H}(\mathrm{HM} \mathrm{pK})$. Zwischen den Werte für die scheinbare $\mathrm{pcV}$ ausgewählter AS gab es dagegen mit Ausnahme von Histidin (His) nur numerische Unterschiede. Tendenziell lag die scheinbare pcV der AS in Versuchsgruppe D (TMP pK) jedoch über Versuchsgruppe H (HM pK). Im Fall von His war dieser Unterschied signifikant $(\mathrm{p}<0,05)$.

Tabelle 32: Mittlere Ergebnisse zur scheinbaren praecaecalen Verdaulichkeit (\%) des Rohproteins und ausgewählter Aminosäuren der Futtermischungen der Versuchsgruppen D (TMP pK) und H (HM pK) in Versuch 3.

\begin{tabular}{ccc}
\hline & D & H \\
Met:Cys & TMP & HM \\
& pK & pK \\
\hline \multirow{2}{*}{ XP } & $80,2^{\mathrm{b}}$ & $76,3^{\mathrm{a}}$ \\
& $\pm 1,3$ & $\pm 1,5$ \\
Lys & 87,2 & 85,9 \\
& $\pm 0,3$ & $\pm 1,2$ \\
Met & 90,3 & 90,7 \\
& $\pm 0,2$ & $\pm 1,4$ \\
Cys & 83,7 & 80,8 \\
& $\pm 2,8$ & $\pm 1,0$ \\
Thr & 79,0 & 77,4 \\
& $\pm 1,3$ & $\pm 1,9$ \\
Arg & 89,7 & 89,6 \\
& $\pm 0,9$ & $\pm 1,4$ \\
His & $82,5^{\mathrm{b}}$ & $78,2^{\mathrm{a}}$ \\
& $\pm 0,9$ & $\pm 1,4$ \\
Ile & 83,3 & 82,7 \\
& $\pm 0,4$ & $\pm 1,8$ \\
Leu & 85,0 & 84,0 \\
& $\pm 0,5$ & $\pm 1,8$ \\
Phe & 84,2 & 82,7 \\
& $\pm 0,4$ & $\pm 2,0$ \\
Val & 77,3 & 75,4 \\
& $\pm 1,4$ & $\pm 2,0$ \\
\hline
\end{tabular}

Angaben als Mittelwerte \pm Standardabweichung, unterschiedliche Hochbuchstaben kennzeichnen signifikante Unterschiede (p $<0,05)$. 


\subsubsection{Proteinqualität und Met-Wirksamkeit}

In der Starterphase von Versuch 3 (Tab. 33) wurde der höchste N-Ansatz in Versuchsgruppe D (TMP pK) und G (HM 60:40) beobachtet, es gab jedoch nur numerische Unterschiede zu Versuchsgruppe $\mathrm{F}$ ( $\mathrm{HM}$ 55:45) und $\mathrm{H}(\mathrm{HM} \mathrm{pK})$. Den niedrigsten $\mathrm{N}$-Ansatz wies Versuchsgruppe A (TMP 50:50) auf und unterschied sich signifikant $(\mathrm{p}<0,05)$ von allen anderen Versuchsgruppen außer B (TMP 55:45). Die Proteinqualitätsparameter ( $b$, PNu, $\left.\mathrm{PNu}_{\text {std. }}\right)$ waren in Versuchsgruppe D (TMP pK) signifikant $(\mathrm{p}<0,05)$ am höchsten. Ein signifikant $(\mathrm{p}<0,05)$ geringerer Wert wurde in Versuchsgruppe H $(\mathrm{HM} \mathrm{pK})$ ermittelt, er unterschied sich aber nur numerisch von den in Versuchsgruppe C (TMP 60:40) und G (HM 60:40) berechneten Proteinqualitätsparametern. Die niedrigste Proteinqualität wurde in Versuchsgruppe A (TMP 50:50) festgestellt, jedoch nur mit tendenziellen Unterschieden zu Versuchsgruppe B (TMP 55:45).

In der Growerphase wies Versuchsgruppe $\mathrm{H}$ ( $\mathrm{HM} \mathrm{pK})$ den höchsten N-Ansatz auf und unterschied sich nur numerisch von Versuchsgruppe D (TMP pK). Der niedrigste N-Ansatz wurde in Versuchsgruppe C (TMP 60:40) beobachtet, jedoch ohne signifikante $(\mathrm{p}<0,05)$ Unterschiede zu Versuchsgruppe F (HM 55:45) und G (HM 60:40). Auch zwischen den Versuchsgruppen A (TMP 50:50), B (TMP 55:45), E (HM 50:50), F (HM 55:45) und G (HM 60:40) gab es nur numerische Unterschiede. Die signifikant $(\mathrm{p}<0,05)$ höchste Proteinqualität ( $b$, $\mathrm{PNu}, \mathrm{PNu}_{\text {std. }}$ ) wurde in Versuchsgruppe $\mathrm{D}$ (TMP $\left.\mathrm{pK}\right)$ und $\mathrm{H}(\mathrm{HM} \mathrm{pK})$ beobachtet. Von den anderen Versuchsgruppen unterschieden sich nur Versuchsgruppe B (TMP 55:45) und C (TMP 60:40) signifikant $(\mathrm{p}<0,05)$ voneinander.

Bezogen auf die gesamte Versuchsdauer wiesen Versuchsgruppe D (TMP pK) und H (HM pK) den signifikant $(\mathrm{p}<0,05)$ höchsten N-Ansatz auf, während es zwischen allen anderen Versuchsgruppen keine signifikanten Unterschiede gab. Auch die Proteinqualität (b, PNu, $\mathrm{PNu}_{\text {std. }}$ ) war in Versuchsgruppe $\mathrm{D}$ (TMP pK) und $\mathrm{H}(\mathrm{HM} \mathrm{pK})$ signifikant $(\mathrm{p}<0,05)$ am höchsten und es gab nur numerische Unterschiede zwischen den anderen Versuchsgruppen. 
Tabelle 33: Ergebnisse der Proteinqualität in Versuch 3.

\begin{tabular}{|c|c|c|c|c|c|c|c|c|}
\hline Met:Cys & $\begin{array}{c}\text { A } \\
\text { TMP } \\
\mathbf{5 0 : 5 0}\end{array}$ & $\begin{array}{c}\text { B } \\
\text { TMP } \\
55: 45\end{array}$ & $\begin{array}{c}C \\
\text { TMP } \\
60: 40\end{array}$ & $\begin{array}{c}\text { D } \\
\text { TMP } \\
\text { pK }\end{array}$ & $\begin{array}{c}\mathbf{E} \\
\text { HM } \\
\mathbf{5 0 : 5 0}\end{array}$ & $\begin{array}{c}\text { F } \\
\text { HM } \\
55: 45\end{array}$ & $\begin{array}{c}G \\
\text { HM } \\
60: 40\end{array}$ & $\begin{array}{c}\text { H } \\
\text { HM } \\
\mathbf{p K}\end{array}$ \\
\hline \multicolumn{9}{|c|}{ Starterphase (Tag 1-21) } \\
\hline $\mathrm{c}_{\text {Met }}(\mathrm{g} / 16 \mathrm{gN})$ & 1,664 & 1,830 & 1,995 & 2,525 & 1,647 & 1,810 & 1,974 & 2,507 \\
\hline $\begin{array}{c}\mathrm{ND} \\
\left(\mathrm{mg} / \mathrm{LM}_{\mathrm{kg}}^{0,67} / \mathrm{d}\right)\end{array}$ & $\begin{array}{c}1659^{\mathrm{a}} \\
\pm 47\end{array}$ & $\begin{array}{c}1670^{\mathrm{ab}} \\
\pm 64\end{array}$ & $\begin{array}{c}1746^{\mathrm{bc}} \\
\pm 45\end{array}$ & $\begin{array}{l}1871^{\mathrm{e}} \\
\pm 51\end{array}$ & $\begin{array}{c}1762^{\mathrm{cd}} \\
\pm 25\end{array}$ & $\begin{array}{c}1806^{\text {cde }} \\
\pm 25\end{array}$ & $\begin{array}{l}1852^{\mathrm{e}} \\
\pm 35\end{array}$ & $\begin{array}{c}1825^{\mathrm{de}} \\
\pm 33\end{array}$ \\
\hline $\begin{array}{l}\text { Modell- } \\
\text { parameter } \\
b\left(* 10^{6}\right)\end{array}$ & $\begin{array}{l}178^{\mathrm{a}} \\
\pm 16\end{array}$ & $\begin{array}{c}192^{\mathrm{ab}} \\
\pm 7\end{array}$ & $\begin{array}{c}198^{\mathrm{bc}} \\
\pm 8\end{array}$ & $\begin{array}{c}233^{\mathrm{d}} \\
\pm 7\end{array}$ & $\begin{array}{l}195^{\mathrm{b}} \\
\pm 5\end{array}$ & $\begin{array}{c}197^{\mathrm{b}} \\
\pm 7\end{array}$ & $\begin{array}{l}203^{b c} \\
\pm 10\end{array}$ & $\begin{array}{r}214^{\mathrm{c}} \\
\pm 4\end{array}$ \\
\hline $\mathrm{PNu}(\%)$ & $\begin{array}{l}56,9^{\mathrm{a}} \\
\pm 4,7\end{array}$ & $\begin{array}{l}61,1^{\mathrm{ab}} \\
\pm 1,7\end{array}$ & $\begin{array}{l}62,1^{b c} \\
\pm 2,2\end{array}$ & $\begin{array}{l}71,4^{\mathrm{d}} \\
\pm 1,4\end{array}$ & $\begin{array}{l}61,0^{\mathrm{ab}} \\
\pm 1,3\end{array}$ & $\begin{array}{c}61,2^{\mathrm{ab}} \\
\pm 1,9\end{array}$ & $\begin{array}{l}62,5^{\mathrm{bc}} \\
\pm 2,8\end{array}$ & $\begin{array}{l}66,1^{\mathrm{c}} \\
\pm 1,1\end{array}$ \\
\hline $\mathrm{PNu}_{\text {std. }}(\%)$ & $\begin{array}{l}57,0^{\mathrm{a}} \\
\pm 3,9\end{array}$ & $\begin{array}{l}60,2^{\mathrm{ab}} \\
\pm 1,7\end{array}$ & $\begin{array}{l}61,5^{\text {bc }} \\
\pm 1,8\end{array}$ & $\begin{array}{l}69,0^{\mathrm{d}} \\
\pm 1,3\end{array}$ & $\begin{array}{l}60,9^{\mathrm{b}} \\
\pm 1,1\end{array}$ & $\begin{array}{l}61,4^{\mathrm{b}} \\
\pm 1,5\end{array}$ & $\begin{array}{l}62,8^{b c} \\
\pm 2,3\end{array}$ & $\begin{array}{l}65,0^{\mathrm{c}} \\
\pm 0,9\end{array}$ \\
\hline
\end{tabular}

\section{Growerphase (Tag 22-35)}

$\begin{array}{llllllll}\mathrm{c}_{\text {Met }}(\mathrm{g} / 16 \mathrm{gN}) & 1,662 & 1,825 & 1,992 & 2,518 & 1,644 & 1,805 & 1,971\end{array}$

\begin{tabular}{|c|c|c|c|c|c|c|c|c|}
\hline $\begin{array}{c}\mathrm{ND} \\
\left(\mathrm{mg} / \mathrm{LM}_{\mathrm{kg}}^{0,67} / \mathrm{d}\right)\end{array}$ & $\begin{array}{l}1837^{\mathrm{bc}} \\
\pm 125\end{array}$ & $\begin{array}{l}1805^{\mathrm{bc}} \\
\pm 110\end{array}$ & $\begin{array}{l}1592^{a} \\
\pm 109\end{array}$ & $\begin{array}{l}1851^{\mathrm{cd}} \\
\pm 53\end{array}$ & $\begin{array}{c}1778^{\mathrm{bc}} \\
\pm 45\end{array}$ & $\begin{array}{c}1701^{\mathrm{abc}} \\
\pm 75\end{array}$ & $\begin{array}{c}1675^{\mathrm{ab}} \\
\pm 86\end{array}$ & $\begin{array}{l}2015^{\mathrm{d}} \\
\pm 90\end{array}$ \\
\hline $\begin{array}{l}\text { Modell- } \\
\text { parameter } \\
b\left(* 10^{6}\right)\end{array}$ & $\begin{array}{l}254^{\mathrm{ab}} \\
\pm 27\end{array}$ & $\begin{array}{l}268^{b} \\
\pm 25\end{array}$ & $\begin{array}{l}229^{a} \\
\pm 15\end{array}$ & $\begin{array}{l}306^{\mathrm{c}} \\
\pm 17\end{array}$ & $\begin{array}{c}253^{\mathrm{ab}} \\
\pm 7\end{array}$ & $\begin{array}{l}241^{\mathrm{ab}} \\
\pm 11\end{array}$ & $\begin{array}{l}235^{\mathrm{ab}} \\
\pm 12\end{array}$ & $\begin{array}{l}319^{c} \\
\pm 22\end{array}$ \\
\hline $\mathrm{PNu}(\%)$ & $\begin{array}{l}56,7^{\mathrm{ab}} \\
\pm 4,3\end{array}$ & $\begin{array}{l}60,5^{\mathrm{b}} \\
\pm 3,8\end{array}$ & $\begin{array}{l}55,0^{\mathrm{a}} \\
\pm 2,3\end{array}$ & $\begin{array}{l}68,3^{\mathrm{c}} \\
\pm 3,5\end{array}$ & $\begin{array}{l}57,9^{\mathrm{ab}} \\
\pm 0,8\end{array}$ & $\begin{array}{l}56,3^{\mathrm{ab}} \\
\pm 1,6\end{array}$ & $\begin{array}{l}55,4^{\mathrm{ab}} \\
\pm 1,6\end{array}$ & $\begin{array}{l}67,4^{\mathrm{c}} \\
\pm 3,1\end{array}$ \\
\hline $\mathrm{PNu}_{\text {std. }}(\%)$ & $\begin{array}{l}60,9^{\mathrm{ab}} \\
\pm 4,5\end{array}$ & $\begin{array}{l}63,2^{\mathrm{b}} \\
\pm 3,7\end{array}$ & $\begin{array}{l}56,9^{\mathrm{a}} \\
\pm 2,6\end{array}$ & $\begin{array}{l}68,8^{\mathrm{c}} \\
\pm 2,3\end{array}$ & $\begin{array}{l}61,0^{\mathrm{ab}} \\
\pm 1,1\end{array}$ & $\begin{array}{l}59,1^{\mathrm{ab}} \\
\pm 1,8\end{array}$ & $\begin{array}{l}58,1^{\mathrm{ab}} \\
\pm 2,0\end{array}$ & $\begin{array}{l}70,6^{\mathrm{c}} \\
\pm 2,9\end{array}$ \\
\hline
\end{tabular}

\section{Gesamte Versuchsphase (Tag 1-35)}

$\begin{array}{ccccccccc}\mathrm{c}_{\text {Met }}(\mathrm{g} / 16 \mathrm{gN}) & 1,663 & 1,827 & 1,993 & 2,521 & 1,645 & 1,807 & 1,972 & 2,505 \\ & & & & & & & & \\ \mathrm{ND} & 1744^{\mathrm{a}} & 1730^{\mathrm{a}} & 1697^{\mathrm{a}} & 1871^{\mathrm{b}} & 1754^{\mathrm{a}} & 1757^{\mathrm{a}} & 1767^{\mathrm{a}} & 1901^{\mathrm{b}} \\ \left(\mathrm{mg} / \mathrm{LM}{ }_{\mathrm{kg}}^{0,67} / \mathrm{d}\right) & \pm 61 & \pm 66 & \pm 47 & \pm 46 & \pm 28 & \pm 41 & \pm 51 & \pm 41 \\ \text { Modell- } & 210^{\mathrm{a}} & 223^{\mathrm{a}} & 216^{\mathrm{a}} & 266^{\mathrm{b}} & 218^{\mathrm{a}} & 217^{\mathrm{a}} & 218^{\mathrm{a}} & 254^{\mathrm{b}} \\ \left.\text { parameter }^{*}{ }^{*} 10^{6}\right) & \pm 16 & \pm 12 & \pm 9 & \pm 9 & \pm 4 & \pm 7 & \pm 9 & \pm 9 \\ & & & & & & & & \\ \mathrm{PNu}(\%) & 57,2^{\mathrm{a}} & 61,0^{\mathrm{a}} & 59,6^{\mathrm{a}} & 70,4^{\mathrm{b}} & 59,3^{\mathrm{a}} & 59,0^{\mathrm{a}} & 59,2^{\mathrm{a}} & 66,6^{\mathrm{b}} \\ & \pm 3,9 & \pm 2,5 & \pm 2,0 & \pm 1,8 & \pm 0,8 & \pm 1,6 & \pm 1,8 & \pm 1,8 \\ \mathrm{PNu}_{\text {std. }}(\%) & 58,6^{\mathrm{a}} & 61,2^{\mathrm{a}} & 59,9^{\mathrm{a}} & 68,8^{\mathrm{b}} & 60,2^{\mathrm{a}} & 60,0^{\mathrm{a}} & 60,3^{\mathrm{a}} & 66,7^{\mathrm{b}} \\ & \pm 3,3 & \pm 2,3 & \pm 1,8 & \pm 1,5 & \pm 0,7 & \pm 1,4 & \pm 1,8 & \pm 1,5\end{array}$

Angaben als Mittelwerte \pm Standardabweichung, unterschiedliche Hochbuchstaben kennzeichnen signifikante Unterschiede (p $<0,05)$. 
Die Ergebnisse der Met-Wirksamkeitsbewertung zeigen die Abbildungen 21-23. Die höchste Met-Wirksamkeit $(\mathrm{p}<0,05)$ in der Starterphase wurde in Versuchsgruppe E (HM 50:50) erreicht (Abb. 21). Es gab keine signifikanten Unterschiede zwischen den Versuchsgruppen A (TMP 50:50), B (TMP 55:45), F (HM 55:45) und G (HM 60:40). Die niedrigste MetWirksamkeit $(\mathrm{p}<0,05)$ wies Versuchsgruppe H (HM pK) auf, jedoch nur mit numerischen Unterschieden zu Versuchsgruppe D (TMP pK).

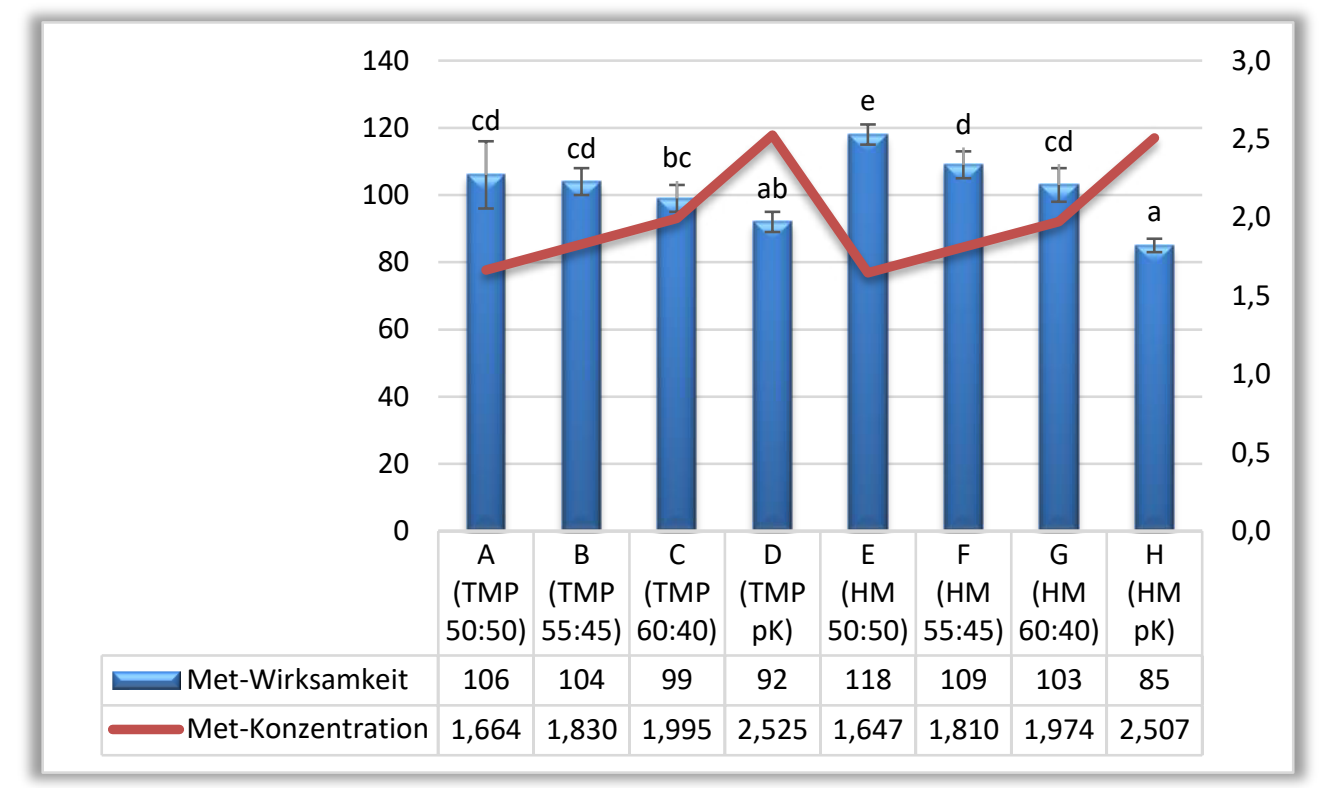

\section{Abbildung 21: Met-Wirksamkeit $\left(b c^{-1}\right)$ und Met-Konzentration (g/16gN) in der Starterphase (Tag 1-21) von Versuch 3. Angaben als Mittelwerte \pm Standardabweichung, unterschiedliche Buchstaben kennzeichnen signifikante Unterschiede $(\mathbf{p}<0,05)$.}

In der Growerphase (Abb. 22) war die Met-Wirksamkeit in Versuchsgruppe A (TMP 50:50) und E (HM 50:50) am höchsten, es gab jedoch nur in der Tendenz Unterschiede zu Versuchsgruppe B (TMP 55:45). Der niedrigste Wert wurde in Versuchsgruppe C (TMP 60:40) beobachtet, er unterschied sich aber nicht signifikant von Versuchsgruppe D (TMP pK), G (HM 60:40) und $\mathrm{H}(\mathrm{HM} \mathrm{pK})$. 


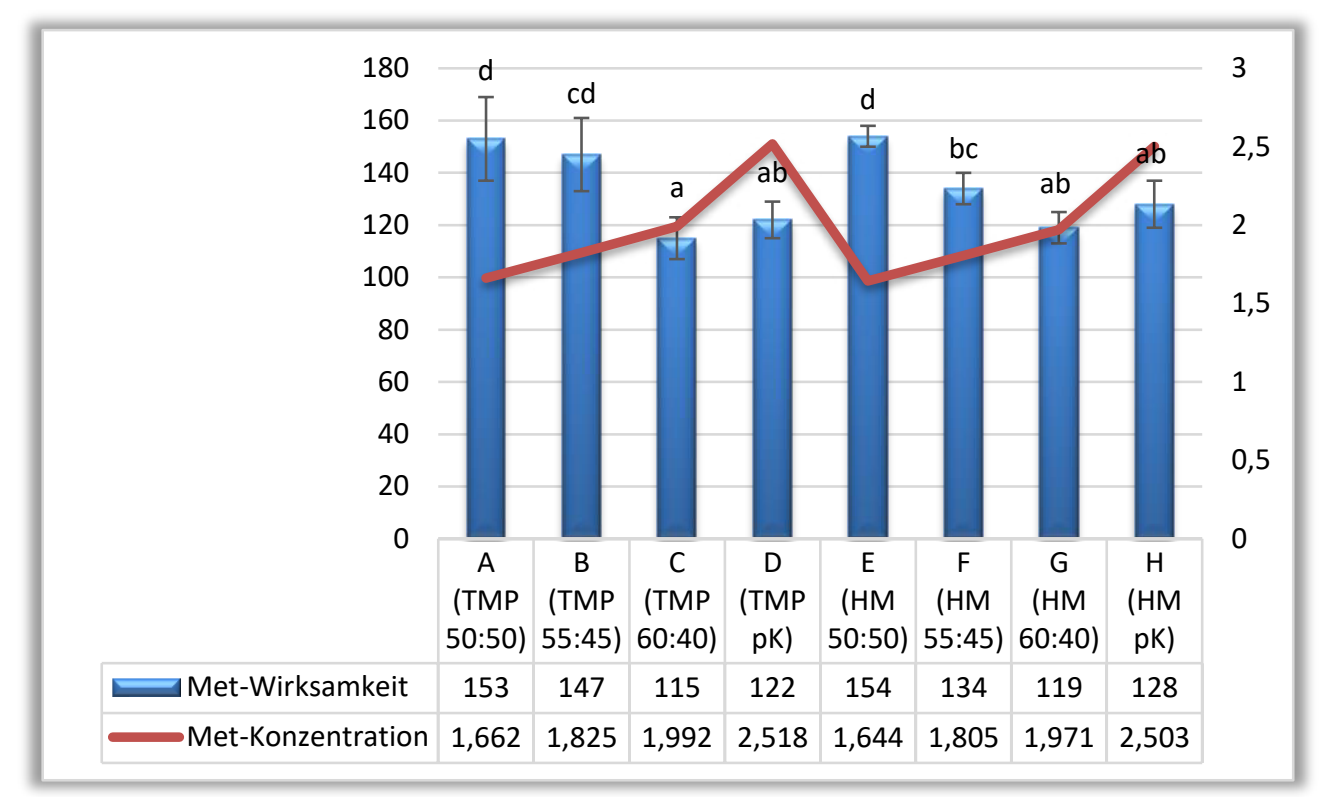

Abbildung 22: Met-Wirksamkeit $\left(b c^{-1}\right)$ und Met-Konzentration (g/16gN) in der Growerphase (Tag 22-35) von Versuch 3. Angaben als Mittelwerte \pm Standardabweichung, unterschiedliche Buchstaben kennzeichnen signifikante Unterschiede $(\mathbf{p}<0,05)$.

Bezogen auf den gesamten Versuchszeitraum (Abb. 23) wurde die höchste Met-Wirksamkeit in Versuchsgruppe E (HM 50:50) beobachtet. Es gab jedoch keine signifikanten Unterschiede zu Versuchsgruppe A (TMP 50:50) und B (TMP 55:45). Versuchsgruppe H (HM pK) wies den niedrigsten Wert für die Met-Wirksamkeit auf, er unterschied sich aber nur numerisch von den in Versuchsgruppe C (TMP 60:40) und D (TMP pK) ermittelten Werten.

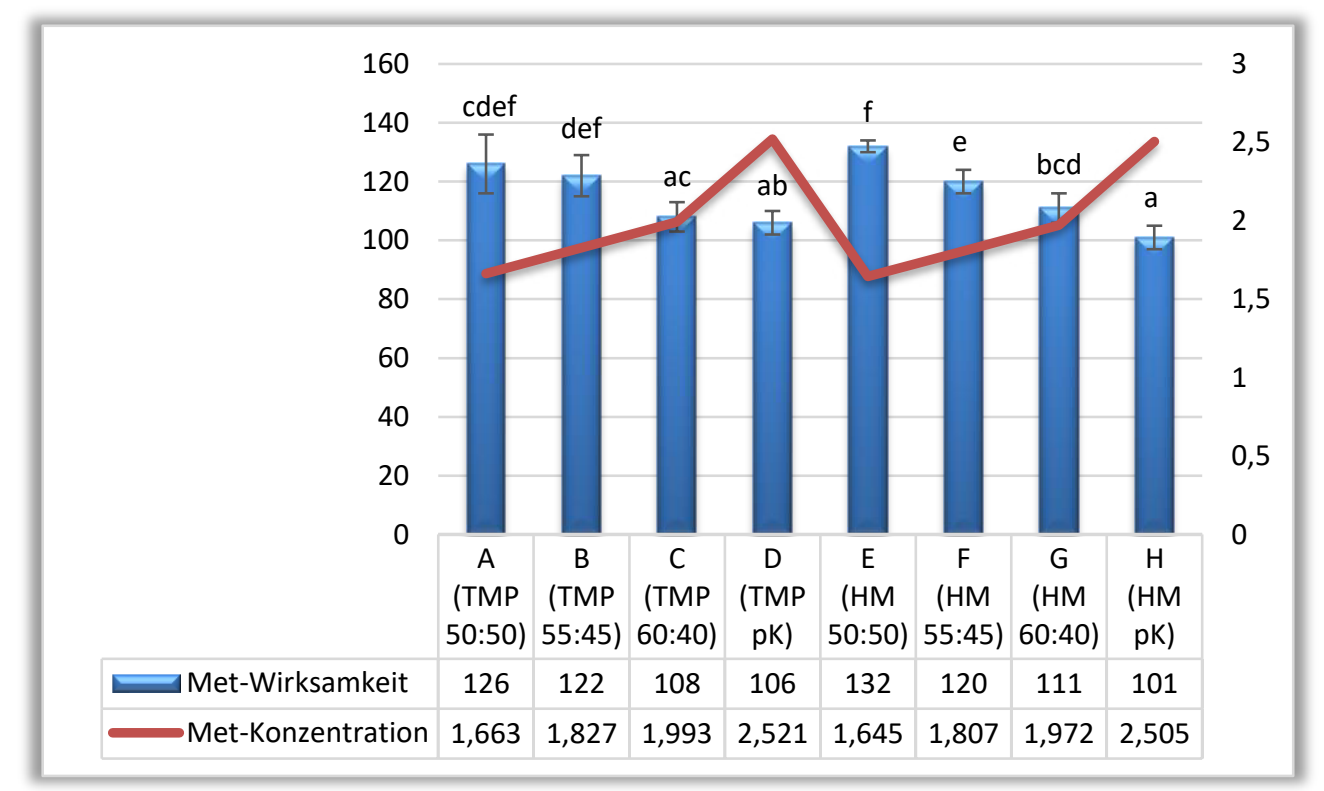

Abbildung 23: Met-Wirksamkeit $\left(b c^{-1}\right)$ und Met-Konzentration (g/16gN) des gesamten Versuchs 3. Angaben als Mittelwerte \pm Standardabweichung, unterschiedliche Buchstaben kennzeichnen signifikante Unterschiede $(\mathbf{p}<\mathbf{0 , 0 5})$. 


\subsubsection{Ableitung des Met-Bedarfs}

Analog zu Versuch 1 und 2 führte auch in der Starterphase von Versuch 3 (Tab. 34) ein Met:Cys-Verhältnis von 50:50 zu den niedrigsten Werten für den abgeleiteten Met-Bedarf und die optimale Met-Konzentration im Futter. Ein Met:Cys-Verhältnis von 55:45 und 60:40 bewirkte eine schrittweise Steigerung der Werte. Beim Einsatz von HM als Hauptproteinquelle wurden im Vergleich zu TMP bei allen untersuchten Met:Cys-Verhältnissen geringere MetBedarfswerte und geringere Bedarfskonzentrationen im Futter ermittelt. Auch in diesem Versuch führte ein steigender XPD zu höheren Werten, während eine steigende FI sinkende optimale Konzentrationen in der Futtermischung mit sich brachte.

In der Growerphase von Versuch 3 (Tab. 35) wurden die Beobachtungen der Starterphase bestätigt. 
Tabelle 34: Abgeleiteter Met-Bedarf in Abhängigkeit von Met:Cys-Verhältnis, Rohproteinansatz und täglicher Futteraufnahme in der Starterphase (Tag 1-21) von Versuch 3 (Mittlere LM:500g).

\begin{tabular}{|c|c|c|c|c|c|c|c|c|c|c|c|c|c|c|c|c|c|c|}
\hline \multirow{3}{*}{ Met:Cys } & \multicolumn{18}{|c|}{ Met-Bedarf } \\
\hline & \multirow{2}{*}{\multicolumn{3}{|c|}{$\begin{array}{l}\text { TMP } \\
50: 50\end{array}$}} & \multirow{2}{*}{\multicolumn{3}{|c|}{$\begin{array}{l}\text { TMP } \\
55: 45\end{array}$}} & \multirow{2}{*}{\multicolumn{3}{|c|}{$\begin{array}{l}\text { TMP } \\
60: 40\end{array}$}} & \multirow{2}{*}{\multicolumn{3}{|c|}{$\begin{array}{c}\text { HM } \\
50: 50\end{array}$}} & \multirow{2}{*}{\multicolumn{3}{|c|}{$\begin{array}{c}\text { HM } \\
55: 45\end{array}$}} & \multirow{2}{*}{\multicolumn{3}{|c|}{$\begin{array}{c}\text { HM } \\
60: 40\end{array}$}} \\
\hline & & & & & & & & & & & & & & & & & & \\
\hline $\begin{array}{l}\text { Met-Wirksamkeit } \\
\qquad\left(b c^{-1}\right)\end{array}$ & \multicolumn{3}{|c|}{106} & \multicolumn{3}{|c|}{104} & \multicolumn{3}{|c|}{99} & \multicolumn{3}{|c|}{118} & \multicolumn{3}{|c|}{109} & \multicolumn{3}{|c|}{103} \\
\hline $\begin{array}{l}\text { XP-Ansatz } \\
\qquad(\mathrm{g} / \mathrm{d})\end{array}$ & 6 & 8 & 10 & 6 & 8 & 10 & 6 & 8 & 10 & 6 & 8 & 10 & 6 & 8 & 10 & 6 & 8 & 10 \\
\hline $\begin{array}{c}\text { Met-Bedarf } \\
\left(\mathrm{mg} / \mathrm{LM}_{\mathrm{kg}}{ }^{0,67}\right)\end{array}$ & 318 & 454 & 631 & 324 & 463 & 643 & 341 & 486 & 676 & 286 & 408 & 567 & 309 & 441 & 614 & 327 & 467 & 649 \\
\hline \multirow[t]{2}{*}{$\begin{array}{l}\text { Met-Bedarf } \\
\text { (g/d) }\end{array}$} & 200 & 285 & 397 & 204 & 291 & 404 & 214 & 306 & 425 & 180 & 256 & 356 & 194 & 278 & 386 & 206 & 294 & 408 \\
\hline & \multicolumn{18}{|c|}{ Optimale Met-Konzentration in der Futtermischung (\%), in Abhängigkeit von der Futteraufnahme } \\
\hline \multicolumn{19}{|l|}{$\begin{array}{l}\text { Futteraufnahme } \\
\qquad(\mathrm{g} / \mathrm{d})\end{array}$} \\
\hline 50 & 0,40 & 0,57 & 0,79 & 0,41 & 0,58 & 0,81 & 0,43 & 0,61 & 0,85 & 0,36 & 0,51 & 0,71 & 0,39 & 0,56 & 0,77 & 0,41 & 0,59 & 0,82 \\
\hline 60 & 0,33 & 0,48 & 0,66 & 0,34 & 0,49 & 0,67 & 0,36 & 0,51 & 0,71 & 0,30 & 0,43 & 0,59 & 0,32 & 0,46 & 0,64 & 0,34 & 0,49 & 0,68 \\
\hline 70 & 0,29 & 0,41 & 0,57 & 0,29 & 0,52 & 0,58 & 0,31 & 0,44 & 0,61 & 0,26 & 0,37 & 0,51 & 0,28 & 0,40 & 0,55 & 0,29 & 0,42 & 0,58 \\
\hline
\end{tabular}


Tabelle 35: Abgeleiteter Met-Bedarf in Abhängigkeit von Met:Cys-Verhältnis, Rohproteinansatz und täglicher Futteraufnahme in der Growerphase (Tag 22-35) von Versuch 3 (Mittlere LM:1500g).

\begin{tabular}{|c|c|c|c|c|c|c|c|c|c|c|c|c|c|c|c|c|c|c|}
\hline \multirow{3}{*}{ Met:Cys } & \multicolumn{18}{|c|}{ Met-Bedarf } \\
\hline & \multicolumn{3}{|c|}{ TMP } & \multicolumn{3}{|c|}{ TMP } & \multirow{2}{*}{\multicolumn{3}{|c|}{$\begin{array}{l}\text { TMP } \\
60: 40\end{array}$}} & \multirow{2}{*}{\multicolumn{3}{|c|}{$\begin{array}{c}\text { HM } \\
50: 50\end{array}$}} & \multirow{2}{*}{\multicolumn{3}{|c|}{$\begin{array}{c}\text { HM } \\
55: 45\end{array}$}} & \multirow{2}{*}{\multicolumn{3}{|c|}{$\begin{array}{c}\text { HM } \\
60: 40\end{array}$}} \\
\hline & & $50: 5$ & & & $55: 45$ & & & & & & & & & & & & & \\
\hline $\begin{array}{l}\text { Met-Wirksamkeit } \\
\qquad\left(b c^{-1}\right)\end{array}$ & \multicolumn{3}{|c|}{153} & \multicolumn{3}{|c|}{147} & \multicolumn{3}{|c|}{115} & \multicolumn{3}{|c|}{154} & \multicolumn{3}{|c|}{134} & \multicolumn{3}{|c|}{119} \\
\hline $\begin{array}{l}\text { XP-Ansatz } \\
\qquad(\mathrm{g} / \mathrm{d})\end{array}$ & 12 & 16 & 20 & 12 & 16 & 20 & 12 & 16 & 20 & 12 & 16 & 20 & 12 & 16 & 20 & 12 & 16 & 20 \\
\hline $\begin{array}{c}\text { Met-Bedarf } \\
\left(\mathrm{mg} / \mathrm{LM}_{\mathrm{kg}}{ }^{0,67}\right)\end{array}$ & 279 & 414 & 616 & 291 & 431 & 641 & 372 & 551 & 820 & 277 & 411 & 612 & 319 & 473 & 704 & 359 & 532 & 792 \\
\hline \multirow{2}{*}{$\begin{array}{l}\text { Met-Bedarf } \\
\qquad(\mathrm{g} / \mathrm{d})\end{array}$} & 366 & 543 & 809 & 381 & 565 & 841 & 487 & 723 & 1076 & 364 & 540 & 803 & 418 & 620 & 923 & 471 & 698 & 1039 \\
\hline & \multicolumn{18}{|c|}{ Optimale Met-Konzentration in der Futtermischung (\%), in Abhängigkeit von der Futteraufnahme } \\
\hline \multicolumn{19}{|l|}{$\begin{array}{l}\text { Futteraufnahme } \\
\qquad(\mathrm{g} / \mathrm{d})\end{array}$} \\
\hline 120 & 0,31 & 0,45 & 0,67 & 0,32 & 0,47 & 0,70 & 0,41 & 0,60 & 0,90 & 0,30 & 0,45 & 0,67 & 0,35 & 0,52 & 0,77 & 0,39 & 0,58 & 0,87 \\
\hline 130 & 0,28 & 0,42 & 0,62 & 0,29 & 0,44 & 0,65 & 0,38 & 0,56 & 0,83 & 0,28 & 0,42 & 0,62 & 0,32 & 0,48 & 0,71 & 0,36 & 0,54 & 0,80 \\
\hline 140 & 0,26 & 0,39 & 0,58 & 0,27 & 0,40 & 0,60 & 0,35 & 0,52 & 0,77 & 0,26 & 0,39 & 0,57 & 0,30 & 0,44 & 0,66 & 0,34 & 0,50 & 0,74 \\
\hline
\end{tabular}




\subsubsection{Körperzusammensetzung}

Am Ende der Starterphase (Tag 21) von Versuch 3 (Tab. 36) war der XP-Gehalt der Tiere aus Versuchsgruppe D (TMP pK) am höchsten, unterschied sich jedoch nur numerisch von dem in den Tieren aus Versuchsgruppe $\mathrm{H}(\mathrm{HM}$ pK) ermittelten Wert. Zwischen allen anderen Versuchsgruppen gab es dagegen keine signifikanten Unterschiede. Der XL-Gehalt war in den Tieren aus Versuchsgruppe B (TMP 45:55) am höchsten, unterschied sich aber nur von Versuchsgruppe D (TMP pK), deren Tiere den niedrigsten XL-Gehalt aufwiesen, signifikant ( $\mathrm{p}$ $<$ 0,05). Den höchsten XA-Gehalt wiesen die Tiere aus Versuchsgruppe A (TMP 50:50) auf, unterschieden sich aber nur numerisch von denen aus Versuchsgruppe B (TMP 55:45), C (TMP 60:40) und D (TMP pK). Auch zwischen den Versuchsgruppen B (TMP 55:45), C (TMP 60:40), D (TMP pK), E (HM 50:50), F (HM 55:45), G (HM 60:40) und H (HM pK) gab es keine signifikanten Unterschiede.

Am Ende der Growerphase (Tag 35) wurde der höchste XP-Gehalt in den Tieren aus Versuchsgruppe D (TMP pK) festgestellt, es gab aber keine signifikanten Unterschiede zu denen aus Versuchsgruppe A (TMP 50:50), B (TMP 55:45), C (TMP 60:40), F (HM 55:45) und H (HM pK). Den niedrigsten XP-Gehalt wiesen die Tiere aus Versuchsgruppe E (HM 50:50) auf, unterschieden sich jedoch nur von denen aus Versuchsgruppe B (TMP 55:45) und D (TMP pK) signifikant ( $<<0,05)$. Der XL-Gehalt war in den Tieren aus Versuchsgruppe E (HM 50:50) am höchsten, unterschied sich aber nur von den Gehalten der Tiere aus Versuchsgruppe B (TMP 55:45) und D (TMP pK) signifikant ( $<<0,05)$. Der XA-Gehalt unterschied sich lediglich zwischen Versuchsgruppe H (HM pK), deren Tiere den höchsten Gehalt aufwiesen, und E (HM 50:50), in der der niedrigste Gehalt ermittelt wurde, signifikant $(\mathrm{p}<0,05)$. 
Tabelle 36: Mittlere Körperzusammensetzung der Tiere am Ende der Starter- (Tag 21) und Growerphase (Tag 35) von Versuch 3.

\begin{tabular}{|c|c|c|c|c|c|c|c|c|}
\hline Met:Cys & $\begin{array}{c}\text { A } \\
\text { TMP } \\
\mathbf{5 0 : 5 0}\end{array}$ & $\begin{array}{c}\text { B } \\
\text { TMP } \\
55: 45\end{array}$ & $\begin{array}{c}\text { C } \\
\text { TMP } \\
60: 40\end{array}$ & $\begin{array}{c}\text { D } \\
\text { TMP } \\
\text { pK }\end{array}$ & $\begin{array}{c}\text { E } \\
\text { HM } \\
\mathbf{5 0 : 5 0}\end{array}$ & $\begin{array}{c}\text { F } \\
\text { HM } \\
55: 45\end{array}$ & $\begin{array}{c}G \\
\text { HM } \\
60: 40\end{array}$ & $\begin{array}{c}\text { H } \\
\text { HM } \\
\mathbf{p K}\end{array}$ \\
\hline \multicolumn{9}{|c|}{ Ende der Starterphase (Tag 21) } \\
\hline $\begin{array}{l}\mathrm{TM} \\
(\%)\end{array}$ & $\begin{array}{c}31,78^{\mathrm{ab}} \\
\pm 1,19\end{array}$ & $\begin{array}{c}32,09^{\mathrm{ab}} \\
\pm 0,98\end{array}$ & $\begin{array}{c}31,50^{\mathrm{ab}} \\
\pm 1,08\end{array}$ & $\begin{array}{c}30,93^{\mathrm{ab}} \\
\pm 0,20\end{array}$ & $\begin{array}{l}31,40^{\mathrm{ab}} \\
\pm 0,61\end{array}$ & $\begin{array}{c}31,90^{\mathrm{ab}} \\
\pm 0,67\end{array}$ & $\begin{array}{l}32,35^{\mathrm{b}} \\
\pm 1,10\end{array}$ & $\begin{array}{l}30,49^{a} \\
\pm 0,89\end{array}$ \\
\hline $\begin{array}{c}\mathrm{XP} \\
(\% \mathrm{TM})\end{array}$ & $\begin{array}{c}49,96^{\mathrm{abc}} \\
\pm 1,94\end{array}$ & $\begin{array}{c}49,65^{\mathrm{ac}} \\
\pm 0,99\end{array}$ & $\begin{array}{c}52,42^{\mathrm{cd}} \\
\pm 2,93\end{array}$ & $\begin{array}{l}55,85^{\mathrm{d}} \\
\pm 1,31\end{array}$ & $\begin{array}{c}50,61^{\mathrm{abc}} \\
\pm 0,44\end{array}$ & $\begin{array}{c}51,46^{\mathrm{abc}} \\
\pm 1,05\end{array}$ & $\begin{array}{c}51,53^{\mathrm{abc}} \\
\pm 3,01\end{array}$ & $\begin{array}{c}53,00^{\text {bd }} \\
\pm 1,61\end{array}$ \\
\hline $\begin{array}{c}\mathrm{XL} \\
(\% \mathrm{TM})\end{array}$ & $\begin{array}{l}41,94^{\mathrm{b}} \\
\pm 2,44\end{array}$ & $\begin{array}{l}42,39^{b} \\
\pm 1,16\end{array}$ & $\begin{array}{c}39,85^{\mathrm{ab}} \\
\pm 3,38\end{array}$ & $\begin{array}{l}36,61^{\mathrm{a}} \\
\pm 1,58\end{array}$ & $\begin{array}{l}42,15^{\mathrm{b}} \\
\pm 0,73\end{array}$ & $\begin{array}{l}41,34^{\mathrm{b}} \\
\pm 1,34\end{array}$ & $\begin{array}{l}41,21^{\mathrm{ab}} \\
\pm 3,38\end{array}$ & $\begin{array}{c}39,78^{\mathrm{ab}} \\
\pm 1,95\end{array}$ \\
\hline $\begin{array}{c}\text { XA } \\
(\% \mathrm{TM})\end{array}$ & $\begin{array}{c}8,10^{\mathrm{b}} \\
\pm 0,56\end{array}$ & $\begin{array}{l}7,96^{\mathrm{ab}} \\
\pm 0,41\end{array}$ & $\begin{array}{l}7,73^{\mathrm{ab}} \\
\pm 0,49\end{array}$ & $\begin{array}{l}7,54^{\mathrm{ab}} \\
\pm 0,31\end{array}$ & $\begin{array}{r}7,24^{\mathrm{a}} \\
\pm 0,49\end{array}$ & $\begin{array}{r}7,20^{\mathrm{a}} \\
\pm 0,43\end{array}$ & $\begin{array}{r}7,26^{\mathrm{a}} \\
\pm 0,41\end{array}$ & $\begin{array}{r}7,23^{\mathrm{a}} \\
\pm 0,43\end{array}$ \\
\hline \multicolumn{9}{|c|}{ Ende der Growerphase (Tag 35) } \\
\hline $\begin{array}{l}\mathrm{TM} \\
(\%)\end{array}$ & $\begin{array}{l}35,12^{\mathrm{b}} \\
\pm 1,81\end{array}$ & $\begin{array}{c}33,66^{\mathrm{ab}} \\
\pm 1,06\end{array}$ & $\begin{array}{c}33,83^{\mathrm{ab}} \\
\pm 1,06\end{array}$ & $\begin{array}{l}32,78^{a} \\
\pm 1,39\end{array}$ & $\begin{array}{l}35,26^{\mathrm{b}} \\
\pm 1,00\end{array}$ & $\begin{array}{c}34,19^{\mathrm{ab}} \\
\pm 1,41\end{array}$ & $\begin{array}{l}35,24^{\mathrm{b}} \\
\pm 0,88\end{array}$ & $\begin{array}{l}32,71^{\mathrm{a}} \\
\pm 1,16\end{array}$ \\
\hline $\begin{array}{c}\mathrm{XP} \\
(\% \mathrm{TM})\end{array}$ & $\begin{array}{c}50,12^{\mathrm{abc}} \\
\pm 2,71\end{array}$ & $\begin{array}{c}52,07^{\mathrm{bc}} \\
\pm 1,89\end{array}$ & $\begin{array}{c}50,90^{\text {abc }} \\
\pm 175\end{array}$ & $\begin{array}{l}53,86^{\mathrm{c}} \\
\pm 2,05\end{array}$ & $\begin{array}{l}47,77^{\mathrm{a}} \\
\pm 1,01\end{array}$ & $\begin{array}{c}49,97^{\mathrm{abc}} \\
\pm 3,23\end{array}$ & $\begin{array}{l}48,52^{\mathrm{ab}} \\
\pm 2,43\end{array}$ & $\begin{array}{c}51,47^{\mathrm{abc}} \\
\pm 1,89\end{array}$ \\
\hline $\begin{array}{c}\mathrm{XL} \\
(\% \mathrm{TM})\end{array}$ & $\begin{array}{c}42,77^{\mathrm{abc}} \\
\pm 2,75\end{array}$ & $\begin{array}{c}40,40^{\mathrm{ab}} \\
\pm 2,34\end{array}$ & $\begin{array}{c}41,63^{\mathrm{abc}} \\
\pm 1,84\end{array}$ & $\begin{array}{l}38,58^{a} \\
\pm 2,19\end{array}$ & $\begin{array}{l}45,62^{c} \\
\pm 1,01\end{array}$ & $\begin{array}{c}43,24^{\mathrm{abc}} \\
\pm 3,64\end{array}$ & $\begin{array}{l}44,40^{\mathrm{bc}} \\
\pm 2,79\end{array}$ & $\begin{array}{c}40,93^{\mathrm{abc}} \\
\pm 2,21\end{array}$ \\
\hline $\begin{array}{c}\mathrm{XA} \\
(\% \mathrm{TM})\end{array}$ & $\begin{array}{l}7,11^{\mathrm{ab}} \\
\pm 0,70\end{array}$ & $\begin{array}{l}7,53^{\mathrm{ab}} \\
\pm 0,55\end{array}$ & $\begin{array}{l}7,46^{\mathrm{ab}} \\
\pm 0,41\end{array}$ & $\begin{array}{l}7,56^{\mathrm{ab}} \\
\pm 0,21\end{array}$ & $\begin{array}{r}6,61^{\mathrm{a}} \\
\pm 0,35\end{array}$ & $\begin{array}{l}6,79^{\mathrm{ab}} \\
\pm 0,53\end{array}$ & $\begin{array}{l}7,08^{\mathrm{ab}} \\
\pm 0,54\end{array}$ & $\begin{array}{l}7,60^{\mathrm{b}} \\
\pm 0,65\end{array}$ \\
\hline
\end{tabular}

Angaben als Mittelwerte \pm Standardabweichung, unterschiedliche Hochbuchstaben kennzeichnen signifikante Unterschiede (p $<0,05)$.

\subsubsection{Protein- und Fettansatz}

In der Starterphase von Versuch 3 (Abb. 24) wurde der höchste XPD von den Tieren der Versuchsgruppen G (HM 60:40) und H (HM pK) erzielt, es gab jedoch nur numerische Unterschiede zu den Tieren aus Versuchsgruppe D (TMP pK), E (HM 50:50) und F (HM 55:45). Den niedrigsten XPD wiesen die Tiere aus Versuchsgruppe A (TMP 50:50) auf, unterschieden sich allerdings nicht signifikant von denen aus Versuchsgruppe B (TMP 55:45) und C (TMP 60:40). Der XLD war bei den Tieren aus Versuchsgruppe E (HM 50:50) und G (HM 60:40) am höchsten, unterschied sich aber nur numerisch von denen aus Versuchsgruppe B (TMP 55:45), F (HM 45:55) und H (HM pK). Der niedrigste XLD wurde dagegen bei den Tieren aus Versuchsgruppe D (TMP pK) festgestellt, es gab aber keine signifikanten Unterschiede zu Versuchsgruppe A (TMP 50:50) und C (TMP 60:40). 


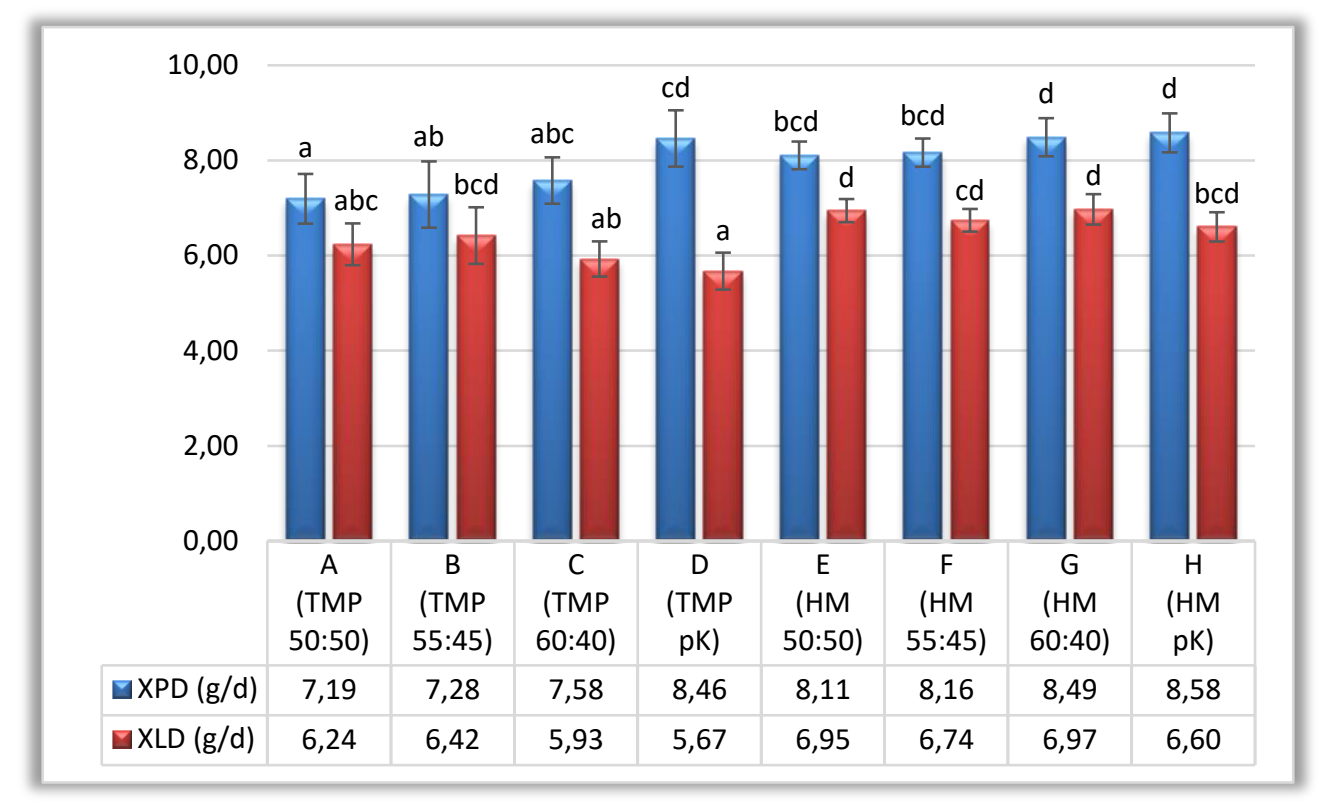

\begin{abstract}
Abbildung 24: Protein- und Fettansatz in der Starterphase (Tag 1-21) von Versuch 3. Angaben als Mittelwerte \pm Standardabweichung, unterschiedliche Buchstaben kennzeichnen signifikante Unterschiede $(\mathbf{p}<\mathbf{0 , 0 5})$.
\end{abstract}

Der XPD in der Growerphase (Abb. 25) war bei den Tieren aus Versuchsgruppe H (HM pK) signifikant $(\mathrm{p}<0,05)$ am höchsten, unterschied sich jedoch nur numerisch von dem der Tiere aus Versuchsgruppe D (TMP pK). Der niedrigste XPD wurde bei den Tieren aus Versuchsgruppe C (TMP 60:40) ermittelt, es gab aber keine signifikanten Unterschiede zu denen aus Versuchsgruppe B (TMP 55:45), F (HM 55:45) und G (HM 60:40). Die Tiere aus Versuchsgruppe E (HM 50:50) wiesen in der Growerphase den höchsten XLD auf, unterschieden sich aber nicht signifikant von denen aus Versuchsgruppe G (HM 60:40) und H (HM pK). Der niedrigste XLD wurde bei den Tieren aus Versuchsgruppe B (TMP 55:45) beobachtet, jedoch gab es nur numerische Unterschiede zu denen aus Versuchsgruppe C (TMP 60:40) und D (TMP pK). 


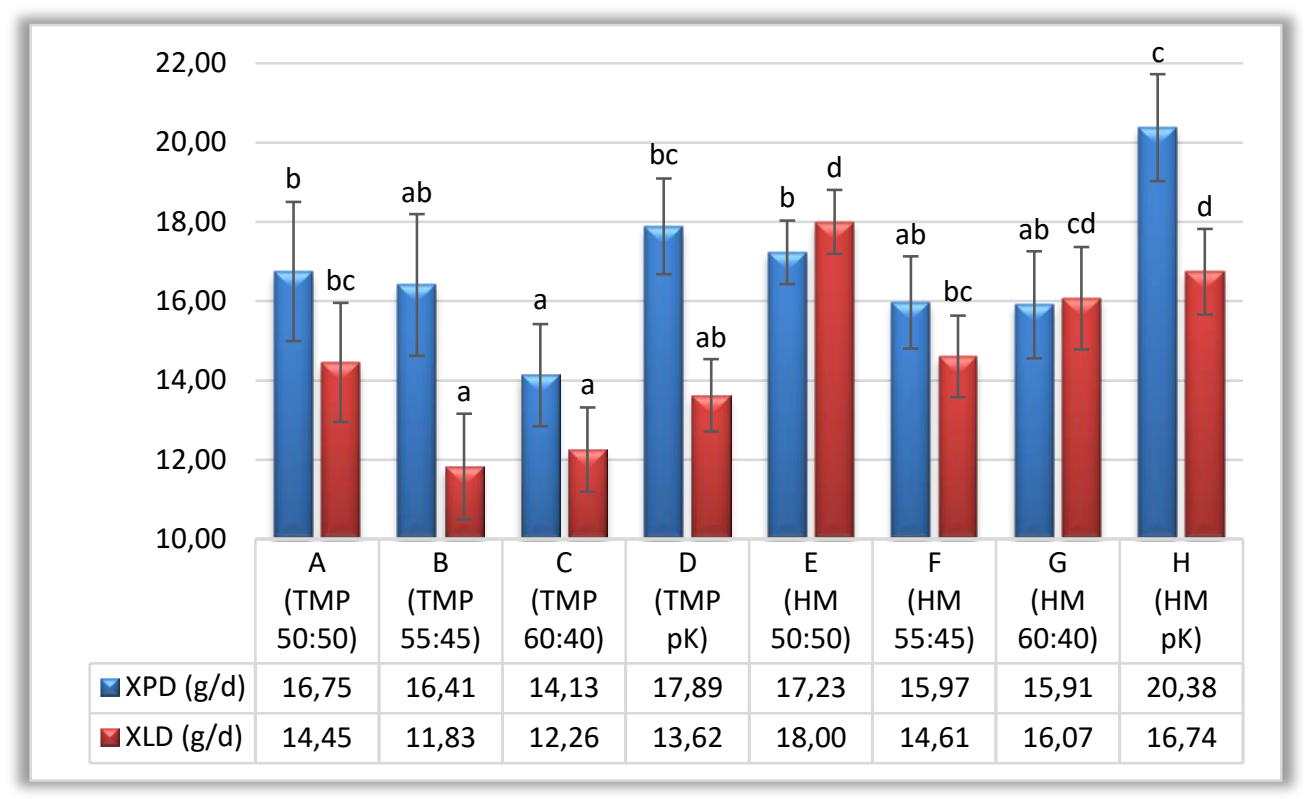

\begin{abstract}
Abbildung 25: Protein- und Fettansatz in der Growerphase (Tag 22-35) von Versuch 3. Angaben als Mittelwerte \pm Standardabweichung, unterschiedliche Buchstaben kennzeichnen signifikante Unterschiede $(\mathbf{p}<\mathbf{0 , 0 5})$.
\end{abstract}

Die Betrachtung des gesamten Versuchszeitraumes von Versuch 3 (Abb. 26) zeigt, dass die Tiere aus Versuchsgruppe H (HM pK) den höchsten XPD aufwiesen, sich von denen aus Versuchsgruppe D (TMP pK) und G (HM 60:40) aber nur numerisch unterschieden. Der niedrigste XPD wurde bei den Tieren aus Versuchsgruppe C (TMP 60:40) beobachtet, es gab jedoch keine signifikanten Unterschiede zu den Tieren aus Versuchsgruppe A (TMP 50:50), B (TMP 55:45), F (HM 55:45) und G (HM 60:40). Den höchsten XLD wiesen, ebenso wie in der Growerphase, die Tiere aus Versuchsgruppe E (HM 50:50) auf, sie unterschieden sich aber nur in der Tendenz von Versuchsgruppe G (HM 60:40) und H (HM pK). Der niedrigste XLD wurde in Versuchsgruppe C (TMP 60:40) ermittelt, jedoch ohne signifikante Unterschiede zu Versuchsgruppe A (TMP 50:50), B (TMP 55:45) und D (TMP pK). 


\section{Ergebnisse}

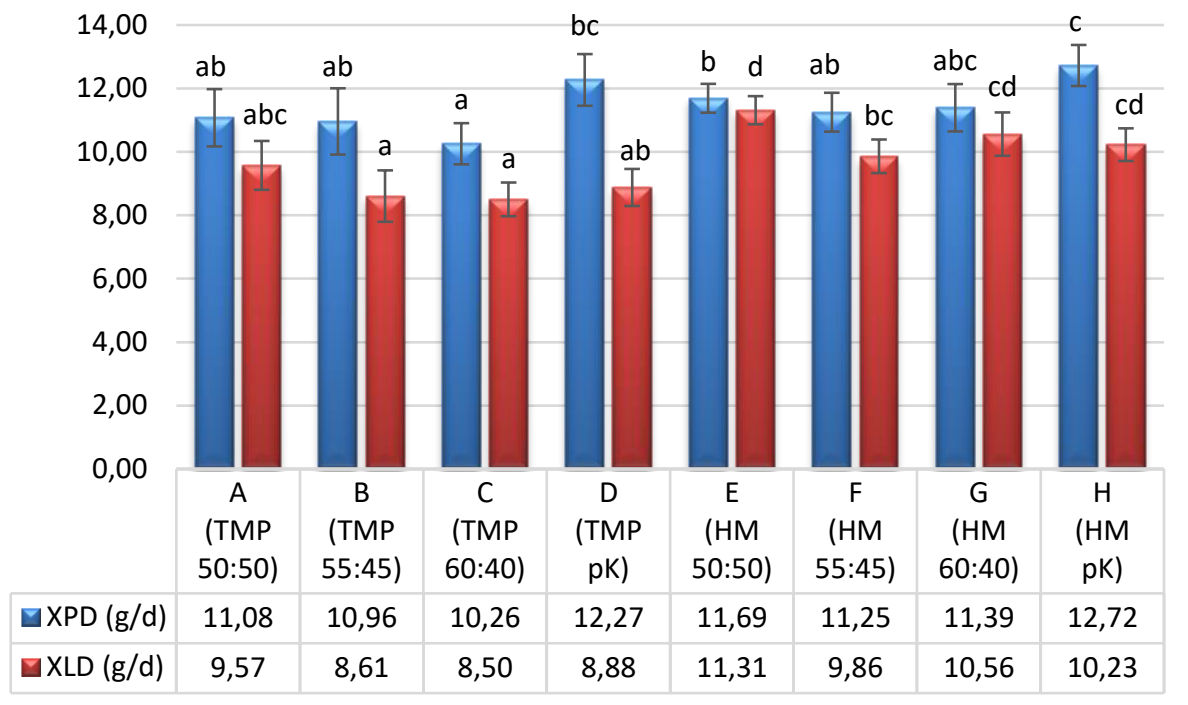

Abbildung 26: Protein- und Fettansatz im gesamten Versuchszeitraum (Tag 1-35) von Versuch 3. Angaben als Mittelwerte \pm Standardabweichung, unterschiedliche Buchstaben kennzeichnen signifikante Unterschiede $(\mathbf{p}<\mathbf{0 , 0 5})$.

Die Ergebnisse von Versuch 3 werden in Kapitel 6.1.3 mit denen der anderen Versuche verglichen, diskutiert und bewertet. 


\section{Diskussion}

\subsection{Bewertung der Met:Cys-Verhältnisse}

Nachfolgend sollen die Auswirkungen der verschiedenen Met:Cys-Verhältnisse in den einzelnen Versuchen ausführlich diskutiert werden.

\subsubsection{Versuch 1}

Das Met:Cys-Verhältnis hatte in Versuch 1 einen signifikanten Einfluss auf die ermittelten zootechnischen Parameter (Tab. 14 und 15). So führte ein Met:Cys-Verhältnis von 40:60 in allen Versuchsphasen zu einer signifikant $(\mathrm{p}<0,05)$ verringerten FI und damit verbunden zu einer signifikant ( $\mathrm{p}<0,05)$ geringeren finalen LM und täglichen LMZ. Es ist davon auszugehen, dass der hohe Cys-Anteil und der damit verbundene Met-Mangel der Grund für die negativen Effekte auf Futterverzehr und Wachstum waren, da sich die eingesetzten Futtermischungen lediglich in ihrem Met:Cys-Verhältnis unterschieden. Diese Beobachtungen wurden auch von anderen Autoren gemacht. So berichteten beispielsweise Graber et al. (1971) ebenfalls von einer verringerten FI bei Cys-Anteilen von $\geq 58 \%$ an den SAS, deren Gesamt-Gehalt unter den Empfehlungen des NRC (1994) und der GfE (1999) lag. Im Gegensatz zu den in Versuch 1 gemachten altersunabhängigen Beobachtungen stellten die Autoren jedoch fest, dass die Höhe des Cys-Anteils an den SAS, der sich nicht negativ auf die FI auswirkte, mit steigendem Alter der Tiere von 2 bis 8 Wochen von 58\% auf 65\% anstieg. Auch Dilger und Baker (2007, 2008a) berichteten von negativen Effekten auf die FI, wenn der Cys-Anteil in einer SAS limitierten Futtermischung mehr als 50\% der SAS betrug. In einer anderen Studie führten dieselben Autoren (Dilger und Baker, 2008b) einen massiven Cys-Überschuss in einer Mais-SESFuttermischung für Masthähnchen herbei, der zu einem Met:Cys-Verhältnis von 13:87 führte und stellten eine Reduktion der FI um 15\% fest. Zudem kamen sie zu dem Schluss, dass zu hohe Cys-Gaben eine akute metabolische Azidose auslösen und zum Tod der Tiere führen können. Featherston und Rogler (1978) beobachteten ein um ca. 30\% geringeres Wachstum von Masthähnchen bei einem Met:Cys-Verhältnis von 30:70 verglichen mit 47:53. Die Autoren merkten dazu an, dass dieser negative Effekt auftrat, obwohl der SAS-Gehalt in der Futtermischung deutlich im Limitierungsbereich lag. Ähnliche Beobachtungen machten auch Sasse und Baker (1974) sowie Sell et al. (1980). Tsiagbe et al. (1987) stellten zwar ein signifikant geringeres Wachstum der Tiere bei einem Cys-Anteil von $62 \%$ an den SAS fest, konnten aber keinen verzehrsdepressiven Einfluss beobachten. Im Vergleich zu den anderen Studien lag hier jedoch keine Limitierung durch die SAS vor. Ein Grund für die starken negativen Auswirkungen hoher Cys-Anteile könnte z.B. eine AS-Imbalance sein, die durch die 


\section{Diskussion}

Limitierung der SAS bei gleichzeitiger bedarfsgerechter Supplementierung der anderen AS ausgelöst wurde. Durch die hohen Cys-Anteile sank zusätzlich das Verhältnis Met:Lys auf 0,20 statt des von Wecke und Liebert (2013) als optimal angegebenen Wertes von 0,40. Kahn et al. (2015a) gaben mit 0,34 ein geringeres optimales Met:Lys-Verhältnis an, das in den in Versuch 1 eingesetzten Futtermischungen mit einem hohen Cys-Anteil jedoch ebenfalls unterschritten wurde. Durch hohe Cys-Anteile an den SAS ausgelöste AS-Imbalancen vermuteten auch Sell et al. (1980) als Ursache für die niedrige FI und das damit verbundene geringe Wachstum der Tiere. Dilger und Baker (2007) gaben an, dass die negativen Effekte bereits durch geringe MetGaben verringert werden konnten und sahen dies ebenfalls als Nachweis für eine Imbalance der AS an. Dass AS-Imbalancen zu einer Verringerung der FI führen können, berichteten auch Swatson et al. (2002) und Kumar et al. (2016). So reagieren die Tiere auf die Stoffwechselbelastung, die durch eine AS-Fehlversorgung entsteht. Lerner und Wight Taylor (1967) gaben an, dass steigende Cys-Konzentrationen die intestinale Absorption von sowohl D- als auch L-Methionin hemmen. Ein solcher Effekt verstärkt einen bestehenden Mangel an Met und hat so einen negativen Einfluss auf das Wachstum der Tiere. Auch Featherston und Rogler (1978) vermuteten, dass ein zwischen Met und Cys bestehender Antagonismus und damit verbunden eine Hemmung der Met-Absorption bei hohen Cys-Gaben der Grund für das geringe Wachstum der Tiere war. Im Gegensatz zu den Ergebnissen von Versuch 1 ermittelten Pesti et al. (1979) die besten Wachstumsergebnisse von Masthähnchen im Alter von 1-3 Wochen jedoch bei einem Met:Cys-Verhältnis von 43:57. Auch Ohta und Ishibashi (1994) gaben Met-Anteile von < 50\% der SAS als optimal an, die aber in Abhängigkeit des gesamten SAS-Gehaltes in der Futtermischung variierten. Hierbei sank der optimale Met-Anteil mit steigendem SAS-Gehalt.

Eine Erhöhung des Met:Cys-Verhältnisses von 40:60 auf 45:55 hatte in Versuch 1 in allen Versuchsphasen signifikant $(\mathrm{p}<0,05)$ positive Auswirkungen auf die FI und das Wachstum der Tiere. Dies ist ein weiteres Indiz dafür, dass die hohen Cys-Anteile der Grund für die beobachteten negativen Effekte bei einem Met:Cys-Verhältnis von 40:60 waren. Auch Bunchasak et al. (1998) gaben an, dass durch eine Supplementation von Cys die Aktivität der Cystathionin-Synthase verringert wurde, was wiederum dazu führte, dass mehr Met für das Wachstum zur Verfügung stand. Durch die Erhöhung des Met-Anteils waren die Aufwandsparameter ebenfalls tendenziell verbessert. Auch Graber et al. (1971) sowie Sasse und Baker (1974) stellten eine bessere Futterverwertung fest, wenn der Cys-Anteil an den SAS weniger als $60 \%$ betrug. In einer Studie von Wecke et al. (2015a) zeigte der Vergleich der 


\section{Diskussion}

Met:Cys-Verhältnisse 40:60 und 45:55 jedoch nur eine tendenzielle Verbesserung des FA mit höherem Met-Anteil an den SAS.

Eine weitere Anhebung des Met:Cys-Verhältnisses auf 50:50 führte in Versuch 1 zu einer z.T. signifikanten Verbesserung des Wachstums der Tiere. Dies bestätigt die Angaben von Graber und Baker (1971), Moran Jr. (1981) und Baker et al. (1996), die ein optimales Met:CysVerhältnis von 50:50 für wachsende Masthähnchen ermittelten. Auch die Ergebnisse von Khan et al. (2015a) sind in diesem Bereich einzuordnen, da die Autoren keine signifikanten Unterschiede zwischen Met:Cys-Verhältnissen von 46:54, 48:52 und 51:49 auf das Wachstum von Masthähnchen feststellten. Während sich der Protein- und Energieaufwand nur tendenziell verbesserten, hatte ein Met:Cys-Verhältnis von 50:50 in der Starterphase und bei Betrachtung des gesamten Versuchszeitraumes eine signifikante $(\mathrm{p}<0,05)$ Verbesserung des FA zur Folge. Diese Entwicklung wurde auch von Marquardt und Campbell (1975) sowie Powell et al. (2011) beobachtet. In einer Studie von Baker et al. (1996) wurde dagegen bei einem Met:CysVerhältnis von 44:56 eine signifikant bessere Futterverwertung als bei einem Met:CysVerhältnis von 50:50 festgestellt.

Wurde das Met:Cys-Verhältnis in Versuch 1 auf 55:45 erhöht, konnte kein signifikanter Effekt festgestellt werden. Diese Beobachtung ist in Übereinstimmung mit den Ergebnissen von Kalinowski et al. (2003a, b), die optimale Met:Cys-Verhältnisse von 52:48 bis 56:44 in Abhängigkeit von Genetik und Alter der Masthähnchen ermittelten. Auch Wheeler und Latshaw (1981) beobachteten einen Einfluss des Alters auf das Met:Cys-Verhältnis. Während sie für die Starterphase einen optimalen Cys-Anteil von 54\% an den SAS angaben, sank der Wert in der Growerphase auf 38-43\%. Im Gegensatz dazu empfahl das NRC (1994) steigende Cys-Anteile von 43\% der SAS in der Starter- und 47\% der SAS in der Growerphase. Auch Wecke et al. (2015a) gaben optimale Cys-Anteile von mind. $45 \%$ und max. 55\% der SAS in der Starter- bzw. Growerphase an.

Während es in der Starterphase bei einem Met:Cys-Verhältnis von 60:40 keine signifikanten Unterschiede im Vergleich zu einem Met:Cys-Verhältnis von 50:50 gab, kam es in der Growerphase und bei Betrachtung des gesamten Versuchszeitraumes zu einem signifikanten ( $p$ $<0,05)$ Rückgang der FI und damit verbunden zu einem signifikant $(\mathrm{p}<0,05)$ schlechteren Wachstum der Tiere. Dies deutet auf einen möglichen Cys-Mangel hin, der durch die Katabolisierung von Met ausgeglichen wurde. Somit stand in der Folge weniger Met für das Wachstum der Tiere zur Verfügung. Im Gegensatz dazu beobachteten Sünder et al. (2015a, b) 


\section{Diskussion}

jedoch zwischen Met:Cys-Verhältnissen von 48:52 und 59:41 keine signifikanten Unterschiede bezüglich FI und Wachstum.

Die Aufwandsparameter wurden in keiner der Wachstumsphasen durch Met-Anteile von $\geq 50 \%$ der SAS signifikant beeinflusst. Dies wird auch durch die Ergebnisse von Marquardt und Campbell (1975) bestätigt. Sünder et al. (2015a, b) stellten im Gegensatz dazu eine signifikante Verschlechterung des Futteraufwands bei einer Erhöhung des Met-Anteils von 48\% auf 59\% der SAS fest.

Grundsätzlich ist jedoch zu beachten, dass in den meisten der aufgeführten Studien die Veränderungen des Met:Cys-Verhältnisse mit einer Steigerung der SAS-Gehalte verbunden war. Dies erschwert einen direkten Vergleich mit den zootechnischen Ergebnissen der vorliegenden Versuche, die den SAS-Gehalt im Futterprotein unverändert ließen.

Die Ergebnisse der scheinbaren pcV in Versuch 1 (Tab. 16) zeigten mit Ausnahme von Met keine signifikanten Unterschiede zwischen den Versuchsgruppen mit unterschiedlichem Met:Cys-Verhältnis. Ein solcher Effekt war auch nicht zu erwarten. Die mit wachsendem MetAnteil an den SAS zunehmende scheinbare $\mathrm{pcV}$ von Met lässt sich durch die steigende Zulage an kristallinem DL-Met erklären. Zum einen wird die scheinbare $\mathrm{pcV}$ mit steigendem ASGehalt erhöht, zum anderen gelten kristalline AS als 100\% verdaulich (Chung und Baker, 1992), wodurch der Effekt noch weiter verstärkt wird. Diese Beobachtung ist dementsprechend nicht auf das Met:Cys-Verhältnis zurückzuführen. Aus diesem Grund wurde von einer nochmaligen Untersuchung der scheinbaren $\mathrm{pcV}$ in allen Versuchsmischungen in Versuch 2 und 3 abgesehen.

Das Met:Cys-Verhältnis hatte in Versuch 1 auch einen Einfluss auf die Proteinqualität und MetWirksamkeit. Die Beobachtung, dass der N-Ansatz mit steigendem Met-Anteil bis zu 50\% der SAS zunahm und bei Met-Anteilen von $>50 \%$ wieder sank, ist dagegen nur indirekt im Met:Cys-Verhältnis begründet. Ein suboptimales Met:Cys-Verhältnis hatte in allen drei Wachstumsphasen Auswirkungen auf die Höhe der FI und damit auch auf die Höhe der NAufnahme. Da die N-Aufnahme den N-Ansatz deutlich beeinflusst, lässt sich die beschriebene Entwicklung erklären.

In allen Wachstumsphasen (Tab. 17) führte ein Met:Cys-Verhältnis von 40:60 zu einer signifikant $(\mathrm{p}<0,05)$ verringerten Proteinqualität. Dies zeigt, welchen großen Einfluss ein Mangel an Met bei gleichzeitigem Cys-Überschuss haben kann. Durch eine Erhöhung des Met:Cys-Verhältnisses auf 45:55 konnten die Proteinqualitätsparameter signifikant ( $\mathrm{p}<0,05)$ verbessert werden. Ein Met:Cys-Verhältnis von 50:50 führte dagegen nur in der Starterphase 


\section{Diskussion}

und bei Betrachtung des Gesamtversuches zu einer weiteren signifikanten $(\mathrm{p}<0,05)$ Verbesserung. Diese Ergebnisse bestätigen die Beobachtungen von Farke et al. (2010), die ebenfalls eine signifikant höhere Proteinqualität bei einem Met:Cys-Verhältnis von 51:49 verglichen mit 42:58 sowohl in der Starter- als auch in der Growerphase feststellten. Auch Liebert et al. (2010) ermittelten in der Starterphase eine in der Tendenz höhere Proteinqualität bei einem Met:Cys-Verhältnis von 51:49 im Vergleich zu 40:60. In der Growerphase beobachteten die Autoren bei einem Met:Cys-Verhältnis von 51:49 jedoch tendenziell einen geringeren Wert. Im Gegensatz dazu führte eine Erhöhung des Met-Anteils von 40\% auf 45\% der SAS in den Versuchen von Wecke et al. (2015a) weder in der Starter- noch in der Growerphase zu einer signifikanten Veränderung der Futterproteinqualität. Während eine Erhöhung des Met-Cys-Verhältnis auf 55:45 in Versuch 1 in allen Wachstumsphasen verglichen mit einem Met:Cys-Verhältnis von 50:50 keine signifikante Veränderung der Proteinqualität bewirkte, führte ein Met:Cys-Verhältnis von 60:40 in der Growerphase und bei Betrachtung des gesamten Versuchszeitraumes zu einer Verschlechterung der Parameter. Verglichen mit einem Met:Cys-Verhältnis von 50:50 war dieser Unterschied signifikant ( $\mathrm{p}<$ 0,05). Daraus lässt sich schließen, dass ein Met-Anteil von 60\% an den SAS zu einem Mangel an Cys geführt hat, der durch den Met-Abbau vermindert werden konnte und in der Folge die Proteinqualität insgesamt negativ beeinflusst hat. Auch Khan et al. (2015a) konnten bei Met:Cys-Verhältnissen von 49:51, 52:48 und 54:46 keine signifikanten Unterschiede in der Proteinqualität feststellen. Im Gegensatz dazu ermittelten Sünder et al. (2015b) und Wecke et al. (2015b) sowohl in der Starter- als auch in der Growerphase eine signifikante Steigerung der Proteinqualität bei Erhöhung des Met:Cys-Verhältnisses von 48:52 auf 54:46 bzw. 59:41. Auch in den Versuchen von Liebert et al. (2010) und Farke et al. (2010) führte ein Met:CysVerhältnis von 57:43 verglichen mit 51:49 zu einer höheren Proteinqualität. Während dies bei Farke et al. (2010) für beide Wachstumsphasen galt, wurde von Liebert et al. (2010) in der Growerphase die gegenteilige Entwicklung feststellt. Allerdings ist zu berücksichtigen, dass auch in vielen dieser Versuche der SAS-Gehalt in den Futtermischungen durch die vorgenommenen Veränderungen des Met:Cys-Verhältnisses variierte. Direkte Vergleiche mit den Ergebnissen aus Versuch 1 sind deshalb erschwert. So wurde ein Mangel an den SAS durch die AS-Supplementation unter Umständen aufgehoben, was per se bereits zu einer Verbesserung der Proteinqualität führte. Dementsprechend sind die Ergebnisse z.T. eher auf unterschiedliche SAS-Gehalte und weniger auf das Met:Cys-Verhältnis zurückzuführen. Dieser zusätzliche Effekt auf die Proteinqualität sollte in den vorliegenden Untersuchungen 


\section{Diskussion}

ausgeschaltet werden, indem der SAS-Gehalt in den verwendeten Futtermischungen konstant gehalten wurde.

Die Methionin-Wirksamkeit $\left(b c^{-1}\right)$ ist ein Ausdruck für die Menge an Met, die benötigt wird, um eine Einheit an ND zu erzielen (Liebert, 2015). In den Wert fließt zum einen der Umfang der Freisetzung von Met aus dem Proteinverband und zum anderen die Absorption und die intermediäre Verwertung ein. Es ist jedoch zu beachten, dass der Parameter nur ermittelt werden kann, wenn die limitierende Position des Mets im Futterprotein sichergestellt ist, da es sonst zu einer Überschätzung des Bedarfs kommt. Außerdem kann die Met-Wirksamkeit nur innerhalb einer Wachstumsphase miteinander verglichen werden (Liebert, 2008). Während in der Starterphase (Abb. 9) die höchste Met-Wirksamkeit bei einem Met:Cys-Verhältnis von 50:50 festgestellt wurde, hatte in der Growerphase (Abb. 10) ein Met:Cys-Verhältnis von 45:55 den höchsten Wert zur Folge. In beiden Wachstumsphasen gab es jedoch keine signifikanten Unterschiede zwischen den Met:Cys-Verhältnissen 40:60, 45:55 und 50:50. Bei Betrachtung des gesamten Versuchszeitraumes (Abb. 11) führte sowohl ein Met:Cys-Verhältnis von 45:55 als auch von 50:50 zur höchsten Met-Wirksamkeit. Es gab auch hier nur numerische Unterschiede zu einem Met:Cys-Verhältnis von 40:60. Dies deutet daraufhin, dass in den Futtermischungen mit einem Met-Anteil von $\leq 50 \%$ an den SAS der Met-Abbau zur Bereitstellung von Cys minimiert war. In allen drei Wachstumsphasen bewirkte eine Erhöhung des Met:Cys-Verhältnisses auf 55:45 und 60:40 einen signifikanten Rückgang der MetWirksamkeit. Dies deutet auf ein suboptimales Met:Cys-Verhältnis hin. Der geringere CysAnteil an den SAS bei einem Met:Cys-Verhältnis von 60:40 hat vermutlich zu einem verstärkten Met-Abbau geführt, was die Wirksamkeit dieser AS für den N-Ansatz verringert hat. Auch Wecke et al. (2015a) beobachteten sowohl in der Starter- als auch in der Growerphase keine signifikanten Unterschiede in der Met-Wirksamkeit bei Met:Cys-Verhältnissen von 40:60 und 45:55, wenn der Met-Gehalt im Futterprotein konstant gehalten wurde. In einer Untersuchung von Liebert et al. (2010) führte eine Veränderung des Met:Cys-Verhältnisses von 40:60 auf 51:49 in der Starterphase ebenfalls nur zu numerischen Unterschieden, in der Growerphase war die Met-Wirksamkeit jedoch bei einem Met:Cys-Verhältnis von 40:60 tendenziell höher. Entgegen den Ergebnissen in Versuch 1 fanden Khan et al. (2015a) weder in der Starter- noch in der Growerphase signifikante Unterschiede in der Met-Wirksamkeit zwischen Met:Cys-Verhältnissen von 49:51, 52:48 und 54:46. Tendenziell kam es in der Starterphase jedoch mit steigendem Met-Anteil an den SAS zu einer Steigerung der MetWirksamkeit, während in der Growerphase die gegenteilige Tendenz beobachtet werden konnte. In Untersuchungen von Sünder et al. (2015b) nahm die Met-Wirksamkeit in der 


\section{Diskussion}

Starterphase dagegen ebenfalls mit steigendem Met:Cys-Verhältnis von 48:52 auf 54:46 und 59:41 ab, der Unterschied war aber nur bei einem Met:Cys-Verhältnis von 59:41 signifikant. Die Autoren begründeten diese Beobachtung ebenfalls mit einem suboptimalen Verhältnis der SAS zueinander, wenn der Met-Anteil an den SAS 59\% betrug. In der Growerphase wurden dagegen keine signifikanten Unterschiede ermittelt, tendenziell stieg die Met-Wirksamkeit jedoch mit steigendem Met-Anteil an den SAS an. Auch Wecke et al. (2015b) stellten in der Starterphase eine sinkende Met-Wirksamkeit bei Veränderung des Met:Cys-Verhältnisses von 48:52 auf 54:46 und 59:41 fest, die bei einem Met:Cys-Verhältnis von 59:41 signifikant war. In der Growerphase gab es dagegen keine signifikanten Unterschiede. Farke et al. (2010) ermittelten ebenfalls eine sinkende Met-Wirksamkeit bei der Erhöhung des Met:CysVerhältnisses von 51:49 auf 57:43, diese Tendenz konnte aber in keiner der Wachstumsphasen signifikant abgesichert werden. Der von Liebert et al. (2010) durchgeführte Vergleich der Met:Cys-Verhältnisse 40:60 und 57:43 ergab dagegen in der Starterphase eine tendenziell höhere Met-Wirksamkeit durch einen Met-Anteil von 57\% an den SAS. In der Growerphase führte jedoch ein Met:Cys-Verhältnis von 40:60 zu der numerisch höheren Met-Wirksamkeit. Dies deutet auf eine mit dem Alter der Tiere steigende Bedeutung der Cys-Versorgung hin, die bei hohen Met-Anteilen an den SAS in der Growerphase einen verstärkten Met-Abbau und damit verbunden einen Rückgang der Met-Wirksamkeit bedingt hat. In einer weiteren Studie von Sünder et al. (2015c) wurde die höchste Met-Wirksamkeit sowohl in der Starter- als auch in der Growerphase bei einem Met:Cys-Verhältnis von 45:55 beobachtet. Ebenso wie in den zuvor genannten Untersuchungen bewirkte ein Met:Cys-Verhältnis von 59:41 einen signifikanten Rückgang der Met-Wirksamkeit. Im Gegensatz zu den Ergebnissen von Sünder et al. (2015b) wurde diese Entwicklung jedoch in beiden Wachstumsphasen festgestellt. Auch in diesem Zusammenhang muss allerdings auf die unterschiedlichen, sich z.T. mit dem Met:Cys-Verhältnis verändernden SAS-Gehalte in den Versuchen hingewiesen werden.

Auf Grundlage der bei unterschiedlichen Met:Cys-Verhältnissen ermittelten Met-Wirksamkeit kann im Rahmen des „Göttinger N-Verwertungsmodells“ der Met-Bedarf bei einer vorgegebenen Leistungshöhe (ND bzw. XPD) abgeleitet werden (s. Gleichung [13]). Zusätzlich ist es möglich, die optimale Met-Konzentration in den Futtermischungen in Abhängigkeit der Futteraufnahme zu ermitteln. In der Starterphase von Versuch 1 (Tab. 18) führte ein Cys-Anteil von $\leq 50 \%$ zu den niedrigsten Bedarfswerten und damit verbunden zu den geringsten optimalen Met-Konzentrationen im Futter. Mit steigendem Met-Anteil an den SAS kam es zu einer Anhebung der Werte. In der Growerphase (Tab. 19) wurden die geringsten Met-Bedarfswerte und optimalen Konzentrationen im Futter bei einem Met:Cys-Verhältnis von 45:55 ermittelt. 


\section{Diskussion}

Ebenso wie in der Starterphase hatte ein Met-Anteil von > 50\% der SAS steigende Werte zur Folge. Diese Entwicklung in Bezug auf den Met-Bedarf wurde auch von Farke et al. (2010) bei Met-Cys-Verhältnissen von 42:58, 51:49 und 57:43 beobachtet. Sünder et al. (2015c) verglichen den erforderlichen Met-Gehalt im Mischfutter für wachsende Masthähnchen bei einem Met:Cys-Verhältnis von 45:55 und 59:41 und stellten ebenfalls höhere Werte bei einem Met-Anteil von 59\% der SAS fest. Der steigende Met-Bedarf ist in der sinkenden MetWirksamkeit bei steigenden Met-Anteilen an den SAS begründet. Eine geringe MetWirksamkeit bedingt eine höhere Menge dieser AS, die für die Realisierung einer Einheit an ND benötigt wird. Dieser Zusammenhang wurde auch von Liebert et al. (2010) herausgestellt. In der Starterphase ergab die Bedarfsableitung bei einer täglichen FI von 50g und einem XPD von $6 \mathrm{~g} / \mathrm{d}$ eine optimale Met-Konzentration von 0,37-0,45\%. Eine Anhebung des XPD auf 10g/d hatte dagegen eine Steigerung auf 0,74-0,89\% Met in der Futtermischung zur Folge. In der Growerphase lagen die Werte bei einer täglichen FI von 120g bei 0,29-0,44 (12g XPD pro Tag) bzw. 0,64-0,97\% (20g XPD pro Tag). Grundsätzlich spiegeln die ermittelten Werte damit die Angaben in der Literatur wider. Während Klain et al. (1960) einen Met-Gehalt von 0,18\% im Futter von Masthähnchen empfahlen, gab Almquist (1952) 0,45\% Met als optimal an und Chamruspollert et al. (2002) bestimmten eine ideale Met-Konzentration von 0,52\% bzw. 0,54\% in Abhängigkeit vom Zielparameter Futterverwertung oder Lebendmassezunahme. Graber et al. (1971) ermittelten einen optimalen Met-Gehalt von 0,60-0,65\%, abhängig vom Alter der Tiere. Auch die Versorgungsempfehlungen des NRC (1994), der GfE (1999) sowie von Aviagen (2014) für Masthähnchen der Genetik Ross 308 liegen je nach Wachstumsphase in einem Bereich von 0,35-0,56\% Met. Es gilt jedoch zu berücksichtigen, dass die Mehrzahl der Bedarfswerte auf zootechnischen Parametern wie dem Wachstum oder der Futterverwertung basiert, während die im Rahmen dieser Arbeit durchgeführte Bedarfsbewertung die MetWirksamkeit und den XPD der Tiere als Grundlage verwenden. Somit finden bei Anwendung des N-Verwertungsmodells zur Bedarfsableitung sowohl tier-, als auch leistungs- und futterspezifische Daten Berücksichtigung. Dies hat eine deutlich genauere Bedarfsermittlung zur Folge und erklärt die vergleichsweise hohen optimalen Met-Konzentrationen bei einem ungünstigen Met:Cys-Verhältnis bzw. einem hohen Proteinansatz. Die Möglichkeit eines direkten Vergleichs der verfügbaren Bedarfswerte ist dementsprechend nicht unmittelbar gegeben. Außerdem spielen verschiedene Einflussfaktoren wie z.B. das Alter, das Geschlecht und die Genetik der Tiere sowie unterschiedliche Versuchsbedingungen und Versuchszielgrößen (Brede et al., 2018) bei der Bedarfsermittlung eine Rolle. Auch die 


\section{Diskussion}

Versorgung mit Cys sollte berücksichtigt werden, da die notwendige Met-Zufuhr bei einem Mangel an Cys aufgrund des Met-Katabolismus steigt.

Ein Vergleich beider Wachstumsphasen zeigt einen Rückgang des Met-Bedarfs mit steigendem Alter der Tiere bei Met-Anteilen von 40-55\% an den SAS. Dies ist kongruent mit den Ergebnissen von Farke et al. (2010) und Sünder et al. (2015c). Auch in den Versorgungsempfehlungen des NRC (1994), der GfE (1999) und von Aviagen (2014) wurde diese altersbedingte Entwicklung des Met-Bedarfs berücksichtigt. Khan et al. (2015b) konnten dagegen keinen eindeutigen Alterseffekt beobachten und in einer Untersuchung von Graber $e t$ al. (1971) stieg die optimale Met-Konzentration im Futter mit steigendem Alter an. Eine solche Entwicklung zeigte sich in Versuch 1 lediglich bei einem suboptimalen Met:Cys-Verhältnis von 60:40.

Zusätzlich zum bereits diskutierten N-Ansatz wurde auch der Einfluss des Met:CysVerhältnisses auf die Körperzusammensetzung (Tab. 20) und den Nährstoffansatz der Tiere untersucht. In der Starterphase nahm der XP-Gehalt der Tiere mit steigendem Met-Anteil an den SAS ab, während der XL-Gehalt anstieg. In beiden Fällen gab es jedoch nur zwischen einem Met:Cys-Verhältnis von 40:60 und 45:55 signifikante $(\mathrm{p}<0,05)$ Unterschiede. Dies kann in der signifikant $(\mathrm{p}<0,05)$ geringeren FI bei einem Met:Cys-Verhältnis von 40:60 begründet sein. Laut Yu et al. (1990) führt eine Restriktion der FI zu erhöhten XP- und niedrigeren XLGehalten in den Tieren. Fatufe und Rodehutscord (2005) stellten einen erhöhten XL-Gehalt bei steigender Met-Konzentration fest, beobachteten jedoch keinen Effekt auf den XP-Gehalt. Im Gegensatz dazu gaben Zhan et al. (2006) an, dass der Gehalt an abdominalem Fett im Körper von Masthähnchen mit steigenden Met-Konzentrationen im Futter sinkt. Die Autoren führten dies auf ein gesteigerte Carnitin-Synthese sowie eine erhöhte Lipase-Aktivität im Stoffwechsel der Tiere zurück.

In der Growerphase gab es im Gegensatz zur Starterphase weder im XP- noch im XL-Gehalt signifikante Unterschiede zwischen den verschiedenen Met:Cys-Verhältnissen. Dies wurde auch von Graber et al. (1971) festgestellt, die die Auswirkungen der Met:Cys-Verhältnisse von 34:66 und 50:50 auf die Körperzusammensetzung untersuchten. Der XA-Gehalt sank in der Starterphase von Versuch 1 bei Veränderung des Met:Cys-Verhältnisses von 40:60 auf 45:55 und 50:50 signifikant $(\mathrm{p}<0,05)$ ab und eine weitere Erhöhung des Met-Anteils an den SAS hatte keine signifikanten Auswirkungen. In der Growerphase nahm der XA-Gehalt dagegen bis zu einem Met:Cys-Verhältnis von 50:50 z.T. signifikant $(\mathrm{p}<0,05)$ ab, um bis zu einem Met:Cys-Verhältnis von 60:40 wieder tendenziell anzusteigen. Ein Grund für den 


\section{Diskussion}

vergleichsweise hohen XA-Gehalt bei einem Met-Anteil $<50 \%$ an den SAS könnte die geringe FI in diesen Versuchsgruppen sein. So beobachtete Santoso (2001) einen signifikant höheren XA-Gehalt in Masthähnchen, die restriktiv gefüttert wurden im Vergleich zu Tieren, die freien Zugang zum Futter hatten.

Die umgekehrte Entwicklung ließ sich für den Nährstoffansatz beobachten. Sowohl der XPD als auch der XLD stieg in allen drei Wachstumsphasen (Abb. 12, 13 und 14) bis zu einem Met:Cys-Verhältnis von 50:50 signifikant $(\mathrm{p}<0,05)$ an und sank bei einer Erhöhung des MetAnteils auf 55 und $60 \%$ an den SAS z.T. signifikant $(\mathrm{p}<0,05)$ ab. Im Gegensatz dazu ermittelten Sasse und Baker (1974) keine Unterschiede im XPD zwischen Cys-Anteilen von 20-50\% an den SAS. Allerdings muss auch hier der bereits beschriebene Zusammenhang der Höhe der FI und dem Nährstoffansatz berücksichtigt werden. Selbstverständlich können bei einer geringen aufgenommenen XP- und XL-Menge auch nur geringe Ansatzwerte erwartet werden. Somit beeinflusste das Met:Cys-Verhältnis die Höhe des XPD und XLD nur indirekt.

\subsubsection{Versuch 2}

Der Einfluss des Met:Cys-Verhältnisses auf die zootechnischen Parameter (Tab. 21 und 22) zeigte sich auch in Versuch 2. Ebenso wie in Versuch 1 führte ein Met:Cys-Verhältnis von 40:60 in allen drei Wachstumsphasen zu einer signifikant $(\mathrm{p}<0,05)$ geringeren FI und damit verbunden $\mathrm{zu}$ einem signifikant $(\mathrm{p}<0,05)$ verringerten Wachstum der Tiere. Diese Beobachtung bestätigt die Vermutung, dass hohe Cys-Anteile an den SAS die FI unabhängig vom Alter der Tiere negativ beeinflussen. Auch andere Autoren stellten diesen Effekt eines Cys-Anteils von $\geq 50 \%$ der SAS auf die FI fest (z.B. Featherston und Rogler, 1974; Sasse und Baker, 1974; Sell et al., 1980; Dilger und Baker, 2007, 2008a, b). Im Gegensatz dazu konnten Tsiagbe et al. (1987) keine Auswirkungen eines Cys-Anteils von 62\% im Vergleich zu 38\% an den SAS auf die FI feststellen, das Wachstum der Tiere war jedoch signifikant verringert. Graber et al. (1971) stellten einen Alterseffekt fest. Sie beobachteten, dass sich der Cys-Anteil an den SAS, der sich negativ auf die FI der Tiere auswirkte, im Altersbereich von 2-8 Wochen von $>58 \%$ auf $>65 \%$ anstieg. Demnach scheinen die Tiere mit steigendem Alter höhere CysAnteile tolerieren zu können. Diese Theorie wird durch die Tatsache untermauert, dass dem Cys mit steigendem Alter der Tiere aufgrund des zunehmenden Federwachstums eine besondere Bedeutung zukommt (Wecke et al., 2017).

Dilger und Baker (2008b) gaben an, dass ein massiver Überschuss an Cys zu einer akuten metabolischen Azidose und damit verbunden zum Tod der Tiere führen kann. Es ist dementsprechend möglich, dass die Reduzierung der FI das Ziel hat, einer 


\section{Diskussion}

Stoffwechselbelastung entgegenzuwirken. Auch eine Imbalance der AS stellt eine mögliche Erklärung dar. Es wurde bereits mehrfach berichtet, dass eine Fehlversorgung mit AS zu einer Reduzierung der FI führt (z.B. Swatson et al., 2002; Kumar et al., 2016). Wie bereits in Versuch 1 ausführlich diskutiert, ist es durchaus denkbar, dass es in der Futtermischung mit einem Met:Cys-Verhältnis von 40:60 zu einer AS-Imbalance gekommen ist.

Obwohl die beobachteten Auswirkungen hoher Cys-Anteile an den SAS durch die aufgeführten Studien verifiziert werden, existieren auch Untersuchungen, in denen die Autoren zu einem gegenteiligen Ergebnis gekommen sind. So gaben sowohl Pesti et al. (1979) als auch Ohta und Ishibashi (1994) optimale Cys-Anteile von > 50\% der SAS an. Ohta und Ishibashi (1994) ermittelten zudem mit dem SAS-Gehalt steigende optimale Cys-Anteile an den SAS.

Im Vergleich zu einem Met:Cys-Verhältnis von 40:60 hatte eine Erhöhung des Met-Anteils auf $45 \%$ der SAS in allen Wachstumsphasen einen signifikant $(\mathrm{p}<0,05)$ positiven Effekt auf die Höhe der FI und damit verbunden auf das Wachstum der Tiere. Auch die Aufwandsparameter zeigten sich verbessert, die Verbesserung konnte jedoch nicht statistisch abgesichert werden. Diese positive Entwicklung wurde bereits in Versuch 1 beobachtet und untermauert einmal mehr die These, dass die negativen Effekte eines Met:Cys-Verhältnisses von 40:60 auf die zootechnischen Parameter in den hohen Cys-Anteilen begründet waren. Auch Graber et al. (1971) und Sasse und Baker (1974) gaben an, dass sich die Futterverwertung verbesserte, wenn der Met-Anteil an den SAS > 40\% betrug. Im Gegensatz dazu stellten Wecke et al. (2015a) jedoch keine signifikanten Unterschiede in Bezug auf die FI, LMZ und den FA bei einem Met:Cys-Verhältnis von 40:60 bzw. 45:55 fest.

Ebenso wie in Versuch 1 führte auch in Versuch 2 ein Met:Cys-Verhältnis von 50:50 zu einer weiteren signifikanten $(\mathrm{p}<0,05)$ Steigerung der FI und des Wachstums. Die Aufwandsparameter waren jedoch wiederum nur tendenziell verbessert. Somit bestätigen die Ergebnisse verschiedene Studien, die einen optimalen Met-Anteil von 50-55\% der SAS angaben (Graber und Baker, 1971; Moran Jr., 1981; Kalinowski et al., 2003a, b; Khan et al., 2015a). Auch Marquardt und Campbell (1975) stellten durch die Erhöhung des Met-Anteils von $41 \%$ auf 52\% der SAS ein signifikant verbessertes Wachstum fest. In dieser Untersuchung und in einer Studie von Powell et al. (2011) zeigte sich jedoch auch die Futterverwertung signifikant verbessert. Baker et al. (1996) ermittelten zwar einen optimalen Met-Anteil von mind. $48 \%$, beobachteten jedoch eine signifikant verringerte Futterverwertung bei einem Met:Cys-Verhältnis von 50:50 verglichen mit 44:56.

Ein Vergleich der zootechnischen Parameter bei einem Met:Cys-Verhältnis von 50:50 und 55:45 zeigte keine signifikanten Unterschiede. Während diese Beobachtungen in Versuch 2 in 


\section{Diskussion}

allen drei Wachstumsphasen gemacht wurden, ergaben einige Untersuchungen jedoch einen Einfluss des Alters der Tiere auf das optimale Met:Cys-Verhältnis. So gaben Wecke et al. (2015a) optimale Anteile von mind. 55\% Met an den SAS in der Starter- und max. 45\% Met an den SAS in der Growerphase an. Auch das NRC (1994) empfahl einen mit steigendem Alter der Tiere sinkenden Met-Anteil von 57\% an den SAS in der Starter- und von 53\% an den SAS in der Growerphase. Im Gegensatz dazu ermittelten Wheeler und Latshaw (1981) jedoch einen optimalen Met-Anteil von $46 \%$ an den SAS für die Starter- und von 57-62\% an den SAS für die Growerphase.

Entgegen den Ergebnissen aus Versuch 1 gab es in Versuch 2 durch die Erhöhung des Met:CysVerhältnisses auf 60:40 in keiner der Wachstumsphasen signifikante Auswirkungen auf die zootechnischen Parameter. Während in der Starterphase in der Tendenz eine Verbesserung der Wachstumsleistung beobachtet werden konnte, waren die Parameter in der Growerphase und bei Betrachtung des gesamten Versuchszeitraumes im Vergleich zu einem Met:Cys-Verhältnis von 50:50 jedoch tendenziell verschlechtert. Dies könnte für eine altersabhängige Toleranz der Tiere gegenüber hohen Met-Anteilen an den SAS und eine steigende Bedeutung des CysAnteils in der Growerphase sprechen. Auch Sünder et al. (2015a, b) konnten keine signifikanten Unterschiede zwischen Met:Cys-Verhältnissen von 48:52 und 59:41 in Bezug auf die FI und das Wachstum von wachsenden Masthähnchen im Alter von 1-3 bzw. 1-5 Wochen feststellen. Marquardt und Campbell (1975) berichteten dagegen von einem signifikant verbesserten Wachstum der Tiere, wenn das Met:Cys-Verhältnis von 52:48 auf 59:41 verändert wurde. Es scheint also Dissonanzen über die Auswirkungen hoher Met-Anteile an den SAS zu geben, die weiterer Klärung bedürfen. Möglicherweise lassen sich die unterschiedlichen Ergebnisse in Versuch 1 und 2 mit der Proteinquelle erklären, da sich die eingesetzten Futtermischungen nur darin unterschieden.

Wie bereits in der Diskussion von Versuch 1 erwähnt, muss jedoch auch bei einem Vergleich der Ergebnisse aus Versuch 2 mit verschiedenen Literaturangaben der möglicherweise unterschiedliche SAS-Gehalt bedacht werden.

Ebenso wie in Versuch 1 nahm der N-Ansatz mit einem steigenden Met-Anteil bis zu 50\% an den SAS zu und sank, wenn der Met-Anteil 50\% an den SAS überschritt. Lediglich in der Starterphase konnte bei einem Met:Cys-Verhältnis von 60:40 eine Steigerung des N-Ansatzes beobachtet werden. Der bereits in der Diskussion zu Versuch 1 beschriebene Zusammenhang zwischen der FI und dem N-Ansatz gilt jedoch selbstverständlich auch in diesem Versuch. Dementsprechend kann auch in diesem Fall nur von einem indirekten Einfluss des Met:CysVerhältnisses auf die Höhe des N-Ansatzes die Rede sein. 


\section{Diskussion}

Das Met:Cys-Verhältnis beeinflusste allerdings die Qualität des Futterproteins. So hatte ein Met:Cys-Verhältnis von 40:60 in allen Wachstumsphasen (Tab. 24) eine verringerte Proteinqualität zur Folge. Während es in der Starter- und Growerphase bei einem Met:CysVerhältnis von 45:55 nur zu einer tendenziellen Verbesserung der Proteinqualitätsparameter kam, konnte bei Betrachtung des gesamten Versuchszeitraumes eine signifikante $(\mathrm{p}<0,05)$ Steigerung beobachtet werden. Auch Wecke et al. (2015a) stellten keine signifikanten Unterschiede in der Proteinqualität zweier Futtermischungen mit einem Met:Cys-Verhältnis von 40:60 bzw. 45:55 fest. Dies galt sowohl für die Starter- als auch für die Growerphase. Eine Erhöhung des Met:Cys-Verhältnisses auf 50:50 in Versuch 2 führte zu einer weiteren Aufwertung der Proteinqualität, die jedoch ebenfalls lediglich in Bezug auf den gesamten Versuchszeitraum signifikant $(\mathrm{p}<0,05)$ war. Im Vergleich zu einem Met:Cys-Verhältnis von 40:60 kam es allerdings in allen drei Wachstumsphasen zu einer signifikanten Verbesserung der Proteinqualität. Auch Liebert et al. (2010) stellten eine solche Entwicklung in der Starterphase fest, in der Growerphase war die Proteinqualität dagegen bei einem Met:CysVerhältnis von 51:49 bzw. 57:43 tendenziell schlechter. In keiner der drei Wachstumsphasen gab es signifikante Unterschiede zwischen einem Met:Cys-Verhältnis von 50:50, 55:45 und 60:40. Das lässt vermuten, dass selbst bei hohen Met-Anteilen von 60\% an den SAS kein Mangel an Cys vorlag, der einen Abbau des Mets zur Folge gehabt und somit die Proteinqualität negativ beeinflusst hätte. Die Ergebnisse ordnen sich in die von Khan et al. (2015a) ein, die ebenfalls keine signifikanten Unterschiede in der Proteinqualität verschiedener Futtermischungen mit einem Met:Cys-Verhältnis von 49:51, 52:48 und 54:46 feststellten. Auch Wecke et al. (2015b) und Sünder et al. (2015a) ermittelten nur numerische Unterschiede zwischen Met:Cys-Verhältnissen von 48:52 und 59:41. In einer weiteren Untersuchung von Sünder et al. (2015b) kam es jedoch sowohl in der Starter- als auch in der Growerphase zu einem signifikanten Rückgang der Proteinqualität, wenn der Met-Anteil an den SAS von 48\% auf 59\% angehoben wurde. Im Gegensatz dazu konnten Farke et al. (2010) in der Starter- und in der Growerphase eine signifikant höhere Proteinqualität bei einem Met:Cys-Verhältnis von 57:43 im Vergleich zu 51:49 ermitteln.

Die Met-Wirksamkeit war in allen drei Wachstumsphasen (Abb. 15, 16 und 17) bei einem Met:Cys-Verhältnis von 50:50 maximiert, es gab jedoch nur zu einem Met:Cys-Verhältnis von 60:40 signifikante $(\mathrm{p}<0,05)$ Unterschiede. Diese Entwicklung kann mit der sich verändernden Met-Konzentration bei vergleichbarer Proteinqualität $b$ erklärt werden und deutet darauf hin, dass bei einem Met:Cys-Verhältnis von 60:40 ein Teil des Mets für die Cys-Synthese verwendet wurde, während der Met-Abbau in den anderen Futtermischungen minimiert war. In Versuch 1 


\section{Diskussion}

wurde im Gegensatz dazu jedoch bereits bei einem Met-Anteil von > 50\% der SAS ein negativer Effekt auf die Met-Wirksamkeit ermittelt. Die Ergebnisse von Khan et al. (2015a) und Wecke et al. (2015a) werden dagegen bestätigt. Die Autoren stellten ebenfalls keine signifikanten Unterschiede in der Met-Wirksamkeit bei verschiedenen Met:Cys-Verhältnisse von 49:51, 52:48 und 54:46 bzw. 40:60 und 45:55 in der Starter- und Growerphase fest. In einer Studie von Liebert et al. (2010) zeigte der Vergleich der Met:Cys-Verhältnisse 40:60 und 51:49 in der Starterphase ebenfalls nur numerische Unterschiede. Tendenziell führte jedoch ein Met:Cys-Verhältnis von 51:49 zu einer größeren Met-Wirksamkeit. In der Growerphase war die Met-Wirksamkeit bei einem Met:Cys-Verhältnis von 51:49 dagegen in der Tendenz geringer.

In Übereinstimmung mit den Ergebnissen aus Versuch 2 beobachteten Wecke et al. (2015b) in der Starterphase ebenfalls einen signifikanten Rückgang der Met-Wirksamkeit bei einem Met:Cys-Verhältnis von 59:41 im Vergleich zu 48:52 und 54:46. In der Growerphase gab es jedoch nur noch numerische Unterschiede. Diese Beobachtung machten auch Sünder et al. (2015b) und vermuteten als Grund einen erhöhten Cys-Bedarf für das Federwachstum in den ersten drei Lebenswochen. In einer Untersuchung von Liebert et al. (2010) führte ein Met:CysVerhältnis von 57:43 verglichen mit 40:60 in der Starterphase zu einer tendenziell höheren MetWirksamkeit, während in der Growerphase die gegenteilige Entwicklung beobachtet wurde. Farke et al. (2010) stellten dagegen weder in der Starter- noch in der Growerphase signifikante Unterschiede in der Met-Wirksamkeit zwischen Met:Cys-Verhältnissen von 51:49 und 57:43 fest.

Dementsprechend gibt es insbesondere hohe Met-Anteile an den SAS betreffend noch Klärungsbedarf. Außerdem sollte ebenso wie in Versuch 1 auch bei einem Vergleich der Ergebnisse aus Versuch 2 mit verschiedenen Literaturangaben bedacht werden, dass der SASGehalt nicht immer konstant gehalten wurde.

Der auf Grundlage der ermittelten Met-Wirksamkeiten abgeleitete Met-Bedarf war in der Starterphase (Tab. 25) bei einem Met:Cys-Verhältnis von 45:55 und 50:50 am niedrigsten, während er sich bei den anderen Met:Cys-Verhältnissen auf einem vergleichbaren, höheren Niveau befand. Der vergleichsweise hohe Met-Bedarf bei einem Met:Cys-Verhältnis von 40:60 steht im Gegensatz zu den Ergebnissen aus Versuch 1 und ist in der geringen Proteinqualität $b$ und der damit verbundenen niedrigen Met-Wirksamkeit begründet. In der Growerphase (Tab. 26) konnte der geringste Met-Bedarf bei einem Met-Anteil von $\leq 50 \%$ der SAS beobachtet werden und steigende Met-Anteile an den SAS hatten steigende Bedarfswerte zur Folge. Dieser Zusammenhang wurde auch von Farke et al. (2010), Liebert et al. (2010) und Sünder et al. 


\section{Diskussion}

(2015c) beobachtet. Zudem zeigte sich beim Vergleich der Starter- und Growerphase ein sinkender Met-Bedarf mit steigendem Alter, was die Ergebnisse von Farke et al. (2010) und Sünder et al. (2015b) sowie die Versorgungsempfehlungen des NRC (1994), der GfE (1999) und von Aviagen (2014) bestätigt.

Die abgeleiteten optimalen Met-Konzentrationen in der Futtermischung waren vergleichbar mit den in Versuch 1 ermittelten Werten. So ergab sich in der Starterphase bei einer täglichen FI von $50 \mathrm{~g}$ und einem XPD von 6g/d eine optimale Met-Konzentration von 0,38-0,43\% abhängig vom Met:Cys-Verhältnis. Wurde dagegen ein XPD von 10g/d angenommen, stiegen die Werte auf $0,75-0,85 \%$. In der Growerphase lagen die optimalen Met-Konzentrationen bei einer täglichen FI von $120 \mathrm{~g}$ zwischen $0,30 \%$ und $0,38 \%$ (12g XPD pro Tag) bzw. $0,66 \%$ und $0,85 \%$ (20g XPD pro Tag). Auch Literaturangaben zum Met-Bedarf befinden sich in diesem Bereich. So schwanken die Empfehlungen zwischen 0,18\% (Klain et al., 1960), 0,45\% (Almquist, 1952), 0,52-0,54\% (Chamruspollert et al., 2002) und 0,60-0,65\% (Graber et al., 1971). Auch die Versorgungsempfehlungen des NRC (1994), der GfE (1999) und von Aviagen (2014) liegen in Abhängigkeit vom Alter der Tiere bei 0,35-0,56\% Met. Gründe für die großen Schwankungsbreiten können z.B. das Alter und die Genetik der Tiere oder unterschiedliche Versuchsbedingungen sein (Brede et al., 2018). Außerdem wurden wie bereits diskutiert z.T. verschiedene Parameter als Grundlage für die Bedarfsbewertung verwendet, die bei einem Vergleich der Daten berücksichtigt werden sollten.

Analog zu Versuch 1 wurde auch in Versuch 2 bei einem Met:Cys-Verhältnis von 40:60, sowohl am Ende der Starter- als auch der Growerphase, der höchste XP-Gehalt in den Tieren ermittelt. Mit steigendem Met-Anteil bis zu 50\% an den SAS nahm der XP-Gehalt ab und stieg bei einer weiteren Erhöhung des Met-Anteils wieder an (Tab. 27). Diese Entwicklung war jedoch nicht signifikant. Der XL-Gehalt war dagegen zu beiden Zeitpunkten in den Tieren der Versuchsgruppe A (TMP 40:60) am geringsten, nahm jedoch bis zu einem Met-Anteil von bis zu 50\% an den SAS tendenziell zu und darüber hinaus wieder ab. Beide Beobachtungen stehen im Zusammenhang mit der FI. Dies wurde auch von Yu et al. (1990) beschrieben. Demnach führt eine verringerte FI zu erhöhten XP- und verringerten XL-Gehalten in den Tieren. Zusätzlich wurde in einigen Studien eine Verbindung zwischen den Met-Konzentrationen im Futter und dem XL-Gehalt in den Tieren festgestellt. So ermittelten Fatufe und Rodehutscord (2005) steigende XL-Gehalte in den Tieren bei steigenden Met-Konzentrationen im Futter. Zhan et al. (2006) beobachteten dagegen jedoch eine negative Korrelation zwischen der MetKonzentration in der Futtermischung und dem Gehalt an abdominalem Fett und begründeten dies mit einer gesteigerten Carnitin-Synthese und einer erhöhten Lipase-Aktivität im 


\section{Diskussion}

Stoffwechsel der Tiere. Im Gegensatz zu den Ergebnissen von Versuch 2 stellten Graber et al. (1971) keine signifikanten Unterschiede im XP- und XL-Gehalt der Tiere bei Met:CysVerhältnissen von 34:66 und 50:50 fest. Während der XA-Gehalt in der Starterphase von Versuch 2 mit steigendem Met-Anteil an den SAS sank, nahm er in der Growerphase nur bis zu einem Met-Anteil von 50\% an den SAS ab und stieg bei steigenden Met-Anteilen tendenziell wieder an. Ebenso wie in Versuch 1 ist eine mögliche Erklärung die geringe FI bei geringen Met-Anteilen an den SAS.

Ebenso wie der XL-Gehalt in den Tieren stieg auch der XLD in allen drei Wachstumsphasen bis zu einem Met:Cys-Verhältnis von 50:50 signifikant $(\mathrm{p}<0,05)$ an. Während eine weitere Erhöhung des Met-Anteils an den SAS in der Starterphase (Abb. 18) keinen signifikanten Effekt hatte, sank der XLD in der Growerphase (Abb. 19) und bei Betrachtung des gesamten Versuchszeitraumes (Abb. 20) bei einem Met:Cys-Verhältnis von 55:45 und 60:40 jedoch signifikant $(\mathrm{p}<0,05) \mathrm{ab}$. Auch der XPD nahm in allen Wachstumsphasen mit steigendem MetAnteil bis zu 50\% an den SAS signifikant $(\mathrm{p}<0,05)$ zu. Im Gegensatz zum XLD hatten Met:Cys-Verhältnisse von 55:45 und 60:40 jedoch in keiner Wachstumsphase einen signifikanten Einfluss. Dieses Ergebnis widerspricht zudem denen aus Versuch 1, in dem der XPD in der Growerphase und bei Betrachtung des gesamten Versuchszeitraumes bei einem Met:Cys-Verhältnis von 60:40 im Vergleich zu 50:50 signifikant abnahm. Es unterstützt jedoch die Angaben von Sasse und Baker (1974), die ebenfalls keine Unterschiede im XPD bei Met:Cys-Verhältnissen zwsichen $20 \%$ und $50 \%$ an den SAS ermittelten. Sowohl in Versuch 1 als auch in Versuch 2 wurde allerdings der Zusammenhang zwischen der FI und dem Nährstoffansatz deutlich, der die unterschiedlichen Ansatzwerte bei verschiedenen Met:CysVerhältnissen erklärt.

Erwartungsgemäß ergab auch die makroskopische Untersuchung (Tab. 28) in Versuch 2 signifikant ( $\mathrm{p}=0,0013)$ geringere LM bei einem Met:Cys-Verhältnis von 40:60 im Vergleich zu 60:40. Während es jedoch in Bezug auf die absolute DDM nur numerische Differenzen gab, unterschied sich die relative DDM signifikant $(\mathrm{p}=0,0079)$ zwischen den Versuchsgruppen. Dies könnte für ein verstärktes Darmwachstum sprechen, das von einem Met-Mangel ausgelöst wurde, der durch ein ungünstiges Met:Cys-Verhältnis bedingt war. Ein längerer Darm bietet eine größere Absorptionsfläche und hat längere Retentionszeiten des Chymus zur Folge. Dies kann als eine Reaktion des Körpers verstanden werden, die Nährstoffaufnahme zu verbessern. Nach Sibly (1981) nimmt das Längenwachstum des Darmes bei Futtermischungen mit einer nicht ausgeglichenen AS-Zusammensetzung zu. In einer Untersuchung von Swatson et al. 


\section{Diskussion}

(2002) hatte eine nicht ausbalancierte Futtermischung dagegen keinen Effekt auf die relative DDM von Masthähnchen.

Weder in Bezug auf die relative Schleimhautoberfläche, die relative Zottenoberfläche noch das Zotten-/Kryptenepithelvolumenverhältnis (Tab. 29) gab es signifikante Unterschiede zwischen einem Met:Cys-Verhältnis von 40:60 und 60:40. Dies stimmt mit den Ergebnissen von Swatson et al. (2002) überein, die ebenfalls nur tendenzielle Unterschiede im Zotten-/Kryptenverhältnis zwischen einer ausbalancierten und einer nicht ausbalancierten Futtermischung feststellten. Da die Absorptionsoberfläche im Dünndarm durch Zotten vergrößert wird (Fuller, 2004), kann das Zotten-/Kryptenverhältnis Auskunft über die Gesundheit der Dünndarmschleimhaut geben. Dabei ist ein hoher Wert ein Anzeichen für eine verringerte Turnover-Rate der Darmschleimhaut, die zu einem geringeren Erhaltungsbedarf führt und somit das Wachstum der Tiere positiv beeinflussen kann (van Nevel et al., 2005). Dementsprechend hatten die eingestellten Met:Cys-Verhältnisse keinen Einfluss auf die Darmgesundheit der Tiere.

\subsubsection{Versuch 3}

Ein Vergleich der Ergebnisse von Versuch 1 und 2 ergab Diskrepanzen in Bezug auf die Auswirkungen eines Met:Cys-Verhältnisses von 60:40. Die in Versuch 1 beobachtete Verschlechterung der erfassten Parameter, konnte in Versuch 2 nicht bestätigt werden. Aus diesem Grund wurde in Versuch 3 ein direkter Vergleich der Met:Cys-Verhältnisse 50:50, 55:45 und 60:40 beim Einsatz von HM und TMP als Hauptproteinquelle vorgenommen.

Weder in der Starter- und Growerphase noch bei Betrachtung des gesamten Versuchszeitraumes (Tab. 30) konnte ein signifikanter Einfluss des Met:Cys-Verhältnisses auf die zootechnischen Parameter festgestellt werden. Die Tiere der HM-Versuchsgruppen wiesen jedoch tendenziell eine höhere FI und damit verbunden höhere finale LM und tägliche LMZ auf. Da es keine signifikanten Unterschiede gab, lag vermutlich in keiner der verwendeten Futtermischungen ein Cys-Mangel vor, der einen Abbau von Met zur Folge gehabt und somit das Wachstum der Tiere negativ beeinflusst hätte. Demnach wurden die Tendenzen aus Versuch 2 bestätigt. Auch in verschiedenen Studien (Moran Jr., 1981; Wheeler und Latshaw, 1981; Kalinowski et al., 2003a; Powell et al., 2011; Khan et al., 2015; Sünder et al., 2015a, b) wurden keine Unterschiede im Wachstum der Tiere bei Met:Cys-Verhältnissen zwischen 47:53 und 60:40 beobachtet. Im Gegensatz dazu ermittelten Marquardt und Campbell (1975) jedoch eine signifikante Steigerung der LMZ, wenn der Met-Anteil von 49\% auf 52\% und 59\% an den SAS angehoben wurde. Literaturangaben zum Einfluss auf die Aufwandsparameter variieren ebenfalls. Während Wheeler und Latshaw (1981) und Powell et al. (2011) in Übereinstimmung 


\section{Diskussion}

mit den Ergebnissen aus Versuch 3 keine signifikanten Unterschiede im FA zwischen Met:CysVerhältnissen von 53:47 und 60:40 bzw. 50:50 und 60:40 feststellten, ermittelten Moran Jr. (1981), Kalinowski et al. (2003a) und Sünder et al. (2015a, b) einen negativen Effekt von MetAnteilen $\geq 55 \%$ an den SAS. Marquardt und Campbell (1975) gaben dagegen einen positiven Effekt einer Erhöhung des Met-Anteils von 49\% auf 52\% und 59\% an den SAS auf den FA an.

Zusätzlich wurden die Auswirkungen der Met:Cys-Verhältnisse auf die zootechnischen Parameter nicht von der Proteinquelle beeinflusst. Entgegen dieser Beobachtung zeigten sich bei der Beurteilung der Proteinqualität (Tab. 33) z.T. jedoch Unterschiede zwischen den Met:Cys-Verhältnissen beim Einsatz von HM und TMP. Obwohl es in der Starterphase keine signifikanten Unterschiede in der Höhe der FI zwischen den Met:Cys-Verhältnissen gab, wurde mit steigendem Met-Anteil von $50 \%$ auf $60 \%$ an den SAS eine signifikante $(\mathrm{p}<0,05)$ Steigerung des N-Ansatzes beobachtet. Diese Entwicklung ist schwer zu erklären. Die höchste Proteinqualität wurde bei einem Met:Cys-Verhältnis von 60:40 erzielt. Während es beim Einsatz von HM jedoch nur numerische Unterschiede zwischen den Met:Cys-Verhältnissen gab, war die Proteinqualität beim Einsatz von TMP bei einem Met-Anteil von $50 \%$ im Vergleich zu 60\% der SAS signifikant ( $<<0,05)$ verringert. In den Versuchen von Farke et al. (2010) und Khan et al. (2015a) konnten in der Starterphase ebenfalls keine signifikanten Unterschiede in der Proteinqualität zwischen einem Met:Cys-Verhältnis von 51:49 und 57:43 bzw. 49:51, 48:52 und 54:46 festgestellt werden. Sünder et al. (2015b) sowie Wecke et al. (2015b) ermittelten dagegen eine signifikant höhere Proteinqualität bei einem Met-Anteil von $48 \%$ verglichen mit $59 \%$ an den SAS.

Zudem wurden in den HM-Futtermischungen im Vergleich zu denen mit TMP tendenziell höhere Werte ermittelt. Ein Grund für diese Beobachtung könnten die höheren Gehalte an kristallinem DL-Met in den HM-Futtermischungen sein. Kristalline AS können im Vergleich zu proteingebundenen AS besser verwertet werden (z.B. Chung und Baker, 1992; Sveier et al., 2001) und führen so zu einer verbesserten Proteinqualität. Auch die Gesamt-Konzentration der limitierenden AS hat einen Einfluss. Da diese sich in den Futtermischungen mit dem gleichen Met:Cys-Verhältnis jedoch nicht unterschied, ist dieser Effekt auszuschließen.

Im Gegensatz zur Starterphase nahm der N-Ansatz in der Growerphase mit steigendem MetAnteil an den SAS ab. Während es beim Einsatz von HM nur tendenzielle Unterschiede zwischen den Versuchsgruppen gab, war in den Versuchsgruppen mit TMP beim Vergleich der Met:Cys-Verhältnisse 50:50 und 60:40 sogar ein signifikanter ( $\mathrm{p}<0,05)$ Rückgang zu beobachten. Dies stimmt mit der Entwicklung der FI in der Growerphase überein. Entgegen den Ergebnissen der Starterphase war die Proteinqualität in den HM-Futtermischungen bei 


\section{Diskussion}

einem Met:Cys-Verhältnis von 55:45 am höchsten und unterschied sich signifikant $(\mathrm{p}<0,05)$ von den für ein Met:Cys-Verhältnis von 60:40 ermittelten Werten. Dies spricht für einen CysMangel bei hohen Met-Anteilen an den SAS, der zu einem Abbau von Met und damit zu einer verminderten Proteinqualität geführt hat. Aufgrund der mit dem Alter der Tiere steigenden Bedeutung von Cys für das Federwachstum trat dieser Effekt erst in der Growerphase auf. Beim Einsatz von TMP wurde die höchste Proteinqualität dagegen bei einem Met-Anteil von 50\% an den SAS erzielt und es gab nur numerische Unterschiede zu Met-Anteilen von 55\% und 60\% an den SAS. Auch Farke et al. (2010), Khan et al. (2015a), Sünder et al. (2015b) und Wecke et al. (2015b) stellten in der Growerphase keine signifikanten Unterschiede in der Proteinqualität zwischen Met:Cys-Verhältnissen von 51:49 und 57:43, 49:51, 48:52 und 54:46 bzw. 48:52 und 59:41 fest.

Tendenziell zeigte der Vergleich der Proteinquellen in der Growerphase zudem eine höhere Proteinqualität in den Futtermischungen mit TMP verglichen mit HM. Dementsprechend stellte sich verglichen mit der Starterphase ein umgekehrtes Bild dar. Möglicherweise ist eine altersabhängige Anpassung der Enzymsysteme in den Tieren an antinutritive Faktoren im TMP der Grund für diese Beobachtung.

Bei Betrachtung des gesamten Versuchszeitraumes unterschied sich die Proteinqualität sowohl beim Einsatz von TMP als auch HM nicht signifikant zwischen den Met:Cys-Verhältnissen. Demnach haben sich die gegenteiligen Effekte der Proteinquellen in der Starter- und Growerphase ausgeglichen. Im Gegensatz dazu stellten Wecke et al. (2015b) jedoch eine signifikant höhere Proteinqualität bei einem Met:Cys-Verhältnis von 48:52 verglichen mit 59:41 für einen Altersbereich von 1-36 Tagen fest.

Auffällig sind zudem die im Vergleich zu HM hohen Standardabweichungen in den Versuchsgruppen mit TMP, die sicherlich einen Einfluss auf die Signifikanzen hatten.

Eine vergleichende Betrachtung der Proteinqualität der Futtermischungen A (TMP 50:50), B (TMP 55:45), C (TMP 60:40), E (HM 50:50), F (HM 55:45) und G (HM 60:40) mit den beiden positiven Kontrollen zeigte signifikante $(\mathrm{p}<0,05)$ Unterschiede. Die signifikant $(\mathrm{p}<0,05)$ höhere Proteinqualität in den positiven Kontrollen beweist, dass die SAS in den anderen Futtermischungen tatsächlich limitierend waren. Die limitierende Position der AS ist eine wichtige Prämisse für die Ermittlung der Met-Wirksamkeit und die Ableitung des Met-Bedarfs.

Die höchste Met-Wirksamkeit wurde sowohl in der Starter- und Growerphase (Abb. 21 und 22) als auch bei Betrachtung des gesamten Versuchszeitraumes (Abb. 23) beim Einsatz beider Proteinquellen bei einem Met:Cys-Verhältnis von 50:50 ermittelt. In den Versuchsgruppen mit TMP gab es in der Starterphase nur tendenzielle Unterschiede zu den anderen Met:Cys- 


\section{Diskussion}

Verhältnissen und die Met-Wirksamkeit unterschied sich in der Growerphase und bei Betrachtung des gesamten Versuchszeitraumes zwischen einem Met-Anteil von 50\% und 55\% an den SAS ebenfalls nur numerisch. Beim Einsatz von HM nahm die Met-Wirksamkeit jedoch mit steigendem Met-Anteil an den SAS signifikant $(\mathrm{p}<0,05)$ ab. Sowohl Sünder et al. $(2015 b)$ als auch Wecke et al. (2015b) ermittelten in der Starterphase eine signifikant höhere MetWirksamkeit bei einem Met:Cys-Verhältnis von 48:52 verglichen mit 59:41. In der Growerphase konnten die Autoren dagegen nur tendenzielle Unterschiede feststellen. Wecke et al. (2015b) untersuchten zusätzlich die Auswirkungen im gesamten Versuchszeitraum (Tag 136) und stellten eine signifikant höhere Met-Wirksamkeit bei einem Met:Cys-Verhältnis von 48:52 verglichen mit 59:41 fest. Im Gegensatz dazu unterschied sich die Met-Wirksamkeit in den Versuchen von Farke et al. (2010) und Khan et al. (2015a) sowohl in der Starter- als auch in der Growerphase bei Met:Cys-Verhältnissen von 51:49 und 57:43 bzw. 49:51, 52:48 und 54:46 nur numerisch voneinander. Wie bereits an anderer Stelle mehrfach erwähnt, muss beim Vergleich der verschiedenen Met:Cys-Verhältnisse aber berücksichtigt werden, dass im Gegensatz zu den in dieser Arbeit aufgeführten Versuchen der Gehalt an SAS in den Futtermischungen nicht immer konstant gehalten wurde. Dadurch wird die Möglichkeit einer vergleichenden Betrachtung eingeschränkt.

Grundsätzlich kann der Rückgang in der Met-Wirksamkeit mit der steigenden MetKonzentration erklärt werden. Es wird jedoch deutlich, dass die Met-Wirksamkeit trotz vergleichbarer Met-Konzentrationen in der Starterphase bei einem Met:Cys-Verhältnis von 50:50 beim Einsatz von HM signifikant $(\mathrm{p}<0,05)$ höher war als in der TMP-Futtermischung mit dem gleichen Met:Cys-Verhältnis. Der Grund hierfür ist die signifikant $(\mathrm{p}<0,05)$ geringere Proteinqualität in Versuchsgruppe A (TMP 50:50) verglichen mit Versuchsgruppe E (HM 50:50). Demnach wurde das HM in der Starterphase von den Tieren besser verwertet und die AS konnten effizienter genutzt werden. In den anderen Wachstumsphasen konnte ein solcher Effekt dagegen nicht festgestellt werden.

Die in Versuch 3 abgeleiteten Met-Bedarfswerte waren sowohl in der Starter- (Tab. 34) als auch in der Growerphase (Tab. 35) bei einem Met:Cys-Verhältnis von 50:50 am niedrigsten und stiegen mit einem steigenden Met-Anteil an den SAS an. Dies ist in den sinkenden Werten für die Met-Wirksamkeit begründet und bestätigt die Ergebnisse aus Versuch 1 und 2. Auch Farke et al. (2010) und Sünder et al. (2015c) ermittelten steigende Met-Bedarfswerte beim Vergleich der Met:Cys-Verhältnisse 51:49 und 57:43 bzw. 45:55 und 59:41.

Eine vergleichende Betrachtung der Bedarfswerte in den beiden Wachstumsphasen zeigte keinen eindeutigen Trend. Ein Met:Cys-Verhältnis von 50:50 führte beim Einsatz beider 


\section{Diskussion}

Proteinquellen zu mit dem Alter der Tiere sinkenden Bedarfswerten. Bei einem suboptimalen Met:Cys-Verhältnis von 60:40 nahm der Met-Bedarf dagegen in beiden Fällen mit steigendem Alter der Tiere zu. Met-Anteile von 55\% an den SAS hatten beim Einsatz von TMP in der Growerphase sinkende Met-Bedarfswerte zur Folge, während beim Einsatz von HM ein mit dem Alter der Tiere steigender Bedarf ermittelt wurde. Ähnliche Differenzen zeigen auch Daten aus der Literatur. Während Farke et al. (2010) und Sünder et al. (2015c) mit steigendem Alter der Tiere sinkende Bedarfswerte feststellten, konnten Khan et al. (2015b) keinen eindeutigen Alterseffekt beobachten. Im Gegensatz dazu stieg die optimale Met-Konzentration in der Futtermischung in einer Untersuchung von Graber et al. (1971) abhängig vom Alter der Tiere an.

Die abgeleiteten optimalen Met-Konzentrationen in der Futtermischung lagen in einem ähnlichen Bereich wie die in Versuch 1 und 2 ermittelten Werte. In der Starterphase wurde bei einer täglichen FI von 50g und einem XPD von 6 bzw. 10 g/d abhängig vom Met:CysVerhältnis eine optimale Met-Konzentration von 0,36-0,43\% bzw. 0,71-0,85\% ermittelt. Die Werte in der Growerphase lagen bei einer täglichen FI von $120 \mathrm{~g}$ bei $0,30-0,41 \%$ (12g XPD pro Tag) bzw. 0,67-0,90\% (20g XPD pro Tag). Demnach spiegeln sie ebenfalls die verschiedenen Literaturangaben zu Met-Gehalten von 0,45\% (Almquist, 1952), 0,52-0,54\% (Chamruspollert et al., 2002) und 0,60-0,65\% (Graber et al., 1971) wider. Auch die Empfehlungen des NRC (1994), der GfE (1999) und von Aviagen (2014) liegen mit 0,35-0,65\% in diesem Bereich. Jedoch gilt es, wie bereits ausführlich diskutiert, die unterschiedlichen Zielgrößen bei der Ermittlung der Bedarfszahlen bei einem Vergleich zu beachten. Hier bietet nur die angewandte Methode basierend auf dem „Göttinger Modell“ klar nachvollziehbare Eckdaten und Zielgrößen bei der Bedarfsbewertung an.

Weder beim Einsatz vom TMP noch HM hatte das Met:Cys-Verhältnis einen Einfluss auf die Körperzusammensetzung der Tiere (Tab. 36). Tendenziell wurde der höchste XP-Gehalt am Ende der Starterphase in den Tieren aus den Versuchsgruppen mit einem Met:Cys-Verhältnis von 50:50 ermittelt, während der tendenziell höchste Wert am Ende der Growerphase bei einem Met:Cys-Verhältnis von 55:45 festgestellt wurde. Der XL-Gehalt war dagegen beim Einsatz von TMP an Tag 21 in den Tieren der Versuchsgruppe B (55:45) und an Tag 35 in den Tieren der Versuchsgruppe A (TMP 50:50) am höchsten. Beim Einsatz von HM wurde zu beiden Zeitpunkten in den Tieren Versuchsgruppe E (HM 50:50) der höchste XL-Gehalt beobachtet. Somit werden sowohl die Ergebnisse aus Versuch 1 und 2 als auch die Angaben von Graber et al. (1971) bestätigt. Die Angaben von Fatufe und Rodehutscord (2005) und Zhan et al. (2006), 


\section{Diskussion}

dass steigende Met-Konzentrationen einen Einfluss auf den XL-Gehalt in den Tieren haben, konnten dagegen nicht unterstützt werden.

Im Gegensatz zu der Körperzusammensetzung gab es zwischen den Versuchsgruppen jedoch Unterschiede in der Höhe des XPD und XLD. Während es in der Starterphase (Abb. 24) nur tendenzielle Unterschiede zwischen den Versuchsgruppen mit einem Met:Cys-Verhältnis von 50:50, 55:45 und 60:40 gab, nahm der XPD in der Growerphase (Abb. 25) mit steigenden MetAnteilen an den SAS ab. Diese Entwicklung war beim Einsatz von TMP zwischen den Met:Cys-Verhältnissen 55:45 und 60:40 signifikant $(\mathrm{p}<0,05)$ und ist nicht im Einklang mit den Ergebnissen von Sasse und Baker (1974), die keine signifikanten Unterschiede im XPD bei Cys-Anteilen zwischen 20 und 50\% an den SAS feststellten. Der XLD sank sowohl in den TMP- als auch in den HM-Versuchsgruppen bei Erhöhung des Met-Anteils von 50\% auf 55\% an den SAS signifikant $(\mathrm{p}<0,05)$ ab. Ein Met-Anteil von $60 \%$ an den SAS hatte dagegen wiederum eine tendenzielle Erhöhung des XLD zur Folge. Bei Betrachtung des gesamten Versuchszeitraumes (Abb. 26) gab es beim Einsatz beider Proteinquellen, ebenso wie in der Starterphase, nur numerische Unterschiede im XPD zwischen den Versuchsgruppen mit einem Met:Cys-Verhältnis von 50:50, 55:45 und 60:40. Zwischen den TMP-Versuchsgruppen unterschied sich zudem auch der XLD nur tendenziell. Beim Einsatz von HM zeigte sich dagegen die gleiche Entwicklung wie in der Growerphase. Grundsätzlich besteht jedoch natürlich auch in diesem Versuch ein Zusammenhang zwischen der Höhe der FI und dem Nährstoffansatz, sodass die beschriebenen Effekte nicht direkt bzw. ausschließlich dem Met:Cys-Verhältnis zuzuordnen sind. Ein Vergleich der Proteinquellen zeigte, dass in den HMVersuchsgruppen z.T. signifikant $(\mathrm{p}<0,05)$ höhere Ansatzwerte ermittelt wurden als in den TMP-Versuchsgruppen. Dies galt vor allem für den XLD und war nicht immer kongruent mit der Entwicklung der FI in den Versuchsgruppen. Da jedoch die Tiere der HM-Versuchsgruppen tendenziell höhere finale LM aufwiesen, haben sie in der Konsequenz auch einen höheren Nährstoffansatz erzielt. Demnach könnte in diesem Fall ein Effekt der Proteinquelle vorliegen. Möglichweise hat auch das unterschiedliche FS-Muster in den Insektenmehlen zu diesen Ergebnissen beigetragen. Machlin und Gordon (1961) gaben an, dass gesättigte FS das Wachstum von Masthähnchen hemmen, während mehrfach ungesättigte FS den gegenteiligen Effekt bewirken. Wie in den Kapiteln 2.2.1 und 2.2.2 aufgeführt, weist Tenebrio molitor einen höheren Gehalt an mehrfach ungesättigten FS wie z.B. Linolsäure auf als Hermetia illucens. Dementsprechend könnte dies eine Erklärung für die Unterschiede im Wachstum der Tiere sein. Zusätzlich hatten die Futtermischungen mit HM einen etwas höheren XL-Gehalt als diejenigen mit TMP (s. Anhangstab. 8 und 10). Auch diese Tatsache kann einen Einfluss gehabt haben. 
Diskussion

\subsection{Bewertung der Eignung von Hermetia illucens und Tenebrio molitor als Proteinquelle in der Mastgeflügelernährung}

Alle drei Wachstumsversuche haben gezeigt, dass eine vollständige Substitution von SES durch HM bzw. TMP in Futtermischungen für wachsende Masthähnchen ohne Leistungseinbußen möglich ist. Obwohl diese Fragestellung nicht der Fokus der vorliegenden Arbeit war, soll die Eignung der verwendeten Insektenmehle als alternative Proteinquelle in der Ernährung von Masthähnchen in der Folge einzeln diskutiert werden.

\subsubsection{Hermetia illucens}

Der Einsatz von HM in Versuch 1 führte zu vergleichbaren Wachstumsergebnissen (Tab. 14 und 15) wie der Einsatz von SES, die Tiere der SES-Versuchsgruppe F wiesen jedoch tendenziell etwas höhere finale LM und tägliche LMZ auf. Die FI war ebenfalls in Versuchsgruppe F (SES 50:50) höher als in Versuchsgruppe C (HM 50:50), in der Starterphase war dieser Unterschied sogar signifikant $(\mathrm{p}<0,05)$. Dies könnte für eine geringere Akzeptanz der Tiere gegenüber dem Insektenmehl sprechen, höchstwahrscheinlich spielt jedoch eher der Energiegehalt der Futtermischungen eine entscheidende Rolle. Aufgrund des höheren XLGehaltes in HM im Vergleich zu SES (14,08\% vs. 2,08\% der TM) führte der Austausch in der Konsequenz zu höheren XL- und damit verbunden auch zu höheren Energie-Gehalten in der Futtermischung (s. Tab. 10). Es wurde bereits in mehreren Studien gezeigt, dass eine Steigerung des Energie-Gehaltes in Futtermischungen für Masthähnchen zu einer Verringerung der FI führt (z.B. Hill und Dansky, 1954; Leeson et al., 1996). Diese Unterschiede zwischen den Futtermischungen hätten durch einen Ausgleich mit z.B. Sojaöl in der SES-Futtermischung vermieden werden können, waren aber gewollt, um die Effekte des Einsatzes von Insektenmehlen $\mathrm{zu}$ demonstrieren. Der höhere Energie- und XP-Gehalt in der HMFuttermischung erklärt zudem, dass es trotz einer geringeren FI zu keinen Unterschieden im Energie- und Proteinaufwand kam. Die höhere FI bei ähnlicher LM-Entwicklung führte jedoch zu einem schlechteren FA in Versuchsgruppe F (SES 50:50). Diese Entwicklung war in der Growerphase und bei Betrachtung des gesamten Versuches signifikant $(\mathrm{p}<0,05)$.

Einen positiven Effekt von Hermetia illucens auf das Wachstum von Masthähnchen stellten auch Moula et al. (2018), Neumann et al. (2018b) und Velten et al. (2018a) fest. Während in einigen anderen Studien (Leiber et al., 2017; Neumann et al., 2018a; Onsogo et al., 2018) dagegen kein signifikanter Einfluss auf die Wachstumsparameter beobachtet wurde, kamen Elwert et al. (2010) zu inkonsistenten Ergebnissen. In ihrem Versuch führte der Einsatz von 4,7\% Hermetia illucens Mehl mit einem XL-Gehalt von 15\% am 10. Lebenstag der Tiere zu 


\section{Diskussion}

einer signifikant verringerten LM, am 24. Lebenstag konnte dieser Effekt jedoch nicht beobachtet werden. Die Gabe von Hermetia illucens Mehl mit 37\% bzw. 22\% XL hatte zu keinem der Zeitpunkte Einfluss auf das Wachstum. Neumann et al. (2018b) stellten sowohl bei 50\%igem als auch bei 100\%igem Austausch von SES durch teilentfettetes Hermetia illucens Mehl (entsprach 14,5/11,9\% bzw. 21,7/12,3\% Hermetia illucens in der Futtermischung der Starter- bzw. Growerphase) einen signifikant positiven Effekt auf das Wachstum fest, während ein 75\%iger Austausch (entsprach 25,0/21,0\% Hermetia illucens in der Futtermischung der Starter- bzw. Growerphase) keine signifikanten Unterschiede bewirkte. Tendenziell wiesen aber auch diese Tiere höhere finale LM auf. Literaturangaben zum Einfluss auf die FI zeigen ebenfalls keinen eindeutigen Trend. Während Leiber et al. (2017), Neumann et al. (2018b), Onsogo et al. (2018) und Velten et al. (2018a) keine signifikanten Unterschiede zwischen Futtermischungen mit und ohne Hermetia illucens feststellten, beobachteten Elwert et al. (2010) und Neumann et al. (2018b) einen Effekt des Alters der Tiere sowie des XL-Gehaltes und der Einsatzhöhe des Insektenmehls. So hatte ein Hermetia illucens Mehl mit einem XLGehalt von 15\% bei Masthähnchen im Alter von 10 Tagen einen negativen Effekt auf die FI, dieser Effekt konnte aber am 24. Lebenstag der Tiere jedoch nicht festgestellt werden. Der Einsatz von Hermetia illucens Mehl mit einem XL-Gehalt von 37\% bzw. $22 \%$ hatte, ebenso wie auf das Wachstum, zu keinem der Zeitpunkte einen Einfluss auf die FI. Neumann et al. (2018b) stellten eine signifikant höhere FI bei 100\%igem Austausch von SES durch Hermetia illucens Mehl fest, ein 50\%iger bzw. 75\%iger Austausch hatte dagegen keinen signifikanten Effekt. Der in Versuch 1 beobachtete bessere FA in der HM-Gruppe wird von den Ergebnissen von Neumann et al. (2018b) bei 100\%igem Austausch von SES und Velten et al. (2018a) bestätigt und kann ebenfalls mit dem höheren Rohnährstoffgehalt in der HM-Futtermischung begründet werden. Elwert et al. (2010), Leiber et al. (2017), Moula et al. (2018) und Onsogo et al. (2018) konnten dagegen keinen signifikanten Effekt auf den FA durch den Einsatz von Hermetia illucens feststellen. Allerdings gilt es zu bedenken, dass in den aufgeführten Studien sowohl unterschiedliche Mengen als auch verschiedene Verarbeitungsformen (z.B. ein unterschiedlicher Grad der Entfettung) an Hermetia illucens eingesetzt wurden, was einen direkten Vergleich erschwert.

Weder in der Starter- und in der Growerphase noch bei Betrachtung des gesamten Versuchszeitraumes (Tab. 17) gab es signifikante Unterschiede in der Proteinqualität und der Met-Wirksamkeit zwischen Versuchsgruppe C (HM 50:50) und F (SES 50:50). Tendenziell wies Versuchsgruppe C (HM 50:50) jedoch etwas höhere Werte auf. Auch Velten et al. (2018b) und Neumann et al. (2018b) stellten bei 50\%igem bzw. 50\%igem und 75\%igem Austausch von 


\section{Diskussion}

SES durch teilentfettetes Hermetia illucens Mehl keine signifikanten Unterschiede in der Proteinqualität fest. Bei einem 100\%igen Austauschniveau (Neumann et al., 2018b) war die Proteinqualität dagegen durch den Einsatz von Hermetia illucens signifikant verbessert. In einer weiteren Studie, in der der 100\%ige Austausch von SES durch Hermetia illucens (entsprach 26,0/22,0\% Hermetia illucens in der Futtermischung der Starter- bzw. Growerphase) untersucht wurde (Neumann et al., 2018a), waren die Ergebnisse allerdings nicht eindeutig. Während in der Starterphase der PNu beim Einsatz von SES signifikant höher war, wurden durch den Austausch mit teilentfettetem Hermetia illucens $\mathrm{Mehl}$ der $\mathrm{PNu}_{\text {std. }}$ und $b$ signifikant verbessert. In der Growerphase war im Gegensatz dazu das Ergebnis aller untersuchten Proteinqualitätsparameter in Versuchsgruppe F (SES 50:50) signifikant besser.

Sowohl in der Starter- (Tab. 18) als auch in der Growerphase (Tab. 19) zeigte sich beim Einsatz von SES im Vergleich zu HM ein höherer Met-Bedarf sowie eine höhere optimale MetKonzentration in der Futtermischung. Der Grund hierfür liegt in der tendenziell höheren Proteinqualität $b$ bei einer geringeren Met-Konzentration und der damit verbundenen höheren Met-Wirksamkeit in Futtermischung C (HM 50:50).

Die beobachtete tendenziell höhere Proteinqualität in Versuchsgruppe C (HM 50:50) könnte auf eine bessere Verwertbarkeit des tierischen Insektenproteins im Vergleich zu Sojaprotein hindeuten. Die Ergebnisse zur scheinbaren pcV des XP und ausgewählter AS (Tab. 16) zeigten jedoch keine signifikanten Unterschiede zwischen der HM- und der SES-Futtermischung. Dies wurde auch von Velten et al. (2018b) bei 50\%igem Austausch von SES durch teilentfettetes Hermetia illucens Mehl (entsprach 14,5/11,9\% Hermetia illucens in der Futtermischung der Starter- bzw. Growerphase) festgestellt. Cullere et al. (2016) ermittelten ebenfalls keine signifikanten Unterschiede in der scheinbaren XP-Verdaulichkeit bezogen auf den gesamten GIT in Futtermischungen für Wachteln mit $10 \%$ bzw. 15\% teilentfettetem Hermetia illucens Mehl. In einer Studie mit Legehennen wurde dagegen eine signifikant geringere scheinbare pcV des XP festgestellt (Loponte et al., 2017).

Im Gegensatz dazu ergab der Vergleich von HM und SES aber einen signifikanten Einfluss auf die Körperzusammensetzung der Tiere (Tab. 20). Die Tiere der Versuchsgruppe C (HM 50:50) wiesen sowohl am Ende der Starter- als auch der Growerphase signifikant geringere XP- und XA-Gehalte auf, während der TS- und XL-Gehalt signifikant höher waren. Diese Ergebnisse bestätigen z.T. die von Velten et al. (2018b), die zwar keine signifikanten Unterschiede in der Körperzusammensetzung der Tiere bei Fütterung von teilentfettetem Hermetia illucens Mehl beobachteten, tendenziell jedoch ebenfalls höhere TS- und XL-Gehalte sowie niedrigere XP- 


\section{Diskussion}

und XA-Gehalte feststellten. Ein Grund dafür, dass die Unterschiede in dieser Studie nicht signifikant waren, könnte die geringere Austauschhöhe von nur 50\% des SES sein. Austauschraten von 75 bzw. 100\% führten in den Versuchen von Neumann et al. (2018b) zu signifikant geringeren XP- und signifikant höheren XL-Gehalten in den Tieren. Grundsätzlich kann der höhere XL-Gehalt in den Tieren aus Versuchsgruppe C (HM 50:50) mit der bereits beschriebenen unterschiedlichen Zusammensetzung der Futtermischungen erklärt werden, die in den Versuchen von Neumann et al. (2018b) und Velten et al. (2018b) ebenfalls auftrat. Auch Deaton und Lott (1985) beobachteten einen positiven Zusammenhang zwischen dem Energiegehalt der Futtermischung und dem Gehalt an abdominalen Fett in den Tierkörpern. Eine Untersuchung mit isoenergetischen Futtermischungen ist empfehlenswert, um mögliche Effekte des HM vollständig ausschließen zu können.

Die unterschiedlichen XL-und Energie-Gehalte der HM- und der SES-Futtermischung hatten dementsprechend auch Auswirkungen auf den XP- und XL-Ansatz. In allen drei Wachstumsphasen (Abb. 12, 13 und 14) wiesen die Tiere aus Versuchsgruppe C (HM 50:50) einen signifikant höheren XLD auf, während sich der XPD nicht signifikant zwischen den Versuchsgruppen unterschied, tendenziell jedoch bei den Tieren aus Versuchsgruppe F (SES 50:50) höher war. Diese Effekte traten trotz der z.T. signifikant $(\mathrm{p}<0,05)$ geringeren FI in Versuchsgruppe C (HM 50:50) auf. Einen signifikant höheren XLD stellten auch Velten et al. (2018b) durch den Einsatz von Hermetia illucens fest, in der Höhe des XPD gab es ebenfalls keine signifikanten Unterschiede, sie war jedoch im Gegensatz zu den Ergebnissen in Versuch 1 in den Tieren, die die Futtermischung mit Hermetia illucens erhielten tendenziell höher als in der Kontrollgruppe.

\subsubsection{Tenebrio molitor}

Der 100\%ige Austausch von SES durch TMP hatte in Versuch 2 weder in der Starter- oder Growerphase noch während des gesamten Versuchszeitraumes (Tab. 21 und 22) Auswirkungen auf das Wachstum und die Höhe der FI der Tiere. Während in der Starterphase jedoch die Tiere aus Versuchsgruppe F (SES 50:50) in der Tendenz höhere finale LM und tägliche LMZ aufwiesen, wurden in der Growerphase und bei Betrachtung der gesamten Versuchsphase bei den Tieren der Versuchsgruppe C (TMP 50:50) tendenziell höhere Werte beobachtet. Die FI war dagegen in allen drei Wachstumsphasen in Versuchsgruppe F (SES 50:50) höher. Dies hatte in der Growerphase und bei Betrachtung des gesamten Versuchszeitraumes signifikante $(\mathrm{p}<0,05)$ Auswirkungen auf den FA, der in Versuchsgruppe C (TMP 50:50) signifikant besser war als in Versuchsgruppe F (SES 50:50). Dieselbe Entwicklung wurde folgerichtig auch beim 


\section{Diskussion}

Protein- und Energieaufwand festgestellt. Ähnlich wie bei den Studien zum Einsatz von Hermetia illucens gibt es auch bei den Literaturangaben zu Tenebrio molitor verschiedene, z.T. widersprüchliche Ergebnisse. So beobachteten Ramos-Elorduy et al. (2002) und Bovera et al. (2015, 2016) keinen signifikanten Einfluss des Einsatzes von 29,65\% Tenebrio molitor Mehl aus nicht-entfetteten Larven auf das Wachstum von Masthähnchen, während Ballitoc und Sun (2013) und Biasato et al. (2018a, b) bei Einsatzmengen von bis zu 15\% positive Effekte feststellten. Im Gegensatz dazu, hatte der Einsatz von 8,1\% teilentfettetem Tenebrio molitor Mehl (3,6\% XL in der TM) in einer Untersuchung von Khan et al. (2018) negative Auswirkungen auf die LMZ. Auch die FI war in dieser Studie durch die Gabe von Tenebrio molitor signifikant verringert. Ramos-Elorduy et al. (2002) und Bovera et al. (2015, 2016) stellten dagegen keinen signifikanten Effekt auf die FI fest, während Biasato et al. (2018a, b) eine signifikant höhere FI beobachtete. Der FA war durch den Einsatz von Tenebrio molitor z.T. signifikant verbessert (Bovera et al., 2015,2016; Khan et al., 2018), z.T. wurden keine signifikanten Unterschiede festgestellt (Ramos-Elorduy et al., 2002). Ballitoc und Sun (2013) und Biasato et al. (2018a, b) beobachteten dagegen einen negativen Effekt auf den FA. Ebenso wie bei Studien zum Einsatz von Hermetia illucens sollte hier allerdings bedacht werden, dass die unterschiedlichen Versuchsbedingungen einen Vergleich der Ergebnisse beeinträchtigen.

In keiner der drei Versuchsphasen gab es signifikante Unterschiede zwischen Versuchsgruppe C (TMP 50:50) und F (SES 50:50) in Bezug auf die Proteinqualität (Tab. 24) und MetWirksamkeit (Abb. 15, 16 und 17). In der Growerphase und bei Betrachtung des gesamten Versuchszeitraumes wies Versuchsgruppe C (TMP 50:50) jedoch tendenziell höhere Werte auf. Bovera et al. (2015) ermittelten den Proteinwirkungsgrad (PER, engl. protein efficiency ratio), der ebenfalls ein Parameter zur ernährungsphysiologischen Bewertung der Proteinqualität ist, in einer Futtermischung für Masthähnchen mit 29,65\% Tenebrio molitor Mehl im Vergleich zu einer Kontrollmischung mit SES. Sie stellten einen signifikant höheren Wert in der Futtermischung mit Tenebrio molitor fest.

Bei der Ableitung der Met-Bedarfswerte ergab sich in der Starterphase (Tab. 25) kein Unterschied zwischen den Proteinquellen. In der Growerphase (Tab 26) zeigte sich jedoch aufgrund der tendenziell höheren Proteinqualität $b$ und der sich daraus ergebenen höhere MetWirksamkeit in Versuchsgruppe C (TMP 50:50) ein geringerer Met-Bedarf sowie eine geringere optimale Met-Konzentration in der Futtermischung.

Die höhere Proteinqualität könnte ebenso wie bei Hermetia illucens für eine bessere Verwertbarkeit des Insektenproteins sprechen. Allerdings zeigte der Vergleich der TMP- und 


\section{Diskussion}

der SES-Futtermischung keine signifikanten Unterschiede in der scheinbaren pcV des XP und ausgewählter AS, mit Ausnahme von Phe (Tab. 23). Die signifikant ( $<<0,05)$ höhere scheinbare $\mathrm{pcV}$ des Phe in Versuchsgruppe F (SES 50:50) kann jedoch mit dem höheren PheGehalt in dieser Futtermischung erklärt werden (s. Anhangstab. 6) und ist nicht auf die Proteinquelle zurückzuführen. Bovera et al. (2016) ermittelten dagegen eine signifikant geringere scheinbare $\mathrm{pcV}$ des XP in einer Futtermischung mit 21,57\% Tenebrio molitor Mehl im Vergleich zu einer Futtermischung mit SES und begründeten dieses Ergebnis mit dem negativen Effekt des Chitins auf die Verdaulichkeit. Wie in Kapitel 2.2.4 ausführlich diskutiert, herrscht diesbezüglich jedoch Unklarheit. Sicherlich kann der Gehalt an Chitin eine Rolle spielen, in dem von Bovera et al. (2016) verwendeten Tenebrio molitor Mehl lag er jedoch bei 4,62\% und damit insgesamt in der Futtermischung unter den Gehalten, die in den in Kapitel 2.2.4 aufgeführten Studien verwendet wurden.

Im Gegensatz zu HM hatte der Einsatz von TMP keinen signifikanten Einfluss auf den Rohnährstoff-Gehalt im Ganzkörper der Tiere (Tab. 27). Lediglich der TM-Gehalt war am Ende der Growerphase in den Tieren aus Versuchsgruppe C (TMP 50:50) signifikant ( $\mathrm{p}<0,05)$ höher. In der Tendenz wiesen jedoch die Tiere aus Versuchsgruppe C (TMP 50:50) einen höheren XL-Gehalt auf, während die Tiere aus Versuchsgruppe F (SES 50:50) tendenziell einen höheren XP-Gehalt aufzeigten. Diese Unterschiede fielen in der Growerphase deutlicher aus als in der Starterphase. Verglichen mit den Futtermischungen in Versuch 1 war die Differenz im Energiegehalt zwischen der TMP- und der SES-Futtermischung geringer, was die Annäherung im XL-Gehalt in den Ganzkörpern erklärt. Auch wenn in den beiden Versuchen unterschiedliche Insektenmehle verwendet wurden, ist dies dennoch ein Hinweis darauf, dass die in Versuch 1 beobachteten Effekte auf die Körperzusammensetzung eher in der Zusammensetzung der Futtermischungen begründet sind als im Einsatz von HM.

Auch Bovera et al. (2016) und Biasato et al. (2018a) stellten keine signifikanten Unterschiede im XP- und XL-Gehalt im Brustfleisch von Masthähnchen bzw. im Gehalt an abdominalem Fett durch den Einsatz von Tenebrio molitor Mehl fest. Im Gegensatz dazu hatten steigende Anteile von Tenebrio molitor Mehl in einer weiteren Untersuchung von Biasato et al. (2018b) einen steigenden Gehalt an abdominalem Fett zur Folge.

Die Tatsache, dass es in der Starterphase keine signifikanten Unterschiede im Rohnährstoffgehalt der Tiere der beiden Versuchsgruppen gab, führte dementsprechend auch zu keinen signifikanten Unterschieden im XPD und XLD in diesem Altersbereich (Abb. 18). In der Growerphase (Abb. 19) und im gesamten Versuchszeitraum (Abb. 20) gab es ebenfalls keine signifikanten Unterschiede im XPD zwischen den Tieren aus Versuchsgruppe C (TMP 


\section{Diskussion}

50:50) und F (SES 50:50), der XLD war jedoch in beiden Versuchszeiträumen in Versuchsgruppe C (TMP 50:50) signifikant ( $\mathrm{p}<0,05)$ höher. Der Effekt trat auf, obwohl die FI in Versuchsgruppe F (SES 50:50) tendenziell höher war und die Futtermischung mit SES einen höheren XL-Gehalt aufwies. Eine mögliche Erklärung ist der signifikant niedrigere TM-Gehalt in Versuchsgruppe C (TMP 50:50), der dazu führte, dass der absolute XL-Gehalt in den Tieren dieser Versuchsgruppe deutlich höher war, was sich wiederum im Nährstoffansatz widerspiegelte.

Ebenso wie die zootechnischen Parameter zeigten die Ergebnisse der Makroskopie (Tab. 28) in Versuchsgruppe A (TMP 40:60) verglichen mit Versuchsgruppe F (SES 50:50) signifikant geringere LM. Sowohl die absolute als auch die relative Dünndarmmasse (DDM) unterschied sich dagegen nur tendenziell zwischen den Versuchsgruppen. Dies spricht dafür, dass der Einsatz des TMP keinen Einfluss auf die makroskopischen Parameter hatte. Im Gegensatz dazu ermittelten Bovera et al. (2016) eine signifikant höhere Masse des gesamten GIT bei Tieren, die eine Futtermischung mit Tenebrio molitor Mehl erhielten und sich in ihrer LM nicht signifikant von den Kontrolltieren unterschieden. Die drei Dünndarmabschnitte waren zudem durch den Einsatz von Tenebrio molitor Mehl verlängert, im Falle des Ileums signifikant.

Während sich die relative Zottenoberfläche und der Zottenvergrößerungsfaktor in den drei Dünndarmabschnitten nicht zwischen den Versuchsgruppen unterschied, war die relative primäre Schleimhautoberfläche im Duodenum der Tiere aus Versuchsgruppe A (TMP 40:60) im Vergleich zu Versuchsgruppe F (SES 50:50) signifikant $(\mathrm{p} \leq 0,01)$ vergrößert (Tab. 29). Dies führt zu einer Vergrößerung der Absorptionsfläche sowie einer Verlängerung der Retentionszeit des Chymus im entsprechenden Darmabschnitt und somit zu einer längeren Einwirkzeit der Pankreasenzyme. Da es jedoch keine signifikanten Unterschiede zwischen Versuchsgruppe E (TMP 60:40) und F (SES 50:50) gab, ist dieser Effekt vermutlich weniger der Proteinquelle als der AS-Versorgung zuzuschreiben.

Das Zotten-/Kryptenepithelvolumenverhältnis unterschied sich nicht signifikant zwischen den Versuchsgruppen. Auch Biasato et al. (2016, 2018b) stellten keine Unterschiede im Zotten/Kryptenverhältnis durch den Einsatz von Tenebrio molitor fest. In einer weiteren Studie (Biasato et al., 2018a) beobachteten dieselben Autoren jedoch ein signifikant verringertes Zotten-/Kryptenverhältnis beim Einsatz von $10 \%$ bzw. 15\% Tenebrio molitor Mehl im Vergleich zum Einsatz von 5\% Tenebrio molitor Mehl und zur Kontrollgruppe mit SES. 


\section{Diskussion}

\subsubsection{Vergleich von Hermetia illucens und Tenebrio molitor}

Versuch 3 erlaubt einen direkten Vergleich der beiden alternativen Proteinquellen HM und TMP. Hierbei sollen nur Versuchsgruppe D (TMP pK) und H (HM pK) verglichen werden, um das ernährungsphysiologische Potential der Insektenmehle einordnen zu können.

Die Betrachtung der Ergebnisse der zootechnischen Parameter zeigte in allen drei Wachstumsphasen (Tab. 30 und 31) nur numerische Unterschiede, lediglich die FI war in den HM-Versuchsgruppen z.T. signifikant $(\mathrm{p}<0,05)$ höher. Tendenziell wiesen die Tiere dieser Versuchsgruppen jedoch auch höhere finale LM und tägliche LMZ auf. Dies könnte für eine bessere Akzeptanz der Tiere gegenüber dem HM im Vergleich zu TMP sprechen. Józefiak et al. (2018) stellten ebenfalls keine signifikanten Unterschiede in Bezug auf die LMZ, die FI und den FA durch den Einsatz von 0,2\% Tenebrio molitor bzw. Hermetia illucens Mehl in Futtermischungen für Masthähnchen fest. Im Gegensatz zu Versuch 3 beobachteten sie jedoch durch die Gabe von Tenebrio molitor Mehl tendenziell eine höhere LMZ und FI sowie einen besseren FA. Allerdings supplementierten die Autoren die Insektenmehle ohne eine Anpassung des Rohnährstoffgehaltes der Futtermischung, was aufgrund des höheren XP- und niedrigeren XL-Gehaltes des eingesetzten Tenebrio molitor Mehls nicht $\mathrm{zu}$ isonitrogenen und isoenergetischen Futtermischungen geführt haben dürfte. Somit ist fraglich, ob die Effekte im Einsatz der Insektenmehle begründet sind und ein Vergleich der Ergebnisse ist nur eingeschränkt möglich.

In der Starterphase gab es zwischen den pK mit HM und TMP nur numerische Unterschiede im N-Ansatz (Tab. 33) und der Met-Wirksamkeit (Abb. 21). Die Proteinqualität war jedoch in der pK mit TMP signifikant $(\mathrm{p}<0,05)$ höher. Im Gegensatz dazu konnten weder in der Growerphase (Tab. 33 und Abb. 22) noch bei Betrachtung des gesamten Versuchszeitraumes (Tab 33 und Abb. 23) signifikante Unterschiede zwischen den beiden Versuchsgruppen beobachtet werden. Der Grund für diese Differenzen zwischen den Wachstumsphasen könnte der Chitin-Gehalt in den Insektenmehlen in Kombination mit der altersabhängigen Entwicklung des GIT sein. So steigt die Verdauungskapazität von Masthähnchen mit steigendem Alter aufgrund der wachsenden Schleimhautoberfläche und damit verbundenen steigenden Enzymaktivität an (Iji et al., 2001). Das heißt, die Möglichkeit der Tiere Chitin zu verdauen, nimmt ebenfalls mit dem Alter zu. Da laut den Literaturangaben (s. Kapitel 2.2.4) der ChitinGehalt in Hermetia illucens den in Tenebrio molitor übersteigt, könnte der Einsatz von HM verglichen mit TMP in der Starterphase einen negativen Einfluss auf die Proteinqualität gehabt haben. Die altersbedingte Entwicklung der Enzymaktivität könnte erklären, wieso mit 


\section{Diskussion}

steigendem Alter der Tiere keine signifikanten Unterschiede mehr festgestellt wurden. Dass auch die scheinbare $\mathrm{pcV}$ des XP in der $\mathrm{pK}$ mit TMP signifikant $(\mathrm{p}<0,05)$ höher war als in der pK mit HM (Tab. 32), könnte dementsprechend auch im unterschiedlichen Chitin-Gehalt der Insektenmehle begründet sein. Ebenso kann er ein Grund für die höhere scheinbare pcV der AS in der $\mathrm{pK}$ mit TMP sein, die im Fall von His sogar signifikant war. Allerdings gilt es zu bedenken, dass sowohl der XP-Gehalt (s. Tab 12) als auch der Gehalt an AS in der pK mit TMP etwas höher war als in der pK mit HM. Dies hat ebenfalls einen Einfluss auf die Höhe der scheinbaren pcV. Auch die Tatsache, dass der Vergleich von HM bzw. TMP mit SES in Versuch1 und 2 nur numerische Unterschiede in der Proteinqualität und der scheinbaren pcV zeigte, widerlegt die Theorie, dass der Chitin-Gehalt einen Einfluss hatte. Zudem wären Kenntnisse über den tatsächlichen Gehalt in den eingesetzten Insektenmehlen bzw. Versuchsmischungen erforderlich, um die These zu untermauern.

Darüber hinaus ist es notwendig zu bedenken, dass die Met-Wirksamkeit in den pK nur eine eingeschränkte Aussagekraft hat, da Met in diesen Futtermischungen nicht limitierend wirkte. Dies hat zur Folge, dass eine weitere Verwendung des Parameters nicht möglich ist (Liebert, 2015). Aus diesem Grund wurde für die beiden pK keine Met-Bedarfsableitung durchgeführt.

Zusätzlich zu den bereits beschriebenen Parametern hatte das Insektenmehl auch keinen signifikanten Einfluss auf die Körperzusammensetzung der Tiere an Tag 21 und 35 (Tab. 36). Tendenziell wiesen die Tiere aus Versuchsgruppe D (TMP pK) jedoch etwas höhere XP- und etwas niedrigere XL-Gehalte auf als die der Versuchsgruppe H (HM pK). Dieser Effekt kann mit dem etwas höheren XP- und dem etwas niedrigeren XL-Gehalt (21,74\% vs. 21,27\% XP in der TM und 6,83\% vs. 7,45\% XL in der TM) in der Futtermischung mit TMP erklärt werden und ist vermutlich nicht dem Insektenmehl geschuldet.

Der XPD unterschied sich in allen drei Versuchsphasen (Abb. 24, 25 und 26) nicht signifikant zwischen den Tieren der Versuchsgruppen D (TMP pK) und H (HM pK), tendenziell wiesen die Tiere der pK mit HM jedoch etwas höhere Werte auf. Der XLD war dagegen sowohl in der Starter- und Growerphase als auch bei Betrachtung des gesamten Versuchszeitraumes in Versuchsgruppe H $(\mathrm{HM} \mathrm{pK})$ signifikant $(\mathrm{p}<0,05)$ höher. Dies ist im höheren XL-Gehalt in der Futtermischung mit HM und der signifikant höheren FI in Versuchsgruppe H (HM pK) begründet und ein direkter Einfluss der Proteinquelle ist unwahrscheinlich. 


\section{Diskussion}

\subsection{Zusammenfassende Diskussion}

Zusammenfassend lässt sich feststellen, dass sowohl Hermetia illucens als auch Tenebrio molitor vielversprechende alternative Proteinquellen für die Masthähnchenernährung sind. In allen drei Versuchen wurde gezeigt, dass ihr Einsatz ohne Leistungseinbußen möglich ist und die Ergebnisse bezüglich der untersuchten Parameter mit SES als Hauptproteinträger vergleichbar sind. Diese Beobachtung ist in Übereinstimmung mit verschiedenen Literaturangaben (z.B. Ramos-Elorduy et al., 2002; Bovera et al., 2015, 2016; Biasato et al., 2018a, b; Neumann et al., 2018a, b; Onsogo et al., 2018; Velten et al., 2018a, b).

Grundsätzlich unterstützen die Ergebnisse der durchgeführten Untersuchungen zudem die Annahme eines optimalen Met:Cys-Verhältnisses von 50:50 in Futtermischungen für wachsende Masthähnchen unabhängig vom Alter der Tiere. Es zeigte sich, dass der metabolische Bedarf an Cys bei diesem Verhältnis gedeckt und der Met-Abbau zur Bereitstellung von Cys minimiert waren. Damit wurden verschiedene Literaturangaben, in denen ebenfalls ein Met:Cys-Verhältnis von 50:50 empfohlen wurde (z.B. Graber und Baker, 1971; Graber et al., 1971; Baker et al., 1996; Dilger und Baker, 2007), bestätigt. Im Gegensatz dazu hatte ein Met:Cys-Verhältnis von 40:60 einen z.T. signifikant ( $p<0,05)$ negativen Effekt. Dies wurde ebenfalls von anderen Autoren (Graber et al., 1971; Sasse und Baker, 1974; Featherston und Rogler, 1978; Sell et al., 1980; Dilger und Baker, 2007, 2008a, b) beobachtet. In Übereinstimmung mit den Angaben verschiedener Studien (z.B. Moran Jr., 1981; Kalinowski et al., 2003a, b; Khan et al., 2015a; Sünder et al., 2015a, b) führte ein Met-Anteil von $>50 \%$ an den SAS zu vergleichbaren Ergebnissen wie ein Met:Cys-Verhältnis von 50:50. Demnach hatten geringe Met-Anteile an den SAS negative Auswirkungen auf die Leistung der Tiere. Geringe Cys-Anteile an den SAS konnten dagegen durch die Katabolisierung von Met ausgeglichen werden und führten nicht zu einem Rückgang der ermittelten Parameter. Lediglich die Met-Wirksamkeit wurde hierdurch beeinflusst.

Die abgeleiteten optimalen Met-Konzentrationen in der Futtermischung in Abhängigkeit von den verschiedenen Met:Cys-Verhältnissen stimmen mit bereits publizierten Daten überein. Grundsätzlich bewirkte ein suboptimales Met:Cys-Verhältnis aufgrund der geringen MetWirksamkeit höhere Met-Bedarfswerte. Auch ein steigender XPD hatte einen steigenden MetBedarf zur Folge, während eine Steigerung der FI erwartungsgemäß zu geringeren optimalen Met-Konzentrationen in der Futtermischung führte.

Zusätzlich konnte in allen drei Versuchen ein Einfluss auf die Körperzusammensetzung und den Nährstoffansatz der Tiere festgestellt werden. Auch hier hatte vor allem ein Met:Cys- 


\section{Diskussion}

Verhältnis von 40:60 einen negativen Einfluss. Es zeigte sich in Übereinstimmung mit den Ergebnissen von Wecke et al. (2018b) ein mit dem Alter der Tiere abnehmender XP-Gehalt, der XL-Gehalt stieg dagegen an. Insbesondere der Nährstoffansatz war in den Versuchen der vorliegenden Arbeit jedoch stark von der Höhe der FI beeinflusst.

Eine weitere Fragestellung dieser Arbeit war der mögliche Einfluss hoher Anteile an Insektenmehlen auf das optimale Met:Cys-Verhältnis in Futtermischungen für Masthähnchen. Grund hierfür ist das weite Met:Cys-Verhältnis in den Insektenmehlen. Sowohl die Ergebnisse der zootechnischen Parameter als auch der Proteinqualität und Met-Wirksamkeit konnten jedoch zeigen, dass die Proteinquelle keinen Einfluss auf das optimale Met:Cys-Verhältnis in Futtermischungen für Masthähnchen hat. 
Ausblick

\section{Ausblick}

Auf Grundlage der Ergebnisse dieser Arbeit sollen nachfolgend Empfehlungen zu weiteren Forschungsansätzen gegeben werden.

Die durchgeführten Untersuchungen haben gezeigt, welche große Bedeutung nicht nur der SAS-Gehalt, sondern auch das Met:Cys-Verhältnis in einer Futtermischung für wachsende Masthähnchen hat. Da die Veränderung des Met:Cys-Verhältnisses in vielen Studien jedoch auch eine Modifikation des Gesamt-SAS-Gehaltes zur Folge hatte, sind weitere Untersuchungen bei konstantem SAS-Gehalt für eine bessere Vergleichsmöglichkeit der Ergebnisse empfehlenswert. Außerdem lag in den eingesetzten Futtermischungen eine Limiterung der SAS vor, da dies eine wichtige Prämisse zur Bestimmung der Met-Wirksamkeit ist. Für die Praxis wäre jedoch zudem von Interesse, ob die ermittelten Effekte der Met:CysVerhältnisse auch in Futtermischungen ohne Limiterung der SAS ihre Gültigkeit behalten.

Da sowohl die Literaturangaben zum Met-Bedarf als auch die mit Hilfe der Met-Wirksamkeit abgeleiteten Bedarfswerte große Schwankungsbreiten aufweisen, empfiehlt sich auch hier eine weitere Verifizierung der Ergebnisse. Zusätzlich wäre es sinnvoll, AS-Bedarfsangaben grundsätzlich in Abhängigkeit des Alters, der Genetik und der Leistung der Tiere zu betrachten, um auf diese Weise eine optimale Versorgung und eine Realisierung der Leistungsziele zu gewährleisten.

Das ernährungsphysiologische Potential von Insekten als Proteinquelle wurde in den Versuchen und den verschiedenen aufgeführten Studien deutlich. Grundsätzlich ist es empfehlenswert, Untersuchungen mit isonitrogenen und isoenergetischen Futtermischungen durchzuführen, um die Auswirkungen der Insektenmehle auf die Körperzusammensetzung zu untersuchen. Zusätzlich sollte der Fokus in Zukunft vor allem auf der Produktion der Insekten liegen, um ein einheitliches und sicheres Produkt zu erhalten und so zu einer Zulassung von verarbeiteten Insekten als Futtermittel für Monogastrier beizutragen. Darüber hinaus müssen für einen Einsatz in der praktischen Tierernährung die Produktionskosten deutlich gesenkt werden. Die in den Versuchen dieser Arbeit Einsatzmengen liegen jedoch mit Sicherheit auch dann noch weit oberhalb aktueller Grenzen von Wirtschaftlichkeitsberechnungen. 


\section{Zusammenfassung}

\section{Zusammenfassung}

Literaturdaten zur optimalen Versorgung von Masthähnchen mit schwefelhaltigen Aminosäuren (SAS) weisen beachtliche Schwankungen auf. Aufgrund der engen metabolischen Verbindung von Methionin (Met) und Cystein (Cys) stellt die Ermittlung des idealen Verhältnisses dieser beiden AS zueinander eine besondere Herausforderung dar. So besteht im Stoffwechsel die Möglichkeit, einen Cys-Mangel durch den schrittweisen Abbau von Met zu Cys auszugleichen. Da die SAS in Futtermischungen für Masthähnchen i.d.R. limitierend sind, wird eine Supplementation von synthetischem L-Met, DL-Met oder dem Hydroxyanalog HMTBA vorgenommen, um den Bedarf zu decken. Dabei sind jedoch nicht nur Kenntnisse über den Bedarf an den Gesamt-SAS, sondern auch über das ideale Met:CysVerhältnis notwendig, da sowohl ein Mangel als auch ein Überschuss an Met und/oder Cys negative Auswirkungen auf das Wachstum hat.

Zurzeit ist die Suche nach alternativen Proteinquellen ein wichtiges Thema in der Tierernährung, um die Einsatzmengen von Soja reduzieren zu können. Eine mögliche Alternative stellen hier Insektenmehle dar. Bisherige Studien haben gezeigt, dass hohe Einsatzmengen ohne Leitungseinbußen möglich sind. Allerdings gibt es noch keine Kenntnisse über den Einfluss von Insektenprotein auf das optimale Met:Cys-Verhältnis.

Ziel dieser Dissertation war es somit, einen Beitrag zur Ermittlung des optimalen Met:CysVerhältnisses in Futtermischungen für wachsenden Masthähnchen mit einem hohen Anteil an Insektenmehl $\mathrm{zu}$ leisten und $\mathrm{zu}$ überprüfen inwieweit die alternative Proteinquelle dieses beeinflusst. Hierfür wurden drei 35-tägige Wachstumsversuche mit männlichen Broilern der Genetik Ross 308 durchgeführt. Jeder der Versuche war in eine Starter- (Tag 1-21) und Growerphase (Tag 22-35) untergliedert. Die Tiere wurden hierbei in Bodenhaltung in 48 Boxen in Gruppen á 5 Tiere gehalten und hatten freien Zugang zu Futter und Wasser. In den eingesetzten Futtermischungen wurde ein vollständiger Austausch des Sojaextraktionsschrotes (SES) durch das teilentfettete Mehl der Larven der Schwarzen Soldatenfliege (Hermetia illucens) bzw. durch einen Presskuchen aus den Larven des Mehlkäfers (Tenebrio molitor) durchgeführt. In den beiden ersten Versuchen wurden dabei verschiedene Met:CysVerhältnisse $(40: 60 ; 45: 55 ; 50: 50 ; 55: 45 ; 60: 40)$ eingestellt und das Verhältnis der SAS zu Lysin lag bei 0,50. Dies sollte gewährleisten, dass die SAS die limitierenden AS waren. Als Kontrolle diente eine Futtermischung mit Sojaextraktionsschrot und einem Met:Cys-Verhältnis von 50:50, in der das Verhältnis der SAS zu Lysin ebenfalls bei 0,50 lag. Im dritten Versuch wurden die beiden Insektenmehle direkt miteinander verglichen. Hierfür wurden jeweils 3 


\section{Zusammenfassung}

Futtermischungen mit verschiedenen Met:Cys-Verhältnissen (50:50; 55:45; 60:40) hergestellt, in denen die SAS limitierend waren. Zusätzlich wurde mit jedem Insektenmehl eine positive Kontrolle eingesetzt, deren AS-Gehalt dem Bedarf der Tiere entsprach. Die Lebendmasseentwicklung und der Futterverzehr wurden in jedem der drei Versuche wöchentlich dokumentiert. Zusätzlich wurde jeweils am Ende der Starter- und der Growerphase ein repräsentatives Tier pro Box für die Ganzkörperanalyse ausgewählt und die Ergebnisse der Analyse mit Hilfe des Göttinger N-Verwertungmodells ausgewertet. Somit erfolgte eine Bewertung der Met:Cys-Verhältnisse sowohl mittels zootechnischen Parametern als auch Angaben zur Proteinqualität und Aminosäuren-Wirksamkeit. Zusätzlich wurden Untersuchungen zur Bestimmung der scheinbaren praecaecalen Verdaulichkeit durchgeführt.

Die Ergebnisse der Versuche zeigen, dass der vollständige Austausch von Sojaextraktionsschrot durch Hermetia illucens oder Tenebrio molitor ohne Leistungseinbußen möglich ist und unterstützen Literaturangaben über ein optimales Met:Cys-Verhältnis von 50:50 in Futtermischungen für wachsende Masthähnchen. Während ein Met:Cys-Verhältnis von 40:60 die Futteraufnahme und in Folge dessen auch die weiteren zootechnischen Parameter negativ beeinflusste, hatte ein Met:Cys-Verhältnis von 60:40 keine derart starken Auswirkungen. Dies lässt darauf schließen, dass ein Met:Cys-Verhältnis von 40:60 zu einem Met-Mangel führte. Ein eventueller Cys-Mangel in den Futtermischungen mit einem Met:CysVerhältnis von 60:40 konnte dagegen durch den Abbau von Met zu Cys kompensiert werden. Auch die Proteinqualität war bei einem Met:Cys-Verhältnis von 50:50 oder höher am höchsten, die Met-Wirksamkeit dagegen erwartungsgemäß in den Futtermischungen mit einem MetAnteil von $\leq 50 \%$ an den SAS. Die auf der Grundlage der Met-Wirksamkeiten abgeleiteten Met-Bedarsfwerte zeigten eine klare Abhängigkeit von der Höhe des Proteinansatzes und der Futteraufnahme sowie vom Met:Cys-Verhältnis. Grundsätzlich lagen die Werte jedoch in einem vergleichbaren Rahmen wie bereits publizierte Daten.

Zudem wurde auch der mögliche Einfluss des Met:Cys-Verhältnisses und der Proteinquelle auf die Körperzusammensetzung und den Nährstoffansatz der Tiere untersucht. Hierbei zeigte sich insbesondere ein negativer Einfluss geringer Met-Anteile von $40 \%$ an den SAS. Unterschiede zwischen den Proteinquellen waren vor allem auf den unterschiedlichen Energiegehalt der Futtermischungen zurückzuführen, der durch den im Vergleich zu SES höheren XL-Gehalt in den Insektenmehlen verursacht wurde.

Zusätzlich wurde die scheinbare praecaecale Verdaulichkeit des XP und ausgewählter Aminosäuren in den Futtermischungen mit Insektenmehl und Sojaextraktionsschrot bestimmt. 


\section{Zusammenfassung}

Die Vergleiche der eingesetzten Proteinquellen zeigten hierbei keine signifikanten Unterschiede.

Abschließend lässt sich festhalten, dass das optimale Met:Cys-Verhältnis in Futtermischungen für Masthähnchen bei 50:50 liegt. Grundsätzlich zeigen die Ergebnisse zudem das große Potential der Insektenmehle als alternative Proteinquelle in der Geflügelernährung und, dass

diese Proteinquelle keinen Einfluss auf das optimale Met:Cys-Verhältnis in den Futtermischungen für Masthähnchen haben. 


\section{Summary}

\section{Summary}

Literature data on the optimal supply of growing meat-type chickens with the sulfur containing amino acids (SAA) show significant variations. Due to the close metabolic link of methionine (Met) and cysteine (Cys), the determination of the optimal ratio between these two amino acids is a methodical challenge. In the metabolism, Met can be catabolized to Cys via various steps and a Cys-deficiency can be alleviated. Because SAA are usually in limiting position in feedstuff for meat-type chickens, Met gets supplementated as L-Met, DL-Met or the Met hydroxyanalogue HMTBA. However, it is not only necessary to have extensive knowledge about the total SAA requirement of the birds, but also about the optimal Met:Cys ratio (MCR), since both an oversupply and a deficiency have a negative impact on growth parameters.

Currently, the search for alternative protein sources is an important topic in animal nutrition to reduce the quantities of soy that are needed to cover protein and amino acid requirements. One possible alternative protein source are insect meals. Several studies have shown that high inclusion rates are possible without any negative effects on growth. However, it is not known whether the insect protein has an influence on the optimal MCR.

Therefore, the aim of this dissertation was to contribute to the determination of the optimal MCR in meat-type chicken diets with high inclusion rates of insect meal and to examine whether the optimal MCR is influenced by this alternative protein source. Three growth studies with 240 male day-old broiler chickens (Ross 308) were conducted, each of them lasted for 35 days and was divided into a starter (day 1-21) and grower period (day 22-35). The birds were kept in 48 floor pens with wood shavings ( 5 birds per pen) and had ad libitum access to feed and water. In the diets soybean meal (SBM) was completely substituted by a meal of partly defatted larvae of the Black Soldier Fly (Hermetia illucens) or a presscake of the Yellow Mealworm (Tenebrio molitor), respectively. The diets had graded MCRs (40:60; 45:55; 50:50; $55: 45 ; 60: 40)$ and the ratio of the SAA to lysine was set at 0.50 in order to ensure the limiting position of the SAA. The control diet with soybean meal had a MCR of 50:50 and the ratio of the SAA to lysine was set at 0.50 as well. In the third study, the two insect meals were directly compared with each other. Therefore, six diets with Hermetia illucens meal respectively Tenebrio molitor presscake and graded MCRs $(50: 50 ; 55: 45 ; 60: 40)$ with the SAA in limiting position were prepared. Additionally, two diets with Hermetia illucens and Tenebrio molitor and an amino acid content according to the current requirement data were used as positive controls. Zoo-technical parameters (growth, feed intake, FCR, mortality) were recorded weekly and both at the end of the starter (day 21) and grower period (day 35) one representative bird 
per pen was chosen for whole body analysis. The results of the analysis were evaluated using the "Goettingen approach". Consequently, the assessment of the different MCRs was done using zootechnical parameters and data for dietary protein quality and Met efficiency. In addition, an evaluation of the apparent preacecal digestibility of protein and amino acids took place at the end of each study.

The results of the three studies demonstrate the possibility of a complete substitution of soybean meal by Hermetia illucens or Tenebrio molitor without any negative effects on growth of the birds. Additionally, they provide information about an optimal MCR of 50:50 in diets for growing meat-type chickens, which underlines literature data. A MCR of 40:60 had a significant negative effect on feed intake and in consequence on the other zootechnical parameters. In contrast, a MCR of 60:40 did not lead to such negative effects. The reason might be a Met deficiency at a MCR of 40:60 and it indicates that a Cys deficiency at a MCR of 60:40 has been alleviated by Met degradation in the metabolism. Protein quality was also highest in diets with a MCR of 50:50 or higher and, as expected, the highest Met efficiency was observed in diets with a MCR of 50:50 or lower. The Met requirement data based on the evaluated Met efficiency was clearly dependent on protein deposition, feed intake and the MCR. In general, the results were comparable with already published data.

Additionally, we investigated the possible impact of the MCR and the protein source on body composition and nutrient deposition of the birds. It became clear, that a low Met percentage of $40 \%$ of the SAA influenced the parameters in a negative way. Observed differences between the used protein sources can be explained by the different energy content of the diets, which was caused by the higher crude lipid content of the insect meals in comparison to SBM.

Furthermore, we determined the apparent preceacal digestibility of the crude protein and chosen amino acids in the diets with insect meal and SBM. The direct comparison of the protein sources showed no significant differences.

In conclusion, it can be stated that the optimal MCR in diets for meat-type chickens is 50:50. Generally, the results of the three studies show the great potential of insect meals as an alternative protein source and demonstrate that this protein source has no impact on the optimal MCR in meat-type chicken diets. 


\section{Literaturverzeichnis}

Adler, S.A., Slizyte, R., Honkapää, K., Løes, A.-K. (2018): In vitro digestibility and amino acid composition in soluble and residual fractions of hydrolyzed chicken feathers. Poultry Science 97, 3343-3357, https://doi.org/10.3382/ps/pey175

Aggrey, S.E., González-Cerón, F., Rekaya, R., Mercier, Y. (2018): Gene expression differences in the methionine remethylation and transsulfuration pathways under methionine restriction and recovery with D,L-methionine or D,L-HMTBA in meat-type chickens. Journal of Animal Physiology and Animal Nutrition 102, e468-e475, https://doi.org/10.1111/jpn.12779

Almquist, H.J. (1952): Amino acid requirements of chickens and turkeys - a review. Poultry Science 31, 966-981, https://doi.org/10.3382/ps.0310966

Aviagen (2014): Ross 308 broiler: Nutrient specifications. Online verfügbar unter: http://en.aviagen.com/tech-center/download/12/Ross-308-Broiler-Nutrition-Specs-2014r17EN.pdf

Baker, D.H. (2006): Comparative species utilization and toxicity of sulfur amino acids. The Journal of Nutrition 136, 1670-1675, https://doi.org/10.1093/jn/136.6.1670S

Baker, D.H. (2009): Advances in protein-amino acid nutrition of poultry. Amino Acids 37, 2941, DOI 10.1007/s00726-008-0198-3

Baker, D.H. und Han, Y. (1994): Ideal amino acid profile for chicks during the first three weeks posthatching. Poultry Science 73, 1441-1447, https://doi.org/10.3382/ps.0731441

Baker, D.H., Fernandez, S.R., Webel, D.M., Parsons, C.M. (1996): Sulfur amino acid requirement and cystine replacement value of broiler chicks during the period three to six weeks posthatching. Poultry Science 75, 737-742, https://doi.org/10.3382/ps.0750737

Baker, D.H., Batal, A.B., Parr, T.M., Augspurger, N.R., Parsons, C.M. (2002): Ideal ratio (relative to lysine) of tryptophan, threonine, isoleucine and valine for chicks during the second and third weeks posthatch. Poultry Science 81, 485-494, https://doi.org/10.1093/ps/81.4.485

Balicka-Ramisz, A., Wojtasz-Pająk, A., Pilarczyk, B., Ramisz, A. (2008): Comparative studies of a coccidiostat (Baycox) and chitosan against coccidiosis in broiler chickens. Bulletin of the Veterinary Institute in Pulawy, 52, 71-73

Ballitoc, D. A. und Sun, S. (2013): Ground Yellow Mealworms (Tenebrio molitor L.) feed supplementation improves growth performance and carcass yield characteristics in broilers. Open Science Repository Agriculture, online (open-access), e23050425, http://dx.doi.org/10.7392/openaccess.23050425

Barker, D., Fitzpatrick, M.P., Dierenfeld, E.S. (1998): Nutrient composition of selected whole invertebrates. Zoo Biology 17, 123-134, https://doi.org/10.1002/(SICI)10982361(1998)17:2\%3C123::AID-ZOO7\%3E3.0.CO;2-B

Barroso, F.G., Sánchez-Muros, M.J., Segura, M., Morote, E., Torres, A., Ramos, R., Guil, J.L. (2017): Insects as food: Enrichment of larvae of Hermetia illucens with omega 3 fatty acids by means of dietary modifications. Journal of Food Composition and Analysis 62, 8-13, https://doi.org/10.1016/j.jfca.2017.04.008 
Biancarosa, I., Liland, N.S., Biemans, D., Araujo, P., Bruckner, C.G., Waagb $\varnothing$, R., Tortensen, B.E., Lock, E.-J., Amlund, H. (2018): Uptake of heavy metals and arsenic in black soldier fly (Hermetia illucens) larvae grown on seaweed-enriched material. Journal of the Science of Food and Agriculture 98, 2176-2183, https://doi.org/10.1002/jsfa.8702

Biasato, I., De Marco, M., Rotolo, L., Renna, M., Lussiana, C., Dabbou, S., Capucchio, M.T., Biasibetti, E., Costa, P., Gai, F., Pozzo, L., Dezzutto, D., Bergagna, S., Martínez, S., Tarantola, M., Gasco, L., Schiavone A. (2016): Effects of dietary Tenebrio molitor meal inclusion in freerange chickens. Journal of Animal Physiology and Animal Nutrition 100, 1104-1112, https://doi.org/10.1111/jpn.12487

Biasato, I., De Marco, M., Renna, M., Rotolo, L., Dabbou, S., Capucchio, M.T., Biasibetti, E., Tarantola, M., Sterpone, L., Cavallarin, L., Gai, F., Pozzo, L., Bergagna, S., Dezzutto, D., Zoccarato, I., Schiavone, A. (2018a): Yellow mealworm larvae (Tenebrio molitor) inclusion in diets for male broiler chickens: effects on growth performance, gut morphology, and histological findings. Poultry Science 97, 540-548, https://doi.org/10.3382/ps/pex308

Biasato, I., Gasco, L., De Marco, M., Renna, M., Rotolo, L., Dabbou, S., Capucchio, M. T., Biasibetti, E., Tarantola, M., Bianchi, C., Cavallarin, L., Gai, F., Pozzo, L., Dezzutto, D., Bergagna, S., Schiavone, A. (2018b): Effects of yellow mealworm larvae (Tenebrio molitor) inclusion in diets for female broiler chickens: implications for animal health and gut histology. Animal Feed Science and Technology 234, 253-263, https://doi.org/10.1016/j.anifeedsci.2017.09.014

Block, R.J. and Mitchell H.H. (1946): The correlation of amino acid composition of proteins with their nutritive value. Nutrition Abstracts \& Reviews, 16, 249-278

Bosch, G., van der Fels-Klerx, H.J., de Rijk, T.C., Oonincx, G.A.B. (2017): Aflatoxin B1 tolerance and accumulation in black soldier fly larvae (Hermetia illucens) and yellow mealworm (Tenebrio molitor). Toxins 9, 1-10, https://dx.doi.org/10.3390/toxins9060185

Bovera, F., Piccolo, G., Gasco, L.; Marono, S., Loponte, R., Vassalotti, G., Mastellone, V., Lombardi, P., Attia, Y.A., Nizza, A. (2015): Yellow mealworm larvae (Tenebrio molitor, L.) as a possible alternative to soybean meal in broiler diets. British Poultry Science 56, 569-575, https://doi.org/10.1080/00071668.2015.1080815

Bovera, F., Loponte, R., Marono, S., Piccolo, G., Parisi, G., Iaconisi, V., Gasco, L., Nizza, A. (2016): Use of Tenebrio molitor larvae meal as protein source in broiler diet: Effect on growth performance, nutrient digestibility, and carcass and meat traits. Journal of Animal Science 94, 639-647, https://doi.org/10.2527/jas.2015-9201

Brandt, M. und Allam, S.M. (1987): Analytik von $\mathrm{TiO}_{2}$ im Darminhalt und Kot nach Kjeldahlaufschluss. Archives of Animal Nutrition 37, 453-454

Brede, A., Wecke, C., Sünder, A., Liebert, F. (2018): Besonderheiten bei der Versorgung mit schwefelhaltigen Aminosäuren unter spezieller Betrachtung der Mastgeflügelernährung. Übersichten zur Tierernährung 43, 1-52

Bregendahl, K., Sell, J.L., Zimmerman, D.R. (2002): Effect of low-protein diets on growth performance and body composition of broiler chicks. Poultry Science 81, 1156-1167, https://doi.org/10.1093/ps/81.8.1156

Brosnan, J.T. und Brosnan, M.E. (2006): The sulfur-containing amino acids: an overview. The Journal of Nutrition 136, 1636S-1640S, https://doi.org/10.1093/jn/136.6.1636S 
Bunchasak, C. (2009): Role of dietary methionine in poultry production. The Journal of Poultry Science 46, 169-179, https://doi.org/10.2141/jpsa.46.169

Bunchasak, C., Kimura, G., Tanaka, K., Ohtani, S., Collado, C.M. (1998): The effect of supplementatig cystine on growth performance and liver lipid and phospholipid contents of broiler chicks. Japanese Poultry Science 35, 60-66, https://doi.org/10.2141/jpsa.35.60

Byrd, J.H. und Castner, J.L. (2010): Forensic entomology: The utility of arthropods in legal investigations. Second Edition. CRC Press

Camenzuli, L., van Dam, R., de Rijk, T., Andriessen, R., van Schelt, J., van der Fels-Klerx, H.J. (2018): Tolerance and excretion of the mycotoxins aflatoxin B1, zearalenone, deoxynivalenol, and ochratoxin A by Alphitobius diaperinus and Hermetia illucens from contaminated substrates. Toxins 10, 1-15, https://doi.org/10.3390/toxins10020091

Carvalho, T.S.M., Sousa, L.S., Nogueira, F.A., Saldanha, M.M., Triginelli, M.V., Pinto, M.F.V.S., Baião, N.C., Lara, L.J.C. (2018): Digestible methionine+cysteine in the diet of commercial layers and its influence on the performance, quality, and amino acid profile of eggs and economic evaluation. Poultry Science 97, 2044-2052, https://doi.org/10.3382/ps/pey036

Cerrate, S., Vignale, S.K., Ekmay, R., England, J., Coon, C. (2018): Effect of dietary nutrients on ileal endogenous losses of threonine, cysteine, methionine, lysine, leucine and protein in broiler chicks. Animal 12, 684-691, https://doi.org/10.1017/S1751731117002166

Chamruspollert, M., Pesti, G.M., Bakalli, R.I. (2002): Determination of the methionine requirement of male and female broiler chicks using an indirect amino acid oxidation method. Poultry Science 81, 1004-1013, https://doi.org/10.1093/ps/81.7.1004

Chen, R., Zhuang, S., Chen, Y.P., Cheng, Y.F., Wen, C., Zhou, Y.M. (2018): Betaine improves the growth performance and muscle growth of partridge shank broiler chickens via altering myogenic gene expression and insulin-like growth factor-1 signaling pathway. Poultry Science, pey303, https://doi.org/10.3382/ps/pey303

Chung, T.K. und Baker, D.H. (1992): Apparent and true amino acid digestibility of a crystalline amino acid mixture and of casein: Comparison of values obtained with ileal-cannulated pigs and cecectomized cockerels. Journal of Animal Science 70, 3781-3790

Cole, D.J.A., Yen, H.T., Lewis, D. (1980): The lysine requirements of growing and finishing pigs - The concept of an ideal protein. In: Proceedings of the 3rd international symposium on protein metabolism and nutrition, Vol. II, EAAP, Braunschweig, Germany, 658-668

Conde-Aguilera, J.A., Cobo-Ortega, C., Tesseraud, S., Lessire, M., Mercier, Y., van Milgen, J. (2013): Changes in body composition in broilers by a sulfur amino acid deficiency during growth. Poultry Science 92, 1266-1275, https://doi.org/10.3382/ps.2012-02796

Conde-Aguilera, J.A., Cholet, J.C.G., Lessire, M., Mercier, Y., Tesseraud, S., van Milgen, J. (2016): The level and source of free-methionine affect body composition and breast muscle traits in growing broilers. Poultry Science 95, 2322-2331, https://doi.org/10.3382/ps/pew105

Cotton, R. (1927): Notes on the biology of the meal worms Tenebrio molitor Linne and T. obscurus Fab. Annals of the Entmological Society of Amercia 20, 81-86, https://doi.org/10.1093/aesa/20.1.81 
Cullere, M., Tasoniero, G., Giaccone, V., Miotti-Scapin, R., Claeys, E., De Smet, S., Dalle Zotte, A. (2016): Black soldier fly as dietary protein source for broiler quails: apparent digestibility, excreta microbial load, feed choice, performance, carcass and meat traits. Animal 10, 1923-1930, https://doi.org/10.1017/S1751731116001270

Deaton, J.W. und Lott, B.D. (1985): Age and dietary effect on broiler abdominal fat deposition. Poultry Science 64, 2161-2164, https://doi.org/10.3382/ps.0642161

Deng, X., Li, X., Liu, P., Yuan, S., Zang, J., Li, S., Piao, X. (2008): Effect of chitooligosaccharide supplementation on immunity in broiler chickens. Asian-Australasian Journal of Animal Sciences 21, 1651-1658, https://doi.org/10.5713/ajas.2008.80056

Derrien, C. und Boccuni, A. (2018): Current status of the insect producing industry in europe. In: Halloran, A., Flore, R., Vantomme, P., Roos, N. (2018): Edible insects as sustainable food systems. Springer International Publishing AG, 471-479

Deutscher Verband Tiernahrung e.V. (DTV) (2016): Futtermittel-Tabellarium Ausgabe 2016

Devic, E. und Fahmi, M.R. (2014): Biology of Hermetia illucens. In: Technical Handbook of domestication and production of diptera Black Soldier Fly (BSF) Hermetia illucens, Stratomyidae. PT Penerbit IBP Press

Diener, S., Zurbrügg, C., Tockner, K. (2009): Conversion of organic material by black soldier fly larvae: establishing optimal feeding rates. Waste Management \& Research 27, 603-610, https://doi.org/10.1177\%2F0734242X09103838

Dilger, R.N. und Baker, D.H. (2007): DL-methionine is as efficacious as L-methionine, but modest L-cystine excesses are anorexigenic in sulfur amino acid-deficient purified and practical-type diets fed to chicks. Poultry Science 86, 2367-2374, https://doi.org/10.3382/ps.2007-00203

Dilger, R.N. und Baker, D.H. (2008a): Cyst(e)ine imbalance and its effect on methionine precursor utilization in chicks. Journal of Animal Science 86, 1832-1840, https://doi.org/10.2527/jas.2007-0712

Dilger, R.N. und Baker, D.H. (2008b): Excess dietary L-cysteine causes lethal metabolic acidosis in chicks. The Journal of Nutrition 138, 1628-1633, https://doi.org/10.1093/jn/138.9.1628

Dozier, W.A. und Mercier, Y. (2013): Ratio of digestible total sulfur amino acids to lysine of broiler chicks from 1 to 15 days of age. The Journal of Applied Poultry Research 22, 862-871, https://doi.org/10.3382/japr.2013-00760

Dreassi, E., Cito, A., Zanfini, A., Materozzi, L., Botta, M., Francardi, V. (2017): Dietary fatty acids influence the growth and fatty acid composition of the yellow mealworm Tenebrio molitor (Coleoptera: Tenebrionidae). Lipids 52, 285-294, https://doi.org/10.1007/s11745-016-4220-3

Dutta, P.K., Dutta, J., Tripathi, V.S. (2004): Chitin and chitosan: chemistry, properties and applications. Journal of Scientific \& Industrial Research 63, 20-31, http://hdl.handle.net/123456789/5397

Elwert, C., Knips, Y., Katz, P. (2010): A novel protein source: Maggot meal of the black soldier fly (Hermetia illucens) in broiler feed. In: 11. Tagung Schweine- und Geflügelernährung, Lutherstadt Wittenberg 
Emmert, J.L. und Baker, D.H. (1997): Use of the ideal protein concept for precision formulation of amino acid levels in broiler diets. The Journal of Applied Poultry Research 6, 462-470, https://doi.org/10.1093/japr/6.4.462

Esteve-Garcia, E. und Khan, D.R. (2018): Relative bioavailability of DL and L-methionine in broilers. Open Journal of Animal Sciences, 8, 151-162, https://doi.org/10.4236/ojas.2018.82011

Europäische Behörde für Lebensmittelsicherheit (EFSA) (2012): Scientific Opinion on DLmethionine, DL-methionine sodium salt, the hydroxy analogue of methionine and the calcium salt of methionine hydroxy analogue in all animal species; on the isopropyl ester of methionine hydroxy analogue and DL-methionine technically pure protected with copolymer vinylpyridine/styrene in dairy cows; and on DL- methionine technically pure protected with ethylcellulose in ruminants. EFSA Journal, https://doi.org/10.2903/j.efsa.2012.2623

Europäische Behörde für Lebensmittelsicherheit (EFSA) (2015): Risk profile related to production and consumption of insects as food and feed. EFSA Journal, https://doi.org/10.2903/j.efsa.2015.4257

European Feed Manufacturers' Federation (FEFAC) (2018): Annual report 2017-2018. Online verfügbar unter: https://www.fefac.eu/files/83625.pdf

Fang, Z., Yao, K., Zhang, X., Zhao, S., Sun, Z., Tian, G., Yu, B., Lin, Y., Zhu, B., Jia, G., Zhang, K., Chen, D., Wu. D. (2010): Nutrition and health relevant regulation of intestinal sulfur amino acid metabolism. Amino Acids 39, 633-640, https://doi.org/10.1007/s00726-010-0502$\underline{\mathrm{x}}$

Farke, J., Wecke, C., Liebert, F. (2010): Methionine efficiency in chicken diets with varying Met to Cys ratio modifies the concluded Met requirements. In: Proceedings of the Society of Nutrition Physiology, DLG-Verlag, Frankfurt am Main, Deutschland, 19, 21

Fast, P.G. (1966): A comparative study of the phospholipids and fatty acids of some insects. Lipids 1, 209-215, https://doi.org/10.1007/BF02531874

Fatufe, A.A. und Rodehutscord, M. (2005): Growth, body composition, and marginal efficiency of methionine utilization are affected by nonessential amino acid nitrogen supplementation in male broiler chicken. Poultry Science 84, 1584-1592, https://doi.org/10.1093/ps/84.10.1584

Featherston, W.R. und Rogler, A.C. (1978): Methionine-cystine interrelations in chicks fed diets containing suboptimal levels of methionine. The Journal of Nutrition 108, 1954-1958, https://doi.org/10.1093/jn/108.12.1954

Ferguson, N.S., Gates, R.S., Taraba, J.L., Cantor, A.H., Pescatore, A.J., Ford, M.J., Burnham, D.J. (1998): The effect of dietary crude protein on growth, ammonia concentration, and litter composition in broilers. Poultry Science 77, 1481-1487, https://doi.org/10.1093/ps/77.10.1481

Finke, M.D. (2002): Complete nutrient composition of commercially raised invertebrates used as food for insectivores. Zoo Biology 21, 269-285, https://doi.org/10.1002/zoo.10031

Finke, M.D. (2007): Estimate of chitin in raw whole insects. Zoo Biology 26, 105-115, https://doi.org/10.1002/zoo.20123

Finke, M.D. (2013): Complete Nutrient Content of Four Species of Feeder Insects. Zoo Biology 32, 27-36, https://doi.org/10.1002/zoo.21012 
Food and Agriculture Organization of the United Nations (FAO) (2009a): The State of Food and Agriculture. Online verfügbar unter: http://www.fao.org/3/a-i0680e.pdf

Food and Agriculture Organization of the United Nations (FAO) (2009b): Global agriculture towards $2050 . \quad$ Online verfügbar unter: http://www.fao.org/fileadmin/templates/wsfs/docs/Issues_papers/HLEF2050_Global_Agricult ure.pdf

Food and Agriculture Organization of the United Nations (FAO) (2012): World agriculture towards 2030/2050 - The 2012 Revision. Online verfügbar unter: http://www.fao.org/docrep/016/ap106e/ap106e.pdf

Food and Agriculture Organization of the United Nations (FAO) (2013): Edible insects: future prospects for food and feed security. Online verfügbar unter: http://www.fao.org/docrep/018/i3253e/i3253e.pdf

Francardi, V., Cito, A., Fusi, S., Botta, M., Dreassi, E. (2017): Linseed to increase N-3 fatty acids in Tenebrio molitor (Coleoptera tenebrionidae). Redia 100, 73-76, http://dx.doi.org/10.19263/REDIA-100.17.08

Fuller, M.F. (Hrsg.) (2004): The encyclopedia of farm animal nutrition. CABI Publishing, Wallingford

Gebhardt, G. (1966): Die Bewertung der Eiweißqualität von Nahrungs- und Futtermitteln mit Hilfe des N-BilanzExperimentes. In: Hock, A.: Vergleichende Ernährungslehre des Menschen und seiner Haustiere. Gustav Fischer Verlag Jena, Germany, 323-348

GfE (Gesellschaft für Ernährungsphysiologie) (1999): Empfehlungen zur Energie- und Nähstoffversorgung der Legehennen und Masthühner (Broiler). DLG-Verlag, Frankfurt am Main

Ghaly, A.E. und Alkoaik, F.N. (2009): The Yellow Mealworm as a novel source of protein. American Journal of Agricultural and Biological Sciences 4, 319-331, http://www.scipub.org/fulltext/AJAB/AJAB44319-331.pdf

Goulart, C.D.C., Guilherme, F., Costa, P., Vilar, J.H, de Souza, J.G., Rodrigues, V.P., Santos, C.F. (2011): Requirements of digestible methionine + cystine for broiler chickens at 1 to 42 days of age. Revista Brasileira de Zootecnia 40, 797-803, http://dx.doi.org/10.1590/S1516$\underline{35982011000400013}$

Graber, G. und Baker, D.H. (1971): Sulfur amino acid nutrition of the growing chick: Quantitative aspects concerning the efficacy of dietary methionine, cysteine and cystine. Journal of Animal Science 33, 1005-1011, https://doi.org/10.2527/jas1971.3351005x

Graber, G., Scott, H.M., Baker, D.H. (1971): Sulfur amino acid nutrition of the growing chick: Effect of age on the capacity of cystine to spare dietary methionine. Poultry Science 50, 14501455, https://doi.org/10.3382/ps.0501450

Hahn, T., Roth, A., Febel, E., Fijalkowska, M., Schmitt, E., Arsiwalla, T., Zibek, S. (2018): New methods for high-accuracy insect chitin measurement. Journal of the Science of Food and Agriculture 98, 5069-5073, https://doi.org/10.1002/jsfa.9044 
Hancock C.E., Bradford G.D., Emmans G.C., Gous R.M. (1995): The evaluation of the growth parameters of six strains of commercial broiler chickens. British Poultry Science 36, 247-264, https://doi.org/10.1080/00071669508417773

Harter, J.M. und Baker, D.H. (1978): Factors affecting methionine toxicity and its alleviation in the chick. The Journal of Nutrition 108, 1061-1070, https://doi.org/10.1093/jn/108.7.1061

Hill, F.W. und Dansky, L.M. (1954): Studies of the energy requirements of chickens: 1. The effect of dietary energy level on growth and feed consumption. Poultry Science 33, 112-119, https://doi.org/10.3382/ps.0330112

Hoehler, D., Lemme, A., Roberson, K., Turner, K. (2005): Impact of methionine sources on performance in turkeys. Journal of Applied Poultry Research 14, 296-305, https://doi.org/10.1093/japr/14.2.296

Hossain, S.M. und Blair, R. (2007): Chitin utilisation by broilers and its effect on body composition and blood metabolites. British Poultry Science 48, 33-38, https://doi.org/10.1080/00071660601156529

Howard, R.S. (1955): The biology of the grain beetle Tenebrio molitor with particular reference to its behavior. Ecology 36, 262-269, https://doi.org/10.2307/1933231

Huang, R.-L., Deng, Z.-Y., Yang, C., Yin, Y.-L., Xie, M.Y., Wu, G.-Y., Li, T.-J., Li, L.-L., Tang, R.-Z., Kang, P., Hou, Z.-P., Deng, D., Xiang, H., Kong, X.F., Guo, Y.-M. (2007): Dietary oligochitosan supplementation enhances immune status of broilers. Journal of the Science of Food and Agriculture 87, 153-159, https://doi.org/10.1002/jsfa.2694

Ibitoye, E.B., Lokman, I.H., Hezmee, M.N.M., Goh, Y.M., Zuki, A.B.Z., Jimoh, A.A., Danmaigoro, A., Pilau Nicholas, N. (2018): Gut health and serum growth hormone levels of broiler chickens fed dietary chitin and chitosan from cricket and shrimp. Poultry Science, pey419, https://doi.org/10.3382/ps/pey419

Iji, P.A., Saki, A., Tivey, D.R. (2001): Body and intestinal growth of broiler chicks on a commercial starter diet. 1. Intestinal weight and mucosal development. British Poultry Science 42, 505-513, https://doi.org/10.1080/00071660120073151

Jahanian, R. und Khalifeh-Gholi, M. (2018): Marginal deficiencies of dietary arginine and methionine could suppress growth performance and immunological responses in broiler chickens. Journal of Animal Physiology and Animal Nutrition 102, e11-e20, https://doi.org/10.1111/jpn.12695

Jankowski, J., Ognik, K., Kubińska, M., Czech, A., Juśkiewicz, J., Zduńczyk, Z. (2017): The effect of DL-. L-isomers and DL-hydroxy analog administered at 2 levels as dietary sources of methionine on the metabolic and antioxidant parameters and growth performance of turkeys. Poultry Science 96, 3229-3238, https://doi.org/10.3382/ps/pex099

Janssen, R.H., Vincken, J.-P., van den Broek, L.A.M., Fogliano, V., Lakemond, C.M.M. (2017): Nitrogen-to-protein conversion factors for three edible insects: Tenebrio molitor, Alphitobius diaperinus, and Hermetia illucens. Journal of Agricultural and Food Chemistry 65, 2275-2278, https://pubs.acs.org/doi/10.1021/acs.jafc.7b00471

Jansson, A. und Berggren, A. (2015): Insects as Food - Something for the future? A report from future agriculture. Uppsala, Swedish University of Agricultural Sciences (SLU). Online verfügbar unter: https://pub.epsilon.slu.se/12935/ 
Jariyahatthakij, P., Chomtee, B., Poeikhampha, T., Loongyai, W., Bunchasak, C. (2018): Effects of adding methionine in low-protein diet and subsequently fed low-energy diet on productive performance, blood chemical profile, and lipid metabolism-related gene expression of broiler chickens. Poultry Science 97, 2021-2033, https://doi.org/10.3382/ps/pey034

Jeuniaux, C. und Cornelius, C. (1978): Distribution and activity of chitinolytic enzymes in the digestive tract of birds and mammals. Proceedings of the $1^{\text {st }}$ international conference on chitin/chitosan, 542-549, http://hdl.handle.net/2268/190140

Jonas-Levi, A. und Itzhak Martinez, J.-J. (2017): The high level of protein content reported in insects for food and feed is overestimated. Journal of Food Composition and Analysis 62, 184188, https://doi.org/10.1016/j.jfca.2017.06.004

Józefiak, A. und Engberg, R.M. (2015): Insects as poultry feed. $20^{\text {th }}$ European Symposium on Poultry Nutrition, Prague, Czech Republic

Józefiak, A., Kierońcuyk, B., Rawski, M., Mazurkiewicz, J., Benzertiha, A., Gobbi, P., Nogales-Mérida, S., Świątkiewicz, S., Józefiak, D. (2018): Full-fat insect meals as feed additive - the effect on broiler chicken growth performance and gastrointestinal tract microbiota. Journal of Animals and Feed Sciences 27, 131-139, https://doi.org/10.22358/jafs/91967/2018

Kaewtapee, C., Eklund, M., Wiltafsky, M., Piepho, H.-P., Mosenthin, R., Rosenfelder, P. (2017): Influence of wet heating and autoclaving on chemical composition and standardized ileal crude protein and amino acid digestibility in full-fat soybeans for pigs. Journal of Animal Science 95, 779-788, https://doi.org/10.2527/jas.2016.0932

Kalinowski, A., Moran, E.T., Wyatt, C.L. (2003a): Methionine and cystine requirements of slow-and fast-feathering male broilers from zero to three weeks of age. Poultry Science 82, 1423-1427, https://doi.org/10.1093/ps/82.9.1423

Kalinowski, A., Moran, E.T., Wyatt, C.L. (2003b): Methionine and cystine requirements of slow-and fast-feathering broiler males from three to six weeks of age. Poultry Science 82, 14281437, https://doi.org/10.1093/ps/82.9.1428

Khan, S.H. (2018): Recent advances in role of insects as alternative protein source in poultry nutrition. Journal of Applied Animal Research 46, 1144-1157, https://doi.org/10.1080/09712119.2018.1474743

Khan, D.R., Wecke, C., Liebert, F. (2015a): An elevated dietary cysteine to methionine ratio does not impact on dietary methionine efficiency and the derived optimal methionine to lysine ratio in diets for meat type chicken. Open Journal of Animal Sciences 5, 457-466, http://doi.org/10.4236/ojas.2015.54047

Khan, D.R., Wecke, C., Liebert, F. (2015b): Does the naked neck meat type chicken yield lower methionine requirement data? Animals 5, 151-160, https://dx.doi.org/10.3390/ani5020151

Khan, S., Khan, R.U., Alam, W., Sultan, A. (2018): Evaluating the nutritive profile of three insect meals and their effects to replace soya bean in broiler diet. Journal of Animal Physiology and Animal Nutrition 102, e662-e668, https://doi.org/10.1111/jpn.12809

Khempaka, S., Mochizuki, M., Koh, K., Karasawa, Y. (2006): Effect of chitin in shrimp meal on growth performance and digestibility in growing broilers. The Journal of Poultry Science 43, 339-343, https://doi.org/10.2141/jpsa.43.339 
Khempaka, S., Chitsatchapong, C., Molee, W. (2011): Effect of chitin and protein constituents in shrimp head meal on growth performance, nutrient digestibility, intestinal microbial populations, volatile fatty acids, and ammonia production in broilers. Journal of Applied Poultry Research 20, 1-11, https://doi.org/10.3382/japr.2010-00162

Klain, G.J., Scott, H.M., Connor Johnson, B. (1960): The amino acid requirement of the growing chick fed a crystalline amino acid diet. Poultry Science 39, 39-44, https://doi.org/10.3382/ps.0390039

Kluth, H. und Rodehutscord, M. (2009): Standardisierte Futterbewertung auf der basis der Aminosäurenverdaulichkeit beim Geflügel. Übersichten zur Tierernährung 37, 1-26

Kluth, H., Mehlhorn, K., Rodehutscord, M. (2005): Studies on the intestine section to be sampled in broiler studies on precaecal amino acid digestibility. Archives of Animal Nutrition 59, 271-279, https://doi.org/10.1080/17450390500217058

Koh, K., und Iwamae, S. (2013): Chitinolytic activity of mucosal enzymes in the different parts of the digestive tract in broilers. The Journal of Poultry Science 50, 65-67, https://doi.org/10.2141/jpsa.0120054

Koide, S.S. (1998): Chitin-chitosan: properties, benefits and risks. Nutrition Research 18, 10911101, https://doi.org/10.1016/S0271-5317(98)00091-8

Kramer, K.J. und Koga, D. (1986): Insect chitin - physical state, synthesis, degradation and metabolic regulation. Insect Biochemistry 16, 851-877, https://doi.org/10.1016/0020$\underline{1790(86) 90059-4}$

Kroeckel, S., Harjes, A.-G.E., Roth, I., Katz, H., Wuertz, S., Susenbeth, A., Schulz, C. (2012): When a turbot catches a fly: Evaluation of a pre-pupae meal of Black Soldier Fly (Hermetia illucens) as fish meal substitute - growth performance and chitin degradation in juvenile turbot (Psetta maxima). Aquaculture 364-365, 345-352,

https://doi.org/10.1016/j.aquaculture.2012.08.041

Kumar, C.B., Gloridoss, R.G., Singh, K.C., Prabhu, T.M., Suresh, B.N. (2016): Performance of broiler chickens fed low protein, limiting amino acid supplemented diets formulated either on total or standardized ileal digestible amino acid basis. Asian-Australasian Journal of Animal Science 29, 1616-1624, https://dx.doi.org/10.5713\%2Fajas.15.0648

Lai, A., Dong, G., Song, D., Yang, T., Zhang, X. (2018): Responses to dietary levels of methionine in broilers medicated or vaccinated against coccidia under Eimeria tenellachallenged condition. BMC Veterinary Research 14, 1-11, https://doi.org/10.1186/s12917-018$\underline{1470-8}$

Lähteenmäki-Uutela, A., Grmelová, N., Hénault-Ethier, L., Deschamps, M.-H., Wandenberg, G.W., Zhao, A., Zhang, Y., Yang, B., Nemane, V. (2017): Insects as food ans feed: laws of the European Union, United States, Canada, Mexico, Australia, and China. Insects as Food and Feed 1, 22-37, https://heinonline.org/HOL/P?h=hein.journals/effl2017\&i=28

Lee, C.G., Da Silva, C.A., Lee, J.-Y., Hartl. D., Elias, J.A. (2009): Chitin regulation of immune responses: An old molecule with new roles. Current Opinion in Immunology 20, 684-689, https://doi.org/10.1016/i.coi.2008.10.002

Leeson, S., Caston, L., Summers, J.D. (1996): Broiler response to diet energy. Poultry Science 75, 529-535, https://doi.org/10.3382/ps.0750529 
Leeson, S. and Summers, J.D. (2001): Nutrition of the chicken. $4^{\text {th }}$ edition, University Books, Ontario, Canada

Leiber, F., Gelencsér, T., Stamer, A., Amsler, Z., Wohlfahrt, J., Früh, B., Maurer, V. (2017): Insect and legume-based protein sources to replace soybean cake in an organic broiler diet: Effects on growth performance and physical meat quality. Renewable Agriculture and Food Systems 32, 21-27, https://doi.org/10.1017/S1742170515000496

Lerner, J. und Wight Taylor, M. (1967): A common step in the intestinal absorption mechnisms of D- and L-methionine. Biochimica et Biophysica Acta 135, 990-999, https://doi.org/10.1016/0005-2736(67)90069-7

Li, X.J., Piao, X.S., Kim, S.W., Liu, P., Wang, L., Shen, Y.B., Jung, S.C., Lee, H.S. (2007): Effects of chito-oligosaccharide supplementation on performance, nutrient digestibility, and serum composition in broiler chickens. Poultry Science 86, 1107-1114, https://doi.org/10.1093/ps/86.6.1107

Liebert, F. (2008): Modelling of protein metabolism yields amino acid requirements dependent on dietary amino acid efficiency, growth response, genotype and age of growing chicken. Avian Biology Research 1, 101-110, https://doi.org/10.3184/175815508X388074

Liebert, F. (2015): Basics and applications of an exponential nitrogen utilization model ("Goettingen approach") for assessing amino acid requirements in growing pigs and meat type chickens based on dietary amino acid efficiency. In: Nutritional Modelling for Pigs and Poultry. Publishing, Wallingford, 73-87

Liebert, F. (2017): Further progress is needed in procedures for biological evaluation of dietary protein quality in pig and poultry feeds. Archives of Animal Breeding 60, 259-270, https://doi.org/10.5194/aab-60-259-2017

Liebert, F. und Gebhardt, G. (1986): Ergebnisse zur Wirksamkeit und zum Bedarf an ausgewählten Aminosäuren beim wachsenden weiblichen Schwein. 1. Mitteilung: Lysin. Archives of Animal Nutrition 36, 1077-1086

Liebert, F. und Gebhardt, G. (1987): Ergebnisse zur Wirksamkeit und zum Bedarf an ausgewählten Aminosäuren beim wachsenden weiblichen Schwein. 2. Mitteilung: Methionin/Cystin. Archives of Animal Nutrition 37, 159-167

Liebert, F. und Gebhardt, G. (1988a): Ergebnisse zur Wirksamkeit und zum Bedarf an ausgewählten Aminosäuren beim wachsenden weiblichen Schwein. 5. Mitteilung: Kombination von Proteinträgern zur Ableitung der Lysinwirksamkeit mit Hilfe des Differenzverfahrens. Archives of Animal Nutrition 38, 27-36

Liebert, F. und Gebhardt, G. (1988b): Ergebnisse zur Wirksamkeit und zum Bedarf an ausgewählten Aminosäuren beim wachsenden weiblichen Schwein. 6. Mitteilung: Zusammenfassende Diskussion und Wertung sowie Anwendungsempfehlungen zur vorgestellten Methode. Archives of Animal Nutrition 38, 453-462

Liebert, F., Farke, J., Wecke, C. (2010): Modelling methionine requirements in growing chickens by using the dietary methionine efficiency. $3^{\text {rd }}$ EAAP International Symposium on Energy and Protein Metabolism and Nutrition, Parma, Italy, 2010, EAAP publication No. 127, 625-626 
Liland, N.S., Biancarosa, I., Araujo, P., Biemans, D., Bruckner, C.G., Waagbø, R. (2017): Modulation of nutrient composition of black soldier fly (Hermetia illucens) larvae by feeding seaweed-enriched media. PLoS ONE 12(8): e0183188, https://doi.org/10.1371/journal.pone.0183188

Liu, X., Chen, X., Wang, H., Yang, Q., ur Rehman, K., Li, W. (2017): Dynamic changes of nutrient composition throughout the entire life cycle of black soldier fly. PLoS ONE 12(8): e0182601, https://doi.org/10.1371/journal.pone.0182601

Loponte, R., Panettieri, V., Gasco, L., Piccolo, G., Bovera, F. (2017): Nutrient digestibility in laying hens fed Hermetia illucens larvae meal from 24 to 45 weeks of age. In: INSECTA Conference 2017, Book of Abstracts, Bornimer Agrartechnische Berichte, Heft 97, 120

Machlin, L.J. und Gordon, R.S. (1961): Effect of dietary fatty acids and cholesterol on growth and fatty acid composition of the chicken. The Journal of Nutrition 75, 157-164, https://doi.org/10.1093/jn/75.2.157

Mack, S., Bercovici, D., de Groote, G., Leclerq, B., Lippens, M., Pack, M., Schutte, J.B., van Cauwenbherge, S. (1999): Ideal amino acid profile and dietary lysine specification for broiler chickens of 20 to 40 days of age. British Poultry Science 40, 257-265, https://doi.org/10.1080/00071669987683

Mahmoudi, M., Azarfar, A., Khosravinia, H. (2018): Partial replacement of dietary methionine with betaine and choline in heat-stressed broiler chickens. The Journal of Poultry Science 55, 28-37, https://doi.org/10.2141/jpsa.0170087

Makama, R.S., Duru, S., Bawa, G.S., Yakubu, S.T., Gandi, B.R. (2017): Effect of supplementing two types of methionine on carcass characteristics of finisher broiler chicken. Journal of Animal Production Research 29, 81-90

Makanya, A. N., Mayhew, T. M., Maina, J. N. (1995): Stereological methods for estimating the functional surfaces of the chiropteran small intestine. Journal of Anatomy 187, 361-368, https://www.ncbi.nlm.nih.gov/pubmed/7591999

Makkar, H.P.S., Tran, G., Heuzé, V., Ankers, P. (2014): State-of-the-art on use of insects as animal feed. Animal Feed Science and Technology 197, 1-33, https://doi.org/10.1016/j.anifeedsci.2014.07.008

Marono, S., Piccolo, G., Loponte, R., Di Meo, C., Attia, Y.A., Nizza, A., Bovera, F. (2015): In vitro crude protein digestibility of Tenebrio molitor and Hermetia illucens insect meals and its correlation with chemical composition traits. Italian Journal of Animal Science 14, 3889, https://doi.org/10.4081/ijas.2015.3889

Marquardt, R.R. und Campbell, L.D. (1975): Performance of chicks fed faba bean (Vicia faba) diets supplemented with methionine, sulfate and cystine. Canadian Journal of Animal Science 55, 213-218, https://doi.org/10.4141/cjas75-025

Maurer, V., Holinger, M., Amsler, Z., Früh, B., Wohlfahrt, J.M., Stamer, A., Leiber, F. (2016): Replacement of soybean cake by Hermetia illucens meal in diets for layers. Journal of Insects as Food and Feed 2, 83-90, https://doi.org/10.3920/JIFF2015.0071

Mayhew, T. M. (1991): The new stereological methods for interpreting functional morphology from slices of cells and organs. Experimental Physiology 76, 639-665, https://doi.org/10.1113/expphysiol.1991.sp003533 
McCusker, S., Buff, P.R., Yu, Z., Fascetti, A.J. (2014): Amino acid content of selected plant, algae and insect species: a search for alternative protein sources for use in pet food. Journal of Nutritional Science 3, e39, 1-5, https://doi.org/10.1017/jns.2014.33

Menconi, A., Pumford, N.R., Morgan, M.J., Bielke, L.R., Kallapura, G., Latorre, J.D., Wolfenden, A.D., Hernandez-Velasco, X., Hargis, B.M., Tellez, G. (2014): Effect of chitosan on Salmonella Typhimurium in broiler chickens. Foodborne Pathogens and Disease 11, 165169, https://doi.org/10.1089/fpd.2013.1628

Meneguz, M., Schiavone, A., Gai, F., Dama, A., Lussiana, C., Renna, M., Gasco, L. (2018): Effect of rearing substrate on growth performance, waste reduction efficiency and chemical composition of black soldier fly (Hermetia illucens) larvae. Journal of the Science of Food and Agriculture 98, 5776-5784, https://doi.org/10.1002/jsfa.9127

Merzendorfer, H. (2006): Insect chitin synthases: a review. Journal of Comparative Physiology B 176, 1-15, https://doi.org/10.1007/s00360-005-0005-3

Moran Jr., E.T. (1981): Cystine requirement of feather-sexed broiler chickens with sex and age. Poultry Science 60, 1056-1061, https://doi.org/10.3382/ps.0601056

Moula, N., Scippo, M.-L., Douny, C., Degand, G., Dawans, E., Cabaraux, J.-F., Hornick, J.-L., Medigo, R.C., Leroy, P., Francis, F., Detilleux, J. (2018): Performances of local poultry breed fed black soldier fly larvae reared on horse manure. Animal Nutrition 4, 73-78, https://doi.org/10.1016/j.aninu.2017.10.002

Naumann, C. und Bassler, R. (1976-2004): Die chemische Untersuchung von Futtermitteln. Methodenbuch, Volume III, VDLUFA-Verlag, Darmstadt, Deutschland

Neumann, C., Velten, S., Liebert, F. (2018a): Improving the dietary protein quality by amino acid fortification with a high inclusion level of micro algae (Spirulina platensis) or insect meal (Hermetia illcuens) in meat type chicken diets. Open Journal of Animal Sciences 8, 12-26, https://doi.org/10.4236/ojas.2018.81002

Neumann, C., Velten, S., Liebert, F. (2018b): The graded inclusion of algae (Spirulina platensis) or insect (Hermetia illucens) meal as a soybean meal substitute in meat type chicken diets impacts on growth, nutrient deposition and dietary protein quality depending on the extent of amino acid supplementation. Open Journal of Animal Sciences 8, 163-183, https://doi.org/10.4236/ojas.2018.82012

Newton, G. L., Sheppard, D.C., Watson, D.W., Burtle, G.J., Dove, C.R., Tomberlin, J.K., Thelen, E.E. (2005): The black soldier fly, Hermetia illucens, as a manure management/resource recovery tool. Symposium on the State of the Science of Animal Manure and Waste Management. January 5-7, 2005, San Antonio, Texas, USA

NRC (National Research Council) (1994): Nutrient Requirements of Poultry, 9th ed.; National Academy Press: Washington, DC, USA

Nuengjamnong, C. und Angkanaporn, K. (2018): Efficacy of dietary chitosan on growth performance, haematological parameters and gut function in broilers. Italian Journal of Animal Science 17, 428-435, https://doi.org/10.1080/1828051X.2017.1373609

Nyengaard, J. R., Alwasel, S. H. (2014): Practical stereology of the stomach and intestine. Annals of Anatomy 196, 41-47, https://doi.org/10.1016/j.aanat.2013.10.007 
Ohta, Y. und Ishibashi, T. (1994): Dietary levels and ratio of methionine and cystine for maximum performance of broilers. The Journal of Poultry Science 31, 369-380, https://doi.org/10.2141/jpsa.31.369

Olojede, O.C., Ford, M.J., Jacob, J.P., Ao, T., Pescatore, A.J., Adedokun, S.A. (2018): The effect of drying method temperature, collection method, and marker type on apparent ileal amino acid digestibility in 21-day-old broilers fed corn.soybean meal-barley based diet. Poultry Science 97, 2106-2112, https://doi.org/10.3382/ps/pey049

Onsongo, V.O., Osuga, I.M., Gachuiri, C.K., Wachira, A.M., Miano, D.M., Tanga, C.M., Ekesi, S., Nakimbugwe, D., Fiaboe, K.K.M. (2018): Insects for income generation through animal feed: Effect of dietary replacement of soybean and fish meal with Black Soldier Fly meal on broiler growth and economic performance. Journal of Economic Entomology 111, 1966-1973, https://doi.org/10.1093/jee/toy118

Oonincx, D.G.A.B., van Broekhoven, S., van Huis, A., van Loon, J.J.A. (2015): Feed conversion, survival and development, and composition of four insect species on diets composed of food by-products. PLoS ONE 10(12), e0144601, https://doi.org/10.1371/journal.pone.0144601

Park, I., Pasquetti, T., Malheiros, R.D., Ferket, P.R., Kim, S.W. (2018): Effects of supplemental L-methionine on growth performance and redox status of turkey poults compared with the use of DL-methionine. Poultry Science 97, 102-109, https://doi.org/10.3382/ps/pex259

Pastor, A., Wecke, C. und Liebert, F. (2013): Assessing the age-dependent optimal dietary branched-chain amino acid ratio in growing chicken by application of a nonlinear modeling procedure. Poultry Science 92, 3184-3195, https://doi.org/10.3382/ps.2013-03340

Pastor, A. (2014): Studien zur Aminosäurewirksamkeit beim Mastgeflügel unter spezifischer Betrachtung der verzweigtkettigen Aminosäuren. Dissertation zur Erlangung des Doktorgrades der Fakultät für Agrarwissenschaften der Georg-August-Universität Göttingen

Peng, J.L., Bai, S.P., Wang, J.P., Ding, X.M., Zeng, Q.F., Zhang, K.Y. (2018): Methionine deficiency decreases hepatic lipid exportation and induces liver lipid accumulation in broilers. Poultry Science, pey317, https://doi.org/10.3382/ps/pey317

Pesti, G.M., Harper, A.E., Sunde, M.L. (1979): Sulfur amino acid and methyl donor status of corn-soy diets fed to starting broiler chicks and turkey poults. Poultry Science 58, 1541-1547, https://doi.org/10.3382/ps.0581541

Pillai, P.B., Fanatico, A.C., Beers, K.W., Blair, M.E., Emmert, J.L. (2006): Homocysteine remethylation in young broilers fed varying levels of methionine, choline and betaine. Poultry Science 85, 90-95, https://doi.org/10.1093/ps/85.1.90

Pontin, C.A., Vieira, S.L., Stefanello, C., Kipper, M., Kindlein, L., Simões, C.T., GonzalezEsquerra, R. (2018): Estimation of broiler responses to increased dietary methionine hydroxy analogue [DL-2-hydroxy-(4-methylthio) butanoic acid] using linear and nonlinear regression models. Poultry Science 97, 865-873, https://doi.org/10.3382/ps/pex330

Powell, S., Bidner, T.D., Southern, L.L. (2011): Effects of glycine supplementation at varying levels of methionine and cystine on the growth performance of broilers fed reduced crude protein diets. Poultry Science 90, 1023-1027, https://doi.org/10.3382/ps.2010-01247 
Prabhakar, S. (2006): Molecular characterization of digestive proteases of the yellow meal worm, Tenebrio molitor L.. Arbeit zu Erlangung des Doktorgrades, Kansas University

Purschke, B., Scheibelberger, R., Axmann, S., Adler, A., Jäger, H. (2017): Impact of substrate contamination with mycotoxins, heavy metals and pesticides on the growth performance and composition of black soldier fly larvae (Hermetia illucens) for use in the feed and food value chain. Food Additives \& Contaminants Part A 34, 1410-1420, https://doi.org/10.1080/19440049.2017.1299946

Ramos-Bueno, R.P., González-Fernández, M.J., Sánchez-Muros-Lozano, M.J., GarcíaBarroso, F., Guil-Guerrero, J.L. (2016): Fatty acid profiles and cholesterol content of seven insect species assesed by several extraction systems. European Food Research and Technology 242, 1471-1477, https://doi.org/10.1007/s00217-016-2647-7

Ramos-Elorduy, J., González, E.A., Hernández, A.R., Pino, J.M. (2002): Use of Tenebrio molitor (Coleoptera: Tenebionidae) to recycle organic wastes and as feed for broiler chickens. Journal of Economic Entomology 95, 214-220, https://doi.org/10.1603/0022-0493-95.1.214

Razdan, A. und Petterson, D. (1994): Effect of chitin and chitosan on nutrient digestibility and plasma lipid concentrations in broiler chickens. British Journal of Nutrition 72, 277-288, https://doi.org/10.1079/BJN19940029

Ruhnke, I., Normant, C., Campbell D.L.M., Iqbal, Z., Lee, C., Hinch, G.N., Roberts, J. (2018): Impact of on-range choice feeding with black soldier fly larvae (Hermetia illucens) on flock performance, egg quality, and range use of free-range lying hens. Animal Nutrition, 4, 452-460, https://doi.org/10.1016/j.aninu.2018.03.005

Rumpold, B.A. und Schlüter, O.K. (2013): Nutritional composition and safety aspects of edible insects. Molecular Nutrition \& Food Research 57, 802-823, https://doi.org/10.1002/mnfr.201200735

Saeed, M., Babaradeh, D., Naveed, M., Asif Arain, M., Ul Hassan, F., Chao, S. (2017): Reconsidering betaine as a natural anti-heat stress agent in poultry industry: a review. Tropical Animal Health and Production 49, 1329-1338, https://doi.org/10.1007/s11250-017-1355-z

Salehifar, E., Shivazad, M., Foroudi, F., Chamani, M., Bahari Kashani, R. (2012): Reevaluation of digestible amino acid requirements of male and female broilers based on different ideal amino acids ratios in starter period. Livestock Science 147, 154-158, https://doi.org/10.1016/j.livsci.2012.04.016

Samadi und Liebert, F. (2006): Estimation of nitrogen maintenance requirements and potential for nitrogen deposition in fast-growing chickens depending on age and sex. Poultry Science 85, 1421-1429, https://doi.org/10.1093/ps/85.8.1421

Samadi und Liebert, F. (2007): Lysine requirement of fast growing chickens - Effects of age, sex, level of protein deposition and dietary lysine efficiency. The Journal of Poultry Science 44, 63-72, https://doi.org/10.2141/jpsa.44.63

Samadi, Wecke, C., Pastor, A., Liebert, F. (2017): Assessing lysine requirement of growing chicken by direct comparison between supplementation technique and "goettingen approach". Open Journal of Animal Sciences 7, 56-69, http://dx.doi.org/10.4236/ojas.2017.71006 
Sánchez-Muros. M.J., De Haro, C., Sanz, A., Trenzado, C.E., Villareces, S., Barroso, F.G. (2016): Nutritional evaluation of Tenebrio molitor meal as fishmeal substitute for tilapia (Orechromis niloticus) diet. Aquaculture Nutrition 22, 943-955, https://doi.org/10.1111/anu.12313

Santoso, U. (2001): Effects of early feed restriction on growth, fat accumulation and meat composition in unsexed broiler chickens. Asian-Australasien Journal of Animal Science 14, 1585-1591, https://doi.org/10.5713/ajas.2001.1585

Sasse, C.E. und Baker, D.H. (1974): Sulfur utilization by the chick with emphasis on the effect of inorganic sulfate on the cystine-methionine interrelationship. The Journal of Nutrition 104, 244-251, https://doi.org/10.1093/jn/104.2.244

Sauer, N., Emrich, K., Piepho, H.-P., Lemme, A., Redshaw, M.S., Mosenthin, R. (2008): Metaanalysis of the relative efficiency of methionine-hydroxy-analogue-free-acid compared with DL-methionine in broilers using nonlinear mixed models. Poultry Science 87, 2023-2031, https://doi.org/10.3382/ps.2007-00514

Schutte, J.B., de Jong, J., Smink, W., Pack, M. (1997): Replacement value of betaine for DLmethionine in male broiler chicks. Poultry Science 76, 321-325, https://doi.org/10.1093/ps/76.2.321

Sekiz, S.S., Scott, M.L., Nesheim, M.C. (1975): The effect of methionine deficiency on body weight, food and energy utilization in the chick. Poultry Science 54, 1184-1188, https://doi.org/10.3382/ps.0541184

Sell, D.R., Featherston, W.R., Rogler, J.C. (1980): Methionine-cystine interrelationships in chicks and rats fed diets containing suboptimal levels of methionine. Poultry Science 59, 18781884, https://doi.org/10.3382/ps.0591878

Schiavone, A., De Marco, M., Martínez, S., Dabbou, S., Renna, M., Madrid, J., Hernandez, F., Rotolo, L., Costa, P., Gai, F., Gasco, L. (2017): Nutritional value of a partially defatted and highly defatted black soldier fly larvae (Hermetia illucens L.) meal for broiler chickens: apparent nutrient digestibility, apparent metabolizable energy and apparent ileal amino acid digestibility. Journal of Animal Science and Biotechnology 8, 51, https://doi.org/10.1186/s40104-017-0181-5

Sibly, R. M. (1981): Strategies of digestion and defecation. In: Physiological Ecology: An evolutionary Approach to Resource Use. Townsend, C. R., Calow, P. (eds), Sunderland, M A, 109-139

Siemianowska, E., Kosewska, A., Aljewicz, M., Skibniewska, K.A., Polak-Juszczak, L., Jarocki, A., Jędras, M. (2013): Larvae of mealworm (Tenebrio molitor L.) as European novel food. Agricultural Sciences 4, 287-291, http://dx.doi.org/10.4236/as.2013.46041

Smith, R. und Barnes, E. (2015): Determining the contribution that insects can make to addressing the protein deficit in Europe. PROteINSECT Consensus Business Case Report. Minerva Health \& care Communications Ltd May 2015. Online verfügbar unter: http://www.proteinsect.eu/fileadmin/user_upload/deliverables/PROteINSECT_CBC_FINALv $\underline{1 . p d f}$ 
Song, Y.-S., Kim, M.-W., Moon, C., Seo, D.-J., Han, Y.S., Jo, Y.H., Noh, M.Y., Park, Y.-K., Kim, S.-A., Kim, Y.W., Jung, W.-J. (2018): Extraction of chitin and chitosan from larval exuvium and whole body of edible mealworm, Tenebrio molitor. Entomological Research 48, 227-233, https://doi.org/10.1111/1748-5967.12304

Spek, J.W. (2018): Standardized ileal digestible methionine and cysteine requirement for broilers. CVB Documentation report nr. 63, Wageningen Livestock Research, https://doi.org/10.18174/455513

Spranghers, T., Ottoboni, M., klootwijk, C., Ovyn, A., Deboosere, S., De Meulenaer, B., Michiels, J., Eeckhout, M., De Clerq, P., De Smet, S. (2017): Nutritional composition of black soldier fly (Hermetia illucens) prepupae reared in different organic waste substrates. Journal of the Science of Food and Agriculture 97, 2594-2600, https://doi.org/10.1002/jsfa.8081

Spring, P. (2013): The challenge of cost effective poultry and animal nutrition: Optimizing existing and applying novel concepts. Lohmann Information 48, 38-46

St-Hilaire, S., Cranfill, K., Tomberlin, J.K., Newton, L., Sealey, W., Sheppard, C., Irving,S. (2007): Fish offal recycling by the Black Soldier Fly produces a foodstuff high in omega-3 fatty acids. Journal of the World Aquaculture Society 38, 309-313, https://doi.org/10.1111/j.1749$\underline{7345.2007 .00101 . x}$

Sünder, A., Wecke, C., Liebert, F. (2015a): Influence of different dietary methionine to cystine ratios on growth performance, feed efficiency and protein deposition in meat type chicken. In: Proceedings of the Society of Nutrition Physiology, DLG-Verlag, Frankfurt am Main, Deutschland, 24, 47

Sünder, A., Wecke, C., Liebert, F. (2015b): Untersuchungen zur Methioninwirksamkeit im Masthähnchenfutter - I. Einfluss steigender Methioningehalte und veränderter Methionin zu Cystin-Verhältnisse. VDLUFA Schriftenreihe 71, 579-585, VDLUFA-Verlag, Darmstadt

Sünder, A., Wecke, C., Liebert, F. (2015c): Einfluss des Methionin:Cystin-Verhältnisses im Futter auf abgeleitete Methioninbedarfswerte beim Masthähnchen. In: 13. Tagung Schweineund Geflügelernährung, 24.-26.November 2015, Lutherstadt Wittenberg, 43-45

Sveier, H., Nordås, H., Berge, G.E., Lied, E. (2001): Dietary inclusion of cystalline D- and Lmethionine: effects on growth, feed and protein utilization, and digestibility in small and large Atlantic salmon (Salmon salar L.). Aquaculture Nutrition 7, 169-181, http://dx.doi.org/10.1046/j.1365-2095.2001.00169.x

Swatson, H.K., Gous, R., Iji, P.A., Zarrinkalam, R. (2002): Effect of dietary protein level, amino acid balance and feeding level on growth, gastrointestinal tract, and mucosal structure of the small intestine in broiler chickens. Animal Research 51, 501-515, https://doi.org/10.1051/animres:2002038

Swennen, Q., Geraert, P.-A., Mercier, Y., Everaert, N., Stinckens, A., Willemsen, H., Li, Y., Decuypere, E., Buyse, J. (2011): Effects of dietary protein content and 2-hydroxy-4methylthiobutanioc acid or DL-methionine supplementation on performance and oxidative status of broiler chickens. British Journal of Nutrition 106, 1845-1854, https://doi.org/10.1017/S0007114511002558 
Tabata, E., Kashimura, A., Wakita, S., Ohno, M., Sakaguchi, M., Sugahara, Y., Kino, Y., Matoska, V., Bauer, P.O., Oyama, F. (2017): Gastric and intestinal proteases resistance of chicken acidic chitinase nominates chitin-containing organisms for alternative whole edible diets for poultry. Scientific Reports 7, 1-11, https://doi.org/10.1038/s41598-017-07146-3

Thong, H.T. und Liebert, F. (2004): Potential for protein deposition and threonine requirement of modern genotype barrows fed graded levels of protein with threonine as limiting amino acid. Journal of Animal Physiology and Animal Nutrition, 88, 196-203, https://doi.org/10.1111/j.1439-0396.2004.00457.x

Tschanz, S.A., Burri, P.H., Weibel, E.R. (2011): A simple tool for stereological assessment of digital images. The STEPanizer. Journal of Microscopy 243, 47-59, https://doi.org/10.1111/j.1365-2818.2010.03481.x

Tschirner, M. und Simon, A. (2015): Influence of different growing substrates and processing on the nutrient composition of black soldier fly larvae destined for animal feed. Journal of Insects as Food and Feed 1, 249-259, https://doi.org/10.3920/JIFF2014.0008

Tsiagbe, V.K., Cook, M.E., Harper, A.E., Sunde, M.L. (1987): Efficiacy of cysteine in replacing methionine in the immune response of broiler chicks. Poultry Science 66, 1138-1146, https://doi.org/10.3382/ps.0661138

van der Fels-Klerx, H.J., Camenzuli, L., van der Lee, M.K., Oonincx, D.G.A.B. (2016): Uptake of cadmium, lead and arsenic by Tenebrio molitor and Hermetia illucens from contaminated substrates. PLoS ONE 11(11), e0166186, https://doi.org/10.1371/journal.pone.0166186

van Nevel, C.J., Decuypere, J.A., Dierick, N.A., Molly, K. (2005): Incorporation of galactomannans in the diet of newly weaned piglets: Effect on bacteriological and some morphological characteristics of the small intestine. Archives of Animal Nutrition 59, 123-138, https://doi.org/10.1080/17450390512331387936

van Raamsdonk, L. W. D., van der Fels-Klerx, H. J., de Jong, J. (2017): New feed ingredients: the insect opportunity. Food Additives \& Contaminants: Part A, 34, 1384-1397, https://doi.org/10.1080/19440049.2017.1306883

Vázquez-Añón, M., González-Esquerra, R., Saleh, E., Hampton, T., Ritcher, S., Firman, J., Knight, C.D. (2006): Evidence for 2-hydroxy-4(methylthio) butanoic acid and DL-methionine having different dose responses in growing broilers. Poultry Science 85, 1409-1420, https://doi.org/10.1093/ps/85.8.1409

Vázquez-Añón, M., Bertin, G., Mercier, Y., Reznik, G., Roberton, J.-L. (2017): Review of the chemistry, metabolism, and dose response of two supplemental methionine sources and the implications in their relative bioefficacy. World's Poultry Science Journal 73, 725-736, https://doi.org/10.1017/S0043933917000551

Veldkamp, T. und Bosch, G. (2015): Insects: a protein-rich feed ingredient in pig and poultry diets. Animal Frontiers 5, 45-50, doi:10.2527/af.2015-00199

Veldkamp, T., van Duinkerken, G., van Huis, A., Lakemond, C.M.M., Ottevanger, E., Bosch, G., van Boekel, M.A.J.S. (2012): Insects as a sustainable feed ingredient in pig and poultry diets - a feasibility study. Report 638, Wageningen UR Livestock Research. Online verfügbar unter: http://library.wur.nl/WebQuery/wurpubs/fulltext/234247 
Velten, S., Neumann, C., Bleyer, M., Gruber-Dujardin, E., Hanuszewska, M., PrzybylskaGornowicz, B., Liebert, F. (2018a): Effect of 50 percent substitution of soybean meal by alternative proteins from Hermetia illucens or Spirulina platensis in meat-type chicken diets with graded amino acid supply. Open Journal of Animal Sciences 8, 119-136, https://doi.org/10.4236/ojas.2018.82009

Velten, S., Neumann, C., Schäfer, J., Liebert, F. (2018b): Effects of the partial replacement of soybean meal by insect or algae meal in chicken diets with graded amino acid supply on parameters of gut microbiology and dietary protein quality. Open Journal of Animal Sciences 8, 259-279, https://doi.org/10.4236/ojas.2018.83020

Vilar da Silva, J.H., González-Cerón, F., Howerth, E.W., Rekaya, R., Aggrey, S.E. (2018): Inhibition of the transsulfuration pathway affects growth and feather follicle development in meat-type chickens. Animal Biotechnology, https://doi.org/10.1080/10495398.2018.1461634

Warnick, R.E. und Anderson, J.O. (1968): Limiting essential amino acids in soybean meal for growing chickens and the effects of heat upon availability of the essential amino acids. Poultry Science 47, 281-287, https://doi.org/10.3382/ps.0470281

Waśko, A., Bulak, P., Polak-Berecka, M., Nowak, K., Polakowski, C., Bieganowski, A. (2016): The first report of the physicochemical structure of chitin isolated from Hermetia illucens. International Journal of Biological Macromolecules 92, 316-320, https://doi.org/10.1016/j.ijbiomac.2016.07.038

Wecke, C. und Liebert, F. (2009): Lysine requirement studies in modern genotype barrows dependent on age, protein deposition and dietary lysine efficiency. Journal of Animal Physiology and Animal Nutrition 93, 295-304, https://doi.org/10.1111/j.1439$\underline{0396.2009 .00923 . x}$

Wecke, C. und F. Liebert (2013): Improving the reliability of optimal in-feed amino acid ratios based on individual amino acid efficiency data from $\mathrm{N}$ balance studies in growing chicken. Animals 3, 558-573, https://dx.doi.org/10.3390/ani3030558

Wecke, C., Pastor, A., Liebert, F. (2013): Ideal in-feed amino acid ratios for growing broiler chicken based on individual amino acid efficiency data derived from $\mathrm{N}$ balance studies. ESPN Potsdam, 152

Wecke, C., Sünder, A., Liebert, F. (2015a): Untersuchungen zur Methioninwirksamkeit im Masthähnchenfutter - II. Einfluss steigender Cystin-Gehalte bei konstantem Methionin zu Cystin-Verhältnis. VDLUFA-Schriftenreihe 71, 586-593, VDLUFA-Verlag, Darmstadt

Wecke, C., Sünder, A., Liebert, F. (2015b): Effect of dietary methionine to cystine ratio on methionine effificiency in growing meat type chicken. In: Proceedings of the Society of Nutrition Physiology, DLG-Verlag, Frankfurt am Main, Deutschland, 24, 164

Wecke, C., Pastor, A., Liebert, F. (2016): Validation of the lysine requirement as reference amino acid for ideal in-feed amino acid ratios in modern fast growing meat-type chickens. Open Journal of Animal Sciences 6, 185-194, http://dx.doi.org/10.4236/ojas.2016.63024

Wecke, C., Khan, D.R., Sünder, A., Liebert, F. (2017): Age and gender depending growth of feathers and feather-free body in modern fast growing meat-type chickens. Open Journal of Animal Sciences, 7, 376-392, https://doi.org/10.4236/ojas.2017.74029 
Wecke, C., Khan, D.R., Sünder, A., Liebert, F. (2018a): Age and gender dependent amino acid concentrations in the feather, feather-free and whole empty body protein of fast growing meattype chickens. Open Journal of Animal Sciences 8, 223-238, https://doi.org/10.4236/ojas.2018.83017

Wecke, C., Khan, D.R., Sünder, A., Liebert, F. (2018b): Age and gender depenent nutrient composition of feather and feather-free body fractions in meat-type chickens. Open Journal of Animal Sciences 8, 74-86, https://doi.org/10.4236/ojas.2018.81006

Wen, C., Jiang, X., Ding, L., Wang, T., Zhou, Y. (2017): Effects of dietary methionine on breast muscle growth, myogenic gene expression and IGF-I signaling in fast- and slow-growing broilers. Scientific Reports 7, 1-7, https://doi.org/10.1038/s41598-017-02142-Z

Wheeler, K.B. und Latshaw, J.D. (1981): Sulfur amino acid requirements and interactions in broilers during two growth periods. Poultry Science 60, 228-236, https://doi.org/10.3382/ps.0600228

Willemsen, H., Swennen, Q., Everaert, N., Geraert, P.-A., Mercier, Y., Stinckens, A., Decuypere, E., Buyse, J. (2011): Effects of dietary supplementation of methionine and its hydroxy analog DL-2-hydroxy-4-methylthiobutanoic acid on growth performance, plasma hormone levels, and the redox status of broiler chickens exposed to high temperatures. Poultry Science 90, 2311-2320, https://doi.org/10.3382/ps.2011-01353

Williams, R.E. (2010): Veterinary Entomology: Livestock and Companion Animals. CRC Press

World's Poultry Science Association (WPSA) (1984): The Prediction of Apparent Metabolizable Energy Values for Poultry in Compound Feeds. World's Poultry Science Journal 40, 181-182

Wu, B., Li, L., Ruan, T., Peng, X. (2018): Effect of methionine deficiency on duodenal and jejunal $\operatorname{IgA}^{+} \mathrm{B}$ cell count and immunoglobulin level of broilers. Iranian Journal of Veterinary Research 19, 165-171, https://www.ncbi.nlm.nih.gov/pubmed/30349561

Xue, J.J., Xie, M., Tang, J., Huang, W., Zhang, Q., Hou, S.S. (2018): Effects of excess DL- and L-methionine on growth performance of starter Pekin ducks. Poultry Science 97, 946-950, https://doi.org/10.3382/ps/pex380

Yu, M.W., Robinson, F.E., Clandinn, M.T., Bodnar, L. (1990): Growth and body composition of broiler chickens in response to different regimens of feed restricition. Poultry Science 69, 2074-2081, https://doi.org/10.3382/ps.0692074

Zduńczyk, Z., Jankowski, J., Kubińska, M., Ognik, K., Czech, A., Juśkiewicz, J. (2017): The effect of different dietary levels of DL-methionine and DL-methionine hydroxy analogue on the antioxidant and immune status of young turkeys. Archives of Animal Nutrition 71, 347361, https://doi.org/10.1080/1745039X.2017.1352328

Zeitz, J.O., Mohrmann, S., Fehse, L., Most, E., Helmbrecht, A., Saremi, B., Eder, K. (2018): Tissue and plasma antioxidant status in response to dietary methionine concentration and source in broilers. Journal of Animal Physiology and Animal Nutrition 102, 999-1011, https://doi.org/10.1111/jpn.12909 
Zhang, L., und Guo, Y. (2018): Effects of liquid DL-2-hydroxy-4-methylthio butanoic acid on growth performance and immune responses in broiler chickens. Poultry Science 87, 1370-1376, https://doi.org/10.3382/ps.2007-00366

Zhang, J., Huang, L., He, J., Tomberlin, J.K., Li, J., Lei, C., Sun, M., Liu, Z., Yu, Z. (2010): An artificial light source influences mating and oviposition of black soldier flies, Hermetia illucens. Journal of Insect Science 10, Article 202, https://doi.org/10.1673/031.010.20201

Zhang, S., Gilbert, E.R., Saremi, B., Wong, E.A. (2018): Supplemental methionine sources have a neutral impact on oxidative status in broiler chickens. Journal of Animal Physiology and Animal Nutrition 102, 1274-1283, https://doi.org/10.1111/jpn.12946

Zhan, X.A., Li, J.X., Xu, Z.R., Zhao, R.Q. (2006): Effects of methionine and betaine supplementation on growth performance, carcase composition and metabolism of lipids in male broilers. British Poultry Science 47, 576-580, https://doi.org/10.1080/00071660600963438

Zhao, L., Zhang, N.-Y., Pan, Y.-X., Zhu, L.-Y., Batonon-Alavo, D.I., Ma, L.-B., Khalil, M.M., Qi, D.-S., Sun, L.-H. (2018): Efficacy of 2-hydroxy-4-methylthiobutanoic acid compared to DL-methionine on growth performance, carcass traits, feather growth, and redox status of Cherry Valley ducks. Poultry Science 97, 3166-3175, https://doi.org/10.3382/ps/pey196

Zielińska, E., Baraniak, B., Karaś, M., Rybczyńska, K., Jakubczyk, A. (2015): Selected species of edible insects as a source of nutrient composition. Food Research International 77, 460-466, https://doi.org/10.1016/j.foodres.2015.09.008 


\title{
11. Publikationen
}

\section{Publikation I}

\section{BESONDERHEITEN BEI DER VERSORGUNG MIT SCHWEFELHALTIGEN AMINOSÄUREN UNTER SPEZIELLER BEACHTUNG DER MASTGEFLÜGELERNÄHRUNG}

\author{
Characteristics of sulfur containing amino acid supply \\ with special reference to poultry nutrition \\ von/by
}

A. Brede, C. Wecke, A. Sünder und F. Liebert

Übersichten zur Tierernährung, 43. Jahrgang, Heft 1, Oktober 2018, 1-52 


\title{
BESONDERHEITEN BEI DER VERSORGUNG MIT SCHWEFELHALTIGEN AMINOSÄUREN UNTER SPEZIELLER BEACHTUNG DER MASTGEFLÜGELERNÄHRUNG
}

\author{
Characteristics of sulfur containing amino acid supply \\ with special reference to poultry nutrition \\ von/by \\ A. Brede ${ }^{1}$, C. Wecke ${ }^{1}$, A. Sünder ${ }^{l}$ und F. Liebert ${ }^{1}$
}

\section{GLIEDERUNG}

1 Einleitung

2 Vorkommen der S-haltigen Aminosäuren

2.1 Tierkörper

2.2 Futtermittel

2.3 Besonderheiten der Analytik der S-haltigen Aminosäuren

2.4 Bioverfügbarkeit der S-haltigen Aminosäuren aus Futtermitteln

2.5 Palette der S-haltigen Aminosäuren als Futterzusatzstoffe

3 Stoffwechsel der S-haltigen Aminosäuren

3.1 Methionin- und Cystein-Umsetzungen

3.2 Wechselwirkungen im Stoffwechsel von Methionin und Cystein

3.3 Wechselwirkungen mit Cholin, Betain, Serin und Glycin

4 Bedarf an S-haltigen Aminosäuren

4.1 Bedarfsableitung

4.2 Versorgungsempfehlungen

4.2.1 Das IAAR-Konzept

4.2.2 Einflussfaktoren

5 Deckung des Bedarfs an S-haltigen Aminosäuren

5.1 Auswirkungen unterschiedlicher Versorgungsgrade

5.2 Potentiale einer Ergänzung mit S-haltigen Aminosäuren

6 Fazit

7 Schrifttum

1 M.Sc. Anne Brede, Dr. Christian Wecke, Dr. Angela Sünder, Prof. Dr. Frank Liebert: Georg-August-Universität Göttingen, Tierernährungsphysiologie, Kellnerweg 6, 37077 Göttingen, Fax.: +49(0)551-3933343, Email: flieber@gwdg.de 


\section{ZUSAMMENFASSUNG}

Auch die Ernährung von Mastgeflügel verfolgt das Ziel, durch eine effiziente Nutzung der Futterinhaltsstoffe einen möglichst hohen Körperproteinansatz bei minimaler N-Ausscheidung zu realisieren. Den S-haltigen Aminosäuren (SAS) Methionin (Met) und Cystein (Cys) kommt dabei infolge der häufig zu geringen Gehalte im Futterprotein eine besondere Rolle zu. Bei vergleichenden Betrachtungen der Gehalte und Proportionen beider Aminosäuren in verschiedenen Einzelfuttermitteln, im Tierkörper insgesamt und in Teilfraktionen wie Federkleid und federfreiem Körper zeigen sich Besonderheiten, die stärkere Beachtung verdienen. Obwohl Met und Cys im Stoffwechsel eng miteinander und mit weiteren strukturähnlichen Verbindungen verknüpft sind, bestehen auch spezifische metabolische Funktionen außerhalb der Proteinsynthese. Diese Sonderstellung wird auch durch spezielle Nachweisverfahren im Rahmen der Analytik und durch das Spektrum von Met-Quellen zum Ausgleich von Versorgungsdefiziten herausgestellt.

In vorliegender Übersichtsarbeit werden zudem Methoden zur Bewertung der SASBioverfügbarkeit dargestellt und hinsichtlich ihrer Grenzen diskutiert. Ebenso werden publizierte Versorgungsempfehlungen einer kritischen Wertung unterzogen und Ursachen für die relativ hohe Variabilität der Aussagen unter Einbeziehung differenzierter Einflussgrößen aufgezeigt. Vor diesem Hintergrund wird für die optimale Versorgung des Geflügels mit Met und Cys bei höherer Verwertungseffizienz weiterer Forschungsbedarf gesehen, der eine Weiterentwicklung des Konzepts „Idealprotein“ ermöglicht. Hierfür sind in weiteren Studien insbesondere systematisch gestaffelte Met:Cys-Verhältnisse unter Beachtung definierter Versorgungsgrade mit allen am SAS-Stoffwechsel beteiligten Futterinhaltsstoffen unter weitestgehend standardisierten Versuchs- und Auswertungsmethoden zu untersuchen.

Schlüsselwörter: Mastgeflügel, schwefelhaltige Aminosäuren, Methionin, Cystein, Verdaulichkeit, Verfügbarkeit, Stoffwechsel, Bedarf, Idealprotein, IAAR

\section{SUMMARY}

It is also aimed in fattening poultry nutrition to yield highly efficient nutrient deposition at lowest nitrogen excretion. Therefore, the sulfur-containing amino acids (SAA) methionine (Met) and cysteine (Cys) play a very important role due to their observed limiting position in poultry nutrition related feed proteins. A comparative view both on the concentration and relation of Met:Cys both in the dietary protein and whole body or its fractions like feathers or carcass provides specific features of these amino acids in poultry nutrition which need more attention. In spite of the fact that the metabolism of both SAA is strongly connected and also linked with other substances of similar structure, specific metabolic functions are well known which are not directly related to synthesis of proteins. The exceptional role is also expressed by specifics in analytical approaches and different Met sources for the supplementation in case of a suboptimal dietary supply.

The current review also deals with the evaluation of different approaches for assessing the bioavailability of SAA. In addition, reported recommended dietary levels are critically reviewed to find out the background and main reasons for the high variability of recommendations for an optimal SAA supply. Further research is needed especially in this area, including a further development of the concept "ideal protein". Therefore, more systematical research is necessary including studies with graded variation of dietary Met:Cys ratios and corresponding to other dietary constituents which are directly linked to SAA metabolism. 
Generally, in this context, more standardized experiments and procedures of data evaluation are needed.

Keywords: Poultry, sulfur containing amino acids, methionine, cysteine, digestibility, bioavailability, metabolism, requirement, ideal protein, ideal amino acid ratio

\section{$1 \quad$ EINLEITUNG}

Im Organismus von Säugetieren und Vögeln werden freier Schwefel, Sulfate und Sulfide absorbiert und dann in Form von Sulfat oder Sulfatestern wieder über den Harn ausgeschieden. Der Bedarf der Tiere an Schwefel kann einzig und allein durch die S-haltigen Aminosäuren (SAS) gedeckt werden (FULLER, 2004). Met und Cys sind proteinogene SAS, aber auch nichtproteinogene Verbindungen wie Homocystein (HCy) und Taurin (Tau) enthalten Schwefel (BROSNAN und BROSNAN, 2006). Da somit nur Met und Cys als klassische Limitierungsfaktoren für die Proteinsynthese in Betracht kommen, liegt der Fokus dieser Übersicht auf diesen beiden SAS. Bei der Synthese von Strukturproteinen entstehen zwischen zwei Cys-Molekülen unter Bildung von Cystin (Cys-Cys; (Cys) $)_{2}$ ) besonders stabile Disulfidbrücken (GRABER et al., 1971a). Somit kommt Cys-Cys eine wichtige strukturbildende Rolle bei der Faltung von Proteinen zu (BROSNAN und BROSNAN, 2006). Nach Hydrolyse kann Cys-Cys auch zur Versorgung mit Cys beitragen (BAKER, 2006). Abbildung 1 zeigt die Grundstruktur dieser SAS.<smiles>CSCCC(N)C(=O)O</smiles>

Methionin<smiles>NC(CS)C(=O)O</smiles>

Cystein<smiles>NC(CSSCC(N)C(=O)O)C(=O)O</smiles>

Cystin

Abbildung 1: Die chemische Struktur der S-haltigen Aminosäuren Methionin, Cystein und Cystin (aus: Lewis, 2003)

Figure 1: $\quad$ The chemical structure of the sulfur-containing amino acids methionine, cysteine and cystine (taken from: Lewis, 2003)

Met und Cys enthalten jeweils ein Schwefelatom und werden den „neutralen“ AS zugeordnet (HOPPE und MARTENS, 1983). Met ist in eine Reihe metabolischer Prozesse involviert, die hier zunächst nur angerissen werden sollen. So tritt Met in allen Zellen als Initiator der Proteinsynthese in Erscheinung, ist also die AS, mit der die Translation beginnt (SHERMAN et al., 1985; BROSNAN und BROSNAN, 2006). Zusätzlich spielt Met indirekt eine wichtige Rolle bei der DNA-Methylierung (JELTSCH, 2002). Zwischenprodukte des Met-Abbaus sind am Kreatinstoffwechsel beteiligt (MARTíN-VENEGAS et al., 2006), wodurch ein direkter Bezug zum Energiewechsel gegeben ist. Ebenso ist Met an der Synthese von L-Carnitin beteiligt und stellt einen wichtigen Faktor der Polyamin-Synthese dar. Die Polyamine Spermin 
und Spermidin sind u. a. in die DNA-Synthese der Lymphozyten eingebunden (FILLINGAME et al., 1975). Da Cys grundsätzlich auch aus dem Met-Abbau bereitgestellt werden kann, gilt nur Met als unentbehrlich (OHTA und ISHIBASHI, 1994). Dessen ungeachtet basieren Bedarfsformulierungen häufig auf der Summe von Met und Cys (u. a. EGGUM, 1973; JENSEN et al., 1989; LUMPKINS et al., 2007; GOULART et al., 2011; DOZIER und MERCIER, 2013), wobei das optimale Verhältnis der beiden AS zueinander durchaus unterschiedlich bewertet wird (z. B. GRABER et al., 1971a; SASSE und BAKER, 1974; BAKER et al., 1996; SÜNDER et al., 2015a). In der Geflügelernährung wird Met in der Regel als erstlimitierende AS angesehen. Hierfür sind einerseits die relativ niedrigen Met-Gehalte in pflanzlichen Futterproteinen (vergl. Tab. 2) und andererseits der in Relation zu anderen Nutztieren höhere Bedarf für die Körperproteinsynthese (BUNCHASAK, 2009) als Gründe zu nennen.

Hiervon ausgehend besteht das Ziel dieser Übersichtsarbeit darin, unter Beachtung der facettenreichen ernährungsphysiologischen Rolle der SAS sowie unter Einbeziehung aktueller Forschungsergebnisse zu einem „update“ bezüglich der optimalen Versorgung des Mastgeflügels mit Met und Cys beizutragen. Dabei wird insbesondere zu klären sein, wie und in welchem Umfang Met in seinen Stoffwechselfunktionen ersetzt werden kann, um eine bevorzugte Nutzung für die Körperproteinsynthese bei produktbildenden Prozessen zu ermöglichen.

\section{VORKOMMEN DER S-HALTIGEN AMINOSÄUREN}

\subsection{TIERKÖRPER}

Wie aus Tabelle 1 hervorgeht, ist Cys in beachtlichen Konzentrationen im Federprotein vertreten, während Met dagegen hauptsächlich im Protein der Muskulatur und Innereien zu finden ist. Dies hat erhebliche Auswirkungen auf das relative Verhältnis beider SAS zueinander sowie auf die Relationen zu Lysin (Lys) als Referenz-AS. Die SAS-Gehalte im Protein von Tierkörper und Federkleid sind jedoch nicht als konstant zu betrachten, je nach Alter und Geschlecht der Tiere liegen Veränderungen vor. Mit zunehmendem Alter steigt die CysKonzentration im Federprotein, während Met mit Werten um 0,5 g/16 g N nahezu unverändert bleibt. Im Protein des federlosen Ganzkörpers steigen die Met-Gehalte mit dem Alter der Tiere dagegen leicht an, während die Cys-Gehalte tendenziell abnehmen (WECKE und LIEBERT, 2016). Bezüglich der Met-Konzentration konnte zudem ein signifikanter Einfluss des Geschlechts beobachtet werden. In den Proteinfraktionen sowohl von Federn als auch vom Restkörper der weiblichen Tiere zeigten sich signifikant höhere Met-Gehalte als bei den männlichen Tieren (WECKE et al., 2015a). Ein enger Zusammenhang zwischen der nutritiven SAS-Versorgung von Masthähnchen und den Gehalten im Körperprotein ist in Anbetracht der grundlegenden Gesetzmäßigkeiten bei der Proteinsynthese sicher nicht zu erwarten, lediglich in den Innereien $(\mathrm{p}=0,08)$ war bei defizitärer SAS-Versorgung ein Rückgang der Konzentration nachweisbar (CONDE-AGUILERA et al., 2013; 2016). Dieser Befund ist nicht im Widerspruch zu Ergebnissen von FATUFE und RODEHUTSCORD (2005) zu sehen, die bei gestaffelter Met-Versorgung signifikant erhöhte Met-Gehalte $(2,0$ gegenüber 1,7 g/16 g N) im Körperproteinzuwachs ableiten konnten. Veränderte Relationen in den Anteilen von Federbzw. Restkörperprotein bei steigender Met-Ergänzung sind mögliche Erklärungen. Allerdings war ein Abfall der Cys-Gehalte im Körperproteinzuwachs mit steigender Met-Zulage kaum erkennbar. 
Neben dem Federprotein weisen auch die Hormone des Hypophysenhinterlappens hohe CysGehalte auf (DU VIGNEAUD, 1952), allerdings dürfte die quantitative Bedeutung dieser Feststellung gering sein.

Zur besseren Einordnung der AS-Gehalte in den Körperfraktionen (Tab. 1) wurden zusätzlich die Gehalte im Vollei als Referenz aufgeführt.

Tabelle 1: Gehalte und Relationen zwischen den S-haltigen Aminosäuren in verschiedenen Körperfraktionen von Masthähnchen (Angaben je kg uS)

Table 1: $\quad$ Contents and ratios of sulfur-containing amino acids in different body fractions of growing chickens (on wet weight basis)

\begin{tabular}{|c|c|c|c|c|c|c|}
\hline \multirow[t]{2}{*}{ Körperfraktion } & \multirow[t]{2}{*}{$\begin{array}{c}\text { Rohprotein } \\
\text { (g/kg) }\end{array}$} & \multicolumn{4}{|c|}{$\begin{array}{l}\text { AS-Gehalte } \\
\text { (g/16 g N) }\end{array}$} & \multirow{2}{*}{ Met:Cys } \\
\hline & & Lys & Met & Cys & Met+Cys & \\
\hline Federn $^{1}$ & $\begin{array}{c}984 \\
(\mathrm{~g} / \mathrm{kg} \mathrm{TM})\end{array}$ & $\begin{array}{l}2,17 \\
(100)\end{array}$ & $\begin{array}{l}0,52 \\
(24)\end{array}$ & $\begin{array}{l}6,83 \\
(315)\end{array}$ & $\begin{array}{l}7,35 \\
(339)\end{array}$ & $1: 13,1$ \\
\hline Federn $^{2}$ & - & $\begin{array}{l}1,80 \\
(100)\end{array}$ & $\begin{array}{l}0,60 \\
(33)\end{array}$ & $\begin{array}{r}8,20 \\
(456)\end{array}$ & $\begin{array}{r}8,80 \\
(489)\end{array}$ & $1: 13,7$ \\
\hline Federloser Ganzkörper ${ }^{1}$ & $\begin{array}{c}639 \\
(\mathrm{~g} / \mathrm{kg} \mathrm{TM})\end{array}$ & $\begin{array}{c}6,84 \\
(100)\end{array}$ & $\begin{array}{l}1,96 \\
(29)\end{array}$ & $\begin{array}{l}0,97 \\
(14)\end{array}$ & $\begin{array}{l}2,93 \\
(43)\end{array}$ & $1: 0,5$ \\
\hline Federloser Ganzkörper ${ }^{2}$ & 165 & $\begin{array}{l}7,00 \\
(100)\end{array}$ & $\begin{array}{l}2,50 \\
(36)\end{array}$ & $\begin{array}{l}1,30 \\
(19)\end{array}$ & $\begin{array}{l}3,80 \\
(54)\end{array}$ & $1: 0,5$ \\
\hline Ganzkörper $^{3}$ & 176 & $\begin{array}{l}6,91 \\
(100)\end{array}$ & $\begin{array}{l}2,05 \\
(30)\end{array}$ & $\begin{array}{l}1,71 \\
(25)\end{array}$ & $\begin{array}{l}3,76 \\
(54)\end{array}$ & $1: 0,8$ \\
\hline Eintagsküken ${ }^{4}$ & $\begin{array}{c}739 \\
(\mathrm{~g} / \mathrm{kg} \mathrm{TM})\end{array}$ & $\begin{array}{l}5,81 \\
(100)\end{array}$ & $\begin{array}{l}1,70 \\
(29)\end{array}$ & $\begin{array}{l}1,77 \\
(31)\end{array}$ & $\begin{array}{l}3,47 \\
(60)\end{array}$ & $1: 1,0$ \\
\hline Musculus pectoralis major ${ }^{3}$ & 211 & $\begin{array}{l}8,69 \\
(100)\end{array}$ & $\begin{array}{l}2,19 \\
(25)\end{array}$ & $\begin{array}{l}1,14 \\
(13)\end{array}$ & $\begin{array}{l}3,33 \\
(38)\end{array}$ & $1: 0,5$ \\
\hline Musculus pectoralis major ${ }^{5}$ & 237 & $\begin{array}{l}8,98 \\
(100)\end{array}$ & $\begin{array}{l}2,85 \\
(32)\end{array}$ & $\begin{array}{l}1,20 \\
(13)\end{array}$ & $\begin{array}{l}4,05 \\
(45)\end{array}$ & $1: 0,4$ \\
\hline Innereien ${ }^{5}$ & 157 & $\begin{array}{c}6,12 \\
(100)\end{array}$ & $\begin{array}{l}2,42 \\
(40)\end{array}$ & $\begin{array}{l}1,29 \\
(21)\end{array}$ & $\begin{array}{l}3,71 \\
(61)\end{array}$ & $1: 0,5$ \\
\hline Blut $^{5}$ & 124 & $\begin{array}{c}8,83 \\
(100)\end{array}$ & $\begin{array}{l}1,34 \\
(15)\end{array}$ & $\begin{array}{l}1,84 \\
(21)\end{array}$ & $\begin{array}{l}3,18 \\
(36)\end{array}$ & $1: 1,4$ \\
\hline Vollei ${ }^{6}$ & 451 & $\begin{array}{l}7,01 \\
(100)\end{array}$ & $\begin{array}{l}3,45 \\
(49)\end{array}$ & $\begin{array}{l}2,48 \\
(35)\end{array}$ & $\begin{array}{l}5,93 \\
(85)\end{array}$ & $1: 0,7$ \\
\hline \multicolumn{7}{|c|}{$\begin{array}{l}\text { 2Mittelwerte nach GfE (1999) } \\
{ }^{3} \text { Mittelwerte nach CONDE-AGUILERA et al. (2016) } \\
{ }^{4} \text { eigene Daten, unveröffentlicht }\end{array}$} \\
\hline 5nach CONDE-AGUILERA et al & 013) & & & & & \\
\hline
\end{tabular}




\section{$2.2 \quad$ FUTTERMITTEL}

In Futterproteinen kommen Met und Cys, gemessen an Bedarfsrelationen, in relativ geringen Konzentrationen vor. In Tabelle 2 sind die Gehalte für eine Auswahl häufig verwendeter Einzelfuttermittel aufgeführt. Es ist erkennbar, dass sich das Fischmehlprotein durch einen besonders hohen Met-Gehalt auszeichnet, während sich relativ hohe Cys-Konzentrationen unter anderem im Protein von Rapsextraktionsschrot und Gerste finden. Noch höhere Konzentrationen an den SAS sind z. B. im Eialbumin (3,6 g Met/16 g N) und Federmehlprotein $(4,22 \mathrm{~g} \mathrm{Cys} / 16 \mathrm{~g} \mathrm{~N})$ enthalten (EVONIK INDUSTRIES, AminoDat ${ }^{\circledR}$ version 5.0). Die von der GfE (1999) und WECKE et al. (2015a) ermittelten Cys-Gehalte in den Federn liegen sogar noch deutlich über diesem Wert (s. Tab. 1). Diese Diskrepanz könnte in der druckthermischen Behandlung des Federmehlproteins, die zu einem deutlichen Cys-Verlust führen kann, begründet sein (s. Kapitel 2.3).

Zudem sind die relativ hohen Met- und Cys-Konzentrationen im Protein von Mais und Rapsextraktionsschrot erwähnenswert. Andererseits unterstreichen die niedrigen Gehalte im Sojaprotein die limitierende Rolle der SAS, insbesondere für das Geflügel mit höheren Versorgungsansprüchen an diesen AS.

Tabelle 2: Gehalte an und Relationen zwischen den S-haltigen Aminosäuren in ausgewählten Einzelfuttermitteln ${ }^{1}$

Table 2: $\quad$ Contents and ratios of sulfur-containing amino acids of selected feedstuffs ${ }^{l}$

\begin{tabular}{|c|c|c|c|c|c|c|}
\hline \multirow[t]{2}{*}{ Futtermittel } & \multirow{2}{*}{$\begin{array}{l}\text { Rohprotein } \\
\text { (g/kg uS) }\end{array}$} & \multicolumn{4}{|c|}{$\mathrm{AS}(\mathrm{g} / 16 \mathrm{~g} \mathrm{~N})$} & \multirow[b]{2}{*}{ Met:Cys } \\
\hline & & Lys & Met & Cys & Met+Cys & \\
\hline Ackerbohnen & 250 & $\begin{array}{c}6,17 \\
(100)\end{array}$ & $\begin{array}{l}0,70 \\
(11)\end{array}$ & $\begin{array}{l}1,20 \\
(19)\end{array}$ & $\begin{array}{l}1,90 \\
(31)\end{array}$ & $1: 1,7$ \\
\hline Erbsen & 201 & $\begin{array}{l}7,27 \\
(100)\end{array}$ & $\begin{array}{l}0,93 \\
(13)\end{array}$ & $\begin{array}{l}1,44 \\
(20)\end{array}$ & $\begin{array}{l}2,37 \\
(33)\end{array}$ & $1: 1,6$ \\
\hline Weizen & 117 & $\begin{array}{c}2,86 \\
(100)\end{array}$ & $\begin{array}{l}1,57 \\
(55)\end{array}$ & $\begin{array}{l}2,25 \\
(79)\end{array}$ & $\begin{array}{c}3,82 \\
(134)\end{array}$ & $1: 1,4$ \\
\hline Gerste & 105 & $\begin{array}{l}3,66 \\
(100)\end{array}$ & $\begin{array}{l}1,64 \\
(45)\end{array}$ & $\begin{array}{l}2,20 \\
(60)\end{array}$ & $\begin{array}{l}3,84 \\
(105)\end{array}$ & $1: 1,3$ \\
\hline Rapsextraktionsschrot & 348 & $\begin{array}{c}5,13 \\
(100)\end{array}$ & $\begin{array}{l}1,94 \\
(38)\end{array}$ & $\begin{array}{l}2,37 \\
(47)\end{array}$ & $\begin{array}{l}4,31 \\
(85)\end{array}$ & $1: 1,2$ \\
\hline Mais & 76 & $\begin{array}{c}3,10 \\
(100)\end{array}$ & $\begin{array}{l}2,11 \\
(69)\end{array}$ & $\begin{array}{l}2,27 \\
(74)\end{array}$ & $\begin{array}{c}4,38 \\
(142)\end{array}$ & $1: 1,1$ \\
\hline Sojaextraktionsschrot & 465 & $\begin{array}{c}6,04 \\
(100)\end{array}$ & $\begin{array}{l}1,33 \\
(22)\end{array}$ & $\begin{array}{l}1,43 \\
(24)\end{array}$ & $\begin{array}{l}2,76 \\
(46)\end{array}$ & $1: 1,1$ \\
\hline Volleipulver & 451 & $\begin{array}{c}7,01 \\
(100)\end{array}$ & $\begin{array}{l}3,45 \\
(49)\end{array}$ & $\begin{array}{l}2,48 \\
(35)\end{array}$ & $\begin{array}{l}5,93 \\
(85)\end{array}$ & $1: 0,7$ \\
\hline Fischmehl & 603 & $\begin{array}{l}6,71 \\
(100)\end{array}$ & $\begin{array}{l}2,47 \\
(37)\end{array}$ & $\begin{array}{l}0,80 \\
(12)\end{array}$ & $\begin{array}{l}3,27 \\
(49)\end{array}$ & $1: 0,3$ \\
\hline
\end{tabular}

${ }^{1}$ AminoDat ${ }^{\circledR}$ version 5.0 (EVONIK INDUSTRIES, Hanau, Germany) 
Große Unterschiede liegen zudem in den Relationen zwischen Met und Cys vor. Das im Ergebnis zahlreicher Studien (u. a. BAKER et al., 1996; POWELL et al., 2011) als weitgehend optimal angesehene Verhältnis zwischen Met und Cys von 1:1 wird annähernd nur von Mais und Sojaextraktionsschrot erreicht, allerdings bei einem niedrigen Niveau dieser AS. Auch die relativen Verhältnisse der SAS zu Lys zeigen teilweise deutliche Abweichungen von den als optimal angenommenen AS-Relationen (s. 4.2.2).

\subsection{BESONDERHEITEN IN DER ANALYTIK S-HALTIGER AMINOSÄUREN}

Auch die SAS liegen in Futtermitteln überwiegend im Protein gebunden vor. Deshalb erfolgt zunächst die Freisetzung der proteingebundenen AS nach der VDLUFA Verbandsmethode 4.11.1 (NAUMANN und BASSLER, 1997) mittels salzsaurer Hydrolyse bei $110{ }^{\circ} \mathrm{C}$. Dabei werden Asparagin und Glutamin vollständig zu Asparaginsäure und Glutaminsäure umgesetzt und mit diesen AS gemeinsam erfasst. Tryptophan wird dabei vollständig zerstört und kann nur durch eine separate basische Hydrolyse der Analytik zugänglich gemacht werden. Met und Cys werden durch die saure Hydrolyse teilweise zersetzt. Eine quantitative Bestimmung ist deshalb nur möglich, wenn sie vor der Hydrolyse bei $0{ }^{\circ} \mathrm{C}$ mit Perameisensäure in die stabilen Verbindungen Methioninsulfon und Cysteinsäure umgesetzt werden. Bei diesem Oxidationsschritt wird allerdings Tyrosin zersetzt.

Eines der häufigsten Verfahren in der Routine-Analytik ist die Ionenaustauschchromatographie mit einer Nachsäulenderivatisierung mit Ninhydrin-Reagenz nach MOORE et al. (1958) und SPACKMAN et al. (1958). Voraussetzung für eine erfolgreiche säulenchromatographische Trennung ist das Vorliegen aller AS als Kation, was bei einem pHWert von exakt 2,20 erreicht wird. Die Detektion des Analysensignals aller primären AS erfolgt mittels Photometer bei einer Wellenlänge von $570 \mathrm{~nm}$ (blau-violetter Farbkomplex mit Ninhydrin) und das der sekundären AS Prolin und Hydroxyprolin bei $440 \mathrm{~nm}$ (gelber Farbkomplex mit Ninhydrin). Neben der Nachsäulenderivatisierung mit Ninhydrin-Reagenz kommt relativ häufig eine Vorsäulenderivatisierung mit dem Fluoreszenzfarbstoff OPA (Orthophthal-[di]-Aldehyd) unter Anwendung der HPLC-Methode zum Einsatz. Der Vorteil dieses Vorgehens ist eine empfindlichere Nachweisgrenze durch den Einsatz eines Fluoreszenzdetektors, der Nachteil die ausschließliche Erfassung der primären AS. Die Detektion von Prolin und Hydroxyprolin ist mit diesem Färbereagenz nicht möglich (ENGELHARDT, 1986). 


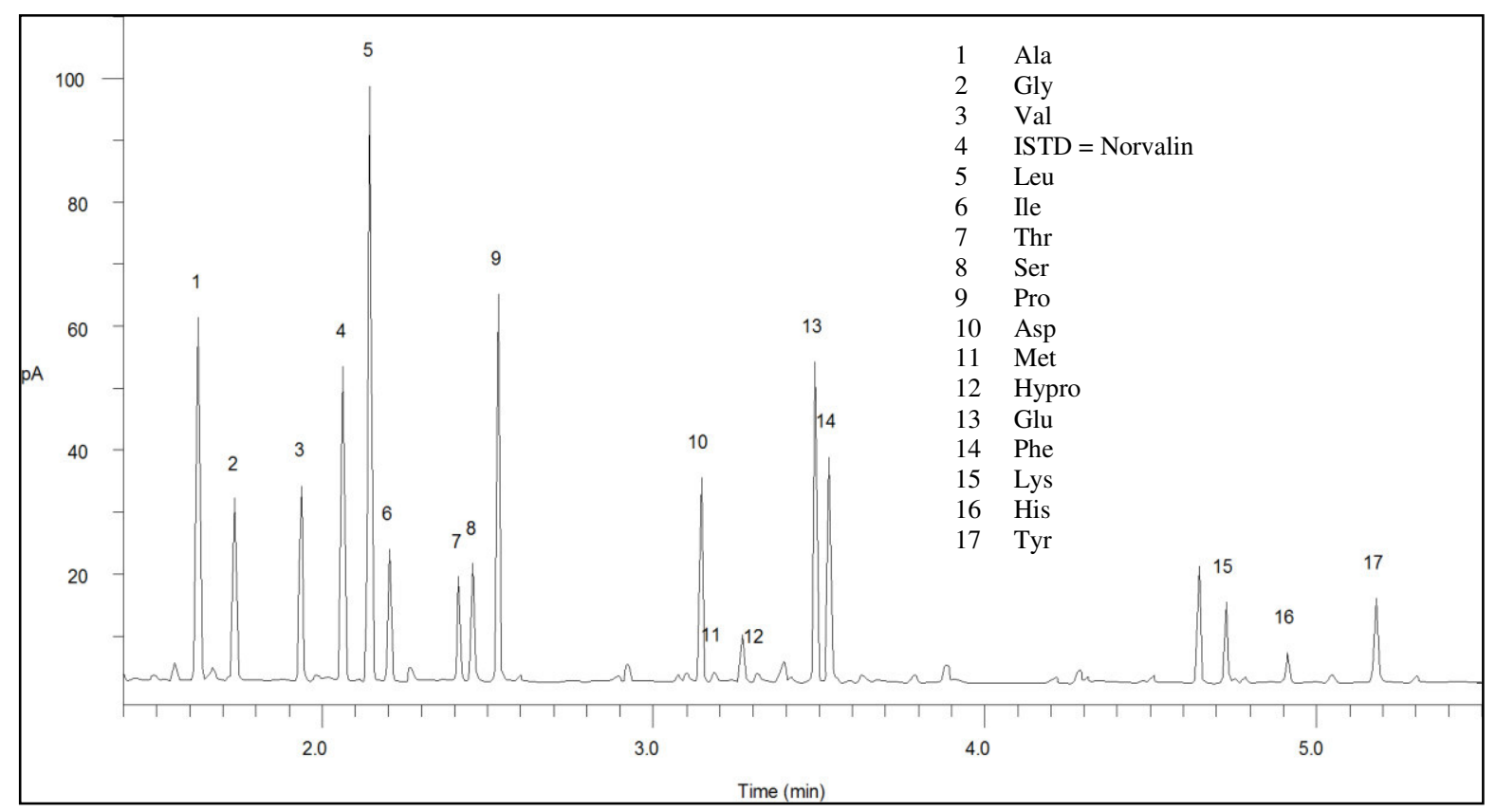

Abbildung 2: GC-Chromatogramm derivatisierter Aminosäuren eines Hydrolysates von Maisschrot (PHENOMENEX APP ID 14346, 2016)

Figure 2: $\quad$ Chromatogram (gas chromatography) of amino acid derivatives in a hydrolysed sample of corn meal (PHENOMENEX APP ID 14346, 2016)

Weiterhin stehen für die AS-Analytik auch diverse gaschromatographische (GC) Methoden zur Verfügung. Für die Verwendung einer GC-Methode müssen sich die AS vor der Trennung vollständig in flüchtige Derivate überführen lassen. Nach verschiedenen Publikationen scheint das größte Problem darin zu bestehen, für alle futtermittelrelevanten AS (vor allem für Arginin) ein geeignetes Derivat für eine simultane Detektion zu finden (GEHRKE et al., 1965; PISANO und BRONZERT, 1969; ADAMS, 1974; HUŠEK, 1991; PHENOMENEX APP ID 14345, 2016). Weiterhin treten bei einigen AS (Ala, Val, Ser, Asp, Met, Glu, Phe, Lys, His) Probleme hinsichtlich ihrer Wiederfindung auf (OBRESHKOVA et al., 2012). Während bei der Methode der Ionenaustauschchromatographie Cystin, Cystein und Cysteinsäure gemeinsam als Cysteinsäure bestimmt werden, sind bei der gaschromatographischen Methode in Abhängigkeit von der Derivatisierung separate Peaks für Cystin und Cystein zu erhalten (OBRESHKOVA et al., 2012; HUŠEK, 1991). In der Probe vorhandene Cysteinsäure geht bei einigen Derivatisierungen verloren (ADAMS, 1974). Generell ist diese Methode sehr schnell $(\leq 6 \mathrm{~min}$ je Chromatogramm der GC-Methode vs. $75 \mathrm{~min}$ je Chromatogramm der Ionenaustauschchromatographie; Abb. 2 und 3), sehr sensitiv und zeichnet sich durch eine sehr niedrige Nachweisgrenze aus (GEHRKE et al., 1965).

Für die quantitative Auswertung hat sich der Einsatz eines internen Standards (ISTD) bewährt. Häufig wird die nichtproteinogene Aminosäure Norleucin verwendet, aber auch Norvalin (OBRESHKOVA et al., 2012) oder Sarcosin (HUTSON et al., 2003) sind als interne Standards in der Literatur beschrieben. In eigenen Untersuchungen musste bei der Untersuchung alternativer Proteinquellen wie Insektenprotein auf S-(2-Aminoethyl)-L-Cystein-Hydrochlorid ausgewichen werden. Die Verwendung eines internen Standards hat den Vorteil, dass die Abnahme der Intensität der Färbung des Ninhydrin-Reagenzes während der relativ langen Chromatogramm-Laufzeiten (vgl. Abb. 3) kompensiert werden kann. Die quantitative Auswertung in der Ionenaustauschchromatographie unter Verwendung eines internen 
Standards erfolgt über die Bewertung der Peakflächen auf Grundlage der Molmasse (M) der jeweiligen AS und der Einwaage (EW) der Probe:

$$
A S-\text { Konz. }(\%)=\frac{\text { Fläche }_{\text {AS in Probe }} \times 0,2 \times M_{A S} \times \text { Fläche }_{\text {Norleucin im Standard }}}{\text { Fläche }_{\text {AS im Standard }} \times E W \times 10.000 \times \text { Fläche }_{\text {Norleucin im Standard }}}
$$

Der Faktor 0,2 ergibt sich aus der Konzentration der Standardlösung in mmol/l. Die Ergebnisangabe der derivatisierten SAS erfolgt als Met und (Cys) 2 .

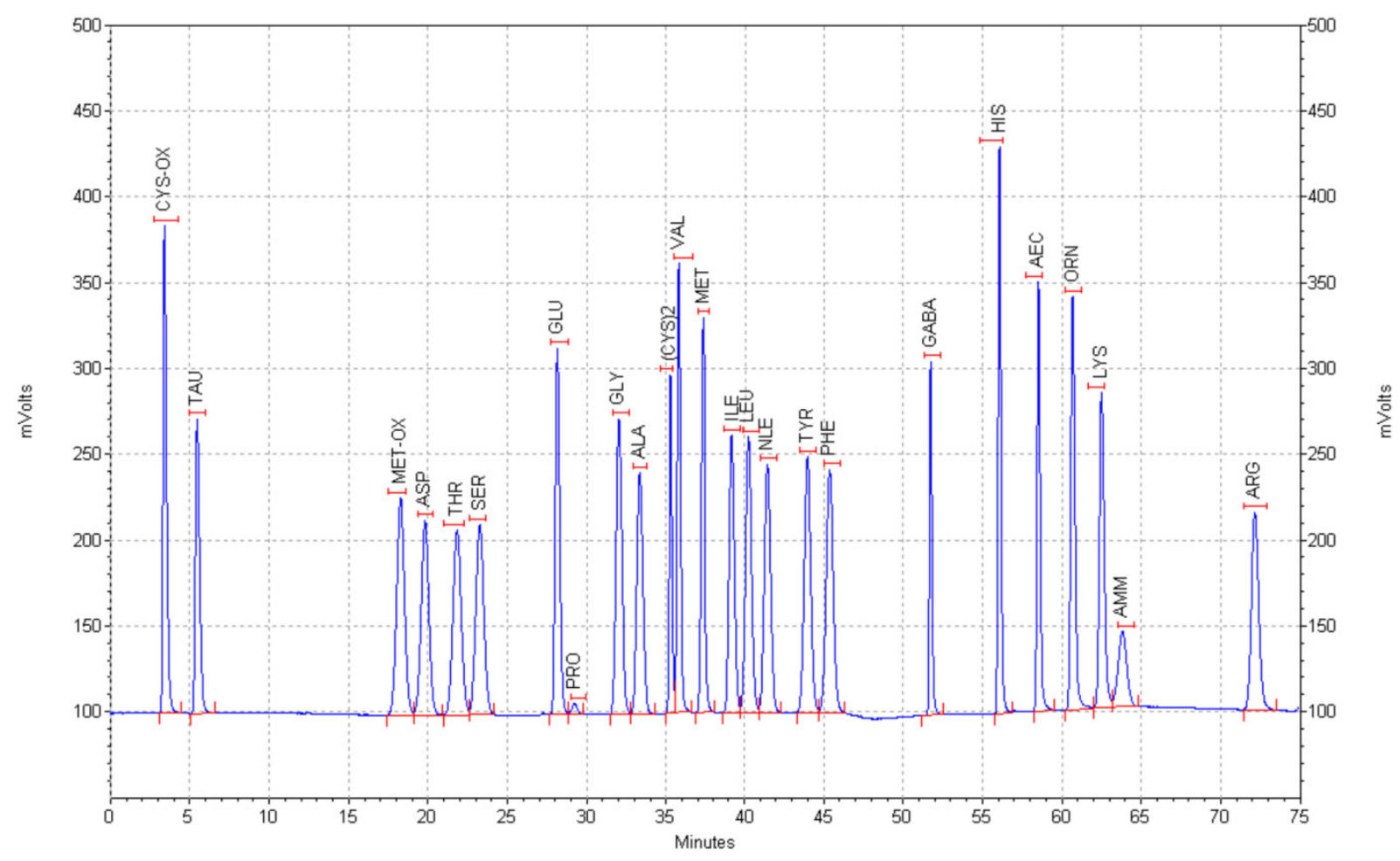

Abbildung 3: Chromatogramm (Ionenaustauschchromatographie) eines Standards bei $570 \mathrm{~nm}$ (Reagenz: Ninhydrin) mit Norleucin (NLE) und S-(2-Aminoethyl)-L-CysteinHydrochlorid (AEC) als interne Standards und einer Gesamtlaufzeit von 91,5 min (Biochrom ${ }^{\circledR}$ B 30)

Figure 3: $\quad$ Chromatogram (ion exchange chromatography) of a standard at $570 \mathrm{~nm}$ (Reagent ninhydrin) with norleucine (NLE) and S-(2-aminoethyl)-L-cysteine-hydrochloride (AEC) as internal standards and 91.5 min running time $\left(\right.$ Biochrom ${ }^{\circledR}$ B 30)

Die Probenvorbereitung erfordert bis auf den Vermahlungsgrad von 0,5 mm keine weiteren Besonderheiten. Für die Bestimmung der AS im Gesamtkörperprotein bzw. in einzelnen Körperproteinfraktionen bestehen hohe Anforderungen an die Probenaufbereitung, um ein repräsentatives Probenmaterial zu gewinnen. Gewöhnlich wird deshalb ein Autoklavierprozess der Tierkörperproben $\left(240 \mathrm{~min}\right.$ bei $\left.110^{\circ} \mathrm{C}\right)$ vorgeschaltet. Danach muss die Probe schrittweise homogenisiert werden, um den Anforderungen an die Entnahme einer Laborprobe zu entsprechen. Bei Vergleichsuntersuchungen an frischen und autoklavierten Fleischknochenprodukten konnte beobachtet werden, dass ca. 30\% des Cys nach dem Autoklavieren nicht mehr nachweisbar waren (vorläufige Daten; Abb. 4). Dieser überraschende 
Befund bedarf weiterer Validierung, insbesondere hinsichtlich der Frage, ob und in welchem Umfang bei autoklavierten Tierkörperproben generell mit einem Cys-Verlust zu rechnen ist und, ob ggf. weitere AS von einem Autoklavierverlust betroffen sein können.

Für die Beprobung von Federn empfiehlt sich nach eigenen Erfahrungen eine grobe Vorzerkleinerung mit einer Schere und anschließend eine Vermahlung (z. B. Zentrifugalmühle ZM 100, Fa. Retsch) unter Verwendung von Trockeneis oder flüssigem Stickstoff.

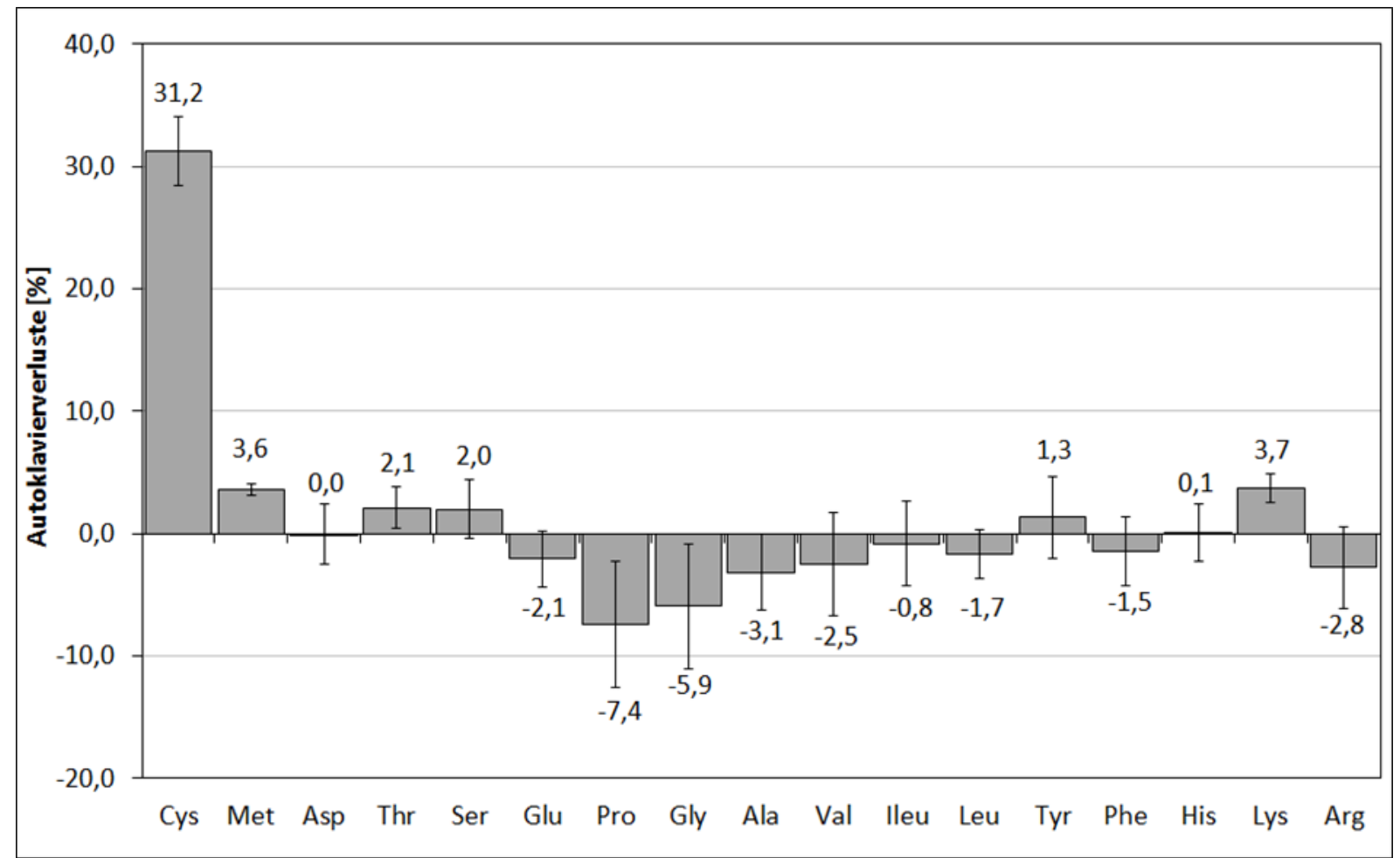

Abbildung 4: Beobachtete Verluste einzelner AS in Tierkörperproben durch das Autoklavieren $(\mathrm{n}=2$; eigene Daten)

Figure 4: $\quad$ Losses of amino acids due to autoclaving of animal body samples ( $n=2$; own data)

\subsection{BIOVERFÜGBARKEIT DER S-HALTIGEN AMINOSÄUREN AUS FUTTERMITTELN}

Die in den verschiedenen Futtermitteln analytisch ermittelten AS-Gehalte (= Brutto-AS) stehen, wie seit langem bekannt, dem Tier nicht in vollem Umfang zur Verfügung. Die entscheidenden Verluste entstehen auf den Ebenen Absorption und postabsorptive Verwertung der mit dem Futter aufgenommenen AS. Für eine realistische Einschätzung von Verwertungsverlusten im Konvertierungsprozess insgesamt bedürfen beide Ebenen einer zuverlässigen Quantifizierung. Bei der Beschreibung der Zielgrößen herrscht jedoch weitgehend begriffliche Konfusion, wozu ggf. auch die gewählte Teilüberschrift beiträgt. Nach FULLER (2004) ist im Einklang mit früheren Definitionen (BATTERHAM, 1992; LEWIS und BAYLEY, 1995) unter Bioverfügbarkeit sinngemäß der Anteil eines Futternährstoffes zu verstehen, der absorbiert wurde und anschließend zur weiteren Verwertung für physiologische Funktionen im Tier zur Verfügung steht. 
Damit ist die Zielgröße für eine Bewertung des Futters klar definiert, methodisch aber schwer erreichbar. $\mathrm{Zu}$ einer ersten Beschreibung dafür, in welchem Umfang die AS zur Nutzung im Tier zur Verfügung steht, wird häufig der Begriff „Verdaulichkeit" verwendet. Als verdaut gilt hierbei der Anteil der aufgenommenen AS, der nicht wieder über den Gastrointestinaltrakt (GIT) ausgeschieden wird (Verschwindensrate aus dem Futter; „Disappearance rate“). Es ist aber festzuhalten, dass das zur Bewertung jeglicher Verdaulichkeit herangezogene Probenmaterial (Ende Dünndarm; Ende GIT) Stickstoff- bzw. AS-haltige Bestandteile aus mindestens drei Quellen aufweist: Neben tatsächlich nicht verdauten/absorbierten Anteilen, sind endogene und mikrobiell modifizierte/synthetisierte Anteile (also Mikrobenprotein) zu erwarten. Letztere können sowohl aus nicht verdauten Futterbestandteilen als auch aus Proteinen der endogenen Sekretion stammen. Eine Differenzierungsmöglichkeit besteht in der Routineuntersuchung definitiv nicht.

Dessen ungeachtet wird die Möglichkeit genutzt, die Verdaulichkeit von AS praecaecal, d. h. im Chymus des terminalen Ileums, zu ermitteln (RODEHUTSCORD und KLUTH, 2003; LEMME et al., 2004; HOEHLER et al., 2006; KLUTH und RODEHUTSCORD, 2009). Es wird der Vorteil erwartet, mikrobielle Umsetzungen weitgehend auszuklammern. Allerdings liegt auch bis zum Dünndarmende keine ausschließliche Verdauung durch körpereigene Enzyme vor (ADEDOKUN et al., 2011). Dennoch kann von einem wichtigen methodischen Fortschritt gesprochen werden. Mit Hilfe eines Markers wird die scheinbare praecaecale Verdaulichkeit (pcV) der Aminosäuren wie folgt berechnet:

$\mathrm{pcV}(\%)=[1-(\mathrm{ID} \times \mathrm{ASI}) /(\mathrm{ASD} \times \mathrm{II})] \times 100$

Wobei:

ID = Konzentration des Markers im Futter

ASI = Konzentration der zu untersuchenden AS im Ileumchymus

$[\mathrm{g} / \mathrm{kg} \mathrm{TM}]$

ASD = Konzentration der zu untersuchenden AS im Futter

$[\mathrm{g} / \mathrm{kg} \mathrm{TM}]$

II = Konzentration des Markers im Ileumchymus

$[\mathrm{g} / \mathrm{kg} \mathrm{TM}]$

$[\mathrm{g} / \mathrm{kg} \mathrm{TM}]$

Da aber, wie bereits angemerkt, nicht alle AS im Chymus tatsächlich aus dem Futter stammen, empfiehlt sich eine Korrektur um diesen endogenen Anteil (HOEHLER et al., 2006). Die endogenen Verluste können in basale und spezifische Ausscheidungen unterteilt werden. Die basalen Anteile sind dabei vor allem abhängig von der Höhe der Futteraufnahme, die spezifischen werden dagegen vom Futtermittel an sich beeinflusst (KLUTH und RODEHUTSCORD, 2006) und sind faktisch nicht zuverlässig zu schätzen, zumal auch Passagerate und mikrobielle Besiedlung weitere Einflussgrößen darstellen dürften (ADEDOKUN et al., 2011). Eine Schätzung der endogenen Verluste wäre klassisch durch Gabe eines proteinfreien Mischfutters, aber auch durch Einsatz hochverdaulicher oder enzymatisch hydrolysierter Proteinträger, durch Nutzung markierter Substanzen bzw. auf Basis einer regressionsanalytischen Ableitung möglich (RODEHUTSCORD und KLUTH, 2003; LEMME et al., 2004; HOEHLER et al., 2006; KLUTH und RODEHUTSCORD, 2009). Die so ermittelten Daten lassen sich bei der Korrektur der scheinbaren praecaecalen Verdaulichkeit einbeziehen.

Das Ergebnis führt zur standardisierten praecaecalen Verdaulichkeit (std. pcV), die sich folgendermaßen berechnen lässt: 
std. $\mathrm{pcV}(\%)=\mathrm{pcV}+(\mathrm{ASLB} / \mathrm{ASD})$

Wobei:

ASLB = basale endogene Verluste der zu untersuchenden AS

[g/kg TM]

ASD $=$ Konzentration der zu untersuchenden AS im Futter

$[\mathrm{g} / \mathrm{kg} \mathrm{TM}]$

In Tabelle 3 sind Angaben zur standardisierten pcV der SAS ausgewählter Futtermittel zusammengestellt. Mais weist eine hohe $\mathrm{pcV}$ von Met und Cys auf. Ebenso zeigen Gerste und Weizen pcV-Werte um $90 \%$ für beide AS. Die niedrigsten Werte liegen für die SAS der Ackerbohne vor. Relativ geringe Unterschiede bestehen in der Regel zur pcV anderer AS, so variieren die Werte für Lys in den hier dargestellten Futtermitteln im Bereich von 80-90 \%. Während Rapsextraktionsschrot höhere SAS-Gehalte im Vergleich zu Sojaextraktionsschrot aufweist, ist die pcV dieser AS geringer und in Abhängigkeit von Bearbeitungsprozessen (PARSONS et al., 1992) auch deutlich variabler.

Tabelle 3: Standardisierte praecaecale Verdaulichkeit der S-haltigen Aminosäuren in ausgewählten Futtermitteln bei Broilern ${ }^{1}$

Table 3: $\quad$ Standardized ileal digestibility of sulphur-containing amino acids in selected feedstuffs for broilers ${ }^{1}$

\begin{tabular}{lcc}
\hline Futtermittel & \multicolumn{2}{c}{ Standardisierte praecaecale Verdaulichkeit (\%) } \\
& Met & Cys \\
\hline Ackerbohnen & 71 & 59 \\
Erbsen & 78 & 71 \\
Fischmehl & 87 & 63 \\
Gerste & 92 & 88 \\
Mais & 95 & 89 \\
Rapsextraktionsschrot & 84 & 77 \\
Sojaextraktionsschrot & 90 & 79 \\
Weizen & 91 & 91 \\
\hline
\end{tabular}

${ }^{1}$ AminoDat ${ }^{\circledR}$ version 5.0 (EVONIK INDUSTRIES, Hanau, Germany)

Es ist generell festzustellen, dass die Angaben zur pcV in Abhängigkeit von verschiedenen Faktoren starken Schwankungen unterliegen. So spielen nicht nur Art und Herkunft der Futtermittel eine entscheidende Rolle, sondern auch solche Einflussgrößen wie Standort, Erntejahr, Genotyp, Behandlungsverfahren und Verarbeitungsprozess (DE COCA-SINOVA et al., 2008; ADEDOKUN et al., 2015; ZUBER et al., 2015, 2016, 2017; DALÓLIO et al., 2016; ULLAH et al., 2016). In aktuellen Studien an caecectomierten Legehennen, in denen umfangreiches Probenmaterial zum Einsatz kam, konnten zum Teil erhebliche Verdaulichkeitsunterschiede nachgewiesen werden. Der Vergleich von 20 verschiedenen Genotypen innerhalb einer Getreideart, die unter standardisierten Bedingungen angebaut 
wurden, ergab Abweichungen zwischen den Werten der pcV beider SAS, die bis zu 18 Prozentpunkte ausmachten (s. Tab. 4).

Tabelle 4: Variation in der praecaecalen Verdaulichkeit der S-haltigen Aminosäuren in verschiedenen Getreide-Genotypen bei Legehennen

Table 4: $\quad$ Differences in the ileal digestibility of sulphur amino acids in various genotypes of cereals

\begin{tabular}{|c|c|c|c|c|}
\hline \multirow[t]{2}{*}{ Getreide } & \multicolumn{2}{|c|}{ AS-Verdaulichkeit (\%) } & \multirow{2}{*}{$\begin{array}{l}\text { Signifikanzlevel } \\
\text { (p) }\end{array}$} & \multirow[t]{2}{*}{ Quelle } \\
\hline & Met & Cys & & \\
\hline Mais & $86-94$ & $80-93$ & $<0,001$ & Zuber und Rodehutscord, 2017 \\
\hline Roggen & $57-75$ & $61-76$ & $<0,001$ & Zuber et al., 2016 \\
\hline Triticale & $77-86$ & $78-86$ & $<0,001$ & Zuber et al., 2017 \\
\hline Weizen & $70-93$ & $78-95$ & $<0,001$ & Zuber und Rodehutscord, 2016 \\
\hline
\end{tabular}

ANGKANAPORN et al. (1994) zeigten den signifikanten negativen Effekt höherer Anteile an Weizen-Pentosanen auf die pcV von Met bei Masthähnchen. Demgegenüber erwiesen sich Trypsininhibitor-Gehalte von 1,7-2,9 mg/g Sojaextraktionsschrot als unerheblich (CLARKE und WISEMAN, 2005). Ein weiterer Einflussfaktor auf die pcV der AS resultiert aus dem Einsatz diverser Futterzusatzstoffe wie Probiotika und Proteasen (z. B. LI et al., 2008; DALÓLIO et al., 2016). Detailbetrachtungen hierzu wären zu weitführend.

Darüber hinaus können aber auch Genotyp, Alter und Geschlecht der verwendeten Versuchstiere einen Einfluss auf die gemessenen Verdaulichkeitswerte haben (z. B. ZUPRIZAL et al., 1992; TEN DOESCHATE et al., 1993; HUANG et al., 2005). Altersbedingte Veränderungen bei der Entwicklung der Verdauungsorgane und der Enzymaktivitäten sind hier als Faktoren zu benennen (z.B. NITSAN et al., 1991; ADEDOKUN et al., 2008; JAMROZ et al., 2002). Demgegenüber konnten AMAD und LIEBERT (2015) keine genotyp- und geschlechtsabhängigen Effekte auf die pcV der AS bei Masthähnchen feststellen. Die noch nicht ausreichende Standardisierung experimenteller Methoden (KLUTH et al., 2005; KLUTH und RODEHUTSCORD, 2009, 2010) erschwert generell die Vergleichbarkeit von Angaben zur pcV von AS. Doch auch bei standardisierten Anbaubedingungen sowie gleicher Behandlung der Proben können die ermittelten Werte aufgrund von Unterschieden im Genotyp der untersuchten Getreideart schwanken (ZUBER und RODEHUTSCORD, 2016, 2017; ZUBER et al., 2016, 2017).

$\mathrm{Zu}$ beachten ist jedoch grundsätzlich, dass die „Verdaulichkeit“ nur einen Teil der „Bioverfügbarkeit“" beschreiben kann. Ungeachtet der Tatsache, dass die enzymatische Freisetzung aus dem Futterproteinverband und die anschließende Absorption der AS als zwei wichtige Schritte bei der Gesamtverwertung im Tierkörper anzusehen sind, muss auch ihrer postabsorptiven Verwertung eine höhere Aufmerksamkeit beigemessen werden. Nach Untersuchungsergebnissen von WU (1998) sowie STOLL und BURRIN (2006) können durch Katabolisierung in den Enterozyten des Dünndarms beachtliche AS-Verluste auftreten, die bei der Bewertung des Verwertungsprozesses nicht unberücksichtigt bleiben dürften. Ohne Zweifel dient diese Katabolisierung im Rahmen der nutritiven Priorisierung der Deckung aktueller 
Versorgungsansprüche im Darmgewebe wie der Regeneration der Darmmukosa. Die auf diese Weise genutzten AS stehen aber für produktbildende Syntheseprozesse, also den Muskelansatz, direkt nicht mehr zur Verfügung. Ein weiterer Aspekt ist durch eine Vielzahl von vergleichenden Studien mit thermisch behandelten Proteinträgern beim Schwein belegt (z. B. BATTERHAM et al., 1990, 1993; VAN BARNEVELD et al., 1994a, b). Diese Studien konnten insbesondere für Lys, Thr sowie Met+Cys zeigen, dass die ausschließliche Betrachtung der pcV dieser AS nach thermischen Behandlungen des Futters keine ausreichende Aussagekraft zum jeweiligen Futterpotenzial besitzt.

Aber auch Angaben zur Gesamtverwertung für den Ansatz unterliegen beachtlichen Unterschieden. Die GfE (1999) leitete Angaben zur Gesamtverwertung der SAS aus Literaturdaten zur wahren $\mathrm{pcV}$ und intermediären Verwertung ab. Die Mittelwerte variierten zwischen $70 \%$ (Met) und $66 \%$ (Met+Cys). EDWARDS und BAKER (1999) sowie CONDEAGUILERA et al. (2013) folgerten, dass sich im Mittel etwa $70 \%$ (Met) bzw. 55 \% (Cys bzw. Met+Cys) der Aufnahme für die Körperproteinsynthese beim Masthähnchen im Ansatz wiederfinden. Ähnliche Werte wurden auch in Versuchen an der Laborratte ermittelt (HEGER und FRYDRYCH, 1985). Die vergleichsweise niedrigere Effizienz der SASGesamtverwertung erklärt sich mit vielfältigen Stoffwechselfunktionen der SAS (HEGER et al., 2002). SILVA et al. (2014) und SAKOMURA et al. (2015) kamen mit ASAnsatzmessungen zu dem Ergebnis, dass bei wachsenden Masthähnchen 71 bzw. $78 \%$ der aufgenommenen SAS für den Ansatz verwertet wurden. Zudem ist altersabhängig mit einem negativen Effekt auf die SAS-Verwertung zu rechnen (ADEOLA, 2007; SILVA et al., 2014). Erwartungsgemäß führen bedarfsüberschreitende Met-Angebote im Broilermastfutter (FATUFE und RODEHUTSCORD, 2005; CONDE-AGUILERA et al., 2013) zu analogen Auswirkungen. Erhöhte Futterproteingehalte (vgl. Abb. 5), die zu einem den Bedarf überschreitenden AS-Angebot beitragen, lassen sich hier ebenfalls einordnen.

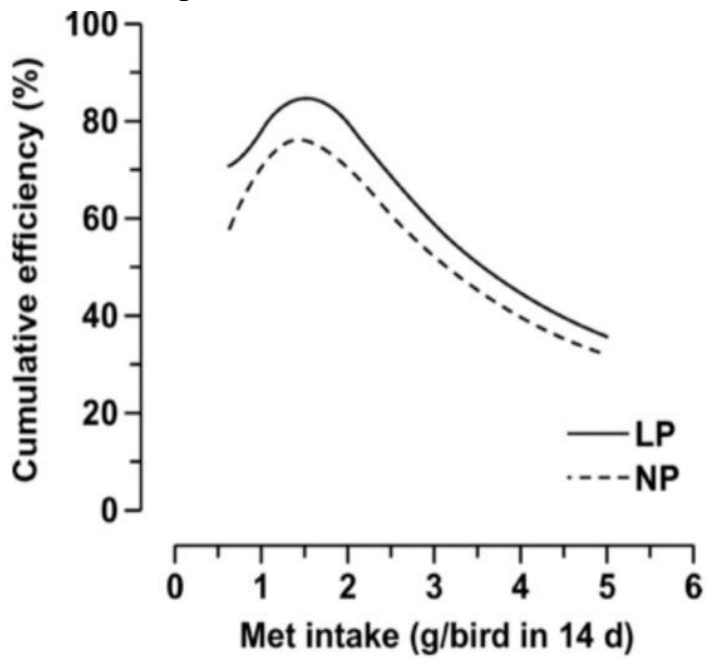

Abbildung 5: Effekt einer steigenden Methionin-Aufnahme auf die kumulative MetGesamtverwertung von Masthähnchen in Abhängigkeit vom Rohproteingehalt des Mischfutters (LP = geringer Proteingehalt, 18,3\% RP; NP = normaler Proteingehalt, 22,9 \% RP; FATUFE und RODEHUTSCORD, 2005)

Figure 5: $\quad$ Effect of dietary methionine intake on cumulative efficiency of methionine utilization of growing chickens depending on dietary crude protein content ( $L P=$ low protein, $18.3 \%$ CP; NP = normal protein, $22.9 \%$ CP; FATUFE and RODEHUTSCORD, 2005) 
Ein grundsätzlich anderer methodischer Ansatz für die Bewertung der AS-Gesamtwirkung ist im „Göttinger Modell“ (LIEBERT und WECKE, 2006; LIEBERT, 2015, 2017) verankert, dessen aktuelle Anwendungen zahlreich beschrieben sind (u. a. SAMADI und LIEBERT, 2006, 2007; PASTOR et al., 2013; LIEBERT, 2015, 2017; KHAN et al., 2015a; WECKE et al., 2016; SAMADI et al., 2017). Zudem wurden umfangreiche Untersuchungen zur Met-Wirksamkeit in Met-limitierten Mischungen aus den Proteinträgern Sojaproteinkonzentrat, Mais, Erbsen und Weizenkleber an Masthähnchen durchgeführt (FARKE, 2011). Unter Beibehaltung eines konstanten Mischungsverhältnisses der Proteinträger wurden nach Grundsätzen der Verdünnungsmethode (FISHER und MORRIS, 1970) sechs Versuchsmischungen mit abgestuften Rohproteingehalten zwischen 6 und $36 \%$ in N-Bilanzversuchen an wachsenden männlichen Broilern (Ross 308) geprüft und die alters- sowie vom Genotyp abhängigen Modellparameter (NDmaxT) aus den beobachteten N-Wirkungskurven abgeleitet (vgl. Abb. 6).

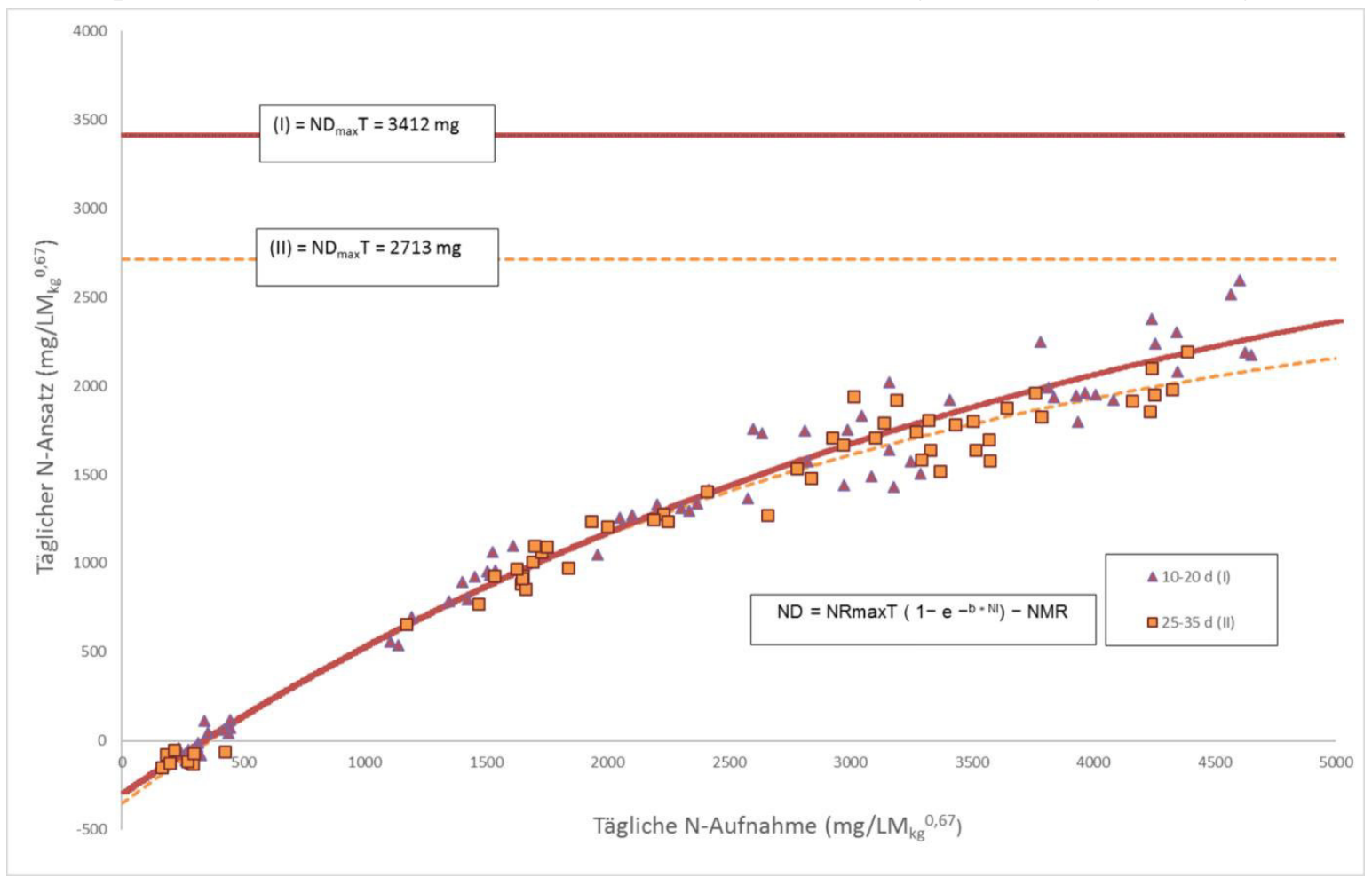

Abbildung 6: Schätzung des theoretischen Grenzwertes für den täglichen N-Ansatz (NDmaxT) von männlichen Broilerküken (Ross 308) in Abhängigkeit von Alter und Wachstumsphase

Figure 6: $\quad$ Estimation of theoretical threshold value for daily N-deposition (NDmaxT) in male growing chicken (Ross 308) dependent on age resp. growth period

Parallel dazu erfolgte, wie an anderer Stelle beschrieben (SÜNDER und LIEBERT, 2005; SAMADI und LIEBERT, 2006), die regressive Ermittlung des N-Erhaltungsbedarfes (NMR) für die Starter- und Growerphase ( $228 \mathrm{bzw} .354 \mathrm{mg} \mathrm{N} / \mathrm{LM}_{\mathrm{kg}}{ }^{0,67}$ ). Auf dieser Grundlage wurden Proteinqualitätsparameter der Mischungen berechnet (Tab. 5). Die Resultate verdeutlichen die bekannte Abhängigkeit des klassischen Physiologischen Nutzwertes (PNu) der Mischungen vom Proteingehalt des Futters $(\mathrm{p}<0,05)$, die nur dann vollständig aufgehoben wird, wenn der Modellparameter $b$ als Maßstab der Proteinqualität dient oder wenn auf dessen Grundlage eine Standardisierung der konventionellen Parameter (wie z. B. des PNu) erfolgt (LIEBERT, 2015, 2017). Hierin erklärt sich auch dessen universelle Eignung für die weitere, vom Proteinniveau 
unabhängige Betrachtung der Met-Wirksamkeit (bc-1) entsprechend der nachfolgenden Schlüsselfunktion:

$$
b c^{-1}=\frac{\ln N R_{\max } T-\ln \left(N R_{\max } T-N R\right)}{16 \times L A A I}
$$

Wobei:

$\mathrm{bc}^{-1}=$ Modellparameter der AS-Wirksamkeit (AS-Gesamtwirkung, AA-Efficiency)

$\mathrm{NR}=\mathrm{N}$-Retention $(\mathrm{N}-$ Deposition $+\mathrm{NMR})$

$\mathrm{ND}=\mathrm{N}$-Ansatz (N-Deposition)

$\mathrm{NMR}=\mathrm{N}$-Erhaltungsbedarf

NRmaxT $=$ theoretisches Maximum der NR

LAAI = Aufnahme an limitierender AS

$$
\begin{aligned}
& {\left[\mathrm{mg} / \mathrm{LM}_{\mathrm{kg}}{ }^{0,67} / \mathrm{d}\right]} \\
& {\left[\mathrm{mg} / \mathrm{LM}_{\mathrm{kg}}{ }^{0,67} / \mathrm{d}\right]} \\
& {\left[\mathrm{mg} / \mathrm{LM}_{\mathrm{kg}}{ }^{0,67} / \mathrm{d}\right]} \\
& {\left[\mathrm{mg} / \mathrm{LM}_{\mathrm{kg}}{ }^{0,67} / \mathrm{d}\right]} \\
& {\left[\mathrm{mg} / \mathrm{LM}_{\mathrm{kg}}{ }^{0,67} / \mathrm{d}\right]}
\end{aligned}
$$

Die beobachtete Höhe der Met-Wirksamkeit bei Proteinstaffelung im Futter, die nur zufällige Mittelwertunterschiede ausweist (Tab. 5), steht scheinbar im Widerspruch zu Beobachtungen von FATUFE und RODEHUTSCORD (2005) nach abgestufter Met-Supplementation. Jedoch zeigten auch diese Untersuchungen eine maximale Met-Gesamtverwertung nur bei suboptimaler Met-Versorgung, allerdings mit erkennbarem Abfall des Met-Wirkungsgrades bereits im Met-Limitierungsbereich. Auch Ergebnisse von WECKE et al. (2015b) ließen insbesondere in der Starterphase trotz Met-Limitierung im Futter einen signifikanten Abfall der Met-Wirksamkeit $\left(\mathrm{bc}^{-1}\right)$ nach Met-Zulagen erkennen, waren aber auf das veränderte Met:CysVerhältnis im Futter zurückzuführen. Dieser Faktor ist in Bedarfsstudien grundsätzlich deutlich stärker zu berücksichtigen, unter 3.2 wird darauf näher eingegangen.

Zudem zeigt Tabelle 5 eine Altersabhängigkeit der Met-Wirksamkeit, die aber vor allem durch die altersabhängigen Grenzwerte für NDmaxT zu erklären ist (WECKE und LIEBERT, 2009; PASTOR et al., 2013; BONATO et al., 2015; KHAN et al., 2015c).

Die mathematische Umstellung der genannten Schlüsselfunktion des „Göttinger Modells“ von der AS-Wirksamkeit $\left(\mathrm{bc}^{-1}\right)$ auf die Aufnahme an limitierender AS (LAAI) liefert die Basis für leistungsabhängige AS-Bedarfsableitungen bei gegebener AS-Wirksamkeit (z. B. PASTOR et al., 2013; KHAN et al., 2015b; WECKE et al., 2016; SAMADI et al., 2017). 
Tabelle 5: Messwerte der Proteinqualität (PNu, b) und Met-Wirksamkeit $\left(\mathrm{bc}^{-1}\right)$ in Mischfuttermitteln für Broiler mit gestaffelten XP-Gehalten bei konstanten Mischungsverhältnissen der Proteinträger ${ }^{1}$

Table 5: $\quad$ Protein quality values $(P N u, b)$ and Met-efficiency $\left(b c^{-1}\right)$ in chicken diets with graded protein contents but constant dietary proportion of protein sources ${ }^{l}$

\begin{tabular}{|c|c|c|c|c|c|c|}
\hline Mischung & 1 & 2 & 3 & 4 & 5 & 6 \\
\hline \multicolumn{7}{|c|}{ Starterperiode (10-20 d) } \\
\hline $\begin{array}{c}\text { XP-Gehalt } \\
(\%)\end{array}$ & 36,7 & 30,6 & 24,4 & 18,3 & 12,2 & 6,1 \\
\hline $\mathrm{PNu}(\%)$ & $58,2^{\mathrm{a}} \pm 4,2$ & $58,8^{a} \pm 4,4$ & $63,2^{\mathrm{a}} \pm 6,9$ & $71,3^{b} \pm 4,8$ & $81,1^{\mathrm{c}} \pm 4,5$ & $86,2^{\mathrm{c}} \pm 14,7$ \\
\hline $\mathrm{PNu}_{\text {std. }}^{2}(\%)$ & $73,5 \pm 6,1$ & $69,2 \pm 7,2$ & $67,5 \pm 7,7$ & $71,3 \pm 4,8$ & $71,8 \pm 4,6$ & $67,6 \pm 8,8$ \\
\hline$b\left(\mathrm{~b} \cdot 10^{6}\right)$ & $271 \pm 31$ & $249 \pm 37$ & $242 \pm 37$ & $260 \pm 25$ & $263 \pm 22$ & $243 \pm 43$ \\
\hline$\left(b c^{-1}\right)^{3}$ & $174 \pm 20$ & $160 \pm 24$ & $155 \pm 24$ & $166 \pm 16$ & $168 \pm 14$ & $156 \pm 28$ \\
\hline \multicolumn{7}{|c|}{ Growerperiode (25-35 d) } \\
\hline $\begin{array}{c}\begin{array}{c}\text { XP-Gehalt } \\
(\%)\end{array} \\
\end{array}$ & 34,9 & 29,1 & 23,3 & 17,5 & 11,6 & 5,8 \\
\hline $\mathrm{PNu}(\%)$ & $55,8^{\mathrm{a}} \pm 2,9$ & $59,7^{\mathrm{a}} \pm 3,4$ & $68,3^{b} \pm 4,2$ & $74,9^{\mathrm{c}} \pm 3,8$ & $80,5^{c} \pm 4,2$ & $105,7^{c} \pm 29,5$ \\
\hline $\mathrm{PNu}_{\text {std. }}{ }^{2}(\%)$ & $71,1 \pm 6,3$ & $69,4 \pm 4,9$ & $74,8 \pm 6,6$ & $70,9 \pm 3,1$ & $71,5 \pm 3,1$ & $72,4 \pm 12,8$ \\
\hline$b\left(\mathrm{~b} \cdot 10^{6}\right)$ & $340 \pm 37$ & $329 \pm 33$ & $368 \pm 52$ & $339 \pm 24$ & $342 \pm 22$ & $360 \pm 101$ \\
\hline$\left(b c^{-1}\right)^{3}$ & $218 \pm 24$ & $211 \pm 21$ & $236 \pm 33$ & $217 \pm 15$ & $219 \pm 14$ & $231 \pm 65$ \\
\hline
\end{tabular}

${ }^{1}$ Angaben als Mittelwerte \pm Standardabweichung; unterschiedliche Hochbuchstaben kennzeichnen signifikante Unterschiede $(\mathrm{p}<0,05)$ zwischen den Mischfuttermitteln

${ }^{2} \mathrm{PNu}_{\text {std. }}=$ Physiologischer Nutzwert standardisiert auf eine einheitliche N-Aufnahme von $2400 \mathrm{mg} / \mathrm{BW}_{\mathrm{kg}}{ }^{0,67}$

${ }^{3}$ Met-Konzentration $(c)=1,56 \mathrm{~g} \mathrm{Met} / 16 \mathrm{~g} \mathrm{~N}$

\subsection{PALETTE DER S-HALTIGEN AMINOSÄUREN ALS FUTTERZUSATZSTOFFE}

Da die SAS in klassischen Proteinträgern für das Geflügel häufig limitierend wirken und über den Weg der Kombination von üblichen Futtermitteln keine ausreichenden Möglichkeiten der Bedarfsdeckung bestehen, ist ein entsprechender Ausgleich erforderlich. Dieser Ausgleich kann konventionell entweder durch synthetisches DL-Met oder ein Met-Hydroxyanalog (MHA; 2Hydroxy-4-Methylthio-Buttersäure, HMTBA) erfolgen (SAUNDERSON, 1991). MHA weist im Gegensatz zu Met am $\alpha$-C-Atom eine Hydroxylgruppe auf (FULLER, 2004). Beide MetQuellen können im Stoffwechsel in L-Met überführt werden (SAUNDERSON, 1991). MHA wird in 2 Schritten zu L-Met umgewandelt. Im ersten Schritt entsteht durch Oxidation der $\alpha-$ Hydroxylgruppe die Verbindung 2-Keto-4-(Methylthio-)Buttersäure, die im zweiten Schritt durch eine Transaminierung am $\alpha$-C-Atom in L-Met überführt wird (KNIGHT und DIBNER, 1984). Die erforderlichen Enzyme (D-AS-Oxidase, D-Hydroxy-AS-Dehydrogenase und LHydroxy-AS-Oxidase) kommen maßgeblich in der Leber, aber auch im GIT vor (MARTÍNVENEGAS et al., 2011; ZHANG et al., 2015). Da das Razemat DL-Met 50 \% D-Met enthält, ist metabolisch eine Transformation in L-Met erforderlich. Für diesen Prozess bestehen nach 
bisheriger Kenntnis infolge ausreichender Aktivität der AS-Oxidase in einer Vielzahl von Körpergeweben (SAUNDERSON, 1991) keine bekannten physiologischen Grenzen. Nach aktuellen Befunden (RIBEIRO et al., 2005; MATSUSHITA et al., 2007; CONDE-AGUILERA et al., 2016; ZHANG et al., 2017) zeigten Vergleiche beider Met-Quellen keinen differenzierbaren Einfluss auf die Wachstumsleistung und den Ansatz an Muskelmasse bei Masthähnchen, wohl aber auf die AS-Zusammensetzung des Körperproteins und die CysVerteilung im Gewebe. So führte die Supplementation mit DL-Met im Vergleich zu MHA zu einer signifikant höheren Menge an Cys im Schlachtkörper. Durch MHA erhöhten sich demgegenüber die Anteile an Cys, Gly, Ser und Ala im Körperprotein (CONDE-AGUILERA et al., 2016). Diese Beobachtungen sind jedoch in einer Verschiebung der Gewebeanteile begründet.

Es konnte festgestellt werden, dass durch einen Zusatz von L-Met, DL-Met oder MHA bei vergleichbaren Effekten auf zootechnische Parameter die Expression mehrerer Nährstofftransporter in verschiedenen Dünndarmabschnitten differenziert beeinflusst wurde (ZHANG et al., 2017). Die MHA-Effekte auf die Genexpression der untersuchten Transporter waren im Vergleich zu DL- und L-Met deutlich schwächer. Ob auf diesem Weg ein quantitativ relevanter Effekt auf die Effizienz der intestinalen AS-Absorption erwartet werden kann, bedarf der abschließenden Klärung. Andererseits erhöhten Zulagen von MHA im Vergleich zu anderen Met-Quellen den Trockensubstanzgehalt in den Exkrementen wachsender Broiler (MATSUSHITA et al., 2007). Veränderungen im Wasserhaushalt sowie strukturbedingte Unterschiede in der Absorption der Met-Quellen wären als Ursache denkbar. Nach BUNCHASAK (2009) erfolgt die Absorption von Met und Cys im Dünndarm, wobei die Absorption von Met im Jejunum sowohl durch $\mathrm{Na}^{+}$-abhängige als auch $\mathrm{Na}^{+}$-unabhängige Carrier-Systeme möglich ist (SORIANO-GARCIA et al., 1998). MHA wird durch Diffusion und Carrier-Systeme aufgenommen. Dies geschieht entlang des gesamten GIT. Es wurde allerdings beobachtet, dass $85 \%$ des MHA bereits im proximalen Teil des GIT, also vor dem Dünndarm im Drüsen- und Muskelmagen absorbiert werden (RICHARDS et al., 2005). Im Gegensatz dazu fanden MAENZ und ENGELE-SCHAAN (1996) keine Anzeichen für Diffusion und folgerten, dass MHA durch $\mathrm{H}^{+}$-abhängige Transportsysteme aufgenommen wird. Es erscheint aus vorliegenden Studien nicht gerechtfertigt, auf der Absorptionsebene schlüssige Aussagen für Wirksamkeitsunterschiede zwischen Met und MHA festzumachen. Gemessen an Wachstumsdaten folgerten SAUER et al. (2008) auf äquimolarer Ebene eine MHA-Effizienz von $81 \%$ des DL-Met. Grundlage für derartige Vergleiche sind in der Regel Dosis-WirkungsStudien und Datenauswertungen anhand exponentieller Modelle unter Berücksichtigung verschiedener Response-Parameter. GONZALES-ESQUERRA et al. (2007) stellten in Versuchen mit Puten jedoch unterschiedliche Plateauwerte fest. Bei Gabe von MHA konnte ein höherer Plateauwert beobachtet werden. AGOSTINI et al. (2016) berücksichtigten in ihren Versuchen zudem die Höhe der Aufnahme an SAS. Bei niedrigen Aufnahmen erwies sich DLMet als effizienter, bei hohen Aufnahmen dagegen MHA. Hierfür sprechen auch Ergebnisse von FARKE (2011), die allerdings trotz Einbeziehung unterschiedlicher Met:Cys-Verhältnisse im Futter und Durchführung mehrerer Versuchsdurchgänge von N-Bilanz- sowie Wachstumsversuchen kein einheitliches Bild bezüglich der Wirksamkeitsvergleiche reproduzieren konnten, im klaren Limitierungsbereich, d. h. bei eher knapper Versorgung, aber Vorteile für DL-Met erkennen ließen. Auch in anderen Studien zeigte sich kein einheitliches Bild zu dieser Fragestellung (u. a. TIPTON et al., 1966; SAUER et al., 2008; BUNCHASAK et al., 2012; CONDE-AGUILERA et al., 2016). Es ist nicht das Ziel dieser Übersicht, hierzu eine finale Bewertung vorzunehmen. Hierfür wäre eine detaillierte Betrachtung des jeweils 
gewählten Versuchsansatzes erforderlich. Ein Aspekt erfordert jedoch gesonderte Beachtung: Da inzwischen neben der klassischen Form DL-Met auch L-Met als Futterzusatzstoff zur Verfügung steht, wurde aktuell über Wirksamkeitsvergleiche berichtet (SHEN et al., 2014, 2015; LIEBERT et al., 2015; HTOO und MORALES, 2016). Da bei einem Teil der Arbeiten fundamentale methodische Grundsätze ignoriert wurden (SHEN et al., 2014, 2015), waren Fehleinschätzungen zugunsten der L-Form die Folge, für die es keinen gesicherten Nachweis gibt. Es kann als erwiesen gelten, dass keine Wirksamkeitsunterschiede zwischen den Isomeren DL-Met und L-Met bestehen (LIEBERT et al., 2015; HTOO und MORALES, 2016; ZHANG et al., 2017).

Somit ist nach vorliegenden Erkenntnissen zwischen den aktuellen Met-Quellen mit eher geringen Wirksamkeitsunterschieden bei produktbildenden Prozessen zu rechnen, hinsichtlich der Beeinflussung biochemischer Stoffwechselwege, wie z. B. der Expression verschiedener intestinaler Transporter, liegen bei DL- und L-Met offensichtlich stärkere Effekte vor (ZHANG et. al., 2017). Hierin einzuordnen sind auch die beim Einsatz von MHA nach einer E. coli Lipopolysaccharid-Injektion bei 23 Tage alten weiblichen Broilern festgestellten niedrigeren Konzentrationen verschiedener Akut-Phase-Proteine im Plasma. Die Autoren bewerteten diese Beobachtung als Hinweis auf einen vergleichsweise höheren entzündungshemmenden Effekt durch MHA (MATSUSHITA et al., 2007). Diese Beobachtungen machen eine weitere quantitative Einordnung und Bewertung erforderlich. Unter Beachtung variabler Met:CysVerhältnisse in den Rohstoffen (Tab. 2) wäre grundsätzlich auch an eine Supplementation von L-Cys-Cys zur Korrektur unphysiologischer Met:Cys-Relationen $\mathrm{zu}$ denken, die futtermittelrechtlichen Voraussetzungen sind dafür vorhanden. Eine metabolische Bereitstellung von Cys aus dem Met-Abbau (vergl. 3.) könnte auf diesem Weg minimiert werden.

\section{STOFFWECHSEL DER S-HALTIGEN AMINOSÄUREN}

\subsection{METHIONIN- UND CYSTEIN-UMSETZUNGEN}

Im Stoffwechsel erfolgen Umsetzungen von L-Met durch Transmethylierung und Transsulfurierung (STIPANUK, 1986). In einem ersten Schritt wird Met durch die MetAdenosyltransferase zu S-Adenosylmethionin (SAM) aktiviert (BROSNAN und BROSNAN, 2006). Die Met-Adenosyltransferase gibt hierfür die funktionelle Gruppe des ATP an das SAtom von Met ab (STIPANUK, 1986). In der Ratte wurden drei Iso-Enzyme der MetAdenosyltransferase nachgewiesen, von denen zwei ausschließlich in der Leber vorkommen (KOTB u. GELLER, 1993). Details zur Komplexität des regulatorischen Zusammenwirkens dieser Transferasen finden sich bei KOTB und GELLER (1993). Es kann erwartet werden, dass die Bildung von SAM in der Leber durch exzessive Met-Gaben stimuliert wird. In allen anderen Geweben ist dies nicht möglich, die Konzentration an SAM bleibt dort relativ konstant (FINKELSTEIN, 1998).

SAM dient zum einen als Methylgruppendonator für Transmethylierungsreaktionen, zum anderen als Vorstufe von Aminopropyllieferanten für die Polyaminsynthese. Seine Methylgruppe wird auf diesem Wege vor allem für die Kreatin- und L-Carnitinsynthese (SCHUTTE et al., 1997; STIPANUK, 2004), aber auch für die Synthese von Cholin (BURKE et al., 1951) genutzt. Das Enzym Kreatin-Kinase übernimmt wichtige Funktionen bei der Energie-Homöostase in den Zellen und beeinflusst so die Impulsweiterleitung in den Nerven (WALLIMAN et al., 1992). So dient Kreatinphosphat in der Muskulatur als Energiereserve und kann in Situationen, in denen viel ATP benötigt wird, ADP in ATP überführen (FULLER, 
2004). L-Carnitin ist als Shuttle für den Transport von langkettigen Fettsäuren durch die innere Mitochondrien-Membran und somit für die weitere $\beta$-Oxidation der Fettsäuren unentbehrlich (FOSTER, 2004; FULLER, 2004). Cholin wird unter anderem für die Synthese von Phosphatidylcholin (Lecithin), einem der wichtigsten Phospholipide, das für die Integrität der Zellmembran und den Transport von Fetten im Körper von Bedeutung ist, benötigt (FULLER, 2004; CHATTOPADHYAY et al., 2006; METZLER-ZEBELI et al., 2009).

Ausgehend vom SAM sind zwei weitere Umsetzungsmöglichkeiten gegeben. Durch eine Decarboxylierung des SAM wird dSAM gebildet. Das dSAM kann Aminopropylgruppen für die Synthese von Spermidin und Spermin liefern. Als Ergebnis der Decarboxylierung entsteht 5'-Methylthioadenosin, dessen Schwefel- und Methylgruppen wieder für die Met-Synthese genutzt werden können (STIPANUK, 1986). Gibt das SAM in seiner Funktion als Methylgruppendonator eine Methylgruppe an einen Akzeptor ab, entsteht SAdenosylhomocystein (AdoHCy) als Co-Produkt der Transmethylierung. Das AdoHCy kann durch die S-Adenosylhomocystein-Hydrolase zu Homocystein (HCy) und Adenosin umgesetzt werden (BROSNAN und BROSNAN, 2006). Dieser Hydrolyseschritt ist reversibel, die Synthese von AdoHCy wird jedoch favorisiert. Die Transmethylierungen können in allen Körperzellen stattfinden (BROSNAN und BROSNAN, 2006). Da die Akkumulierung von AdoHCy die Transmethylierungsprozesse hemmen kann, ist eine weitere Metabolisierung des AdoHCy erforderlich. Hierfür gibt es drei verschiedene Wege. Zum einen kann es zu Cys abgebaut werden, zum anderen intrazellulär an spezifische Zellproteine binden. Sind diese beiden Möglichkeiten ausgeschöpft, muss das AdoHCy aus der Zelle ausgeschleust werden. Aus der extrazellulären Flüssigkeit kann die Exkretion über die Nieren erfolgen (FINKELSTEIN, 1998).

Die weitere Umsetzung von HCy ist auf zwei Wegen möglich. Der Weg zum Cys erfolgt zunächst über eine Cystathionin- $\beta$-Synthase zu Cystathionin und weiter über Cystathionin- $\gamma-$ Lyase zu Cys. Diese Prozesse können grundsätzlich im Leber-, Nieren-, Darm- und Pankreasgewebe ablaufen und sind irreversibel (BROSNAN und BROSNAN, 2006). Die stattfindende Transsulfurierung bedeutet faktisch den Katabolismus des Met (STIPANUK, 1986). Vitamin B6 dient hierfür als wichtiger Cofaktor (FANG et al., 2002). Andererseits ist ausgehend vom HCy eine Remethylierung zu Met möglich. Diese erfolgt entweder über eine Folsäure- und Vitamin B12-abhängige Met-Synthase oder durch Betain-HCyMethyltransferase (PILLAI et al., 2006). Das Enzym Met-Synthase kommt in allen Geweben vor, die Betain-HCy-Methyltransferase dagegen nur in Leber und Niere (BROSNAN und BROSNAN, 2006). Der vorherrschende Weg der Remethylierung von HCy ist in dem Weg über die Met-Synthase zu sehen. Beim Geflügel ist jedoch in Anbetracht des erhöhten CysBedarfes bisher unklar, in welchem Umfang HCy überhaupt remethyliert wird (PILLAI et al., 2006). Für eine bedarfsangepasste Cys-Bereitstellung ist die metabolische Verfügbarkeit von Glycin (Gly) oder Serin (Ser) von entscheidender Bedeutung, da Met nur einen Teil des CysMoleküls liefert (DU VIGNEAUD et al., 1944). Das Kohlenstoffskelett des Cys wird von Ser bereitgestellt (DEWITT STETTEN, 1942). Bei ausreichender metabolischer Verfügbarkeit von Met, Gly oder Ser kann die Bereitstellung von Cys gesteigert werden (POWELL et al., 2011). Abbildung 7 zeigt in einem vereinfachenden Schema die Hauptschritte der metabolischen Überführung von Met in Cys. Eine ausführliche Darstellung findet sich u. a. bei STIPANUK (2004).

Neben der bedarfsgerechten Cys-Bereitstellung für die Körperproteinsynthese ist eine Reihe weiterer Umsetzungen des Cys möglich: Cys kann durch Dioxygenase zu Alanin-3-Sulfonat oxidiert werden, dessen Decarboxylierung Hypotaurin liefern kann. Durch eine 
Transaminierung entsteht 3-Sulfinylpyruvat. Hypotaurin kann weiter zu Taurin sowie 3Sulfinylpyruvat zu Sulfat und Pyruvat oxidiert werden (KRIJGSHELD et al., 1981). Taurin schützt die Zellen vor oxidativem Stress und ist wichtiger Bestandteil von konjugierten Gallensäuren im Prozess der intestinalen Fettemulgierung (VESSEY, 1978; ZHANG et al., 2004). Das ebenfalls entstehende Glutathion kommt vorwiegend im Cytosol der Zellen vor (HANDY et al., 2006). Es spielt eine wichtige Rolle bei der Eliminierung von Peroxiden und freien Radikalen. Darüber hinaus ist es über die Aktivierung von T-Lymphozyten an der Auslösung von Immunreaktionen beteiligt (DU VIGNEAUD, 1952; MEISTER, 1981; WANG et al., 1997; WU et al., 2004).

Der Stoffwechsel von Met und Cys steht im engen Zusammenhang zur Vitaminversorgung. So werden nicht nur die Vitamine B12, B6 und Folsäure für die Remethylierung und Transsulfurierung benötigt, sondern die Met-Synthase spielt auch eine wichtige Rolle bei der Assimilation von Folsäure in den Zellen. Reguliert wird der Stoffwechsel von Met und Cys entweder durch allosterische Regulation über SAM oder aber durch eine Regulation der Expression beteiligter Enzymsysteme (BROSNAN und BROSNAN, 2006). Bei Labortieren modulierte der Protein- oder Met-Gehalt im Mischfutter die Expression von diversen am MetStoffwechsel beteiligten Enzymen (FINKELSTEIN, 1998).

Sowohl Met als auch Cys sind außerdem von Bedeutung für das Immunsystem. So konnte ihr stimulierender Einfluss auf die IgG-Gehalte im Blut nach Met-Ausgleich in einem Metdefizitären Mischfutter gezeigt werden (TSIAGBE et al., 1987a). Zudem ist Cys für die Synthese von Coenzym A erforderlich und dient als Akzeptor von Selen für die Synthese von Enzymen und Selenoproteinen (BAKER, 2006). 


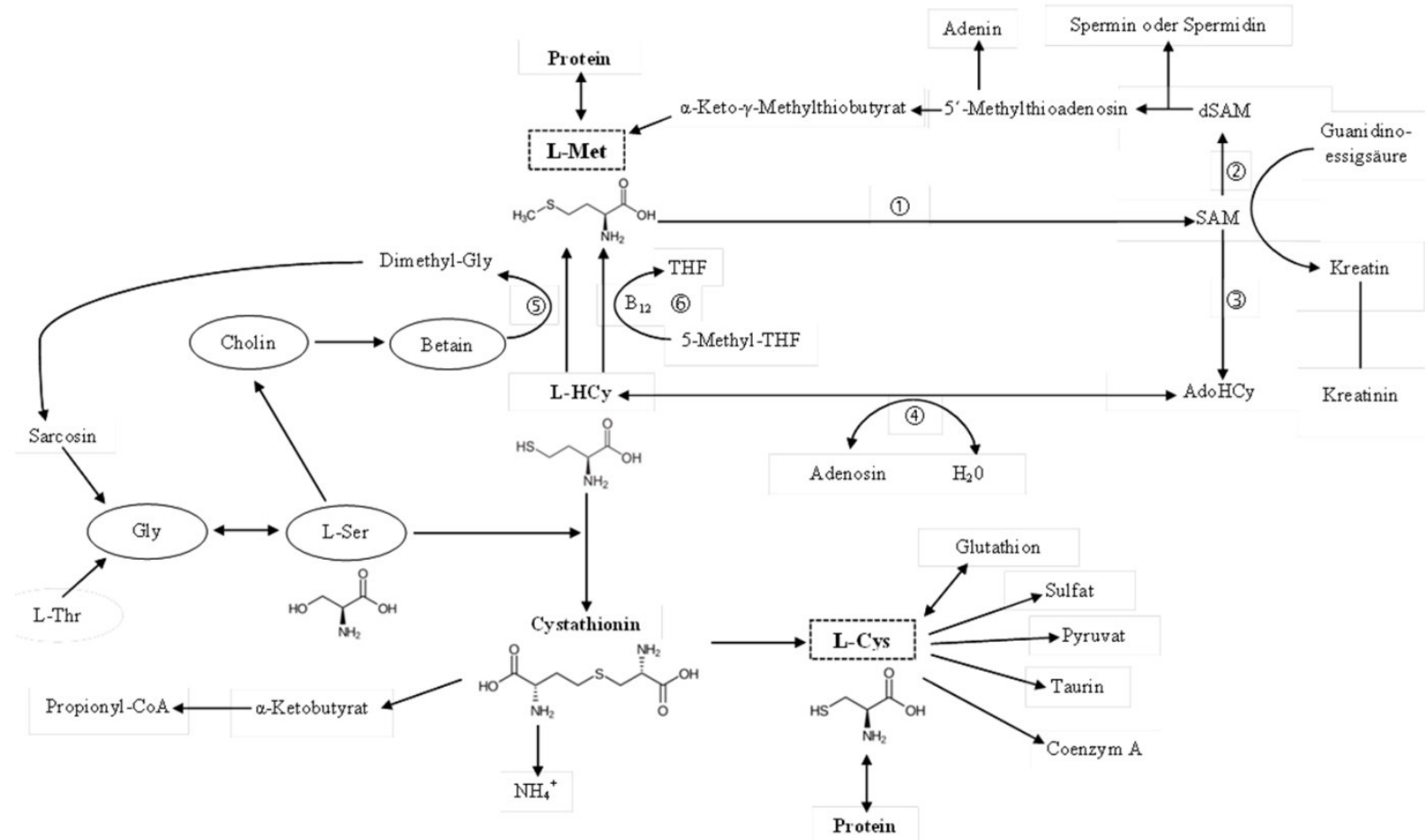

Abbildung 7: Wichtige Stoffwechselwege bei der Umsetzung von L-Methionin (1) MetAdenosyltransferase, (2) S-Adenosylmethionin-Decarboxylase ,(3) Methyltransferasen, (4) Adenosylhomocystein-Hydrolase, (5) Betain-Homocystein-Methyltransferase, (6) Met-Synthase; L-Met = L-Methionin, Gly = Glycin, THF = Tetrahydrofolat, $\mathrm{SAM}=\mathrm{S}$-Adenosylmethionin,$\quad \mathrm{dSAM}=$ decarboxyliertes $\quad \mathrm{SAM}, \quad \mathrm{AdoHCy}=\mathrm{S}-$ Adenosylhomocystein, $\mathrm{HCy}=$ Homocystein, $\mathrm{L}-\mathrm{Ser}=\mathrm{L}-\mathrm{Serin}, \mathrm{L}-\mathrm{Cys}=\mathrm{L}-\mathrm{Cystein})$

Figure 7: Important metabolic pathways of methionine metabolism (1) Met-Adenosyltransferase, (2) S-Adenosylmethionine-Decarboxylase,

(4) Adenosylhomocysteine-Hydrolase,

(3) Methyltransferase, Met-Synthase; $\quad$ L-Met $=$ L-Methionine,$\quad$ Gly $=$ Glycin, THF $=$ Tetrahydrofolate, $S A M=S$-Adenosylmethionine,$\quad d S A M=$ decarboxylated $\quad S A M, \quad$ AdoHCy $=S$ Adenosylhomocysteine, $H C y=$ Homocysteine, $L$-Ser $=L$-Serine, $L$-Cys $=L$-Cysteine)

\subsection{WECHSELWIRKUNGEN IM STOFFWECHSEL VON MET UND CYS}

Aufgrund der engen metabolischen Beziehungen zwischen Met und Cys besteht ein grundsätzliches wissenschaftliches und praktisches Interesse an der Klärung der Frage, ob der gezielte Abbau von Met zur Bereitstellung von Cys dann minimiert werden kann, wenn optimale Verhältnisse beider AS im Futter eingestellt werden. Deshalb ist in dieser Frage ein wichtiger Ansatzpunkt früherer, aber auch aktueller Forschung, zu sehen. Bereits WOMACK und ROSE (1941) stellten fest, dass bei sub-optimaler Met-Versorgung Cys-Zulagen das Wachstum von Ratten steigerten, wobei der Cys-Anteil im Futter etwa $63 \%$ der SAS entsprach. Zugleich erwiesen sich Zulagen an Cys oder HCy als nicht geeignet, um einen Met-Mangel auszugleichen (KLOSE und ALMQUIST, 1941). EGGUM (1973) setzte sich mit dieser Problematik umfassend auseinander und verwies in Anbetracht der unterschiedlichen Literaturbefunde (SHELTON et al., 1951; BECKER et al., 1955; RAO et al., 1961; BAKER et al., 1969) auf Einflüsse der Versuchsmethodik sowie der unterschiedlichen Beachtung von 
weiteren Methylgruppenlieferanten wie Cholin und Betain sowie die Versorgungslage mit Vitamin B12. Doch selbst in den umfangreichen Studien an der Laborratte mit wechselnden Met:Cys-Verhältnissen in Soja- oder Kasein-basierten Diäten konnte keine endgültige Klärung herbeigeführt werden (EGGUM, 1973). In Kasein-Diäten waren mit einem Cys-Anteil oberhalb von $37 \%$ an den SAS keine Proteinqualitätsverbesserungen nachweisbar.

Demnach stellen sich Untersuchungsbefunde zum optimalen Met:Cys-Verhältnis als sehr heterogen dar. Bei Masthähnchen beobachteten FEATHERSTON und ROGLER (1978) nach Cys-Zulagen zu einem Met-defizitären Mischfutter mit $58 \%$ Cys an den SAS sogar einen signifikanten Wachstumsrückgang, der allerdings auch mit einer verminderten Futteraufnahme, wie bei Cys-Anteilen von über $50 \%$ der SAS beobachtet (SELL et al., 1980; DILGER und BAKER, 2007), einhergehen kann.

Nach GRABER et al. (1971a) kann der Anteil von Cys bis zu 56 \%, 65 \% bzw. 67 \% (2., 5. bzw. 8. Lebenswoche) der SAS im Broilermastfutter betragen. WHEELER und LATSHAW (1981) kamen altersabhängig mit maximal $54 \%$ (Starterperiode) bzw. 38-43\% (Growerperiode) Cys-Anteil an den SAS zu einem gegenteiligen Befund. Das NRC (1994) empfiehlt für Masthähnchen in den ersten drei Lebenswochen einen Cys-Anteil von $43 \%$ der SAS, der in den darauffolgenden Wochen auf $47 \%$ erhöht werden sollte. Sowohl BAKER et al. (1996) als auch POWELL et al. (2011) schlugen vor, dass Met und Cys zu jeweils $50 \%$ im Broilermastfutter vertreten sein sollten. Hierin einzuordnen sind auch die Befunde von KHAN et al. (2015a), wonach Cys-Anteile zwischen $46 \%$ und $51 \%$ der Gesamtsumme an SAS keinen signifikanten Einfluss auf die Futterproteinqualität und Met-Wirksamkeit hatten. Neuere Ergebnisse (SÜNDER et al., 2015a) sprechen für einen Cys-Anteil von über $50 \%$, da die MetWirksamkeit im Masthähnchenfutter bei geringeren Cys-Anteilen $(\leq 46 \%)$ signifikant abfiel. Ergebnisse von FARKE et al. (2010), die bei einem Anteil von $59 \%$ Cys die höchste MetWirksamkeit im Growerfutter erbrachten, bestätigen diese Schlussfolgerung. Für Schweine ergab sich nach Einsatz halbsynthetischer Mischungen ein optimaler Cys-Anteil an den SAS von $70 \%$ (MITCHELL et al., 1968).

Die hier benannten, zum Teil sehr widersprüchlichen Befunde bezüglich des optimalen CysAnteils an den SAS im Broilerfutter müssen unbedingt unter Berücksichtigung der absoluten Met- und Cys-Gehalte (OHTA und ISHIBASHI, 1994; SÜNDER et al., 2015a,b; WECKE et al., 2015b) einschließlich deren Verdaulichkeit bzw. Verfügbarkeit (siehe 2.4) sowie des Alters der Tiere (Anteil Federkleid am Gesamtkörper; siehe 2.1) weiter verifiziert werden. Eine Optimierung der Met-Wirksamkeit durch eine angemessene Cys-Versorgung stand als Zielgröße bislang nur in wenigen Studien im Mittelpunkt des Interesses.

Weiterhin ist darauf hinzuweisen, dass das optimale Met:Cys-Verhältnis auch durch die Versorgung der Tiere mit anderen S-haltigen Verbindungen beeinflusst werden kann. In Versuchen von SASSE und BAKER (1974) lag der optimale Cys-Anteil in der positiven Kontrollmischung bei $54 \%$. Wurde zu dieser Mischung sowie zu einer SAS-defizitären Mischung $\mathrm{K}_{2} \mathrm{SO}_{4}$ supplementiert, konnte der Cys-Anteil an den SAS auf $48 \%$ bzw. bis zu $41 \%$ reduziert werden. Nicht zuletzt muss möglichen Wechselwirkungen mit weiteren Methylgruppenlieferanten (vgl. Abb. 7) verstärkt Beachtung geschenkt werden.

\subsection{WECHSELWIRKUNGEN MIT CHOLIN, BETAIN, SERIN UND GLYCIN}

Ebenso wie Met sind auch Cholin und Betain (N,N,N,-Trimethylglycerin) potenzielle Methylgruppenlieferanten (BUNCHASAK, 2009). Deshalb stellt sich grundsätzlich die Frage, ob und in welchem Umfang der metabolische Verbrauch von Met durch das parallele Angebot 
von Cholin bzw. Betain als alternative Lieferanten für Methylgruppen gesenkt und damit die Met-Bioverfügbarkeit für die Proteinsynthese im Körper erhöht werden kann.

Cholin ist aktuell als vitaminähnliche Substanz klassifiziert, wurde aber in der Vergangenheit auch den B-Vitaminen zugerechnet (HOLLENBECK, 2012). Wesentliche Mengen sind in Ölsamen und Futtermitteln tierischen Ursprungs enthalten (FULLER, 2004). Cholin ist an der Synthese von Phospholipiden sowie des Neurotransmitters Acetylcholin beteiligt (ZEISEL, 1992), ebenso an der Remethylierung von HCy zu Met (siehe Abb. 7). Darüber hinaus kommt Cholin eine wichtige Rolle im Fettstoffwechsel zu (QUILLIN et al., 1961). Als lipotroper Faktor senkt Cholin den Gehalt an Glycerin und Sterylestern in der Leber (BEST et al., 1946) und wirkt so einer Leberverfettung entgegen (MC HENRY und PATTERSON, 1944). Bei der Oxidation von Cholin kann über die Zwischenstufe Betainaldehyd letztlich Betain bereitgestellt werden (KIDD et al., 1997).

Cholin-Zulagen zu Met-defizitären Mischfuttermitteln zeigten bei Masthähnchen häufig signifikante Effekte auf Wachstum und Futteraufwand (QUILLIN et al., 1961; PESTI et al., 1979; BAKER et al., 1982; TSIAGBE et al., 1987b), die grundsätzlich für eine MetSparwirkung sprechen. Im Vergleich zu einer Met-Supplementation waren die Zulageeffekte jedoch geringer. PILLAI et al. (2006) sowie RAFEEQ et al. (2011) konnten bei einer CholinZulage zu einem Met-defizitären Mischfutter für Broiler dagegen keinen Effekt feststellen. Bei bedarfsdeckender Versorgung mit SAS blieb ein höheres Cholin-Angebot erwartungsgemäß wirkungslos (WALDROUP und FRITTS, 2005; WALDROUP et al., 2006). Andererseits konnte bei adäquater Met-Versorgung trotz Cholin-Zulage eine gesteigerte Aktivität der MetAdenosyltransferase beobachtet werden (SAUNDERSON und MACKINLEY, 1990). Dies spricht eher für einen erhöhten Met-Abbau, der ggf. mit der vergleichsweise stärkeren Limitierung des Cys-Angebotes (0,30 \% im Mischfutter) erklärt werden kann. Zugleich war die Aktivität der Cholin-Oxidase in der Leber erhöht, was auf eine vermehrte Cholinoxidation zu Betain hinweisen könnte.

Kombinierte Zulagen von Cholin und HCy (KLOSE und ALMQUIST, 1941) bzw. HCy und Betain (STEKOL et al., 1953) zeigten bei Broilern im Met-Mangel positive Effekte auf das Wachstum. Der Einsatz von Cholin und Betain bei adäquater SAS-Versorgung führte dagegen nur zu schwach ausgeprägten, weitgehend ungerichteten Effekten (WALDROUP und FRITTS, 2005). Betain soll als Lieferant für Methylgruppen bis zu $50 \%$ des Cholins in einem Geflügelfutter ersetzen können (METZLER-ZEBELI et al., 2009). Das Trimethylglycin basiert auf dem C-Skelett von Gly und kann metabolisch auch durch den oxidativen Abbau von Cholin bereitgestellt werden (vgl. Abb. 7). Betain ist am Fettstoffwechsel sowie an der zellulären Osmoregulation beteiligt (RATRIYANTO et al., 2009). So hemmt Betain die Transkription einiger an der Lipogenese beteiligten Gene (XING et al., 2011) und schützt Dünndarmepithelien durch Begrenzung des Wasseraustausches vor osmotischem Stress (KETTUNEN et al., 2001).

Während die Zulage von Betain zu einem Met-defizitären Masthähnchenfutter in einigen Versuchen positive Effekte auf Wachstum und Futterverwertung zeigte (PESTI et al., 1979; VIRTANEN und ROSI, 1995; SCHUTTE et al., 1997; GARCIA-NETO et al., 2000; ATTIA et al., 2006; ZHAN et al., 2006; RAFEEQ et al., 2011), konnten andere Autoren trotz defizitärer Met-Versorgung keine signifikanten Wirkungen feststellen (ROSTANGO und PACK, 1996; ESTEVE-GARCIA und MACK, 2000; PILLAI et al., 2006). GARCIA-NETO et al. (2000) verglichen den Effekt einer Met- und einer Betain-Supplementation zu einem Met-defizienten Mischfutter für Broiler und stellten deutliche Vorteile der Met-Zulage bezogen auf das 
Wachstum, die Futterverwertung sowie den Fettanteil im Tierkörper fest. Analog zum Cholin ist die Frage von grundsätzlicher Bedeutung, ob positive Effekte einer Zulage von Betain auch in Mischfuttermitteln mit adäquater Versorgungslage an SAS zu beobachten sind, oder ob diese auf den Bereich suboptimaler Met+Cys Versorgung beschränkt bleiben. KHAN et al. (2015a) konnten trotz suboptimaler Versorgung mit Met+Cys keinen Effekt einer Betain-Zulage auf die Futterproteinqualität und Met-Wirksamkeit nachweisen. Allerdings lag in diesen Untersuchungen mit einem Cys:Met-Verhältnis von 51:49 ein vergleichsweise komfortables Cys-Angebot vor. Dieser wichtige Faktor findet in der Mehrzahl der Studien bislang unzureichend Beachtung. Eine effiziente Nutzung des Methylgruppendonators Betain setzt zudem das Vorhandensein von HCy voraus (STEKOL et al., 1953).

Erwartungsgemäß blieben Betain-Zulagen bei ausreichender Versorgung mit SAS weitgehend wirkungslos (MC DEVITT et al., 1999; WALDROUP und FRITTS, 2005; WALDROUP et al., 2006). Allerdings beobachteten MC DEVITT et al. (2000) sowie WALDROUP et al. (2006) auch unter diesen Bedingungen ein forcierteres Brustmuskelwachstum durch Betain-Zulagen. MC DEVITT et al. (1999) machten diese Beobachtung bereits bei Met-defizitärer Versorgungslage. Zwar konnte dieser Befund von ESTEVE-GARCIA und MACK (2000) nicht unmittelbar bestätigt werden, eine verbesserte Schlachtleistung deutete jedoch darauf hin. RATRIYANTO et al. (2009) fanden bei Betain-Zulage einen geringeren Fettgehalt im Schlachtkörper von Broilern, wofür in Anlehnung an XING et al. (2011) eine geringere Lipogenese bzw. Veränderungen der $\beta$-Oxidation als mögliche Ursachen diskutiert wurden (LENG et al., 2016).

Bei Met-defizitärer Versorgung und zusätzlicher Belastung durch eine Kokzidieninfektion bewirkten Betain-Zulagen weniger infektionsbedingte Läsionen im Duodenum und Jejunum sowie positive Effekte auf Verdaulichkeits- und Futteraufwandsparameter (AMERAH und RAVINDRAN, 2015). Zudem ergaben sich Hinweise auf eine mögliche Beeinflussung des hormonellen Status durch Betain-Zulagen. Insbesondere für das Wachstumshormon und den insulinähnlichen Wachstumsfaktor 1 konnten sowohl beim Schwein (YU et al., 2001; HUANG et al., 2006, 2007) als auch bei der Legehenne (CHOE et al., 2010) erhöhte Werte beobachtet werden, wenn Betain ergänzt wurde. PARK et al. (2006) stellten zudem erhöhte Gehalte an Melatonin und Östradiol im Serum von Legehennen fest. Hinsichtlich der zugrundeliegenden Mechanismen besteht noch Klärungsbedarf.

Ser ist an der irreversiblen Überführung von HCy über Cystathionin zu Cys beteiligt (POWELL et al., 2009), wobei die Ser-Bereitstellung auch aus Gly erfolgen kann (vgl. Abb. 7). Damit bestehen zugleich Beziehungen zum irreversiblen Thr-Abbau, der in der Praxis sicher nicht zu favorisieren ist, grundsätzlich aber Gly liefern kann. Somit ist das Angebot dieser Proteinbausteine als eine weitere Einflussgröße im Stoffwechsel der SAS zu betrachten.

Zulagen an Gly zeigten bei Broilerküken (0-18 d) mit suboptimalem Cys-Angebot positive Effekte auf die Futtereffizienz (POWELL et al., 2011). Eine Begrenzung der metabolischen Überführung von Met in Cys durch das Gly-Angebot könnte hier vorgelegen haben (POWELL et al., 2009). Suboptimale Cys-Gehalte und zu geringe Cys-Anteile an den SAS führen zu einem erhöhten Bedarf an Gly-Äquivalenten (SIEGERT et al., 2015), die grundsätzlich über Gly und/oder Ser aus der Hydroxymethylierung von Gly bereitgestellt werden können. Bei Masthähnchen wurden positive Effekte der Zulage von Gly-Äquivalenten auch hinsichtlich der intestinalen Mikrostruktur und Funktion der Mukosa (z. B. erhöhte Muzinsekretion) in Verbindung mit einer günstigeren Nährstoffverwertung bei suboptimaler Cys-Versorgung beobachtet (OSPINA-ROJAS et al., 2013). 


\section{DECKUNG DES BEDARFS AN S-HALTIGEN AMINOSÄUREN}

\subsection{BEWERTUNGSMETHODEN}

Grundsätzlich stehen auch zur SAS-Bedarfsableitung faktorielle Methoden und DosisWirkungs-Studien zur Verfügung. Eine umfassende Bewertung der Vor- und Nachteile diverser methodischer Ansätze, die als Kriterium der Wirkung im Stoffwechsel auch Messungen der AS-Oxidation in Abhängigkeit vom Versorgungsgrad zum Gegenstand haben können, ist im vorliegenden Rahmen nicht möglich.

Das faktorielle Vorgehen erfordert zuverlässige Daten zum Erhaltungs- und Nettobedarf (Ansatz von Körperprotein und Federn) sowie verallgemeinerungsfähige Wirkungsgrade für diesen Protein- bzw. AS-Ansatz. Dosis-Wirkungs-Studien nach der überwiegend angewandten Supplementationsmethode beschreiben den funktionalen Zusammenhang zwischen gestaffelter Zufuhr der AS, ausgehend von klaren Limitierungsbedingungen bis zu bedarfsüberschreitenden Gaben, und dem jeweiligen Wirkungs-Kriterium. Letzteres kann u. a. durch einfache zootechnische Parameter (Zunahmen, gain:feed) oder aber auch den tatsächlichen Nährstoffansatz im Tier definiert sein. Festzustellen ist, dass sich bei diesem Vorgehen der Anteil von freier zu proteingebundener AS mit jeder Zulagestufe verändert und zudem teilweise starke Imbalancen in der AS-Versorgung (Mangel versus Überschuss) in Kauf genommen werden müssen. Da für die gestaffelt zugesetzte kristalline AS eine $100 \%$ ige Absorption bis zum Dünndarmende unterstellt wird, ergeben sich zwangsläufig inkonsistente Verdaulichkeitswerte auf der Dosisachse. Die Zusammenhänge zwischen Dosis und Wirkung werden gegenwärtig i. d. R. durch nichtlineare Funktionen abgebildet und schließlich als Abszissenwert für eine dosisabhängig erzielte Wirkungshöhe aus einer dosisabhängigen Wirkungskurve ein Bedarfswert, in der Regel als Bedarfskonzentration im Futter, abgeleitet. Eine experimentelle Überprüfung und methodische Bewertung dieses Vorgehens findet sich bei SAMADI et al. (2017).

Im Gegensatz dazu werden bei Anwendung von Grundsätzen der Verdünnungsmethode (GOUS und MORRIS, 1985) abgestufte Gehalte der limitierenden AS (LAS) in den Versuchsmischungen unter Beibehaltung der Mischungsverhältnisse der Proteinträger ausgehend von einem proteinreichen Mischfutter durch schrittweise „Verdünnung“ mit einer proteinfreien Komponente (z. B. Getreidestärke) erreicht. Gemessen wird demzufolge immer die Wirkung der jeweiligen AS in proteingebundener nativer Form. Im Vergleich zur Supplementationsmethode liefert dieses Vorgehen stärker abgesicherte Schätzwerte (MORRIS et al., 1999). Als validierter methodischer Ansatz, der auf dem Wege der Modellierung die ASWirksamkeitsbewertung mit der AS-Bedarfsableitung für gestaffelte Leistungsziele verbinden kann, gilt das „Göttinger Modell“ (z. B. LIEBERT und WECKE, 2006; PASTOR et al., 2013; BONATO et al., 2015; KHAN et al., 2015b; LIEBERT 2015; WECKE et al., 2016; SAMADI et al., 2017).

\subsection{VERSORGUNGSEMPFEHLUNGEN}

Die Versorgungsempfehlungen des NRC (1994) und der GfE (1999) für SAS im Broilermastfutter werden in Tabelle 6 vergleichend dargestellt. Tendenziell liegen die NRCEmpfehlungen für Broiler im Alter von bis zu drei Lebenswochen höher, ab der dritten Lebenswoche empfiehlt die GfE (1999) höhere SAS-Gehalte im Futter. Da letztere für jede einzelne Lebenswoche Empfehlungen gibt und zudem zwischen männlichen und weiblichen Tieren unterscheidet, sind in diesem Fall Schwankungsbreiten angegeben. 
Tabelle 6: Vergleich der Versorgungsempfehlungen des NRC (1994) und der GfE (1999) für die Shaltigen Aminosäuren im Broilermastfutter (Angaben in \% der TM)

Table 6: $\quad$ Comparison of recommendations of NRC (1994) and GfE (1999) for sulfur-containing amino acids in diets for growing chickens (in \% of DM)

\begin{tabular}{|c|c|c|c|c|c|c|}
\hline \multirow[b]{2}{*}{$\begin{array}{c}\text { Alter der } \\
\text { Tiere }\end{array}$} & \multicolumn{3}{|c|}{ NRC (1994) } & \multirow[b]{2}{*}{$\begin{array}{c}\mathrm{AME}_{\mathrm{N}} \\
(\mathbf{M J} / \mathbf{k g})\end{array}$} & \multicolumn{2}{|c|}{ GfE (1999) } \\
\hline & Met+Cys & $\begin{array}{r}\text { Met } \\
(\%\end{array}$ & $\begin{array}{l}\text { Cys } \\
\text { AS) }\end{array}$ & & Met+Cys & Met \\
\hline 0-3 Wochen & 1,00 & 0,56 & 44,0 & $14,0-14,8$ & $0,81-0,92$ & $0,44-0,46$ \\
\hline 3-6 Wochen & 0,80 & 0,42 & 47,5 & 14,8 & $0,82-0,96$ & $0,35-0,43$ \\
\hline 6-8 Wochen & 0,66 & 0,36 & 45,5 & 13,9 & $0,72-0,89$ & $0,31-0,38$ \\
\hline
\end{tabular}

In der Literatur sind zahlreiche Studien zur Ableitung quantitativer SAS-Bedarfswerte für das Mastgeflügel auf unterschiedlichen Betrachtungsebenen (Brutto versus verdaulich) vorhanden. Die vorliegende Übersicht kann diesen Umfang nicht in voller Breite abbilden, deshalb sollen einige Studien exemplarisch erläutert werden.

ALMQUIST (1952) fasste die bis dato ermittelten Bedarfswerte zusammen und empfahl einen Gehalt von 0,80\% Met oder 0,45\% Met plus 0,35\% Cys in einem Alleinfutter für Masthähnchen. GRABER und BAKER (1971) stellten demgegenüber fest, dass ein Gehalt von 0,52 \% Met+Cys den Bedarf wachsender Masthähnchen an SAS ebenso deckt wie 0,63\%. JENSEN et al. (1989) zogen aus Versuchen mit 3-6 Wochen alten Masthähnchen den Schluss, dass die damalige Empfehlung des NRC (1983) von 0,72 \% SAS im Mischfutter deutlich zu niedrig lag und empfahlen eine Anhebung auf 0,78\%. BAKER et al. (1996) folgerten unter Anwendung eines broken-line-Modells für den Zeitraum 21.-42. Lebenstag bei Verwendung von Mais-Erdnussschrot-Mischungen eine optimale Konzentration von 0,61\% verdauliche SAS. Nach ihrer Einschätzung war jedoch für Mais-Soja-Mischungen erst ein höherer Wert $(0,72 \%$ verdauliche SAS) adäquat. ATENCIO et al. (2004) ermittelten eine optimale Konzentration an verdaulichem SAS von $0,808 \%$ für die ersten 20 Lebenstage. In den darauffolgenden Altersabschnitten (24-38 bzw. 44-56 Tage) sollten auch niedrigere Werte ausreichen $(0,767 \%$ bzw. 0,668 \%). Einen deutlichen Alterseffekt konnten auch GOULART et al. (2011) zeigen, indem sie die prozentualen Bedarfsangaben für Broiler von 0,87 \% (1.-7. Lebenstag) auf 0,66 \% verdauliche SAS (36.-42. Lebenstag) herabsetzten.

Durch Untersuchungen von BECK et al. (1998), basierend auf Mischfuttermitteln mit 0,30\% bzw. 0,25\% Cys, die nur bei DL-Met-Zulagen einen weiteren Leistungseffekt bewirkten, wurden die Empfehlungen des NRC (1994) von 0,40 \% Cys im Mischfutter für den Abschnitt von 0-21 Tagen kritisch hinterfragt. OHTA und ISHIBASHI (1994) ermittelten in ihren Versuchen einen SAS-Bedarf wachsender Broiler im Alter von 8-14 Tagen von 0,66 \%, der zu $55 \%$ von Cys gedeckt werden sollte. In Abhängigkeit vom Alter empfahl MORAN (1981) CysAnteile von $47 \%$ (1.-2. Lebenswoche) bzw. $59 \%$ (5.-7. Lebenswoche). SÜNDER et al. (2015b) wiesen auf die begrenzte Datenlage zum optimalen Cys-Anteil hin und untersuchten an Broilern Mischfuttermittel mit variablen Met:Cys-Relationen. Im Ergebnis konnte für einen Cys-Anteil größer $50 \%$ (Met:Cys = 48:52) eine Met-Sparwirkung festgestellt werden. KHAN et al. (2015a) fanden dagegen keine Verbesserung der mit dem „Göttinger Modell“" abgeleiteten Met-Wirksamkeit bei Anteilen von $\geq 50 \%$ Cys an der Gesamtsumme der SAS. 
Generell zeigt sich damit, dass insbesondere die Rolle des relativen Cys-Anteils mit großen Unsicherheiten für aktuelle Versorgungsempfehlungen verbunden ist. Auch neuere Untersuchungen (z.B. GOLSHAHI et al., 2013; BONATO et al., 2015; FALUYI et al., 2015; SHAKOURI und MALEKZADEH, 2016; OPOOLA et al., 2016; AKHAVAN KHALEGHI et al., 2016) erbrachten hierzu keine weitere systematische Aufklärung.

\subsubsection{DAS IAAR KONZEPT}

Die Suche nach einem ,idealen Protein“ als Referenz beschäftigt Ernährungswissenschaftler bereits seit Mitte des letzten Jahrhunderts (z. B. ALMQUIST und GRAU, 1944; OSER, 1951; DEAN und SCOTT, 1965). In seiner heutigen Form wurde das Idealproteinkonzept auf der Grundlage „Idealer AS-Verhältnisse“ (engl.: ideal amino acid ratio, IAAR) erstmals von COLE (1980) für die Schweineernährung empfohlen. Für die Geflügelernährung wird es derzeit beständig weiterentwickelt. Das Konzept beruht auf einer möglichst idealen Balance der AS im Futterprotein, gemessen an den Bedarfsrelationen (DOZIER und MERCIER, 2013), wobei Lys als Referenz-AS dient. Lys eignet sich insbesondere, da es häufig als LAS in Erscheinung tritt, zuverlässig zu analysieren ist, fundierte Bedarfswerte vorliegen und überwiegend für den Proteinansatz genutzt wird (BAKER und HAN, 1994; EMMERT und BAKER, 1997; MACK et al., 1999). Von Vorteil ist weiterhin, dass die AS-Bedarfsrelationen im Gegensatz zu quantitativen Bedarfswerten nicht durch Veränderungen im Energie- oder Proteinniveau des Mischfutters verändert werden (DOZIER und MERCIER, 2013). Es ist davon auszugehen, dass das IAAR für Masthähnchen weder vom Genotyp noch vom Geschlecht beeinflusst wird (BAKER und HAN, 1994), wenngleich altersbedingte Unterschiede für einzelne AS, insbesondere für die SAS, aufgrund ihrer unterschiedlichen Bedeutung im Erhaltungs- und Leistungsstoffwechsel nicht ausgeschlossen werden können (BAKER, 2003; s. auch 4.2.2). Vorschläge zum IAAR in der Masthähnchenernährung liegen in größerem Umfang vor (u.a. BAKER und HAN, 1994; MACK et al., 1999; BAKER et al., 2002; BAKER 2003; GOULART et al., 2011; SALEHIFAR et al., 2012; PASTOR et al., 2013; WECKE und LIEBERT, 2013a; WECKE et al., 2013).

Tabelle 7 vermittelt einen Überblick über die idealen Verhältnisse der SAS zu Lys. Es ist erkennbar, dass sich die Angaben in Abhängigkeit von Alter, AS-Bewertungsebene und methodischer Vorgehensweise zum Teil erheblich unterscheiden. Selbst zwischen den Versorgungsempfehlungen des NRC (1994) und der GfE (1999) bestehen beachtliche Diskrepanzen, insbesondere im Hinblick auf den altersbedingten Verlauf. Das von DORIGAM et al. (2015) für adultes Geflügel nachgewiesene sehr weite Verhältnis von Met:Lys unterstreicht die wichtige Rolle von Met im Erhaltungsstoffwechsel. All diese Einflussgrößen erschweren einen direkten und uneingeschränkten Vergleich der abgeleiteten idealen ASVerhältnisse. Auch an dieser Stelle ist zu betonen, dass eine stärkere Vereinheitlichung und Validierung methodischer Ansätze als wesentliche Vorbedingung für zuverlässige ASVersorgungsempfehlungen, insbesondere hinsichtlich des Met:Cys-Verhältnisses, beitragen könnte. 


\subsubsection{EINFLUSSFAKTOREN}

Wie bereits an anderer Stelle (WECKE und LIEBERT, 2013a; KHAN et al., 2015a; WECKE et al., 2016; SAMADI et al., 2017) umfassend diskutiert, sind die publizierten Bedarfswerte nur bedingt vergleichbar, da sie unter sehr verschiedenen Bedingungen ermittelt wurden. Im Hinblick auf den erreichten züchterischen Fortschritt (HAVENSTEIN et al., 2003; SCHMIDT et al., 2009) sind tierspezifische Effekte wie Genotyp, Geschlecht, Alter bzw. Lebendmasse und Leistungsvermögen (Lebendmassezunahme, Proteinansatz) bei der Bewertung von ASBedarfsangaben zu berücksichtigen. Da der quantitative AS-Bedarf ganz wesentlich von der Leistungshöhe abhängt, ist es unbedingt erforderlich, stets einen Bezug sowohl zur Leistung als auch zum Futterverzehr herzustellen (SAMADI und LIEBERT, 2007; KHAN et al., 2015a, b; LIEBERT, 2015; WECKE et al., 2016; SAMADI et al., 2017). Letzteres ist die entscheidende Voraussetzung für die Ableitung von bedarfsdeckenden Konzentrationen im Futter. Für die SAS gelten diese Erfordernisse im besonderen Maße, da wechselnde Relationen zwischen dem Leistungs- und Erhaltungsanteil auf Grund steigender relativer Bedeutung der SAS im Erhaltungsumsatz (DORIGAM et al., 2015) modulierend wirken.

Weiterhin zu beachten sind Rohstoffzusammensetzung, Proteingehalt der Mischung, ASBalance und die Gesamtverwertung der aufgenommenen AS sowie mögliche Effekte antinutritiver Faktoren. Auch das Produktionsziel beeinflusst den Bedarf (z. B. GRABER et al., 1971b; SCHUTTE und PACK, 1995; PESTI et al., 1996; KNOWLES und SOUTHERN, 1998; GOULART et al., 2011). Bei vergleichenden Betrachtungen sind zudem methodische Fragen des Vorgehens zu analysieren, da auch in diesem Bereich Ursachen für deutlich abweichende Ergebnisse liegen können (vergl. 4.1). Untersuchungen zu diesem Thema finden sich unter anderem bei ROBBINS et al. (1979), BAKER (1986), RODEHUTSCORD und PACK (1999), VEDENOV und PESTI (2008), SAKI et al. (2012) sowie SAKOMURA et al. (2015). 
Publikation I

Schwefelhaltige Aminosäuren beim Mastgeflügel

Übers. Tierernährg. 43 (2018), 1-52

Tabelle 7: $\quad$ Empfehlungen zum idealen Verhältnis der S-haltigen Aminosäuren zu Lysin (Lys = 100) bei Masthähnchen

Table 7: $\quad$ Recommended ideal ratios of S-containing amino acids to Lysine $($ Lys $=100)$ for growing chickens

\begin{tabular}{|c|c|c|c|c|c|c|}
\hline Alter & Betrachtungsebene & Methode & Met+Cys & Met & Cys & Quelle \\
\hline $1-21 d$ & wahr verdaulich & Metaanalyse & 72 & & & $\begin{array}{l}\text { Baker und } \\
\text { Han, } 1994\end{array}$ \\
\hline $1-21 \mathrm{~d}$ & \multirow{3}{*}{ brutto } & \multirow{3}{*}{ Metaanalyse } & 82 & & & \multirow{3}{*}{$\begin{array}{c}\text { NRC, } \\
1994\end{array}$} \\
\hline $21-42 \mathrm{~d}$ & & & 72 & & & \\
\hline $42-56 \mathrm{~d}$ & & & 70 & & & \\
\hline $1-7 \mathrm{~d}$ & \multirow{8}{*}{ brutto } & \multirow{8}{*}{ Metaanalyse } & 66 & & & \multirow{8}{*}{ GfE, 1999} \\
\hline $7-14 d$ & & & 68 & & & \\
\hline $14-21 \mathrm{~d}$ & & & 78 & & & \\
\hline $21-28 \mathrm{~d}$ & & & 81 & & & \\
\hline $28-35 \mathrm{~d}$ & & & 87 & & & \\
\hline $35-42 \mathrm{~d}$ & & & 91 & & & \\
\hline $42-49 \mathrm{~d}$ & & & 94 & & & \\
\hline $49-56 \mathrm{~d}$ & & & 97 & & & \\
\hline $1-20 \mathrm{~d}$ & \multirow{3}{*}{ verdaulich } & \multirow{3}{*}{ broken-line } & 70 & & & \multirow{3}{*}{$\begin{array}{c}\text { Atencio et } \\
\text { al., } 2004\end{array}$} \\
\hline 24-38 d & & & 72 & & & \\
\hline $44-56 \mathrm{~d}$ & & & 71 & & & \\
\hline $1-7 d$ & \multirow{4}{*}{ verdaulich } & \multirow{4}{*}{ Regressionsanalyse } & 71 & & & \multirow{4}{*}{$\begin{array}{l}\text { Goulart et } \\
\text { al., } 2011\end{array}$} \\
\hline $8-21 \mathrm{~d}$ & & & 70 & & & \\
\hline $22-35 d$ & & & 76 & & & \\
\hline $36-42 \mathrm{~d}$ & & & 72 & & & \\
\hline $1-7 \mathrm{~d}$ & \multirow{3}{*}{ verdaulich } & broken-line (quadratisch) & 78 & & & \multirow{3}{*}{$\begin{array}{l}\text { Dozier und } \\
\text { Mercier, } \\
2013\end{array}$} \\
\hline $1-14 \mathrm{~d}$ & & broken-line (quadratisch) & 77 & & & \\
\hline $1-14 d$ & & broken-line (linear) & 74 & & & \\
\hline $1-35 d$ & brutto + verdaulich & Metaanalyse & 74 & 40 & & $\begin{array}{c}\text { Wecke } \\
\text { und } \\
\text { Liebert, } \\
\text { 2013a }\end{array}$ \\
\hline $0-21 \mathrm{~d}$ & \multirow{2}{*}{ wahr verdaulich } & \multirow{2}{*}{ Regressionsanalyse } & 72 & 36 & 36 & \multirow{2}{*}{$\begin{array}{c}\text { Baker, } \\
1996\end{array}$} \\
\hline $21-42 \mathrm{~d}$ & & & 75 & 36 & 39 & \\
\hline $10-20 \mathrm{~d}$ & \multirow{2}{*}{ brutto } & \multirow{2}{*}{$\begin{array}{l}\text { exponentielles } \mathrm{N}- \\
\text { Verwertungsmodell }\end{array}$} & & 39 & & \multirow{2}{*}{$\begin{array}{l}\text { Wecke et } \\
\text { al., } 2013\end{array}$} \\
\hline $25-35 \mathrm{~d}$ & & & & 40 & & \\
\hline $3-16 d$ & verdaulich & Regressionsanalyse & & 48 & & $\begin{array}{l}\text { Mehri et } \\
\text { al., } 2012\end{array}$ \\
\hline $0-21 \mathrm{~d}$ & wahr verdaulich & $\begin{array}{c}\text { Bedarfsdaten und } \\
\text { Körperzusammensetzung }\end{array}$ & & 40 & 32 & Wu, 2014 \\
\hline $10-35 \mathrm{~d}$ & brutto & $\begin{array}{c}\text { exponentielles N- } \\
\text { Verwertungsmodell } \\
\end{array}$ & & 34 & & $\begin{array}{c}\text { Khan et } \\
\text { al., 2015a }\end{array}$ \\
\hline adult & brutto & Regressionsanalyse & & 276 & & $\begin{array}{l}\text { Dorigam } \\
\text { et al., } 2015\end{array}$ \\
\hline
\end{tabular}


Zunächst wäre unter dem Aspekt Genotyp zu vermuten, dass Zeitpunkt (Phase), Geschwindigkeit und Grad der Befiederung eine deutliche Einflussgröße darstellen. Untersuchungen von KALINOWSKI et al. (2003a, b) mit Masthähnchen unterschiedlicher Befiederungs-Geschwindigkeit konnten jedoch zeigen, dass der Met-Bedarf unbeeinflusst blieb. Rascheres Federwachstum erhöhte aber den Cys-Bedarf. Der SAS-Bedarf insgesamt zeigte sich allerdings im Vergleich von konventioneller und Nackthalsgenetik kaum beeinflusst (PESTI et al., 1996; YALCIN et al., 1999; KHAN et al., 2015b). Es erscheint jedoch notwendig, diese Beobachtungen im Hinblick auf das Met:Cys-Verhältnis im Futter weiter zu spezifizieren (KHAN et al., 2015b). Der Einfluss des Genotyps auf AS-Versorgungsansprüche wird auch durch Untersuchungen belegt, bei denen die SAS nicht im Mittelpunkt standen (PLAVNIK und HURWITZ, 1982; LECLERCQ et al., 1993; ALLEMAN et al., 2000).

Tabelle 8: Empfehlungen für die Versorgung von Broilern verschiedener Genetik mit S-haltigen Aminosäuren

Table 8: $\quad$ Recommendations for the supply of broiler chicken of different genetic lines with sulphurcontaining amino acids

\begin{tabular}{|c|c|c|c|c|c|c|c|}
\hline \multirow{3}{*}{ Genetik } & \multirow{3}{*}{ Phase } & \multicolumn{4}{|c|}{ Empfohlener Gehalt im Futter } & \multicolumn{2}{|c|}{$\begin{array}{c}\text { Verhältnis zu Lysin } \\
(\mathbf{1 0 0})\end{array}$} \\
\hline & & \multicolumn{2}{|c|}{ Met+Cys $(\%)$} & \multicolumn{2}{|c|}{$\operatorname{Met}(\%)$} & \multirow{2}{*}{ Met+Cys } & \multirow{2}{*}{ Met } \\
\hline & & total & verdaulich & total & verdaulich & & \\
\hline \multirow{5}{*}{$\begin{array}{c}\text { Arbor } \\
\text { Acres, Ross } \\
308 \& 708^{1}\end{array}$} & $0-10 d$ & 1,08 & 0,95 & 0,56 & 0,51 & 75 & 39 \\
\hline & $11-24 d$ & 0,99 & 0,87 & 0,51 & 0,47 & 77 & 40 \\
\hline & $25-39 d$ & 0,90 & 0,80 & 0,47 & 0,43 & 78 & 41 \\
\hline & $40-46 d$ & 0,85 & 0,75 & 0,44 & 0,40 & 79 & 41 \\
\hline & $\begin{array}{c}47 \mathrm{~d}- \\
\text { Schlachtung }\end{array}$ & 0,82 & 0,73 & 0,42 & 0,39 & 79 & 40 \\
\hline \multirow{4}{*}{ Cobb $500^{2}$} & $0-10 d$ & 0,98 & 0,88 & 0,50 & 0,45 & 74 & 38 \\
\hline & $11-22 \mathrm{~d}$ & 0,89 & 0,80 & 0,48 & 0,42 & 75 & 40 \\
\hline & $23-42 d$ & 0,82 & 0,74 & 0,43 & 0,39 & 78 & 41 \\
\hline & $\begin{array}{c}43 \mathrm{~d}- \\
\text { Schlachtung }\end{array}$ & 0,78 & 0,70 & 0,41 & 0,37 & 78 & 41 \\
\hline
\end{tabular}

${ }^{1}$ nach AVIAGEN (2014 a, b)

${ }^{2}$ nach COBB (2015)

Wie aus Tabelle $8 \mathrm{zu}$ entnehmen ist, können SAS-Versorgungsempfehlungen für Masthähnchen unterschiedlicher Genetik zum Teil erheblich variieren. Während für die Genetik Arbor Acres, Ross 308 und Ross 708 sehr ähnliche Empfehlungen vorliegen, ordnen sich die Angaben für die Genetik Cobb 500 deutlich darunter ein. Das relative Verhältnis der SAS zu Lys ist aber von diesen Unterschieden kaum betroffen. Deshalb kann vermutet werden, dass die ausgewiesenen Konzentrationsempfehlungen im Wesentlichen auf unterschiedliche Erwartungen zur altersabhängigen Futteraufnahme zurückzuführen sind. Nach LECLERCQ et al. (1993) und MORAN (1994) können neben den vom Genotyp abhängigen Unterschieden in der Futteraufnahme auch Fragen der Partitionierung von Protein- und Fettansatz Einflussgrößen darstellen. 
Daneben gilt das Geschlecht als eine Einflussgröße. Die GfE (1999) differenziert in ihren Versorgungsempfehlungen zwischen männlichen und weiblichen Tieren. Auch aktuelle Untersuchungen konnten für weibliche Tiere einen höheren Federanteil am Gesamtkörper nachweisen, zudem bestanden im Vergleich zu den männlichen Tieren gleichen Alters signifikant höhere Met-Gehalte im Feder- und Restkörperprotein (WECKE et al., 2015a). Generell werden bei männlichen Tieren höhere Bedarfswerte erwartet. PLAVNIK und HURWITZ (1982) vermuteten als Ursache für diese Annahme die größere Wachstumsgeschwindigkeit der männlichen Tiere. Dementsprechend kamen BAKER et al. (1996) zur Empfehlung von 0,67 \% bzw. 0,64 \% verdauliche SAS im Futter für männliche bzw. weibliche Broiler in der 3.-6. Lebenswoche. CHAMRUSPOLLERT et al. (2002) konnten mit Hilfe der indirekten Oxidationsmethode jedoch keinen signifikant höheren Met-Bedarf männlicher Tiere nachweisen. Für die Kriterien Lebendmassezunahme und Brustmuskelansatz kamen LUMPKINS et al. (2007) zu einem analogen Befund.

Mit zunehmendem Alter sind grundsätzlich Veränderungen im Nährstoffbedarf zu erwarten. Ein Grund hierfür sind altersabhängige Veränderungen im Verdauungs- und Absorptionsvermögen (WALLIS und BALNAVE, 1984; BATAL und PARSONS, 2002), die durch Reifungsprozesse des Verdauungstraktes und steigende Enzymaktivitäten bedingt sind. Dennoch beobachteten ZUPRIZAL et al. (1992) eine Abnahme der Verdaulichkeit von Sojaund Rapsextraktionsschrot bei Masthähnchen oberhalb der 3. Lebenswoche. Leider ist über diese altersabhängigen Veränderungen beim Geflügel im Detail wenig Neues bekannt, es kann an dieser Stelle aber auf eine aktuelle Übersicht beim Schwein verwiesen werden (PLUSKE, 2016).

Ursache für altersabhängige Einflüsse sind neben wechselnden Relationen von Erhaltungs- und Leistungsbedarf nicht zuletzt die Veränderungen der Protein- und Fettgehalte im Gesamtkörper (PLAVNIK und HURWITZ, 1982; WECKE et al., 2017a) sowie der Körperzusammensetzung im Hinblick auf die Verteilung von Met und Cys im Federprotein bzw. im federlosen Körperprotein (WECKE et al., 2015a; WECKE und LIEBERT, 2016). Der steigende Federanteil mit zunehmendem Alter der Tiere (s. Tab. 9) und die sich verändernden Met- und Cys-Anteile im Federprotein (s. Tab. 10) unterstreichen die Bedeutung der SAS bei der Entwicklung des Federkleids. Da das intensive Federwachstum sich mit der Zeit des maximalen Ansatzes überschneidet, gilt es, dies bei der Ermittlung des AS-Bedarfs der Tiere zu berücksichtigen. 
Tabelle 9: Körper- und Federmassen sowie Federanteil wachsender Broiler in Abhängigkeit von Alter und Geschlecht (Wecke et al., 2017b)

Table 9: $\quad$ Body and feather weight data and feather percentage depending on age and gender of broiler chickens (Wecke et al., 2017b)

\begin{tabular}{|c|c|c|c|c|c|c|c|c|c|}
\hline \multirow[t]{2}{*}{ Alter (d) } & \multicolumn{3}{|c|}{$\begin{array}{c}\text { Lebendmasse } \\
\text { (g) }\end{array}$} & \multicolumn{2}{|c|}{$\begin{array}{l}\text { Leerkörper } \\
\text { (g) }\end{array}$} & \multicolumn{2}{|c|}{$\begin{array}{c}\text { Federn } \\
\text { (g) }\end{array}$} & \multicolumn{2}{|c|}{$\begin{array}{c}\text { Federanteil } \\
\text { (\% des } \\
\text { Leerkörpers) }\end{array}$} \\
\hline & & $\mathrm{m}$ & w & $\mathrm{m}$ & w & $\mathrm{m}$ & $\mathrm{w}$ & $\mathrm{m}$ & w \\
\hline 1 & & 45,1 & 46,6 & 42,0 & 43,0 & 1,4 & 1,3 & 3,34 & 2,95 \\
\hline 8 & & 180 & 195 & 154 & 170 & 2,9 & 4,3 & 1,85 & 2,54 \\
\hline 15 & & 437 & 516 & 392 & 475 & 9,7 & 16,3 & 2,38 & 3,42 \\
\hline 22 & & 952 & 1045 & 866 & 964 & 28,3 & 35,9 & 3,26 & 3,72 \\
\hline 29 & & 1749 & 1655 & 1632 & 1534 & 53,8 & 62,6 & 3,28 & 4,10 \\
\hline 36 & & 2499 & 2437 & 2305 & 2278 & 83,1 & 91,7 & 3,61 & 4,04 \\
\hline \multirow[t]{2}{*}{ Mittelwert } & & 990 & 975 & 910 & 904 & 30,3 & 35,1 & 2,97 & 3,47 \\
\hline & \multicolumn{9}{|c|}{$\underline{\text { ANOVA Signifikanzlevel }(p)}$} \\
\hline Alter (A) & \multicolumn{3}{|c|}{$<0,001$} & \multicolumn{2}{|c|}{$<0,001$} & \multicolumn{2}{|c|}{$<0,001$} & \multicolumn{2}{|c|}{$<0,001$} \\
\hline Geschlecht $(C$ & \multicolumn{3}{|c|}{0,746} & \multicolumn{2}{|c|}{0,433} & \multicolumn{2}{|c|}{$<0,001$} & \multicolumn{2}{|c|}{$<0,001$} \\
\hline$A \times G$ & \multicolumn{3}{|c|}{0,006} & & & \multicolumn{2}{|c|}{0,011} & \multicolumn{2}{|c|}{$<0,001$} \\
\hline \multicolumn{10}{|l|}{$\begin{array}{l}\mathrm{m}=\text { männlich } \\
\mathrm{w}=\text { weiblich }\end{array}$} \\
\hline & \multicolumn{9}{|c|}{$\begin{array}{l}\text { Protein- und Aminosäurengehalte in Federn männlicher Masthähnchen (Fisher et al., } \\
\text { 1981) }\end{array}$} \\
\hline Table 10: & \multicolumn{9}{|c|}{ Protein and amino acid composition of feathers from male broilers (Fisher et al., 1981) } \\
\hline \multirow{2}{*}{\multicolumn{2}{|c|}{ Alter (Wochen) }} & \multirow{2}{*}{\multicolumn{3}{|c|}{ Rohprotein $(\%)$}} & \multicolumn{5}{|c|}{ Aminosäuren (\%) } \\
\hline & & & & & Met & \multicolumn{2}{|c|}{ Met+Cys } & \multicolumn{2}{|c|}{ Lys } \\
\hline \multicolumn{2}{|l|}{1} & \multicolumn{3}{|c|}{89,92} & 0,67 & \multicolumn{2}{|r|}{11,37} & \multicolumn{2}{|c|}{2,40} \\
\hline \multicolumn{2}{|l|}{2} & \multicolumn{3}{|c|}{91,43} & 0,78 & & 13,36 & & 67 \\
\hline 3 & & & 92,10 & & 0,58 & & 15,13 & & 89 \\
\hline 4 & & & 96,30 & & 0,46 & & 14,66 & & 92 \\
\hline 5 & & & 90,00 & & 0,61 & & 12,53 & & 41 \\
\hline 6 & & & 92,60 & & 0,51 & & 14,86 & & 75 \\
\hline 7 & & & 97,60 & & 0,36 & & 11,69 & & 37 \\
\hline
\end{tabular}


Mit steigendem Alter der Tiere verändert sich jedoch nicht nur der SAS-Gehalt in den Federn, sondern auch im Ganzkörper. Tabelle 11 zeigt die SAS-Gehalte im Leerkörper von Masthähnchen in Abhängigkeit vom Alter.

Tabelle 11: SAS-Gehalte im Leerkörper von Masthähnchen in Abhängigkeit vom Alter (eigene Daten $)^{1}$

Table 11: $\quad$ Age dependent sulfur amino acid content in the carcass of broiler chicken (own data) ${ }^{l}$

\begin{tabular}{ccccccc}
\hline & \multicolumn{7}{c}{ Alter (Lebenstag) } \\
\cline { 2 - 7 } & 1 & 8 & 15 & 22 & 29 & $36^{2}$ \\
\hline Met (g/16gN) & 1,70 & 1,83 & 1,86 & 1,83 & 1,86 & 1,84 \\
Cys (g/16gN) & 1,77 & 1,38 & 1,33 & 1,42 & 1,49 & 1,58 \\
\hline
\end{tabular}

${ }^{1}$ Ross 308, Mittelwert von jeweils 3 männlichen und 3 weiblichen Tieren

235. Lebenstag bei männlichen Tieren

Für den altersabhängigen Wachstumsverlauf bei hoher Ausschöpfung des Wachstumspotenzials von Broilern folgerten GOULART et al. (2011) rückläufige Werte im Bedarf an verdaulichen SAS von 0,87 \% (1.-7. Lebenstag) über 0,71\% (8.-21. Lebenstag) und $0,75 \%$ (22.-35. Lebenstag) auf 0,66 \% (36.-42. Lebenstag). Zugleich veränderte sich das ideale relative Verhältnis der SAS zum verdaulichen Lys im Futter in den zuvor genannten Altersabschnitten (71\%; $70 \% ; 76 \% ; 72 \%$ ). Auch FARIDI et al. (2016) stellten fest, dass der Bedarf an SAS mit steigendem Alter zurückgeht. Der von LEMME et al. (2006) herausgestellte grundsätzliche Einfluss der physikalischen Form des Futters und damit letztlich der realen Höhe des Futterverzehrs auf die optimale AS-Konzentration im Futter bleibt bei der Diskussion bedarfsdeckender Konzentrationsangaben für AS überwiegend unzureichend beachtet.

Unter den relevanten Umweltfaktoren wurden insbesondere die Art der Haltung und die Raumtemperatur untersucht. Nach LUMPKINS et al. (2007) hatten Käfig- oder Bodenhaltung keinen Einfluss auf den SAS-Bedarf beim Geflügel. Für Hitzestress sind negative Effekte auf die zootechnischen Parameter von Broilern bekannt (z. B. CHENG et al., 1997b; QUINTEIROFILHO et al., 2010). Dies gilt insbesondere für die Futteraufnahme. Zusätzlich konnte gezeigt werden, dass auch die wahre AS-Verdaulichkeit von Soja- und Rapsextraktionsschrot durch Hitzestress signifikant zurückgeht (ZUPRIZAL et al., 1993). Laut ATTIA et al. (2006) lassen sich die negativen Effekte, die hohe Temperaturen auf das Wachstum und die Futterverwertung von Broilern haben, durch eine Anhebung der SAS-Konzentration im Futter abmildern. Andere Studien konnten erhöhte AS-Bedarfswerte bei hohen Temperaturen aber nicht belegen (CHENG et al., 1997a; KUBENA et al., 1972; ZARATE et al., 2003; SILVA et al., 2006). In Met-defizitären Mischfuttermitteln für Masthähnchen konnte bei Hitzestress allerdings gezeigt werden, dass Met-Zulagen die Expression der Enzyme Glutathion-Synthase, Cystathionin- $\beta$ Synthase und Glutathion-Peroxidase steigerten (DEL VESCO et al., 2015). Dies könnte unter den Bedingungen von Hitzestress (oxidativer Stress) ein Vorteil sein, da diese Enzyme eine hohe antioxidative Aktivität aufweisen. Quantitative Auswirkungen auf die notwendige MetVersorgung blieben aber gering. Ein Grund hierfür könnte eine verringerte Genexpression für proteinanabole Prozesse bei hohen Umgebungstemperaturen sein, die dazu führt, dass der Bedarf der Tiere an AS zurückgeht. 
Allerdings wurden Unterschiede in der Wirksamkeit der Verabreichungsform von Met-Zulagen berichtet. Als Ursache für die beobachtete höhere Effizienz von MHA im Vergleich zu DL-Met bei Hitzestress (WILLEMSEN et al., 2011) wird eine erleichterte Aufnahme in die Darmepithelien diskutiert (DIBNER et al., 1992). Unter tropischen Bedingungen waren unterschiedliche Effekte von MHA und DL-Met bei Masthähnchen aber nicht zu bestätigen (YODSERANEE und BUNCHASAK, 2012).

Eine weitere Besonderheit des Geflügels, die in einer nachweislichen „Umkehrperistaltik“ bei der Chymuspassage zurück bis in den Muskelmagen zu sehen ist (SACRANIE et al., 2012) und durch unterschiedliche Faktoren wie Futterstruktur und Kontinuität des Futterangebotes ausgelöst werden kann (KWAKKEL und MOQUET, 2012), ist im Hinblick auf Festlegungen zur Höhe von Versorgungsempfehlungen für AS gegenwärtig nicht abschätzbar. Eine Diskussion unter quantitativen Aspekten kann deshalb aktuell nicht erfolgen.

Eine weitere Einflussgröße auf die Höhe des AS-Bedarfes stellt der Stimulationsgrad des Immunsystems dar. Relevante Untersuchungsergebnisse zu diesen Zusammenhängen und den teilweise widersprüchlichen Befunden in Bezug zum AS-Bedarf sind aber nur punktuell vorhanden (z. B. WILLIAMS et al., 1997a, b; WEBEL et al., 1998a, b; KLASING, 2006; STAR et al., 2012; LIEBOLDT et al., 2016). Ein Met-Mangel bei Masthähnchen führte zu negativen Effekten auf zahlreiche Parameter der Immunantwort (WU et al., 2012, 2013). So waren die antioxidativen Funktionen der Milz und die Entwicklung der Bursa fabricii beeinträchtigt. Außerdem war die Anzahl der Lymphozyten in den lymphatischen Follikeln der Bursa fabricii signifikant verringert. Eine Hemmung des Zellzyklus und eine höhere Apoptoserate in der Bursa fabricii wurden als Folge des Met-Mangels diskutiert. Zugleich führten Met-Gaben um bis zu $40 \%$ über Versorgungsempfehlungen (NRC, 1994) zu immunstimulierenden Effekten (BOUYEH, 2012).

Somit gibt es durchaus Hinweise, dass den SAS eine besondere Rolle für das Immunsystem zukommt. Einfluss auf die Aktivierung von Lymphozyten und Stimulierung der Bildung von Antikörpern und Cytokinen sind belegt (z. B. BOUYEH, 2012). Grundsätzlich ist dem Met für das Immunsystem, also z. B. der Antikörperstruktur bzw. dem Antigen-Rezeptor der T-Zellen, eine größere Bedeutung beizumessen als dem Cys (ACUTOS und REINHERZ, 1985). So beobachteten TSIAGBE et al. (1987a), dass erhöhte Met-Gaben neben Leistungseffekten zugleich die Response von Parametern des Immunsystems (Antikörpertiter, Phytohämagglutinin-Response) signifikant steigerten. Zugleich wurde eine signifikante Beeinträchtigung dieser Parameter im Met-Überschuss (1,45\% des Futters) beobachtet (TSIAGBE et al., 1987b). Somit hat eine suboptimale Met-Versorgung eine verminderte Immunkompetenz zur Folge. Allerdings ist auch zu vermuten, dass ein Met-Exzess bereits zu einer verminderten Immunkompetenz führt, bevor ein Effekt auf zootechnische Parameter festzustellen ist (HAFEZ et al., 1978).

Dennoch konnten TAKAHASHI et al. (1997) nach einer Injektion von E. coliLipopolysacchariden bei Broilern zeigen, dass erhöhte Werte an Interleukin-1 im Plasma vom Met:Cys-Verhältnis im Futter abhängig waren, dieses also doch eine Rolle für die Immunantwort spielt. Bei infizierten Ratten zeigte sich der Turnover von Glutathion deutlich erhöht und auch die Transsulfurierung von Met zu Cys war gesteigert (MALMEZAT et al., 2000), woraus eine verstärkte Notwendigkeit der Beachtung des Zusammenhanges zwischen Immunstatus und SAS-Bedarf gefolgert wurde. RUBIN et al. (2007a) konnten nach der Vakzination von Masthähnchen bei Gehalten an verdaulichem Met von 0,51\% (Starter) bzw. $0,49 \%$ (Grower) die stärkste humorale Immunantwort beobachteten. Weder höhere noch niedrigere Met-Gehalte hatten einen Einfluss auf die Immunantwort. Die Versorgung mit SAS 
war mit 0,80\% im Futter für die Starter- und 0,75\% für die Growerphase adäquat. Höhere SAS-Angebote (RUBIN et al., 2007b) konnten die Immunresponse nicht steigern.

KLASING und BARNES (1988) lösten bei Broilern Immunstress durch Injektionen von E. coli-Lipopolysacchariden oder von abgetöteten Staphylococcus aureus aus. Es zeigte sich, dass die negativen Auswirkungen der Injektionen auf die Lebendmassezunahmen und die Futterverwertung bei einer Met-Überversorgung sogar stärker ausfielen als bei einer adäquaten Versorgung. Dies könnte für eine toxische Wirkung des Met sprechen. POURALI et al. (2014) supplementierten eine Basalmischung mit zusätzlichen $50 \%$ Met und untersuchten den Effekt auf die Leistung und die Gesundheit von adulten männlichen Broilern, die mit Eimeria sp. infiziert waren. Durch den erhöhten Gehalt an Met verbesserten sich die täglichen Zunahmen der Tiere signifikant. Außerdem verringerte sich der Gehalt an Oozysten pro g Kotprobe. Auf die Aktivität antioxidativer Enzyme hatten die SAS jedoch keinen Effekt.

Hinsichtlich der quantitativen Rolle des Met-Verbrauches für das Immunsystem bestehen unterschiedliche Auffassungen. Selbst in einem Infektionsgeschehen mit dem Newcastle-Virus sind die für die Zunahmen erforderlichen Met-Mengen und -Anteile höher als für die dann laufenden Prozesse der humoralen Abwehr (BHARGAVA et al., 1970). SWAIN und JOHRI (2000) kamen demgegenüber zu gegenteiligen Auffassungen. Generell erscheint es aber nicht zwingend, diesen Widerspruch aufzulösen, denn klassische Methoden der Bedarfsbewertung (s. 4.1) sind auf die Gesamtwirkung, d. h. Deckung des Verbrauches für das Immunsystem als Teil des Erhaltungsbedarfes, fokussiert. Lediglich für ein faktorielles Vorgehen könnte hier ein spezifischer Quantifizierungsbedarf gesehen werden.

\section{BEDARFSDECKUNG MIT S-HALTIGEN AMINOSÄUREN}

\subsection{AUSWIRKUNGEN UNTERSCHIEDLICHER VERSORGUNGSGRADE}

Die Auswirkungen unterschiedlicher Versorgungsgrade mit SAS auf Wachstum, Futterverwertung, Schlachtkörperqualität und Tiergesundheit sind durch zahlreiche Studien belegt. Gezielte Unterversorgung von Masthähnchen mit Met (SEKIZ et al., 1975; SÜNDER, et al., 2015a) oder Cys (GRABER und BAKER, 1971; OHTA und ISHIBASHI, 1994; DILGER und BAKER, 2007) bewirkte eine signifikante Reduktion der Futteraufnahme und nachfolgend eine Beeinträchtigung von Wachstum, Futterverwertung und insbesondere der Schlachtkörperzusammensetzung (SEKIZ et. al., 1975; CONDE-AGUILERA et al., 2013, 2016). Aber auch bei einer Überversorgung mit Met wurden signifikant verminderte Futteraufnahmen und verschlechterte zootechnische Parameter festgestellt (HARTER und BAKER, 1978; EDMONDS und BAKER, 1987; HAN und BAKER, 1993; ACAR et al., 2001; XIE et al., 2007; BOUYEH, 2012). Überhöhte Cys-Gehalte führten zu Einbußen in der Wachstumsleistung und Effizienz der Futterverwertung von Masthähnchen (SASSE und BAKER, 1974; FEATHERSTON und ROGLER, 1978; SELL et al., 1980; DILGER und BAKER, 2007). DILGER und BAKER (2007) beobachteten zudem eine signifikant verringerte Futteraufnahme bei steigenden Cys-Zulagen $\mathrm{zu}$ SAS-defizienten Mischfuttermitteln. Außerdem wurde bei überhöhten Cys-Supplementationen ein vermehrtes Auftreten von Dyschondroplasie der Tibia beobachtet (ORTH et al., 1992). Die Ursache hierfür ist jedoch noch ungeklärt.

Aus diesen nachteiligen Effekten einer nicht bedarfsgerechten Versorgung mit Met und Cys auf zootechnische Parameter und die Tiergesundheit ist das Erfordernis abzuleiten, sowohl quantitativ als auch im Verhältnis der beiden SAS zueinander optimierte Versorgungsgrade anzustreben. 


\subsection{POTENZIALE EINER ERGÄNZUNG MIT S-HALTIGEN AMINOSÄUREN}

Wie unter 2.2 dargestellt, ist in relevanten Einzelfuttermitteln mit erheblichen Unterschieden im Gehalt an Met und Cys zu rechnen. Häufig verwendete Mischungen auf Basis von Mais und Sojaextraktionsschrot weisen im Vergleich zu den Versorgungsempfehlungen deutliche SASMindergehalte auf (z. B. PESTI et al., 1979; ELKIN und HESTER, 1983; TILLMAN und PESTI, 1986). Diese Lücke ist durch das verfügbare Futtermittelspektrum auf dem Wege der Kombination von Einzelfuttermitteln nicht zu schließen, da keine Proteinträger mit überproportional hohen SAS-Gehalten in der Proteinfraktion verfügbar sind. Neuzüchtungen mit erhöhten Met-Gehalten (RAVINDRAN et al., 2002) ist derzeit keine wirtschaftliche Relevanz beizumessen.

Tabelle 12 zeigt vergleichend den Gehalt an SAS und Lysin in Getreide/Sojaschrot basierten Mischfuttermitteln für Broiler mit unterschiedlichen XP-Gehalten. Es wird deutlich, dass eine bedarfsangepasste Supplementation mit diesen AS unerlässlich ist.

Tabelle 12: Vergleich der Aminosäurengehalte verschiedener Mischfuttermittel für Masthähnchen ${ }^{1}$ Table 12: $\quad$ Comparison of the amino acid content in different broiler diets ${ }^{1}$

\begin{tabular}{|c|c|c|c|c|c|}
\hline & & \multicolumn{4}{|c|}{ AS- Gehalte im Mischfutter (\%) } \\
\hline & & \multicolumn{2}{|c|}{$\begin{array}{c}\text { Weizen }+ \\
\text { Sojaextraktionsschrot }\end{array}$} & \multicolumn{2}{|c|}{$\begin{array}{c}\text { Mais + } \\
\text { Sojaextraktionsschrot }\end{array}$} \\
\hline \multicolumn{2}{|c|}{$\begin{array}{l}\text { Anteile beider Futtermittel } \\
\qquad(\mathrm{g} / \mathrm{kg})\end{array}$} & $600 / 290$ & $510 / 380$ & $560 / 330$ & $480 / 410$ \\
\hline Aminosäure & Bedarf $(\%)$ & $19 \% \mathrm{XP}$ & $22 \% \mathrm{XP}$ & $19 \% \mathrm{XP}$ & $22 \% \mathrm{XP}$ \\
\hline Lys & 1,350 & 0,939 & 1,147 & 0,988 & 1,179 \\
\hline Met+Cys & 0,999 & 0,587 & 0,657 & 0,569 & 0,638 \\
\hline
\end{tabular}

Somit kann eine bedarfsgerechte Versorgung des Geflügels ohne den Einsatz S-haltiger FutterAS (DL-Met, L-Met, Met-Analoga) nicht erreicht werden, vor allem, wenn gleichzeitig eine den ökologischen Erfordernissen Rechnung tragende Reduktion des Futterproteingehaltes angestrebt wird. Neben einer optimalen Kombination herkömmlicher Einzelfuttermittel ist insbesondere das Spektrum verfügbarer Futter-AS (wie z. B. L-Lys·HCl, L-Thr, L-Trp, L-Ile, L-Val, L-Arg) geeignet, um spezifische AS-Überangebote im Futter weiter abzubauen und idealen AS-Verhältnissen (siehe 4.4) möglichst nahe zu kommen (WECKE und LIEBERT, 2013b). Dabei könnte auch eine Erweiterung des Spektrums (z. B. um L-His) relevant werden.

Tabelle 12 ist zu entnehmen, dass Met-Ergänzungen eine außerordentliche Rolle zukommt, um die XP-Gehalte im Broilermastfutter von üblicherweise 20-22\% spürbar auf 17-18\% abzusenken (JEROCH und PACK, 1995; BUNCHASAK et al., 1997; BLAIR et al., 1999; SAKI et al., 2007). Aus ernährungsphysiologischer Sicht erscheint es nicht unrealistisch, unter Nutzung des vorhandenen Spektrums an Futter-AS den Proteingehalt auf 15-16 \% und ggf. noch tiefer zu reduzieren (DAGHIR, 1983). Bei diesen Optimierungsmaßnahmen muss dem idealen Met:Cys-Verhältnis im Futter (siehe 3.2 bzw. 4.2) besondere Beachtung beigemessen werden (SI et al., 2004; KHAN et al., 2015a; SÜNDER et al. 2015b), nicht zuletzt, um eine 
hohe Met-Wirksamkeit im Prozess der Gesamtproteinverwertung zu erreichen (SÜNDER et al., 2015a; WECKE et al., 2015b). Dies ist nur dann zu erwarten, wenn der metabolische Verbrauch der unentbehrlichen AS Met für Prozesse, die nicht direkt auf diesen Proteinbaustein angewiesen sind, minimiert wird. Hierfür besteht nach wie vor ein hoher Forschungsbedarf.

\section{$6 \quad$ FAZIT}

Im Vergleich mit anderen essentiellen AS weisen die S-haltigen AS einige Besonderheiten im Hinblick auf ihr Vorkommen in Körper und Futtermitteln, die Analytik, Beteiligung an Stoffwechselprozessen und, damit in Verbindung stehend, ihre Verwertung für den Ansatz auf. Die SAS-Gehalte in den Körperproteinfraktionen des Geflügels zeigen alters- und geschlechtsbedingte Veränderungen bzw. Unterschiede. Met kommt vor allem im Protein der Muskelgewebe und Innereien vor, auf Cys entfallen hohe Anteile (\%) im Federprotein. In Relation zum Bedarf kommt Met im Geflügelfutter häufig eine limitierende Rolle zu. Auf Grund begrenzter Möglichkeiten zum Ausgleich dieser Versorgungsdefizite auf dem Weg der Proteinträgerkombination sind Supplementationen verschiedener Met-Quellen (DL-Met, LMet, MHA) relevant, die auf äquimolarer Basis vergleichbare Wirksamkeiten aufweisen. Diese gezielte Ergänzung mit spezifischen AS ist zudem die entscheidende Voraussetzung, den Rohproteingehalt im Futter ohne Leistungseinbußen für das Tier abzusenken, zugleich mit positiven Umwelt-Effekten im Hinblick auf die weitere Minimierung tierischer NAusscheidungen.

Für den Supplementationserfolg sind neben zuverlässigen Analysenwerten zu den verfügbaren Einzelfuttermitteln sowohl Kenntnisse zur Bioverfügbarkeit für das Tier als auch valide Bedarfswerte notwendig. Bedarfsangaben in der Literatur streuen leider ganz erheblich. Insbesondere für das alters- und vom Genotyp abhängige optimale Met:Cys-Verhältnis im Futter besteht weiterhin Klärungsbedarf. Daneben erscheinen methodische Fragen der Bewertungsebene und nicht zuletzt der angewandten Methode bei der Bedarfsableitung entscheidend für die Verbesserung von Vergleichbarkeit und Validität der Aussagen. In Verbindung mit den facettenreichen metabolischen Funktionen der SAS wird die Steigerung der Met-Effizienz als proteinogene AS als besondere Herausforderung gesehen. Alternative Methylgruppenlieferanten (Betain, Cholin) sowie bedarfsangepasste Cys-Bereitstellung über das Futter, verbunden mit minimaler Cys-Bereitstellung über den Met-Abbau, lassen sich als erfolgversprechende Instrumente für eine Met-Sparwirkung identifizieren. Die in der Mischfutterkonzeption übliche summarische Betrachtung von Met und Cys ist unter Berücksichtigung dieser Aspekte für eine bedarfsgerechte Versorgung nicht ausreichend. Daneben sind bei minimierter Met-Katabolisierung auch Beziehungen zum metabolischen Verbrauch weiterer proteinogener AS (Gly, Thr) gegeben, die hinsichtlich ihrer quantitativen Rolle für eine effiziente Stoffwechselökonomie noch nicht abschließend eingeschätzt werden können.

Unter möglichst standardisierten Versuchsbedingungen sind weitere experimentelle Arbeiten für eine optimale Versorgung von Geflügel mit Met und Cys erforderlich, um einerseits vorliegende Vorstellungen zum IAAR weiter zu präzisieren und andererseits durch eine Vermeidung von Mangel-/Überschuss-Situationen bzw. AS-Imbalancen nicht zuletzt auch Tierwohlaspekten gerecht zu werden. 
ACAR, N., BARBATO, G.F. und PATTERSON, P.H. (2001): 2. The effect of feeding excess methionine on live performance, carcass traits, and ascitic mortality. Poult. Sci. 80, 1585-1589

ACUTOS, O. und E.L. REINHERZ (1985): The human T-cell receptor. Structure and function. New. Engl. J. Med. 312, 1100-1111

ADAMS, R.F. (1974): Determination of amino acid profiles in biological samples by gas chromatography. J. Chrom. A, 95, 189-212

ADEDOKUN, S.A., ADEOLA, O., PARSONS, C.M., LILBURN, M.S., APPLEGATE, T.J. (2008): Standardized ileal amino acid digestibility of plant feedstuffs in broiler chickens and turkey poults using a nitrogen-free or casein diet. Poult. Sci. 87, 2535-2548

ADEDOKUN, S.A., ADEOLA, O., PARSONS, C.M., LILBURN, M.S., APPLEGATE, T.J. (2011): Factors affecting endogenous amino acid flow in chickens and the need for consistency in methodology. Poult. Sci. 90, $1737-1748$

ADEDOKUN, S.A., JAYNES, P., PAYNE, R.L., APPLEGATE, T.J. (2015): Standardized ileal amino acid digestibility of corn, corn distillers' dried grains with solubles, wheat middlings and bakery by-products in broilers and laying hens. Poult. Sci. 94, 2480-2487

ADEOLA, O. (2007): Efficiency of methionine retention in ducks. Br. J. Nutr. 97, 478-483

AGOSTINI, P.S., DALIBARD, P., MERCIER, Y., VAN DER AAR, P., VAN DER KLIS, J.D. (2016): Comparison of methionine sources around requirement levels using a methionine efficacy method in 0 to 28 day old broilers. Poult. Sci. 95, 560-569

AKHAVAN KHALEGHI, A., GOLIAN, A., ABADI, H.A., RAJI, A.R. (2016): Effect of digestible protein and sulfur amino acids in starter diet on performance and small intestinal (jejunum) morphology of broilers. Iran. J. Anim. Sci. Res. 7, 437-446

ALlEMAN, F., MICHEL, J., CHAGNEAU, A.M., LECLERCQ, B. (2000): The effects of dietary protein independent of essential amino acids on growth and body composition in genetically lean and fat chickens. $\mathrm{Br}$. Poult. Sci. 41, 214-218

ALMQUIST, H.J. (1952): Amino acid requirements of chickens and turkeys - a review. Poult. Sci. 31, 966-981

ALMQUIST, H.J. und C.R. GRAU (1944): The amino acid requirement of the chick. J. Nutr. 28, 325 - 331

AMAD, A.A. und F. LIEBERT (2015): The effects of naked neck (Na) gene and sex on the apparent ileal nitrogen and amino acids digestibility in growing meat type chicken. J. Poult. Res. 12, 23-27

AMERAH, A.M. und V. RAVINDRAN (2015): Effect of coccidia challenge and natural betaine supplementation on performance, nutrient utilization and intestinal lesion scores of broiler chickens fed suboptimal level of dietary methionine. Poult. Sci. 94, 673-680

ANGKANAPORN, K., CHOCT, M., BRYDEN, W.L., ANNISON, F., ANNISON, G. (1994): Effects of wheat pentosans on endogenous amino acid losses in chickens. J. Sci. Food. Agric. 66, 399-404

ATENCIO, A., ALBINO, L.F.T., ROSTAGNO, H.S., VIEITES, F.M. (2004): Methionine + cysteine requirement of male broilers from 1 to 20, 24 to 38 and 44 to 56 days of age. R. Bras. Zootec. 33, 1152-1166

ATTIA, Y.A., BÖHMER, B.M. und ROTH-MAIER, D.A. (2006): Responses of broiler chicks raised under constant relatively high ambient temperature to enzymes, amino acid supplementations or a high-nutrient diet. Arch. Geflügelk. 70, 80-91

AVIAGEN (2014a): Ross 308 broiler: Nutrition specifications. Aviagen, Huntsville, USA

AVIAGEN (2014b): Arbor Acres plus broiler nutrition specifications. Aviagen, Huntsville, USA

BAKER, D.H. (1986): Problems and pitfalls in animal experiments designed to establish dietary requirements for essential nutrients. J. Nutr. 116, 2339-2349

BAKER, D.H. (1996): Advances in amino acid nutrition and metabolism of swine and poultry. In: Nutrient management of food animals to enhance and protect the environment. (E.T. KORNEGAY Hrsg.). CRC Press, Boca Raton, 41-54

BAKER, D.H. (2003): Ideal amino acid patterns for broiler chicks. In: Amino acids in animal nutrition. (J.P.F. D’MELLO Hrsg.). CABI Publishing, Wallingford, 223-236

BAKER, D.H. (2006): Comparative species utilization and toxicity of sulfur amino acids. J. Nutr. 136, 1670-1675

BAKER, D.H. und Y. HAN (1994): Ideal amino acid profile for chicks during the first three weeks posthatching. Poult. Sci. 73, 1441-1447 
BAKER, D.H., WARREN, W., CLAUSING, W.W., HARMON, B.G., JENSEN, A.H., BECKER, D.E. (1969): Replacement value of cysteine for methionine for the young pig. J. Anim. Sci. 29, 581-584

BAKER, D.H., HALPIN, K.M., CZARNECKI, G.L., PARSONS, C.M. (1982): The choline-methionine interrelationship for growth of the chick. Poult. Sci. 62, 133-137

BAKER, D.H., FERNANDEZ, S.R., WEBEL, D.M., PARSONS, C.M. (1996): Sulfur amino acid requirement and cystine replacement value of broiler chicks during the period three to six weeks posthatching. Poult. Sci. 75, 737-742

BAKER, D.H., BATAL, A.B., PARR, T.M., AUGSPURGER, N.R., PARSONS, C.M. (2002): Ideal ratio (relative to lysine) of tryptophan, threonine, isoleucine and valine for chicks during the second and third weeks posthatch. Poult. Sci. 81, 485-494

BATAL, A.B. und C.M. PARSONS (2002): Effects of age on nutrient digestibility in chicks fed different diets. Poult Sci. 81, 400-407

BATTERHAM, E.S. (1992): Availability and utilization of amino acids for growing pigs. Nutr. Res. Rev. 5, 1-18

BATTERHAM, E.S., ANDERSEN, L.M., BAIGENT, D.R., BEECH, S.A., ELLIOTT, R. (1990): Utilization of ileal digestible amino acids by pigs: lysine. Br. J. Nutr. 64, 679-690

BATTERHAM, E.S., ANDERSEN, L.M. und BAIGENT, D.R. (1993): Utilization of ileal digestible amino acids by growing pigs: methionine. Br. J. Nutr. 70, 711-720

BECK, C.R., HARMS, R.H. und RUSSELL, G.B. (1998): Is the cystine content of the diet of concern for broilers from 0 to 21 days of age? J. Appl. Poult. Res. 7, 233-238

BECKER, D.E., JENSEN, A.H., TERRILL, S.W., NORTON, H.W. (1955): The methionine-cysteine need of the young pig. J. Anim. Sci. 14, 1086-1094

BEST, C.H., LUCAS, C.C., PATTERSON, J.M., RIDOUT, J.H. (1946): The influence of biotin upon the relative lipotropic effects of choline and inositol. Biochem. J. 40, 368-373

BHARGAVA, K.K., HANSON, R.P. und SUNDE, M.L. (1970): Effects of methionine and valine on antibody production in chicks infected with newcastle disease virus. J. Nutr. 100, 241-248

BLAIR, R., JACOB, J.P., IBRAHIM, S., WANG, P. (1999): A quantitative assessment of reduced protein diets and supplements to improve nitrogen utilization. J. Appl. Poult. Res. 8, 25-47

BONATO, M.A., SAKOMURA, N.K., DORIGAM, J.C.P., GOUS, R.M. (2015): Maintenance requirements for amino acids in poultry. In: Nutritional Modelling for Pigs and Poultry. (N. K. SAKOMURA/R. M. GOUS/I. KYRIAZAKIS/L. HAUSCHILD Hrsg.). CABI Publishing, Wallingford, 209-222

BOUYEH, M. (2012): Effect of excess lysine and methionine on immune system and performance of broilers. Ann. Biol. Res. 3, 3218-3224

BROSNAN, J. und M. BROSNAN (2006): The sulfur-containing amino acids: an overview. J. Nutr. 136, 1636S $-1640 \mathrm{~S}$

BURKE, K.A., NYSTROM, R.F. und CONNOR JOHNSON, B. (1951): The role of methionine as a methyl donor for choline synthesis in the chick. J. Biol. Chem. 188, 723-728

BUNCHASAK, C. (2009): Role of dietary methionine in poultry production. J. Poult. Sci. 46, 169-179

BUNCHASAK, C., SANTOSO, U., TANAKA, K., OHTANI, S., COLLADO, C.M. (1997): The effect of supplementing methionine plus cystine to a low-protein diet on the growth performance and fat accumulation of growing broiler chicks. Asian-Aust. J. Anim. Sci. 10, 185-191

BUNCHASAK, C., RATCHADAPORNVANITCH, Y. und THIENGTHAM, J. (2012): Comparative effects of supplemental DL-2-hydroxy-4-(methylthio) butanoic acid and DL-methionine in diet on egg production and quality in laying hens. J. Poult. Sci. 49, 260-267

CHENG, T.K., HAMRE, M.L. und COON, C.N. (1997a): Responses of broilers to dietary protein levels and amino acid supplementation to low protein diets at various environmental temperatures. J. Appl. Poult. Res. 6, 18-33

CHENG, T.K., HAMRE, M.L. und COON, C.N. (1997b): Effect of environmental temperature, dietary protein and energy levels on broiler performance. J. Appl. Poult. Res. 6, 1-17

CHOE, H.S., LI, H.L., PARK, J.H., KANG, C.W., RYU, K.S. (2010): Effects of dietary betaine on the secretion of insulin-like growth factor-I and insuline-like growth factor binding protein-1 and -3 in laying hens. AsianAust. J. Anim. Sci. 23, 379-384

CHATTOPADHAY, K., MONDAL, M.K. und ROY, B. (2006): Comparative efficacy of DL-methionine and herbal methionine on performance of broiler chicken. Int. J. Poult. Sci. 5, 1034-1039 
CHRAMUSPOLlERT, M., PESTI, G.M. und BAKALLI, R.I. (2002): Determination of the methionine requirement of male and female broiler chicks using an indirect amino acid oxidation method. Poult. Sci. 81, 1004-1013

CLARKE, E. und J. WISEMAN (2005): Effects of variability in trypsin inhibitor content of soya bean meals on true and apparent ileal digestibility of amino acids and pancreas size in broiler chicks. Anim. Feed Sci. Technol. $121,125-138$

COBB (2015): Cobb500 broiler performance \& nutrition supplement. Siloam Springs, USA

COLE, D.J.A., YEN, H.T. und LEWIS, D. (1980): The lysine requirements of growing and finishing pigs - The concept of an ideal protein. In: Proceedings of the 3rd international symposium on protein metabolism and nutrition, Vol. II, (H.J. OSLAGE/K. ROHR Hrsg.) EAAP, Braunschweig, Germany, 658-668

CONDE-AGUILERA, J.A., COBO-ORTEGA, C., TESSERAUD, S., LESSIRE, M., MERCIER, Y., VAN MILGEN, J. (2013): Changes in body composition in broilers by a sulfur amino acid deficiency during growth. Poult. Sci. 92, 1266-1275

CONDE-AGUILERA, J.A., CHOLET, J.C.G., LESSIRE, M., MERCIER, Y., TESSERAUD, S., VAN MILGEN, J. (2016): The level and source of free-methionine affect body composition and breast muscle traits in growing broilers. Poult. Sci. 95, 2322-2331

DAGHIR, N.J. (1983): Effect of lysine and methionine supplementation of low protein roaster diets fed after six weeks of age. Poult. Sci. 62, 1572-1575

DALÒLIO, F.S., ALBINO, L.F.T., ROSTAGNO, H.S., DA SILVA, D.L., DE LUCAS XAVIER JUNIOR, M., DE OLIVEIRA, V.D. (2016): Metabolizable energy and digestible amino acids of full-fat soybean without or with protease supplementation in diets for broilers. Ciência e Agrotecnologia 40, 565-576

DEAN, W.F. und H.M. SCOTT (1965): The development of an amino acid reference diet for the early growth of chicks. Poult. Sci. 44, 803-808

DE COCA-SINOVA, A., VALENCIA, D.G., JIMÈNEZ-MORENO, E., LÀZARO, R, MATEOS, G.G. (2008): Apparent ileal digestibility of energy, nitrogen and amino acids of soybean meals of different origin in broilers. Poult. Sci. 87, 2613-2623

DEL VESCO, A.P., GASPARINO, E., DE OLIVEIRA GRIESER, D., ZANCANELA, V., MENCK SOARES, M.A., DE OLIVEIRA NETO, A.R. (2015): Effects of methionine supplementation on the expression of oxidative stress-related genes in acute heat stress-exposed broilers. Br. J. Nutr. 113, 549-559

DEWITT STETTEN, J. (1942): The fate of dietary serine in the body of the rat. J. Biol. Chem. 144, 501-506

DIBNER, J.J., ATWELL, C.A. und IVEY, F.J. (1992): Effect of heat stress on 2-hydroxy-4-(methylthio)butanoic acid and DL-methionine absorption measured in vitro. Poult. Sci. 71, 1900-1910

DILGER, R.N. und D.H. BAKER (2007): DL-methionine is as efficacious as L-methionine, but modest L-cystine excesses are anorexigenic in sulfur amino acid-deficient purified and practical-type diets fed to chicks. Poult. Sci. 86, 2367-2374

DORIGAM, J.C.P., SAKOMURA, N.K., DE LIMA, M.B., SARCINELLI, M.F., SUZUKI, R.M. (2015): Establishing an essential amino acid profile for maintenance in poultry using deletion method. J. Anim. Physiol. Anim. Nutr. 100, 1-9

DOZIER, W.A. und Y. MERCIER (2013): Ratio of digestible total sulfur amino acids to lysine of broiler chicks from 1 to 15 days of age. J. Appl. Poult. Res. 22, 862-871

DU VIGNEAUD, V. (1952): A trail of research in sulfur chemistry and metabolism and related fields. Cornell University Press, London.

DU VIGNEAUD, V., KILMER, G.W., RACHELE, J.R., COHN, M. (1944): On the mechanism of the conversion in vivo of methionine to cystine. J. Biol. Chem. 155, 645-651

EDMONDS, M.S. und D.H. BAKER (1987): Comparative effects of individual amino acid excesses when added to a corn-soybean meal diet: effects on growth and dietary choice in the chick. J. Anim. Sci. 65, 699-705

EDWARDS, H.M. III. und D.H. BAKER (1999): Maintenance sulfur amino acid requirements of young chicks and efficiency of their use for accretion of whole-body sulfur amino acids and protein. Poult. Sci. 78, 14181423

EGGUM, B.O. (1973): A study of certain factors influencing protein utilization in rats and pigs. 406. beretning fra forsøgslaboratoriet, København

ELKIN, R.G. und P.Y. HESTER (1983): A comparison of methionine sources for broiler chickens fed cornsoybean meal diets under simulated commercial grow-out conditions. Poult. Sci. 62, 2030-2043 
EMMERT, J.L. und D.H. BAKER (1997): Use of the ideal protein concept for precision formulation of amino acid levels in broiler diets. J. Appl. Poult. Res. 6, 462-470

ENGELHARDT, H. (1986): HPLC von Aminosäuren und Proteinen. In: Analytiker-Taschenbuch. (W. FRESENUIS/H. GÜNZLER/W. HUBER/I. LÜDERWALD/G. TÖLG/H. WISSER Hrsg.). AnalytikerTaschenbuch, vol 6. Springer, Berlin, Heidelberg

ESTEVE-GARCIA, E. und S. MACK (2000): The effect of DL -methionine and betaine on growth performance and carcass characteristics in broilers. Anim. Feed Sci. Technol. 87, 85-93

EVONIK INDUSTRIES (2016): AMINO Dat® 5.0 Platinum Edition (Download). Evonik Degussa GmbH, Hanau-Wolfgang

FALUYI, O.B., ADEBAYO, I.A. und AGBEDE, J.O. (2015): Influence of hypo and hyper methionine supplementation on growth performance and immunological responses to newcastle disease vaccinations of broiler chickens. African J. Food. Agric. Nutr. Dev. 15, 10597-10613

FANG, Y.Z., YANG, S. und WU, G. (2002): Free radicals, antioxidants and nutrition. Nutrition 18, 872-879

FARIDI, A., GITOEE, A., SAKOMURA, N.K., DONATO, D.C.Z., GONSALVES, C.A., SARCINELLI, M.F., DE LIMA, M. B., FRANCE, J. (2016): Broiler responses to digestible total sulphur amino acids at different ages: a neural network approach. J. Appl. Anim. Res. 44, 315-322

FARKE, J. (2011): Studien zur Aminosäurenwirksamkeit beim Mastgeflügel unter spezifischer Betrachtung der schwefelhaltigen Aminosäuren. Dissertation zur Erlangung des Doktorgrades der Fakultät für Agrarwissenschaften der Georg-August-Universität Göttingen

FARKE, J., WECKE, C. und LIEBERT, F. (2010): Methionine efficiency in chicken diets with varying Met to Cys ratio modifies the concluded Met requirements. Proc. Soc. Nutr. Physiol. 19, 21

FATUFE, A.A. und M. RODEHUTSCORD (2005): Growth, body composition and marginal efficiency of methionine utilization are affected by nonessential amino acid nitrogen supplementation in male broiler chicken. Poult. Sci. 84, 1584-1592

FEATHERSTON, W.R. und A.C. ROGLER (1978): Methionine-cystine interrelations in chicks fed diets containing suboptimal levels of methionine. J. Nutr. 108, 1954-1958

FILLINGAME, R.H., JORSTAD, C.M. und MORRIS, D.R. (1975): Increased cellular levels of spermidine or spermine are required for optimal DNA synthesis in lymphocytes activated by concanavalin A. Proc. Natl. Acad. Sci. 72, 4042-4045

FINKELSTEIN, J.D. (1998): The metabolism of homocysteine: pathways and regulation. Eur. J. Pediatr. 157, S40-S44

FISHER, C. und T.R. MORRIS (1970): The determination of the methionine requirement of laying pullets by a diet dilution technique. Br. Poult. Sci. 11, 67-82

FOSTER, D.W. (2004): The role of the carnitine system in human metabolism. Ann. N.Y. Acad. Sci. 1033, 1-16

FULLER, M.F. (Hrsg.) (2004): The encyclopedia of farm animal nutrition. CABI Publishing, Wallingford

GARCIA-NETO, M., PESTI, G.M. und R.I. BAKALLI (2000): Influence of dietary protein level on the broiler chicken's response to methionine and betaine supplements. Poult. Sci. 79, 1478-1484

GEHRKE, C.W., LAMKIN, W.M., STALLING, D.L., SHAHROKHI, F. (1965): Quantitative gas chromatography of amino acids. Biochem. Biophys. Res. Commun. 19, 328-334

GfE [Gesellschaft für Ernährungsphysiologie] (1999): Empfehlungen zur Energie- und Nähstoffversorgung der Legehennen und Masthühner (Broiler). DLG-Verlag, Frankfurt am Main

GOLSHAHI, A., NASR, J., RAHMATNEJAD, E., MOHAMMADI, A. (2013): Broiler performance in response to different methionine levels. J. Agric. Technol. 9, 1399-1404

GONZALES-ESQUERRA, R., VÁZQUEZ-AÑóN, M., HAMPTON, T., YORK, T., FEINE S., WUELLING, C., KNIGHT, C. (2007): Evidence of a different dose response in turkeys when fed 2-hydroxy-4(methylthio) butanoic acid versus DL-methionine. Poult. Sci. 86, 517-524

GOULART, C.D.C., GUILHERME, F., COSTA, P., VILAR, J.H, DE SOUZA, J.G., RODRIGUES, V.P., SANTOS, C.F. (2011): Requirements of digestible methionine + cystine for broiler chickens at 1 to 42 days of age. Rev. Bras. Zootec. 40, 797-803

GOUS, R.M. und T.R. MORRIS (1985): Evaluation of a diet dilution technique for measuring the response of broiler chickens to increasing concentrations of lysine. Br. Poult. Sci. 26, 147-161

GRABER, G. und D.H. BAKER (1971): Sulfur amino acid nutrition of the growing chick: quantitative aspects concerning the efficiacy of dietary methionine, cysteine and cystine. J. Anim. Sci. 33, 1005-1011 
GRABER, G., SCOTT, H.M. und BAKER, D.H. (1971a): Sulfur amino acid nutrition of the growing chick: effect of age on the capacity of cystine to spare dietary methionine. J. Anim. Sci. 33, 1450-1455

GRABER, G., SCOTT, H.M. und BAKER, D.H. (1971b): Sulfur amino acid nutrition of the growing chick: effect of age on the dietary methionine requirement. J. Anim. Sci. 33, 854-858

HANDY, D.E., HANG, G., SCOLARO, J., METES, N., RAZAQ, N., YANG, Y., LOSCALZO, J. (2006): Aminoglycosides decrease glutathione peroxidase-1 activity by interfering with selenocysteine incorporation. J. Biol. Chem. 281, 3382-3388

HAFEZ, Y.S.M., CHAVEZ, E., VOHRA, P., KRATZER, F.H. (1978): Methionine toxicity in chicks and poults. Poult. Sci. 57, 699-703

HAN, Y. und BAKER, D.H. (1993): Effects of excess methionine or lysine for broilers fed a corn-soybean meal diet. Poult. Sci. 72, 1070-1074

HARTER, J.M. und BAKER, D.H. (1978): Factors affecting methionine toxicity and its alleviation in the chick. J. Nutr. 108, 1061-1070

HAVENSTEIN, G.B., FERKET, P.R. und QURESHI, M.A. (2003): Growth, livability and feed conversion of 1957 versus 2001 broilers when fed representative 1957 and 2001 broiler diets. Poult. Sci. 82, 1500-1508

HEGER, J. und Z. FRYDRYCH (1985): Efficiency of utilization of essential amino acids in growing rats at different levels of intake. Br. J. Nutr. 54, 499-508

HEGER, J., VAN PHUNG, T. und KŔİŻOVÁ, L. (2002): Efficiency of amino acid utilization in the growing pig at suboptimal levels of intake: lysine, threonine, sulphur amino acids and tryptophan. J. Anim. Physiol. a. Anim. Nutr. 86, 153-165

HOEHLER, D., LEMME, A., RAVINDRAN, V., BRYDEN, W.L., ROSTAGNO, H.S. (2006): Feed formulation in broiler chickens based on standardized ileal amino acid digestibility. Av. en Nutr. Acuícola VIII.VIII Simp. Int. Nutr. Acuícola. 15-17 Noviembre, 197-212

HOLLENBECK, C.B. (2012): The importance of being choline. J. Am. Diet. Assoc. 110, 1162-1165

HOPPE, B. und J. MARTENS (1983): Aminosäuren - Bausteine des Lebens. Chemie unserer Zeit 17, 41-53

HTOO, J. und J. MORALES (2016): Bioavailability of L-methionine relative to DL-methionine as a methionine source for weaned pigs. J. Anim. Sci. 94, 249-252

HUANG, K.H., RAVINDRAN, V., LI, X., BRYDEN, W.L. (2005): Influence of age on the apparent ileal amino acid digestibility of feed ingredients for broiler chickens. Br. Poult. Sci. 46, 236-245

HUANG, Q.C., XU, Z.R., HAN, X.Y., LI, W.F. (2006): Changes in hormones, growth factor and lipid metabolism in finishing pigs fed betaine. Livest. Sci. 105, 78-85

HUANG, Q.C., XU, Z.R., HAN, X.Y., LI, W.F. (2007): Effect of betaine on growth hormone pulsatile secretion and serum metabolites in finishing pigs. J. Anim. Physiol. Anim. Nutr. 91, 85-90

HUŠEK, P. (1991): Rapid derivatization and gas chromatographic determination of amino acids. J. Chrom. A 552 , 289-299

HUTSON, P.R., CRAWFORD, M.E. und SORKNESS, R.L. (2003): Liquid chromatographic determination of hydroxyproline in tissue samples. J. Chrom. B 791, 427-430

JAMROZ, D., WILICZKIEWICZ, A., ORDA, J., WERTELECKI, T. SKORUPIŃSKA, J. (2002): Aspects of development of digestive activity of intestine in young chickens, ducks and geese. J. Anim. Physiol. Anim. Nutr. $86,353-366$

JELTSCH, A. (2002): Beyond Watson and Crick: DNA methylation and molecular enzymology of DNA methyltransferases. Chem. Bio. Chem. 3, 274-293

JENSEN, L.S., WYATT, C.L. und FANCHER, B.I. (1989): Sulfur amino acid requirement of broiler chickens from 3 to 6 weeks of age. Poult. Sci. 68, 163-168

JEROCH, H. und M. PACK (1995): Effects of dietary sulfur amino acids and crude protein on the performance of finishing broilers. Arch. Tierern. 48, 109-118

KALINOWSKI, A., MORAN, E.T. und WYATT, C.L. (2003a): Methionine and cystine requirements of slowand fast-feathering male broilers from zero to three weeks of age. Poult. Sci. 82, 1423-1427

KALINOWSKI, A., MORAN, E.T. und WYATT, C.L. (2003b): Methionine and cystine requirements of slowand fast-feathering broiler males from three to six weeks of age. Poult. Sci. 82, 1428-1437

KETTUNEN, H., PEURANEN, S. und TIIHONEN, K. (2001): Betaine aids in the osmoregulation of duodenal epithelium of broiler chicks and effects the movement of water across the small intestinal epithelium in vitro. Comp. Biochem. Physiol. A 129, 595-603 
KHAN, D.R., WECKE, C. und LIEBERT, F. (2015a): An elevated dietary cysteine to methionine ratio does not impact on dietary methionine efficiency and the derived optimal methionine to lysine ratio in diets for meat type chicken. Open J. Anim. Sci. 5, 457-466

KHAN, D.R., WECKE, C. und LIEBERT, F. (2015b): Does the naked neck meat type chicken yield lower methionine requirement data? Animals 5, 151-160

KHAN, D.R., WECKE, C., SHARIFI, A.R. und LIEBERT, F. (2015c): Evaluating the age-dependent potential for protein deposition in naked neck meat type chicken. Animals 5, 56-70

KIDD, M.T., FERKET, P.R. und GARLICH, J.D. (1997): Nutritional and osmoregulatory functions of betaine. Worlds Poult. Sci. J. 53, 125-139

KLASING, K.C. (2006): Negative consequences of immune response: What can be done by nutritionists? Proc. Soc. Nutr. Physiol. 15, 17-23

KLASING, K.C. und D.M. BARNES (1988): Decreased amino acid requirements of growing chicks due to immunologic stress. J. Nutr. 118, 1158-1164

KLOSE, A.A. und H J. ALMQUIST (1941): Methionine in the diet of the chick. J. Biol. Chem. 138, 467-469

KLUTH, H. und M. RODEHUTSCORD (2006): Comparison of amino acid digestibility in broiler chickens, turkeys and pekin ducks. Poult. Sci. 85, 1953-1960

KLUTH, H. und M. RODEHUTSCORD (2009): Standardisierte Futterbewertung auf der Basis der Aminosäurenverdaulichkeit beim Geflügel. Übers. Tierernährg. 37, 1-26

KLUTH, H. und M. RODEHUTSCORD (2010): Effect of the duration of prefeeding on amino acid digestibility of wheat distiller grains with solubles in broiler chicken. Poult. Sci. 89, 681-687

KLUTH, H., MEHLHORN, K. und RODEHUTSCORD, M. (2005): Studies on the intestine section to be sampled in broiler studies on praecaecal digestibility. Arch. Anim. Nutr. 59, 271-279

KNIGHT, C.D. und A.J. DIBNER (1984): Comparative absorption of 2-hydroxy-4-(methylthio)-butanoic acid and L-methionine in the broiler chick. J. Nutr. 114, 2179-2186

KNOWLES, T.A. und L.L. SOUTHERN (1998): The lysine requirement and ratio of total sulfur amino acids to lysine for chicks fed adequate or inadequate lysine. Poult. Sci. 77, 564-569

KOTB, M. und A.M. GELLER (1993): Methionine adenosyltransferase: structure and function. Pharmac. Ther. 59, 125-143

KRIJGSHELD, K.R., GLAZENBURG, E.J., SCHOLTENS, E., MULDER, G.J. (1981): The oxidation of L- and D-cysteine to inorganic sulfate and taurine in the rat. Biochim. Biophys. Acta 677, 7-12

KUBENA, L.F., DEATON, J.W., REECE, F.N., MAY, J.D., VARDAMAN, T.H. (1972): The Influence of temperature and sex on the amino acid requirements of the broiler. Poult. Sci. 51, 1391-1396

KWAKKEL, R.P. und P.C.A. MOQUET (2012): Feeding to enhance refluxing properties of the intestinal tract. Proceeding of the NZ Poultry Industry Conference 11, 167-176

LECLERCQ, B., CHAGNEAU, A., COCHARD, T., HAMZAOUI, S., LARBIER, M. (1993): Comparative utilisation of sulphur-containing amino acids by genetically lean or fat chickens. Br. Poult. Sci. 34, 383-391

LEMME, A., RAVINDRAN, V., BRYDEN, W.L. (2004): Ileal digestibility of amino acids in feed ingredients for broilers. World's Poult. Sci. J, 60, 421-435

LEMME, A., WIJTTEN, P.J.A., VAN WICHEN, J., PETRI, A., LANGHOUT, D.J. (2006): Responses of male growing broilers to increasing levels of balanced protein offered as coarse mash or pellets of varying quality. Poult. Sci. 85, 721-730

LENG, Z., FU, Q., YANG, X., DING, L. (2016): Increased fatty acid $\beta$-oxidation as a possible mechanism for fatreducing effect of betaine in broilers. Anim. Sci. J. 87, 1005-1010

LEWIS, A.J. (2003): Methionine-cysteine relationships in pig nutrition. In: Amino acids in animal nutrition. (J.P.F. D’MELLO Hrsg.). CABI Publishing, Wallingford, 143-156

LEWIS, A.J. und H.S. BAYLEY (1995): Amino acid bioavailability. In: Bioavailability of nutrients for animals: Amino acids, minerals, vitamins. (C.B. AMMERMAN/D.P. BAKER/A.J. LEWIS Hrsg.). Academic Press, San Diego, 35-65

LI, L.L., HOU, Z.P., LI, T.J., WU, G.Y., HUANG, R.L., TANG, Z.R., YANG, C.B., GONG, J., YU, H., KONG, X.F., PAN, E., RUAN, Z., XHU, W.Y., DENG, Z.Y., XIE, M., DENG, J., YIN, F.G., YIN, Y.L. (2008): Effects of dietary probiotic supplementation on ileal digestibility of nutrients and growth performance in 1- to 42-dayold broilers. J. Sci. Food Agric. 88, 35-42 
LIEBERT, F. (2015): Basics and applications of an exponential nitrogen utilization model ("Goettingen approach") for assessing amino acid requirements in growing pigs and meat type chickens based on dietary amino acid efficiency. In: Nutritional Modelling for Pigs and Poultry. (N. K. SAKOMURA/R. M. GOUS/I. KYRIAZAKIS/L. HAUSCHILD Hrsg.). CABI Publishing, Wallingford, 73-87

LIEBERT, F. (2017): Further progress is needed in procedures for biological evaluation of dietary protein quality in pig and poultry feeds. Arch. Anim. Breed. 60, 259-270

LIEBERT, F. und C. WECKE (2006): Grundsätze eines exponentiellen N-Verwertungsmodells zur Bewertung von Proteinansatzvermögen, Aminosäurenwirksamkeit und leistungsabhängigem Aminosäurenbedarf beim wachsenden Schwein. In: Empfehlungen zur Energie- und Nährstoffversorgung von Schweinen. (Ausschuss für Bedarfsnormen der Gesellschaft für Ernährungsphysiologie Hrsg.). DLG-Verlag, Frankfurt am Main, 221-232

LIEBERT, F., WECKE, C. und SÜNDER, A. (2015): Besteht Korrekturbedarf bei der optimalen Versorgung von Masthähnchen mit schwefelhaltigen Aminosäuren? In: 13. Tagung Schweine- und Geflügelernährung, 24.-26. November 2015, Lutherstadt Wittenberg. (A. ZEYNER/H. KLUTH/M. BULANG/M. BOCHNIA/M. GLATTER Hrsg.), 32-39

LIEBOLDT, M.A., FRAHM, J., HALLE, I., GÖRS, S., SCHRADER, L., WEIGEND, S., PREISINGER, R., METGES, C.C., BREVES, G., DÄNICKE, S. (2016): Metabolic and clinical response to Escherichia coli lipopolysaccharide in layer pullets of different genetic backgrounds supplied with graded dietary L-arginine. Poult Sci. 95, 595-611

LUMPKINS, B.S., BATAL, A.B. und BAKER, D.H. (2007): Variations in the digestible sulfur amino acid requirement of broiler chickens due to sex, growth criteria, rearing environment and processing yield characteristics. Poult. Sci. 86, 325-330

MACK, S., BERCOVICI, D., DE GROOTE, G., LECLERCQ, B., LIPPENS, M., PACK, M., SCHUTTE, J.B., VAN CAUWENBERGHE, S. (1999): Ideal amino acid profile and dietary lysine specification for broiler chickens of 20 to 40 days of age. Br. Poult. Sci. 40, 257-265

MAENZ, D.D. und C.M. ENGELE-SCHAAN (1996): Methionine and 2-hydroxy-4-methylthiobutanoic acid are transported by distinct $\mathrm{Na}+-$ dependent and $\mathrm{H}+-$ dependent systems in the brush border membrane of the chick intestinal epithelium. J. Nutr. 126, 529-536

MAlmeZAT, T., BREUIllÉ, D., POUYET, C., BUFFiÈRE, C., DENIS, P., PATUREAU MiRAND, P., OBLED, C. (2000): Methionine transsulfuration is increased during sepsis in rats. Am. J. Physiol. Endocrinol. Metab. 279, E1391-E1397

MARTÍN-VENEGAS, R., BRUFAU, M.T., MERCIER, Y., GERAERT, P.A., FERRER, R. (2011): Intestinal cell conversion of DL-2-hydroxy-(4-methylthio) butanoic acid in vitro: dietary up-regulation by this methionine precursor. Br. J. Nutr. 106, 350-356

MARTÍN-VENEGAS, R., GERAERT, P.A. und FERRER, R. (2006): Conversion of the methionine hydroxy analogue DL-2-hydroxy-(4-methylthio) butanioc acid to sulfur-containing amino acids in the chicken small intestine. Poult. Sci. 85, 1932-1938

MATSUSHITA, K., TAKAHASHI, K. und AKIBA, Y. (2007): Effects of adequate or marginal excess of dietary methionine hydroxy analogue free acid on growth performance, edible meat yields and inflammatory response in female broiler chickens. J. Poult. Sci. 44, 265-272

MC DEVITT, R.M., MACK, S. und WALLIS, I.R. (1999): The effect of DL-methionine and betaine supplementation on growth performance and carcass composition in male broilers. Aust. Poult. Sci. Symp. 11, 73-76

MC DEVITT, R.M., MACK, S. und WALLIS, I.R. (2000): Can betaine partially replace or enhance the effect of methionine by improving broiler growth and carcase characteristics? Br. Poult. Sci. 41, 473-480

MC HENRY, E.W. und J.M. PATTERSON (1944): Lipotropic factors. Physiol. Rev. 24, 128-167

MEHRI, M., DAVARPANAH, A.A. und MIRZAEI, H.R. (2012): Estimation of ideal ratios of methionine and threonine to lysine in starting broiler chicks using response surface methodology. Poult. Sci. 91, 771-777

MEISTER, A. (1981): Metabolism and functions of glutathione. T. Biochem. Sci. 6, 231-234

METZLER-ZEBELI, B.U., EKLUND, M. und MOSENTHIN, R. (2009): Impact of osmoregulatory and methyl donor functions of betaine on intestinal health and performance in poultry. Worlds. Poult. Sci. J. 65, 419-442

MITCHELL, J.R., BECKER, D.E., HARMON, B.G., NORTON, H.W., JENSEN, A.H. (1968): Some amino acid needs of the young pig fed a semisynthetic diet. J. Anim. Sci. 27, 1322-1326

MOORE, S., SPACKMAN, D.H. und STEIN, W.H. (1958): Chromatography of amino acids on sulfonated polystyrene resins - An improved system. Analyt. Chem. 30, 1185-1190 
MORAN, E.T. (1994): Response of broiler strains differing in body fat to inadequate methionine: live performance and processing yields. Poult. Sci. 73, 1116-1126

MORAN, E.T. (1981): Cystine requirement of feather-sexed broiler chickens with sex and age. Poult. Sci. 60, 1056-1061

MORRIS, T.R., GOUS, R.M. und FISHER, C. (1999): An analysis of the hypothesis that amino acid requirements for chicks should be stated as a proportion of dietary protein. Worlds Poult. Sci. J. 55, 7-22

NAUMANN, C. und R. BASSLER (1997): Die chemische Untersuchung von Futtermitteln. Methodenbuch Band III, VDLUFA-Verlag Darmstadt

NITSAN, Z., BEN-AVRAHAM, G., ZOREF, Z., NIR, I. (1991): Growth and development of the digestive organs and some enzymes in broiler chicks after hatching. Br. Poult. Sci. 32, 515-523

NRC [National Report Council] (1984): Nutrient Requirements of Poultry. 8thb Revised Edition. National Academy Press, Washington D.C.

NRC [National Report Council] (1994): Nutrient requirements of poultry. 9th Revised Edition. National Academy Press, Washington D.C.

OBRESHKOVA, D.P., TSVETKOVA, D.D. und IVANOV, K.V. (2012): Simultaneous identification and determination of total content of amino acids in food supplements-tablets by gas chromatography. Asian J. Pharm. Clin. Res. 5, 57-68

OHTA, Y. und T. ISHIBASHI (1994): Dietary levels and ratio of methionine and cystine for maximum performance of broilers. Japanese Poult. Sci. 31, 369-380

OPOOLA, E., OGUNDIPE, S.O., BAWA, G.S., MAKINDE, O.J., ABEJIDE, O., OLAYINKA, O.I. (2016): Determination of optimum methionine requirements of broiler chickens reared during the hot season under tropical environment. Anim. Res. Int. 13, 2421-2427

ORTH, M.W., BAI, Y., ZEYTÃOEN, I.H., COOK, M.E. (1992): Excess levels of cysteine and homocysteine induce tibial dyschondroplasia in broiler chicks. J. Nutr. 122, 482-487

OSER, B.L. (1951): Method of integrating essential amino acid content in the nutritional evaluation of protein. J. Am. Diet. Assoc. 27, 396-402

OSPINA-ROJAS, I.C., MURAKAMI, A.E., OLIVEIRA, C.A.L., GUERRA, A.F.Q.G. (2013): Supplemental glycine and threonine effects on performance, intestinal mucosa development and nutrient utilization of growing broiler chickens. Poult. Sci. 92, 2724-2731

PARK, J.H., KANG, C.W. und RYU, K.S. (2006): Effects of feeding betaine on performance and blood hormone in laying hens. Koran J. Poult. Sci. 33, 323-328

PARSONS, C.M., HASHIMOTO, K., WEDEKIND, K.J., HAN, Y., BAKER, D.H. (1992): Effect of overprocessing on availability of amino acids and energy in soybean meal. Poult. Sci. 71, 133-140

PASTOR, A., WECKE, C. und LIEBERT, F. (2013): Assessing the age-dependent optimal dietary branched-chain amino acid ratio in growing chicken by application of a nonlinear modeling procedure. Poult. Sci. 92, 31843195

PESTI, G.M., HARPER, A.E. und SUNDE, M.L. (1979): Sulfur amino acid and methyl donor status of corn-soy diets fed to starting broiler chicks and turkey poults. Poult. Sci. 58, 1541-1547

PESTI, G.M., LECLERCQ, B., CHAGNEAU, A.M., COCHARD, T. (1996): Effects of the naked neck (Na) gene on the sulfur-containing amino acid requirements of broilers. Poult. Sci. 75, 375-380

PHENOMENEX APPLICATION 14345 (2016): Free Amino Acids in Corn Meal (GC-FID)

PHENOMENEX APPLICATION 14346 (2016): Amino Acids in Corn Meal Hydrolysate

PILLAI, P.B., FANATICO, A.C., BEERS, K.W., BLAIR, M.E., EMMERT, J.L. (2006): Homocysteine remethylation in young broilers fed varying levels of methionine, choline and betaine. Poult. Sci. 85, 90-95

PISANO, J.J. und T.J. BRONZERT (1969): Analysis of amino acid phenylthiohydantoins by gas chromatography. J. Biol. Chem. 244, 5597-5607

PLAVNIK, I. und S. HURWITZ (1982): Organ weights and body composition in chickens as related to the energy and amino acid requirements: Effects of strain, sex and age. Poult. Sci. 62, 152-163

PLUSKE, J.R. (2016): Invited review: Aspects of gastrointestinal tract growth and maturation in the pre- and postweaning period of pigs. J. Anim. Sci. 94, 399-411

POURALI, M., KERMANSHAHI, H., GOLIAN, A., RAZMI, G.R., SOUKHTANLOO, M. (2014): Antioxidant and anticoccidial effects of garlic powder and sulfur amino acids on eimeria -infected and uninfected broiler chickens. Iran. J. Vet. Res. 15, 227-232 
POWELL, S., BIDNER, T.D. und SOUTHERN, L.L. (2009): The interactive effects of glycine, total sulfur amino acids and lysine supplementation to corn-soybean meal diets on growth performance and serum uric acid and urea concentrations in broilers. Poult. Sci. 88, 1407-1412

POWELL, S., BIDNER, T.D. und SOUTHERN, L.L. (2011): Effects of glycine supplementation at varying levels of methionine and cystine on the growth performance of broilers fed reduced crude protein diets. Poult. Sci. 90, 1023-1027

QUILLIN, E.C., COMBS, G.F., CREEK, R.D., ROMOSER, G.L. (1961): Effect of choline on the methionine requirements of broiler chickens. Poult. Sci. 40, 639-645

QUINTEIRO-FILHO, W.M., RIBEIRO, A., FERRAZ-DE-PAULA, V., PINHEIRO, M.L., SAKAI, M., SÁ, L.R.M., FERREIRA, A.J.P., PALERMO-NETO, J. (2010): Heat stress impairs performance parameters, induces intestinal injury and decreases macrophage activity in broiler chickens. Poult. Sci. 89, 1905-1914

RAO, P.B.R., NORTON, H.W. und JOHNSON, B.C. (1961): The amino acid composition and nutritive value of proteins. IV. Phenylalanine, tyrosine, methionine and cysteine requirements of the growing rat. J. Nutr. 73, 3842

RAFEEQ, M., PASHA, T.N., TARIQ, M.M., BAJWA, M.A. (2011): Performance of broiler chicken in early life on methionine deficient feed with added choline and betaine. Int. J. Livest. Prod. 2, 142-144

RATRIYANTO, A., MOSENTHIN, R., BAUER, E., EKLUND, M. (2009): Metabolic, osmoregulatory and nutritional functions of betaine in monogastric animals. Asian-Aust. J. Anim. Sci. 22, 1461-1476

RAVINDRAN, V., TABE, L.M., MOLVIG, L., HIGGINS, T.J.V, BRYDEBN, W.L. (2002): Nutritional evaluation of transgenic high-methionine lupins (Lupinus angustifolius L) with broiler chickens. J. Sci. Food Agric. 82, 280-285

RAVINDRAN, V., HEW, L.I., RAVINDRAN, G., BRYDEN, W.L. (2004): Endogenous amino acid flow in the avian ileum: quantification using three techniques. Br. J. Nutr. 92, 217-223

RIBEIRO, A.M.L., DAHLKE, F. und KESSLER, A.M. (2005): Methionine sources do not affect performance and carcass yield of broilers fed vegetable diets and submitted to cyclic heat stress. Brazilian J. Poult. Sci. 7, 59-164

RICHARDS, J.D., ATWELL, C.A., VÁZQUEZ-AÑÓN, M., DIBNER, J.J. (2005): Comparative in vitro and in vivo absorption of 2-hydroxy-4(methylthio) butanoic acid and methionine in the broiler chicken. Poult. Sci. 84, $1397-1405$

ROBBINS, K.R., NORTON, H.W. und BAKER, D.H. (1979): Estimation of nutrient requirements from growth data. J. Nutr. 109, 1710-1714

RODEHUTSCORD, M. und M. PACK (1999): Estimates of essential amino acid requirements from dose-response studies with rainbow trout and broiler chicken: Effect of mathematical model. Arch. Tierern. 52, 223-244

RODEHUTSCORD, M. und H. KLUTH (2003): Aminosäurenverdaulichkeit als ein Futterwertkriterium in der Geflügelfütterung: Methodische Aspekte zur Messung. Lohmann Information 4, 8-15

ROSTAGNO, H.S. und M. PACK (1996): Can betaine replace supplemental DL-methionine in broiler diets? J. Appl. Poult. Res. 5, 150-154

RUBIN, L.L., CANAL, C.W., RIBEIRO, A.L.M., KESSlER, A., SILVA, I., TREVIZAN, L., VIOLA, T., RABER, M., GONCALVES, T.A., KRAS, R. (2007a): Effects of methionine and arginine dietary levels on the immunity of broiler chickens submitted to immunological stimuli. Brazilian J. Poult. Sci. 9, 241-247

RUBIN, L.L., RIBEIRO, A.M.L., CANAL, C.W., SILVA, I.C., TREVIZAN, L., VOGT, L.K., PEREIRA, R.A., LACERDA, L. (2007b): Influence of sulfur amino acid levels in diets of broiler chickens submitted to immune stress. Brazilian J. Poult. Sci. 9, 53-59

SACRANIE, A., SVIHUS, B., DENSTADLI, V., MOEN, B., IJI, P.A., CHOCT, M. (2012): The effect of insoluble fiber and intermittent feeding on gizzard development, gut motility and performance of broiler chickens. Poult. Sci. 91, 693-700

SAKI, A.A., MOHAMMAD POU, H., AHMDI, A., AKHZAR, M., TABATABIE, M. (2007): Decreasing broiler crude protein requirement by methionine supplementation. Pakistan J. Biol. Sci. 10, 757-762

SAKI, A.A., NASERI HARSINI, R., TABATABIE, M.M., ZAMANI, P., HAGHIGHT, M. (2012): Estimates of methionine and sulfur amino acid requirements for laying hens using different models. Brazilian J. Poult. Sci. $14,159-232$

SAKOMURA, N.K., SILVA, E.P., DORIGAM, J.C.P., GOUS, R.M., ST-PIERRE, N. (2015): Modeling amino acid requirements of poultry. J. Appl. Poult. Res. 24, 267-282 
SALEHIFAR, E., SHIVAZAD, M., FOROUDI, F., CHAMANI, M., BAHARI KASHANI, R. (2012): Reevaluation of digestible amino acid requirements of male and female broilers based on different ideal amino acids ratios in starter period. Livest. Sci. 147, 154-158

SAMADI und F. LIEBERT (2006): Estimation of nitrogen maintenance requirements and potential for nitrogen deposition in fast-growing chickens depending on age and sex. Poult. Sci. 85, 1421-1429

SAMADI und F. LIEBERT (2007): Lysine requirement of fast growing chickens - Effects of age, sex, level of protein deposition and dietary lysine efficiency. J. Poult. Sci. 44, 63-72

SAMADI, WECKE, C., PASTOR, A., LIEBERT, F. (2017): Assessing lysine requirement of growing chicken by direct comparison between supplementation technique and "goettingen approach". Open J. Anim. Sci. 7, 56-69

SASSE, C.E. und D.H. BAKER (1973): Availability of sulfur amino acids in corn and corn gluten meal for growing chicks. J. Anim. Sci. 37, 1351-1355

SASSE, C.E. und D.H. BAKER (1974): Sulfur utilization by the chick with emphasis on the effect of inorganic sulfate on the cystine-methionine interrelationship. J. Nutr. 104, 244-251

SAUER, N., EMRICH, K. PIEPHO, H.P. LEMME, A., REDSHAW, M.S., MOSENTHIN, R. (2008): Metaanalysis of the relative efficiency of methionine-hydroxy-analogue-free-acid compared with DL-methionine in broilers using nonlinear mixed models. Poult. Sci. 87, 2023-2031

SAUNDERSON, C.L (1991): Metabolism of methionine and its nutritional analogues. Poult. Int. 30, 34-38

SAUNDERSON, C. und J. MACKINLAY (1990): Changes in body-weight, composition and hepatic enzyme activities in response to dietary methionine, betaine and choline levels in growing chicks. Br. J. Nutr. 63, 339349

SCHMIDT, C.J., PERSIA, M.E., FEIERSTEIN, E., KINGHAM, B., SAYLOR, W.W. (2009): Comparison of a modern broiler line and a heritage line unselected since the 1950s. Poult. Sci. 88, 2610-2619

SCHUTTE, J.B. und M. PACK (1995): Sulfur amino acid requirement of broiler chicks from fourteen to thirtyeight days of age. 1. Performance and carcass yield. Poult. Sci. 74, 480-487

SCHUTTE, J.B., DE JONG, J., SMINK, W., PACK, M. (1997): Replacement value of betaine for DL-methionine in male broiler chicks. Poult. Sci. 76, 321-325

SEKIZ, S.S., SCOTT, M.L. und NESHEIM, M.C. (1975): The effect of methionine deficiency on body weight, food and energy utilization in the chick. Poult. Sci. 54, 1184-1188

SELL, D.R., FEATHERSTON, W.R. und ROGLER, J.C. (1980): Methionine-cystine interrelationships in chicks and rats fed diets containing suboptimal levels of methionine. Poult. Sci. 59, 1878-1884

SHAKOURI, M.D. und M. MALEKZADEH (2016): Responses of broiler chickens to the nutrient recommendations of NRC (1994) and the Ross broiler management manual. Rev. Colomb. Ciencias Pecu. 29, 91-98

SHELTON, D.C., BEESON, W.M. und MERTZ, E.T. (1951): The effect of methionine and cysteine on the growth of weanling pigs. J. Anim. Sci. 10, 57-64

SHEN, Y.B., WEAVER, A.C. und KIM, S.W. (2014): Effect of feed grade L-methionine on growth performance and gut health in nursery pigs compared with conventional DL-methionine. J. Anim. Sci. 92, 5530-5539

SHEN, Y.B., FERKET, P., PARK, I., MALHEIROS, R.D., KIM, S.W. (2015): Effects of feed grade L-methionine on intestinal redox status, intestinal development and growth performance of young chickens compared with conventional DL-methionine. J. Anim. Sci. 93, 2977-2986

SHERMAN, F., STEWART, J.W. und TSUNASAWA, S. (1985): Methionine or not methionine at the beginning of a protein. Bioessays 3, 27-31

SI, J., FRITTS, C.A., WALDROUP, P.W., BURNHAM, D.J. (2004): Effects of excess methionine from meeting needs for total sulfur amino acids on utilization of diets low in crude protein by broiler chicks. J. Appl. Poult. Res. 13, 579-587

SIEGERT, W., AHMADI, H. und RODEHUTSCORD, M. (2015): Meta-analysis of the influence of dietary glycine and serine, with consideration of methionine and cysteine, on growth and feed conversion of broilers. Poult. Sci. 94, 1853-1863

SILVA, R.G.C.J., LANA, G.R.Q., BOA-VIAGEM RABELLO, C., LANA, S.R.V., BARBOZA, W.A. (2006): Requirements of methionine + cystine for female broilers chickens from 1 to 21 and 22 to 42 days old on tropical climate region. Rev. Bras. Zootec. 35, 497-503

SILVA, E.P., SAKOMURA, N.K., DORIGAM, J.C.P., MALHEIROS, E.B., KNOCHENBORGER FERNANDES, J.B., DE ARAUJO, J.A. (2014): A procedure to evaluate the efficiency of utilization of dietary amino acid for poultry. Acta Sci. Anim. Sci. Mar. 36, 163-169 
SORIANO-GARCIA, J.F., TORRAS-LLORT, M., FERRER, R., MORETO, M. (1998): Multiple pathways for methionine transport in brush-border membrane vesicles from chicken jejunum. J. Physiol. 509, 527-539

SPACKMAN, D.H., STEIN, W.H. und MOORE, S. (1958): Automatic recording apparatus for use in the chromatography of amino acids. Analyt. Chem. 30, 1190-1206

STAR, L., ROVERS, M., CORRENT, E., VAN DER KLIS, J.D. (2012): Threonine requirement of broiler chickens during subclinical intestinal Clostridium infection. Poult. Sci. 91, 643-652

STEKOL, J.A., HSU, P.T., WEISS, S., SMITH, P. (1953): Labile methyl group and its synthesis de novo in relation to growth in chicks. J. Biol. Chem. 203, 763-773

STIPANUK, M.H. (1986): Metabolism of sulfur-containing amino acids. Annu. Rev. Nutr. 6, 179-209

STIPANUK, M.H. (2004): Sulfur amino acid metabolism: Pathways for production and removal of homocysteine and cysteine. Rev. Lit. Arts Am. 24, 72-81

STOLL, B. und D.G. BURRIN (2006): Measuring splanchnic amino acid metabolism in vivo using stable isotopic tracers. J. Anim. Sci. 84, E60-E72

SÜNDER, A. und F. LIEBERT (2005): Comparison of different methods for estimation of the N-maintenance requirement (NMR) in different species based on N-rise balance experiments. Proc. Soc. Nutr. Physiol. 14, 33

SÜNDER, A., WECKE, C. und LIEBERT, F. (2015a): Einfluss des Methionin:Cystein-Verhältnisses im Futter auf abgeleitete Methioninbedarfswerte beim Masthähnchen. In: 13. Tagung Schweine- und Geflügelernährung, 24.-26. November 2015, Lutherstadt Wittenberg. (A. ZEYNER/H. KLUTH/M.BULANG/M. BOCHNIA/M. GLATTER Hrsg.), 43-45

SÜNDER, A., WECKE, C. und LIEBERT, F. (2015b): Influence of different dietary methionine to cystine ratios on growth performance, feed efficiency and protein deposition in meat type chicken. Proc. Soc. Nutr. Physiol. 24,47

SWAIN, B.K. und T.S. JOHRI (2000): Effect of supplemental methionine, choline and their combinations on the performance and immune response of broilers. Br. Poult. Sci. 41, 83-88

TAKAHASHI, K., OHTA, N. und AKIBA, Y. (1997): Influences of dietary methionine and cysteine on metabolic responses to immunological stress by Escherichia coli lipopolysaccharide injection and mitogenic response in broiler chickens. Br. J. Nutr. 78, 815-821

TEN DOESCHATE, R.A.H.M., SCHEELE, C.W., SCHREURS, V.V.A.M., VAN DER KLIS, J.D. (1993): Digestibility studies in broiler chickens: Influence of genotype, age, sex and method of determination. Br. Poult. Sci. 34, 131-146

TILLMAN, P.B. und G.M. PESTI (1986): The response of male broiler chicks to a corn-soy diet supplemented with L-methionine, L-cystine, choline, sulfate and vitamin B12. Poult. Sci. 65, 1741-1748

TIPTON, H.C., DILWORTH, B.C. und DAY, E.J. (1966): A comparison of D-, L-, DL-methionine and methionine hydroxy analogue calcium in chick diets. Poult. Sci. 45, 381-387

TSIAGBE, V.K., COOK, M.E., HARPER, A.E., SUNDE, M.L. (1987a): Enhanced immune responses in broiler chicks fed methionine-supplemented diets. Poult. Sci. 66, 1147-1154

TSIAGBE, V.K., COOK, M.E., HARPER, A.E., SUNDE, M.L. (1987b): Efficacy of cysteine in replacing methionine in the immune responses of broiler chicks. Poult. Sci. 66, 1138-1146

ULLAH, Z., AHMED, G., UN NISA, M., SARWAR, M. (2016): Standardized ileal amino acid digestibility of commonly used feed ingredients in growing broilers. Asian-Aust. J. Anim. Sci. 29, 1322-1330

VAN BARNEVELD, R.J., BATTERHAM, E.S. und NOTRON, B.W. (1994a): The effect of heat on amino acids for growing pigs. 2. Utilization of ileal-digestible lysine from heat-treated field peas (Pisum sativum cultivar Dundale). Br. J. Nutr. 72, 243-256

VAN BARNEVELD, R.J., BATTERHAM, E.S. und NOTRON, B.W. (1994b): The effect of heat on amino acids for growing pigs. 2. The availability of lysine from heat-treated field peas (Pisum sativum cultivar Dundale) determined using the slope-ratio assay. Br. J. Nutr. 72, 257-275

VEDENOV, D. und G.M. PESTI (2008): A comparison of methods of fitting several models to nutritional response data. J. Anim. Sci. 86, 500-507

VESSEY, D.A. (1978): The biochemical basis for the conjugation of bile acids with either glycine or taurine. Biochem. J. 174, 621-626

VIRTANEN, E.I. und I. ROSI (1995): Effects of betaine on methionine requirement of broilers under various environmental conditions. Aust. Poult. Sci. Symp. 7, 88-92 
WALDROUP, P. und C. FRITTS (2005): Evaluation of separate and combined effects of choline and betaine in diets for male broilers. Int. J. Poult. Sci. 4, 442-448

WALDROUP, P.W., MOTL, M.A., YAN, F., FRITTS, C.A. (2006): Effects of betaine and choline on response to methionine supplementation to broiler diets formulated to industry standards. J. Appl. Poult. Res. 15, 58-71

WALLIMANN, T., WYSS, M., BRDICKA, D., NICOLAY, K., EPPENBERGER, H.M. (1992): Intracellular compartmentation, structure and function of creatine kinase isoenzymes in tissues with high and fluctuating energy demands: the 'phosphocreatine circuit' for cellular energy homeostasis. Biochem. J. 281, 21-40

WALLIS, I.R. und D. BALNAVE (1984): The influence of environmental temperature, age and sex on the digestibility of amino acids in growing broiler chickens. Br. Poult. Sci. 25, 401-407

WANG, S.Y., BOTTJE, W., MAYNARD, P., DIBNER, J., SHERMER, W. (1997): Effect of Santoquin® and oxidized fat on liver and intestinal glutathione in broilers. Poult. Sci. 76, 961-967

WEBEL, D.M., JOHNSON, R.W. und BAKER, D.H. (1998a): Lipopolysaccharide-induced reductions in body weight gain and feed intake do not reduce the efficiency of arginine utilization for whole-body protein accretion in the chick. Poult. Sci. 77, 1893-1898

WEBEL, D.M., JOHNSON, R.W. und BAKER, D.H. (1998b): Lipopolysaccharide-induced reductions in food intake do not decrease the efficiency of lysine and threonine utilization for protein accretion in chickens. J. Nutr. 128, 1760-1766

WECKE, C. und F. LIEBERT (2009): Lysine requirement studies in modern genotype barrows dependent on age, protein deposition and dietary lysine efficiency. J. Anim. Phys. a. Anim. Nutr. 93, 295-304

WECKE, C. und F. LIEBERT (2013a): Improving the reliability of optimal in-feed amino acid ratios based on individual amino acid efficiency data from $\mathrm{N}$ balance studies in growing chicken. Animals 3, 558-573

WECKE, C. und F. LIEBERT (2013b): Umweltverträgliche Protein- und Aminosäurenversorgung von Geflügel und Schwein nach dem Konzept des Idealproteins. VDLUFA-Schriftenreihe 69, 695-702

WECKE, C. und F. LIEBERT (2016): Nitrogen and sulfur containing amino acid concentration in feather and feather-free body protein of fast growing meat type broiler chicken dependent on gender and age. Proc. Soc. Nutr. Physiol. 25, 29

WECKE, C., PASTOR, A. und LIEBERT, F. (2013): Ideal in-feed amino acid ratios for growing broiler chicken based on individual amino acid efficiency data derived from $\mathrm{N}$ balance studies. ESPN Potsdam, 152

WECKE, C., KHAN, D.R., SÜNDER, A., LIEBERT, F. (2015a): Aminosäurengehalte im Körperprotein von Masthähnchen in Abhängigkeit von Geschlecht und Alter. In: 13. Tagung Schweine- und Geflügelernährung, 24.-26. November 2015, Lutherstadt Wittenberg. (A. ZEYNER/H. KLUTH/M. BULANG/M. BOCHNIA/M. GLATTER Hrsg.), 40-42

WECKE, C., SÜNDER, A. und LIEBERT, F. (2015b): Influence of different dietary methionine to cystine ratios on growth performance, feed efficiency and protein deposition in meat type chicken. Proc. Soc. Nutr. Physiol. 24,164

WECKE, C., PASTOR, A. und LIEBERT, F. (2016): Validation of the lysine requirement as reference amino acid for ideal in-feed amino acid ratios in modern fast growing meat-type chickens. Open J. Anim. Sci. 6, 185-194

WECKE, C., KHAN, D.R., SÜNDER, A., LIEBERT, F. (2017a): Crude protein and ash contents of feathers and feather-free body of actual meat type chicken (Ross 308) depending on age and sex. Proc. Soc. Nutr. Physiol. 26

WECKE, C., KHAN, D.R., SÜNDER, A., LIEBERT, F. (2017b): Age and gender depending growth of feathers and feather-free body in modern fast growing meat-type chickens. Open J. Anim. Sci (in press)

WHEELER, K.B. und J.D. LATSHAW (1981): Sulfur amino acid requirements and interactions in broilers during two growth periods. Poult. Sci. 60, 228-236

WILLEMSEN, H., SWENNEN, Q., EVERAERT, N., GERAERT, P.A., MERCIER, Y., STINCKENS, A., DECUYPERE, E., BUYSE, J. (2011): Effects of dietary supplementation of methionine and its hydroxy analog DL-2-hydroxy-4-methylthiobutanoic acid on growth performance, plasma hormone levels and the redox status of broiler chickens exposed to high temperatures. Poult. Sci. 90, 2311-2320

WILLIAMS, N.H., STAHLY, T.S. und ZIMMERMANN, D.R. (1997a): Effect of chronic immune system activation on body nitrogen retention, partial efficiency of lysine utilization and lysine needs of pigs. J. Anim. Sci. 75, 2472-2480

WILLIAMS, N.H., STAHLY, T.S. und ZIMMERMANN, D.R. (1997b): Effect of chronic immune system activation on the rate, efficiency and composition of growth and lysine needs of pigs fed from 6 to $27 \mathrm{~kg}$. $\mathrm{J}$. Anim. Sci. 75, 2463-2471 
WOMACK, M. und W.C. ROSE (1941): The partial replacement of dietary methionine by cysteine for purposes of growth. J. Biol. Chem. 141, 375-370

WU, G. (1998): Intestinal mucosal amino acid catabolism. J. Nutr. 128, 1249-1252

WU, G. (2014): Dietary requirements of synthesizable amino acids by animals: a paradigmen shift in protein nutrition. J. Anim. Sci. Biotechnol. 5, 34

WU, G., FANG, Y.Z., YANG, S., LUPTON, J.R., TURNER, N.D. (2004): Glutathione metabolism and its implications for health. J. Nutr. 134, 489-492

WU, B., CUI, H., PENG, X., FANG, J., CUI, W., LIU, X. (2012): Pathology of spleen in chickens fed on a diet deficient in methionine. Health 4, 32-38

WU, B., CUI, H., PENG, X., FANG, J., CUI, W, LIU, X. (2013): Pathology of bursae of fabricius in methioninedeficient broiler chickens. Nutrients 5, 877-886

XIE, M., HOU, S.S., HUANG, W., FAN, H.P. (2007): Effect of excess methionine and methionine hydroxy analogue on growth performance and plasma homocysteine of growing pekin ducks. Poult. Sci. 86, 1995-1999

XING, J., KANG, L. und JIANG, Y. (2011): Effect of dietary betaine supplementation on lipogenesis gene expression and $\mathrm{CpG}$ methylation of lipoprotein lipase gene in broilers. Mol. Biol. Rep. 38, 1975-1981

YALCIN, S., OZKAN, S., ACIKGOZ, Z., OZKAN, K. (1999): Effect of dietary methionine on performance, carcase characteristics and breast meat composition of heterozygous naked neck $(\mathrm{Na} / \mathrm{na}+)$ birds under spring and summer conditions. Br. Poult. Sci. 40, 688-694

YODESERANEE, R. und C. BUNCHASAK (2012): Effects of dietary methionine source on productive performance, blood chemical and hematological profiles in broiler chickens under tropical conditions. Trop. Anim. Health Prod. 44, 1957-1963

YU D.Y., FENG J. und XU, Z.R. (2001): Effects of betaine on fat and protein metabolism in different stages of swine. Chin. J. Vet. Sci. 21, 200-203

ZARATE, A.J., MORAN, E.T. und BURNHAM, D.J. (2003): Exceeding essential amino acid requirements and improving their balance as a means to minimize heat stress in broilers. J. Appl. Poult. Res. 12, 37-44

ZEISEL, S.H. (1992): Choline: an important nutrient in brain development, liver function and carcinogenesis. J. Am. Coll. Nutr. 11, 473-481

ZHAN, X.A., LI, J.X., XU, Z.R., ZHAO, R.Q. (2006): Effects of methionine and betaine supplementation on growth performance, carcase composition and metabolism of lipids in male broilers. Br. Poult. Sci. 47, 576-580

ZHANG, M., IZUMI, I., KAGAMIMORI, S., SOKEJIMA, S., YAMAGAMI, T., LIU, Z., QI, B. (2004): Role of taurine supplementation to prevent exercise-induced oxidative stress in healthy young men. Amino Acids 26, 203-207

ZHANG, S., WONG, E.A. und GILBERT, E.R. (2015): Bioavailability of different dietary supplemental methionine sources in animals. Front. Biosci. (Elite Ed.) 7, 478-490

ZHANG, S., SAREMI, B., GILBERT, E.R., WONG, E.A. (2017): Physiological and biochemical aspects of methionine isomers and a methionine analogue in broilers. Poult. Sci. 96, 425-439

ZUBER, M., MIEDANER, T., ROSENFELDER, P., BACH KNUDSEN, K.E., RODEHUTSCORD, M. (2015): Untersuchungen zur Aminosäureverdaulichkeit verschiedener Roggengenotypen bei Legehennen. In: 13. Tagung Schweine- und Geflügelernährung, 24.-26. November 2015, Lutherstadt Wittenberg. (A. ZEYNER/H. KLUTH/M. BULANG/M. BOCHNIA/M. GLATTER Hrsg.), 49-52

ZUBER, T., ROSENFELDER, P. und RODEHUTSCORD, M. (2016): Variation of amino acid digestibility of maize grains from different genotypes in caecectomised laying hens. Proc. Soc. Nutr. Physiol. 25, 35

ZUBER, T., MAURER, H.P., MÖHRING, J., NAUTSCHER, N., SIEGERT, W., ROSENFELDER, P., RODEHUTSCORD, M. (2017): Variability in amino acid digestibility of triticale grain from diverse genotypes as studied in caecectomized laying hens. Poult. Sci. 95, 2861-2870

ZUPRIZAL, LARBIER, M. und CHAGNEAU, A.M. (1992): Effect of age and sex on true digestibility of amino acids of rapeseed and soybean meals in growing broilers. Poult. Sci. 71, 1486-1492

ZUPRIZAL, LARBIER, M., CHAGNEAU, A.M., GERAERT, P.A. (1993): Influence of ambient temperature on true digestibility of protein and amino acids of rapeseed and soybean meals in broilers. Poult. Sci. 72, 289-295 
Publikation II

DOES THE OPTIMAL DIETARY METHIONINE TO CYSTEINE RATIO IN DIETS FOR GROWING CHICKENS RESPOND TO HIGH INCLUSION RATES OF INSECT MEAL FROM HERMETIA ILLUCENS?

von/by

A. Brede, C. Wecke und F. Liebert

Animals 2018, 8, 187 
Article

\title{
Does the Optimal Dietary Methionine to Cysteine Ratio in Diets for Growing Chickens Respond to High Inclusion Rates of Insect Meal from Hermetia illucens?
}

\author{
Anne Brede, Christian Wecke and Frank Liebert * \\ Department of Animal Sciences, Division of Animal Nutrition Physiology, Georg-August-University of \\ Goettingen, 37077 Goettingen, Germany; anne.brede@agr.uni-goettingen.de (A.B.); cwecke@gwdg.de (C.W.) \\ * Correspondence: flieber@gwdg.de; Tel.: +49-551-39-23331
}

Received: 28 September 2018; Accepted: 20 October 2018; Published: 23 October 2018

check for updates

Simple Summary: Currently, several alternative protein sources are under investigation for replacing soybean meal in poultry diets. One alternative is larvae meal of the black soldier fly (Hermetia illucens) with a specific sulfur amino acid composition. The larvae meal is limiting in sulfur amino acids supply and provides a wide methionine:cysteine ratio of 61:39. Currently, it is not known whether the insect meal has an impact on the optimal ratio of methionine to cysteine in broiler chicken diets. The methionine:cysteine ratio significantly influences animal growth and welfare. Both methionine and cysteine excess and deficiency can lead to an impaired feed intake, growth, and feed efficiency. Therefore, the aim of this study was to investigate whether the optimal methionine:cysteine ratio is modulated when a high inclusion rate of partly defatted Hermetia illucens meal is applied. The results show that a methionine:cysteine ratio of 50:50 yields superior growth and dietary protein quality. It can be concluded that the insect meal under study is a promising alternative protein source without modulating the optimal methionine:cysteine ratio in broiler chicken diets.

\begin{abstract}
The dietary methionine:cysteine (Met:Cys) ratio (MCR) is an important factor influencing the optimal growth of chickens. Therefore, this study aimed to contribute to the assessment of the optimal dietary MCR in diets with the complete replacement of soybean meal (SBM) by a partly defatted larvae meal of Hermetia illucens (HM). A growth study with 240 male meat-type chickens (Ross 308) was conducted, also assessing the body nutrient deposition both at the end of the starter (day 21) and the grower (day 35) period. Birds were fed experimental diets based on wheat, maize, and insect meal $(23 \% / 21 \% \mathrm{HM}$ in starter/grower diets). Sulfur amino acids were created as the limiting AA in diets with graded MCR $(40: 60 ; 45: 55 ; 50: 50 ; 55: 45 ; 60: 40)$. The control diet contained SBM instead of HM with a MCR of 50:50. The current results based on growth parameters, dietary protein quality, and Met efficiency data gave support to the previous assumption of an ideal MCR of 50:50, which was also valid in diets with a high proportion of insect meal. The lowest MCR of 40:60 led to significantly impaired feed intake and growth of the birds, while the response to the highest MCR (60:40) was moderate.
\end{abstract}

Keywords: growing chickens; sulfur containing amino acids; methionine; cysteine; amino acid digestibility; protein quality; amino acid efficiency; insect meal; Hermetia illucens

\section{Introduction}

The sulfur containing amino acids (SAA) methionine (Met) and cysteine (Cys) play important roles in cell metabolism [1]. For example, Met initiates the protein synthesis in all eukaryotic cells $[1,2]$. Furthermore, Met is a methyl and sulfur donor and an important factor for antibody response [3-6]. 
Cys is directly involved in body sulfur transport processes, active sulfate biosynthesis, and the synthesis of, e.g., taurine, coenzyme A, and glutathione [7-9]. Met is mainly found in the muscles [10,11], while the feathers are characterized by a high Cys content [12]. This underlines the importance of these amino acids (AA) for growth and feather development in meat-type chickens. A dietary deficiency of Met or Cys leads to a significant decline in feed intake, and as a consequence, impairs growth and feed efficiency, as well as yields alterations in carcass composition [10,11,13-15]. Similar effects on feed intake, growth, and feed efficiency have also been observed due to an oversupply of Met or Cys [16-21].

However, most of the feedstuffs used in poultry nutrition do not contain a sufficient quantity of Met and Cys. In consequence, SAA are often the most limiting factor for feed protein quality in frequently used chicken diets $[5,9,22-24]$. In order to compensate the SAA-deficiency, broiler chicken diets are usually supplemented with either DL-Met, L-Met or a Met-hydroxy-analogue [25]. Aviagen [26,27] recommends 1.08-0.82\% SAA and 0.56-0.42\% Met in practical diets for Arbor Acres, Ross 308 and Ross 708 broilers depending on the age of the birds providing a Met:Cys ratio (MCR) of 52:48.

However, literature data reporting the optimal Met:Cys ratio (MCR) in broiler diets differ markedly. While the National Research Council (NRC) [28] recommended a Cys percentage of 43 or $47 \%$ of the SAA for the starter and grower diet, Baker et al. [8], Powell et al. [29], and Khan et al. [30] proposed a MCR of 50:50 in broiler chicken diets. Wheeler and Latshaw [31] stated that diets for growing chickens should maximally contain $54 \%$ and $38-43 \%$ Cys in the starter and grower period, respectively. However, the results of Farke et al. [32] and Sünder et al. [33] indicated a sparing effect for Met at a Cys proportion $>50 \%$ of the total SAA content. One important influencing factor is that the metabolic degradation of the indispensable AA Met may yield Cys [1,34-36]. Consequently, an appropriate amount of Cys leads to a decrease in cystathionine synthase and, therefore, increases the availability of Met [37]. However, the close metabolic link between Met and Cys makes it more difficult to assess both the animals' requirement for total SAA and the optimal dietary MCR. In order to minimize the metabolic degradation of the indispensable Met, it is not only important to know the total SAA requirement, but also the optimal dietary ratio between Met and Cys. The methodology used in AA requirement studies is only valid for the indispensable Met, but determining under which metabolic conditions Met degradation is found to be minimized could provide more information about the optimal dietary supply of Cys.

Currently, conventional feeds for growing chickens usually contain soybean meal (SBM) as the main protein source. However, several alternative protein sources are under investigation to lower the contribution of imported proteins to animal feeds. One possible alternative could be insect meal from Black Soldier Fly, Hermetia illucens (HM), larvae, which is characterized by a high protein content and a well-balanced AA profile [38-45]. Recent studies have demonstrated that the replacement of SBM by $\mathrm{HM}$ from $5 \%$ up to $100 \%$ is possible in AA balanced diets for both laying hens [41] and growing chickens [44-51]. However, according to the specific AA composition high inclusion rates of insect meals may alter the MCR in chicken diets and it remains unknown whether they affect the efficiency of dietary Met or Cys.

Therefore, the aim of this study was to evaluate the dietary Met efficiency at graded MCR in mixed feeds for growing chickens with a high inclusion rate of $\mathrm{HM}$, as an alternative protein source that completely replaces SBM.

\section{Materials and Methods}

The experiment was conducted at the facilities of the Division Animal Nutrition Physiology, Department of Animal Sciences, Georg-August-University of Goettingen. Investigations were approved by the Animal Welfare Committee of Lower Saxony, Germany (AZ 17A119). 


\subsection{Birds and Housing}

To begin, 240 male day-old chickens (Ross 308) were purchased from a commercial hatchery and kept on wood shavings in a floor pen for the first $24 \mathrm{~h}$ while receiving a standard starter diet. The next day, the birds were individually weighed and allotted to 48 experimental pens in order to yield a similar average body weight $\left(\mathrm{BW} ; \mathrm{BW}_{\text {start }}=55 \mathrm{~g}\right)$ per pen at the start of the experiment. Each pen $\left(\geq 1.05 \mathrm{~m}^{2}\right)$ was equipped with an individual feeder and an automatic drinking system (five birds per pen). Birds were bedded on wood shavings. The growth study was divided into a starter (day 1-21) and a grower period (day 22-35). Housing temperature was $32-26{ }^{\circ} \mathrm{C}$ in the starter and $25-22{ }^{\circ} \mathrm{C}$ in the grower period. Monochromatic light was provided for $23 \mathrm{~h}$ per day.

\subsection{Diets and Feeding}

The diets were based on wheat, maize, and SBM or insect meal. The AA content of the main ingredients is shown in Table 1.

Table 1. Analyzed amino acid content of the main feed ingredients (g/16 gN).

\begin{tabular}{ccccc}
\hline Amino Acid (g/16 gN) & Wheat & Maize & Soybean Meal & Partly Defatted Hermetia illucens Meal \\
\hline Lys & 2.72 & 2.62 & 6.07 & 5.42 \\
Met & 1.46 & 1.77 & 1.28 & 1.24 \\
Cys & 2.23 & 1.96 & 1.46 & 0.80 \\
Thr & 2.86 & 3.34 & 3.78 & 3.57 \\
Arg & 4.47 & 4.09 & 7.19 & 4.12 \\
Val & 3.85 & 4.34 & 4.37 & 5.36 \\
Leu & 6.18 & 11.37 & 7.32 & 6.24 \\
Ile & 3.07 & 3.18 & 4.34 & 3.86 \\
His & 2.19 & 2.65 & 2.53 & 2.73 \\
\hline
\end{tabular}

The AA content of the experimental diets (Table 2) was set according to the currently recommended [52] ideal amino acid ratio (IAAR), making exceptions for Met and Cys. The ratio of total SAA to lysine was fixed at 0.50 in order to ensure the limiting position of SAA in each of the diets under study. This was the precondition for evaluating the dietary AA efficiency based on the application of the "Goettingen approach" (see Section 2.5). Diets A-E contained 23.00/22.28\% (starter/grower period) partly defatted HM with graded MCR from 40:60 to 60:40 (see Table 1). The insect meal was provided by a commercial producer (Hermetia Futtermittel GbR, Baruth/Mark, Germany) and contained 60.8\% crude protein (CP), $14.1 \%$ crude lipids (CL), and $7.5 \%$ crude ash (CA) on a dry matter (DM) base. For further information see also Neumann et al. [46,47] and Velten et al. [48,49]. SBM was utilized as the reference protein source in diet F at a fixed MCR of 50:50. Grower diets were manufactured by dilution of starter diets with wheat starch in order to ensure a constant ratio between the protein sources and a consistent protein quality in the diets. In addition, as an indigestible marker, titanium dioxide was included in grower diets for assessing the apparent precaecal protein and AA digestibility by application of the marker technique.

The pelleted feed was offered ad libitum, and feeders and the drinking system were checked twice a day and cleaned if needed. The analyzed nutrient composition of the diets is shown in Table 3. 
Table 2. Composition of the experimental diets $(\mathrm{g} / \mathrm{kg})$.

\begin{tabular}{|c|c|c|c|c|c|c|c|c|c|c|c|c|}
\hline \multirow{3}{*}{ Diet } & \multicolumn{6}{|c|}{ Starter Period (Days 1-21) } & \multicolumn{6}{|c|}{ Grower Period (Days 22-35) } \\
\hline & A & B & $\mathrm{C}$ & D & $\mathbf{E}$ & $\mathbf{F}$ & A & B & $\mathrm{C}$ & $\mathbf{D}$ & E & $\mathbf{F}$ \\
\hline & HM & HM & HM & HM & HM & SBM & HM & HM & HM & HM & HM & SBM \\
\hline Met:Cys & $40: 60$ & $45: 55$ & $50: 50$ & $55: 45$ & $60: 40$ & $50: 50$ & $40: 60$ & $45: 55$ & $50: 50$ & $55: 45$ & $60: 40$ & $50: 50$ \\
\hline Hermetia meal & 230 & 230 & 230 & 230 & 230 & - & 212.8 & 212.8 & 212.8 & 212.8 & 212.8 & - \\
\hline Soybean meal & - & - & - & - & - & 350 & - & - & - & - & - & 323.8 \\
\hline Wheat & 500 & 500 & 500 & 500 & 500 & 398 & 462.5 & 462.5 & 462.5 & 462.5 & 462.5 & 368.2 \\
\hline Maize & 140 & 140 & 140 & 140 & 140 & 112 & 129.5 & 129.5 & 129.5 & 129.5 & 129.5 & 103.6 \\
\hline Wheat starch & 12.0 & 12.2 & 12.3 & 12.5 & 12.6 & 16.7 & 86.4 & 86.6 & 86.7 & 86.8 & 87.0 & 83.2 \\
\hline Soybean oil & 70 & 70 & 70 & 70 & 70 & 75 & 65 & 65 & 65 & 65 & 65 & 80 \\
\hline $\mathrm{DCP}$ & 10 & 10 & 10 & 10 & 10 & 16 & 8 & 8 & 8 & 8 & 8 & 12 \\
\hline $\mathrm{CaCO}_{3}$ & 11 & 11 & 11 & 11 & 11 & 11 & 8 & 8 & 8 & 8 & 8 & 8 \\
\hline $\mathrm{NaCl}$ & 2 & 2 & 2 & 2 & 2 & 5 & 1 & 1 & 1 & 1 & 1 & 2.5 \\
\hline Premix ${ }^{1}$ & 10 & 10 & 10 & 10 & 10 & 10 & 10 & 10 & 10 & 10 & 10 & 10 \\
\hline L-Lysine $\cdot \mathrm{HCl}$ & 5.65 & 5.65 & 5.65 & 5.65 & 5.65 & 3.74 & 5.21 & 5.21 & 5.21 & 5.21 & 5.21 & 3.44 \\
\hline L-Cysteine $\cdot \mathrm{HCl} \cdot \mathrm{H}_{2} \mathrm{O}$ & 2.24 & 1.73 & 1.22 & 0.73 & 0.22 & 0.03 & 2.06 & 1.58 & 1.13 & 0.66 & 0.19 & 0.03 \\
\hline L-Arginine & 5.77 & 5.77 & 5.77 & 5.77 & 5.77 & 1.02 & 5.35 & 5.35 & 5.35 & 5.35 & 5.35 & 0.96 \\
\hline L-Threonine & 1.35 & 1.35 & 1.35 & 1.35 & 1.35 & 0.85 & 1.23 & 1.23 & 1.23 & 1.23 & 1.23 & 0.77 \\
\hline DL-Methionine & - & 0.35 & 0.71 & 1.04 & 1.39 & 0.65 & - & 0.33 & 0.65 & 0.96 & 1.29 & 0.59 \\
\hline $\mathrm{TiO}_{2}$ & - & - & - & - & - & - & 3 & 3 & 3 & 3 & 3 & 3 \\
\hline
\end{tabular}

${ }^{1}$ Added per $\mathrm{kg}$ of final diet: $2.1 \mathrm{~g}$ calcium, $0.8 \mathrm{~g}$ sodium, $5000 \mathrm{IU}$ vitamin $\mathrm{A}, 1000 \mathrm{IU}$ vitamin $\mathrm{D} 3,30 \mathrm{mg}$ vitamin $\mathrm{E}$, $2.6 \mathrm{mg}$ vitamin B1, $4.8 \mathrm{mg}$ vitamin B2, 3.2 mg vitamin B6, $20 \mu \mathrm{g}$ vitamin B12, $3 \mathrm{mg}$ vitamin $\mathrm{K} 3,50 \mathrm{mg}$ nicotinic acid, $10 \mathrm{mg}$ calcium pantothenate, $0.9 \mathrm{mg}$ folic acid, $100 \mu \mathrm{g}$ biotin, $1000 \mathrm{mg}$ choline chloride, $50 \mathrm{mg}$ Fe as iron-II-sulfate, monohydrate, $15 \mathrm{mg} \mathrm{Cu}$ as copper-II-sulfate, pentahydrate, $120 \mathrm{mg} \mathrm{Mn}$ as manganese-II-oxide, $70 \mathrm{mg} \mathrm{Zn}$ as zinc oxide, $1.4 \mathrm{mg}$ I as calcium iodate, hexahydrate, $0.28 \mathrm{mg}$ Se as sodium selenite, $0.55 \mathrm{mg}$ Co as alkaline cobalt-II-carbonate, monohydrate, and $100 \mathrm{mg}$ butylhydroxytoluol.

Table 3. Analyzed nutrient content of the experimental diets.

\begin{tabular}{|c|c|c|c|c|c|c|c|c|c|c|c|c|}
\hline \multirow{3}{*}{ Diet } & \multicolumn{6}{|c|}{ Starter Period (Days 1-21) } & \multicolumn{6}{|c|}{ Grower Period (Days 22-35) } \\
\hline & A & B & $\mathrm{C}$ & D & $\mathrm{E}$ & $\mathbf{F}$ & A & B & $\mathrm{C}$ & D & $\mathbf{E}$ & F \\
\hline & HM & HM & HM & HM & HM & SBM & HM & HM & HM & HM & HM & SBM \\
\hline Met:Cys & $40: 60$ & 45:55 & $50: 50$ & $55: 45$ & $60: 40$ & $50: 50$ & $40: 60$ & 45:55 & $50: 50$ & $55: 45$ & $60: 40$ & $50: 50$ \\
\hline \multicolumn{13}{|c|}{ Crude nutrient composition (\% DM) } \\
\hline Crude protein & 23.8 & 23.9 & 23.4 & 23.3 & 23.3 & 22.9 & 22.2 & 22.0 & 22.1 & 22.5 & 21.6 & 21.1 \\
\hline Crude lipids & 12.1 & 12.8 & 12.8 & 12.8 & 12.2 & 10.7 & 11.4 & 11.1 & 11.1 & 11.4 & 11.5 & 11.0 \\
\hline Crude fiber & 4.3 & 4.2 & 3.9 & 3.9 & 3.8 & 4.3 & 3.7 & 3.7 & 3.7 & 3.7 & 3.8 & 4.0 \\
\hline Crude ash & 5.5 & 5.7 & 5.6 & 5.5 & 5.6 & 7.2 & 5.2 & 5.1 & 5.2 & 5.2 & 5.2 & 6.2 \\
\hline $\mathrm{AME}_{\mathrm{n}}(\mathrm{MJ} / \mathrm{kg} \mathrm{DM})^{1}$ & 15.8 & 15.8 & 15.8 & 15.8 & 15.8 & 14.2 & 15.8 & 15.8 & 15.8 & 15.8 & 15.8 & 14.5 \\
\hline \multicolumn{13}{|c|}{ Amino acid composition $(\mathrm{g} / 16 \mathrm{gN})^{2}$} \\
\hline Lys & 6.16 & 6.16 & 6.16 & 6.16 & 6.16 & 6.41 & 6.16 & 6.16 & 6.17 & 6.17 & 6.17 & 6.42 \\
\hline Met & 1.22 & 1.38 & 1.54 & 1.69 & 1.85 & 1.61 & 1.23 & 1.39 & 1.54 & 1.70 & 1.90 & 1.61 \\
\hline Met + Cys & 3.08 & 3.08 & 3.08 & 3.08 & 3.08 & 3.21 & 3.08 & 3.08 & 3.09 & 3.08 & 3.08 & 3.21 \\
\hline Thr & 3.70 & 3.70 & 3.70 & 3.70 & 3.70 & 3.85 & 3.70 & 3.70 & 3.70 & 3.70 & 3.70 & 3.85 \\
\hline Arg & 6.47 & 6.47 & 6.47 & 6.47 & 6.47 & 6.73 & 6.47 & 6.47 & 6.47 & 6.47 & 6.47 & 6.73 \\
\hline Val & 4.49 & 4.49 & 4.49 & 4.49 & 4.49 & 4.13 & 4.49 & 4.49 & 4.49 & 4.49 & 4.49 & 4.13 \\
\hline Leu & 6.00 & 6.00 & 6.00 & 6.00 & 6.00 & 7.04 & 6.00 & 6.00 & 6.00 & 6.00 & 6.00 & 7.04 \\
\hline Ile & 3.31 & 3.31 & 3.31 & 3.31 & 3.31 & 3.89 & 3.31 & 3.31 & 3.31 & 3.31 & 3.31 & 3.89 \\
\hline His & 2.36 & 2.37 & 2.37 & 2.37 & 2.37 & 2.39 & 2.37 & 2.37 & 2.37 & 2.37 & 2.37 & 2.39 \\
\hline
\end{tabular}

${ }^{1} \mathrm{~N}$-corrected apparent metabolizable energy, calculated according to WPSA [53]; ${ }^{2}$ Final AA content of the mixed diets derived from analyzed AA composition of the ingredients.

\subsection{Chemical Analysis}

Feed ingredients as well as final diets, chyme, and animal bodies were analyzed according to the national standards of the Association of German Agricultural Analytic and Research Institutes (VDLUFA) [54]. Chyme samples were freeze-dried for $48 \mathrm{~h}$ (Model $\alpha 1-4^{\circledR}$, Christ GmbH, Osterode am Harz, Germany) before analysis. Whole bodies were homogenized without defrosting using a band saw (Model FK 22, Bizerba SE \& Co. KG, Balingen, Germany) and a mincing machine (Model EM 82 VL-S, Edertal Elektromotoren GmbH \& Co. KG, Wabern, Germany). A representative sample of the body 
homogenate was freeze-dried before analysis. This time-consuming procedure was applied to prevent body SAA losses during usual autoclaving processes [24,55] before further homogenization. The $\mathrm{N}$ content was quantified by the Dumas method (TruMac ${ }^{\circledR}$, Leco Instrument GmbH, Moenchengladbach, Germany) and CP was calculated with a factor of 6.25. AA analysis was conducted using ion-exchange chromatography (Biochrom ${ }^{\circledR}$ 30, Biochrom Ltd., Cambridge, UK) following acid hydrolysis with or without an oxidation step for the quantitative determination of SAA. CL content was analyzed following $\mathrm{HCl}$ hydrolysis of the feed samples. CL content of the animal bodies was calculated by difference $(C L=100-C P-C A)$ and expressed as percent of DM.

\subsection{Growth, Feed Efficiency, and Digestibility Data}

Individual bird BW and feed intake per pen were monitored weekly in order to calculate daily body weight gain (BWG), dry matter intake (DMI), and feed conversion ratio (FCR). Additionally, 20 birds per diet were chosen for assessing apparent precaecal digestibility (apD). Therefore, pooled precaecal samples $(n=5)$ were collected from the last 2/3 between Meckel's diverticulum and $2 \mathrm{~cm}$ before the ileo-caecal junction after slaughtering on day 36 and were immediately frozen and stored at $-20{ }^{\circ} \mathrm{C}$ until further analysis. apD was calculated as follows:

$$
\operatorname{apD}(\%)=100-100 \times \frac{\left(\text { marker }_{\text {feed }} \times \text { nutrient }_{\text {chyme }}\right)}{\left(\text { marker }_{\text {chyme }} \times \text { nutrient }_{\text {feed }}\right)}
$$

where: marker $_{\text {feed }}=$ concentration of the marker in the feed $(\% \mathrm{DM})$, marker $_{\text {chyme }}=$ concentration of the marker in the chyme $(\% \mathrm{DM})$, nutrient $_{\text {chyme }}=$ concentration of the nutrient $(\mathrm{CP}, \mathrm{AA})$ in the chyme $(\% \mathrm{DM})$, and nutrient $_{\text {feed }}=$ concentration of the nutrient $(\mathrm{CP}, \mathrm{AA})$ in the feed $(\% \mathrm{DM})$.

\subsection{Body N deposition, Dietary Protein Quality, and Met Efficiency Parameters}

Following a $24 \mathrm{~h}$ feed deprivation period, both at the end of the starter (day 21) and grower period (day 35), one representative bird per pen was chosen for whole body $\mathrm{N}$ analysis. The selected birds were euthanized via carbon dioxide exposure according to animal welfare regulations and subsequently frozen $\left(-20^{\circ} \mathrm{C}\right)$ until further sample preparation. Based on the comparative slaughter technique, average daily $\mathrm{N}$ deposition $(N D)$ was calculated using the difference between the analyzed final quantity of body $\mathrm{N}$ and initial body $\mathrm{N}$ for the starter, grower, and total growth period. Data for the initial quantity of body $\mathrm{N}$ were taken from an earlier study with the same genotype [56]. Calculated mean daily $N D$ values were related to the corresponding average metabolic $\mathrm{BW}\left(\mathrm{mg} \mathrm{N} / \mathrm{BW}_{\mathrm{kg}}{ }^{0.67}\right)$.

According to earlier reports [30,57-64] the "Goettingen approach" was applied as follows:

$$
\begin{gathered}
N R=N R_{\max } T\left(1-e^{-N I \times b}\right) \\
N D=N R_{\max } T\left(1-e^{-N I \times b}\right)-N M R \\
b=\left[\ln N R_{\max } T-\ln \left(N R_{\max } T-N R\right)\right]: N I
\end{gathered}
$$

where: $N R=$ daily $\mathrm{N}$ retention $\left(\mathrm{mg} / \mathrm{BW}_{\mathrm{kg}}{ }^{0.67}\right), N R_{\max } \mathrm{T}=$ daily theoretical maximum of the $\mathrm{N}$ retention $\left(\mathrm{mg} / \mathrm{BW}_{\mathrm{kg}}{ }^{0.67}\right), \mathrm{ND}=$ daily $\mathrm{N}$ deposition $\left(\mathrm{mg} / \mathrm{BW}_{\mathrm{kg}}{ }^{0.67}\right), \mathrm{NMR}=$ daily $\mathrm{N}$ maintenance requirement $\left(\mathrm{mg} / \mathrm{BW}_{\mathrm{kg}}{ }^{0.67}\right), \mathrm{NI}=$ daily $\mathrm{N}$ intake $\left(\mathrm{mg} / \mathrm{BW}_{\mathrm{kg}}{ }^{0.67}\right), b=$ slope of the $\mathrm{N}$ retention curve (indicating the feed protein quality independent of $N I)$, and $e=$ base number of the natural logarithm $(\ln )$.

The model parameters for daily $N M R\left(240 \mathrm{mg} / \mathrm{BW}_{\mathrm{kg}}{ }^{0.67}\right)$ and $N R_{\max } T(4240,3440$, and $3840 \mathrm{mgN} / \mathrm{BW}_{\mathrm{kg}} 0.67 / \mathrm{d}$ as applied for starter, grower, and the whole growth periods, respectively) were taken from earlier experiments with the same genotype [62]. 
Due to the fact that traditional protein quality parameters were not independent of the level of realized protein intake [65-67], a standardization of protein intake was conducted by the "Goettingen approach" according to earlier reports [46-49,60,64,66,67]:

$$
N P U_{s t d .}(\%)=N R_{\max } T \times \frac{\left(1-e^{-b \times N I_{\text {std. }}}\right)}{N I_{\text {std. }}} \times 100
$$

The standardized $\mathrm{N}$ intake as applied was $3300 \mathrm{mg} / \mathrm{BW}_{\mathrm{kg}} 0.67$ (starter period), $3000 \mathrm{mg} / \mathrm{BW}_{\mathrm{kg}}^{0.67}$ (grower period), and $3200 \mathrm{mg} / \mathrm{BW}_{\mathrm{kg}}{ }^{0.67}$ (total growth period). The model parameter $b$ as derived from the exponential function (Equation (3)) is a prerequisite for applying this standardization procedure.

According to Samadi and Liebert [68], the model parameter $b$ is closely related to the concentration of the limiting AA $(c)$. The quotient $b c^{-1}$ describes the slope of this linear relationship and indicates the efficiency of utilizing the limiting AA in the diet $[58,66]$ :

$$
b c^{-1}=\frac{b}{c}
$$

where: $b=$ slope of the $\mathrm{N}$ retention curve (indicating the feed protein quality independent of NI) and $c=$ concentration of the limiting AA in the feed protein $(\mathrm{g} / 16 \mathrm{gN})$.

\subsection{Body Protein and Body Fat Deposition}

The protein and fat deposition were determined by computing the difference between the analyzed nutrient contents in the whole body of birds at the end and the start of each growth period, respectively. Data for the initial quantity of body protein and body fat were taken from an earlier study with the same genotype [56].

\subsection{Statistical Analysis}

Statistical analyses were conducted with SPSS software package (IBM SPSS Statistics, Version 24.0). One-way analysis of variance (ANOVA) tests were performed to compare means and standard deviations of all data. Dependent on the variance homogeneity (evaluated by Levene-Test), identification of significant differences $(p \leq 0.05)$ was carried out making use of the Games-Howell test and Tukey post-hoc test, respectively.

\section{Results}

\subsection{Growth and Feed Efficiency}

The zoo-technical results (Table 4) demonstrated that in the starter period diet C (HM 50:50) and diet F (SBM 50:50) yielded both superior final body weight (FBW) and daily body weight gain (BWG), but did not significantly differ from diet D (HM 55:45). The response with diet $\mathrm{C}$ was significant as compared to the diets with a lower MCR (A,B), but did not differ significantly from diet E (HM 60:40). Significant effects were seen for daily dry matter intake (DMI), which was consistently below diet $\mathrm{F}$ $(p<0.05)$, but highest with diet C between SBM substituted diets. Consequently, the feed conversion ratio (FCR) was impaired with diet $F$, but the effect was insignificant. The best FCR was found in diet C (HM 50:50) with only numerous differences to diets with a higher MCR (D,E) and the SBM diet F. Diet A (HM 40:60) yielded the lowest DMI, and as a consequence, the lowest FBW $(p<0.05)$. In general, modulating the MCR significantly affected zoo-technical data in the starter period. 
Table 4. Results of growth and feed efficiency parameters ${ }^{1}$.

\begin{tabular}{|c|c|c|c|c|c|c|}
\hline $\begin{array}{c}\text { Diet } \\
\text { Met:Cys }\end{array}$ & $\begin{array}{c}\text { A } \\
\text { HM } \\
40: 60\end{array}$ & $\begin{array}{c}\text { B } \\
\text { HM } \\
45: 55\end{array}$ & $\begin{array}{c}\text { C } \\
\text { HM } \\
50: 50\end{array}$ & $\begin{array}{c}\text { D } \\
\text { HM } \\
55: 45\end{array}$ & $\begin{array}{c}\text { E } \\
\mathrm{HM} \\
60: 40\end{array}$ & $\begin{array}{c}\text { F } \\
\text { SBM } \\
50: 50\end{array}$ \\
\hline \multicolumn{7}{|c|}{ Starter period (days 1-21) } \\
\hline FBW $(\mathrm{g})$ & $622^{a} \pm 91$ & $847^{b} \pm 72$ & $978^{\mathrm{cd}} \pm 83$ & $911^{\mathrm{bcd}} \pm 78$ & 879 bc \pm 72 & $1021^{\mathrm{d}} \pm 46$ \\
\hline BWG $(\mathrm{g} / \mathrm{d})$ & $27^{\mathrm{a}} \pm 4$ & $38^{b} \pm 3$ & $44^{\mathrm{cd}} \pm 4$ & $41^{\mathrm{bcd}} \pm 4$ & $39^{b c} \pm 3$ & $46^{\mathrm{d}} \pm 2$ \\
\hline DMI $(\mathrm{g} / \mathrm{d})$ & $40.4^{\mathrm{a}} \pm 4.8$ & $51.1^{\mathrm{b}} \pm 4.6$ & $54.4^{\mathrm{b}} \pm 4.3$ & $51.7^{\mathrm{b}} \pm 2.4$ & $49.9^{b} \pm 5.0$ & $61.7^{\mathrm{c}} \pm 4.6$ \\
\hline FCR & $1.51^{\mathrm{a}} \pm 0.15$ & $1.36^{\mathrm{ab}} \pm 0.07$ & $1.24^{\mathrm{c}} \pm 0.07$ & $1.27^{\mathrm{bc}} \pm 0.08$ & $1.27^{\mathrm{bc}} \pm 0.09$ & $1.34^{\mathrm{abc}} \pm 0.06$ \\
\hline \multicolumn{7}{|c|}{ Grower period (days 22-35) } \\
\hline FBW $(\mathrm{g})$ & $1307^{\mathrm{a}} \pm 227$ & $1780^{\mathrm{b}} \pm 150$ & $2064^{c} \pm 232$ & $1838^{\mathrm{bc}} \pm 153$ & $1628^{b} \pm 161$ & $2108^{c} \pm 150$ \\
\hline BWG (g/d) & $49^{\mathrm{a}} \pm 11$ & $67^{b c} \pm 10$ & $78^{c} \pm 13$ & $66^{\mathrm{bc}} \pm 8$ & $54^{\mathrm{ab}} \pm 7$ & $78^{c} \pm 8$ \\
\hline DMI $(g / d)$ & $77.5^{\mathrm{a}} \pm 16.3$ & $99.4^{b c} \pm 12.7$ & $114.1^{\mathrm{cd}} \pm 14.2$ & $102.5^{\mathrm{bc}} \pm 10.2$ & $86.3^{\mathrm{ab}} \pm 8.6$ & $131.2^{\mathrm{d}} \pm 12.5$ \\
\hline FCR & $1.59^{\mathrm{ab}} \pm 0.11$ & $1.51^{\mathrm{b}} \pm 0.17$ & $1.49^{b} \pm 0.12$ & $1.55^{\mathrm{ab}} \pm 0.07$ & $1.62^{\mathrm{ab}} \pm 0.09$ & $1.69^{\mathrm{a}} \pm 0.03$ \\
\hline \multicolumn{7}{|c|}{ Total growth period (days 1-35) } \\
\hline FBW $(\mathrm{g})$ & $1307^{\mathrm{a}} \pm 227$ & $1780^{\mathrm{b}} \pm 150$ & $2064^{c} \pm 232$ & $1838^{b c} \pm 153$ & $1628^{b} \pm 161$ & $2108^{c} \pm 150$ \\
\hline BWG (g/d) & $36^{a} \pm 7$ & $49^{b} \pm 4$ & $57^{c} \pm 7$ & $51^{\mathrm{bc}} \pm 4$ & $45^{\mathrm{b}} \pm 5$ & $59^{c} \pm 4$ \\
\hline DMI $(\mathrm{g} / \mathrm{d})$ & $55.6^{a} \pm 9.0$ & $70.5^{\mathrm{bc}} \pm 6.2$ & $78.3^{c} \pm 7.1$ & $72.0^{\mathrm{bc}} \pm 8.1$ & $64.5^{\mathrm{ab}} \pm 5.8$ & $89.5^{\mathrm{d}} \pm 7.2$ \\
\hline FCR & $1.55^{\mathrm{ab}} \pm 0.08$ & $1.43^{\mathrm{abc}} \pm 0.10$ & $1.37^{c} \pm 0.08$ & $1.42^{c} \pm 0.03$ & $1.44^{b c} \pm 0.06$ & $1.53^{\mathrm{a}} \pm 0.03$ \\
\hline
\end{tabular}

Accordingly, the results of the grower period follow a similar trend as those of the starter period. Both diets with an MCR of 50:50 (diet C and F) yielded superior FBW and BWG without significant differences between them. In addition, as in the starter period, there was no observed significant difference to diet D (HM 55:45) for FBW and BWG, but a trend was seen. However, in contrast to the starter period, the FCR between diet $C$ and F was significantly different. The FCR of the SBM based $\operatorname{diet} \mathrm{F}$ was significantly impaired. The decline of the MCR (diet A) led to significantly impaired DMI and related zoo-technical results. DMI with diet $\mathrm{F}$ was the highest $(p<0.05)$, but not significantly different from diet C.

Summarizing the results of the total growth period underlines that diet $\mathrm{C}$ (HM 50:50) and $\operatorname{diet} \mathrm{F}$ (SBM 50:50) achieved superior zoo-technical results, that were not significantly different from diet D (HM 55:45). However, birds fed diet F also revealed a significantly higher DMI, leading to an impaired FCR, even lower than that of diet A (HM 40:60). Diet A also led to the lowest DMI and declined FBW and BWG $(p<0.05)$.

\subsection{Apparent Precaecal Digestibility}

Both the apD of crude protein and all AA, except for Met, were not significantly different between the HM diets A-E (Table 5). The apD of Met was the highest in diet E (HM 60:40) and significantly different $(p<0.05)$ from both diet A (HM 40:60) and diet F (SBM 50:50). A comparison of diet C (HM 50:50) and F (SBM 50:50) showed no significant differences in the apD of crude protein and individual AAs. However, significant differences $(p<0.05)$ in the apD of Met, Thr, and Leu between $\operatorname{diet} \mathrm{E}$ (HM 60:40) and F (SBM 50:50) were observed. ApD of Arg and Val differed significantly $(p<0.05)$ between diet D (HM 55:45), E (HM 60:40), and F (SBM 50:50), while apD of Cys was even significantly lower $(p<0.05)$ in diet $\mathrm{F}$ than in all HM diets, except for $\operatorname{diet} \mathrm{C}$ (HM 50:50). 
Table 5. Apparent precaecal digestibility (\%) of crude protein (CP) and selected amino acids in the experimental diets $(n=5)^{1}$.

\begin{tabular}{|c|c|c|c|c|c|c|}
\hline Met:Cys & $\begin{array}{c}\text { A } \\
\text { HM } \\
40: 60\end{array}$ & $\begin{array}{c}\text { B } \\
\text { HM } \\
45: 55\end{array}$ & $\begin{array}{c}\text { C } \\
\text { HM } \\
50: 50\end{array}$ & $\begin{array}{c}\text { D } \\
\text { HM } \\
55: 45\end{array}$ & $\begin{array}{c}\text { E } \\
\text { HM } \\
60: 40\end{array}$ & $\begin{array}{c}F \\
\text { SBM } \\
50: 50\end{array}$ \\
\hline $\mathrm{CP}$ & $74.2 \pm 4.0$ & $76.7 \pm 2.8$ & $76.0 \pm 2.9$ & $79.2 \pm 2.7$ & $79.6 \pm 2.0$ & $77.7 \pm 1.9$ \\
\hline Lys & $83.4 \pm 2.2$ & $84.9 \pm 3.4$ & $83.4 \pm 3.9$ & $86.7 \pm 2.5$ & $88.1 \pm 1.6$ & $83.4 \pm 2.0$ \\
\hline Met & $82.1^{\mathrm{a}} \pm 2.2$ & $85.8^{\mathrm{ab}} \pm 4.5$ & $87.6^{\mathrm{ab}} \pm 5.4$ & $88.3^{\mathrm{ab}} \pm 2.6$ & $91.3^{b} \pm 1.6$ & $83.6^{a} \pm 2.2$ \\
\hline Cys & $66.6^{b} \pm 4.0$ & $68.2^{b} \pm 3.6$ & $61.6^{\mathrm{ab}} \pm 4.1$ & $69.8^{b} \pm 4.8$ & $63.3^{b} \pm 6.1$ & $52.7^{\mathrm{a}} \pm 1.0$ \\
\hline Thr & $73.2^{\mathrm{ab}} \pm 2.2$ & $76.2^{\mathrm{ab}} \pm 4.3$ & $72.9^{\mathrm{ab}} \pm 4.1$ & $77.7^{\mathrm{ab}} \pm 3.0$ & $78.8^{b} \pm 2.6$ & $69.5^{\mathrm{a}} \pm 5.7$ \\
\hline Arg & $88.4^{\mathrm{ab}} \pm 1.7$ & $89.0^{\mathrm{ab}} \pm 2.5$ & $87.7^{\mathrm{ab}} \pm 3.0$ & $89.9^{b} \pm 2.2$ & $91.3^{b} \pm 1.2$ & $84.9^{\mathrm{a}} \pm 1.4$ \\
\hline His & $79.9 \pm 2.2$ & $81.2 \pm 2.9$ & $80.4 \pm 3.2$ & $83.1 \pm 2.7$ & $84.3 \pm 1.7$ & $81.3 \pm 1.7$ \\
\hline Ileu & $80.9 \pm 1.9$ & $82.3 \pm 3.8$ & $81.0 \pm 4.2$ & $83.9 \pm 2.9$ & $85.4 \pm 2.2$ & $79.3 \pm 2.0$ \\
\hline Leu & $81.7^{a b} \pm 2.2$ & $83.3^{a b} \pm 4.6$ & $81.7^{\mathrm{ab}} \pm 4.0$ & $84.8^{a b} \pm 2.8$ & $86.3^{b} \pm 1.9$ & $79.7^{a} \pm 2.1$ \\
\hline Phe & $83.3 \pm 1.8$ & $85.0 \pm 3.9$ & $82.8 \pm 3.7$ & $86.3 \pm 2.6$ & $84.4 \pm 1.9$ & $82.0 \pm 1.6$ \\
\hline Val & $73.4^{\mathrm{ab}} \pm 2.7$ & $76.2^{\mathrm{ab}} \pm 3.8$ & $73.9^{\mathrm{ab}} \pm 3.2$ & $78.7^{b} \pm 2.5$ & $79.6^{b} \pm 2.8$ & $71.5^{\mathrm{a}} \pm 2.2$ \\
\hline
\end{tabular}

${ }^{1}$ Means \pm standard deviations, different superscript letters reveal significant differences between diets $(p<0.05)$.

\subsection{Protein Quality and Met Efficiency}

In the starter period (Table 6), the $\mathrm{N}$ deposition $(N D)$ data and derived parameters of both dietary protein quality $\left(b, \mathrm{NPU}_{\text {std. }}\right)$ and Met efficiency $\left(b c^{-1}\right)$ are in general agreement with the summarized results of the growth study (Table 5). Diet C (HM 50:50) and diet F (SBM 50:50) yielded the highest ND data, and diet A (HM 40:60) was inferior $(p<0.05)$. Increasing the MCR led to a significant increase in $N D$ values yielding a plateau with $\operatorname{diet} C$. As a consequence, a further increase of the MCR tended to decrease $N D$. The protein quality parameters of diet C (HM 50:50) were neither significantly different from diet F (SBM 50:50), diet D (HM 55:45), nor diet E (60:40). However, diet A (HM 40:60) yielded the lowest protein quality $(p<0.05)$. The observed Met efficiency was the highest across diets A (HM 40:60), B (HM 55:45), and C (HM 50:50), but declined $(p<0.05)$ when the MCR increased (diets D,E). Diet F (SBM 50:50) tended to have a lower Met efficiency as compared to diets A, B, and C $(p>0.05)$.

Table 6. Results of dietary protein quality $\left(b, \mathrm{NPU}_{\text {std. }}\right)$ and Met efficiency $\left(b c^{-1}\right)^{1}$.

\begin{tabular}{|c|c|c|c|c|c|c|}
\hline $\begin{array}{c}\text { Diet } \\
\text { Met:Cys }\end{array}$ & $\begin{array}{c}\text { A } \\
\text { HM } \\
40: 60\end{array}$ & $\begin{array}{c}\text { B } \\
\text { HM } \\
45: 55\end{array}$ & $\begin{array}{c}\text { C } \\
\text { HM } \\
50: 50\end{array}$ & $\begin{array}{c}\text { D } \\
\text { HM } \\
55: 45\end{array}$ & $\begin{array}{c}\text { E } \\
\mathrm{HM} \\
60: 40\end{array}$ & $\begin{array}{c}\text { F } \\
\text { SBM } \\
50: 50\end{array}$ \\
\hline \multicolumn{7}{|c|}{ Starter period (days 1-21) } \\
\hline $\begin{array}{c}N D^{2} \\
b\left(\times 10^{6}\right)^{3} \\
\text { NPU }_{\text {std. }}(\%)^{3} \\
b c^{-1}\left(\times 10^{6}\right)^{3}\end{array}$ & $\begin{array}{c}1294^{\mathrm{a}} \pm 91 \\
140^{\mathrm{a}} \pm 15 \\
47.3^{\mathrm{a}} \pm 4.0 \\
114^{\mathrm{bc}} \pm 12\end{array}$ & $\begin{array}{c}1511^{\mathrm{b}} \pm 81 \\
157^{\mathrm{b}} \pm 9 \\
52.0^{\mathrm{b}} \pm 2.2 \\
114^{\mathrm{bc}} \pm 6\end{array}$ & $\begin{array}{c}1636^{\mathrm{cd}} \pm 58 \\
178^{\mathrm{c}} \pm 11 \\
57.1^{\mathrm{c}} \pm 2.5 \\
116^{\mathrm{c}} \pm 7\end{array}$ & $\begin{array}{c}1594^{\mathrm{bc}} \pm 57 \\
174^{\mathrm{bc}} \pm 11 \\
56.0^{\mathrm{bc}} \pm 2.7 \\
103^{\mathrm{ab}} \pm 7\end{array}$ & $\begin{array}{c}1576^{\mathrm{bc}} \pm 56 \\
175^{\mathrm{bc}} \pm 13 \\
56.2^{\mathrm{bc}} \pm 3.1 \\
94^{\mathrm{a}} \pm 7\end{array}$ & $\begin{array}{c}1706^{\mathrm{d}} \pm 33 \\
175^{\mathrm{c}} \pm 8 \\
56.4^{\mathrm{c}} \pm 1.9 \\
109^{\mathrm{bc}} \pm 5\end{array}$ \\
\hline \multicolumn{7}{|c|}{ Grower period (days 22-35) } \\
\hline $\begin{array}{c}N D^{2} \\
b\left(\times 10^{6}\right)^{3} \\
\mathrm{NPU}_{\text {std. }}(\%)^{3} \\
b c^{-1}\left(\times 10^{6}\right)^{3}\end{array}$ & $\begin{array}{c}1185^{\mathrm{ab}} \pm 155 \\
189^{\mathrm{a}} \pm 16 \\
49.6^{\mathrm{a}} \pm 3.1 \\
154^{\mathrm{d}} \pm 13\end{array}$ & $\begin{array}{c}1412^{\mathrm{c}} \pm 165 \\
222^{\mathrm{bc}} \pm 32 \\
55.5^{\mathrm{bc}} \pm 5.5 \\
160^{\mathrm{d}} \pm 23\end{array}$ & $\begin{array}{c}1532^{\mathrm{c}} \pm 170 \\
235^{\mathrm{c}} \pm 27 \\
57.9^{\mathrm{c}} \pm 4.4 \\
153^{\mathrm{cd}} \pm 18\end{array}$ & $\begin{array}{c}1383^{\mathrm{bc}} \pm 122 \\
215^{\mathrm{abc}} \pm 12 \\
54.4^{\mathrm{abc}} \pm 2.3 \\
127^{\mathrm{b}} \pm 7\end{array}$ & $\begin{array}{c}1156^{\mathrm{a}} \pm 111 \\
195^{\mathrm{ab}} \pm 13 \\
50.8^{\mathrm{ab}} \pm 2.5 \\
106^{\mathrm{a}} \pm 7\end{array}$ & $\begin{array}{c}1519^{\mathrm{c}} \pm 100 \\
212^{\mathrm{abc}} \pm 7 \\
54.0^{\mathrm{abc}} \pm 1.3 \\
132^{\mathrm{bc}} \pm 4\end{array}$ \\
\hline \multicolumn{7}{|c|}{ Total growth period (days 1-35) } \\
\hline $\begin{array}{c}N D^{2} \\
b\left(\times 10^{6}\right)^{3} \\
\mathrm{NPU}_{\text {std. }}(\%)^{3} \\
b c^{-1}\left(\times 10^{6}\right)^{3}\end{array}$ & $\begin{array}{c}1250^{\mathrm{a}} \pm 101 \\
160^{\mathrm{a}} \pm 11 \\
48.0^{\mathrm{a}} \pm 2.5 \\
131^{\mathrm{c}} \pm 9\end{array}$ & $\begin{array}{c}1461^{b} \pm 60 \\
183^{b} \pm 12 \\
53.1^{b} \pm 2.6 \\
132^{c} \pm 9\end{array}$ & $\begin{array}{c}1594^{c d} \pm 83 \\
203^{c} \pm 14 \\
57.3^{c} \pm 2.7 \\
132^{c} \pm 9\end{array}$ & $\begin{array}{c}1509^{\mathrm{bc}} \pm 57 \\
193^{\mathrm{bc}} \pm 7 \\
55.3^{\mathrm{bc}} \pm 1.4 \\
114^{\mathrm{b}} \pm 4\end{array}$ & $\begin{array}{c}1408^{\mathrm{b}} \pm 65 \\
187^{\mathrm{b}} \pm 9 \\
54.1^{\mathrm{b}} \pm 2.0 \\
101^{\mathrm{a}} \pm 5\end{array}$ & $\begin{array}{c}1631^{\mathrm{d}} \pm 55 \\
193^{\mathrm{bc}} \pm 6 \\
55.3^{\mathrm{bc}} \pm 1.1 \\
120^{\mathrm{c}} \pm 3\end{array}$ \\
\hline
\end{tabular}

In the grower period, diet C (HM 50:50) and F (SBM 50:50) yielded the highest ND data, but differed only numerically from diet B (HM 45:55) and D (HM 55:45). Diets A (HM 40:60) and E 
(HM 60:40) had the lowest ND values. Diet C (HM 50:50) yielded superior protein quality, but the value was not significantly different from diets B (HM 45:55), D (HM 55:45), and F (SBM 50:50). The lowest protein quality was observed with diets A (HM 40:60) and E (HM 60:40). Surprisingly, the protein quality parameters of diet F (SBM 50:50) were not significantly different from diet A (HM 40:60). As in the starter period, Met efficiency was the highest in diets with a MCR $<1$ (diets A and B), but only numerically different from diet C (HM 50:50). However, Met efficiency in diet F (SBM 50:50) was significantly lower compared to diets A and B. Diet E (HM 60:40) generally impaired the Met efficiency $(p<0.05)$.

In summary across the entire growth period, ND data between diet C (HM 50:50) and diet F (SBM 50:50) were very similar $(p>0.05)$ and differed only numerically from diet B. In addition, no significant effects on ND were observed between diets B (HM 45:55), D (HM 55:45), and E (HM 60:40). As in the starter and grower period, diet A (HM 40:60) achieved both inferior ND data and dietary protein quality $(p<0.05)$. Increasing the MCR above 40:60 improved the dietary protein quality significantly, but the Met efficiency remained more or less unchanged up to an MCR = 50:50, as in diet C. A further increase of the MCR led to a decline $(p<0.05)$ in the Met efficiency with diets D and E. An intermediate Met efficiency was observed with the SBM based diet F, but not significantly below the superior level of diet $C$ with an equal MCR.

\subsection{Body Protein and Body Fat Deposition}

The graded dietary MCR was also a factor of influence on the nutrient deposition in the bird's bodies (Table 7). In the starter period, diet A (HM 40:60) yielded both inferior crude protein (CPD) and crude lipid deposition (CLD). Both parameters could be significantly improved by increasing the MCR to 50:50 (diet C), while a further increase of the MCR had no significant effect. CPD was highest in diet F (SBM 50:50), but not significantly different from diet C (HM 50:50) and D (HM 55:45). In contrast, the highest CLD was observed in diets $C$ and D. Both values were significantly different from CLD of diets $\mathrm{A}$ and $\mathrm{D}$ and the reference diet $\mathrm{F}$.

Table 7. Body crude protein (CPD) and body crude fat deposition (CLD) in the growth periods ${ }^{1}$.

\begin{tabular}{|c|c|c|c|c|c|c|}
\hline $\begin{array}{c}\text { Diet } \\
\text { Met:Cys }\end{array}$ & $\begin{array}{c}\text { A } \\
\text { HM } \\
40: 60\end{array}$ & $\begin{array}{c}\text { B } \\
\text { HM } \\
45: 55\end{array}$ & $\begin{array}{c}\mathrm{C} \\
\mathrm{HM} \\
50: 50\end{array}$ & $\begin{array}{c}\text { D } \\
\text { HM } \\
55: 45\end{array}$ & $\begin{array}{c}\text { E } \\
\text { HM } \\
60: 40\end{array}$ & $\begin{array}{c}\text { F } \\
\text { SBM } \\
50: 50\end{array}$ \\
\hline \multicolumn{7}{|c|}{ Starter period (days 1-21) } \\
\hline $\mathrm{CPD}(\mathrm{g} / \mathrm{d})$ & $3.93^{a} \pm 0.63$ & $5.54^{b} \pm 0.50$ & $6.58^{\mathrm{cd}} \pm 0.59$ & $6.12^{d} \pm 0.56$ & $5.92^{b c} \pm 0.52$ & $7.04^{\mathrm{d}} \pm 0.33$ \\
\hline $\operatorname{CLD}(g / d)$ & $3.22^{\mathrm{a}} \pm 0.49$ & $5.25^{b c} \pm 0.46$ & $6.39^{\mathrm{d}} \pm 0.55$ & $6.01^{\mathrm{d}} \pm 0.52$ & $5.88^{\mathrm{cd}} \pm 0.49$ & $4.99^{b} \pm 0.23$ \\
\hline \multicolumn{7}{|c|}{ Grower period (days 22-35) } \\
\hline $\mathrm{CPD}(\mathrm{g} / \mathrm{d})$ & $7.28^{a} \pm 1.63$ & $10.61^{b c} \pm 1.54$ & $12.73^{\mathrm{cd}} \pm 2.07$ & $10.71^{b c} \pm 1.25$ & $8.43^{a b} \pm 1.18$ & $12.83^{\mathrm{d}} \pm 1.32$ \\
\hline $\operatorname{CLD}(\mathrm{g} / \mathrm{d})$ & $8.33^{\mathrm{a}} \pm 1.71$ & $10.87^{\mathrm{ab}} \pm 1.54$ & $13.51^{\mathrm{c}} \pm 2.17$ & $11.47^{b c} \pm 1.31$ & $9.44^{\mathrm{ab}} \pm 1.26$ & $11.36^{\mathrm{ab}} \pm 1.09$ \\
\hline \multicolumn{7}{|c|}{ Total growth period (days $1-35$ ) } \\
\hline $\mathrm{CPD}(\mathrm{g} / \mathrm{d})$ & $5.56^{\mathrm{a}} \pm 1.00$ & $7.82^{b} \pm 0.68$ & $9.24^{\mathrm{cd}} \pm 1.06$ & $8.20^{\mathrm{bc}} \pm 0.70$ & $7.22^{b} \pm 0.73$ & $9.87^{\mathrm{d}} \pm 0.72$ \\
\hline
\end{tabular}

${ }^{1}$ Means \pm standard deviations, different superscript letters reveal significant differences between diets $(p<0.05)$.

Accordingly, in the grower period inferior CPD and CLD were observed in diet A (HM 40:60), but could be improved by increasing the MCR to 50:50 (diet C). In contrast to the starter period, a further increase of the MCR led to a significant decrease of CPD and CLD in diets D and E. Again, CPD was highest in diet F (SBM 50:50), but not significantly different from diet C (HM 50:50). The highest CLD was found in diet $C$ with a significant difference to diet $F$. The observed results and trends of the grower period were confirmed in the total growth period. 


\section{Discussion}

In accordance with recent studies [41,46,47], our current results underline the possibility of a complete substitution of SBM by partly defatted HM meal in diets for growing chickens. This is an important additional result, but not the main focus of this research to be discussed further.

Within each of the growth periods under study, the MCR of 50:50 led to superior results for the growth parameters, and therefore seems to be favorable in diets for growing broiler chickens. This confirms the observations of Moran Jr. [69], Baker et al. [8], Powell et al. [29], and Khan et al. [30]. However, an increased Met proportion of 55\% did not impair growth. This agrees with Grau and Almquist [70] who stated that Met should contribute $50-55 \%$ of the total SAA content in diets for growing chickens. According to earlier observations [13,16-18,71-74], our results provide evidence that a Met ratio of less than $50 \%$ of the SAA impaired feed intake and growth response, respectively. In two studies Dilger and Baker $[15,16]$ concluded explicitly that the elevated MCR caused an anorexic effect, and due to the fact that the experimental diets only differed in MCR, our results are in line with these conclusions. Sell et al. [72] assumed that an AA imbalance was the reason for the impaired feed intake and growth at high Cys proportions. Dilger and Baker [16] came to the same conclusion and stated that the growth-depressive effect of Cys could be already alleviated by the supplementation of small amounts of Met. A negative effect of an AA imbalance on feed intake was also observed by Kumar et al. [75]. Featherson and Rogler [18] suspected that an intestinal antagonism between Met and Cys causes the inferior growth at high Cys proportions. Both Sell et al. [76] and Lerner and Taylor [77] found evidence for an inhibition of intestinal Met absorption with increasing Cys supply. In contrast, Graber et al. [13], Sünder et al. [33], and Pesti et al. [78] stated that Cys could supply $>50 \%$ of the total SAA requirement. Ohta and Ishibashi [79] observed a maximal growth response at an MCR of 45:55, but also concluded that the optimal Cys ratio increases with increasing SAA levels in the diets.

Because growth parameters in our study could be improved by increasing the MCR up to 50:50, it can be concluded that the birds' requirement for Cys was efficiently covered and metabolic Met degradation in order to provide Cys did not exceed the physiological normal level.

The MCR of 60:40 in the present study led to a decline in feed intake and growth compared to a MCR of 50:50. This observation was even significant in the grower period and could be explained by a metabolic Cys deficiency resulting in elevated Met degradation and lower Met supply for growth. In contrast, Featherston and Rogler [18] and Grau and Almquist [70] stated that a MCR of 76:24 was superior for growth in diets with an adequate SAA supply. Marquardt and Campbell [74] and Beck et al. [80] also found superior growth performance of broiler chickens at a Met proportion $\geq 60 \%$ of the SAA. However, several other authors also found an age-dependent effect on the optimal MCR. For example, Wheeler and Latshaw [31] observed a decline in the optimal Cys ratio from $54 \%$ (1-21 days) to $38-43 \%$ (21-42 days) of the SAA due to increasing importance of Met for growth in older birds. The NRC [28] also recommended an increasing Cys ratio, $43 \%$ of the SAA in the first three weeks of age and subsequently $47 \%$ of the SAA. In contrast, Kalinowski et al. [81,82] did not observe a different optimal Cys ratio in growing chickens between 0-3 and 3-6 weeks of age (44\% resp. $47 \%$ of the SAA, but dependent on genotype).

The FCR in our study tended to be improved in diets with an MCR of 50:50 in comparison to a MCR of 60:40. Moran Jr. [69] found a significantly improved FCR when increasing the Cys ratio from 40 to $50 \%$ of the SAA in diets for broiler chickens from 0-14 days of age. However, Featherston and Rogler [18] observed a significantly improved FCR in diets with an MCR of 61:39, compared to diets with an MCR of 44:56. Similar results were reported elsewhere [16,31]. In contrast, Graber et al. [13] found no significant effects on the FCR when the Cys proportion was between 0 and $58 \%$ of the SAA.

Nevertheless, it has to be kept in mind that in contrast to our experiment, in most of the reported studies the sum of SAA in the diets was not held constant. In addition, the SAA were not generally in a limiting position. However, Sasse and Baker [71] emphasized that if the total SAA content exceeds the requirement, the optimal Cys proportion will be overestimated. 
A direct comparison of diet C (HM 50:50) and diet F (SBM 50:50) yielded no significant differences in growth parameters indicating the possibility of a complete substitution of SBM by HM. This observation is in line with the results of Neumann et al. [46] and Leiber et al. [50]. However, the FCR with diet F was slightly impaired as related to actual results with a similar ingredient composition [46-48], but in these studies a more balanced SAA:Lys ratio was applied. As mentioned above, the limiting position of SAA was intentional in our current study. On the contrary, Dabbou et al. [45] found a significantly impaired FCR in AA-balanced diets with $15 \% \mathrm{HM}$ compared to a control diet with SBM. Leiber et al. [50] applied 7.8\% HM in diets for growing chickens and observed no significant effect on FCR.

The observed results of apD of $\mathrm{CP}$ and selected AAs showed no significant differences between $\operatorname{diet}$ C (HM 50:50) and F (SBM 50:50) and are in line with findings of Velten et al. [49]. The MCR did not have a consistent effect on AA digestibility. The significant response of increased apD with a higher MCR between diet A (HM 40:60) and diet E (HM 60:40) should not be over interpreted according to the methodical background. Increasing Met concentration in the feed protein yielded elevated apD of Met due to the well-known relationship between the level of AA intake and observed apD. Additionally, this observed effect is supported by the elevated contents of crystalline DL-Met, which are expected to be completely digestible in the digestive tract. Several authors examined the coefficients of apparent digestibility of the total intestinal tract (CITAD) and apparent ileal digestibility coefficients (AIDC) for HM $[43,44]$. De Marco et al. [43] observed a CITAD for CP of 0.51, but the AIDC differed between e.g., 0.42 (Lys), 0.46 (Met) and 0.82 (Cys). Shiavone et al. [44] compared partly and highly defatted HM and found no effect on CITAD for CP (0.62) and the AIDC for Lys (0.80). However, AIDC for Met was higher in partly defatted HM (0.83 vs. 0.78$)$, but the AIDC for Cys was higher in highly defatted HM (0.65 vs. 0.44$)$. Nevertheless, different methodology and the fact that we examined the apD only in the mixed diets limit direct comparisons of the results.

The dietary protein quality as reflected by the $\mathrm{N}$ intake independent model parameter $b$ was significantly affected by the MCR. Diet C, with an MCR of 50:50, yielded a superior response indicating that this ratio supported the highest feed protein quality. Otherwise, an MCR of 40:60 led to a severe depression in the feed protein quality parameter indicating that a Met deficiency has an enormous impact on protein utilization. The fact that dietary protein quality was increased by elevating the MCR up to 50:50 validated that Met was the limiting AA. Regarding different age periods, both in the grower period and across the total growth period a MCR above 50:50 impaired the dietary protein quality. This effect was significant between diets C (HM 50:50) and E (HM 60:40) within these age periods, but only numerical differences were observed in the starter period. As a consequence, an age dependent effect on the optimal MCR is indicated and supports the increasing importance of Cys supply within the total SAA in older birds. In contrast to the actual results, Liebert et al. [83] observed superior protein quality with an MCR of 40:60 compared to an MCR of 51:49 in the grower period, but applied a corn-SBM-legume diets. Khan et al. [30] found no significant difference in protein quality and Met efficiency for a MCR between 46:54 and 51:49 in starter and grower period, but it was not designed as a systematic study with clearly graded MCR in the diet. In our study, we observed significantly lower protein quality for an $\mathrm{MCR}=45: 55$ compared to an $\mathrm{MCR}=50: 50$ in the starter and total growth period. However, the observed Met efficiency was not significantly influenced indicating that the effect on dietary protein quality was mostly related to the different Met concentration in the feed protein.

The dietary Met efficiency $\left(b c^{-1}\right)$ provides at least a measure for the quantity of Met that is needed to yield one unit of $N D$, but also indirectly indicates how the individual AA is involved in metabolic processes [61]. As a consequence, the daily quantity of an individual AA for metabolic needs strongly influences the numerical value of $b c^{-1}$ for the AA under study. However, comparisons between $b c^{-1}$ data for the limiting AA under study yield important information about the level of utilization for the metabolic purposes taking into account both the maintenance and performance processes. Due to the identical diet composition and the fact that Met was the limiting AA in all diets, comparison of Met efficiency data $\left(b c^{-1}\right)$ can be applied as an important tool to identify metabolic 
situations with different efficiencies of Met utilization. As observed, $b c^{-1}$ was highest in the diets A (HM 40:60), B (HM 45:55), and C (HM 50:50) with an MCR of 50:50 or lower. Farke et al. [32] also stated that an MCR of 40:60 improves the dietary Met-efficiency due to minimized Met degradation in diets with a low Met proportion. In our study, increasing the MCR in diets D and E impaired the Met efficiency significantly, indicating that Met was partially degraded to improve the metabolic Cys supply. Otherwise, results with diets A, B, and C underline that the MCR was sufficient and Met catabolism to yield Cys was not stimulated. These results are in line with Khan et al. [30] who also found no differences in Met efficiency between MCRs of 46:54, 48:52, and 51:49.

Directly comparing the HM diet C (50:50) and the SBM diet F (50:50) over the age periods under study provided no significant effect both on protein quality and Met efficiency. However, as in accord with reports from Neumann et al. [46,47] and Velten et al. [49], diet C (HM 50:50) yielded a trend of superior protein quality and Met efficiency as compared to the SBM based diet F. This trend might indicate an improved AA availability in the animal protein-based diet (HM 50:50) as compared to the plant based diet (SBM 50:50).

Both CPD and CLD increased with an increasing MCR ratio up to 50:50 and decreased with a ratio of 55:45 or higher. A low MCR as applied in diet A (HM 40:60) created a stronger negative effect than a lower Cys percentage of SAA as utilized in diet E (HM 60:40). Accordingly, Fatufe and Rodehutscord [84] also observed an increase in CLD with increasing Met concentration in diets for growing chickens, but they observed no effect on CPD. Otherwise, Graber et al. [13] did not find an effect of the MCR on the body composition of growing chickens. However, in contrast to our study, the total SAA content was not held constant in those investigations.

The observed effects on CPD and CLD in the bird's bodies between diet C (HM 50:50) and F (SBM 50:50) were expected and can be explained by the different energy content between control and insect-meal-based experimental diets. Both the higher fat content in the insect meal and the lower proportion of wheat and maize in the SBM based diet $F$ created this response founded on the energy content. However, it was not the aim within the current study to compensate this difference, but to demonstrate by example the effect that a high inclusion rate of insect meal could have on body composition when the dietary energy content is not adapted. Generally, this effect on dietary energy concentration can be alleviated by diet formulation with a modulated oil percentage.

\section{Conclusions}

In conclusion, the partly defatted HM meal under study could completely substitute SBM in diets for growing chickens without significant effects on growth, apD, and dietary protein quality when adequately supplemented with SAA. The results from chicken diets with a suboptimal SAA supply and Met as limiting AA indicated that an optimal dietary MCR of 50:50 was also valid at high inclusion rates of insect meal. However, a decline of the MCR to 40:60 impaired growth and feed efficiency. Otherwise, an elevated MCR exceeding the optimal ratio was not so meaningful due to the possibility of Met degradation in order to ensure the metabolic Cys supply. The observations underline the importance of taking into account not only quantitative requirements but also the optimal balance between dietary amino acids, namely the SAA methionine and cysteine. The high inclusion rate of $\mathrm{HM}$ and its specific AA composition did not modify the optimal MCR in broiler chicken diets.

Author Contributions: F.L. and A.B. conceived and designed the study; A.B. performed the experiments; C.W. and A.B. analyzed the data; A.B., C.W., and F.L. discussed the results; A.B. did the original draft preparation; C.W. and F.L. reviewed and edited the paper.

Funding: This research was funded by the Ministry for Science and Culture, Lower Saxony, Germany, grant number ZN 3041. We acknowledge support by the German Research Foundation and the Open Access Publication Funds of the Goettingen University.

Acknowledgments: We thank the staff of the Division of Animal Nutrition Physiology for their assistance in taking care of the animals and chemical analyses of feed and whole-body samples.

Conflicts of Interest: The authors declare no conflict of interest. 


\section{References}

1. Brosnan, J.T.; Brosnan, M.E. The sulfur-containing amino acids: An overview. J. Nutr. 2006, 136, 1636S-1640S. [CrossRef] [PubMed]

2. Bhargava, K.K.; Hanson, R.P.; Sunde, M.L. Effects of methionine and valine on growth and antibody production in chicks infected with live or killed Newcastle disease virus. J. Nutr. 1970, 100, 241-248. [CrossRef] [PubMed]

3. Tsiagbe, V.K.; Cook, M.E.; Harper, A.E.; Sunde, M.L. Enhanced immune responses in broiler chicks fed methionine-supplemented diets. Poult. Sci. 1987, 66, 1147-1154. [CrossRef] [PubMed]

4. Swain, B.K.; Johri, T.S. Effect of supplemental methionine, choline and their combinations on the performance and immune response of broilers. Br. Poult. Sci. 2000, 41, 83-88. [CrossRef] [PubMed]

5. Bunchasak, C. Role of dietary methionine in poultry production. J. Poult. Sci. 2009, 46, 169-179. [CrossRef]

6. Sherman, F.; Stewart, J.W.; Tsunasawa, S. Methionine or not methionine at the beginning of a protein. Bioessays 1985, 3, 27-31. [CrossRef] [PubMed]

7. Wu, G. Amino acids: Metabolism, functions, and nutrition. Amino Acids 2009, 37, 1-17. [CrossRef] [PubMed]

8. Baker, D.H.; Fernandez, S.R.; Webel, D.M.; Parsons, C.M. Sulfur amino acid requirement and cystine replacement value of broiler chicks during the period three to six weeks posthatching. Poult. Sci. 1996, 75, 737-742. [CrossRef] [PubMed]

9. Baker, D.H. Comparative species utilization and toxicity of sulfur amino acids. J. Nutr. 2006, 136, 1670-1675. [CrossRef] [PubMed]

10. Conde-Aguilera, J.A.; Cobo-Ortega, C.; Tesseraud, S.; Lessire, M.; Mercier, Y.; van Milgen, J. Changes in body composition in broilers by a sulfur amino acid deficiency during growth. Poult. Sci. 2013, 92, 1266-1275. [CrossRef] [PubMed]

11. Conde-Aguilera, J.A.; Cholet, J.C.G.; Lessire, M.; Mercier, Y.; Tesseraud, S.; van Milgen, J. The level and source of free-methionine affect body composition and breast muscle traits in growing broilers. Poult. Sci. 2016, 95, 2322-2331. [CrossRef] [PubMed]

12. Gesellschaft für Ernährungsphysiologie (GfE). Empfehlungen zur Energie- und Nähstoffversorgung der Legehennen und Masthühner (Broiler); DLG-Verlag: Frankfurt am Main, Germany, 1999. (In German)

13. Graber, G.; Scott, H.M.; Baker, D.H. Sulfur amino acid nutrition of the growing chick: Effect of age on the capacity of cystine to spare dietary methionine. Poult. Sci. 1971, 50, 1450-1455. [CrossRef] [PubMed]

14. Sekiz, S.S.; Scott, M.L.; Nesheim, M.C. The effect of methionine deficiency on body weight, food and energy utilization in the chick. Poult. Sci. 1975, 54, 1184-1188. [CrossRef] [PubMed]

15. Dilger, R.N.; Baker, D.H. Excess dietary L-cysteine causes lethal metabolic acidosis in chicks. J. Nutr. 2008, 138, 1628-1633. [CrossRef] [PubMed]

16. Dilger, R.N.; Baker, D.H. DL-methionine is as efficacious as L-methionine, but modest L-cystine excesses are anorexigenic in sulfur amino acid-deficient purified and practical-type diets fed to chicks. Poult. Sci. 2007, 86, 2367-2374. [CrossRef] [PubMed]

17. Dilger, R.N.; Baker, D.H. Cyst(e)ine imbalance and its effect on methionine precursor utilization in chicks. J. Anim. Sci. 2008, 86, 1832-1840. [CrossRef] [PubMed]

18. Featherston, W.R.; Rogler, A.C. Methionine-cystine interrelations in chicks fed diets containing suboptimal levels of methionine. J. Nutr. 1978, 108, 1954-1958. [CrossRef] [PubMed]

19. Harter, J.M.; Baker, D.H. Factors affecting methionine toxicity and its alleviation in the chick. J. Nutr. 1978, 108, 1061-1070. [CrossRef] [PubMed]

20. Xie, M.; Hou, S.S.; Huang, W.; Fan, H.P. Effect of excess methionine and methionine hydroxy analogue on growth performance and plasma homocysteine of growing pekin ducks. Poult. Sci. 2007, 86, 1995-1999. [CrossRef] [PubMed]

21. Acar, N.; Barbato, G.F.; Patterson, P.H. 2. The effect of feeding excess methionine on live performance, carcass traits, and ascites mortality. Poult. Sci. 2001, 80, 1585-1589. [CrossRef] [PubMed]

22. Warnick, R.E.; Anderson, J.O. Limiting essential amino acids in soybean meal for growing chickens and the effects of heat upon availability of the essential amino acids. Poult. Sci. 1968, 47, 281-287. [CrossRef] [PubMed]

23. Emmert, J.L.; Baker, D.H. Use of the ideal protein concept for precision formulation of amino acid levels in broiler diets. J. Appl. Poult. Res. 1997, 6, 462-470. [CrossRef] 
24. Brede, A.; Wecke, C.; Sünder, A.; Liebert, F. Characteristics of Sulfur Containing Amino Acid Supply with Special Reference to Poultry Nutrition. Übers. Tierern. 2018, 43. in press. (In German)

25. Saunderson, C.L. Metabolism of methionine and its nutritional analogues. Poult. Int. 1991, 30, 34-38.

26. Ross 308 broiler: Nutrition specifications. Aviagen 2014. Available online: http:/ / en.aviagen.com/techcenter/download/12/Ross-308-Broiler-Nutrition-Specs-2014r17-EN.pdf (accessed on 9 September 2016).

27. Arbor Acres plus broiler nutrition specifications. Aviagen 2014. Available online: http:/ /en.aviagen.com/ assets/Tech_Center/AA_Broiler/AABroilerNutritionSpecs2014-EN.pdf (accessed on 9 September 2016).

28. National Report Council (NRC). Nutrient Requirements of Poultry, 9th ed.; National Academy Press: Washington, DC, USA, 1994.

29. Powell, S.; Bidner, T.D.; Southern, L.L. Effects of glycine supplementation at varying levels of methionine and cystine on the growth performance of broilers fed reduced crude protein diets. Poult. Sci. 2011, 90, 1023-1027. [CrossRef] [PubMed]

30. Khan, D.R.; Wecke, C.; Liebert, F. An elevated dietary cysteine to methionine ratio does not impact on dietary methionine efficiency and the derived optimal methionine to lysine ratio in diets for meat type chicken. Open J. Anim. Sci. 2015, 5, 457-466. [CrossRef]

31. Wheeler, K.B.; Latshaw, J.D. Sulfur amino acid requirements and interactions in broilers during two growth periods. Poult. Sci. 1981, 60, 228-236. [CrossRef] [PubMed]

32. Farke, J.; Wecke, C.; Liebert, F. Methionine efficiency in chicken diets with varying Met to Cys ratio modifies the concluded Met requirements. In Proceedings of the Society of Nutrition Physiology; DLG-Verlag: Frankfurt am Main, Germany, 2010; Volume 19, p. 21.

33. Sünder, A.; Wecke, C.; Liebert, F. Influence of different dietary methionine to cystine ratios on growth performance, feed efficiency and protein deposition in meat type chicken. In Proceedings of the Society of Nutrition Physiology; DLG-Verlag: Frankfurt am Main, Germany, 2015; Volume 24, p. 47.

34. D'Mello, J.P.F. An Outline of pathways in amino acid metabolism. In Amino Acids in Animal Nutrition, 2nd ed.; CAB International: Wallingford, UK, 2003; pp. 143-156. ISBN 085199654 X.

35. Stipanuk, M.H. Metabolism of sulfur-containing amino acids. Ann. Rev. Nutr. 1986, 6, 179-209. [CrossRef] [PubMed]

36. Stipanuk, M.H. Sulfur amino acid metabolism: Pathways for production and removal of homocysteine and cysteine. Ann. Rev. Nutr. 2004, 24, 539-577. [CrossRef] [PubMed]

37. Bunchasak, C.; Kimura, G.; Tanaka, K.; Ohtani, S.; Collado, C.M. The effect of supplementing cystine on the growth performance and liver lipid and phospholipid contents of broiler chicks. Jpn. Poult. Sci. 1998, 35, 60-66. [CrossRef]

38. Finke, M.D. Complete nutrient composition of commercially raised invertebrates used as food for insectivores. Zoo Biol. 2002, 21, 269-285. [CrossRef]

39. Finke, M.D. Complete Nutrient content of four species of feeder insects. Zoo Biol. 2013, 32, 27-36. [CrossRef] [PubMed]

40. Makkar, H.P.S.; Tran, G.; Heuzé, V.; Ankers, P. State-of-the-art on use of insects as animal feed. Anim. Feed Sci. Technol. 2014, 197, 1-33. [CrossRef]

41. Maurer, V.; Holinger, M.; Amsler, Z.; Früh, B.; Wohlfahrt, J.M.; Stamer, A.; Leiber, F. Replacement of soybean cake by Hermetia illucens meal in diets for layers. J. Insects Food Feed 2015, 2, 83-90. [CrossRef]

42. Veldkamp, T.; Bosch, G. Insects: A protein-rich feed ingredient in pig and poultry diets. Anim. Front. 2015, 5, 45-50.

43. De Marco, M.; Sartínez, S.; Hernandez, F.; Madrid, J.; Gai, F.; Rotolo, L.; Belforti, M.; Bergero, D.; Katz, H.; Dabbou, S.; et al. Nutritional value of two insect larvae meals (Tenebrio molitor and Hermetia illucens) for broiler chickens: Apparent nutrient digestibility, apparent ileal amino acid digestibility and apparent metabolizable energy. Anim. Feed Sci. Technol. 2015, 209, 211-218. [CrossRef]

44. Shiavone, A.; De Marco, M.; Martínez, S.; Dabbou, S.; Renna, M.; Madrid, J.; Hernandez, F.; Rotolo, L.; Gai, F.; Gasco, L. Nutritional value of a partially defatted and highly defatted black soldier fly larvae (Hermetia illucens L.) meal for broiler chickens: Apparent nutrient digestibility, apparent metabolizable energy and apparent ileal amino acid digestibility. J. Anim. Sci. Biotechnol. 2017, 8, 51. [CrossRef] [PubMed] 
45. Dabbou, S.; Gai, F.; Biasato, I.; Capucchio, M.T.; Biasibetti, E.; Dezzutto, D.; Meneguz, M.; Plachà, I.; Gasco, L.; Shiavone, A. Black soldier fly defatted meal as a dietary protein source for broiler chickens: Effects on growth performance, blood traits, gut morphology and histological features. J. Anim. Sci. Biotechnol. 2018, 9, 49. [CrossRef] [PubMed]

46. Neumann, C.; Velten, S.; Liebert, F. Improving the dietary protein quality by amino acid fortification with a high inclusion level of micro algae (Spirulina platensis) or insect meal (Hermetia illcuens) in meat type chicken diets. Open J. Anim. Sci. 2018, 8, 12-26. [CrossRef]

47. Neumann, C.; Velten, S.; Liebert, F. The graded inclusion of algae (Spirulina platensis) or insect (Hermetia illucens) meal as a soybean meal substitute in meat type chicken diets impacts on growth, nutrient deposition and dietary protein quality depending on the extent of amino acid supplementation. Open J. Anim. Sci. 2018, 8, 163-183. [CrossRef]

48. Velten, S.; Neumann, C.; Bleyer, M.; Gruber-Dujardin, E.; Hanuszewska, M.; Przybylska-Gornowicz, B.; Liebert, F. Effect of 50 percent substitution of soybean meal by alternaive proteins from Hermetia illucens or Spirulina platensis in meat-type chicken diets with graded amino acid supply. Open J. Anim. Sci. 2018, 8, 119-136. [CrossRef]

49. Velten, S.; Neumann, C.; Schäfer, J.; Liebert, F. Effects of the partial replacement of soybean meal by insect or algae meal in chicken diets with graded amino acid supply on parameters of gut microbiology and dietary protein quality. Open J. Anim. Sci. 2018, 8, 259-279. [CrossRef]

50. Leiber, F.; Gelencsér, T.; Stamer, A.; Amsler, Z.; Wohlfahrt, J.; Früh, B.; Maurer, V. Insect and legume-based protein sources to replace soybean cake in an organic broiler diet: Effects on growth performancephysical meat quality. Renew. Agric. Food Syst. 2017, 32, 21-27. [CrossRef]

51. Onsogo, V.O.; Osuga, M.; Gachuiri, C.K.; Wachira, A.M.; Miano, D.M.; Tanga, C.M.; Ekesi, S.; Nakimbugwe, D.; Fiaboe, K.K.M. Insects for income generation through animal feed: Effect of dietary replacement of soybean and fish meal with black soldier fly meal in broiler growth and economic performance. J. Econ. Entomol. 2018, 111, 1966-1973. [CrossRef] [PubMed]

52. Wecke, C.; Liebert, F. Improving the reliability of optimal in-feed amino acid ratios based on individual amino acid efficiency data from $\mathrm{N}$ balance studies in growing chicken. Animals 2013, 3, 558-573. [CrossRef] [PubMed]

53. WPSA (World's Poultry Science Association). The prediction of apparent metabolizable energy values for poultry in compound feeds. World's Poult. Sci. J. 1984, 40, 181-182.

54. Naumann, C.; Bassler, R. Die Chemische Untersuchung von Futtermitteln; Methodenbuch, Volume III; VDLUFA-Verlag: Darmstadt, Germany, 1976-2004.

55. Wecke, C.; Khan, D.R.; Sünder, A.; Liebert, F. Age and gender dependent amino acid concentrations in the feather, feather-free and whole empty body protein of fast growing meat-type chickens. Open J. Anim. Sci. 2018, 8, 376-392. [CrossRef]

56. Pastor, A. Studien zur Aminosäurenwirksamkeit beim Mastgeflügel unter spezifischer Betrachtung der verzweigtkettigen Aminosäuren. Ph.D. Thesis, Georg-August-Universität, Göttingen, Germany, 2014.

57. Liebert, F.; Gebhardt, G. Results of the effectivity and the requirement of selected amino acids of growing female pigs. Arch. Anim. Nutr. 1988, 38, 453-462. (In German)

58. Liebert, F. Estimation of nitrogen maintenance requirements and potential for nitrogen deposition in fast-growing chickens depending on age and sex. Poult. Sci. 2006, 85, 1421-1429. [CrossRef]

59. Liebert, F. Lysine requirement of fast growing chickens-Effects of age, sex, level of protein deposition and dietary lysine efficiency. J. Poult. Sci. 2007, 44, 63-72. [CrossRef]

60. Pastor, A.; Wecke, C.; Liebert, F. Assessing the age-dependent optimal dietary branched-chain amino acid ratio in growing chicken by application of a nonlinear modeling procedure. Poult. Sci. 2013, 92, 3184-3195. [CrossRef] [PubMed]

61. Liebert, F. Basics and applications of an exponential nitrogen utilization model ("Goettingen approach") for assessing amino acid requirements in growing pigs and meat type chickens based on dietary amino acid efficiency. In Nutritional Modelling for Pigs and Poultry; Sakomura, N.K., Gous, R., Kyriazakis, I., Hauschild, L., Eds.; CABI Publishing: Wallingford, UK, 2015; pp. 73-87. ISBN 97817806441102014011160.

62. Wecke, C.; Pastor, A.; Liebert, F. Validation of the lysine requirement as reference amino acid for ideal in-feed amino acid ratios in modern fast growing meat-type chickens. Open J. Anim. Sci. 2016, 6, 185-194. [CrossRef] 
63. Wecke, C.; Pastor, A.; Liebert, F. Assessing lysine requirement of growing chicken by direct comparison between supplementation technique and "goettingen approach". Open J. Anim. Sci. 2017, 7, 56-69. [CrossRef]

64. Liebert, F. Further progress is needed in procedures for biological evaluation of dietary protein quality in pig and poultry feeds. Arch. Anim. Breed. 2017, 60, 259-270. [CrossRef]

65. Block, R.J.; Mitchell, H.H. The correlation of amino acid composition of proteins with their nutritive value. Nutr. Abstr. Rev. 1946, 16, 249-278.

66. Thong, H.T.; Liebert, F. Potential for protein deposition and threonine requirement of modern genotype barrows fed graded levels of protein with threonine as limiting amino acid. J. Anim. Physiol. Anim. Nutr. 2004, 88, 196-203. [CrossRef] [PubMed]

67. Wecke, C.; Liebert, F. Lysine Requirement Studies in Modern Genotype Barrows Dependent on Age, Protein Deposition and Dietary Lysine Efficiency. J. Anim. Physiol. Anim. Nutr. 2009, 93, 295-304. [CrossRef] [PubMed]

68. Samadi; Liebert, F. Modelling the optimal lysine to threonine ratio in growing chickens depending on age and efficiency of dietary amino acid utilization. Br. Poult. Sci. 2008, 49, 45-54. [CrossRef] [PubMed]

69. Moran, E.T., Jr. Cystine requirement of feather-sexed broiler chickens with sex and age. Poult. Sci. 1981, 60, 1056-1061. [CrossRef]

70. Grau, C.R.; Almquist, H.J. The utilization of the sulfur amino acids by the chick. J. Nutr. 1943, 26, 631-640. [CrossRef]

71. Sasse, C.E.; Baker, D.H. Sulfur utilization by the chick with emphasis on the effect of inorganic sulfate on the cystine-methionine interrelationship. J. Nutr. 1974, 104, 244-251. [CrossRef] [PubMed]

72. Sell, D.R.; Featherston, W.R.; Rogler, J.C. Methionine-cystine interrelationships in chicks and rats fed diets containing suboptimal levels of methionine. Poult. Sci. 1980, 59, 1878-1884. [CrossRef] [PubMed]

73. Tsiagbe, V.K.; Cook, M.E.; Harper, A.E.; Sunde, M.L. Efficiacy of cysteine in replacing methionine in the immune response of broiler chicks. Poult. Sci. 1987, 66, 1138-1146. [CrossRef] [PubMed]

74. Marquardt, R.R.; Campbell, L.D. Performance of chicks fed faba bean (Vica faba) diets supplemented with methionine, sulfate and cystine. Can. J. Anim. Sci. 1975, 55, 213-218. [CrossRef]

75. Kumar, C.B.; Gloridoss, R.G.; Singh, K.C.; Prabhu, T.M.; Suresh, B.N. Performance of broiler chickens fed low protein, limiting amino acid supplemented diets formulated either on total or standardized ileal digestible amino acid basis. Asian Australas. J. Anim. Sci. 2016, 29, 1616-1624. [CrossRef] [PubMed]

76. Sell, D.R.; Rogler, J.C.; Featherston, W.R. Influence of dietary cystine on intestinal absorption and tissue distribution of methionine in the chick. Poult. Sci. 1980, 59, 1885-1891. [CrossRef] [PubMed]

77. Lerner, J.; Taylor, M.W. A common step in the intestinal absorption mechanisms of D- and L-methionine. Biochim. Biophs. Acta 1967, 135, 990-999. [CrossRef]

78. Pesti, G.M.; Harper, A.E.; Sunde, M.L. Sulfur amino acid and methyl donor status of corn-soy diets fed to starting broiler chicks and turkey poults. Poult. Sci. 1979, 58, 1541-1547. [CrossRef] [PubMed]

79. Ohta, Y.; Ishibashi, T. Dietary levels and ratio of methionine and cystine for maximum performance of broilers. Jpn. Poult. Sci. 1994, 31, 369-380. [CrossRef]

80. Beck, C.R.; Harms, R.H.; Russell, G.B. Is the cystine content of the diet of concern for broilers from 0 to 21 days of age? J. Appl. Poult. Res. 1998, 7, 233-238. [CrossRef]

81. Kalinowski, A.; Moran, E.T.; Wyatt, C.L. Methionine and cystine requirements of slow-and fast-feathering male broilers from zero to three weeks of age. Poult. Sci. 2003, 82, 1423-1427. [CrossRef] [PubMed]

82. Kalinowski, A.; Moran, E.T.; Wyatt, C.L. Methionine and cystine requirements of slow-and fast-feathering broiler males from three to six weeks of age. Poult. Sci. 2003, 82, 1428-1437. [CrossRef] [PubMed]

83. Liebert, F.; Farke, J.; Wecke, C. Modelling methionine requirements in growing chicken by using the dietary methionine efficiency. In Proceedings of the 3rd EAAP International Symposium on Energy and Protein Metabolism and Nutrition, Parma, Italy, 6-10 September 2010; pp. 625-626.

84. Fatufe, A.A.; Rodehutscord, M. Growth, body composition and marginal efficiency of methionine utilization are affected by nonessential amino acid nitrogen supplementation in male broiler chicken. Poult. Sci. 2005, 84, 1584-1592. [CrossRef] [PubMed]

(C) 2018 by the authors. Licensee MDPI, Basel, Switzerland. This article is an open access article distributed under the terms and conditions of the Creative Commons Attribution (CC BY) license (http://creativecommons.org/licenses/by/4.0/). 


\section{Anhangstabellen}

Anhangstabelle 1: Analysierte Rohnährstoff- und Aminosäuregehalte der verwendeten Einzelfuttermittel.

\begin{tabular}{lccc}
\hline Rohnährstoffgehalt & Mais & Sojaextraktionsschrot & Weizen \\
\hline TM (\%) & 89,81 & 89,45 & 86,94 \\
XP (\% TM) & 9,76 & 48,05 & 12,59 \\
XL (\% TM) & 5,10 & 2,10 & 2,29 \\
XF (\% TM) & 2,09 & 9,27 & 2,88 \\
XA (\% TM) & 1,20 & 6,88 & 1,57 \\
\hline Aminosäuregehalt (g/16gN) & & & \\
\hline Lys & 2,62 & 6,07 & 2,72 \\
Met & 1,77 & 1,28 & 1,46 \\
Cys & 1,96 & 1,46 & 2,23 \\
Thr & 3,34 & 3,78 & 2,86 \\
Arg & 4,09 & 7,19 & 4,47 \\
Leu & 11,37 & 7,32 & 6,18 \\
Ile & 3,18 & 4,34 & 3,07 \\
His & 2,65 & 2,53 & 2,19 \\
Val & 4,34 & 4,37 & 3,85 \\
\hline
\end{tabular}


Anhangstabelle 2: Zusammensetzung des verwendeten Premixes.

\begin{tabular}{|c|c|}
\hline Mengenelement/Spurenelement/Vitamin & Gehalt pro kg Premix \\
\hline Calcium & $210.000 \mathrm{mg}$ \\
\hline Natrium & $80.000 \mathrm{mg}$ \\
\hline Vitamin A & 500.000 I.E. \\
\hline Vitamin D3 & 100.000 I.E. \\
\hline Vitamin E & $3.000 \mathrm{mg}$ \\
\hline Vitamin B1 & $260 \mathrm{mg}$ \\
\hline Vitamin B2 & $480 \mathrm{mg}$ \\
\hline Vitamin B6 & $320 \mathrm{mg}$ \\
\hline Vitamin B12 & $2 \mathrm{mg}$ \\
\hline Vitamin K3 & $300 \mathrm{mg}$ \\
\hline Nikotinsäure & $5.000 \mathrm{mg}$ \\
\hline Calciumpantothenat & $1.000 \mathrm{mg}$ \\
\hline Folsäure & $90 \mathrm{mg}$ \\
\hline Biotin & $10 \mathrm{mg}$ \\
\hline Cholinchlorid & $100.000 \mathrm{mg}$ \\
\hline Eisen als Eisen-II-Sulfat Monohydrat & $5.000 \mathrm{mg}$ \\
\hline Kupfer als Kupfer-II-Sulfat Pentahydrat & $1.500 \mathrm{mg}$ \\
\hline Mangan als Mangan-II-Oxid & $12.000 \mathrm{mg}$ \\
\hline Zink als Zinkoxid & $7.000 \mathrm{mg}$ \\
\hline Iod als Calciumiodat Hexahydrat & $140 \mathrm{mg}$ \\
\hline Selen als Natriumselenit & $28 \mathrm{mg}$ \\
\hline $\begin{array}{l}\text { Cobalt als alkalisches Cobalt-II-Carbonat } \\
\text { Monohydrat }\end{array}$ & $55 \mathrm{mg}$ \\
\hline Butylhydroxytoluol & $10.000 \mathrm{mg}$ \\
\hline
\end{tabular}


Anhangstabelle 3: Zusammensetzung der in Versuch 1 verwendeten Futtermischungen.

\begin{tabular}{|c|c|c|c|c|c|c|c|c|c|c|c|c|}
\hline \multirow[b]{2}{*}{ Versuchsgruppe } & \multicolumn{6}{|c|}{ Starterphase (Tag 1-21) } & \multicolumn{6}{|c|}{ Growerphase (Tag 22-35) } \\
\hline & $\begin{array}{c}\text { A } \\
\text { HM } \\
40: 60\end{array}$ & $\begin{array}{c}\text { B } \\
\text { HM } \\
45: 55\end{array}$ & $\begin{array}{c}\text { C } \\
\text { HM } \\
\mathbf{5 0 : 5 0}\end{array}$ & $\begin{array}{c}\text { D } \\
\text { HM } \\
\text { 55:45 }\end{array}$ & $\begin{array}{c}\text { E } \\
\text { HM } \\
60: 40\end{array}$ & $\begin{array}{c}\text { F } \\
\text { SES } \\
\mathbf{5 0 : 5 0}\end{array}$ & $\begin{array}{c}\text { A } \\
\text { HM } \\
40: 60\end{array}$ & $\begin{array}{c}\text { B } \\
\text { HM } \\
\text { 45:55 }\end{array}$ & $\begin{array}{c}\text { C } \\
\text { HM } \\
\mathbf{5 0 : 5 0}\end{array}$ & $\begin{array}{c}\text { D } \\
\text { HM } \\
\text { 55:45 }\end{array}$ & $\begin{array}{c}\text { E } \\
\text { HM } \\
60: 40\end{array}$ & $\begin{array}{c}\text { F } \\
\text { SES } \\
\mathbf{5 0 : 5 0}\end{array}$ \\
\hline Hermetia illucens Mehl & 230 & 230 & 230 & 230 & 230 & - & 212,8 & 212,8 & 212,8 & 212,8 & 212,8 & - \\
\hline Sojaextraktionsschrot & - & - & - & - & - & 350 & - & - & - & - & - & 323,8 \\
\hline Weizen & 500 & 500 & 500 & 500 & 500 & 398 & 462,5 & 462,5 & 462,5 & 462,5 & 462,5 & 368,2 \\
\hline Mais & 140 & 140 & 140 & 140 & 140 & 112 & 129,5 & 129,5 & 129,5 & 129,5 & 129,5 & 103,6 \\
\hline Weizenstärke & 12,0 & 12,2 & 12,3 & 12,5 & 12,6 & 16,7 & 86,4 & 86,6 & 86,7 & 86,8 & 87,0 & 83,2 \\
\hline Sojaöl & 70 & 70 & 70 & 70 & 70 & 75 & 65 & 65 & 65 & 65 & 65 & 80 \\
\hline Dicalciumphosphat & 10 & 10 & 10 & 10 & 10 & 16 & 8 & 8 & 8 & 8 & 8 & 12 \\
\hline Calciumcarbonat & 11 & 11 & 11 & 11 & 11 & 11 & 8 & 8 & 8 & 8 & 8 & 8 \\
\hline Viehsalz & 2,0 & 2,0 & 2,0 & 2,0 & 2,0 & 5,0 & 1,0 & 1,0 & 1,0 & 1,0 & 1,0 & 2,5 \\
\hline Prämix & 10 & 10 & 10 & 10 & 10 & 10 & 10 & 10 & 10 & 10 & 10 & 10 \\
\hline L-Lysin- $\mathrm{HCl}$ & 5,65 & 5,65 & 5,65 & 5,65 & 5,65 & 3,74 & 5,21 & 5,21 & 5,21 & 5,21 & 5,21 & 3,44 \\
\hline $\mathrm{L}-\mathrm{Cysteine} \cdot \mathrm{HCl} \cdot \mathrm{H}_{2} \mathrm{O}$ & 2,24 & 1,73 & 1,22 & 0,73 & 0,22 & 0,03 & 2,06 & 1,58 & 1,13 & 0,66 & 0,19 & 0,03 \\
\hline L-Arginin & 5,77 & 5,77 & 5,77 & 5,77 & 5,77 & 1,02 & 5,35 & 5,35 & 5,35 & 5,35 & 5,35 & 0,96 \\
\hline L-Threonin & 1,35 & 1,35 & 1,35 & 1,35 & 1,35 & 0,85 & 1,23 & 1,23 & 1,23 & 1,23 & 1,23 & 0,77 \\
\hline DL-Methionin & - & 0,35 & 0,71 & 1,01 & 1,39 & 0,65 & - & 0,33 & 0,65 & 0,96 & 1,29 & 0,59 \\
\hline $\mathrm{TiO}_{2}$ & - & - & - & - & - & - & 3 & 3 & 3 & 3 & 3 & 3 \\
\hline
\end{tabular}


Anhangstabelle 4:Rohnährstoff- und Aminosäure-Gehalte der in Versuch 1 verwendeten Futtermischungen.

\begin{tabular}{|c|c|c|c|c|c|c|c|c|c|c|c|c|}
\hline \multirow[b]{2}{*}{ Versuchsgruppe } & \multicolumn{6}{|c|}{ Starterphase (Tag 1-21) } & \multicolumn{6}{|c|}{ Growerphase (Tag 22-35) } \\
\hline & $\begin{array}{c}\text { A } \\
\text { HM } \\
40: 60\end{array}$ & $\begin{array}{c}\text { B } \\
\text { HM } \\
45: 55\end{array}$ & $\begin{array}{c}\text { C } \\
\text { HM } \\
\mathbf{5 0 : 5 0}\end{array}$ & $\underset{\text { H5:45 }}{\stackrel{D}{\text { DM }}}$ & $\begin{array}{c}E \\
\text { HM } \\
60: 40\end{array}$ & $\begin{array}{c}\text { F } \\
\text { SES } \\
\mathbf{5 0 : 5 0}\end{array}$ & $\begin{array}{c}\text { A } \\
\text { HM } \\
40: 60\end{array}$ & $\begin{array}{c}\text { B } \\
\text { HM } \\
45: 55\end{array}$ & $\begin{array}{c}\text { C } \\
\text { HM } \\
\mathbf{5 0 : 5 0}\end{array}$ & $\underset{\text { H5:45 }}{\stackrel{D}{\text { DM }}}$ & $\begin{array}{c}\mathrm{E} \\
\mathrm{HM} \\
60: 40\end{array}$ & $\begin{array}{c}\text { F } \\
\text { SES } \\
\mathbf{5 0 : 5 0}\end{array}$ \\
\hline $\mathrm{TM}(\%)^{1}$ & 92,28 & 92,00 & 92,20 & 92,23 & 92,45 & 91,98 & 91,34 & 91,65 & 91,76 & 91,86 & 91,62 & 91,51 \\
\hline $\mathrm{XP}(\% \mathrm{TM})^{1}$ & 23,82 & 23,91 & 23,37 & 23,25 & 23,28 & 22,87 & 22,15 & 21,96 & 22,14 & 22,54 & 21,56 & 21,09 \\
\hline $\mathrm{XL}(\% \mathrm{TM})^{1}$ & 12,07 & 12,77 & 12,84 & 12,78 & 12,17 & 10,76 & 11,44 & 11,05 & 11,11 & 11,39 & 11,54 & 10,98 \\
\hline $\mathrm{XF}(\% \mathrm{TM})^{1}$ & 4,27 & 4,19 & 3,88 & 3,94 & 3,84 & 4,32 & 3,67 & 3,67 & 3,72 & 3,69 & 3,80 & 4,01 \\
\hline $\mathrm{XA}(\% \mathrm{TM})^{1}$ & 5,52 & 5,69 & 5,60 & 5,54 & 5,64 & 7,17 & 5,20 & 5,11 & 5,19 & 5,16 & 5,15 & 6,24 \\
\hline \multicolumn{13}{|c|}{ Aminosäure $(\mathrm{g} / 16 \mathrm{gN})^{2}$} \\
\hline Lys & 6,16 & 6,16 & 6,16 & 6,16 & 6,16 & 6,41 & 6,16 & 6,16 & 6,17 & 6,17 & 6,17 & 6,42 \\
\hline Met & 1,22 & 1,38 & 1,54 & 1,69 & 1,85 & 1,61 & 1,23 & 1,39 & 1,54 & 1,70 & 1,85 & 1,61 \\
\hline Cys & 1,86 & 1,70 & 1,54 & 1,39 & 1,23 & 2,60 & 1,85 & 1,69 & 1,54 & 1,38 & 1,23 & 1,60 \\
\hline Met + Cys & 3,08 & 3,08 & 3,08 & 3,08 & 3,08 & 3,21 & 3,08 & 3,08 & 3,08 & 3,08 & 3,08 & 3,21 \\
\hline Thr & 3,69 & 3,70 & 3,70 & 3,70 & 3,70 & 3,85 & 3,70 & 3,70 & 3,70 & 3,70 & 3,70 & 3,85 \\
\hline Arg & 6,46 & 3,47 & 6,47 & 6,47 & 6,47 & 6,73 & 6,47 & 6,47 & 6,47 & 6,48 & 6,48 & 6,74 \\
\hline Leu & 6,00 & 6,00 & 6,00 & 6,01 & 6,01 & 7,04 & 6,00 & 6,00 & 6,00 & 6,00 & 6,01 & 7,04 \\
\hline Ile & 3,31 & 3,31 & 3,31 & 3,31 & 3,31 & 3,89 & 3,31 & 3,31 & 3,31 & 3,31 & 3,31 & 3,89 \\
\hline His & 2,36 & 2,37 & 2,37 & 2,37 & 2,37 & 2,39 & 2,36 & 2,37 & 2,37 & 2,37 & 2,37 & 2,39 \\
\hline Val & 4,49 & 4,49 & 4,49 & 4,49 & 4,49 & 4,13 & 4,49 & 4,49 & 4,49 & 4,49 & 4,49 & 4,13 \\
\hline Phe & 3,40 & 3,40 & 3,40 & 3,40 & 3,40 & 4,56 & 3,40 & 3,40 & 3,40 & 3,40 & 3,40 & 4,56 \\
\hline Trp & 1,20 & 1,20 & 1,20 & 1,20 & 1,20 & 1,32 & 1,20 & 1,20 & 1,20 & 1,20 & 1,20 & 1,32 \\
\hline
\end{tabular}

${ }^{1}$ mind. in Doppelbestimmung analysiert, Werte wurden anschließend gemittelt; ${ }^{2}$ auf Basis der analysierten Aminosäuregehalte der Komponenten berechnet 
Anhangstabelle 5: Zusammensetzung der in Versuch 2 verwendeten Futtermischungen.

\begin{tabular}{|c|c|c|c|c|c|c|c|c|c|c|c|c|}
\hline \multirow[b]{2}{*}{ Versuchsgruppe } & \multicolumn{6}{|c|}{ Starterphase (Tag 1-21) } & \multicolumn{6}{|c|}{ Growerphase (Tag 22-35) } \\
\hline & $\begin{array}{c}\text { A } \\
\text { TMP } \\
40: 60\end{array}$ & $\begin{array}{c}\text { B } \\
\text { TMP } \\
45: 55\end{array}$ & $\begin{array}{c}\text { C } \\
\text { TMP } \\
\mathbf{5 0 : 5 0}\end{array}$ & $\begin{array}{c}\text { D } \\
\text { TMP } \\
55: 45\end{array}$ & $\begin{array}{c}\text { E } \\
\text { TMP } \\
\text { 60:40 }\end{array}$ & $\begin{array}{c}\text { F } \\
\text { SES } \\
\mathbf{5 0 : 5 0}\end{array}$ & $\begin{array}{c}\text { A } \\
\text { TMP } \\
40: 60\end{array}$ & $\begin{array}{c}\text { B } \\
\text { TMP } \\
\text { 45:55 }\end{array}$ & $\begin{array}{c}\text { C } \\
\text { TMP } \\
\mathbf{5 0 : 5 0}\end{array}$ & $\begin{array}{c}\text { D } \\
\text { TMP } \\
55: 45\end{array}$ & $\begin{array}{c}\text { E } \\
\text { TMP } \\
\text { 60:40 }\end{array}$ & $\begin{array}{c}\text { F } \\
\text { SES } \\
\mathbf{5 0 : 5 0}\end{array}$ \\
\hline $\begin{array}{l}\text { Tenebrio molitor } \\
\text { Presskuchen }\end{array}$ & 160 & 160 & 160 & 160 & 160 & - & 148,80 & 148,80 & 148,80 & 148,80 & 148,80 & - \\
\hline Sojaextraktionsschrot & - & - & - & - & - & 321 & - & - & - & - & - & 298,53 \\
\hline Weizen & 580 & 580 & 580 & 580 & 580 & 374 & 539,40 & 539,40 & 539,40 & 539,40 & 539,40 & 347,82 \\
\hline Mais & 160 & 160 & 160 & 160 & 160 & 170 & 148,80 & 148,80 & 148,80 & 148,80 & 148,80 & 158,10 \\
\hline Weizenstärke & 13,34 & 13,50 & 13,64 & 13,80 & 13,90 & 8,28 & 80,17 & 80,31 & 80,44 & 80,60 & 80,66 & 73,69 \\
\hline Sojaöl & 30 & 30 & 30 & 30 & 30 & 80 & 30 & 30 & 30 & 30 & 30 & 80 \\
\hline Dicalciumphosphat & 23 & 23 & 23 & 23 & 23 & 15 & 19 & 19 & 19 & 19 & 19 & 11 \\
\hline Calciumcarbonat & 6 & 6 & 6 & 6 & 6 & 10 & 5 & 5 & 5 & 5 & 5 & 8 \\
\hline Viehsalz & 2,5 & 2,5 & 2,5 & 2,5 & 2,5 & 3,0 & 2 & 2 & 2 & 2 & 2 & 2 \\
\hline Prämix & 10 & 10 & 10 & 10 & 10 & 10 & 10 & 10 & 10 & 10 & 10 & 10 \\
\hline L-Lysin- $\mathrm{HCl}$ & 6,23 & 6,23 & 6,23 & 6,23 & 6,23 & 4,63 & 5,70 & 5,70 & 5,70 & 5,70 & 5,70 & 4,21 \\
\hline L-Cysteine $\cdot \mathrm{HCl} \cdot \mathrm{H}_{2} \mathrm{O}$ & 1,93 & 1,43 & 0,94 & 0,45 & - & 0,24 & 1,76 & 1,30 & 0,85 & 0,37 & - & 0,20 \\
\hline L-Arginin & 5,20 & 5,20 & 5,20 & 5,20 & 5,20 & 1,85 & 4,78 & 4,78 & 4,78 & 4,78 & 4,78 & 1,66 \\
\hline L-Threonin & 1,31 & 1,31 & 1,31 & 1,31 & 1,31 & 1,24 & 1,16 & 1,16 & 1,16 & 1,16 & 1,16 & 1,10 \\
\hline DL-Methionin & 0,12 & 0,46 & 0,81 & 1,14 & 1,49 & 0,76 & 0,09 & 0,41 & 0,73 & 1,05 & 1,36 & 0,69 \\
\hline L-Tryptophan & 0,37 & 0,37 & 0,37 & 0,37 & 0,37 & - & 0,34 & 0,34 & 0,34 & 0,34 & 0,34 & - \\
\hline $\mathrm{TiO}_{2}$ & - & - & - & - & - & - & 3 & 3 & 3 & 3 & 3 & 3 \\
\hline
\end{tabular}


Anhangstabelle 6: Rohnährstoff- und Aminosäuregehalt der in Versuch 2 verwendeten Futtermischungen.

\begin{tabular}{|c|c|c|c|c|c|c|c|c|c|c|c|c|}
\hline \multirow[b]{2}{*}{ Versuchsgruppe } & \multicolumn{6}{|c|}{ Starterphase (Tag 1-21) } & \multicolumn{6}{|c|}{ Growerphase (Tag 22-35) } \\
\hline & $\begin{array}{c}\text { A } \\
\text { TMP } \\
40: 60 \\
\end{array}$ & $\begin{array}{c}\text { B } \\
\text { TMP } \\
45: 55 \\
\end{array}$ & $\begin{array}{c}\mathbf{C} \\
\text { TMP } \\
\mathbf{5 0 : 5 0} \\
\end{array}$ & $\begin{array}{c}\text { D } \\
\text { TMP } \\
55: 45 \\
\end{array}$ & $\begin{array}{c}\text { E } \\
\text { TMP } \\
\text { 60:40 }\end{array}$ & $\begin{array}{c}\text { F } \\
\text { SES } \\
50: 50\end{array}$ & $\begin{array}{c}A \\
\text { TMP } \\
40: 60\end{array}$ & $\begin{array}{c}\text { B } \\
\text { TMP } \\
45: 55 \\
\end{array}$ & $\begin{array}{c}\text { C } \\
\text { TMP } \\
\mathbf{5 0 : 5 0}\end{array}$ & $\begin{array}{c}\text { D } \\
\text { TMP } \\
55: 45\end{array}$ & $\begin{array}{c}\mathbf{E} \\
\text { TMP } \\
60: 40 \\
\end{array}$ & $\begin{array}{c}\text { F } \\
\text { SES } \\
\mathbf{5 0 : 5 0}\end{array}$ \\
\hline $\mathrm{TM}(\%)^{1}$ & 90,72 & 90,60 & 90,58 & 90,19 & 90,14 & 90,84 & 90,08 & 89,17 & 89,19 & 89,16 & 89,25 & 89,79 \\
\hline $\mathrm{XP}(\% \mathrm{TM})^{1}$ & 22,58 & 22,95 & 22,43 & 22,53 & 22,64 & 23,00 & 21,36 & 21,08 & 21,29 & 21,35 & 21,66 & 21,72 \\
\hline $\mathrm{XL}(\% \mathrm{TM})^{1}$ & 6,63 & 6,74 & 6,72 & 6,85 & 6,78 & 10,61 & 6,39 & 6,40 & 6,61 & 7,08 & 6,64 & 11,57 \\
\hline $\mathrm{XF}(\% \mathrm{TM})^{1}$ & 3,16 & 3,30 & 3,19 & 3,20 & 3,36 & 4,46 & 3,13 & 3,00 & 3,05 & 2,81 & 2,79 & 3,69 \\
\hline $\mathrm{XA}(\% \mathrm{TM})^{1}$ & 5,32 & 5,31 & 5,33 & 5,40 & 5,41 & 6,47 & 5,24 & 5,15 & 5,12 & 5,14 & 5,19 & 6,11 \\
\hline \multicolumn{13}{|c|}{ Aminosäure $(\mathrm{g} / 16 \mathrm{gN})^{2}$} \\
\hline Lys & 6,69 & 6,70 & 6,70 & 6,70 & 6,70 & 6,64 & 6,68 & $6,, 68$ & 6,68 & 6,68 & 6,68 & 6,62 \\
\hline Met & 1,34 & 1,51 & 1,68 & 1,84 & 2,01 & 1,66 & 1,33 & 1,50 & 1,67 & 1,84 & 2,00 & 1,66 \\
\hline Cys & 2,01 & 1,84 & 1,67 & 1,51 & 1,36 & 1,66 & 2,00 & 1,84 & 1,67 & 1,50 & 1,37 & 1,66 \\
\hline Met + Cys & 3,35 & 3,35 & 3,35 & 3,35 & 3,37 & 3,32 & 3,33 & 3,34 & 3,34 & 3,34 & 3,37 & 3,32 \\
\hline Thr & 4,02 & 4,02 & 4,02 & 4,02 & 4,02 & 3,98 & 4,00 & 4,00 & 4,00 & 4,01 & 4,01 & 3,97 \\
\hline $\operatorname{Arg}$ & 7,03 & 7,03 & 7,04 & 7,04 & 7,04 & 6,97 & 7,01 & 7,01 & 7,02 & 7,02 & 7,02 & 6,95 \\
\hline Leu & 6,72 & 6,72 & 6,72 & 6,73 & 6,73 & 7,04 & 6,73 & 6,73 & 6,73 & 6,74 & 6,74 & 7,05 \\
\hline Ile & 3,38 & 3,38 & 3,38 & 3,38 & 3,38 & 3,79 & 3,38 & 3,38 & 3,38 & 3,39 & 3,39 & 3,80 \\
\hline His & 2,52 & 2,52 & 2,53 & 2,53 & 2,53 & 2,35 & 2,53 & 2,53 & 2,53 & 2,53 & 2,53 & 2,36 \\
\hline Val & 4,42 & 4,42 & 4,42 & 4,42 & 4,42 & 4,06 & 4,42 & 4,42 & 4,43 & 4,43 & 4,43 & 4,07 \\
\hline Phe & 3,68 & 3,68 & 3,68 & 3,68 & 3,68 & 4,48 & 3,69 & 3,69 & 3,69 & 3,69 & 3,69 & 4,49 \\
\hline $\operatorname{Trp}$ & 1,14 & 1,14 & 1,14 & 1,14 & 1,14 & 1,27 & 1,14 & 1,14 & 1,14 & 1,14 & 1,14 & 1,28 \\
\hline
\end{tabular}

${ }^{1}$ mind. in Doppelbestimmung analysiert, Werte wurden anschließend gemittelt; ${ }^{2}$ auf Basis der analysierten Aminosäuregehalte der Komponenten berechnet 
Anhangstabelle 7: Zusammensetzung der in der Starterphase (Tag 1-21) von Versuch 3 verwendeten Futtermischungen.

\begin{tabular}{|c|c|c|c|c|c|c|c|c|}
\hline Versuchsgruppe & $\begin{array}{c}\text { A } \\
\text { TMP } \\
50: 50\end{array}$ & $\begin{array}{c}\text { B } \\
\text { TMP } \\
55: 45\end{array}$ & $\begin{array}{c}\text { C } \\
\text { TMP } \\
\text { 60:40 }\end{array}$ & $\begin{array}{c}\text { D } \\
\text { TMP } \\
\text { pK }\end{array}$ & $\begin{array}{c}\text { E } \\
\underset{\text { HM }}{\mathbf{5 0 : 5 0}}\end{array}$ & $\begin{array}{c}\text { F } \\
\text { HM } \\
55: 45\end{array}$ & $\begin{array}{c}\text { G } \\
\underset{6 M}{\mathrm{HM}} \\
\text { 60:40 }\end{array}$ & $\begin{array}{c}\mathbf{H} \\
\mathbf{H M} \\
\mathbf{p K}\end{array}$ \\
\hline $\begin{array}{l}\text { Tenebrio molitor } \\
\text { Presskuchen }\end{array}$ & 162 & 162 & 162 & 157 & - & - & - & - \\
\hline $\begin{array}{l}\text { Hermetia illucens } \\
\text { Mehl }\end{array}$ & - & - & - & - & 185,5 & 185,5 & 185,5 & 181,0 \\
\hline Weizen & 580 & 580 & 580 & 600 & 560 & 560 & 560 & 560 \\
\hline Mais & 160 & 160 & 160 & 140 & 150 & 150 & 150 & 140 \\
\hline Weizenstärke & 10,81 & 10,98 & 11,06 & 8,50 & 21,42 & 21,56 & 21,73 & 28,99 \\
\hline Sojaöl & 30 & 30 & 30 & 32 & 29 & 29 & 29 & 30 \\
\hline Dicalciumphosphat & 23 & 23 & 23 & 23 & 10 & 10 & 10 & 11 \\
\hline Calciumcarbonat & 6 & 6 & 6 & 6 & 11 & 11 & 11 & 11 \\
\hline Viehsalz & 2,5 & 2,5 & 2,5 & 2,5 & 2,0 & 2,0 & 2,0 & 2,0 \\
\hline Prämix & 10 & 10 & 10 & 10 & 10 & 10 & 10 & 10 \\
\hline L-Lysin- $\mathrm{HCl}$ & 6,13 & 6,13 & 6,13 & 6,38 & 7,18 & 7,18 & 7,18 & 7,33 \\
\hline $\begin{array}{l}\mathrm{L}- \\
\text { Cysteine } \cdot \mathrm{HCl} \cdot \mathrm{H}_{2} \mathrm{O}\end{array}$ & 0,93 & 0,42 & - & 3,13 & 1,29 & 0,80 & 0,29 & 3,46 \\
\hline L-Arginin & 5,13 & 5,13 & 5,13 & 5,28 & 6,52 & 6,52 & 6,52 & 6,67 \\
\hline L-Threonin & 1,25 & 1,25 & 1,25 & 1,40 & 2,07 & 2,07 & 2,07 & 2,13 \\
\hline DL-Methionin & 0,79 & 1,13 & 1,47 & 2,62 & 0,92 & 1,26 & 1,60 & 2,69 \\
\hline L-Tryptophan & 0,36 & 0,36 & 0,36 & 0,65 & - & - & - & - \\
\hline L-Isoleucin & 0,57 & 0,57 & 0,57 & 0,70 & 0,96 & 0,96 & 0,96 & 1,09 \\
\hline L-Leucin & 0,53 & 0,53 & 0,53 & 0,84 & 2,15 & 2,15 & 2,15 & 2,42 \\
\hline $\mathrm{TiO}_{2}$ & - & - & - & - & - & - & - & - \\
\hline
\end{tabular}


Anhangstabelle 8: Rohnährstoff- und Aminosäuregehalt der in der Starterphase (Tag 1-21) von Versuch 3 verwendeten Futtermischungen.

\begin{tabular}{|c|c|c|c|c|c|c|c|c|}
\hline Versuchsgruppe & $\begin{array}{c}\text { A } \\
\text { TMP } \\
50: 50\end{array}$ & $\begin{array}{c}\text { B } \\
\text { TMP } \\
55: 45\end{array}$ & $\begin{array}{c}\text { C } \\
\text { TMP } \\
60: 40\end{array}$ & $\begin{array}{c}\text { D } \\
\text { TMP } \\
\text { pK }\end{array}$ & $\begin{array}{c}\text { E } \\
\text { HM } \\
\mathbf{5 0 : 5 0}\end{array}$ & $\begin{array}{c}\text { F } \\
\text { HM } \\
55: 45\end{array}$ & $\begin{array}{c}G \\
\text { HM } \\
60: 40\end{array}$ & $\begin{array}{c}\text { H } \\
\text { HM } \\
\text { pK }\end{array}$ \\
\hline $\mathrm{TM}(\%)^{1}$ & 90,52 & 90,17 & 90,18 & 90,16 & 90,69 & 89,83 & 90,66 & 90,05 \\
\hline $\mathrm{XP}(\% \mathrm{TM})^{1}$ & 23,08 & 23,17 & 23,25 & 23,13 & 22,98 & 22,84 & 22,90 & 22,87 \\
\hline $\mathrm{XL}(\% \mathrm{TM})^{1}$ & 7,02 & 7,08 & 7,01 & 7,25 & 7,90 & 7,95 & 7,79 & 7,77 \\
\hline $\mathrm{XF}(\% \mathrm{TM})^{1}$ & 2,98 & 2,86 & 2,84 & 2,81 & 3,55 & 3,70 & 3,70 & 3,21 \\
\hline $\mathrm{XA}(\% \mathrm{TM})^{1}$ & 5,43 & 5,46 & 5,36 & 5,39 & 5,48 & 5,48 & 5,55 & 5,46 \\
\hline \multicolumn{9}{|c|}{ Aminosäure $(\mathrm{g} / 16 \mathrm{gN})^{2}$} \\
\hline Lys & 6,65 & 6,65 & 6,65 & 6,64 & 6,58 & 6,58 & 6,58 & 6,60 \\
\hline Met & 1,66 & 1,83 & 2,00 & 2,53 & 1,65 & 1,81 & 1,97 & 2,51 \\
\hline Cys & 1,67 & 1,50 & 1,35 & 2,39 & 1,65 & 1,49 & 1,32 & 2,38 \\
\hline Met+Cys & 3,33 & 3,33 & 3,35 & 4,92 & 3,30 & 3,30 & 3,29 & 4,89 \\
\hline Thr & 3,99 & 3,99 & 3,99 & 3,98 & 3,94 & 3,95 & 3,95 & 3,96 \\
\hline Arg & 6,99 & 6,99 & 6,99 & 6,98 & 6,91 & 6,91 & 6,91 & 6,93 \\
\hline Leu & 6,70 & 6,99 & 6,99 & 6,97 & 6,91 & 6,91 & 6,91 & 6,93 \\
\hline Ile & 3,66 & 3,66 & 3,66 & 3,66 & 3,62 & 3,62 & 3,62 & 3,63 \\
\hline His & 2,53 & 2,53 & 2,53 & 2,47 & 2,26 & 2,27 & 2,27 & 2,23 \\
\hline Val & 4,42 & 4,43 & 4,43 & 4,33 & 4,26 & 4,26 & 4,26 & 4,19 \\
\hline Phe & 3,68 & 3,68 & 3,68 & 3,62 & 3,35 & 3,35 & 3,35 & 3,30 \\
\hline Trp & 1,13 & 1,14 & 1,14 & 1,26 & 1,15 & 1,15 & 1,15 & 1,26 \\
\hline
\end{tabular}

${ }^{1}$ mind. in Doppelbestimmung analysiert, Werte wurden anschließend gemittelt; ${ }^{2}$ auf Basis der analysierten Aminosäuregehalte der Komponenten berechnet 
Anhangstabelle 9: Zusammensetzung der in der Growerphase (Tag 22-35) von Versuch 3 verwendeten Futtermischungen.

\begin{tabular}{|c|c|c|c|c|c|c|c|c|}
\hline Versuchsgruppe & $\begin{array}{c}\text { A } \\
\text { TMP } \\
\text { 50:50 }\end{array}$ & $\begin{array}{c}\text { B } \\
\text { TMP } \\
55: 45\end{array}$ & $\begin{array}{c}\text { C } \\
\text { TMP } \\
60: 40\end{array}$ & $\begin{array}{c}\text { D } \\
\text { TMP } \\
\text { pK }\end{array}$ & $\begin{array}{c}\mathbf{E} \\
\mathbf{H M} \\
\mathbf{5 0 : 5 0}\end{array}$ & $\begin{array}{c}\text { F } \\
\text { HM } \\
55: 45\end{array}$ & $\begin{array}{c}\text { G } \\
\text { HM } \\
60: 40\end{array}$ & $\begin{array}{c}\text { H } \\
\text { HM } \\
\text { pK }\end{array}$ \\
\hline $\begin{array}{l}\text { Tenebrio molitor } \\
\text { Presskuchen }\end{array}$ & 150,66 & 150,66 & 150,66 & 146,01 & - & - & - & - \\
\hline $\begin{array}{l}\text { Hermetia illucens } \\
\text { Mehl }\end{array}$ & - & - & - & - & 172,52 & 172,52 & 172,52 & 168,33 \\
\hline Weizen & 539,40 & 539,40 & 539,40 & 558,00 & 520,80 & 520,80 & 520,80 & 520,80 \\
\hline Mais & 148,80 & 148,80 & 148,80 & 130,20 & 139,50 & 139,50 & 139,50 & 130,20 \\
\hline Weizenstärke & 72,39 & 72,55 & 72,59 & 70,13 & 82,90 & 83,06 & 83,20 & 89,88 \\
\hline Sojaöl & 30 & 30 & 30 & 32 & 29 & 29 & 29 & 30 \\
\hline Dicalciumphosphat & 23 & 23 & 23 & 23 & 10 & 10 & 10 & 11 \\
\hline Calciumcarbonat & 6 & 6 & 6 & 6 & 11 & 11 & 11 & 11 \\
\hline Viehsalz & 2,5 & 2,5 & 2,5 & 2,5 & 2,0 & 2,0 & 2,0 & 2,0 \\
\hline Prämix & 10 & 10 & 10 & 10 & 10 & 10 & 10 & 10 \\
\hline L-Lysin-HCl & 5,61 & 5,61 & 5,61 & 5,84 & 6,59 & 6,59 & 6,59 & 6,72 \\
\hline $\begin{array}{l}\mathrm{L}- \\
\text { Cysteine } \cdot \mathrm{HCl} \cdot \mathrm{H}_{2} \mathrm{O}\end{array}$ & 0,83 & 0,36 & - & 2,87 & 1,17 & 0,70 & 0,24 & 3,17 \\
\hline L-Arginin & 4,71 & 4,71 & 4,71 & 4,85 & 6,01 & 6,01 & 6,01 & 6,14 \\
\hline L-Threonin & 1,11 & 1,11 & 1,11 & 1,25 & 1,87 & 1,87 & 1,87 & 1,93 \\
\hline DL-Methionin & 0,72 & 1,03 & 1,35 & 2,41 & 0,84 & 1,15 & 1,47 & 2,48 \\
\hline L-Tryptophan & 0,33 & 0,33 & 0,33 & 0,59 & - & - & - & 0,18 \\
\hline L-Isoleucin & 0,50 & 0,50 & 0,50 & 0,62 & 0,86 & 0,86 & 0,86 & 0,98 \\
\hline L-Leucin & 0,44 & 0,44 & 0,44 & 0,73 & 1,94 & 1,94 & 1,94 & 2,19 \\
\hline $\mathrm{TiO}_{2}$ & 3 & 3 & 3 & 3 & 3 & 3 & 3 & 3 \\
\hline
\end{tabular}


Anhangstabelle 10: Rohnährstoff- und Aminosäuregehalt der in der Growerphase (Tag 22-35) von Versuch 3 verwendeten Futtermischungen.

\begin{tabular}{|c|c|c|c|c|c|c|c|c|}
\hline Versuchsgruppe & $\begin{array}{c}\text { A } \\
\text { TMP } \\
50: 50\end{array}$ & $\begin{array}{c}\text { B } \\
\text { TMP } \\
55: 45\end{array}$ & $\begin{array}{c}C \\
\text { TMP } \\
\text { 60:40 }\end{array}$ & $\begin{array}{c}\text { D } \\
\text { TMP } \\
\text { pK }\end{array}$ & $\begin{array}{c}\text { E } \\
\text { HM } \\
\mathbf{5 0 : 5 0}\end{array}$ & $\begin{array}{c}\text { F } \\
\underset{\text { HM }}{55: 45}\end{array}$ & $\begin{array}{c}\text { G } \\
\text { HM } \\
60: 40\end{array}$ & $\begin{array}{c}\text { H } \\
\text { HM } \\
\text { pK }\end{array}$ \\
\hline $\mathrm{TM}(\%)^{1}$ & 90,16 & 89,08 & 88,02 & 88,58 & 87,63 & 88,33 & 87,79 & 89,04 \\
\hline $\mathrm{XP}(\% \mathrm{TM})^{1}$ & 21,60 & 21,74 & 21,63 & 21,74 & 21,34 & 21,21 & 21,58 & 21,27 \\
\hline $\mathrm{XL}(\% \mathrm{TM})^{1}$ & 6,69 & 6,73 & 6,64 & 6,83 & 7,55 & 7,49 & 7,56 & 7,45 \\
\hline $\mathrm{XF}(\% \mathrm{TM})^{1}$ & 2,90 & 2,90 & 2,82 & 2,74 & 3,28 & 3,58 & 3,42 & 3,38 \\
\hline $\mathrm{XA}(\% \mathrm{TM})^{1}$ & 5,65 & 5,73 & 5,58 & 5,54 & 5,60 & 5,52 & 5,59 & 5,55 \\
\hline \multicolumn{9}{|c|}{ Aminosäure $(\mathrm{g} / 16 \mathrm{gN})^{2}$} \\
\hline Lys & 6,63 & 6,64 & 6,64 & 6,62 & 6,56 & 6,56 & 6,56 & 6,58 \\
\hline Met & 1,66 & 1,83 & 1,99 & 2,52 & 1,64 & 1,81 & 1,97 & 2,50 \\
\hline Cys & 1,66 & 1,49 & 1,36 & 2,38 & 1,64 & 1,47 & 1,31 & 2,37 \\
\hline Met+Cys & 3,32 & 3,32 & 3,35 & 4,90 & 3,28 & 3,28 & 3,28 & 4,87 \\
\hline Thr & 3,98 & 3,98 & 3,98 & 3,97 & 3,94 & 3,94 & 3,94 & 3,95 \\
\hline Arg & 6,97 & 6,97 & 6,97 & 6,96 & 6,89 & 6,89 & 6,90 & 6,91 \\
\hline Leu & 6,97 & 6,97 & 6,97 & 6,96 & 6,89 & 6,89 & 6,89 & 6,91 \\
\hline Ile & 3,65 & 3,65 & 3,65 & 3,65 & 3,61 & 3,61 & 3,61 & 3,62 \\
\hline His & 2,53 & 2,53 & 2,53 & 2,48 & 2,27 & 2,27 & 2,27 & 2,30 \\
\hline Val & 4,43 & 4,43 & 4,43 & 4,34 & 4,27 & 4,27 & 4,27 & 4,19 \\
\hline Phe & 3,69 & 3,69 & 3,69 & 3,62 & 3,36 & 3,36 & 3,36 & 3,30 \\
\hline $\operatorname{Trp}$ & 1,14 & 1,14 & 1,14 & 1,26 & 1,15 & 1,15 & 1,15 & 1,25 \\
\hline
\end{tabular}

${ }^{1}$ mind. in Doppelbestimmung analysiert, Werte wurden anschließend gemittelt; ${ }^{2}$ auf Basis der analysierten Aminosäuregehalte der Komponenten berechnet 


\section{Wissenschaftliche Publikationen und Beiträge zu wissenschaftlichen Tagungen}

Brede, A., Wecke, C., Liebert, F. (2018): Does the optimal dietary methionine to cysteine ratio in diets for growing chickens respond to high inclusion rates of insect meal from Hermetia illucens? Animals 8 (11), 187

Brede, A., Wecke, C., Sünder, A., Liebert, F. (2018): Besonderheiten bei der Versorgung mit schwefelhaltigen Aminosäuren unter spezieller Beachtung der Mastgeflügelernährung. Übersichten Tierernährung 43 (1), 1-52

Brede, A., Sünder, A., Wecke, C., Liebert F. (2018): First investigations on the optimal methionine:cysteine ratio in diets for growing chickens with a Tenebrio molitor press cake as an alternative protein source. In: Proc. Soc. Nutr. Physiol. 27, (ISBN 978-3-7690-4111-8)

Brede, A., Wecke, C., Liebert, F. (2017): Erste Untersuchungsergebnisse zum optimalen Met:Cys-Verhältnis in Insektenprotein basierten Futtermischungen für Masthähnchen. In: Tagungsband 14.Tagung Schweine- und Geflügelernährung Wittenberg 2017, 34-36, (ISBN 978-3-86829-891-8)

Brede, A., Neumann, C., Velten, S., Liebert, F. (2016): Evaluation of Hermetia illucens and Spirulina platensis proteins in semi-synthetic diets for the laboratory rat. In: Proc. Soc. Nutr. Physiol. 25, 31, (ISBN: 978-3-7690-4109-5) 


\section{Danksagung}

An erster Stelle möchte ich mich bei Herrn Prof. Liebert für die Ermöglichung der Promotion und für die Überlassung des Themas bedanken. Außerdem vielen Dank, dass Sie sich immer Zeit genommen haben und mir mit wissenschaftlichem Rat zur Seite standen.

Mein weiterer Dank gilt Herrn Dr. Wecke, der mir ebenfalls sowohl bei der Planung und Auswertung der Versuche als auch beim Verfassen wissenschaftlicher Publikationen immer mit Rat und Tat zur Seite stand.

Zusätzlich bedanke ich mich bei Frau Dr. Sünder und allen Labormitarbeitern/innen, die mir bei der Analyse der Proben viel Arbeit abgenommen haben.

Dasselbe gilt auch für Nicole, Thomas und Mario, die mich bei der Arbeit im Stall unterstützt haben.

Danke auch an Kerstin, Anne, Amelie und Henner für die Hilfe im Stall und bei der Probenaufarbeitung.

Weiterer Dank gilt Carmen und Susanne für die schöne gemeinsame Zeit sowohl im Institut und auch nach Feierabend. Ich finde, wir waren immer ein gutes Team.

Außerdem möchte ich mich bei Sophie und Leni bedanken. Ihr ward immer für mich da, hattet immer ein offenes Ohr für mich und habt mir sehr geholfen.

Auch meine Familie hat mich nicht nur während der Promotionszeit immer unterstützt. Vielen Dank! 